PNL- -8171

DE92 016648

\title{
ENVIRONMENTAL RESTORATION AND WASTE MANAGEMENT MANPOWER NEEDS ASSESSMENT: \\ U.S. DEPARTMENT OF ENERGY COMPLEX
}
C. W. Holmes
R. E. Lewis
S. T. Hunt
M. G. Finn (a)

June 1992

Prepared for the U.S. Department of Energy under Contract DE-ACO6-76RLO 1830

Pacific Northwest Laboratory Richland, Washington 99352

(a) Oak Ridge Associated Universities, Inc. Oak Ridge, Tennessee 37831-0117

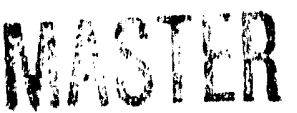




\section{ABSTRACT}

A study was conducted by Pacific Northwest Laboratory and Oak Ridge Associated Universities, Inc. to assess the supply and demand for 53 scien. tific, engineering, and technical occupations relevant to the U.S. Department of Energy's (DOE's) Office of Environmental Restoration and Waste Management (EM). These assessments were made by examining budget projections and the input of program/project and human resources managers throughout the DOE complex. Quantitative projections of full-time equivalent employees slots for each occupation have been developed for the 1993-1997 time frame. Qualitative assessments of the factors that affect recruitment, staffing, and retention are also reported. The implications of the study are discussed within the likely skills mix of the future workforce and the education and organization interventions most likely to address the needs of the DOE complex. 
-

- 


\section{EXECUTIVE SUMMARY}

\section{OVERVIEW}

A study was conducted by Pacific Northwest Laboratory and Oak Ridge Associated Universities, Inc. to assess the supply and demand for scientific, engineering, and technical occupations relevant to the U.S. Department of Energy's (DOE's) Office of Environmental Restoration and Waste Management (EM). The assessments were made by examining budget projections and the input of program/project and human resources managers throughout the DOE complex.

Managers feel the complex faces a large percentage increase in the number of individuals who will be employed in environmental restoration and waste management (ER/WM) activities over the 1993-1997 Five-Year Plan (FYP) time frame. Their requirements-based estimates project a 45\% increase (over a 1991 base) in the number of individuals employed by DOE and its contractors over the period covered by the 1993-1997 FYP. Budget-driven figures for the same time period project $49 \%$ and $87 \%$ increases for constrained and unconstrained budget scenarios, respectively. Managers do not, however, feel that the technical skills mix of occupations will change markedly over this time period. Selected "niche" occupations will be difficult to staff, but training and education options can ease shortages. Managers report, however, that organizational and institutional barriers have a marked impact on the ability of the complex to staff and retain qualified individuals.

\section{INTRODUCTION}

Shifts in funding priorities and the DOE's increasing emphasis on environmental clean-up and hazardous waste management are likely to disrupt traditional DOE employment patterns. Whereas DOE has typically recruited engineers, scientists, and technicians for nuclear production occupations, it must now recruit for openings in environmental management, and there is widespread concern that there will not be enough workers having the proper ski11s to meet future demand. Declines in both student achievement scores and enrollment in science and engineering programs indicate that possibly too few qualified 
individuals will be available to perform the research and develop the technologies needed to accomplish the remediation and restoration goals of DOE's EM organization.

This study is designed to reduce uncertainty regarling the current and future ER/WM workforce. It systematically identifies and characterizes current and expected (Fiscal Year 1997) staffing patterns in 53 scientific, engineering, and technical occupations. Furthermore, this study assesses the impact of various organizational interventions, especially educational programs, on staffing levels to determine which are most likely to provide the skills relevant to ER/WM. This information permits more accurate short-term workforce planning and coherent long-term policy decisions. Moreover, it facilitates the productive investment of resources in the programs most likely to yield a supply of appropriately qualified workers for the ER/WM mission.

The occupations identified by managers as most in need within the DOE complex will be discussed as will the factors, as perceived by managers, which affect staffing levels within the complex. Recommendations regarding the types of policies and programs most likely to yield qualified science, engineering, and technical personnel will be offered.

\section{METHOD}

A series of approaches were used in fulfilling the goals of the study. The EM's need for various skills in the future workforce was determined by obtaining two measures of "demand": one based on budgets and the other based on the requirements of the work to be done. A budget-driven econometric model was developed to determine, based on two budget scenarios, the need for individuals in 53 science, engineering, technical, and other occupations. This "top-down" model was contrasted with "bottom-up" requirements-driven estimates derived from survey responses of DOE and DOE-contractor program/ project and human resources managers regarding the same occupations. Both sets of estimates are based on the 1993-1997 FYP. Managers estimated their need for each occupation in full-time equivalents (FTES) as well as the level of academic degree they would expect the typical incumbent would hold. They were also asked to provide an indication of how critical each occupation is to meeting 
the goals of the site--essentially, a measure of the extent to which occupational shortages cause bottlenecks within the system.

The remaining tasks were used to characterize the likely availability of appropriately trained personnel. First, DOE and DOE-contractor human resources managers were surveyed to determine current and future hiring conditions and difficulties related to staffing DOE and contractor positions. In addition, characteristics were projected regarding the anticipated supply of science, engineering, and technical students from college and university programs across the nation.

Focus groups were conducted with program/project manager and human resources survey respondents as part of the data collection effort. These workshops provided qualitative information and data beyond that collected via the surveys.

\section{RESULTS}

Fifty-four human resources managers and 121 program/project managers from 19 sites participated in the survey exercise. Nearly all of these individuals also participated in the focus groups.

\section{Quantitative Analyses}

Managers across the complex, based on the work to be done, project a $45 \%$ increase in the number of individuals employed by DOE and its contractors over the 1993-1997 FYP: "Top-down" budget-driven figures project $49 \%$ and $87 \%$ increases for constrained and unconstrained budget scenarios for the same period respectively. Table ES.I contains demand, supply, and degree information for selected occupations. Occupations which are in the highest demand are not necessarily those deemed most critical for meeting ER/WM goals. According to the data collected from program/project and human resources managers, the occupations which should command DOE's highest priority are environmental engineer, project manager, heal th physics technician, and 


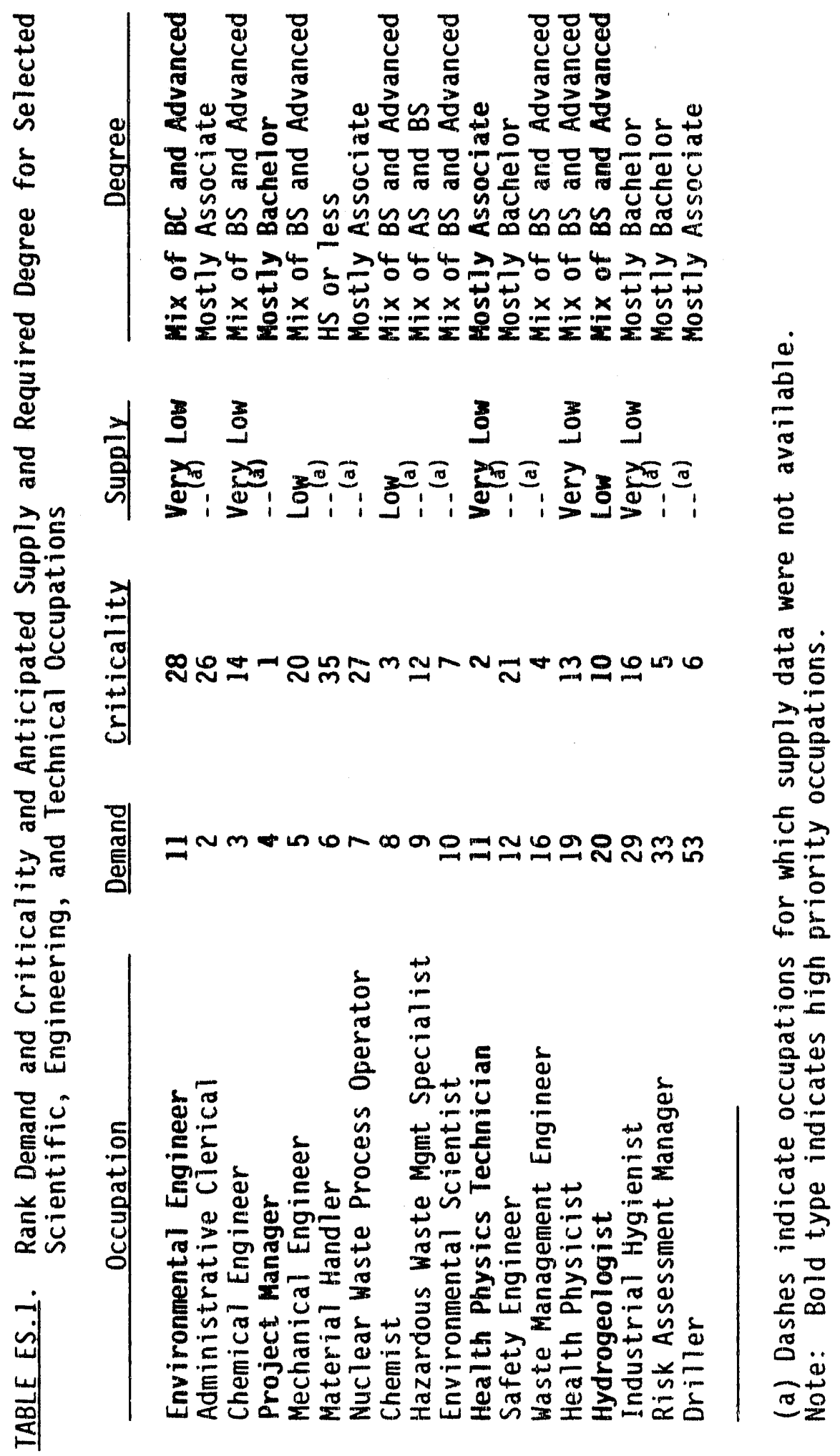


hydrogeologist. The need in FTEs for hydrogeologists is moderate, but the need is highly critical relative to other occupations and hydrogeologists are in short supply. The remaining high priority occupations are characterized by high demand, low or very low anticipated supply, and/or high criticality.

Chemical engineers, environmental scientists, chemists, waste management engineers, health physicists, industrial hygienists, and risk assessment managers should command the next level of priority.

Some occupations, which are rated as highly needed, are not priority occupations because of anticipated adequate supply or because preparatory requirements are minimal. For instance, the needs for material handlers is extremely high but requires no more than a high school diploma and training can be accomplished relatively quickly. Similar circumstances exist for administrative and clerical workers. These occupations should receive attention, but are not as high a priority as occupations which require longer or more substantial investments in training and education.

\section{Qualitative Analyses}

Focus groups were conducted with most managers who completed surveys. This data yielded information regarding characteristics of the occupations under consideration and the best methods by which to recruit, train staff, and educate workers. Themes conveyed by focus group participants and discussion follow.

- There is little need for large changes in the workforce skills mix. Although managers expect totaT employment in the DOE complex to grow markedly, they feel the mix of skills needed to accomplish the restoration and remediation goals will change little over the next 5 years. Strong basic science skills are perceived to be largely non-specific in application. Managers believe that well-trained technical people can transfer readily among programs and require only a short period of time to become re-oriented. Given this bel ief and the diversity of skills and knowledge presently found within the complex, managers feel that the skilis of many of the engineers and technicians trained in nuclear production should transfer readily to the environmental area. They noted also that changes in mission and headcount have occurred previously and that they can be handled with sufficient time, resources, and planning.

- Certain occupations will be difficult to fill. Managers did recognize, however, that certain occupations will be difficult to staff. 
These occupations are generally unique to the DOE complex and can be characterized by the highly specialized training or skills they require, such as for hydrogeologists, waste certification engineers, and regulatory analysts. Entrance to these occupations is often not via college degree programs, as is the case with mechanical engineering, for example. Instead, entrance to these occupations is governed by experience and the specific needs of the complex. The need for these "niche" occupations is projected to be high throughout the time period considered. Interestingly, it is for these reasons that the extreme need for environmental engineers may be misleading. Respondents reported that environmental engineering is not yet a well-defined discipline and that substantially similar skills are found in civil and chemical engineers. Thus, environmental engineers do not constitute a "niche" and may be drawn from a variety of industries and/or academic degree programs.

- Organizational and institutional barriers are the most significant obstacles to manpower planning, recruiting, and retention.

Although low supply results in shortages in some occupations, paperwork, administrative burdens and restrictions, funding inconsistencies, regulatory conflicts, and the lack of clear work plans are the barriers most impacting manpower issues. Planning for needed skills is difficult because of fluctuations in funding, the perceived inconsistency of specific remediation and restoration goals, and regulatory conflicts. Recruiting and staffing are made difficult by headcount restrictions, the administrative processes associated with security clearances and hiring, and salary restrictions. Fluctuations in funding and salary caps and the increased paperwork for scientists and engineers result in retention difficulties. Managers at the local level feel strongly that DOE could clear some of these barriers by assuming more control over those functions which may be logically consolidated at DOE Headquarters and providing guidance for those most effectively administered locally.

- Regulatory training is critical, but inadequate. Managers feel that regulatory training is critical, but not currently adequate to meet current demands. They characterize current offerings as contract negotiation training or a "you' 11 go to jail for this" lecture. Classes are often not conducted by individuals with hands-on regulatory experience or a strong knowledge of the DOE complex. Hence, they feel the classes convey neither the essence of the regulations nor the impact they have on the technical work that needs to be accomplished. Respondents emphasized the need for regulatory training throughout all levels of the complex; they feel al1 employees could benefit from an understanding of the impact that regulations and regulatory agreements have on their jobs. 
- Education initiatives are vital to the long-term success of the envilonmental mission. It is the overwhelming belief among respondents that education initiatives are vital to the long-term success of the environmental mission. If used well, internships, faculty fellowships, univelsity research contracts, and educational outreach programs are cost-effective recruiting, education, and public relations tools. Many of these programs not only solve the immediate problem of bringing qualified individuals onsite but have the added advantage of gaining allies on campus to ensure that DOE gets the best students. These programs, however, are not adequately integrated into the management system; program/project managers are often unaware of them or may have misconceptions concerning them. Internship programs are often inconsistently funded out of discretionary monies, and managers are given little incentive or reward for mentoring students. Consequently, students may work on hastily conceived or poorly supervised projects which contribute little to their education. Thus, internship experiences sometimes drive students away from the complex, and they lose a valuable opportunity for gaining relevant experience to round out their education.

- Initiatives at individual sites directed at addressing manpower staffing/recruiting issues have vielded data and valuable experience to 1OCal DOE and contractor offices. Manpower planning issues are primarily local in origin and most fruitfully addressed via local initiatives. Broad macroeconomic data provide little insight into the recruiting and planning difficulties faced by the local sites. Since the sites differ in their emphasis on production or research, the occupations needed by each site will differ somewhat. Under these circumstances, bottom-up approaches to determining need should be emphasized more and combined with top-down budgetary approaches.

Sites also vary tremendously in terms of location, the non-DOE industrial base in the local economy, access to pools of local minority employees, and characteristics of the community. In an effort to meet staffing needs, sites have begun to address these local variables by establishing educational programs, increasing recruiting, and making contacts in the community. These initiatives no doubt vary in their complexity and maturity. Assistance from DOE is perceived as most helpfui when it coordinates these efforts.

- Integrated manpower planning is a broad-based organizational activity. Traditionally, manpower planning has been a numbers-generating activity. Preferring mathematical models of workforce movements through organizations, operations researchers and others have eschewed investigating the location, organizational climate, culture, and skill-based factors that significantly affect an organization's ability to influence and recruit from the labor pool. 
However, workers with the appropriate skills can be found not only by increasing the size of the market (via macroeconomic incentives) but also by increasing market share (becoming an employer of choice). Consequently, determining the number of people needed to accomplish a mission cannot be conducted independently of the after-work needs, desires, and preferences of the individuals who will be recruited.

- Results from the current study are most useful in developing interventions designed to affect the educational choices of students entering programs which will prepare them for occupations requiring 2 to 4 years of post-secondary education. A 1 imitation implicit in the design of the study is the focus on the 1993-1997 FYP. The relatively short-term focus of this study makes the conclusions more valid for occupations characterized by geographical mobility and shorter education cycles (AA and BS degrees) that provide skills that may be common to a variety of occupations.

Limits on the planning which can be done for PhDs and highly specialized occupations requiring lengthy preparatory periods are imposed by the time frame adopted in this study. Five years, for instance, is not enough time to affect the educational process for PhD hydrogeologists. However, it appears unlikely that any technique will allow DOE to pinpoint the number of PhDs needed 10 years hence with high accuracy, given that budgets (which ultimately determine the number of workers with in the complex) are not planned that far into the future.

\section{CONCLUSIONS}

Although managers anticipate difficulty staffing some occupations, they do not feel that the change in mission presents unique manpower problems. They feel that similar changes have occurred previously, that the skills mix needed to accomplish ER/WM activities will not differ markedly from the ones presently in existence, and that individuals in the complex largely have flexible science, engineering, and technical backgrounds allowing them to work productively in the environmental field.

Selected occupations, typically those characterized by unique skills and/or highly specialized training, will be difficult to staff. Educational programs which encourage students to enter technical fields, both at the college and vocational levels, will help alleviate shortfalls in both general technical and "niche" occupations. Internal training courses for occupations unique to DOE will develop a strong in-house supply. These interventions serve to increase the supply of workers with skills relevant to the DOE 
complex. The largest impediments to successful staffing and retention, however, are organizational and institutional barriers. These range from headcount and citizenship restrictions to salary limitations and difficulties caused by inconsistent funding and conflicting regulations. Interventions designed to address these barriers will help the DOE complex achieve status as an employer of choice and gird against potential labor shortfalls.

\section{RECOMMENDATIONS}

The following recommendations are made as a result of this study.

\section{Priority Occupations}

EM should focus resources on developing programs designed to increase enrollment in educational programs granting the $A A$ and $B S$ degrees that are relevant to high-demand/low-supply occupations and those expected to be undersupplied in the future.

For high demand/low supply occupations requiring relatively long preparatory periods, EM should develop programs designed to increase the likelihood of DOE and contractors attracting people who are just completing their educational programs (i.e., focus on increasing the market share).

EM should continue to update manpower data and develop evaluation programs and feedback loops to its educational programs and human resources functions to ensure that efforts targeted at specific academic disciplines are shifted as needs change.

\section{Organizational and Institutional Barriers}

The DOE should facilitate short- to medium-term planning efforts by providing more consistent direction regarding broad mission objectives and concentrating more resources on explaining and solving regulatory issues. Reducing paperwork and administrative requirements will allow internal resources to be concentrated on the work at hand and decrease DOE's need to tap the market for additional manpower. 


\section{Education and Training}

Managers feel that educational programs directed toward the college level should promote strong basic science skills and target students for internships earlier in their academic career (as sophomores rather than juniors/seniors). In this way a more flexible workforce which is predisposed to work for the DOE complex may be developed.

Internships and like programs should be broken out of the budget as separate line items (as opposed to discretionary items) to give them the consistent funding and administrative control needed to ensure an effective program.

Training prigrams should focus mainly on the skills, knowledge, and abilities unique to the DOE complex. Courses that capitalize on the expertise of persons within the complex would provide the hands-on training needed by people filling "niche" occupations. Among the occupations which should be considered for course development are regulatory analyst, quality assurance engineer, safety engineer, waste certification engineer, arid technicians.

\section{Local Site Initiatives}

The DOE might find it most effective to assume the role of data coordinator rather than data collector. Sponsoring roundtables and similar forums for exchanging ideas, successes, and failures would facilitate the dissemination of information throughout the complux.

DOE should also control and consolidate functions that transcend indiridual sites, such as public relations and recruiting. By endorsing a consistent theme, DOE can become a more credible source of information in the public debate and generate good publicity for itself and its contractors. DOE may also reduce the cost and inefficiencies associated with recruiting by coordinating activities such as job fairs and targeted marketing across the complex.

\section{Integrated Manpower Planning}

Manpower planning activities should be integrated with data contained in human resource information systems, coordinated across the DOE complex, and 
tailored to local needs. A consistent taxonomy of job titles and related characterization of the knowledge, skills, abilities, and training required to perform an occupation should be implemented across the complex. Such a system would permit a more accurate specificntion of projected needs and a more detailed analysis of the extent to which the current workforce could take on new activities. Training, project management, human resource, and planning departments could then have a common basis for conducting their activities. In this way, the DOE may discover targeted cost-effective methods of increasing its market share of the local labor pool that do not involve broad macro-economic interventions. 
-

- 


\section{ACRONYMS}

DOE - U.S. Department of Energy

DOE-HQ - U.S. Department of Energy Headquarters

DOL - U.S. Department of Labor

EM - Office of Environmental Restoration and Waste Management

ER/WM - Environmental Restoration and Waste Management

FTE - Full-time Equivalent

FYP - Five-Year Plan

IPA - Inter-agency Personnel Assignments

MRG - Manpower Research Group

SCHC - Survey of Current Hiring Conditions

S\&E - Science and engineering

UMTRA - Uranium Mill Tailings Remedial Actions

WIPP - Waste Isolation Pilot Plant

WNAS - Workforce Needs Assessment Survey 
-

-

xviji 


\section{ACKNOWLEDGMENTS}

This study would not have been possible without the time and effort generously offered by field office and area office staff who contacted study participants and assisted in collecting data. The help of the following staff is greatly appreciated.

Karen Agogino, DOE-AL; David Caughey, DOE-AL, KCA0; Paul Dickinson, LLNL; Amy Diltz, LBL; Nate Ellis, DOE-SR; Bill Fitch, DOE-ID; Marv Gross, WEMCO; John Ha11, DOE-NV; Bill Holman, DOE-SF; David Ingle, DOE-AL, PAO; Lynn Lohman, DOE-CH; Johnny Moore, DOE-OR; Dick Neff, EG\&G-Mound; Brian Shea, DOEHQ; Ted Taylor, DOE-AL, AAO; Reg Tyler, DOE-RF; and Steve Webster, DOE-CH.

In addition, the following Hanford Site staff supported and guided the project team via their comments, advice, and informal reviews: Steve Bork, Manpower Assessment Program Manager, KEH; Joyce Gilbert, Human Resources, DOE-RL; and June 011ero, Director of Human Resources, DOE-RL.

We also thank the members of the Manpower Research Group for their guidance, reviews, and advice throughout the project. Lastly, we wish to thank the study participants who volunteered their time and shared their knowledge with us. 
-

- 


\section{CONTENTS}

ABSTRACT ...................................... i

EXECUTIVE SUMMARY ....................... . v

ACRONYMS ......................... . . . . . . . . . . . . . . . . . . . .

ACKNOWLEDGMENTS ...................... .

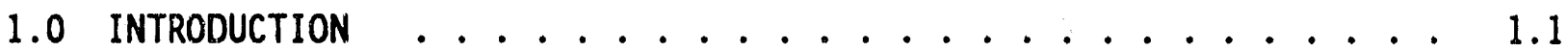

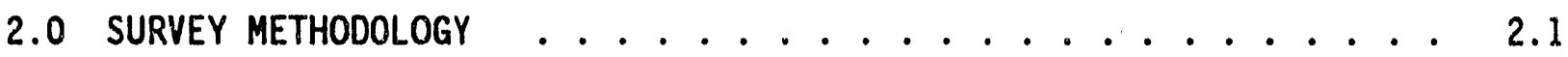

2.1 SURVEY CONSTRUCTION . . . . . . . . . . . . . 2.1

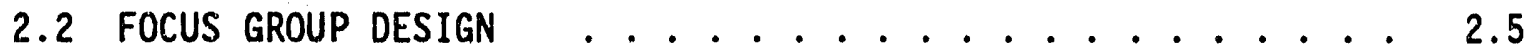

2.3 ASSUMPTIONS . . . . . . . . . . . . . . . 2.6

2.4 PRE-TEST OF INSTRUMENTS . . . . . . . . . . . . . 2.7

2.5 SELECTION OF WORKSHOP SITES AND PARTICIPANTS . . . . . . 2.7

2.6 DATA COLLECTION PROCEDURE . . . . . . . . . . . 2.10

3.0 SURVEY RESULTS . . . . . . . . . . . . . . . . . . . 3.1

3.1 QUANTITATIVE RESULTS FROM SURVEYS . . . . . . . . . . 3.1

3.1.1 Complex-Wide Results from Workforce Needs Assessment Survey and Survey of Current Hiring Conditions Surveys ............... 3.1

3.1.2 Cross-Site Differences in Need and Criticality . . 3.10

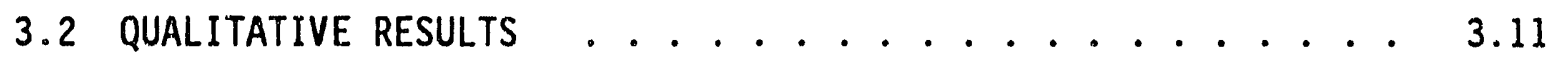

3.2.1 Data Coding and Compilation .......... 3.11

3.2.2 Skills Needed to Accomplish the Environmental

3.2.3 Occupations Perceived to be Critical and/or
Difficult to Fill . . . . . . . 3.15

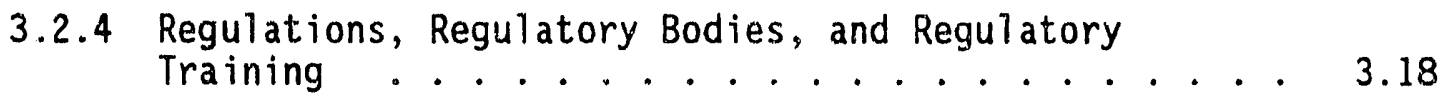

3.2.5 DOE-Contractor Relationship . . . . . . . . . 3.19 
3.2.6 Education and Training .......... 3.20

3.2.7 Minority Recruiting and Retention Issues ..... 3.23

3.2.8 Salary and Benefits ........... . . 3.25

3.2.9 Organizational and Institutional Barriers .... 3.26

3.2.10 Quantitative Results from the Survey of Occupational Deployment (Task 4) ........... 3.29

4.0 BUDGET-BASED EMPLOYMENT PROJECTIONS . . . . . . . . . 4.1

4.1 EMPLOYMENT PROJECTIONS ..................... 4.1

4.2 EXAMINATION OF THE DIFFERENCES BETWEEN THE WORKFORCE

NEEDS ASSESSMENT SUMMARY-BASED PROJECTION OF EMPLOYMENT

AND BUDGET-BASED PROJECTIONS OF EMPLOYMENT $\ldots \ldots . . . . .4 .5$

4.3 ESTIMATES OF REPLACEMENT NEEDS $\ldots \ldots \ldots$

\begin{tabular}{l}
4.4 IDENTIFICATION OF HIGH GROWTH AND HIGHLY CRITICAL \\
OCCUPATIONS FOR SUPPLY CHARACTERIZATION $\ldots \ldots \ldots . . . .$. \\
\hline
\end{tabular}

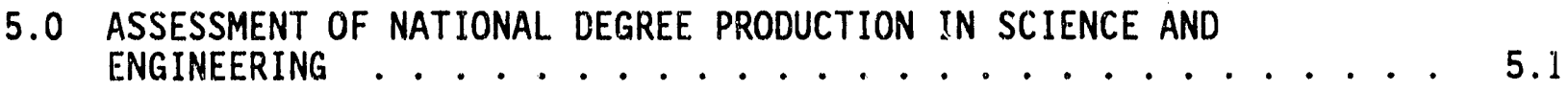

5.1 GENERAL SUPPLY TRENDS FOR SCIENCE AND ENGINEERING FIELDS . . 5.1

5.2 CURRENT DEGREE PRODUCTION IN SCIENCE AND ENGINEERING . . . 5.3

5.3 PROJECTED SUPPLY OUTLOOK FOR SELECTED HIGH GROWTH AND
CRITICAL OCCUPATIONS . . . . . . . . . . . . . . . . . . . . 5.7

5.4 COMPARING SUPPI.Y AND DEMAND MEASURES . . . . . . . 5.11

6.0 CONCLUSIONS AND RECOMMENDATIONS .................. 6.1

6.1 CONCLUSIONS DRAWN DIRECTLY FROM RESEARCH RESULTS . . . . 6.1

6.2 CONCLUSIONS AND RECOMMENDATIONS OF THE RESEARCHERS . . . 6.7

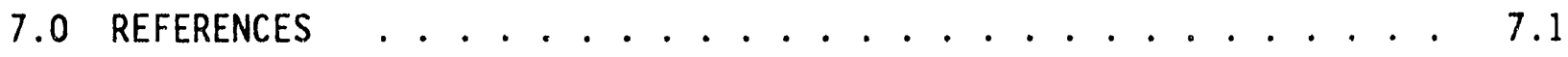

APPENDIX A - WORKFORCE NEEDS ASSESSMENT SURVEY . . . . . . . . . . A.1

APPENDIX B - SURVEY OF CURRENT HIRING CONDITIONS . . . . . . . . B.1

APPENDIX $C$ - MODERATOR'S GUIDE FOR PROGRAM/PROJECT MANAGERS $\ldots$ 
APPENDIX D - MODERATOR'S GUIDE FOR HUMAN RESOURCE MANAGERS WORKSHOP • D.1

APPENDIX E - JOB SORTS ON ALL VARIABLES FOR ENTIRE COMPLEX . . . . . E.1

APPENDIX F - SIMPLE STATISTICS: INTERCORRELATION AMONG VARIABLES AND JOB SORTS ON ALL VARIABLES FOR ALBUQUERQUE ONLY . . F.1

APPENDIX G - SIMPLE STATISTICS: INTERCORRELATION AMONG VARIABLES AND JOB SORTS ON ALL VARIABLES FOR CHICAGO ONLY . . . . G.1

APPENDIX H - SIMPLE STATISTICS: INTERCORRELATION AMONG VARIABLES AND JOB SORTS ON ALL VARIABLES FOR FERNALD ONLY ..... H.1

APPENDIX I - SIMPLE STATISTICS: INTERCORRELATION AMONG VARIABLES AND JOB SORTS ON ALL VARIABLES FOR GRAND JUNCTION

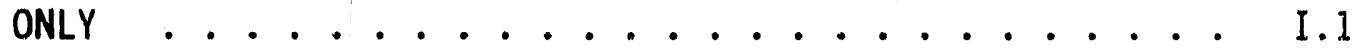

APPENDIX J - SIMPLE STATISTICS: INTERCORRELATION AMONG VARIABLES AND JOB SORTS ON ALL VARIABLES FOR RICHLAND ONLY . . . . J.1

APPENDIX K - SIMPLE STATISTICS: INTERCORRELATION AMONG VARIABLES AND JOB SORTS ON ALL VARIABLES FOR IDAHO ONLY . . . . . K. K

APPENDIX L - SIMPLE STATISTICS: INTERCORRELATION AMONG VARIABLES AND JOB SORTS ON ALL VARIABLES FOR KANSAS CITY ONLY . . . L.I

APPENDIX M - SIMPLE STATISTICS: INTERCORRELATION AMONG VARIABLES AND JOB SORTS ON ALL VARIABLES FOR MOUND ONLY . . . . . M.1

APPENDIX N - SIMPLE STATISTICS: INTERCORRELATION AMONG YARIABLES AND JOB SORTS ON ALL VARIABLES FOR NEVADA ONLY . . . . N.

APPENDIX 0 - SIMPLE STATISTICS: INTERCORRELATION AMONG VARIABLES AND JOB SORTS ON ALL VARIABLES FOR OAK RIDGE ONLY . . . . 0.1

APPENDIX P - SIMPLE STATISTICS: INTERCORRELATION AMONG VARIABLES AND JOB SORTS ON ALL VARIABLES FOR PANTEX ONLY . . . . . P.I

APPENDIX Q - SIMPLE STATISTICS: INTERCORRELATION AMONG VARIABLES AND JOB SORTS ON ALL VARIABLES FOR PINELLAS ONLY . . . . Q.1

APPENDIX R - SIMPLE STATISTICS: INTERCORRELATION AMONG VARIABLES AND JOB SORTS ON ALL VARIABLES FOR ROCKY FLATS ONLY . . . R.1

APPENDIX S - SIMPLE STATISTICS: INTERCORRELATION AMONG VARIABLES AND JOB SORTS ON ALL VARIABLES FOR SAN FRANCISCO ONLY . . S.1

APPENDIX T - SIMPLE STATISTICS: INTERCORRELATION AMONG VARIABLES AND JOB SORTS ON ALL VARIABLES FOR SAVANNAH RIVER ONLY 
APPENDIX U - SIMPLE STATISTICS: INTERCORRELATION AMONG VARIABLES AND JOB SORTS ON ALL VARIABLES FOR UMTRA ONLY . . . . . . U.1

APPENDIX V - SIMPLE STATISTICS: INTERCORRELATION AMONG VARIABLES AND JOB SORTS ON ALL VARIABLES FOR WEST VALLEY ONLY . . . $\quad$ v. 1

APPENDIX $W$ - QUESTIONNAIRE .................... . . . . . 


\section{FIGURES}

1.1 Study Activities and Possible Intervention Programs ...... 1.3

2.1 Field Office Site Visits and Offsite Locations Contacted . . . 2.9

\section{TABLES}

ES.1 Rank Demand and Criticality and Anticipated Supply and

Required degree for Selected Scientific, Engineering, and

Technical occupations .......................... vii

2.1 Workforce Needs Assessment Survey: Dimension Rating Scales . . 2.4

2.2 Survey of Current Hiring Conditions: Dimension Rating Scales . 2.4

2.3 Occupational Deployment Data Request Form: Variables

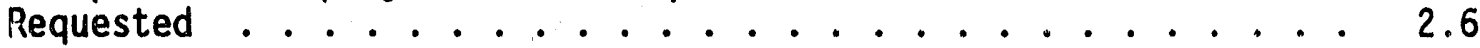

3.1 Surveys Received from Each Site ............ 3.2

3.2 Means and Standard Deviations for Relative Survey Ratings . . 3.2

3.3 Frequencies of Confidence Ratings on WNAS and SCHC ..... 3.3

3.4 Intercorrelations Among Survey Variables . . . . . . 3.4

3.5 Need for Occupations Ranked by Program/Project Managers . . . . 3.6

3.6 Ranking of Top Fifteen Occupations Based on Program/Project

Managers' Rankings of the Difficulty Caused by a Shortage

Critiality ...................... 3.7

3.7 Ranking of Top Ten Occupations Based on Human Resource

Managers' Ratings of Perceived Need for Each Occupation . . . . 3.9

3.8 Frequency Breakdown of Feedback Questionnaire

Responses by Field office ............... 3.12

3.9 Characteristics of Occupational Deployment Database . . . . 3.30

4.1 Current and Anticipated Full-time Equivalent Levels Based on
Constrained and Unconstrained Budget Projections...... 4.3

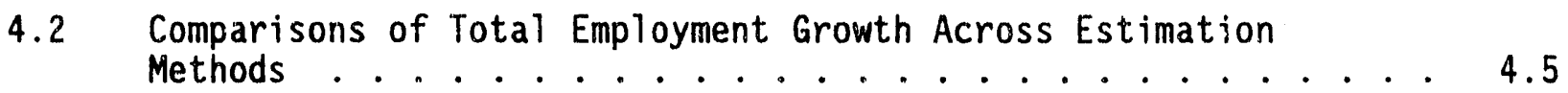

4.3 Replacement Needs in Constrained Case, 1991-1997 . . . . . . 4.11 
4.4 Priority Rankings for Candidate Occupations Based on Supply and

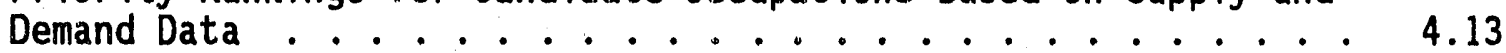

5.1 B.S. Science and Engineering Degrees Awarded in 1990 and Projected to 1997 . . . . . . . . . . . . . . 5.2

5.2 Ratings of Current Supply in Science and Engineering Fields Relevant to Environmental Restoration and Waste Management Mission ................. . 5.5

5.3 Employed 1988 and 1989 Bachelors in Science and Engineering Fields, Ranked by the Ratio of Jobs to Degrees Reported for Each Degree Field in 1990 . . . . . . . . . . . . 5.6

5.4 Employed 1988 and 1989 Bachelors in Science and Engineering Fields, Ranked by the Ratio of the Median Salary for Each Field Divided by the Median Salary for All Employed Bachelors in Science and Engineering ............. 5.7

5.5 Synthesis of Demand and Supply Data for High Growth and Critical Occupations ................. 


\subsection{INTRODUCTION}

The U.S. Department of Energy (DOE) has historically been a producer of research and materials which facilitated the development of nuclear weapons and power systems. The skills possessed by the individuals who have generally occupied positions within the DOE and its contractors reflected that mission. Nuclear engineers and scientists and chemical, civil, and electrical engineers have tended to fill positions in the DOE scientific and engineering community. Technicians have generally been trained by DOE or contractor-sponsored technical and science programs in local community colleges; these technicians have been typically employed in production and operation fields.

However, shifts in funding priorities and the DOE's increasing emphas is on environmental clean-up and hazardous waste management may disrupt these traditional employment patterns. In fact, it has been speculated that the new Environmental Restoration and Waste Management (ER/WM) mission will require a workforce with a skill set markedly different than the one currently available, to DOE and its contractors. Furthermore, the existence of the DOE's Office of Technology Development (EM-50), and particularly of its Division of Environmental Education and Development (EM-522), is predicated on a projected shortfall in appropriately trained human resources to accomplish the new ER/WM mission. The Environmental Restoration and Waste Management Five-Year Plan (DOE 1989b) and the Applied Research, Development, Demonstration, Test, and Evaluation Plan (DOE 1989a) have both stated that a significant potential constraint on implementing the DOE Environmental Management (EM) program is the availability of qualified human resources.

This study was designed to reduce uncertainty regarding the current and future ER/WM workforce in order to permit national-level education policy decisions. Estimates of the need for various occupations are compared with characterizations of the availability of workers in those occupations in 1 ight of program $\mathrm{plans,} \mathrm{market} \mathrm{forces,} \mathrm{and} \mathrm{institutional/organizational} \mathrm{constraints.}$ With this information, resources can be invested in a set of interventions likely to attract and retain appropriately qualified workers for the ER/WM 
mission. A conceptual overview of this process and intervention programs which may result is presented in Figure 1.1.

The scope of the study is limited primarily to those occupations that are most affected by education intervention programs. Specifically, it identifies and characterizes current and expected staffing difficulties in selected science, engineering, and technician occupations for the entire DOE ER/WM complex. Since workforce needs cannot be determined independent of the work to be accomplished, the study is also limited to the planning timeframe (Fiscal Years 1993-1997) considered in the Environmental Restoration and Waste Management Five-Year Plan. The goals of this study are accomplished via six tasks which were developed based on recommendations made by the Manpower Research Group (MRG) (a) to 1) develop budget-based total ER/WM employment estimates for relevant occupations based on Five-Year Plan projections; 2) survey DOE ER/WM and contractor ER/WM program/project managers to develop occupational staffing patterns and identify occupations for which current and/or expected meeds are perceive! as high; 3 ) estimate the availability of workers by examining current recruiting conditions; 4) estimate the availability of workers by examining the current deployment of DOE and contractor workers; 5). estimate the availability of future workers by examining the strength of relationships with educational institutions; and 6) estimate the availability of future workers by examining degree production at the national level for relevant disciplines.

Referring again to Figure 1.1, Tasks 1 and 2 were primarily intended to generate data regarding national level need or demand for workers in ER/WMrelevant occupations. Tasks $3,4,5$, and 6 were primarily intended to generate data regarding the availability or supply of such workers on a national level.

The actual implementation of the six tasks presented in Figure 1.1 was accomplished in the following manner. Tasks 2, 3, and 4 were linked and data supporting the tasks were collected using surveys and coded data requests

(a) See "Action Plan for ER/WM Manpower Assessment," U.S. Department of Energy, Office of Technology Development, Environmental Education and Development Branch, March 1991. 


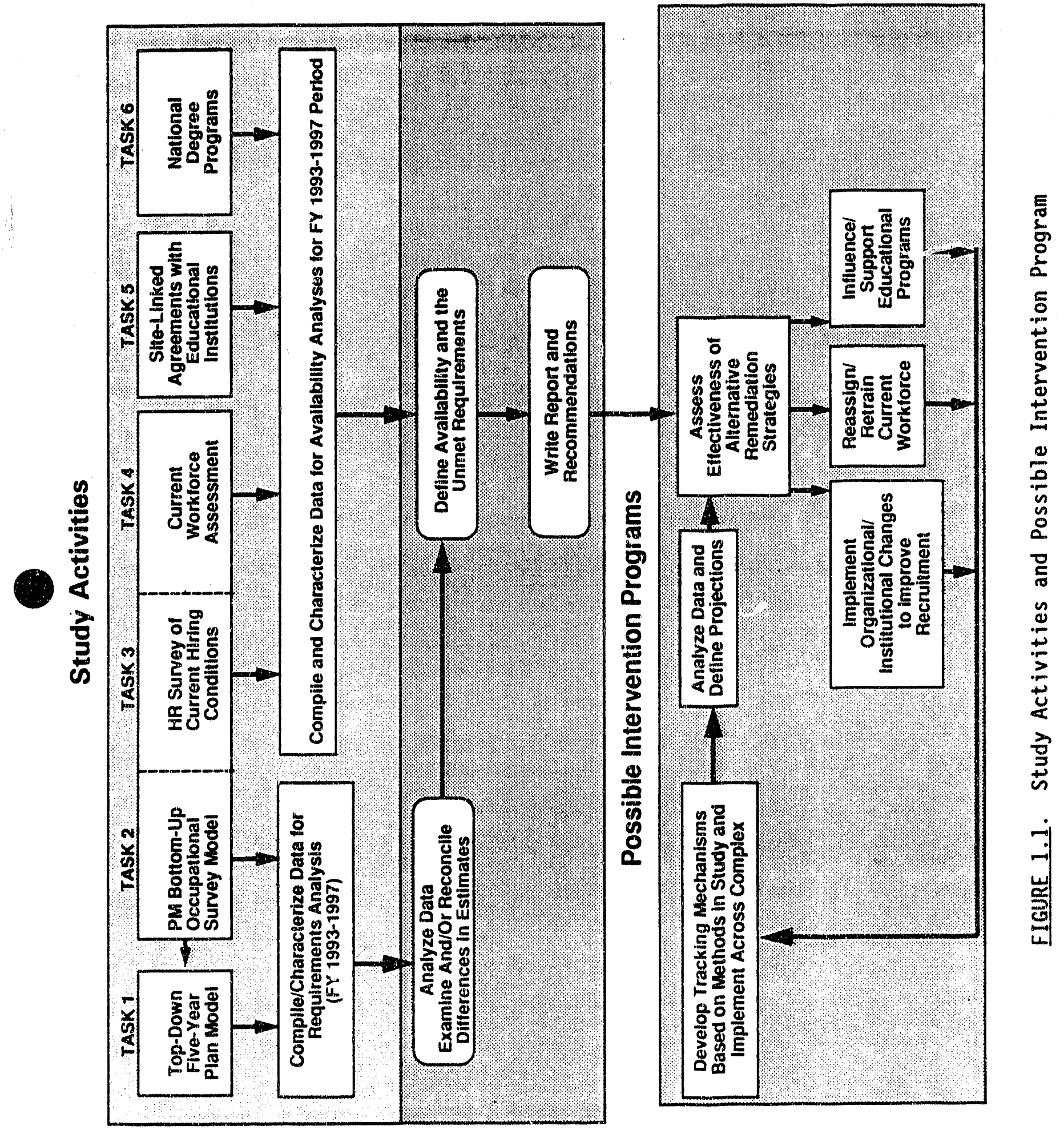


implemented in workshop (focus group) settings. Data for Task 1 were developed using staffing patterns from data collected as part of Task 2, for a set of occupations identified as relevant to the ER/WM mission and budget projections contained in the FY 1993-1997 Environmental Restoration and Waste Management Five-Year Plan (DOE 1989b).

Data for Task 5, which was intended to assess the extent to which sitelinked agreements with educational institutions serve as pipelines for new workers, were gathered in two phases. First, DOE and contractor staff participating in the workshops for Tasks 2, 3, and 4 were requested to identify any agreements they were aware of and provide points of contact regarding educational programs in their organizations. Follow-up contacts were then made with these points of contact to collect data regarding educational programs.

As noted above, Task 5 was originally intended to identify and provide an assessment of the degree to which agreements with various educational institutions serve to enhance the supply of workers available to DOE and its contractors. However, as data collection progressed for Task 5 it became apparent that such an undertaking was not possible given the lack of informa: tion regarding education assessment and tracking programs in the DOE system. Hence, the researcher conducting Task 5 chose to focus on developing an integrated compilation of agreements in place with various educational institutions across the DOE complex (this effort could serve an excellent baseline for the development of more formal evaluation programs). Also, where possible, qualitative assessments of educational programs were made. The results of this undertaking are presented in a separate document. (a) Accordingly, a discussion of Task 5 is not included in this document.

Data for Task 6 were generated from a variety of archival data sources and current studies, from organizations such as the U.S. Bureau of Labor and the National Science Foundation, regarding national degree production in scientific and engineering fields.

(a) Draft Report, "Education Programs and Related Agreements Between DOE Designated Sites and the Education Community." April 1992. Associated Western Universities, Inc., Salt Lake City, Utah. 
Given relationships between the tasks outlined above, the remainder of this document is organized in the following manner. A presentation of the methods and results for Tasks 2, 3, and 4 (which were conducted in concert and provide a basic framework for the remaining tasks) is presented first. A presentation of the methods and results for Task 1 and a discussion of the differences in employment estimates and staffing patterr, generated via the survey and budget models is then made. Following this is a presentation of the results from Task 6--national degree production in scientific and engineering fields--and a synthesis and discussion of demand and supply estimates for relevant occupations. Overall conclusions and recommendations based on the results from all of the tasks are then provided.

Finally, it is important to note that the current study represents an initial step in an overall process of assessing employment issues for the ER/WM mission. As depicted in Figure 1.1, such a process should be ongoing, iterative, and designed to refine and validate information regarding workforce issues. The study's results regarding expected employment issues for the ER/WM mission are useful only when viewed in the broader context of educational, technical, and management problems encountered in the process of obtaining qualified workers for the DOE ER/WM mission. 


\subsection{SURVEY METHODOLOGY}

Given the broad nature of the issues to be examined, a combination of qualitative and quantitative data collection techniques was deemed most appropriate for implementing Tasks 2, 3, and 4 in the current study. Specifically, a workshop format was developed consisting of survey and focus group segments for both program/project managers and human resources representatives. The combination of quantitative data collection via surveys and qualitative data collection via small group discussions provided for a rich dataset from which to assess workforce issues for the Environmental Restoration/Waste Management (ER/WM) mission.

\subsection{SURVEY CONSTRUCTION}

Two related surveys were developed to implement Tasks 2 and 3 of the Action Plan. The Workforce Needs Assessment Survey (WNAS) was constructed to obtain "bottoms-up" estimates of site-specific occupational needs and associated potential staffing difficulties from program/project managers. The Survey of Current Hiring Conditions ( $\mathrm{SCHC}$ ) was constructed to gather data from individuals in human resources departments on occupational turnover, recruit. ing difficulty, and the need for additional employees. The surveys are reproduced in Appendixes $A$ and $B$.

Given that specific job titles and responsibilities often vary greatly among organizations, functional descriptions were developed for each occupation included in the surveys, based primarily on the U.S. Department of Labor Dictionary of Occupational Titles (DOL 1977) and the U.S. Bureau of Labor Statistics Occupational Employment Survey taxonomies (Bureau of Labor Statistics 1988). This approach is consistent with that taken in similar occupational surveys (e.g., salary surveys), and it was thought that functional definitions would apply to a wider variety of sites, be easily understood by respondents, and permit a more accurate assignment of anticipated occupational needs to post-secondary degree programs.

The 53 occupations were drawn from a larger list of job titles obtained from the Dictionary of Occupational Titles (DOL 1977), the Occupational 
Employment Survey, the Hazardous Waste Action Coalition salary survey conducted by $\mathrm{Wm}$. M. Mercer, Inc., and staffing profiles obtained from U.S. Department of Energy (DOE)-contractor organizations. The final list of occupations was designed to sample both the established production and newly emerging remediation and restoration areas. The feasibility of using the specific occupations included in the survey was assessed by contractors and the Manpower Research Group (MRG). Since this list could only be representative of the relevant occupations, respondents were given the option of adding occupations in an "Other" category. Finally, it should be noted that the 53 occupations included in the survey heavily emphasized scientific, engineering, and technical career fields; this is consistent with the DOE. (EM-522) emphasis on developing educational and training programs designed to increase the availability of qualified workers in these areas to DOE and its contractors. However, selected occupations of potential interest were also included in the surveys under an "Administrative/Other Career" category.

Survey respondents rated the same 53 occupations in the technician, engineering, scientific, and administrative/other occupational fields on six dimensions in the WNAS and on five dimensions in the SCHC. Dimensions varied across surveys, based on the knowledge that each set of respondents was expected to be able to provide. Program/project managers were believed to have relatively greater insight into program-specific needs for occupations. Since scientists and engineers are often recruited via friends and professional networks, it was also believed that program/project managers would have some feel for recruiting opportunities in the external market. It was thought that human resources representatives would have a keen understanding of the external market, recruiting difficulties, and turnover, but be less aware of the difficulty caused by a shortage of qualified practitioners in a specific occupation and the need for various occupations.

The program/project managers were requested to rate three of the dimensions on the WNAS in an absolute manner and three in a relative manner. Absolute ratings by occupation were obtained from the program/project managers including 1) the current number of full-time equivalent employees (FTES) in their organization, 2) the number of FTEs they anticipated would be needed in 
Fiscal Year 1997 to accomplish the goals outlined in the ER/WM Five-Year Plan, and 3 ) the peak number of employees they would need during the five-year period to accomplish the ER/WM goals. It was explained to respondents that peak numbers were being collected to detect short-term fluctuations in employment due to, among other reasons, program shutdowns or site/facility decommissioning. Accordingly, respondents were told to use the peak column to indicate peaks or troughs in employment when appropriate.

The dimensions rated in a relative manner by the program/project managers and their accompanying scales are presented in Table 2.1. All of the dimensions used by the human resources representatives in rating the occupations are presented in Table 2.2 with the accompanying rating scales. The use of the "Difficulty Caused by a Shortage" scale warrants some discussion. It is intended as a measure of criticality--the extent to which a shortage experienced for an occupation would affect achieving mission goals. Traditionally, manpower planning is equated with a simple head count; an occupation with 100 open positions generally is more important to consider than an occupation with one or two positions. Yet, occupations that do not account for a large fraction of the current occupational deployment or that may be in relatively less need in a numerical sense may nevertheless warrant attention. The measure of "Difficulty Caused by a Shortage," or criticality, serves as a way of identifying such occupations. Criticality is not intended to be a measure of substitutability; it does not indicate which occupations may be replaced most readily or share the most skills with other occupations. Instead, it indicates which occupations may become bottlenecks and which could produce severe constraints in the system when qualified practitioners are in short supply.

The size and format of the surveys prevented scale anchors from being placed at the top of each page of the survey. In order to give respondents ready access to the anchors, they were printed on a loose-leaf page and included with the survey.

As is evident in Tables 2.1 and 2.2, two core dimensions were included in both surveys to allow for cross-group comparisons: 1) the degree to which 
IABLE 2.1. Workforce Needs Assessment Survey: Dimension Rating Scales TECHNICIANS

DIFFICULTY CAUSED BIY A SHORTAGE

1. Slight amount

2. Limited amount

3. Moderate amount

4. Considerable amount

5. Extreme amount

ANTICIPATED ABILITY TO RECRUIT

1. Very easy to recruit

2. Easy to recruit

3. Somewhat difficult to recruit

4. Difficult to recruint

5. Very difficult to irecruit

TYPICAL DEGREE LEVEL

1. High school degree or less

2. Associate degrees

3. Mix of Associate \& Bachelor degrees

4. Bachelor degrees

5. Advanced degrees
ENGINEERS/SCIENTISTS/OTHERS

DIFFICULTY CAUSED BY A SHORTAGE

1. Slight amount

2. Limited amount

3. Moderate amount

4. Considerable amount

5. Extreme amount

ANTICIPATED ABILITY TO RECRUIT

1. Very easy to recruit

2. Easy to recruit

3. Somewhat difficult to recruit

4. Difficult to recruit

5. Very difficult to recruit

TYPICAL DEGREE LEVEL

1. Mostly Associate degrees

2. Mix of Associate \& Bachelor

3. Mostly Bachelor degrees

4. Mix of Bachelor \& Advanced degrees

5. Mostly Ph.D. degrees

TABLE 2.2. Survey of Current Hiring Conditions: Dimension Rating Scales

DIFFICULTY CAUSED BY A SHORTAGE

1. Slight amount

2. Limited amount

3. Moderate amount

4. Considerable amount

5. Extreme amount

NEED FOR ADDITIONAL EMPLOYEES

1. Very low need

2. Some need

3. Moderate need

4. High need

5. Very high need

CURRENT EASE OF RECRUITMENT

1. Very easy to recruit

2. Easy to recruit

3. Somewhat difficult to recruit

4. Difficult to recruit

5. Very difficult to recruit
ANTICIPATED EASE OF RECRUITMENT

1. Very easy to recruit

2. Easy to recruit

3. Somewhat difficult to recruit

4. Difficult to recruit

5. Very difficult to recruit

CURRENT ANNUAL. TURNOVER

1. Very low

2. Low

3. Moderate

4. High

5. Very high 
a shortage of workers would impact the organization's ability to accomplish the goals specified in the ER/WM Five-Year Plan; and 2) the anticipated degree of difficulty expected in recruiting qualified individuals to fill positions within the occupational categories. Respondents to both surveys rated the same 53 occupations. In order to ensure that responses were based on the same assumptions and unit of analysis, directions were printed on the survey and given verbally. Respondents were asked to provide ratings for their EM programs only, to base estimates on the 1993-1997 Five-Year Plan, to include estimates for subcontractors in their estimates, and to assume that current technology will be used to meet the Five-Year Plan goals (see Appendixes A and $B$ ).

In order to implement Task 4 of the Action Plan, a generic dati request form was developed. Participants in the human resources focus groups were requested to provide data regarding the current deployment of their organization's workforce in electronic form (computer files in ASCII format). The decision to request actual computerized data was made on the basis of recommendations from the MRG. Participants were requested to provide data and coding explanations for ten generic variables deemed relevant to the study (see Table 2.3). The variables were selected on the basis of the researchers' expertise and recommendations made by the MRG. Human resources representatives from two DOE contractor organizations were also consulted regarding the selection of the variables. As with the SCHC the data request form was distributed to the human resource participants during the focus groups, and a discussion of the background and purpose of the data request was conducted.

\subsection{FOCUS GROUP DESIGN}

Focus groups were conducted using tailored Moderator's Guides, based on information derived from informal discussions with program/project managers and human resources representatives at the Hanford Site as well as recommendations provided by the MRG. These Moderator's Guides are presented in Appendixes $C$ and $D$. In all cases, a single moderator facilitated the discussions, and one to two recorders were present to assist the moderator by 
IABLE 2.3. Occupational Deployment Data Request Form: Variables Requested Variable

1. Exempt/non-exempt status (or other broad categorizations in use at the site, such as union/non-union, etc.)

2. Job title (and if relevant "job level" to allow differentiation among different levels of employees with the same job title such as first level, middle, or senior managers)

3. Job family

(such as management, engineering, scientist, crafts, technicians, etc.)

4. Highest degree

(highest degree each individual held)

5. Degree major

(the major of the highest degree)

6. Age

7. Race

8. Sex

9. Tenure

10. Program assignment/ organizational code

taking notes. Focus groups were used to elicit broad issues and generate discussion on topics that could not be tapped adequately by the surveys. Groups consisting of human resources professionals were kept distinct from those consisting of program/project managers in order to independently obtain their perceptions and examine the issues germane to each group.

\subsection{ASSUMPTIONS}

The assumptions made while developing the assessment methodology are outlined below:

- The 1993-1997 ER/WM Five-Year Plan time frame is a valid point of reference for workforce ard educational initiative planning. 
- Institutional, cultural, and organizational factors, in addition to economic supply and demand variables, influence manpower needs and recruiting success.

- A focus group format would yield data beyond that which could be gained solely from survey instruments.

- The 53 occupations included in the survey cover the EM field in sufficient breadth to permit valid inferences regarding scientist, engineer, and technician manpower needs.

\subsection{PRE-TEST OF INSTRUMENTS}

Draft surveys and focus group Moderator Guides were distributed to members of the MRG for comment before data collection. Suggestions regarding the anchors, scale formats, and occupational titles were incorporated in subsequent drafts of the surveys. Comments on the issues to be addressed in the focus groups were used to refine the proposed questions.

A pre-test was then conducted at Hanford to obtain the input of potential respondents. Four surveys and focus group Moderator's Guides were distributed to contractor and DOE program/project managers and human resources representatives. Comments regarding the wording of questions, format of the survey, and appropriateness of respondents were addressed. Participants in the pre-test generally felt the 53 occupations comprehensively addressed the domain of occupations relevant to the ER/WM mission. Two respondents completed the survey during the pre-test. Their data were included with that collected during the study since only minor changes were made to the wording of the instructions in the surveys following the pre-test.

The data request form for the survey of current occupational deployment was not formally pre-tested. However, as noted above, human resource representatives from two. DOE contractor organizations were consulted regarding its development.

\subsection{SELECTION OF WORKSHOP SITES AND PARTICIPANTS}

A comprehensive sample of DOE sites with varying missions, long-range schedules, and locations is included in the database. Site visits, telephone/ video conferences, and mail contacts were conducted at a variety of sites and 
field offices. Contacts were made with as many sites as possible on each site visit; thus, a trip to the Field office, Albuquerque, also permitted the opportunity to collect data from Los Alamos National Laboratory, Sandia National Laboratory, and the Uranium Mill Tailings Remedial Action (UMTRA). A map of site contacts is shown in Figure 2.1.

Efforts were made to ensure that participants in the workshops could adequately characterize the needs and issues at their site. Onsite points of contact made through the MRG or other projects helped identify and recruit appropriate personnel. Specifically, program/project managers were recruited who accounted for EM programs onsite, especially those who could represent major programs. Consistent with the emphasis on obtaining "bottom-up" estimates, the individuals recruited were those who were involved with manpower issues and/or the ER/WM Five-Year Plan as they pertained to their program, project, or organizational unit. Stated differently, an emphas is was placed on recruiting individuals with sufficient program oversight responsibilities to be knowledgeable about broad manpower issues affecting the program, yet with enough day-to-day contact to know specific manpower needs and difficulties. In some cases, programs were represented by program managers, but more often the individuals with the most relevant knowledge were at the project or line management level. They typically held titles of project manager or senior engineer. The DOE participants were typically branch chiefs and technical program officers. It was anticipated that individuals outside program/project management and human resources would add relatively little independent information. Therefore, they were not included in survey or workshop data collection efforts.

Human resources participants were recruited from a variety of functions, including staffing, recruiting, compensation, and educational and training programs. For human resource participants, the mixtures of managers and non-managers varied for DOE and contractor organizations, depending on the structure of each organization. However, it was apparent that human resource participants generally maintained close contact both with their internal clients and with the external human resource community. Thus, they were able to communicate a variety of perspectives during the focus groups. 


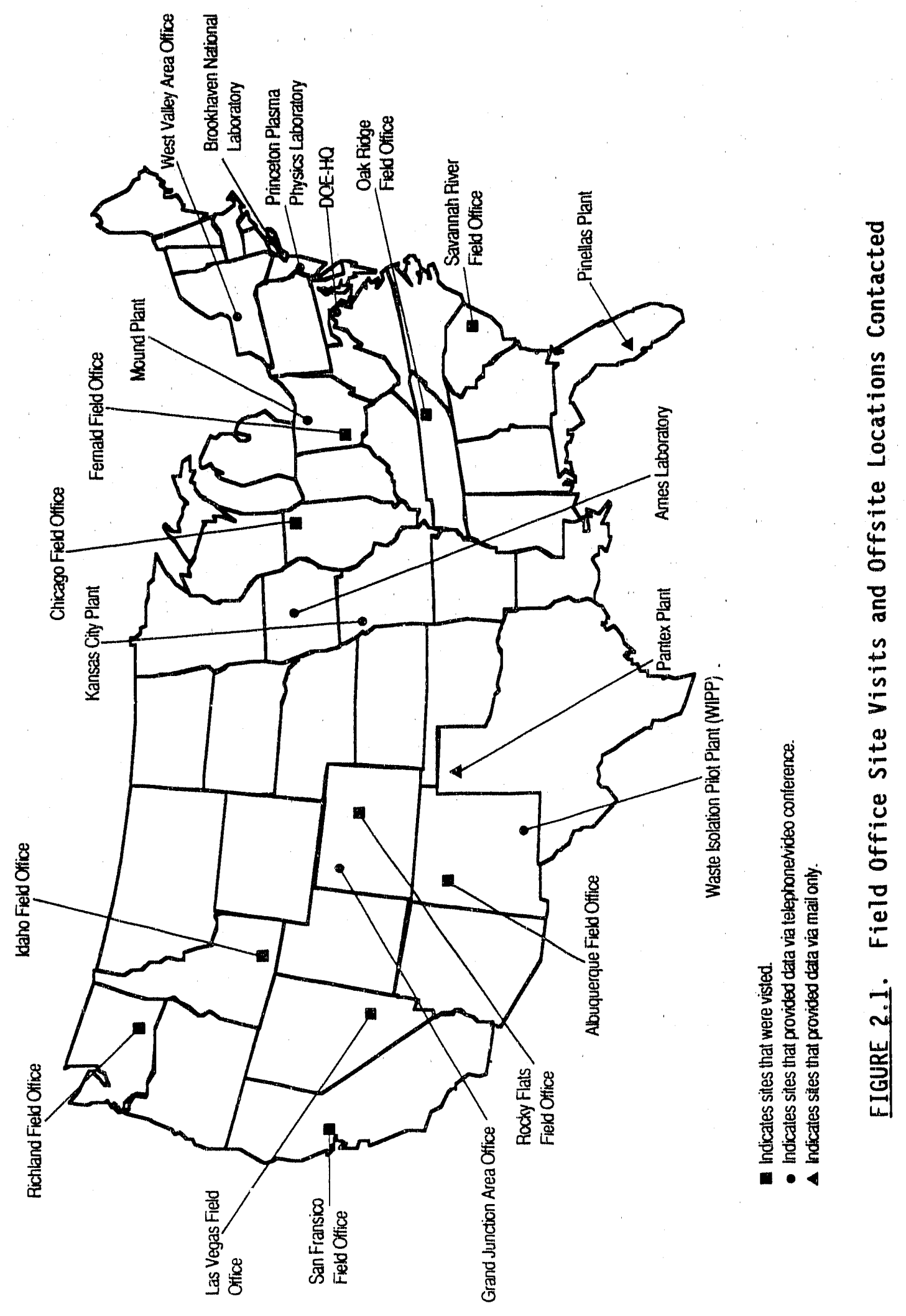




\subsection{DATA COLLECTION PROCEDURE}

The number of workshops conducted at each site varied based on the size of the site, number of programs, and schedules of participants. Workshops generally lasted three to four hours. Participants were briefed on the purpose of the study and introduced to the focus group leaders at the beginning of each workshop. The surveys were then explained and distributed, and approximately 45 minutes was devoted to completing them. Respondents were instructed to pull out the page containing the scale anchors and refer to it as they progressed through the survey. A general discussion about the survey opened the focus-group portion of the workshop and led into the broader issues outlined in the Moderator's Guide. At many sites, however, respondents wanted more time to examine and complete the survey than could be allotted in the workshop. In these cases the surveys were completed subsequent to the focus group and returned to the researchers via mail. Individual interviews or group teleconferences were scheduled with program/project managers who could not attend the workshops. The same issues probed in the focus groups were also covered in the interviews and conferences.

In the human resource representatives focus groups, the data request form for Task 5 was distributed and discussed at the completion of the focus group session. In several cases participants indicated that they would need to contact more appropriate individuals to determine the availability of the data. These individuals were requested to provide the form to the appropriate personnel, and the researchers provided their phone numbers in case additional questions arose. In all cases the current deployment data was mailed to the researchers at a later date. 


\subsection{SURVEY RESULTS}

The following section presents analyses of the quantitative data collected in the surveys. Complex-wide results for the Workforce Needs Assessment Survey (WNAS) and Survey of Current Hiring Conditions (SCHC) are presented first, followed by analyses of cross-site differences, and then, results regarding the attempt to characterize the current deployment of the DOE workforce. Finally qualitative results from the focus groups are summarized.

\subsection{QUANTITATIVE RESULTS FROM SURVEYS}

The quantitative results of the surveys are discussed in the following subsections.

\subsubsection{Complex-Wide Results from Workforce Needs Assessment Survey and Survey of Current Hiring Conditions Surveys}

Human resources respondents completed 54 SCHC forms, whereas 121 WNAS forms were completed by program/project managers. A breakdown of the number of surveys received from each site is shown in Table 3.1. Means and standard deviations for the relative ratings provided by human resources representatives and program/project managers across sites are listed in Table 3.2 . Responses to the variables seem bias-free; mean ratings are quite close to the scale midpoint, and minimums, maximums, and standard deviations suggest that responses are distributed normally. Turnover, which was generally rated as low, is the only exception. Thus, respondents appear to have used the full range of scale responses available to them.

Respondents did not express $100 \%$ confidence in their ability to rate the variables included on the surveys. Frequencies of confidence ratings are presented in Table 3.3. The large majority of responses for both program/project managers and human resources professionals fall in the $40-80 \%$ confidence ranges. Program managers verbally expressed little confidence in their abil. ity to accurately estimate the absolute number of full time equivalent employees (FTES) needed in the future, but high confidence in their ability to determine the relative mix of FTEs across occupations. That is, al though they would quickly beg off their FTE estimates (say, 20 chemical engineers and 
TABLE 3.1. Surveys Received from Each Site

\begin{tabular}{|c|c|c|}
\hline Site & $\begin{array}{l}\text { WNAS } \\
\text { Surveys }\end{array}$ & $\begin{array}{c}\text { SCHC } \\
\text { Surveys }\end{array}$ \\
\hline $\begin{array}{l}\text { Albuquerque } \\
\text { Kansas City } \\
\text { Mound } \\
\text { Pantex } \\
\text { Pinellas } \\
\text { UMTRA } \\
\text { WIPP } \\
\text { Chicago } \\
\text { DOE-HQ } \\
\text { Fernald } \\
\text { Idaho } \\
\text { Grand Junction } \\
\text { West. Valley } \\
\text { Nevada } \\
\text { Oak Ridge } \\
\text { Weldon Springs } \\
\text { Richland } \\
\text { Rocky Flats } \\
\text { San Francisco } \\
\text { Savannah River }\end{array}$ & $\begin{array}{r}9 \\
6 \\
1 \\
2 \\
2 \\
3 \\
0 \\
4 \\
0 \\
13 \\
31 \\
1 \\
2 \\
7 \\
10 \\
0 \\
19 \\
6 \\
5 \\
0\end{array}$ & $\begin{array}{r}7 \\
1 \\
1 \\
1 \\
0 \\
3 \\
0 \\
7 \\
0 \\
1 \\
4 \\
0 \\
0 \\
1 \\
4 \\
0 \\
16 \\
1 \\
3 \\
1\end{array}$ \\
\hline Total & 121 & 54 \\
\hline
\end{tabular}

TABLE 3.2. Means and Standard Deviations for Relative Survey Ratings Variable Mean Standard Deviation

WNAS (Program Managers)

Difficulty Caused by a Shortage Anticipated Arility to Recruit Degree Level

SCHC (Human Resources)

Difficulty Caused by a Shortage Need for Additional Employees Anticipated Ability to Recruit Annual Turnover
2.84
0.45
2.74
0.47
$3.32^{(a)}$
$0.84^{(a)}$
2.68
0.57
2.50
0.51
2.75
0.49
1.99
0.34

All ratings made on a 1 (lowest) to 5 (highest) Likert Scale. See Table 2.1 for specific scale anchors.

(a) Scale anchors for Degree Level varied based on occupation (see Table 2.1). 
TABLE 3.3. Frequencies of Confidence Ratings on WNAS and SCHC

Confidence Band

0 to $20 \%$

21 to $40 \%$

41 to $60 \%$

61 to $80 \%$

81 to $100 \%$

No rating

\begin{tabular}{r}
\hline Freque \\
\hline 1 \\
15 \\
34 \\
40 \\
13 \\
18
\end{tabular}

18

\section{WNAS}

Percent

1
12
28
33
11
15

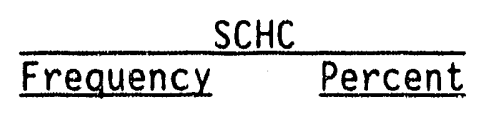

$$
\begin{array}{r}
2 \\
4 \\
10 \\
42 \\
13 \\
30
\end{array}
$$

10 chemical technologists), they felt that the 2 to 1 ratio of chemical engineers to technologists would be stable and accurate. Human resources respondents are more confident in their ratings than program managers, possibly because human resource surveys did not require point estimates of FTES.

Correlations among survey variables plus FTE GROWTH, a difference vari-. able created by subtracting current FTE deployment from anticipated FTE estimates, are presented in Table 3.4. Correlations among the variables rated by respondents from human resources are quite high. Thus, human resources representatives perceive that the occupations highest in demand tend to be those that will cause the most difficulty if in shortage and also pose the most difficult recruiting challenges. To a slightly lesser extent, they are also the occupations most likely to suffer turnover. Further, occupations for which recruiting is currently difficult are anticipated to remain so into the future $(r=.96, p<.01)$. Notably, at least some growth is expected in all but two occupational titles.

Program/project managers appear to see different patterns among the variables for which they provided point estimates and ratings. Total point estimates of current and anticipated number of FTEs are quite highly correlated, indicating that these managers do not anticipate the relative overall 


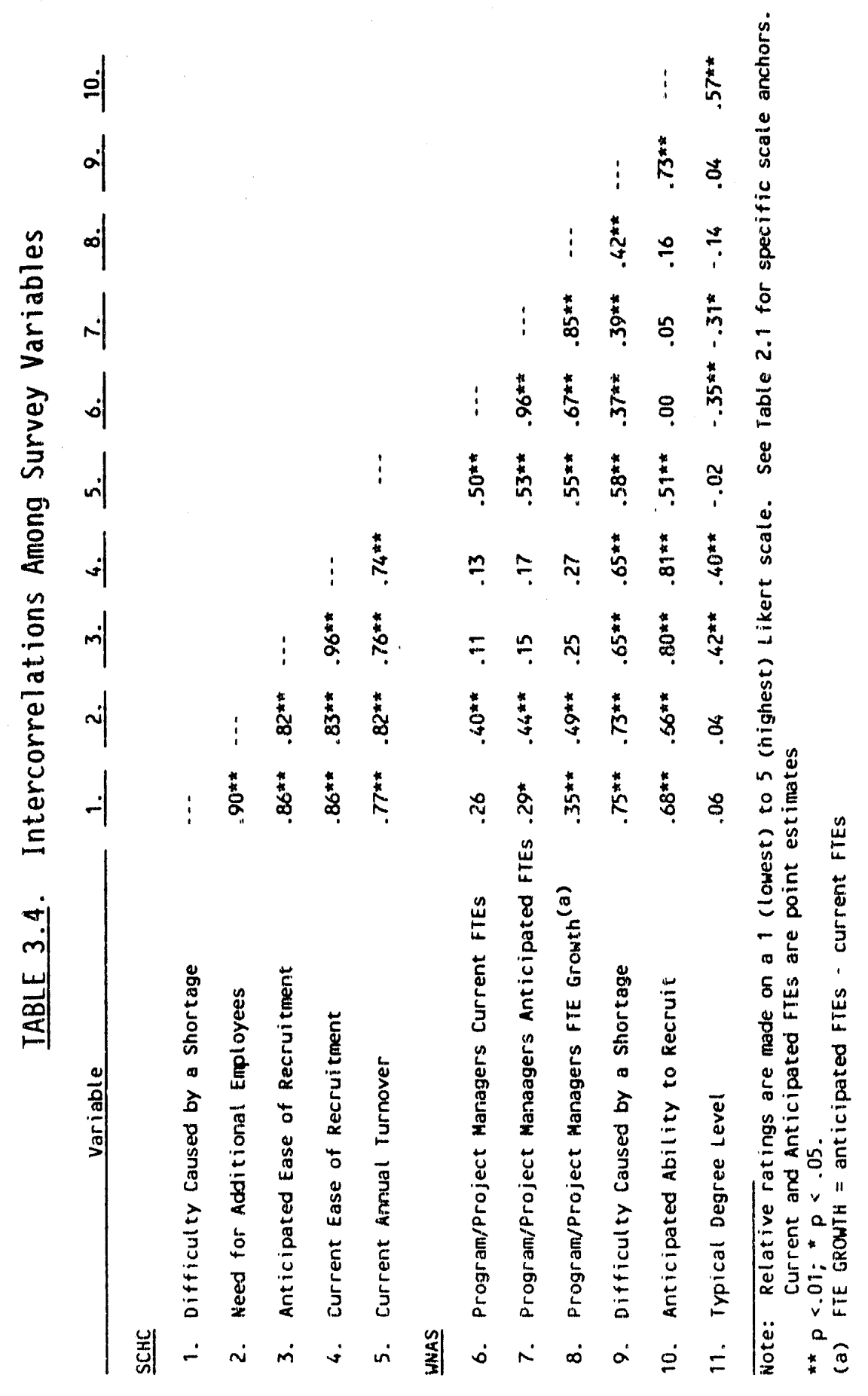


skills mix among occupations to change markedly. (a) However, the strong correlations between the FTE GROWTH variable and current $(r=.67, p<.01)$ and anticipated $(r=.85, p<.01)$ FTEs indicate that program/project managers were simply not adding a constant number to all current FTEs to calculate anticipated FTEs. Hence, although the proaram managers do not expect the overall skills mix to change radically over the Five-Year Plan period, they do expect absolute occupational growth to occur differentially among the occupations examined.

Rankings of the occupations most needed by program/project managers appear in Table 3.5 along with values for current, anticipated, and growth in FTEs, and the preferred degree levels. Needs, which reflect the absolute increase in employment projected for each occupation, were categorized as extreme, high, moderate, low, and minimal, based on the distribution of FTE GROWTH. Extreme needs are reported for environmental, mechanical, and chemical engineers, administrative and clerical workers, project managers, and material handlers. A variety of engineers and technicians are anticipated to be in high demand.

Program/project managers appear to have discriminated between projected growth in FTEs and the difficulty that would be caused by a shortage of employees. The occupations with the largest projected increases in employment are only partly those occupations that program/project managers believe to be the most critical $(r=.42, p<.01)$. Table 3.6 compares program/project manager ratings of "Difficulty Caused by a Shortage" with the need (i.e., the projected growth) for employees for the 15 occupations ranked most critical for meeting goals. (See Appendix E for a complete listing of the occupations

(a) Since peak estimates were not made by a large segment of the program managers. Results regarding peak FTE estimates are not presented or discussed for the overall complex. Respondents were instructed to use the "peak" column to register peaks/troughs in FTEs they expected to occur between FY 1993 and FY 1997. Nonrespones to this variable, then, indicate linear growth assumptions on their part. Further, peaks and troughs occur in different years at different sites. Hence, summing estimates across sites is conceptually inappropriate. (See Section 3.1 .2 regarding the relevance of peak estimates to cross-site comparisons.) 


\section{TABLE 3.5. Need for Occupations Ranked by Program/Project Managers}

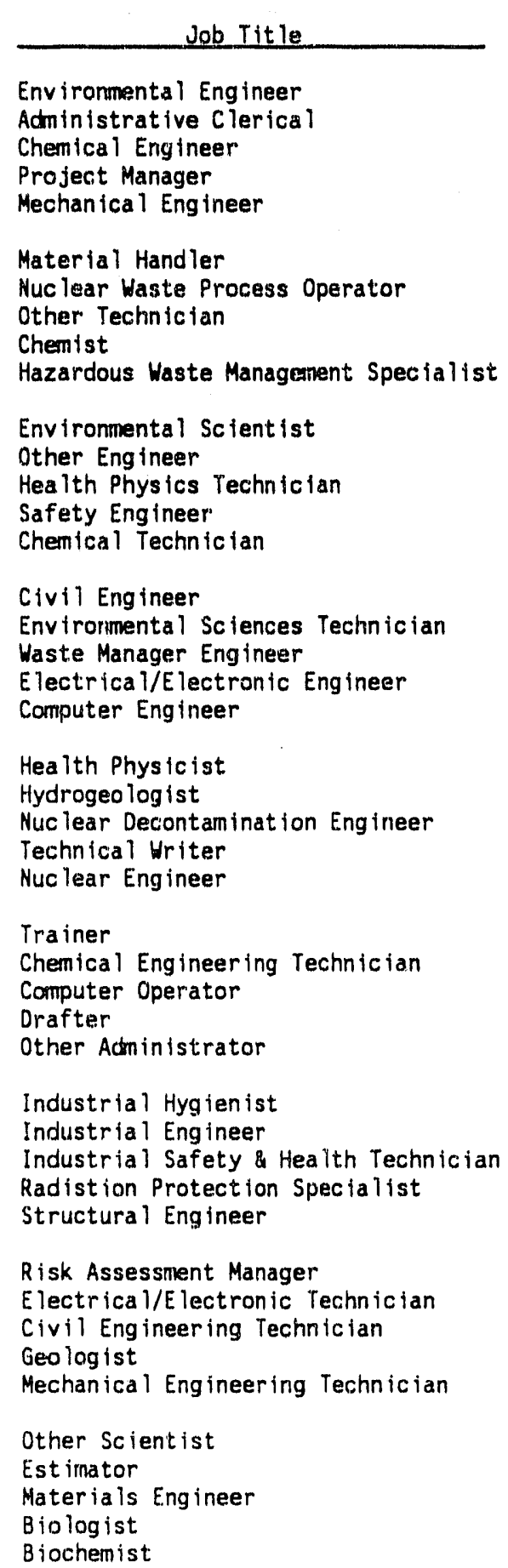

\begin{tabular}{|c|c|c|c|}
\hline ETE GROWTH & $\begin{array}{c}\text { FTE } \\
\text { Current }\end{array}$ & $\begin{array}{c}\text { FTE } \\
\text { Anticipated }\end{array}$ & Deqree Leve 1 \\
\hline $\begin{array}{l}286 \\
283 \\
525 \\
251 \\
247\end{array}$ & $\begin{array}{l}515 \\
987 \\
264 \\
619 \\
495\end{array}$ & $\begin{array}{r}891 \\
1279 \\
789 \\
879 \\
742\end{array}$ & $\begin{array}{l}\text { Mix of BS and Advanced } \\
\text { Mostly Associate } \\
\text { Mix of BS and Advanced } \\
\text { Most ly Bache lor } \\
\text { Mix of BS and Advanced }\end{array}$ \\
\hline $\begin{array}{l}212 \\
167 \\
151 \\
112 \\
101\end{array}$ & $\begin{array}{l}398 \\
615 \\
416 \\
371 \\
181\end{array}$ & $\begin{array}{l}610 \\
782 \\
567 \\
483 \\
282\end{array}$ & $\begin{array}{l}\text { HS or less } \\
\text { Mostly Associate } \\
\text { Mix of BS and Advanced } \\
\text { Mix of AS and BS }\end{array}$ \\
\hline $\begin{array}{r}100 \\
99 \\
98 \\
87 \\
84\end{array}$ & $\begin{array}{r}290 \\
161 \\
451 \\
59 \\
289\end{array}$ & $\begin{array}{l}380 \\
260 \\
549 \\
146 \\
373\end{array}$ & $\begin{array}{l}\text { Mix of BS and Advanced } \\
\text { Mostly Associate } \\
\text { Mostly Bache lor } \\
\text { Mix of AS and BS }\end{array}$ \\
\hline $\begin{array}{l}84 \\
83 \\
77 \\
73 \\
73\end{array}$ & $\begin{array}{l}315 \\
249 \\
214 \\
215 \\
164\end{array}$ & $\begin{array}{l}399 \\
332 \\
291 \\
288 \\
237\end{array}$ & $\begin{array}{l}\text { Mix of BS and Advanced } \\
\text { Mix of AS and BS } \\
\text { Mix of BS and Advanced } \\
\text { Most ly Bachelor } \\
\text { Mostly Bachelor }\end{array}$ \\
\hline $\begin{array}{l}70 \\
67 \\
67 \\
64 \\
61\end{array}$ & $\begin{array}{r}102 \\
132 \\
40 \\
110 \\
117\end{array}$ & $\begin{array}{l}172 \\
199 \\
197 \\
174 \\
178\end{array}$ & $\begin{array}{l}\text { Mix of BS and Advanced } \\
\text { Mix of BS and Advanced } \\
\text { Mix of BS and Advanced } \\
\text { Mix of } A S \text { and } B S \\
\text { Mix of BS and Advanced }\end{array}$ \\
\hline $\begin{array}{l}59 \\
59 \\
57 \\
55 \\
54\end{array}$ & $\begin{array}{l}134 \\
125 \\
123 \\
158 \\
271\end{array}$ & $\begin{array}{l}193 \\
184 \\
180 \\
213 \\
325\end{array}$ & $\begin{array}{l}\text { Mix of AS and BS } \\
\text { Mostly Associate } \\
\text { Mix of AS and BS } \\
\text { Mastiy Associate }\end{array}$ \\
\hline $\begin{array}{l}51 \\
45 \\
42 \\
40 \\
37\end{array}$ & $\begin{array}{r}56 \\
113 \\
84 \\
87 \\
59\end{array}$ & $\begin{array}{r}107 \\
158 \\
126 \\
127 \\
96\end{array}$ & $\begin{array}{l}\text { Mostly Bachelor } \\
\text { Mostly Bachelor } \\
\text { Mix of AS and BS } \\
\text { Mix of AS and BS } \\
\text { Mix of BS and Advanced }\end{array}$ \\
\hline $\begin{array}{l}36 \\
35 \\
36 \\
29 \\
26\end{array}$ & $\begin{array}{r}50 \\
179 \\
43 \\
191 \\
128\end{array}$ & $\begin{array}{r}86 \\
214 \\
73 \\
220 \\
154\end{array}$ & $\begin{array}{l}\text { Mostly Bachelor } \\
\text { Mostly Associate } \\
\text { Mostly Associate } \\
\text { Mix of BS and Advanced } \\
\text { Mostly Associate }\end{array}$ \\
\hline $\begin{array}{l}24 \\
23 \\
23 \\
22 \\
22\end{array}$ & $\begin{array}{r}52 \\
187 \\
44 \\
45 \\
18\end{array}$ & $\begin{array}{r}76 \\
210 \\
67 \\
67 \\
40\end{array}$ & $\begin{array}{l}\text { Mix of } A S \text { and } B S \\
\text { Mix of } B S \text { and Advanced } \\
\text { Mix of BS and Advanced } \\
\text { Mostly PhD }\end{array}$ \\
\hline
\end{tabular}

(continued on next page) 
TABLE 3.5. (contd)

Job Title

Survey \& Mapping Technician

Statistician

Remediation Specialist

Physicist

Materials Scientist

Ecologist

Mathematician

Petroleum Mining Engineer

Operations Researcher

Seismologist

Irrigation Engineer

Driller

Summary Technician (a)

Summary Engineer (a)

Totals

FIE GROW
21
19
19
15
15
15
10
9
7
2
-1
-5
618
198
44

5.016

-1
.5

618

44
FTE

Current:

\section{9}

16

102

27

16

37

. 18

29

7
2

5

150
149

11,028
Fre

Anticipated

40

35

121

42

31

52

28

38

14
7

$14 \quad 13$

13
63

63
902

348

193

16.044
Degree Level

Mostly Associate

Mix of BS and Advanced Mix of $A S$ and $B S$

Mix of $B S$ and Advanced

Mix of BS and Advanced

Mix of BS and Advanced

Mix of $B S$ and Advanced

Mix of $B S$ and Advanced

Mix of $B S$ and Advanced

Mostly PhD

Mix of $A S$ and $B S$

Mostly Associate

Ncte: Savannah River. WIPP, and DOE-HQ are not included in totals

(a) Indicates the total FTE values of one respondent who failed to allocate occupational family totals across individual occupations.

TABLE 3.6. Ranking of Top Fifteen Occupations Based on Program/Project Managers' Rankings of the Difficulty Caused by a Shortage Criticality

Occupation

Project Manager

Health Physics Technician

Chemist

Waste Management Engineer

Risk Assessment Manager

Driller

Environmental Scientist

Environmental Engineer

Radiation Protection Specialist

Hydrogeologist

Nuclear Decontamination Engineer

Hazardous Waste Management Specialist

Health Physicist

Chemical Engineer

Industrial Safety \& Health Technician
Criti-

cality Need

1

2

1

38

$4 \quad 16$

533

$6 \quad 53$

$7 \quad 10$

8

9

10

1

31

20

11

12
21

9

19

3

$\frac{\text { Degree Level }}{\text { Mostly Bachelor }}$
Mostly Associate
Mix of BS and Advanced
Mix of BS and Advanced
Mostly Bachelor

Mostly Associate

Mix of BS and Advanced

Mix of BS and Advanced

Mix of $A S$ and $B S$

Mix of $B S$ and Advanced

Mix of BS and Advanced

Mix of $A S$ and $B S$

Mix of BS and Advanced

Mix of BS and Advanced

Mix of $A S$ and $B S$ 
sorted by each of the rated variables.) of these 15 highly critical occupations, seven are anticipated to experience moderate or minimal growth.

This pattern suggests two different dimensions for projecting manpower needs based on program/project managers' ratings. First, consideration must be given to the absolute increase in FTEs by occupation. A second dimension, however, is the criticality of the occupation to the goals of the mission. Occupations high on both dimensions, such as project manager, environmental engineer, and chemical engineer warrant particular attention.

Unlike human resources respondents, program/project managers see 1 ittle relationship between projected increases in FTEs and the ease with which individuals can be recruited $(r=.16$, ns). They did, however, anticipate that the most critical occupations would also be the most difficult to successfully recruit in the future $(r=.73, p<.01)$. Correlations of typical degree level with the other variables indicate that program/project managers anticipate that individuals with advanced degrees will be the most difficult to recruit $(r=.57, p<.01)$, but that these individuals will not account for the bulk of the anticipated workforce increase. In fact, the level of education is negatively correlated with both current $(r=-.35, p<.01)$ and anticipated FTES $(r=-.31, p<.05)$.

Program/project manager ratings of difficulty caused by a shortage (criticality) and anticipated ability to recruit correlated highly with ratings of those same variables made by human resources respondents $(r=.76$ and $.80, p^{\prime} s<.01$, respectively). Ratings of occupational need by human resource managers, however, do not correlate as highly as might have been expected with program manager ratings of anticipated FTES and the FTE GROWTH measure $\left(r^{\prime} s=.44\right.$ and .49 , respectively, $\left.p^{\prime} s<.01\right)$.

Perceptions among program/project management and human resources respondents of the need for specific occupations and associated degree levels are compared in Table 3.7. Five occupations are common to the top ten on each table: environmental engineer and scientist, chemical engineer, hazardous waste management specialist, and chemist. Beyond this core group, the respondents perceived needs differently. Program/project managers see more need for 
TABLE 3.7. Ranking of Top Ten Occupations Based on Human Resource

Managers' Ratings of Perceived Need for Each Occupation

\begin{tabular}{|c|c|c|c|}
\hline Job Title & $\begin{array}{l}\text { Human } \\
\text { Resources } \\
\text { Need } \\
\end{array}$ & $\begin{array}{c}\text { Program } \\
\text { Manager } \\
\text { Need }\end{array}$ & Degree Level \\
\hline $\begin{array}{l}\text { Environmental Engineer } \\
\text { Health Physicist } \\
\text { Environmental Scientist } \\
\text { Waste Management Engineer } \\
\text { Health Physics Technician }\end{array}$ & $\begin{array}{l}1 \\
2 \\
3 \\
4 \\
5\end{array}$ & $\begin{array}{l}1 \\
19 \\
10 \\
16 \\
11\end{array}$ & $\begin{array}{l}\text { Mix of BS and Adv } \\
\text { Mix of BS and Adv } \\
\text { Mix of BS and Adv } \\
\text { Mix of BS and Adv } \\
\text { Mostiy Associate }\end{array}$ \\
\hline $\begin{array}{l}\text { Chemical Engineer } \\
\text { Nuclear Decontamination Engineer } \\
\text { Hazardous Waste Management Specialist } \\
\text { Chemist } \\
\text { Hydrogeologist }\end{array}$ & $\begin{array}{r}6 \\
7 \\
8 \\
9 \\
10\end{array}$ & $\begin{array}{r}3 \\
21 \\
9 \\
8 \\
20\end{array}$ & $\begin{array}{l}\text { Mix of BS and Adv } \\
\text { Mix of BS and Adv } \\
\text { Mix of AS and BS } \\
\text { Mix of BS and Adv } \\
\text { Mix of BS and Adv }\end{array}$ \\
\hline
\end{tabular}

technicians and administrative employees (four occupations listed) than did human resources respondents, who listed only two such occupations. Those inhuman resources report higher needs for engineers and scientists (eight of the ten highest-need occupations) than program/project managers (six science and engineering occupations).

Similar patterns result when the typical degree levels associated with high-need occupations are examined. Human resources representatives see more need for individuals with higher degrees (eight of the ten positions typically carry bachelors and advanced degrees). Only one position identified by human resources typically carries an associate degree, whereas none carrying high school degrees are listed. Program/project managers see relatively less need for employees with advanced degrees (six of ten) and relatively more need for occupations typically carrying high school or associate degrees (four of ten).

Respondents listed a total of 129 occupations in the "Other" sections of the surveys. Program and project managers added 38 technician, 25 engineer, 13 scientist, and 35 administrative positions. Human resources respondents added 10 technician, 3 scientist, and 5 administrative occupations. Many of these additions, however, do not appear to be truly different from the survey occupations. Rather, they appear to be slightly different occupational titles. Many of the administrative positions, for instance, are variations on 
budget, financial, and program analyst and administrator titles, all of which can be assumed to perform related duties. The engineering positions listed are primarily in the plant, quality, and safety engineering disciplines. These positions correspond to no particular college discipline and were mentioned often in the focus groups as homegrown specialties difficult to staff. They are examined more fully in Section 3.2.3. Overal1, the additions to other occupational families are too broad to categorize into meaningful subgroups for further analyses.

\subsubsection{Cross-Site Differences in Need and Criticality}

A variety of analyses were conducted to determine if there were substantial, meaningful cross-site differences in need and criticality for the 53 occupations. All analyses essentially indicated that sites did not differ markedly among themselves in the occupations they judged as critical or most in need; the most critical and needed overall occupations tend also to be the ones identified by individual sites. The exception is the need for certain occupations in the UMTRA and West Valley programs. Unlike other sites these are slated for closure in the very near future. They therefore report substantial projected declines in workforce, particularly for those occupations in demand elsewhere (health physics iecrinicians, civil engineers, and administrative/clerical occupations). Rocky flats also tended to show declines in several of these occupations, and sites with smaller workforces in general tended to show nonlinear growth/decline patterns. These declines, however, appear neither sufficient in magnitude nor appropriately timed to satisfy the vast majority of demand at other sites. Results consistent with those presented in Section 3.1.1, as well as peak FTE estimates, are presented for each site inciependently in Appendixes $F$ through $V$.

However, readers should take extreme caution in interpreting sitespecific data. The purpose of the current study was to identify changing trends in occupational deployment and growth at the national level, and data were collected and aggregated to serve that end. A somewhat different dataset is required to complete local analyses; hence, drawing specific, site-level conclusions from disaggregated national data may be inappropriate. 


\subsection{QUALITATIVE RESULTS}

Qualitative results are described in the following subsections.

\subsubsection{Data Coding and Compilation}

Moderators and recorders kept notes of focus group sessions. They recorded general themes, quotes, and specific topics that occurred. Notes consist of logical segments defined by the notetaker. Moderators and recorders independently linked to these segments key words to facilitate categorizing the comments. However, the key words were agreed upon by the notetakers to ensure consistency of information retrieval. Categories of notes were then examined by the authors for internal consistency, relevance, and parsimonious presentation.

In addition, steps were taken to give focus group participants feedback on the workshop and extend them the opportunity to provide feedback to the investigators. A summary of the ideas, comments, and concerns that were recorded was sent to each participant along with a cover letter and short feedback questionnaire (see Appendix $W$ ). (Due to an administrative error, feedback questionnaires were not included in the packages sent to Albuquerque participants.) Participants were asked to evaluate how well investigators interpreted the discussion by circling the appropriate number on a 5-point Likert-type scale ( $1=$ summary captures none of the main points, $5=$ summary captures all of the main points). Participants were also asked to add/delete items, revise any they felt needed changing, and assess whether any functions or departments were missing from the focus group workshop.

Seventeen responses were received from participants. A frequency breakdown of responses by field office is listed in Table 3.8. Respondents felt that the summary accurately reflected the points expressed during the focus group (mean rating $=4.89$ ). Overall, few additions, deletions, or changes to the write-ups were suggested, and respondents largely felt that the proper organizational units were represented in the groups.

The categorization and feedback process resulted in the following focus group themes:

- the skills mix necessary to accomplish the ER/WM mission 
TABLE 3.8. Frequency Breakdown of Feedback Questionnaire Responses by Field office

\section{Field Office Frequency}

Albuquerque

Fernald

Savannah River

Oak Ridge

Rocky Flats

Richland

Chicago

Total
2
2
2
1
3
7
0

17

- occupations perceived to be critical and/or difficult to fill

- the impact of regulations, regulatory bodies, and regulatory training on mission definition and accomplishment

- the DOE-contractor working relationship

- education and training initiatives

- minority recruiting and retention issues

- issues regarding salary and benefits

- organizational and institutional barriers to manpower planning and staffing.

\subsubsection{Skills Needed to Accompl ish the Environmental Restoration and Waste} Management Mission

Individuals in human resources and program management functions (both DOE and contractors) report little need for large-scale, immediate changes in the overall workforce skills mix in order to meet currently identified ER/WM goals. Although many managers feel the spectrum of skills needs will be broad regardless of staffing levels, the DOE complex can capitalize on current scientific, engineering, and technical skills to begin remediation and restoration activities. Further, any changes in the skills mix will occur rather gradually over time and become more apparent as the technologies and the extent of clean-up are defined. 
Managers' belief that few immediate changes are necessary is based on the skills of the people currently employed within the complex, the nature of the jobs they fill, and the manner in which technologies are developed and applied to the field. Strong basic science and technical skills are perceived to be largely non-specific in application with the exception of hybrid or specialty occupations. Well-trained technical people, it is believed, can transfer readily among programs and need only a short period of time to become re-oriented--"an engineer is a portable person." Difficulties experienced when moving individuals from one technical position to another are due mainly to lack of interest (i.e., a scientist who wishes to remain in a particular research area, such as theoretical nuclear physics). Many managers feel that personal initiative and ability to learn on the job are the most crucial attributes one can bring to the organization. One stated, "If I could get aggressive people who understand technical issues (no matter what major they are) and are willing to learn, we could accomplish $90 \%$ of what needs to be done."

DOE, especially, has made use of versatile employee technical skills. DOE managers continue to use individuals with general backgrounds who are capable of overseeing a variety of projects. The talents DOE has hired have changed little despite the broader types of degree majors that DOE is now willing to consider. Many field offices, for instance, have begun recruiting physical scientists for positions which previously had been filled exclusively by engineers. Scientists are reported to be in greater supply than engineers and are perceived to bring to DOE technical talents similar to those of engineers at lower cost. Thus, the versatility of well-trained scientists, engineers, and technicians reduces the need for radical retraining or wholesale changes in the workforce.

Similarities between current technical positions and future ones also mitigate the need for radically new skills. Managers feel that the skills of many of the trained engineers and technicians in nuclear production should transfer readily to the ER/WM area. In the words of one program manager, the difference between whether a technician is conducting waste management functions or nuclear production functions often depends on whether he/she takes a 
sample at the beginning of a process or "fifty feet down the line." Many respondents noted that since waste management activities have historically been part of production activities at several sites, contractors have employees familiar with the basic tasks that will be used to accomplish EM goals, especially in the near term. For instance, they noted that the need to handle drums filled with radioactive material from a production line versus drums filled with radioactive soil from a clean-up site does not markedly change the job of a certified material handler. Many of the same comments were applied to positions such as soil testers and certified laboratory. technicians.

To the extent that training at the scientist, engineer, and technician level is necessary, respondents feel that there is time to accomplish it. Technologies evolve and are applied to the field over time. Field applications, in turn, influence the evolution of technology. Rarely are radically new technologies developed independently of the field and the skills of people in the field. Managers, therefore, see little benefit in waiting for the "right" people or "ideal" technologies to come along before beginning" work in earnest. Managers also emphasize that shutting down production programs takes more time than those only casually acquainted with the problem realize. For that reason, there will be a continuing need for some people with the very skills that many anticipate will soon be obsolete. The need for "old" skills eases whatever immediate retraining demands exist and provides an opportunity for gradually obtaining a mix of new skills from current and future workers. Additionally, managers felt that the broad science skills already in the workforce need only be augmented by specialized training for application to new fields or the new operational status. For instance, the conduct of operations philosophy adopted within the complex has not introduced new technologies, but has required that DOE line supervisors devote their efforts to more fields and integrate more activities. Training has been a necessary part of that transition, and for that reason, many program/project and human resource managers do not perceive the need for technical training to wane. On the contrary, this type of training may increase. Managers simply felt that this type of training has occurred under similar circumstances in the past, that it could be implemented with relative ease now, and that shut-down activities provide a 
time frame for doing it. Furthermore, human resource managers feel that retraining requirements are minimal if the time is taken to interview people and place them appropriately. Retraining becomes expensive when time is constrained and people are forced into positions that do not make the best use of their skills.

The same cannot necessarily be said for many of the production activities found at the Rocky Flats site and, to a lesser extent, Savannah River. Whereas sites such as Hanford, Fernald, and Oak Ridge have a large number of associate-degreed technical employees, the Rocky Flats and Savannah River sites have a larger percentage of non-college-degreed skilled crafts and semi-skilled individuals. Employees at these sites, such as machinists and floor production workers, are perceived to lack the scientific and technical background necessary for quick retraining. For this reason, attempts to transfer these individuals into the ER/WM mission via retraining are anticipated to be expensive and time-consuming.

\subsubsection{Occupations Perceived to be Critical and/or Difficult to Fill}

Although there is the general perception that massive retraining will not be necessary to obtain the proper skills mix for the EM mission, respondents did recognize that certain occupations necessary to the mission will be difficult co obtain. Generally, the occupations of most concern are not necessarily those with the highest numerical need, but those unique to the DOE complex. These occupations are characterized by highly specialized training or skills, such as hydrogeologists (low need in terms of absolute demand, but high need in terms of criticality) and regulatory analysts (high in current and continuing need and criticality). Other "niche" positions within the DOE complex are waste certification engineers, material science technicians, quality assurance engineers, radio-chemists, and health physics technicians/radiation monitors.

Regulatory analysts currently appear to be a mix of attorneys, scientists, and self-taught regulatory experts. Both program/project managers and human resources professionals perceive a high and continuing need for individuals in this area. Most desirable are inose who combine an engineering or scientific background (preferably in chemical engineering) with regulatory 
experience or a law/contracts education. As it currently stands, the field is also largely homegrown within DOE, but individuals who have gained experience at other federal agencies, such as the U.S. Environmentai Protection Agency and the Occupational Safety and Health Adininistration, would be desirable. Most respondents who recognized the need for this occupation also noted that formal training and certification standards are necessary.

Quality assurance and safety engineers were also mentioned often as critical, homegrown occupations. Since quality assurance and safety are not college degree programs, these uccupations have traditionally been staffed by people who have transferred from other areas without much previous experience in quality and safety areas. The need now is to obtain people who have received in-depth training in quality assurance and safety principles and techniques.

Environmental safety and health occupations in general are in high demand. Health physicists and technicians, industrial hygienists, and industrial safety and health professionals, especially those with radiological backgrounds, are difficult to find. Employees in this area should also have toxicology experience. The health physics professions are so hard to recruit that any experience at all is desirable; finding a health physics technician with radiological experience is a bonus. Chemist and chemical engineer were often mentioned as occupations difficult to staff because of competition with the private sector for individuals having those backgrounds.

Environmental engineering and science, in the eyes of the focus group participants, has not yet developed as a specialty area or identity that is highly distinct from other engineering or scientific fields. At many sites managers tend to see environmental engineering slots as general entry-level science/engineering positions in which people can get experience and grow. Accordingly, the high need for environmental engineers identified in the quantitative results may be somewhat misleading. In practice, they are entrylevel civil, chemical, and mechanical engineers who apply their skills specifically to environmental concerns. It was also noted that many individuals who are perceived as typical environmental engineers do not have a sufficiently comprehensive understanding of the special issues associated with 
radioactive wastes. Clearly, these issues should be addressed if specialized curricula are to be developed that are designed to produce environmental engineers to support the DOE ER/WM mission.

Program and project managers are seen as difficult to find for a number of reasons. First, this position entails high responsibility and risk in the current regulatory environment. Second, many individuals with the appropriate technical and scientific background are not sufficiently well versed in business and management concepts to grasp the scope of the job, and few universities offer the engineering management curriculum that would teach those skills. Those that do are either not well known or not actively supported by the DOE community. Focus group respondents could not resolve whether an individual with well-developed program management skills, but with a non-technical background, could function as a program manager in the DOE complex. The need for program project managers is not perceived to be the result of attrition. Programs are simply expanding.

The perceived need for administrative support is high. Difficulties are reported from a variety of sites filling program/project administrator and data management positions. These individuals handle project filing systems and are a crucial, but often overlooked, aspect of the staffing plan. Sites which reported difficulties staffing these positions mentioned strong competition from local industry and the poor local education levels as factors. There is also a current need for schedulers and cost estimators which is expected to increase in the future as program planning and cost effectiveness receive increased emphasis.

Certain occupations are not of concern currently, but are perceived to become so as mission plans are operationalized. Managers noted that the onset of field remediation activities, for instance, is likely to increase the need for nuclear decontamination and decommissioning engineers and technicians, construction personnel, shipping/transportation coordinators, and packaging specialists. Interestingly, the entire area of transportation and where these activities will be "housed" is not well defined, considering the current uncertainty regarding the start-up of large-scale shipping. This causes unease 
among individuals involved in planning activities given that there is no clear understanding of which entities will be responsible for maintaining a transportation function.

\subsubsection{Regulations, Regulatory Bodies, and Regulatory Training}

Issues involving regulations and regulatory bodies and training are perceived to have a significant effect on all aspects of manpower planning. In fact, there is a perceived turf battle between EPA, DOE, and the various states. Moreover, characterization regulations differ from compliance regulations. These conflicting and competing priorities and regulations not only make it difficult to plan for the expertise needed to reach goals, but are responsible for technical people being placed in circumstances where they do too little technical work. Highly trained science and engineering professionals are working on regulatory, compliance, and quality review items instead of the work they are trained to do. The perception is that these people are too expensive and too highly trained to put their skills to use in this way and are frustrated by having to do so. Both recruiting and retention suffer as a resuit.

Regulations have grown more quickly than the ability of the complex to absorb them; managers cannot keep current because of time pressures and the lack of quality regulatory classes. Sending fully trained individuals into the field is therefore consistently difficult. These pressures are perceived to lead to overimplementation in order to avoid regulatory violations, which decreases productivity and increases even further the demand for regulatory experts and knowledge.

Respondents believe it is critical to ensure that people are trained in the regulations that apply to each site and that the appropriate people are trained to track regulatory changes. In addition to the need for regulatory analysts noted earlier, managers indicate strong demand for technically qualified individuals who understand the implications of regulations for the daily work of waste management and environmental restoration. Thus, there is the need for increased training on environmental issues, regulatory processes, and statutes. 
The regulatory training currently offered is characterized as contract negotiation training or a "you'11 go to jail for this" lecture. Classes are often not conducted by individuals with hands-on experience or a strong knowledge of the DOE complex. Hence, the classes convey neither the essence of the regulations nor the impact they have on the technical work that needs to be accomplished. Too little use is made of in-house regulatory expertise. Individuals within the DOE complex could expand their skills and enrich their jobs by conducting classes for individuals who need to comply with regulations in the course of their jobs. Additionally, the process of training employees of subcontractors, such as construction firms, is perceived as terribly burdensome because of the lack of qualified trainers.

Thus, manpower planning problems resulting from environmental regulation and compliance issues are twofold. In general, conflicting regulations and unclear jurisdictional authority complicate the specification of strategic and operational goals and objectives, thereby restricting the ability of human resources planners to conduct proactive manpower planning. This in turn largely ensures that, at the site level, specific needs regarding regulatory training are not addressed.

\subsubsection{DOE-Contractor Relationship}

The working relationship between DOE and its prime and subcontractors is materially influenced by differences among the institutional restrictions placed on each. The DOE is bound to certain hiring practices regarding salaries and degree majors. Prime contractors have more latitude than the DOE, whereas the subcontractors have few restrictions at a11. Prime contractors take pains to avoid the perception that they are using their salary advantage to attract people away from the DOE. Although respondents felt that they could remain sensitive to this for most occupations, they noted difficulties regarding occupations that are largely "grown" within the DOE complex.

Subcontractors and consulting firms are relied upon quite heavily throughout the complex for a variety of tasks. In many cases, they are the only source for highly specialized, hard-to-find occupational categories, such as hydrogeologists and regulatory analysts. Since they are subject to fewer restrictions, subcontractors can pay higher salaries and, at some sites, 
attract qualified individuals away from prime contractors and DOE. Once they spend time with the subcontractors these individuals can move back to a prime contractor or the DOE, often at a higher salary than an individual who stayed with one employer.

Although the salary differentials cause friction, managers noted that the use of subcontractors may be cost effective. Many waste management subcontractors have their own disposal facilities and include the cost of waste disposal in their estimates. Subcontractors generally handle many paperwork requirements and reduce the costs of maintaining a workforce. For instance, they eliminate the cost of employee benefits to DOE and allow DOE to avoid a reduction in force in a downturn or time of budget uncertainty. Sub. contractors are not bound by the restrictions placed on DOE and so have the flexibility to substitute experience for degrees when hiring employees.

Interestingly, subcontractors may fili an important part of the supply pipeline for the DOE complex. DOE cannot provide the hands-on experience that scientists and engineers who are beginning their careers need for rounding out their education. The exposure to numerous problems at a variety of sites that individuals receive in the consulting and subcontracting firms may be invaluable to career growth and maturity. DOE and prime contractors can capitalize on this breadth and maturity (which they cannot themselves provide), once individuals who entered consulting begin to need the security and stability the DOE or a prime contractor can offer.

Managers noted that while it is not desirable to have large numbers of employees who move from one subcontractor or prime contractor to another, it is important to recognize that these skills are still within the complex and that DOE and the contractors are "a11 in it together." More coordination is needed at the DOE-Headquarters (HQ) level to ensure these skills stay in the complex and are used productively.

\subsubsection{Education and Training}

It is the overwhelming belief among respondents that education and training initiatives are vital to the long-term success of the environmental mission. Moreover, if used well, respondents find internships, faculty 
fellowships, university research contracts, and educational outreach programs to be cost-effective recruiting and public relations tools. Local field offices, in conjunction with DOE-HQ, have invested heavily in a wide variety of educational programs for students from elementary school through the postgraduate level. Managers find that internships, fellowships, and research contracts directed at the university level not only solve the immediate problem of bringing qualified individuals onsite but have the added advantage of gaining allies on campus to ensure that DOE gets the best-performing students. Educational outreach programs at the secondary and primary school levels are believed to build goodwill in the local schools and larger community, as well as to expose students to science and technology careers. At many sites, particularly those at remote locations, strong support for secondary school programs is maintained because the local school system often supplies employees for technical, crafts, operator, and administrative positions.

A consistent and strong qualifier regarding educational programs, however, is the phrase "if used we11." These programs are uften seen as difficult to budget, inadequately followed up, difficult to administer, inconsistently evaluated, and lacking clear ownership. The process of sending excess equipment to universities, for example, was described as an "administrative nightmare" and few sites could document any tangible results from their educational programs. Oftentimes, project and program managers had only a vague awareness of internship programs.

Program/project management and human resources reported the concern that student interns at both the graduate and undergraduate levels are not fully integrated into the system. Responsibility for the internship programs is divided among too many entities, such that funding lines are not clear, programs are not publicized within sites, and the bureaucracy is difficult to negotiate. Respondents at many sites also believed that student interns affect headcount limitations, which conflicts with the drive to establish programs to bring in interns. Field office intern tracking systems are all but non-existent, making it difficult to follow up with students, expand further their exposure to DOE, and capitalize on the obvious recruiting potential. Many respondents felt too many internship and cooperative slots were filled by 
children of employees. The opportunity to integrate students into the complex who would not otherwise be exposed to the opportunities DOE has to offer is thereby lost.

In addition, it was felt that mentoring is left too much to the discretion of individual managers, who generally are not rewarded for this activity. Too often the demands a manager faces to meet productivity and/or compliance objectives diminish the time that could be spent with an intern. Consequentiy, many students perform tasks that do not build on or contribute to their education. The obvious losses to the complex are the current students who decline to interview for a full-time position because of a poor internship experience and the future students who decline internships because of their questionable reputation. The loss that is not obvious is based on the overwhelming belief among managers that schooling provides only a minor portion of the skills relevant to effective job performance. According to managers, internships are valuable because relevant schooling is not lacking, but relevant experience is. Students in poor internship or co-op programs miss the opportunity to gain the deep, first-hand knowledge of the DOE system, technical capabilities, and problems and challenges the complex sorely needs. For this reason, respondents placed special emphasis on the need for first-rate internship and co-op programs.

Additional perceived needs at the post-secondary level are to bolster the technical ranks and give more guidance to historically Black colleges and universities. It was believed that a stronger, vocationally-oriented secondary school system would prepare individuals for the two-year degrees and technical jobs that will be needed. This was also seen as a means of reaching minorities who might not be ready for the four-year college track. The experience and schooling obtained in the technical track would expose these individuals to the variety of careers available and perhaps encourage them to pursue bachelor's degrees in the future. Respondents reported the perception that historically Black colleges and universities are not contributing students to the "right" disciplines, a problem shared by colleges and univer. sities in general. More DOE efforts are needed to encourage these universities to fund the science programs DOE finds important. 
Technical and management training programs are considered the most appropriate method of developing those skills that are unique to DOE complex work. Respondents felt that DOE could use its funds most profitably by investing in relevant specialized training while leaving the broader technical and scientific training to academia. Training courses are less preferable than ot er training options, such as mentoring and guided assignments. Job rotations, Inter-agency Personnel Assignments (IPAs), and the detailee program are the preferred methods of broadening personnel, expanding management skills, and increasing cooperation between DOE-HQ and the field. It was suggested that DOE-HQ personnel take assignments in the field to complement the typical field-to-HQ detailee experience.

Management training is viewed as a particularly strong need. Too often employees in the complex are promoted on the basis of technical talent rather than ability to manage. The result is management that fails to capitalize adequately on the talents at hand, which thereby increases manpower needs. Increased emphasis on the tools needed by managers to plan, administer, and assess programs and people would be welcome.

One DOE management intervention that has been especially well received is the creation of Facility Representative positions. Facility "Reps," in concert with the "conduct of operations" philosophy now being promoted, assume complete responsibility as the DOE contact for a functional unit. The program reduces manpower demands by capitalizing on the capabilities of current employees, reducing lines of authority, and concentrating responsibilities. The program attracts employees who want hands-on, highly demanding and responsible positions--the very ones DOE is reported to lose to subcontractors. Training programs that support the Facility Representative program have been well received, as has the expanded responsibility attendant to the facility Representative position. Respondents encourage creating similar programs to more fully make use of the capabilities of current employees.

\subsubsection{Minority Recruiting and Retention Issues}

In many cases, managers reported that the primary factors that make it difficult to staff the complex with minorities are institutional, not cultural, in nature. These issues, in fact, are the ones that make it difficult 
to hire majority group members with strong skills and include the difficulties encountered with security and hiring procedures, headcount restrictions, the lack of mentoring in the complex, relatively low starting salaries for new hires, difficulties involved in obtaining educational benefits; and colleges not having the "right" curricula or people with the "right" experience.

Unique difficulties in recruiting and retaining minorities across sites are reported to mainly involve the competitive market for professional minorities. Private industries outside the DOE complex offer stiff competition in terms of salary and potential for upward mobility for the very people recruited by DOE and its contractors. Essentially, the number of appropriately skilled minority candidates remains low relative to the demand for these individuals. Minority staffing was reported easier at sites located near metropolitan areas, such as Denver, San Francisco, and Washington, D.C. Unique to foreign-born minority members is the difficulty they experience in obtaining proper security clearances. Some sites noted losing very qualified Asian and Indian technical candidates because of security requirements.

Remote sites report substantially greater difficulty in staffing positions with minorities. These sites tend to have highly educated, predominantly white male employees. Although many institutions have similar workforces, many also have the advantage of being in cities with established minority communities. Remote DOE sites generally lack the ethnic and cultural communities that would attract minority candidates. Many minority employees who leave DOE and its contractors report doing so because of this lack of social support.

Interestingly, Hispanics and Blacks are perceived to have the advantage of "knowing the system" as compared with other minorities; that is, they are familiar with the cultural norms found in many industries. Respondents especially emphasized that Native Americans generally do not have this experience. In fact the Native American community is struggling internally with the question of mainstreaming versus remaining separate. Unlike perceptions of the Black and Hispanic communities, the mainstreaming element of the Native American community is believed to be less than the element remaining separate. 
It was consistently noted that many minority recruiting issues cannot be separated from issues involving educational initiatives. Long-term success in equalizing opportunity for minorities is believed to depend heavily on involving minority students in internships, research programs, and outreach initiatives.

\subsubsection{Salary and Benefits}

Although salary and benefit guidelines/restrictions are organizational. or institutional in nature, they were mentioned frequently as issues of concern and warranting separate consideration. Respondents generally had three perceptions about salaries: 1) contractor salary levels will attract qualified individuals but not necessarily retain them; 2) DOE salary levels are competitive to mid-management, but not for entry or upper levels; and 3 ) benefits tend to be attractive for contractors and DOE. Salary levels were often mentioned as a key constraint to staffing within the complex. In fact, many managers claim that salary differentials, not labor shortages, are the root cause of hard-to-fill positions. Some human resources respondents thought that salary surveys commissioned by DOE tend to compare DOE and contractor salaries without considering external competition. More specifically, they felt that salary comparisons are not made against non-Federal-agency competitors in the waste management and remediation industry. The result is to underestimate the impact that salary has on the DOE complex's competitiveness in the marketplace.

Salaries are not perceived to keep pace with the market, which prompts talented individuals to join consulting and subcontracting firms not burdened by the headcount and salary limitations that often apply to prime contractors and DOE. Once established at a higher salary level, these individuals can leverage their way back to the prime contractors (who generally offer better benefits and more security) at a high salary. Although the practice of jobhopping is reported to have declined considerably, institutional salary constraints on the DOE and prime contractors require steps to actively manage the movement of employees within the complex.

Although they are considered generally attractive, benefits are not a strong recruiting lever since candidates usually consider salary and benefits 
simultaneously. As a result, the negative effects of salary restrictions outweigh the competitive benefits offered by DOE and its contractors.

Certain institutional restrictions on benefits also hamper recruiting. Contractors, for instance, cannot offer moving expense relocation packages to nonexempt employees. Consequently, local labor pools must be relied upon to provide nonexempt talent. While this may be sufficient for many staffing needs, it decreases the attractiveness of sites competing for nonexempt technician skills which are in high demand and short supply. Moreover, it puts remote sites at a particular disadvantage. These sites find it hard to obtain technician skills in high supply because of the lack of a local technical labor pool.

\subsubsection{Organizational and Institutional Barriers}

Despite the fair amount of time respondents spent discussing the staffing implications of salary, and benefits, issues regarding organizational and institutional barriers are perceived to be the most significant factors affecting planning, recruiting, and retention. Focus groups generally concluded with a summary discussion of the interventions that would have the greatest positive impact on workforce staffing. Of the 23 interventions suggested, nearly three-quarters concerned eliminating organizational and institutional barriers. Significantly, not one suggestion involved raising salaries.

Generally, respondents suggested that approaches be taken to reduce paperwork and red tape, stabilize and clarify plans, and coordinate functions across the complex. Specifically, managers felt that DOE-HQ should act to facilitate the planning and decision-making process by more clearly identifying the scope of remediation and restoration activities and creating priorities, reducing the burdensome administrative process associated with hiring employees, and acting as an information and publicity coordinator/clearinghouse regarding activities which are tailored to local needs.

The most significant element preventing adequate manpower planning and staffing is the perceived lack of focused work plans, clear goals and directions, and consistent funding. Managers recognize that the coordination 
difficulties associated with starting an organization factor into this state and that a more consistent direction will emerge with organizational maturity. Nevertheless, these issues, combined with regulatory inconsistencies, create uncertainties that continue into the fiscal year and cause wisk stoppages and hiring difficulties. Inconsistencies in funding and shifts in priority also prevent turning the short-run costs of training, staffing, and organizational infrastructure development into long-run gains. Instead, the perceived rapid program, goal, and priority shifts result in reactive staffing, too-frequent organizational restructuring, and a "crisis of the week" mentality. For instance, delays in specifying and obtaining funding often cause research projects to shut down intermittently, demoralizing and frustrating scientists within the complex and contributing to retention difficulties. Some managers believe that fluctuating funding and project priorities drive more people from their organization than salary limitations.

Contractor managers feel also that DOE has shifted from coordinating and facilitating programs to micromanaging them. They cite increases in the paperwork required to justify and perform technical work, the lack of scope definition and standard setting, and DOE restrictions on headcount.

Paperwork is perceived to account for an ever-increasing portion of the work to be accomplished by scientists and engineers as well as managers. Respondents note that DOE organizations are often not coordinated within themselves or related external agencies. Consequently, sites contend with numerous last minute reviews and audits and requests for data which differ only slight?y in format. For example, one site reported having to send the same data to a field office in four different formats to satisfy a DOE-HQ request. These increasing administrative demands strain the ability of the complex to complete technical work and frustrate employees. Some managers feel that man-power demands could be reduced significantly by eliminating the duplication of efforts throughout the complex.

Issues of scope need to be more clearly defined and/or communicated. Managers characterize the environmental work as proceeding in phases requiring constant adjustments as more is learned about the character and magnitude of the problem. For that reason, managers find it difficult to project long-term 
(i.e. ten years or longer) work goals and manpower needs. "It should not, however, be difficult to estimate intermediate-term plans or needs (e.g., for a Five-Year Plan) if reasonably consistent budget estimates and a well-defined scope of work is provided. The perception is that DOE-HQ must assume more leadership in defining these issues.

Headcount restrictions are believed to cause a peculiar set of difficulties. Field managers believe that DOE Orders, commitments, and requirements increase with insufficient increases in manpower. As a result, people throughout the complex are spread too thin. Headcount limitations force the organization to hire people of higher quality (so a broader array of functions can be accomplished with fewer people), but also force them to perform tasks which could otherwise be delegated (since more tasks must be assumed by fewer people). At certain sites, managers complain of headcount, salary, and relocation restrictions which result in hiring master's degree- level employees to perform what is largely technician-level work. This is a particularly troubling issue for the Laboratories, who have developed an expensive in-house labor pool that is not being used efficiently.

Managers universally characterized the administrative requirements involved in hiring personnel as burdensome. The process of obtaining prehiring clearances, salary reviews, and approvals is so long that most prospective candidates receive rival job offers before DOE can offer a package. It is not uncommon for the complex to take six months to extend an offer to a candidate. Thus, the opportunity to hire individuals who may be available to the complex due to the current poor economy is lost; they simply cannot afford to wait for a job offer. Furthermore, the hiring process seems to be so degree-driven that many program/project managers feel qualified individuals are rejected because of the lack of a specific degree despite their experience.

DOE-HQ is perceived as most helpful when it coordinates the activities of local sites to prevent conflicts and duplication of efforts. For instance, respondents conveyed the notion that there are fundamental issues of publicizing and recruiting at all DOE sites that DOE-HQ should address. It is believed that publicizing the environmental side of the mission, even the 
wildlife refuge aspects, would help establish a coordinated, complex-wide direction. Recruiting efforts led by DOE-HQ would also alleviate confusion over whether contractors should promote their particular organization or the DOE site and reduce harmful competition among the Laboratories, production sites, and field offices. By establishing links with other industries outside the DOE sites, DOE-HQ would help the more remote sites by strengthening local ties and creating a more attractive community setting for potential job applicants.

\subsubsection{Quantitative Results from the Survey of Occupational Deployment (Task 4)}

Task 4 was designed to determine the potential skills from non-EM programs in the DOE Complex that may be brought to bear on the EM mission. Fifty percent of the organizations contacted via workshops and/or telephone provided data regarding the deployment and backgrounds of their current workforce. Table 3.9 characterizes the data received on the basis of format (electronic or hard copy) and the extent to which each database contained the ten variables requested.

Although fe: sites were able to distinguish Environmental Management (EM) from other DOE programs, most were able to provide the following vari. ables: job titie, highest degree, degree major, age, race, sex, and exempt/ non-exempt status. Half the responding organizations provided data on these seven variabies. Thus, it appears that organizations across the complex can provide data on variables relevant to manpower planning.

The manner in which these variables are coded, however, presents two problems for complex-wide manpower analyses. One difficulty involves the coding schemes used to classify data. Race, for instance, is coded with 11 different schemes such that the race "white" is coded in various datasets as: "c, " "Caucasian," "E," " $1, "$ "W," "A," and "0." These differences are largely superficial in nature; that is, a coding key may be used to force consistent classifications across datasets. Though time consuming, this approach can yield variables which can be aggregated for complex-wide analyses. 
TABLE 3.9. Characteristics of Occupational Deployment Databases

$\begin{array}{lr}\text { Organizations Surveyed: } & 65 \\ \text { Organizations Responding: } & 23 \\ & \\ \text { Electronic Data: } & 19 \\ \text { Hard Copy: } & 4\end{array}$

Percentage of organizations providing the variables requested (number of coding schemes):

Variable

Exempt/non-exempt status
Job Title:
Job Family:
Highest Degree:
Degree Major:
Age:
Race:
Sex:
Tenure:
Organization Code:

Percent No. of Coding Schemes

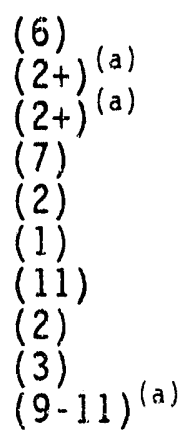

(a) Field contains subjective text descriptions difficult to resolve.

A more significant set of problems results from qualitatively different coding schemes. The "tenure" variable provides a good example. Many organizations recorded tenure as calendar start date or in years/months/days. Correspondence between these two measures can be readily achieved via a simple computer program. In other words, the two measures differ only on a quantitative basis. Some organizations, however, reported tenure as net credited federal service, a measure which has little or no correspondence with tenure dated on a true calendar basis. Tenure also varied as "time with organization" or "time in position/grade." Qualitatively different coding schemes also exist for job title and family; approximately one-third of the responding organizations provided titles and families based on functional descriptions, whereas the remainder base their titles/families on compensation-driven or administratively derived categories. Differences such as these are unresolvable and will yield substantial missing data points or double-counting (depending on the categorization) in any complex-wide analysis. Beyond the 
variables listed above, the race, degree major, and organization code variables suffer from qualitatively different coding schemes.

These problems coupled with the low overall response rate $(50 \%)$ in the current study, make any attempt to characterize the deployment of the entire DOE and contractor workforces at a national level futile. Thus, the Task 4 occupational deployment data as currently maintained provides a better framework and starting point for site-specific rather than complex-wide manpower analyses. 


\subsection{BUDGET-BASED EMPLOYMENT PROJECTIONS}

Anticipated employment levels based on budget projections contained in the Fiscal Year 1993-1997 Environmental Restoration and Waste Management Five-Year Plan (DOE 1980b) are calculated to provide additional estimates of the need for various occupations. These estimates are refined by considering 1) a discussion of the differences in the projected growth rates between the survey or requirements-based estimates and the budget-based estimates of environmental restoration and waste management (ER/WM) employment, 2) estimates of replacement needs for the occupations included in the Workforce Needs Assessment Survey (WNAS) and Survey of Current Hiring Conditions (SCHC) over the Five-Year Plan (FYP) period, and 3) an identification of the high growth and highly critical occupations for the Office of Environmental Restoration and Waste Management (EM) mission for which supply estimates should be investigated.

\subsection{EMPLOYMENT PROJECTIONS}

Budget-driven employment projections depend on three components:

1) projected budgets, 2) current and projected staffing patterns, and 3) cost per full-time equivalent (FTE) employee. Using cost per FTE one can estimate the total amount of labor purchased by a given budget; this total can then be disaggregated into occupations given staffing pattern assumptions.

The following employment projections are derived from two budget scenarios in the most recent ER/WM FYP. The higher scenario (Preliminary Unvalidated Case or Unconstrained (ase) projects total spending to increase from a 1991 base of $\$ 3.69$ billion to $\$ 8.44$ billion in 1997 . The lower case scenario posits slower growth from the same base to $\$ 6.70$ billion in 1997 .

For purposes of projecting manpower needs, budget projections are adjusted for anticipated inflation and decreased by the spending earmarked for capital expenditures. Actual ER/WM funding will depend on the annual budgeting and appropriations process. Hence, the projections contained in this section provide information regarding occupational requirements given the specific budget assumptions available at this time. 
The second component of the projections, the staffing pattern, is derived from survey data collected from program/project managers via the WNAS. Each reporting manager was classified by the FYP program area which provides his/her funding. Data for managers with multiple funding sources were divided appropriately. These four program areas are:

- Corrective Activities (to comply with regulatory requirements)

- Technology Development (research and development)

- Environmental Restoration (actual remediation activities)

- Waste Management (ongoing waste management activities)

Disaggregation of the total workforce into these four program areas created subsets of roughly similar work activities. Employment in these four categories was then treated in a fashion similar to the way the Bureau of Labor Statistics treats employment by industry in its projection methodology (Carey and Franklin 1991.)

An estimate of employment in each program area was developed for 1991. Anticipated employment levels are assumed to grow at the same rate as the adjusted budget projection for each activity.

Finally, adjustment was made to the total estimated and projected employment growth for the occupations under consideration to account for missing data from the Savannah River Site and the Waste Isolation Pilot Plant (WIPP) by assuming that current staffing per dollar for those sites is the same as the average of other sites in the same budget categories. ${ }^{\text {(a) }}$

The estimates for total current employment for the occupations included in the study and anticipated employment based on each of the funding scenarios in the FYP, and the difference between the estimated current employment and each of the projected employment rates for each occupation are presented in Table 4.1.

(a) Information on current employment at WIPP was received as this report was being prepared. This will be used in the future to refine these estimates, but a preliminary review of these data indicate that the use of actual staffing for WIPP would not substantially change the results. 
TABLE 4.1. Current and Anticipated Full-Time Equivalent Levels Based on Constrained and Unconstrained Budget Projections

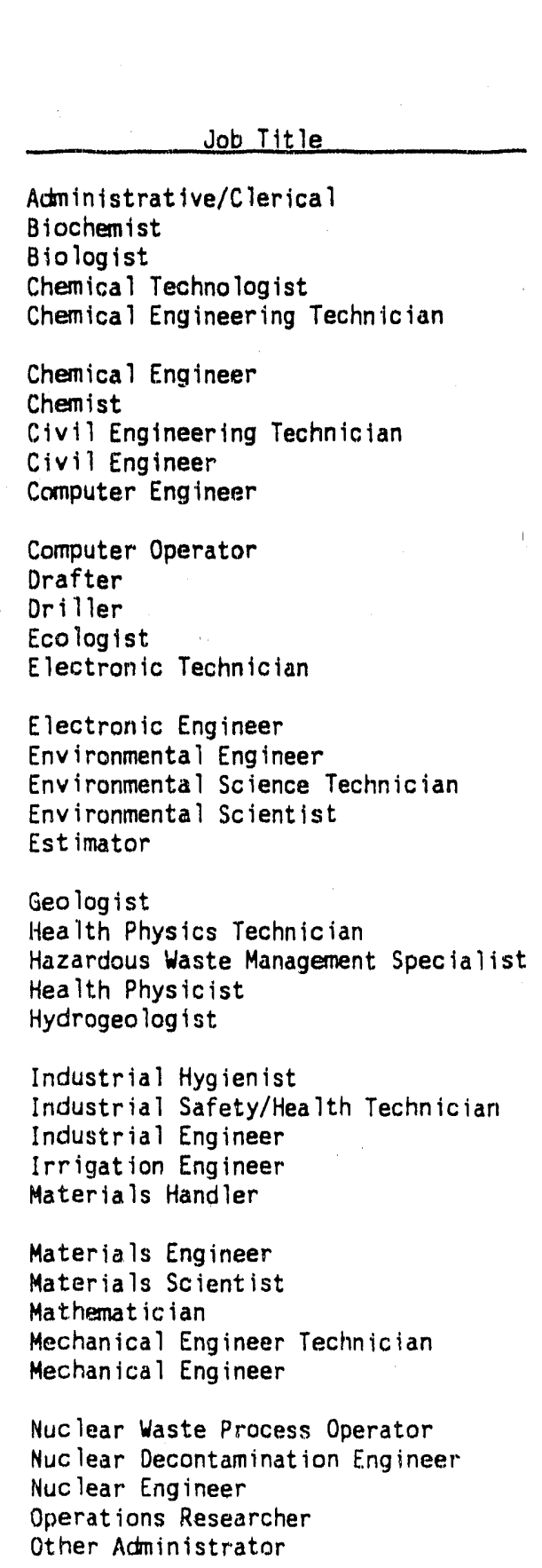


TABLE 4.1. (contd)

\begin{tabular}{|c|c|c|c|c|c|}
\hline \multirow[b]{2}{*}{ Job Title } & \multirow[b]{2}{*}{$\begin{array}{l}\text { Emp loyment } \\
\text { in } 1991 \\
\end{array}$} & \multicolumn{2}{|c|}{ Constratned Case } & \multicolumn{2}{|c|}{ Unconstrained Case } \\
\hline & & $\begin{array}{l}\text { Projected } \\
\text { Emp loyment } \\
\text { in } 1997 \\
\end{array}$ & $\begin{array}{l}\text { Projected } \\
\text { Emp loyment } \\
\text { Increase, } \\
1991-1997 \\
\end{array}$ & $\begin{array}{l}\text { Projected } \\
\text { Employment } \\
\text { in } 1997 \\
\end{array}$ & $\begin{array}{l}\text { Projected } \\
\text { Employment } \\
\text { Increase, } \\
1991-1997\end{array}$ \\
\hline $\begin{array}{l}\text { Other Engineer } \\
\text { Other Scient ist } \\
\text { Other Technictan } \\
\text { Petroleum/Mining Engineer } \\
\text { Phys ic ist }\end{array}$ & $\begin{array}{r}211 \\
66 \\
571 \\
38 \\
33\end{array}$ & $\begin{array}{r}332 \\
100 \\
849 \\
50 \\
51\end{array}$ & $\begin{array}{r}121 \\
34 \\
279 \\
12 \\
18\end{array}$ & $\begin{array}{r}428 \\
123 \\
1,971 \\
63 \\
60\end{array}$ & $\begin{array}{r}209 \\
57 \\
501 \\
25 \\
28\end{array}$ \\
\hline $\begin{array}{l}\text { Project Manager } \\
\text { Radiation Protection Specialist } \\
\text { Remediation Specialist } \\
\text { Risk Assessment Manager } \\
\text { Safety Eng ineer }\end{array}$ & $\begin{array}{l}737 \\
121 \\
127 \\
60 \\
78\end{array}$ & $\begin{array}{r}1,959 \\
264 \\
171 \\
108 \\
202\end{array}$ & $\begin{array}{r}323 \\
83 \\
44 \\
48 \\
124\end{array}$ & $\begin{array}{r}1.318 \\
257 \\
216 \\
135 \\
254\end{array}$ & $\begin{array}{r}581 \\
136 \\
89 \\
76 \\
176\end{array}$ \\
\hline $\begin{array}{l}\text { Seismologist } \\
\text { Statistician } \\
\text { Structural Engineer } \\
\text { Survey/Map Technician } \\
\text { Technical Writer }\end{array}$ & $\begin{array}{r}7 \\
21 \\
83 \\
26 \\
124\end{array}$ & $\begin{array}{r}8 \\
41 \\
154 \\
61 \\
214\end{array}$ & $\begin{array}{r}1 \\
21 \\
71 \\
36 \\
89\end{array}$ & $\begin{array}{r}9 \\
51 \\
195 \\
78 \\
268\end{array}$ & $\begin{array}{r}3 \\
30 \\
112 \\
52 \\
143\end{array}$ \\
\hline $\begin{array}{l}\text { Trainer } \\
\text { Waste Managenent Engineer }\end{array}$ & $\begin{array}{l}172 \\
302 \\
\end{array}$ & $\begin{array}{l}250 \\
457 \\
\end{array}$ & $\begin{array}{r}77 \\
156 \\
\end{array}$ & $\begin{array}{l}315 \\
578 \\
\end{array}$ & $\begin{array}{l}1.43 \\
277 \\
\end{array}$ \\
\hline Total & 13,762 & 20,520 & 6,758 & 25,753 & 11.991 \\
\hline
\end{tabular}

Although the total employment in each program area is projected to grow in proportion to adjusted budgets, the workforce skills mix is projected to change disproportionally in certain occupations. For example, as the office of Environmental Restoration and Waste Management (EM) program moves from site characterization to site remediation activities, one can expect that a smaller proportion of the EM workforce will be made up of the occupations associated with the up-front characterization activities (e.g., drillers) and that occupations involved in the remediation work (e.g., material handlers) will account for a larger proportion of the total workforce. Estimates of the expected changes in these staffing patterns came directly from the estimate of the 1997 workforce provided by each program manager. 


\subsection{EXAMINATION OF THE DIFFERENCES BETWEEN THE WORKFORCE NEEDS ASSESSMENT SURVEY-BASED PROJECTION OF EMPLOYMENT AND BUDGET-BASED PROJECTIONS OF EMPLOYMENT}

Budget-based projections are likely to differ from the sum of the program manager's projections in four principal respects. First, the total budget-based projection of employment growth was forced to be consistent with the growth of real, non-capital spending in the FYP budget projections. Second, the relative mix of occupations differs according to the allocation of the budget to the four program areas identified above. Third, the budgetbased projection produced current and projected employment for portions of the ER/WM program that did not participate in the survey of managers (i.e., Savannah River and WIPP). Finally, one program manager did not disaggregate his survey-based estimates of employment at the occupational level. Rather, this individual reported total employment and employment projections for all scientists, all engineers, and all technicians. No attempt was made to disaggregate these estimates in the report of survey-based estimates. In the budget mode], these estimates were disaggregated using proportions from other program managers which were consistent with funding allocations for this individual.

Table 4.2 provides a comparison between the employment estimated for 1991 and projected for 1997 using the two alternative methods. The differences in 1991 employment estimates stem entirely from the fact that the

TABLE 4.2. Comparisons of Total Employment Growth Across Estimation Methods

\begin{tabular}{lcccc} 
Estimation Method & $\begin{array}{c}\text { Current } \\
\text { Full-Time } \\
\text { Equivalent }\end{array}$ & $\begin{array}{c}\text { Anticipated } \\
\text { Full-Time } \\
\text { Equivalent }\end{array}$ & Growth \\
\cline { 1 - 2 } WNAS & 11,028 & & 16,000 & $45 \%$ \\
Budget Constrained & 13,762 & & 20,500 & $49 \%$ \\
Budget Unconstrained & 13,762 & & 25,800 & $89 \%$
\end{tabular}


WNAS did not include employment at Savannah River and WIPP, while the estimates of 1991 employment based on the budget do. These were based upon budget data employment profiles at similar facilities. The $49 \%$ increase indicated by the constrained-case of the budget model would have been much higher if employment were simply assumed to grow at the same rate as the expenditures projected in the constrained-case of the FYP. It is lower because future inflation was assumed at the level projected in the President's FY 1993 budget and because additional adjustments were made for expected growth in capital expenditures. The WNAS projection of the $45 \%$ increase in employment is connected to the FYP also because program managers were asked to estimate the number of FTE positions needed in each occupation to meet their FYP goals ending in 1997. Clearly, the collective estimates of the program/project managers correspond closely to the employment growth implied by the "Validated Target Level" of expenditures in the FYP, the basis for our constrained-case budget scenario.

In contrast, the unconstrained-case budget-based projection of employment is $89 \%$ greater than the estimated 1991 employment. This is based on the "Preliminary Unvalidated Case" in the FYP, which was in turn based on submissions from the field. However, DOE-Headquarters (HQ) eliminated low priority activities to move from this "Preliminary Unvalidated Case" to the "Validated Target Level" case, the basis for our constrained-case scenario. Program managers appear to have acknowledged the prioritization process used by DOE-HQ since their estimates more closely match the lower of these two budget scenarios.

In this study, cost per FTE was not measured directly but was calculated from the current employment and budget data. The source of information on current FTEs for both the WNAS and the budget-based estimates was the data collected in the WNAS. The reason the budget-based methods show higher current FTEs is that they started with the 11,028 FTEs reported in the WNAS, then adjusted for missing data from two sites. These adjustments used known budgets and staffing at other sites to estimate the 1991 employment in each of the four program areas. 
To further examine potential differences in employment estimates generated by the alternative methods, correlation coefficients were calculated between the increase in FTE employment generated by the different estimation methods. This effort found a high correlation between the change in employment projected by program/project managers and the changes projected by the budget-based models $\left(r^{\prime} s=.94\right.$ and .93 , respectively $\left.p^{\prime} s<.01\right)$. However, this is not surprising because the budget-based models assumed that within specific program areas the percentage distribution of employment would be the same as projected for 1997 by the program/project managers. What would be perhaps a more difficult test of the plausibility of these results would be to examine the sensitivity to alternative estimates of the cost per FTE employee.

This study did not collect cost, or cost per FTE directly from the program/project managers interviewed. Instead, employment data were collected and summed by site and by program area; this permits a calculation of cost per FTE. The calculations indicate that the average cost per FTE was $\$ 252,000$ in 1991. Given that FTE employment is defined to include all the occupations described in this report, including technicians and clerical workers, this strikes some observers as being rather high. The study staff asked responding program/project managers to 1 ist employees who work for subcontractors as we 11 as to list their own employees. However, the study did not have any built-in checks to verify that all such employment was counted. There is no verified undercount, but given that 1991 expenditures imply a cost per FTE of $\$ 252,000$, it is recommended that the possibility of an undercount be investigated in future efforts.

Insight into the significance of the study's findings can be enhanced by considering the likely direction and effect of errors in estimating current and projected employment. As stated above, the cost per FTE averages $\$ 252,000$. Since lower cost per FTE is sometimes reported for programs at DOE M\&O facilities, there is at least the possibility of an undercount of personnel in 1991. If such an undercount occurred, the methodology used to project future employment is such that one could expect the error to affect the projection of the total number of job openings but to have little effect on the projected relative growth rates of different occupations. For example, if 
1991 employment were underestimated by 10\% then the 1991-1997 increase in the number of jobs would be underestimated by about $10 \%$ as we11. In such a case, however, little or no change is likely to occur in the ranking of occupations by expected increase in employment from 1991 to 1997. It should be noted though that the staff who participated in collecting the employment data for 1991 believe that the employment estimates obtained and thus the cost per FTE of $\$ 252,000$ seem reasonable in view of the nature of the activities involved.

\subsection{ESTIMATES OF REPLACEMENT NEEDS}

In order to examine the potential effects of turnover during the FYP period, estimates of replacement needs were made for the occupations under study. Turnover can generally be attributed to one of the following reasons: 1) death; 2) retirement; 3) withdrawal from the labor force for other reasons; 4) unemployment, looking for work; 5) working with other employer in a different occupation; 6) working with other employer, same occupation.

The managers at each site have to replace all workers who leave unless total employment needs are declining. However, from the standpoint of the entire national employment picture, those in the last category 1isted above do not have to be replaced. One employer's loss is another employer's gain. From the national employment standpoint there is no replacement need generated if a person working as a chemical engineer in one firm goes to work as a chemical engineer in another firm. However, for each of the other kinds of losses listed above there is a replacement need generated. Thus, an attempt was made to estimate the losses that the current ER/WM workforce can expect to experience over the study time period.

To estimate replacement needs, recently published projections of annual average replacement rates produced by the U.S. Department of Labor Bureau of Labor Statistics (BLS 1991) were used to develop initial estimates. These replacement rates are based on "net separation" rates estimated by BLS during the 1980s for as many detailed occupations as possible. However, there are three issues in using these BLS projections of replacement rates.

First, the BLS occupation-specific replacement rate projections are based on "net" separations rather than "total" separations. Estimates of net 
separation rates are lower than total separation rates because they do not try to count a person who switches employers without changing occupations. This seems appropriate. If we do not focus on net separations (instead of total separations), we would have to measure likely in-mobility as a source of supply. It is simpler to handle this once by using replacement rate projections that are based on "net" separation rates.

Second, the net separation rates experienced in ER/WM employment may differ from the national averages for a variety of reasons. While this is a concern, there is little choice but to use the national average data; data specific to ER/WM are not available.

Third, the method used by the BLS is new and untested. It seems to have a bias towards producing rather low estimates of net separations. There are two principal reasons for this assertion. One is that the BLS uses the separation rate for some large occupations (e.g., electrical and mechanical engineering) as a proxy for a rate for some smaller occupations (e.g., nuclear engineering). This is a generally accepted approach because of the sampling error associated with small occupations. Nevertheless, the small occupations probably have higher separation rates because more of the possible moves one can make out of a small occupation would constitute occupational out-mobility. The second reason to believe that the BLS method underestimates net separations is because it counts no exits at all from an occupation for age cohorts where in-movement exceeds out-movement. Thus, for example, it counts no net mobility out of nursing before age 40 . However, it appears that there is net mobility at the earlier ages from many of these occupations but that the BLS method misses it because the BLS method nets out all in-mobility even if it occurs as a result of enabling training. (a)

The unweighted average of the BLS-based replacement rates for all the occupations employed in ER/WH work is $2.3 \%$. This is only slightly more than the approximately $2 \%$ rate that usually results from assessing losses due to

(a) The reader is referred to the following working paper, "A Critical Review of BLS's New Estimates of Net Occupational Separations, " 1992 , by J. G. Baker and M. G. Finn, Oak Ridge Associated Universities, Oak Ridge, Tennessee. 
death, retirement, and labor force withdrawals using work-life tables. (a) Rates that are only slightly higher than rates based on work-life tables are in effect assuming that occupational mobility out of the occupations employed in ER/WM will be almost completely. offset by mobility from other occupations into these occupations.

The scientific and technical occupations in this study must have enough out-mobility to accommodate normal losses due to death and retirement and also to provide supply for the growth of occupations such as "project manager." Even if the BLS estimates were perfectly adequate to describe the national average in the past, an increase would have to be expected if these rates were not high enough to supply the needed new entrants to management positions.

For these reasons an alternative estimate was made using rates that average 1.5 times the BLS rates. Replacement rate estimates based on both of the methods discussed above and the projected increase in employment in the constrained case are presented in Table 4.3. Both estimates of replacement needs show relatively modest needs in comparison to overall growth. Hence, for all occupations the choice of replacement rate assumption has an effect that is relatively small in the context of total job openings (growth plus replacement). Therefore, while there is a need for better information on replacement needs, high growth rates of funding and employment growth mean that the results of this study are not very sensitive to alternative rates of replacement needs.

\subsection{IDENTIFICATION OF HIGH GROWTH AND HIGHLY CRITICAL OCCUPATIONS FOR SUPPLY CHARACTERIZATION}

Given the results discussed in previous sections, the following approach was used in identifying occupations for which the development of supply estimates was deemed relevant. First, occupations characterized as in extreme

(a) BLS estimates of separation rates based on work-life tables range from $1.8 \%$ to $2.2 \%$. The average of two alternative data sources is $2.0 \%$. (See BLS 1991, pp. 19-20.) 
TABLE 4.3. Replacement Needs in Constrained Case, 1991-1997

Job Title

Administration/Clerical

Blochemist

Biologist

Chemical Technologist

Chemical Engineering Technician

Chemica 1 Engineer

Chemist

Civil Engineering Technician

Civil Engineer

Computer Engineer

Computer Operator

Drafter

Driller

Ecologist

Electronic Technician

Electronic Engineer

Environmental Engineer

Environmental Science Technician

Environmental Scient ist

Est imator

Geologist

Health Physics Technician

Hazardous Waste Management Specialist

Hea ith Phys ic ist

Hydrogeologist

Industrial Hygienist

Industrial Safety/Health Technician

Industrial Engineer

Irrigation Engineer

Materials Handler

Materials Engineer

Materials Scientist

Mathematician

Mechanical Engineer Technician

Mechantcal Engineer

Nuc lear Waste Process Operator

Nuc lear Decontamination Eng ineer

Nuc lear Eng ineer

Operations Researcher

Other Administrator

Other Engineer

Other Scientist

Other Technician

Petroleum/Mining Engineer

Physicist

\section{Projected \\ Increase in \\ Emp loyment \\ $1991-1997$}

491

22

22

133

96

365

139

53

139

99

105

108

7

14

107

137

361

106

145

41

25

253

186

101

79

92

79

79

433

29

13

9
69

382

380

38
115

88
115
7

7

108

121

34

279

12

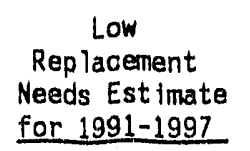

198

6

12

72

34

124

100

13

63

36

11

53

11

10

24

47

119
59

59
61

21

47

115

115
54

54
26
37

37

17

23

27

3

108

10
3

3
2

17

129

150

14

31

40

38

15

15
15
6

6
8
High

Replacement

Needi. Est imate

for 1991-1997

(cont inued on next page)

299

8

17

103

49

185

138

19

97

54

26

72

18

13

45

72

177

85

84

38

65

165

77

39

51

25

34

40

4

162

15

5

4
32

189

224

21

46

69

57

21

164

11 
TABLE 4.3. (contd)

Job Title

Project Manager

Radiation Protection Specialist

Remediation Specilalist

Risk Assessment Manager

Safety Eng ineer

Se ismo logist

Statistician

Structural Engireer

Survey/Map Technician

Technical Writer

Trainer

Waste Management. Engineer

Total
Projected

Increase in

Emp loyment

$1991-1.997$

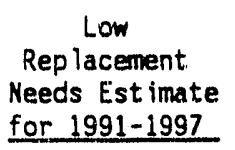

for 1991-1997
High
Rep lacement

Rep lacement

Needs Estimate

for 1991-1997.

NOTE: Low estimate of replacement needs based on BLS rates; high estimate based on rates an average of $58 \%$ higher than BLS rate.

or high need, based on the WNAS results, were included in an initial set of occupations for further examination. Next, occupations rated as highly critical to the EM mission (see Table 3.6) which were not included in the initial set of occupations based on need were added to the 1ist. Finally, two occupations electrical/electronic engineer and electrical/electronic technician, were added to the list based on projected growth rates for these occupations in the budget models (see Table 4.1).

This procedure resulted in a final list of 25 candidate occupations for which supply estimates were examined. These occupations and the indices used to identify them are presented in Table 4.4 . 
TABLE 4.4. Priority Rankings for Cididate Occupations Based on Supply and Demand Data

\begin{tabular}{|c|c|c|c|}
\hline Job Title & $\begin{array}{l}\text { Rank } \\
\text { Need } \\
\end{array}$ & $\begin{array}{c}\text { Rating of } \\
\text { Difficulty Caused } \\
\text { by a Shortage }\end{array}$ & $\begin{array}{l}\text { Budget } \\
\text { Constrained } \\
\text { Growth } \\
\text { Delta } \\
\end{array}$ \\
\hline $\begin{array}{l}\text { Environmental Engineer } \\
\text { Administrative/Clerical } \\
\text { Chemical Engineer } \\
\text { Project Manager } \\
\text { Mechanical Engineer }\end{array}$ & $\begin{array}{l}1 \\
2 \\
3 \\
4 \\
5\end{array}$ & $\begin{array}{l}3.42 \\
2.79 \\
3.23 \\
3.70 \\
2.93\end{array}$ & $\begin{array}{l}361 \\
491 \\
365 \\
323 \\
382\end{array}$ \\
\hline $\begin{array}{l}\text { Materials Handler } \\
\text { Nuclear Waste Process Operator } \\
\text { Chemist } \\
\text { Hazardous Waste Management Specialist } \\
\text { Environmental Scientist }\end{array}$ & $\begin{array}{r}6 \\
7 \\
8 \\
9 \\
10\end{array}$ & $\begin{array}{l}2.63 \\
2.79 \\
3.50 \\
3.32 \\
3.44\end{array}$ & $\begin{array}{l}433 \\
380 \\
139 \\
186 \\
145\end{array}$ \\
\hline $\begin{array}{l}\text { Health Physics Technician } \\
\text { Safety Engineer } \\
\text { Chemical Technologist } \\
\text { Civil Engineer } \\
\text { Environmental Science Technician }\end{array}$ & $\begin{array}{l}11 \\
12 \\
13 \\
14 \\
15\end{array}$ & $\begin{array}{l}3.62 \\
2.93 \\
2.91 \\
2.77 \\
2.94\end{array}$ & $\begin{array}{l}253 \\
124 \\
133 \\
139 \\
106\end{array}$ \\
\hline $\begin{array}{l}\text { Waste Management Engineer } \\
\text { Electronic Engineer } \\
\text { Health Physicist } \\
\text { Hydrogeologist. } \\
\text { Nuclear Decontamination Engineer } \\
\text { Nuclear Engineer } \\
\text { Industrial Hygienist } \\
\text { Industrial Safety/Health Technician } \\
\text { Radiation Protection Specialist } \\
\text { Risk Assessment Manager }\end{array}$ & $\begin{array}{l}16 \\
17 \\
19 \\
20 \\
21 \\
23 \\
28 \\
30 \\
31 \\
33\end{array}$ & $\begin{array}{l}3.49 \\
3.11 \\
3.23 \\
3.33 \\
3.32 \\
3.09 \\
3.11 \\
3.21 \\
3.37 \\
3.45\end{array}$ & $\begin{array}{r}156 \\
137 \\
101 \\
79 \\
88 \\
115 \\
92 \\
79 \\
83 \\
48\end{array}$ \\
\hline $\begin{array}{l}\text { Electronic Technician } \\
\text { Driller }\end{array}$ & $\begin{array}{l}34 \\
53\end{array}$ & $\begin{array}{l}2.58 \\
3.44\end{array}$ & $\begin{array}{r}107 \\
7\end{array}$ \\
\hline
\end{tabular}




\subsection{ASSESSMENT OF NATIONAL DEGREE PRODUCTION IN SCIENCE AND ENGINEERING}

National degree production in the fields of science and engineering (S\&E) are assessed in the following sections, and a synthesis of demand and supply data generated from the current study is presented.

\subsection{GENERAL SUPPLY TRENDS FOR SCIENCE AND ENGINEERING FIELDS}

Two main factors affect the supply of scientists and engineers: demography and market forces. (Leslie and Oaxaca 1990.) Reliable demographic projections based on the 1990 Census of Population indicate that the number of 18- to 22-year-olds will decline through the mid 1990s. This decline is greater than the increase in educational attainments in the population in general, indicating that entrants to college and, by extension, the S\&E fields, will decline. For instance, the fraction of the 18-to-22-age group awarded science or engineering degrees has varied from a low of $3.7 \%$ in 1963 to a high of $5.2 \%$ in 1986. The U.S. Department of Labor has made projections of S\&E degree awards assuming that the "S\&E rate" will stay near its historic high of $5.2 \%$. The U.S. Department of Labor's recent report on this projects a $7 \%$ decline in S\&E bachelors degrees from 1989 to 1997 (Braddock 1992). However, the rate at which young people earn S\&E degrees is affected by the relative salary offers to new graduates in S\&E fields versus non-S\&E fields. The salary premium earned by new S\&E graduates in 1991 is closer to the historical average than to the all-time high and thus is consistent with a more conservative assumption regarding the proportion of young people who will earn S\&E degrees in 1997. One such assumption is illustrated as the mid-case in Table 5.1 and indicates a decline of 13\% in S\&E degree awards from 1990 to 1997.

Market forces are 1ikely to affect not only the number of S\&E degrees but also the distribution of these degrees among college majors. Fields with a relatively weak labor market will probably experience sharper than average declines whereas fields with better than average employment opportunities may experience no decline and may even see an increase in degrees. Continued growth in computer science employment is expected to cause growth in 
TABLE 5.1. B.S. Science and Engineering Degrees Awarded in 1990 and Projected to 1997 (Excluding B.S. in Engineering Technology)

\begin{tabular}{|c|c|c|c|c|}
\hline & \multirow[b]{2}{*}{1990} & \multicolumn{3}{|c|}{1997} \\
\hline & & Low & Mid & High \\
\hline Total & 177,700 & 122,000 & 154,000 & 172,000 \\
\hline $\begin{array}{l}\text { Enginetring } \\
\text { Civil } \\
\text { Chemical } \\
\text { Electrical } \\
\text { Mechanical/Aeronautical } \\
\text { Other }\end{array}$ & $\begin{array}{r}8,000 \\
3,900 \\
23,200 \\
18,900 \\
11,200\end{array}$ & $\begin{array}{r}4,900 \\
3,200 \\
14,300 \\
10,700 \\
5,700\end{array}$ & $\begin{array}{r}6,200 \\
4,000 \\
18,000 \\
13,400 \\
7,200\end{array}$ & $\begin{array}{r}6,900 \\
4,400 \\
20,000 \\
15,000 \\
8,000\end{array}$ \\
\hline $\begin{array}{l}\text { Natural Sciences } \\
\text { Mathematics \& Computer Science } \\
\text { Chemistry } \\
\text { Physics } \\
\text { Geosciences } \\
\text { Biological Sciences } \\
\text { Agricultural Sciences } \\
\text { Other }\end{array}$ & $\begin{array}{r}42,500 \\
8,300 \\
4,000 \\
2,300 \\
39,100 \\
13,600 \\
1,900\end{array}$ & $\begin{array}{r}42,000 \\
4,700 \\
2,700 \\
2,700 \\
23,500 \\
7,000 \\
500\end{array}$ & $\begin{array}{r}53,100 \\
5,900 \\
3,400 \\
3,400 \\
29,600 \\
8,800 \\
1,000\end{array}$ & $\begin{array}{r}59,300 \\
6,600 \\
3,800 \\
3,800 \\
33,100 \\
9,800 \\
1,200\end{array}$ \\
\hline
\end{tabular}

NOTES:

(a) All projections assume 2,446,000 graduating from high school in 1992 .

(b) "Low" scenario assumes B.S. completion rate = lowest 3 -year period in past 20 years.

(c) "High" scenario assumes B.S. completion rate = highest 3 -year period in past 20 years.

(d) "Mid" scenario assumes B.S. completion rate consistent with 1991 starting salaries.

(e) "Science \& Engineering" defined to include: physical science, mathematics, computer science, biological and agricultural sciences, and engineering (not B.S. in engineering technology, social science or psychology).

Source: NSF 1991, NSF 91-314, updated to 1990 with unpublished NCES data; report in process by M. G. Finn and J. G. Baker, Oak Ridge Associated Universities, Oak Ridge, Tennessee, "Assessing the Adequacy of Science and Engineering Degree Awards."

Mathematics/Computer Science degrees. Projections of degree awards at three different "S\&E rates" that are within historical experience are shown in Table 5.1 . 
Thus, whereas the total number of degrees is greatly affected by demographics, over a period of several years the share of degrees in each S\&E field generally moves in concert with the share of job growth projected to occur for that field.

In the interest of brevity, this review of supply does not distinguish degree awards by sex or race. It recognizes, however, that increased college attendance by women and increased enrollments of coijege women in S\&E fields are important components of the increase during the 1980 s that lead to record high proportions of the population receiving S\&E degrees. While a detailed examination of the effect of demographic change would disaggregate by sex, it would probably not change the outlook very much. Researchers have found that the number of 22-year-olds and relative salaries influence changes in S\&E bachelors awards to women in ways that are very similar to the way they influence bachelors awards to men (Collins 1991).

\subsection{CURRENT DEGREE PRODUCTION IN SCIENCE AND ENGINEERING}

The current supply in each field of S\&E might be characterized by assessing the adequacy of degrees in some absolute sense. However, there is no generally agreed upon method for determining that there is or is not an' adequate supply in a given field at the present time.

An alternative and relatively noncontroversial way to characterize supply is to rank fields by sorie relative measure of supply-demand balance. Though there are different measures which could be used in making such assessments, they tend to be positively correlated. Consequently, the results are not very sensitive to the choice of measures. Two different measures are used here to characterize current supply conditions. Then the two are averaged together to provide average percentile rankings for all the major fields of S\&E.

The first of these measures is the level of salary offers to new bachelors graduates. This is a proxy for supply-balance in the sense that salary offers tend to move up when a field is in relatively short supply. One advantage of this measure is that relatively current. (1991) data are available. 
The second measure of supply conditions used in the current study is computed from the 1990 Survey of Natural and Social Science and Engineering Gradistes of recent B.S. and M.S. graduates who earned degrees in one of the scitice or erigineering fields. This representative national sample of 1988 and 1989 graduates was interviewed in 1990 and can be classified by either degree field or employment field. They were tabulated each way and then compared and ranked by the ratio of occupations to digrees. For example, there were 290 graduates reporting environmental engineering jobs for every 100 reporting an environmental engineering degree, so the ratio is 2.9 in this case. In other fields, the same ratio is less than one.

A composite measure of current supply is shown in Table 5.2. It is constructed so that $20 \%$ of all S\&E graduates fall into each category, with the supply categories ranging from very high to very low.

While more than $20 \%$ of the degree fields are described as having "very low" supply, this is because some of the biggest fields (e.g., biological and social sciences) are not very finely disaggregated. The number of bachelors degrees in each category does not exceed $20 \%$ of the total number of S\&E bachelors degrees.

Three fields in Table 5.2 were classified using salary data and interview reports instead of using the method described above. These are industrial hygiene, health physics, health physics technicians. The classification of these fields was somewhat subjective, but an attempt was made to place them in the categories they would occupy had it been possible to classify them in the same manner as the fields included in the survey of recent graduates.

Table 5.3 and Table 5.4 report the data on relative salaries and on the ratio of jobs to degrees which were used to construct Table 5.2. 
TABLE 5.2. Ratings of Current Supply in Science and Engineering Fields Relevant to Environmental Restoration ard Waste Management Mission

\begin{tabular}{ll}
\multicolumn{1}{c}{ Degree Field } & Score \\
\hline & \\
\hline Environmental Engineering & Very Low \\
Nuclear Engineering & Very Low \\
Materials & Very Low \\
Other Engineering & Very Low \\
Petroleum & Very Low \\
Computer Science & Very Low \\
Computer Engineering & Very Low \\
Mining Engineering & Very Low \\
Chemical Engineering & Very Low \\
Health Physics & Very Low \\
Health Physics Technician & Very Low \\
Industrial Hygiene & Very Low \\
& \\
Other Physical Science & Low \\
Civil Engineering & Low \\
Earth Science \& Geology & Low \\
Chemistry & Low \\
Electrical Engineering & Low \\
Mechanical Engineering & Low \\
Industrial Engineering & Low \\
& \\
Agricultural Sciences & Average \\
Mathematics/Statistics & Average \\
Physics & Average \\
Biological \& Medicine & \\
Fconomics & High \\
Other Social Sciences & High \\
& Very High \\
\end{tabular}

NOTES: Score is based on an unweighted average of percentile rankings on the two measures shown in Tables 5.3 and 5.4 that follow. The degree fields rated "Very Low" contain the $1 / 5$ of a11 S\&E graduates with the highest combined ranking; fields rated "Low" coritain the second $1 / 5$, etc.

Three of these fields (health physics, health physics technicians, industrial hygiene) were rated subjectively by the authors using information obtained from interviews and surveys by Oak Ridge Associated Universities. 
TABLE 5.3. Employed 1988 and 1989 Bachelors in Science and Engineering Fields, Ranked by the Ratio of Jobs to Degrees Reported for Each Degree Field in 1990

Degree Field

Environmental Engineering Nuclear Engineering Materials Engineering Other Engineering

Petroleum Engineering Computer Specialist Computer Engineering Other Physical Science Civil Engineering Mining Engineering Earth Science and Geology Chemistry Chemical Engineering Electrical Engineering Agricultural Science Mechanical Science Mathematics/Statistics Industrial Engineering Biological \& Medicine Physics other Social Sciences Economics

\author{
Occupation/ \\ Degree \\ Ratio
}

\subsection{0}

2.47

1.70

1.70

1.42

1.24

1.16

1.03

0.96

0.90

0.71

0.70

0.66

0.60

0.59

0.56

0.55

0.52

0.44

0.24

0.19

0.18

Source: Tabulated from the "1990 Survey of Natural and Social Science and Engineering Graduates" conducted by Oak Ridge Associated Universities, 1991 . 
TABLE 5.4. Employed 1988 and 1989 Bachelors in Science and Engineering Fields, Ranked by the Ratio of the Median Salary for Each Field Divided by the Median Salary for all Employed Bachelors in Science and Engineering

\begin{tabular}{|c|c|c|}
\hline Degree Field & $\begin{array}{c}1991 \\
\text { Median } \\
\text { Salary } \\
\text { (in S000's) } \\
\end{array}$ & $\begin{array}{l}\text { Ratio of } \\
\text { Median Salary } \\
\text { to Median for } \\
\text { All S/E Fields }\end{array}$ \\
\hline $\begin{array}{l}\text { Petroleum Engineering } \\
\text { Chemical } \\
\text { Mechanical } \\
\text { Materials } \\
\text { Mining } \\
\text { Computer } \\
\text { Electrical } \\
\text { Nuclear } \\
\text { Industrial } \\
\text { Other Engineering } \\
\text { Computer Specialist } \\
\text { Civil } \\
\text { Environmental } \\
\text { Physics } \\
\text { Earth Science \& Geology } \\
\text { Mathmatics/Statistics } \\
\text { Chemistry } \\
\text { Economics } \\
\text { Agricultural Science } \\
\text { Biological \& Medicine } \\
\text { Other Social Science }\end{array}$ & $\begin{array}{l}38.9 \\
37.4 \\
34.0 \\
33.4 \\
33.4 \\
33.2 \\
33.2 \\
32.4 \\
32.2 \\
31.7 \\
30.7 \\
29.7 \\
29.0 \\
28.5 \\
28.4 \\
28.0 \\
27.1 \\
25.9 \\
21.8 \\
21.5 \\
21.2\end{array}$ & $\begin{array}{l}1.56 \\
1.50 \\
1.36 \\
1.34 \\
1.34 \\
1.33 \\
1.33 \\
1.30 \\
1.29 \\
1.27 \\
1.23 \\
1.19 \\
1.16 \\
1.14 \\
1.14 \\
1.12 \\
1.08 \\
1.04 \\
0.87 \\
0.86 \\
0.85\end{array}$ \\
\hline
\end{tabular}

Source: Tabulated from the "1990 Survey of Natural and Social Science and Engineering Graduates" conducted by Oak Ridge Associated Universities, 1991.

\subsection{PROJECTED SUPPLY OUTLOOK FOR SELECTED HIGH GROWTH AND CRITICA!. OCCUPATIONS}

Projected supply assessments were made based on available data for selected critical and/or needed occupations. To the extent possible these assessments are based on the data and projections already reviewed in this chapter. Since total S\&E degree awards are expected to decline, fields that are projected to show any increase at all are exceptions to the general trend. However, the assessments were made in a qualitative manner and also take into account other data available to one of the researchers from in-house databases 
and previously conducted studies. Also, note that the assessments made here are for changes expected between 1991 and 1997. The conditions during the early 1990s may be the same as the conditions expected at the end of this 7-year period, but this is not necessarily the case.

Selected high growth and critical occupations are assessed in the following.

\section{Geology/Hydrogeology}

The number of new graduates in geology has been falling for several years and is now lower than the level called for to sustain even the modest growth in employment shown in Bureau of Labor Statistics (BLS) and National Science Foundation (NSF) mid-case employment projections for the entire U.S. economy. Thus, Table 5.2 indicates a modest increase in degree awards. No projections are available for the subfield of hydrogeology but anecdotal evidence suggest that enrollments in this subfield will increase. This is because colleges are expanding offerings in this area to help their graduates find employment in the face of weak demand from the traditional employers of geologists.

\section{Chemical Engineering}

The decrease in B.S. awards in this field is expected to be small; not because total employment growth is expected to be above average, but because the large declines in this field in the past few yaars have amounted to what is probably an overcorrection. The modest growth called for by BLS and NSF will help keep degrees from falling much further.

\section{Chemistry}

Further decline in degree awards is expected.

\section{Civil Engineering}

These degrees are expected to continue to decline. However, civil engineering is relatively unaffected by cuts in defense spending and is experiencing a relatively strong job market right now. Consequently, the decline in degrees shown in Table 5.1 may be overstated. Some civil engineers take 
specialized course work relevant to waste management, and when they graduate are qualified to take jobs as waste management engineers or environmental engineers.

\section{Environmental Engineering}

This is a small field. With a strong market, M.S. degree awards rose 63\% from 1986-1991 (EMC 1991). M.S. degree awards exceed B.S. awards in this field. Current levels of degree production are probably not sufficient to handle the needs of the U.S. Department of Energy (DOE) and others over the next 5 years. In recent years, new graduates from other fields of E\&S (e.g., biological sciences) have been hired as environmental engineers. Although this trend is decreasing, 1990 data indicate about 290 recent B.S. or M.S. graduates reporting environmental engineering jobs for every 100 reporting environmental engineering degrees. (a)

\section{Environmental Sciences}

There is so little agreement on the definition of this field that it is difficult to assess current supply or project its future course of growth.

\section{Nuclear Decontamination Engineer/Nuclear Engineer}

Nuclear engineering degree awards have been decreasing even though the market is quite strong. The National Research Council projects no increase in degree awards for 1989 through 2000 (National Research Council 1990b).

\section{Mechanical Engineering}

The supply of new graduates has declined somewhat in recent years and is expected to experience further substantial decline.

\section{Health Physics}

Degree awards have been nearly flat in recent years in spite of a strong job market. Salaries have increased to near parity with engineering salaries in the past few years with little effect on supply. Degree production must.

(a) Special tabulation from the "1990 Survey of National and Social Science and Engineering Graduates" conducted by Oak Ridge Associated Universities, 1991 . 
increase to meet ER/WM growth as most of the current level is sufficient only to provide attrition replacement for the approximately 6,000 health physicists now employed in the United States (ORAU 1991).

\section{Industrial Hygiene}

M.S. degree awards have increased nearly $50 \%$ in the past 5 -years. While projections are not available, increasing enrollments suggest that further increases in degree awards are likely.

There are no national statistics on 2-year degree awards for Health Physics Technicians and no projections. However, short supplies and recent growth in wages to the upper end of the technician scale are well documented, indicating that supply is low relative to demand.

\section{Industrial Safety and Health Technician}

There are no national statistics on 2-year degree awards, but there is evidence of a strong market at present indicating that supply is low relative to demand.

\section{Chemical Technologist/Chemical Engineering Technician}

National statistics on 2-year degree awards exist, but not projections. However, many in the ER/WM system have 4-year degrees (e.g., B.S. in chemistry) and this supply is projected to decline.

\section{Material Handling Technician}

Most are not college graduates. In view of the cutbacks in DOE's defense programs, it appears likely that many of ER/WM's material handling technician jobs can be filled through reassignment and retraining of workers in these programs.

\section{Electrical/Electronic Engineering}

These degrees grew rapidly during the early 1980 s then declined from about 25,000 bachelor degrees in 1987 to "only" about 20,000 in 1991 (EMC 
1991). A further decline is expected during the 1990 s as electrical/ electronic engineering employment is not expected to grow faster than total S\&E employment.

\subsection{COMPARING SUPPLY AND DEMAND MEASURES}

The occupations rated highest in need and criticality are listed in Table 5.5 with an assessment of the availability of each based on anticipated ability to recruit (rated by human resources professionals) and current and projected degree production. Priority ratings were assigned to each occupation by the researchers on the basis of both supply and demand measures.

Environmental engineering, project manager, health physics technician, and hydrogeologist are the occupations which should command DOE's highest priority. The need for hydrogeologists is rated by program managers as moderate; however, hydrogeologists are highly critical relative to other occupations and are in short supply. The remaining occupations are characterized by high or extreme needs, low or very low anticipated supply, and high criticality (i.e., difficulty caused by a shortage).

Chemical engineers, environmental scientists, environmental sciences technicians, waste management engineers, health physicists, industrial hygienists, radiological protection specialists, and risk assessment managers/ specialists are of high priority.

Some occupations, which are rated by program managers as high or extreme in need, are not priority occupations due to anticipated adequate supplies or minimal preparatory requirements. For instance, a large number of job openings are projected for material handlers but they are not required to have Occupations more than a high school education and can be trained relatively quickly. Similar circumstances exist for administrative and clerical workers. These occupations should receive attention, but are not as difficult to staff as occupations which require longer and more specialized training and education. 


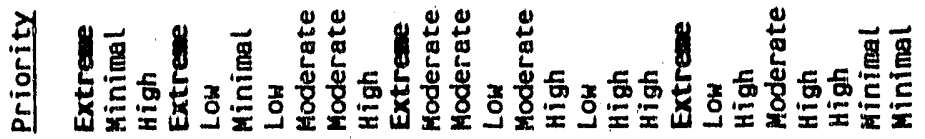

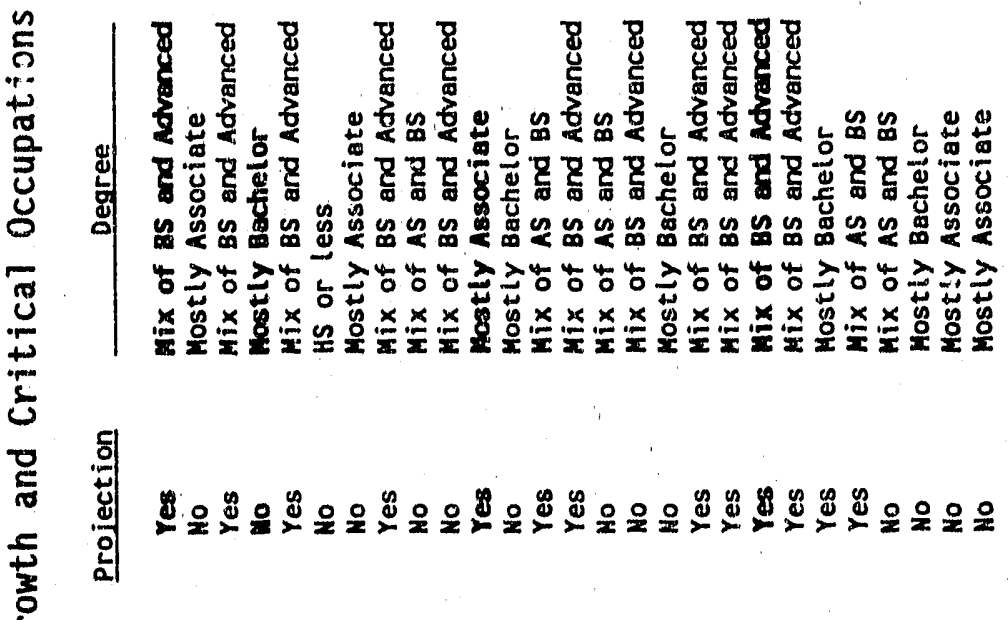

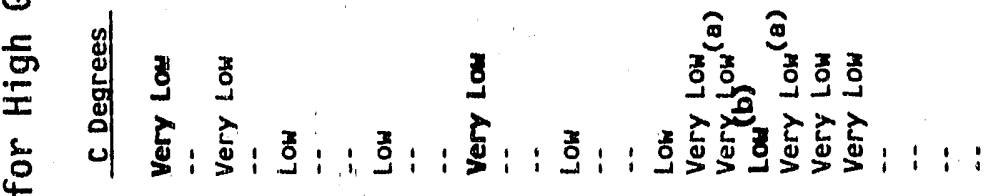

莙

范

을

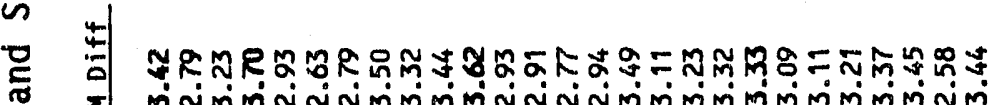

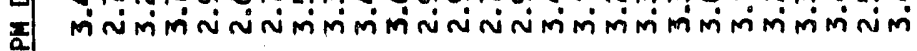

을

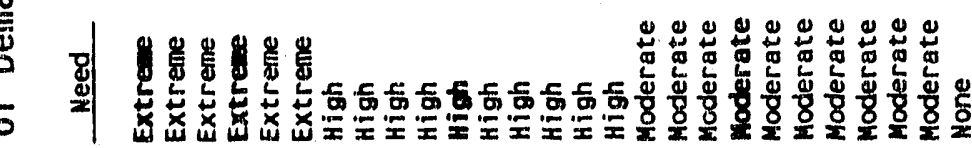

ڤn

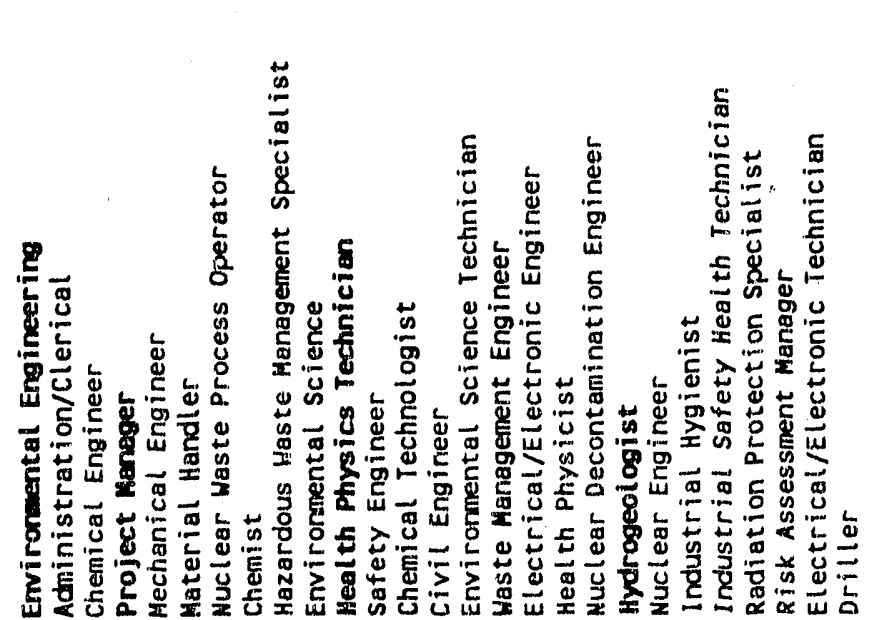




\subsection{CONCLUSIUNS AND RECOMMENDATIONS}

In general, respondints saw the transition to an Office of Environmental Restoration and Waste Management (EM)-oriented workforce as being accomplished most efficiently through locally driven programs coordinated and encouraged by U.S. Department of Energy (DOE) initiatives. The respondents proposed that at the national level, DOE Headquarters ( $H Q$ ) could coordinate the implementation of education initiatives at appropriate levels (i.e., national versus local); increase publicity and public relations activities; clarify mission objectives, regulatory issues, and funding lines; and encourage bottom-up communications. Proposed local initiatives include greater involvement in the local community and educational system, more concentration on identifying DOE and contractor needs, and greater consideration of the quality-of-life issues that affect recruiting and retention.

This section summarizes major conclusions drawn from the current research efforts and examples of specific recommendations for potential interventions based on information provided by the study participants. It aiso includes general conclusions drawn by the researchers based on insights developed through the process of conducting the study.

\subsection{CONCLUSIONS DRAWN DIRECTLY FROM RESEARCH RESULTS}

Although significant overall growth in employment is expected in a variety of occupations, no great. immediate change in the current skills mix is needed to accomplish EM goals.

The mix of basic scientific knowledge needed to continue to move forward with restoration and remediation activities is present in the workforce--the need for radically new fields is small in the near term. Individuals with good basic science skills will be able to apply these skills to the environmental field as the scope of the activities and nature of the problems become more clearly defined. This is especially true of science and engineering (S\&E) occupations. Beyond the need for knowledge-based regulatory training, most sites anticipate implementing a manageable system of formal courses to 
move individuals into new work applications. The skills and experience these individuals have acquired in their current production-oriented jobs can be transferred readily and augmented with on-the-job training. Managers feel that these transitions have been accomplished in the past and that a time frame sufficient to meet training and employment goals currently exists if appropriate interventions are implemented in a timeiy manner.

Highly specialized occupations, such as hydrogeology, will be needed but such occupations are not anticipated to assume a significant percentage of total headcounts. Though they are critical occupations in some cases, the absolute anticipated need is small to moderate. It should be noted that these highly specialized occupations have traditionally been a small and, from an employer's viewpoint, competitive market.

Managers believe employees in the non-degreed skilled craft production occupations are likely to see the need for their skills decline as the DOE devotes more resources to the EM organization and de-emphasizes others. These individuals will require retraining to introduce them to the technician or construction positions that are anticipated. Though individuals such as these are employed at all sites, they account for a significant part of the workforce at the Rocky Flats Plant and Savannah River Site.

Landlord and general and administrative functions must aiso be factored into the workforce regardless of the mission. The demand for services such as power, roads, heating and cooling, craft services, and computing, legal, and accounting assistance will vary with phases of remediation and restoration but will not introduce new skills into the workforce. These jobs generally account for a significant portion of the total employment at each site.

Lastly, comprehensive clean-up efforts will require, at least for a short time, skills similar to those currentiy in a large portion of the workforce. This opens a window for implementing the retraining that will be required for workers whose jobs will be phased out over time and for implementing recruiting and/or educational initiatives to meet employment needs which cannot be met by shifting the current workforce. 


\section{Recommendation}

Certain occupations should be given special attention when considering manpower intervention programs. High needs and low supply are projected for environmental and chemical engineers and program/project managers, all of which are also rated as highly critical occupations. Other priority occupations are environmental scientist, health physics technician, health physicist, waste management engineers, hydrologists, nuclear decontamination engineers, radiological protection specialists, and risk assessment (regulatory) specialists. Designing interventions to ensure adequate staffing of these occupations should take high precedence. Some occupations rated as high in need are deemed lower in priority due to anticipated adequate supplies or minimal preparatory requirements. These occupations, such as administrative/ clerical workers and material handlers, should receive attention, but the lead time necessary to develop pools of individuals with these skills is relatively short and the interventions required straightforward.

\section{Recommendation}

Issues regarding the retraining of production-oriented crafts and semiskilled workers should be examined. Data collected in this study indicate that the Rocky Flats Plant and Savannah River Site are appropriate places to begin such a study, but other sites should be included as well.

\section{Organizational and institutional barriers are the most significant obstacles} to manpower planning. recruiting, and retention.

Although low supply results in shortages in some occupations, paperwork, administrative burdens and restrictions, funding inconsistencies, regulatory conflicts, and the lack of clear work plans are the barriers with the most impact on manpower issues. Planning for needed skills is difficult due to fluctuations in funding, the perceived lack of specific remediation and restoration goals, and regulatory conflicts. Recruiting and staffing is made difficult by headcount restrictions, the administrative processes associated with security clearances and hiring, and salary restrictions. Fluctuations in funding and salary caps and the increased paperwork load on scientists and 
engineers result in retention difficulties. Managers at the local level feel strongly that DOE could clear some of these barriers by assuming more control over those functions that may be logically consolidated at DOE-HQ and providing guidance for those most effectively administered locally.

\section{Recommendation}

The DOE could facilitate short- to medium-term planning efforts by providing more consistent direction regarding broad mission objectives and concentrating more resources on explaining and solving regulatory issues. Reducing organizational and administrative barriers would substantially improve the DOE complex's position in the employment marketplace.

\section{Educational and training initiatives are crucial to DOE's long-term mission} accompl ishment.

Exposing students to math and science concepts as eariy in their education as possible is vital to ensuring that future workforces have the skills needed to succeed in the DOE community. Faculty fellowship and intern arrangements are perceived to be cost-effective and highly beneficial in terms of the work accomplished, goodwill generated, and research contacts gained. However, faculty fellowships and internship programs are both difficult to administer and track. Although DOE and its contractors tend to recruit college students mainly during their senior year, good students are "spoken for" by the time they become seniors via the internships, scholarships, and work opportunities they have had in private industry. The DOE complex is a late entry to the process and should not expect to attract many of these students unless changes are made in how internships are handled. Technical and managenent training programs are considered the most appropriate method of developing the skills unique to DOE complex work.

\section{Recommendation}

Broader support is needed for initiatives in primary and secondary schools, such as business-school partnerships, teacher-for-a-day programs, and teacher education/fellowship opportunities. Moreover, innovative educational outreach programs should be implemented. Efforts have been made to contact 
native ethnic minorities and migrant farm worker communities. Similarly creative, locally tailored programs should be encouraged.

\section{Recommendation}

Internships and co-op programs need to be funded more clearly, perhaps by being broken out as a separate item in budgets and assigned to one clear authority for administration at each site. Systems that reward scientists and managers for mentoring interns should be promoted. Steps to facilitate the implementation of these programs should be investigated.

\section{Recommendation}

The DOE and its contractors should be involved earlier in the education and recruiting process by extending internships to students in their sophomore year, funding multi-year lines of research at universities that promote student/faculty research, and enriching the experience of consortium interns. Furthermore, DOE should encourage the development of a tracking system to permit assessments of the effectiveness of education programs and monitor the progress of students throughout their academic careers. Tying such a system to Human Resources may decrease recruiting costs and allow staffing organizations to plan workforce levels and skills mixes more accurately.

\section{Recommendation}

Skills unique to the DOE complex should be developed through internal training. Guided assignments and structured mentoring programs will broaden personnel, expand their management skills, and thereby make better use of the workforce skills on hand. Many benefits may be obtained by conducting internally-developed reguiatory classes; in-house regulatory experts can sharpen their skills and capitalize more fully on their talents, whereas course participants will benefit from trainers who have knowledge of the DCE complex and relevant work experience.

\section{Recommendation}

The DOE is encouraged to investigate methods of capitalizing on local efforts to address manpower problems. Soliciting comments from the field and funding innovative programs found at field offices would be beneficial.

\section{5}


Initiatives at individual sites directed at addressing manpower staffing/ recruiting issues have yielded data and valuable experience to local DOE and contractor offices.

Manpower planning issues are primarily local in origin and most fruitfully addressed via local initiatives. Broad macroeconomic data provide little insight into the recruiting and planning difficulties faced by the local sites. Since the sites differ in their emphasis on production or research, the priority placed on occupations needed by each site will differ somewhat. Under these circumstances, bottom-up approaches to determining need should be emphasized more and combined with top-down budgetary approaches.

Although the same set of occupations are in high demand across the complex, sites also vary tremendously in terms of location, the non-DOE industrial base in the local economy, access to pools of local minority employees, and characteristics of the community. In an effort to meet staffing needs, sites have begun to address these local variables by establishing educational programs, increasing recruiting, and making contacts in the community. These initiatives no doubt vary in their complexity and maturity. Assistance from DOE is most helpful when it coordinates these efforts.

\section{Recommendation}

The DOE might find it most effective to assume the role of data coordinator rather than data collector. Roundtables and similar forums for exchanging ideas, successes, and failures would facilitate the dissemination of information throughout the complex. For instance, sites that have experienced all phases of restoration and remediation, such as Grand Junction, may provide valuable insights, technologies, and processes to other sites. Adopting the role of facilitator would enable DOE-HQ to highlight the local accomplishments and diminish the need for local sites to vie for DOE-HQ attention.

\section{Recommendation}

DOE should coordinate and consolidate functions that transcend individual sites, such as publicity and recruiting for occupations in national labor markets. Attempts to more aggressively promote the DOE, its new environmental 
mission, and the positive benefits that will result are best consolidated at the HQ level. By broadcasting a consistent theme, DOE can become a more credible source of information in the public debate and generate goodwill for itself and its contractors.

DOE may also reduce the cost and inefficiencies associated with recruiting by coordinating activities such as job fairs and targeted marketing across the complex.

\subsection{CONCLUSIONS AND RECOMMENDATIONS OF THE RESEARCHERS}

Results from the current study are most useful in developing interventions designed to affect the educational choices of students entering programs which will prepare them for occupations requiring 2 to 4 years of post-secondary education.

A limitation implicit in the design of the study is the focus on the 1993-1997 Five-Year Plan (FYP). The relatively short-term focus of this study makes the conclusions more valid for occupations characterized by geographical mobility and shorter education cycles (associate and bachelor degrees) that provide skills that may be common to a variety of occupations.

Limits on the planning which can be done for PhDs and highly specialized occupations requiring lengthy preparatory periods are imposed by the time frame adopted. Five years, for instance, is not enough time to affect the educational process for occupational positions requiring PhDs. Further, it appears unlikely that any technique will allow DOE to pinpoint the number of PhDs needed 10 years hence with high accuracy, given that budgets (which ultimately determine the number of workers within the complex) are not planned that far into the future.

\section{Recommendation}

Resources should be focused on developing programs designed to increase enrollment in educational programs granting the associate and bachelor degrees that are relevant to high-demand/low-supply occupations and those expected to be undersupplied in the future. 


\section{Recommendation}

For high demand/low supply occupations requiring relatively long preparatory periods, EM should develop programs designed to increase the likelihood of DOE and contractors attracting people who are just completing their educational programs (i.e., focus on increasing market share).

\section{Recommendation}

EM should continue to update manpower data and develop evaluation programs and feedback loops to its educational programs to ensure that efforts targeted at specific academic disciplines are shifted as needs change over. These data should also be coordinated with local site human resources functions in order to capitalize on recruiting potentials.

\section{Recommendation}

EM should rely on multiple sources of information, including national macroeconomic studies, when developing its overall educational program. A portfolio management strategy should be employed in fine-tuning EM educational programs. By employing such a strategy, the benefits of intervention programs targeted at increasing higher degree production in various disciplines and employee retraining can be evaluated in conjunction with the benefits of programs designed to increase overall environmental awareness and the interest of young schoolchildren in science. Appropriate investment decisions can thus be made in each of these areas.

\section{Program/project managers and human resources professionals of fer complementary} perspectives of manpower planning issues.

Program/project managers seem to have a sense of technical needs, distinguish readily between needs of number and criticality, and tend to see manpower planning in terms of organizational and administrative constraints. The human resources professionals are sensitive to cultural, community, and minority issues; can characterize the external labor market; and can clearly assess the recruiting difficulties to be encountered. 


\section{Recommendation}

Collaboration between human resources and program/project management, both within and across organizations, should be encouraged to yield integrated, relevant, grassroots solutions to local problems.

Two primary dimensions of manpower need are apparent.

Obviously, the absolute increase in projected full-time equivalents (FTEs) by occupation should be assessed. Perhaps equally important is an assessment of the occupations most critical to meeting the goals of the mission. Determining only those occupations projected to have the greatest growth would exclude from consideration many of the vital skills needed to perform the work.

\section{Recomnendation}

Macroeconomic data on granting of degrees and projected national workforce numbers should continue to be complemented by, and integrated with, Tocal measures of job criticality.

\section{Integrated manpower planning is a broad-based organizational activity.}

Traditionally, manpower planning has been a numbers-generating activity. Preferring mathematical nodels of workforce movements through organizations, operations researchers and others have eschewed investigating the location, organizational climate, culture, and skill-based factors that significantly affect an organization's ability to influence and recruit from the 1 abor pool.

However, workers with the appropriate skills can be found not only by increasing the size of the market (via macroeconomic incentives) but also by increasing the market share (becoming an employer of choice). Consequently, determining the number of people needed to accomplish a mission cannot be conducted independently of the after-work needs, desires, and preferences of the individuals who will be recruited. 


\section{Recommendation}

Manpower planning activities should be integrated with data contained in human resource information systems, coordinated across the complex, and tailored to local needs. A consistent taxonomy of job titles and related characterization of the knowledge, skills, abilities, and training characteristics of an occupation should be implemented across the complex. Such a system would permit a more accurate specification of projected needs and a more detailed analysis of the extent to which the current workforce could take on new activities. Training, project management, human resource, and planning departments could then have a common basis for conducting their manpoweroriented activities.

\section{Recommendation}

Programs to enhance the attractiveness of the DOE complex as a place of employment should be investigated to determine if they can markedly increase DOE's competitive position in the marketplace in a cost-effective manner relative to the cost of macroeconomic interventions designed to affect supply. 


\subsection{REFERENCES}

Braddock, D. J. 1992. "Scientific and Technical Employment, 1990-2005." Monthly Labor Review 115(2):28-41.

Bureau of Labor Statistics (BLS). 1988. National Survey of Professional, Administrative, Technical, and Clerical Pay, Vol. 2. U.S. Department of Labcic, Bureau of Labor Statistics, Washington, D.C.

Bureau of Labor Statistics (BLS). 1991. Occupational Employment Survey. U.S. Department of Labor, Bureau of Labor Statistics, Washington, D.C.

Carey, M., and J. C. Franklin. 1991. "Industry Output and Job Growth Continues Slow into the Next Century." Monthly Labor Review 114(11):45-63.

Collins, E. L. 1991. "Sensitivity of Science and Engineering Baccalaureates to Starting Salary and Underlying Population." Paper presented at the meeting of the American Association for the Advancement of Science, February 16, 1991 . National Science Foundation, Washington, D.C.

Engineering Manpower Commission (EMC). 1991. "Engineering and Technology Degrees." Engineering Manpower Commission of the Association of Engineering Societies, Washington, D.C.

Environmental and Waste Industry Compensation Survey. 1991. Wm. M. Mercer, Inc., Denver, Colorado.

Les7ie, L. L., and Oaxaca, R. 1990. "Scientist and Engineer Supply and Demand: A Review." A Report to the National Science Foundation, Division of Science Resources Studies.

National Research Council. 1990a. "Fostering Flexibility in the Engineering Workforce." National Academy Press, Washington, D.C.

National Research Council. 1990b. "U.S. Nuclear Education: Status and Prospects." National Academy Press, Washington, D.C.

National Science Foundation. 1989. "The Future Supply of Natural Scientists and Engineers," in The State of Academic Science. National Science Foundation, Washington, D.C.

National Science Foundation (NSF). 1991. Science and Engineering Degrees: 1966-89. A Source Book, NSF 91-314, Detailed Staistical Tables. National Science Foundation, Washington, D.C.

Oak Ridge Associated Universities, (ORAU) Inc. November 1991. "Labor Market Trends for Health Physics." Oak Ridge Associated Universities, Inc., Oak Ridge, Tennessee. 
U.S. Department of Energy (DOE). 1989a. Applied Research Development, Demonstration, Testing and Evaluation Plan. U.S. Department of Energy, Washington, D.C.

U.S. Department of Energy (DOE). 1989b. Environmental Restoration and Waste Management Five-Year Plan. DOE/S-0070, U.S. Department of Energy, Washington, D.C.

U.S. Department of Labor (DOL), U.S. Employment Service. 1977. Dictionary of Occupational Titles. 4th ed. U.S. Government Printing Office, Washington, D.C. 
APPENDIX A

WORKFORCE NEEDS ASSESSMENT SURYEY 
Environmental Restoration/Waste Management Activities Workforce Needs Assessment Survey
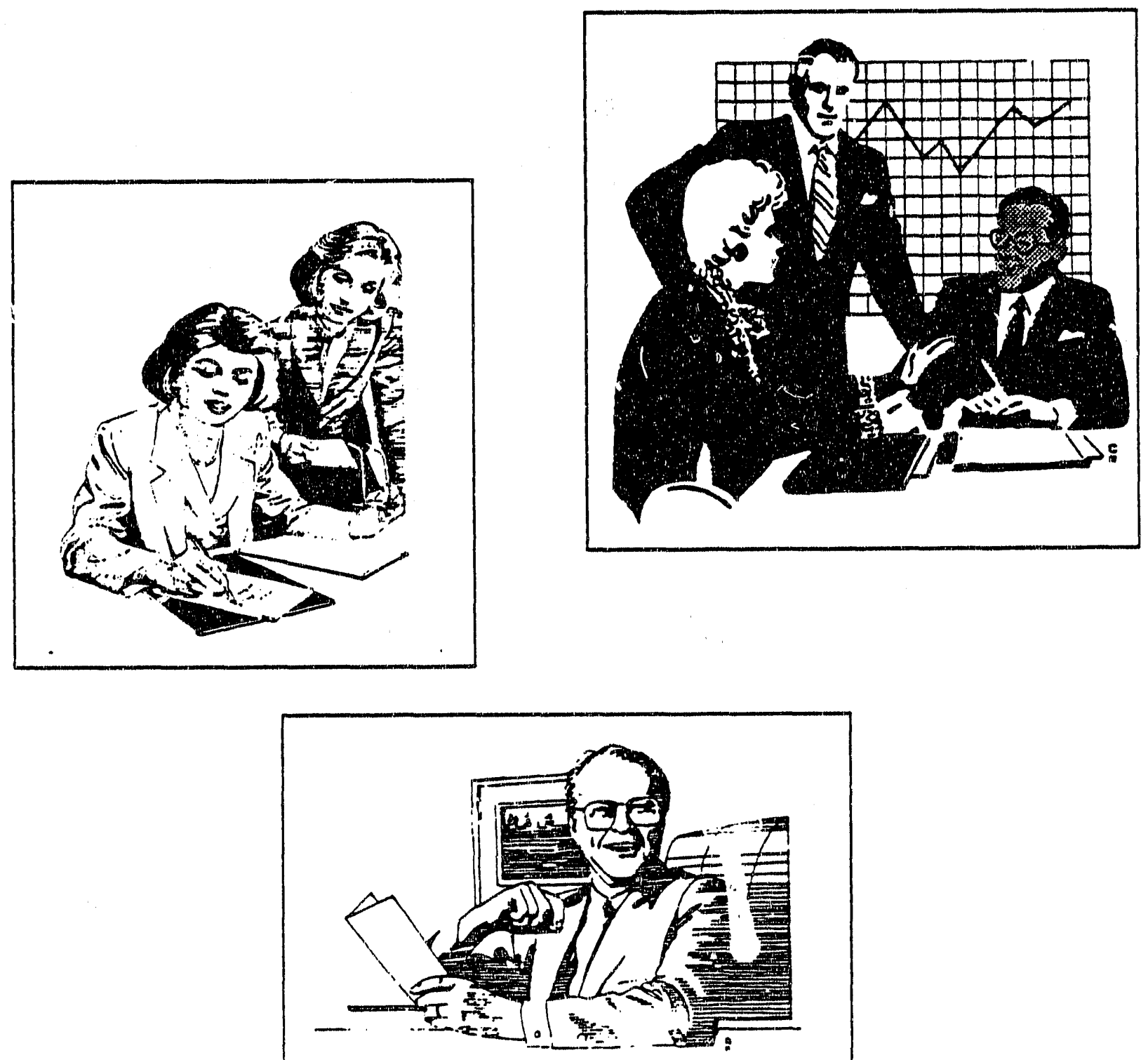

A. 1 


\section{Instructions}

Fifty-three technical, support, engineering and scientific occupations relevant to EM activities are listed. For each occupation you'll estimate certain parameters. Your estimates will be used to make manpower and workforce transition projections that the Office of Technology Development (OTD) will use to direct resources into education and employee development programs. This exercise, therefore, is a critical element of ensuring that there will be individuals who can assume the jobs needed to fulfill ER/WM Five Year Plan goals.

Assumptions are a necessary part of any survey instrument. For this exe cise please assume:

- you will use current technology to meat EM/Five Year Plan gotds

- you are including subcontractors in your estimate

- you are estimating the requirements for your EM programs only

- estimates are based on the 1993-1997 Five Year Plan

Please determine:

1. The number of current full-time equivalent employes: (FTEs) in each occupation working on ER/WM Five Year Plan activities by writing the number in the space provided.

2. The number of FTEs in each occupation you will need in your organizatiun/program in 1997 to meet your Five Year Plan goals ending 1997.

3. The peak number of FTEs you anticipate employing in each occupation over the 1993-1997 Five Year Plan.

4. The difficulty you would experience meeting Five Year Plan goals with a shortage of workers in this occupation by circling the appropriate number.

5. Your anticipatec ability to recruit qualified individuals in each occupation by circling the appropriate number.

6. The typical college degree level held by new hires who will be recruited for each occupation by circling the appropriate number.

Werealize that specific job titles often vary arross organizations. Therefore, fun :tional definitions for each occupational title have been adapted from the Dictionary of Jccupatioral Tiles. Please base your estimates for each occupation on the definitions. Spaces marked "Other" are available for you to specify occupations not listed in the survey which you feel are important for EM activities.

The last page contains space for open-ended comments. One of the goals of this survey is to identify occupations crucial or unique to EM activities. If you have knowledge of particular specialties or sub-specialties not identified on the form please note them in the spaces provided. We are especially interested in learning of occupations which cut across traditional disciplines.

If you have questions or comments feei free to call

Dr. Robert E. Lewis

(509) 376-4744, FTS 444-4744

or

Dr. Christopher W. Holmes

(509) 376-5893. FTS 444-5893
Our fax number is:

(509) 376-5484

Our address is:

Battelle Pacific Northwest Laboratory

P.O. Box 999, K6-66

Richland, WA 99352 


\section{Background Information}

The following background information permits a more thorough analysis of the data. Please identify whether your organization is DOE or contractor, your site, and EM program.

The results of the study will be made available through normal channels. If you would like a copy sent directly to you please provide your full address.

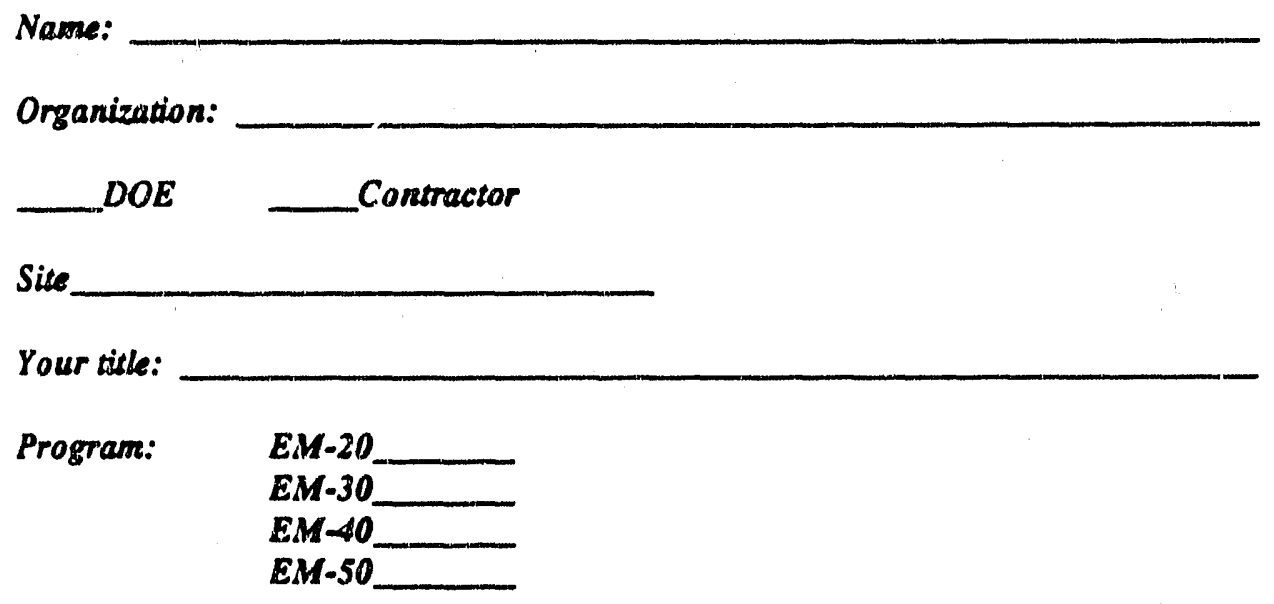

Please estimate the percentage of your budget allocated to each EM activity:

Corrective Activities

Environmental Restoration

Waste Management

Technology Development. 


\section{ENGINEERING TECHNICIANS}

Chentical Engineering Technictan applies chemical engineering principles and technical skills to assist a chemical engineer in developing, improving and testing chemical-plant processes, products and equipment. May set up apparaus, collect data and help write reports. (chemical engineering assistant, or chemical lab technician)

Civil Englneoring Tochnician conducts surveys and inspects existing infrastructure systems such as wastewater treament. irrigation, and roads, as well as environmental health and management systems. Sets up and maintains equipment. tabulates data, and prepares reports in consultation with a civil engineer. (civil engireering assistant, associate engineer, engineering technician, or surveyor)

Computer Operator oversees the operations of computer facilities and remedies software-related off-normal conditions. Operates peripheral machines, such as tape machines and printers, to provide data access to computer users. May advise computer users regarding the capabilities of cornputing resources, use of operating systems, file transfer and management, etc. (computer technician, compuser consultant, systems consultant, or computer lab assistant)

Orafter prepares working plans and detailed drawings from rough or detailed sketches or notes for engineering or manufacturing purposes according to specified dimensions. Utilizes knowledge of various machines, engineering practices, mathernatics, building materials, and other physical sciences to complete drawings. May use computerassisted drafting $(C A D)$ equipment and be designated $C A D$ drafter.

Eectricalelectronic Techrictan applies electrical/electronic theory and related knowledge to test and modify, lay out, troubleshoot and repair electronic or electrical equipment. Adjusts and maintains test equipment and generally works in consultation with an electrical/electronic engineer. May do bench-or fieldwork. (electronic sechnician/specialist, computer technician, or electrical technician)

Mechanical Engineering Technician develops and tests machinery and equipment, applying knowledge of mechanical engineering technology, under direction of engineering staff. May set up and conduct tests of complete mechanical units or components. (mechanical engineering assistant, mechanic, or field equipment technician)

Surveying and Mapping Tecrulcian praforms surveying and mapping duties to oblain data pertaining to angles, elevations, points and contours used for construction, mapmaking, boundary location, mining or other purposes. Calculates mapmaking intormation from field notes using teference tables. surveyors, cartographers, or geodeists.

* Definitions marked with an asterisk are drawn fror 1991 Environmental and Waste Industry Compensation Survey. Copyright William M. Mercer. Inc. Denver, CO. Used with permission. 


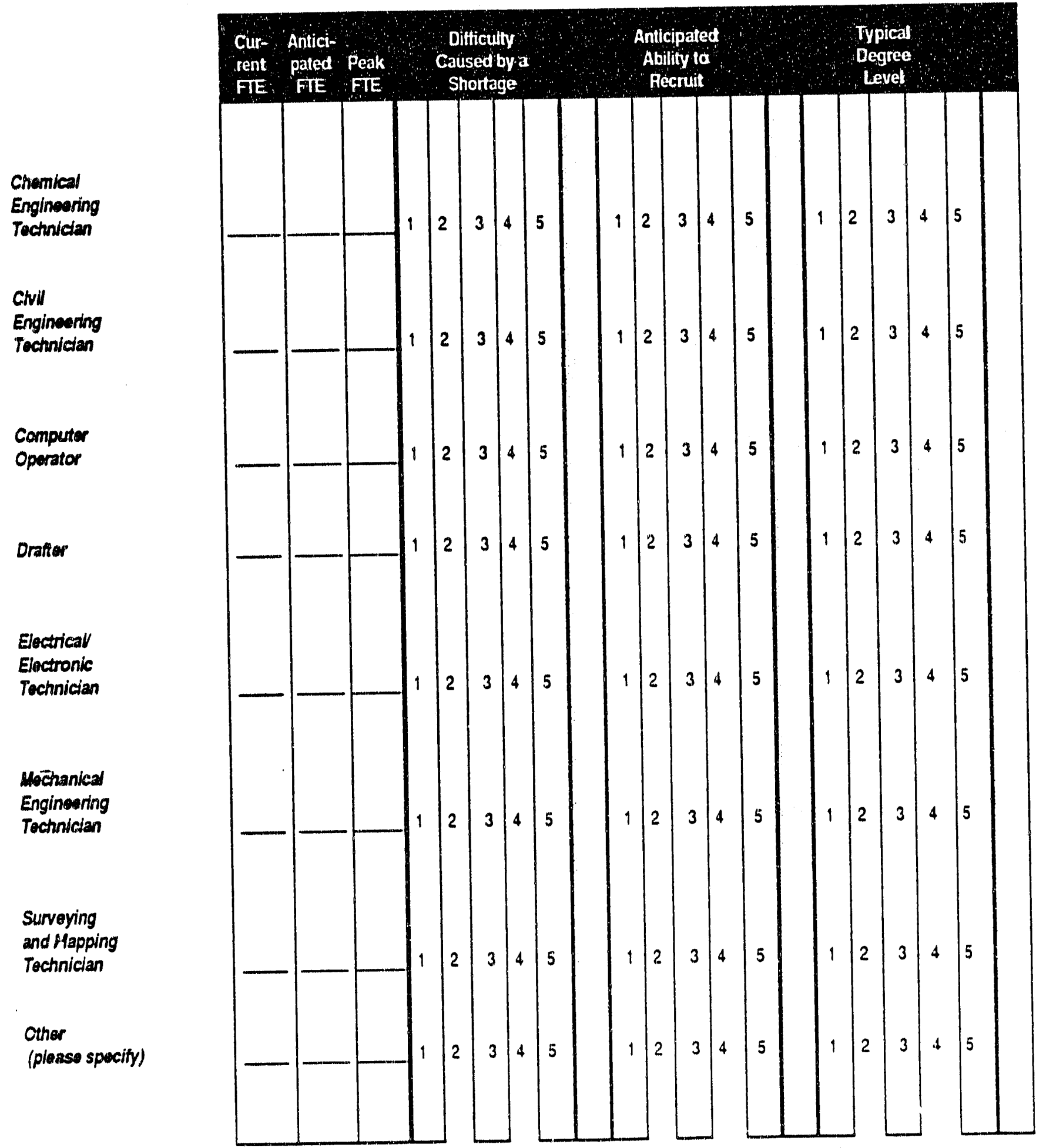

A. 5 


\section{PHYSICAL \& LIFE SCIENCES TECHNICLANS \& TECHNOLOGISTS}

Chemical Technologist conducts chemical and physical laboratory tests to assist scientists in making qualitative and quantitative analyses for work involving experimental, theoretical or practical application of chemistry and related sciences.

Heatth Physics Techniclan monitors personnel, plant facilities and work environment to detect radioactive contamination using radiation detectors and other instruments. Assesses worker exposure, operating practices, and material contamination in hazardous waste disposal areas. Works with health physicist to determine exposure limits of personnel and decontamination recommendations (physical sciense sechnician desimetry lechnician).

Inctustrial Hygienist conducts health programs to recognize, eliminate and control occupational health hazards and diseases. Evaluates exposure to ionizing and non-ionizing radiation and recommends measures 10 insure maximum employee procection. Prepares reports, participates in educational meecings, and collaborates with occupational physicians.

Incustrial Safaty and Health Techrician plans and directs safety and health activities to evaluate and control environmental hazards. Tests noise and air levels, maintains and calibrates instruments, administers hearing test, develops and monitors emergency accion plans, investigates accidents and prepares accident reports. Recommends changes in policies and procedures it prevent accident and illness.

Radjation Protoction Speciallst tests and monitors equipment and environment w detect and control radiatic a hazards. Visits sites to assess the adequacy of shielding and operator competence. Explains changes in shielding or processes needed to conform to regulations. 


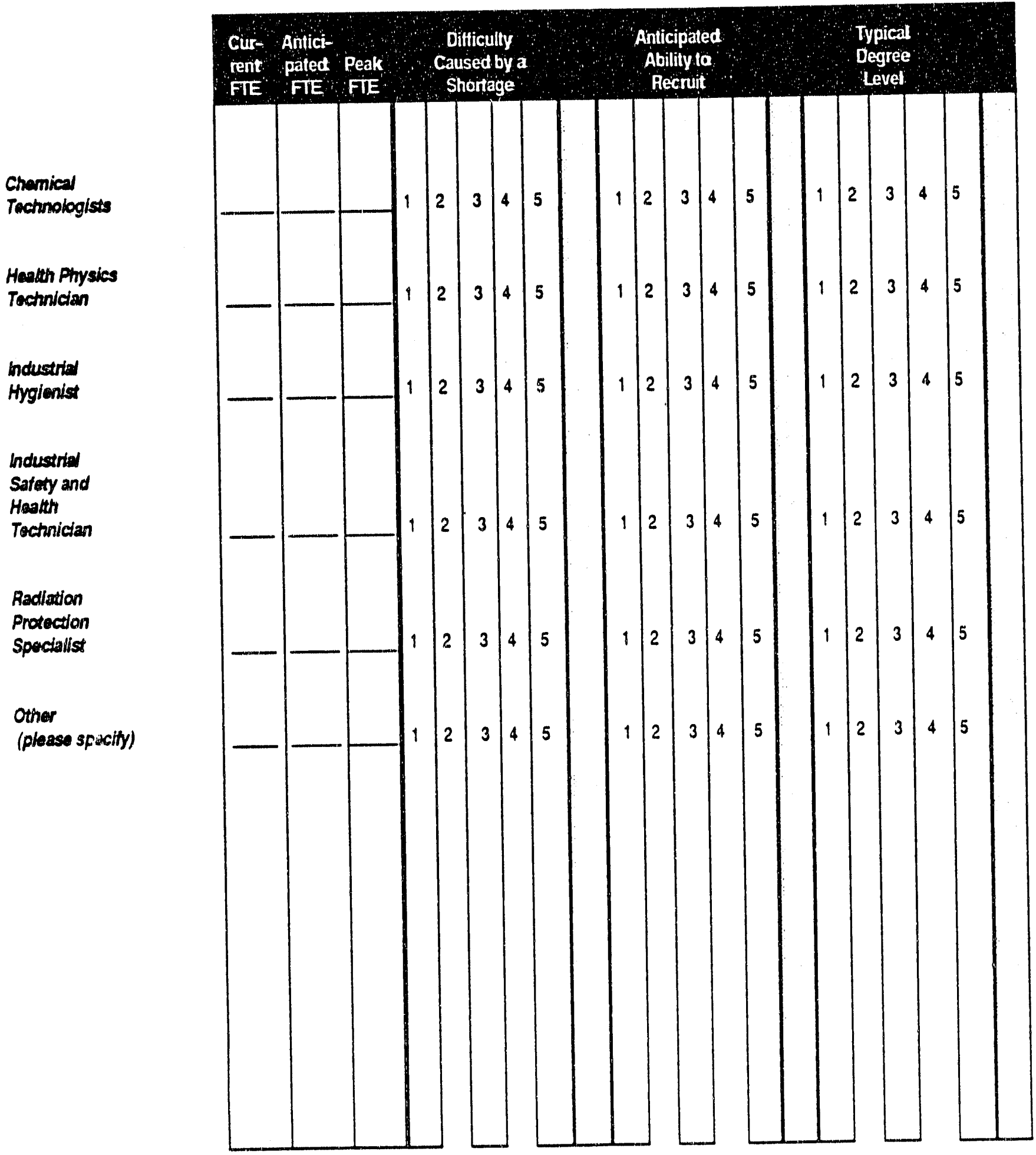




\section{ENVIRONMENTAL \& WASTE MANAGEMENT TECHNICIANS}

Onliter uses drilling or boring machines to sink wells or holes for experimental, exploratory, or monitaring purposes only. Do not include constrection excavation accupations. (Driller operator, machine driller, prospecting driller, pipe lester, core driller, well driller, rotary driller, testing-10ol operator, well puller, or rig operator.

Environmental Sciences Tectnician conducts tests and field investigations to obtain data for use by environmental. engineering and scientific personnel in determining sources and methods of controlling pollutants in air, water and soil. Uses knowledge of agriculture, chemistry, metoorology and engineering principles and applied technologies. May work under the supervision of civil, chemical or environmental engineers or physical or earth scientists. (environmental field technician, site monitor specialist, hydrographer, soil tester, geological assistant, or environmental analyst)

Hazardous Wasto Management Spectallst conducts studies on hazardous waste management projects and provides information on treatment and containment of hazardous waste. Under the general supervision of a scientist or manager, participates in developing hazardous waste rules and regulacions, assesses available hazardous waste treatment and disposal alternatives, and provides technical assistance in the event of an emergency. May provide inputs that help evaluate the economic impact of various treatment and disposal alternatives and write reports.

Material Handler loads, unloads and moves hazardous or non-hazardous materials within or near plants or field sites. Uses knowledge of radiation and effects of radiation to protect self and environment when working with hazardous materials. May operate heavy equipment. (hazardous material handler, rad-waste disposal technician, hawardous landfill technician, or heavy equipment operator)

Nuclear Waste Process Operator controls equipment to decontaminate, neutralize and dispose of radioactive waste liquids collected from chemical processing operations. Tests samples for radioactivity and records data. May monitor panelboard to control operation of recovery systems that store or dispose of radioactive waste.

Remediation Specialist " under general supervision performs non-routine and occasionally heavy labor tasks related to on-site hazardous waste remediation. Collects samples and maintains record logs. Uses knowledge of radiacion effects of radiation to protect self and environment when working with hazardous materials. Generally operates light and heavy equipment.

Other please specify and provide estimates for technical positions not listed above that maybe involved in ER/WM activities. 


\section{ENVIRONMENTAL \&}

WASTE MANAGEMENT

TECHNLCLANS

Driller

Environmental

Sciences

Tectunician

\section{Hazardous \\ Waste \\ Managomant \\ Speciallst}

Material

Handler

Nuctear

Waste

Process

Operator

Remodiation

Specialist

Other

(please specify)

\begin{tabular}{|c|c|c|c|c|c|}
\hline $\begin{array}{l}\text { Cur- } \\
\text { rent } \\
\text { FIE }\end{array}$ & $\begin{array}{l}\text { Antici- } \\
\text { pated } \\
\text { FIE }\end{array}$ & $\begin{array}{l}\text { Peak } \\
\text { FIE }\end{array}$ & $\begin{array}{l}\text { Difficullty } \\
\text { Caused by a } \\
\text { Shortage }\end{array}$ & $\begin{array}{l}\text { Anticipated } \\
\text { Ability to } \\
\text { Fecruit }\end{array}$ & $\begin{array}{l}\text { Typical } \\
\text { Degree } \\
\text { Level }\end{array}$ \\
\hline
\end{tabular}

$\begin{array}{lllll}2 & 3 & 4 & 5\end{array}$

$\begin{array}{lllllllllllll}1 & 2 & 3 & 4 & 5 & & 1 & 2 & 3 & 4 & 5\end{array}$

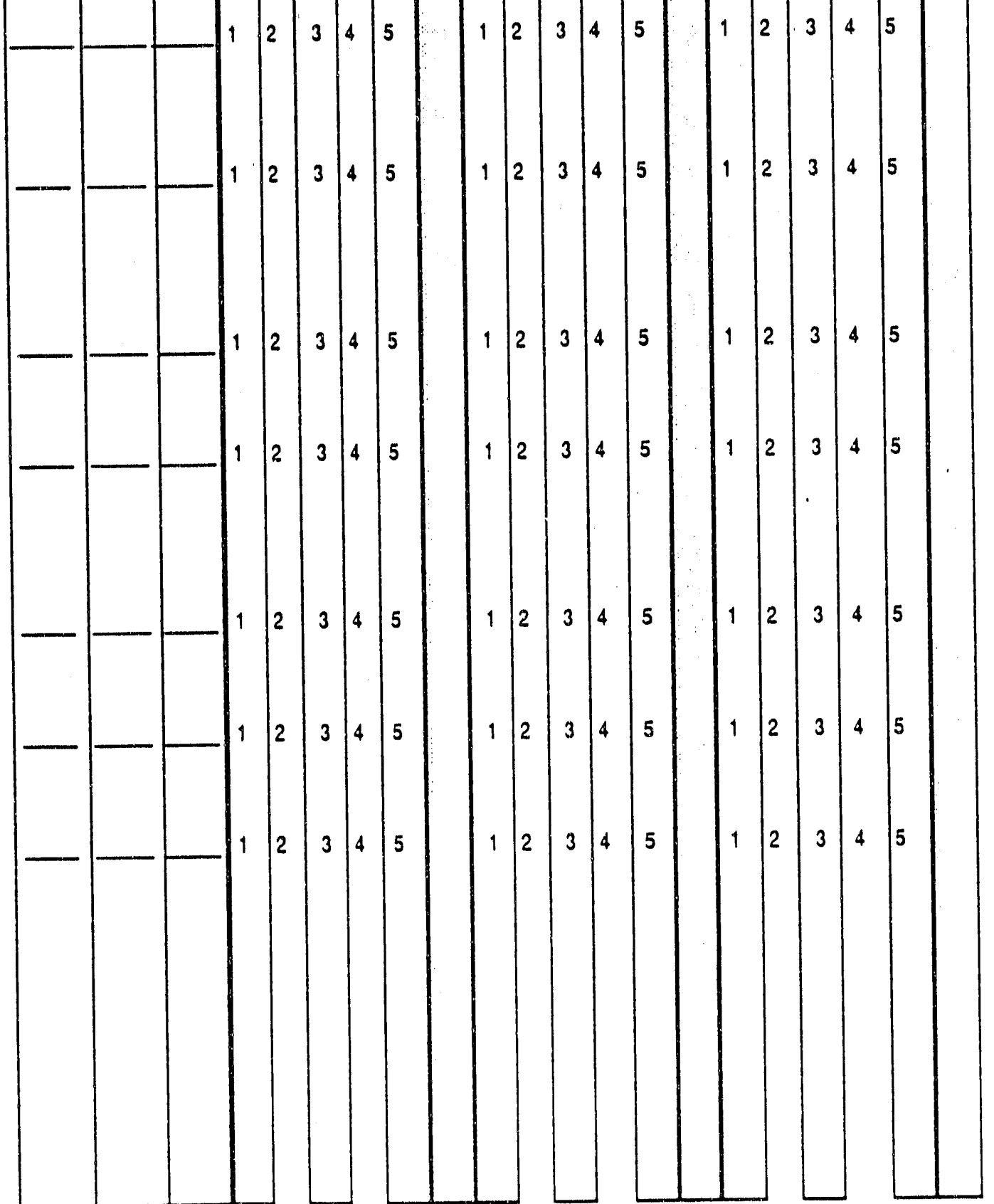

A. 9 


\section{ENGINEERS}

Chemical Engineer designs equipment and develops processes for manufacturing chemicals and related products utilizing principles and technology of chemistry, physics, mathematics, engineering, and related physical and natural sciences. Analyzes procedures, oversees workers, designs equipment and performs tests. Do not include those employees with chemical engineering backgrounds who work primarily or exclusively as environmental engineers.

Clvil Enginoer plans, designs, and directs construction and maintenance of structures and facilities, such as roads, dams, and irrigation and sanitary systems. Include the following job titles: sanitary engineer and transportation engineer. Do not include occupations concerned with the design and construction of hazardous waste sites when those occupations are commonly known as environmental engineers.

Computer Engineer develops software and efficient computer (non-hardware) operating systems. Makes extensive use of mathematics, statistics, logic and computer programming languages. (computer programmer, programmer/analyst, computer scientist, software developer, or software engineer)

Environmental Enginoer applies engineering knowledge and technology to identify, solve, or allevitte environmental problems. Include engineers with formal training in civil and chemical engineering who specialize in environmental problems and do not hold the title of chemical engineer or civil engineer. (industrial health engineer, pollution control engineer, or environmental research engineer)

EectricalElectronic Enginear applies the lawis of electrical energy and the principles of engineering for the generation, transmission and use of electricity. May design, manufacture, and/or test electrical or electronic systems or components.

Incustrtal Engineer plans utilization of production facilities and personnel to improve efficiency of operations in industrial establishments. Establishes work measurement programs, analyzes utilization of manpower, and plans space layout of facilities. (quality-control engineer)

Irrigation Engineor plans, designs and oversees construction of irrigation projects. Plans and designs irrigation fixtures and installation of fixtures. Conducts research on problems of soil drainage and conservation, applying knowledge of civil engineering.

Materials Engineer evaluates, plans and implements processes to develop new materials to meet product specifications, performance standards, and cost specifications. (metallurgical engineer or ceramic engineer) 
Chemieal

Clvil

Engineer

Computer

Enginear

Environmental

Enginaer

\section{Eloctrical \\ Electronic \\ Enginewr}

Industrial Engineer

Irrigation Enginoer

Materials

Engineer

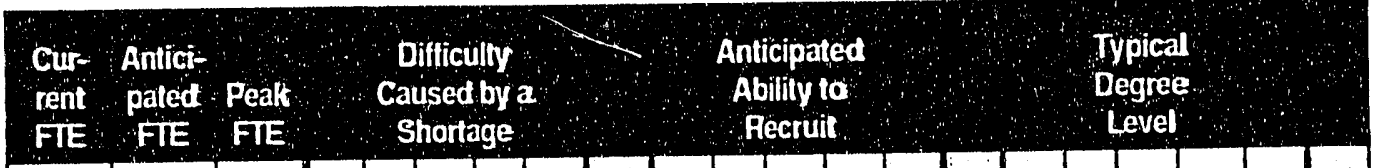

\begin{tabular}{lllllll|l|l|l|l|l|l|l|l|l|l|l}
1 & 2 & 3 & 4 & 5 & & 1 & 2 & 3 & 4 & 5 & & 1 & 2 & 3 & 4 & 5
\end{tabular}

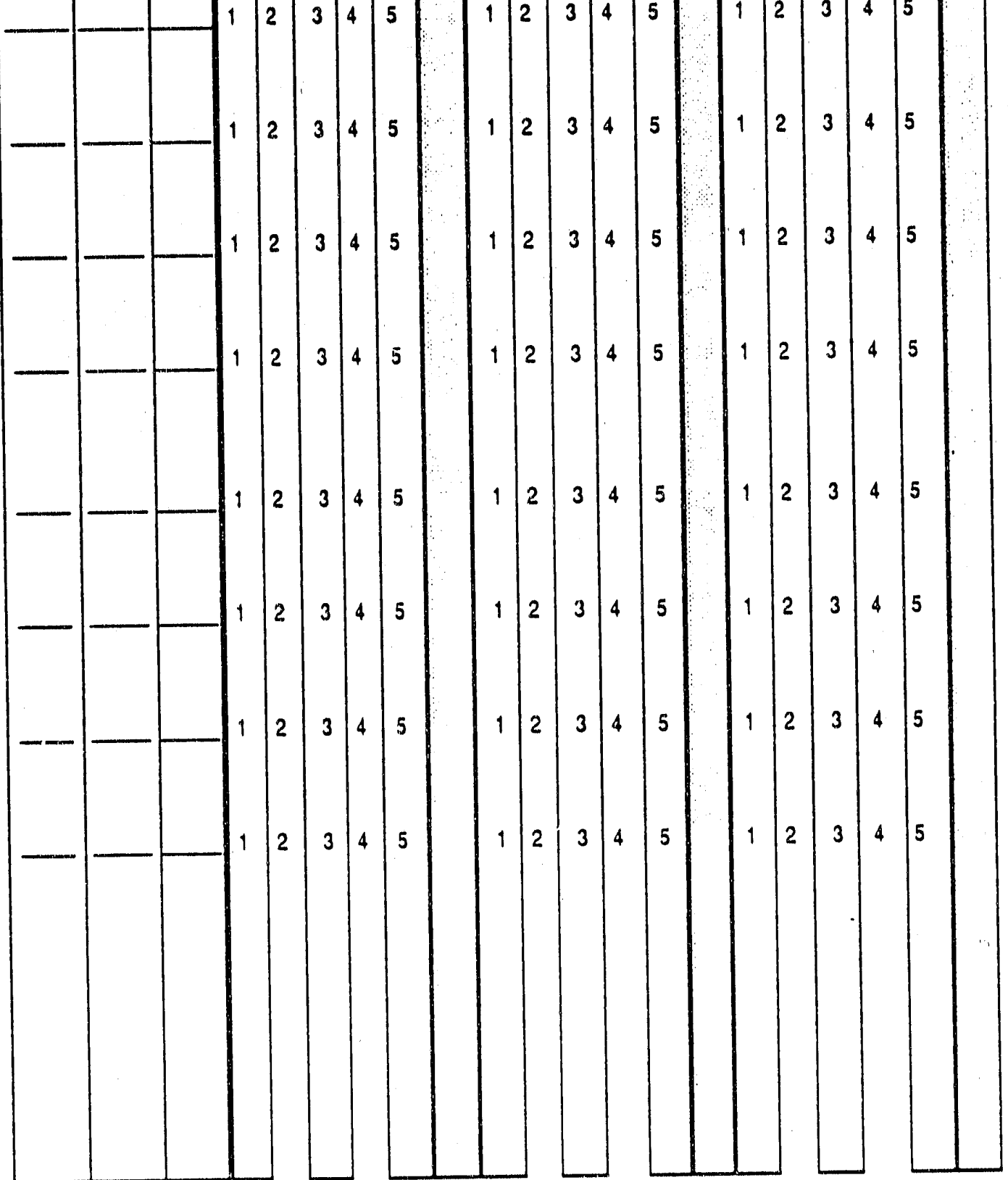

A. 11 


\section{ENGINEERS}

(contrued)

Mechanical Engineer plans and designs mechanical and/or electromechanical systerns or products. Plans and directs engineering personnel in the fabrication of equipment and test-control apparatus. (heat-transfer engineer, controls and instrumentation engineer, or hydraulic engineer). Product design engineer or test engineer when mechanical engineering principles are used primarily.

Neclear Engineor designs, develops and tests nuclear equipment and systems; monitors testing, operation and maintenance of nuclear reactors. Studies nuclear fuel cycie to define most economical uses of nuclear material and safest means of waste products disposal. (nuclear-fuels reclamation engineer, nuclear-criticality engineer or nuclear-fuels research engineer)

Nuclear Decontamination Engineer applies principals of nuclear and chemical engineering to decontaminate radioactive equipment and work areas in nuclear plants, laboratories and other facilities. Minimizes the risk to personnei and the volume of waste.

Petroleum/Mining Engineor includes occupations concemed with the extraction of minerals from the earth. Plans and develops mining excavations and well drillings. Accessory techniques include those used in metallurgy and geology. Directs engineering and technical personnel through the drilling, boring, cutting, excavating and grading processes. Typical specializations are according to the activities or substance involved. (geological engineer, engineering geologist, exploration engineer, coal engineer or miseral extraction engineer)

Safoty Engineer applies knowledge of industrial processes, mechanics, chemistry, psychology, and industrial health and safety laws to prevent or correct injurious environmental conditions and minimize effects of human traits that create hazards to life and property or reduce worker morale and efficiency.

Structural Englneer directs or participates in planning, designing or reviewing plans for erection of structures requiring stress analysis. May inspect existing projects and recommend repair and replacement of defective members or rebuilding of entire structure.

Waste Management Engineer designs, implements and tests systems and procedures to reduce volume and dispose of waste materials and contaminated objects including nuclear waste. Advises management on selection of lands suitable for use as waste disposal sites and on establishment of effective safety, operating, and closure procedures.

Other please specify and provide estimates for any engineering occupations not listed above that maybe involved in ER/WM activities. 
ENGINEERS

(continued)

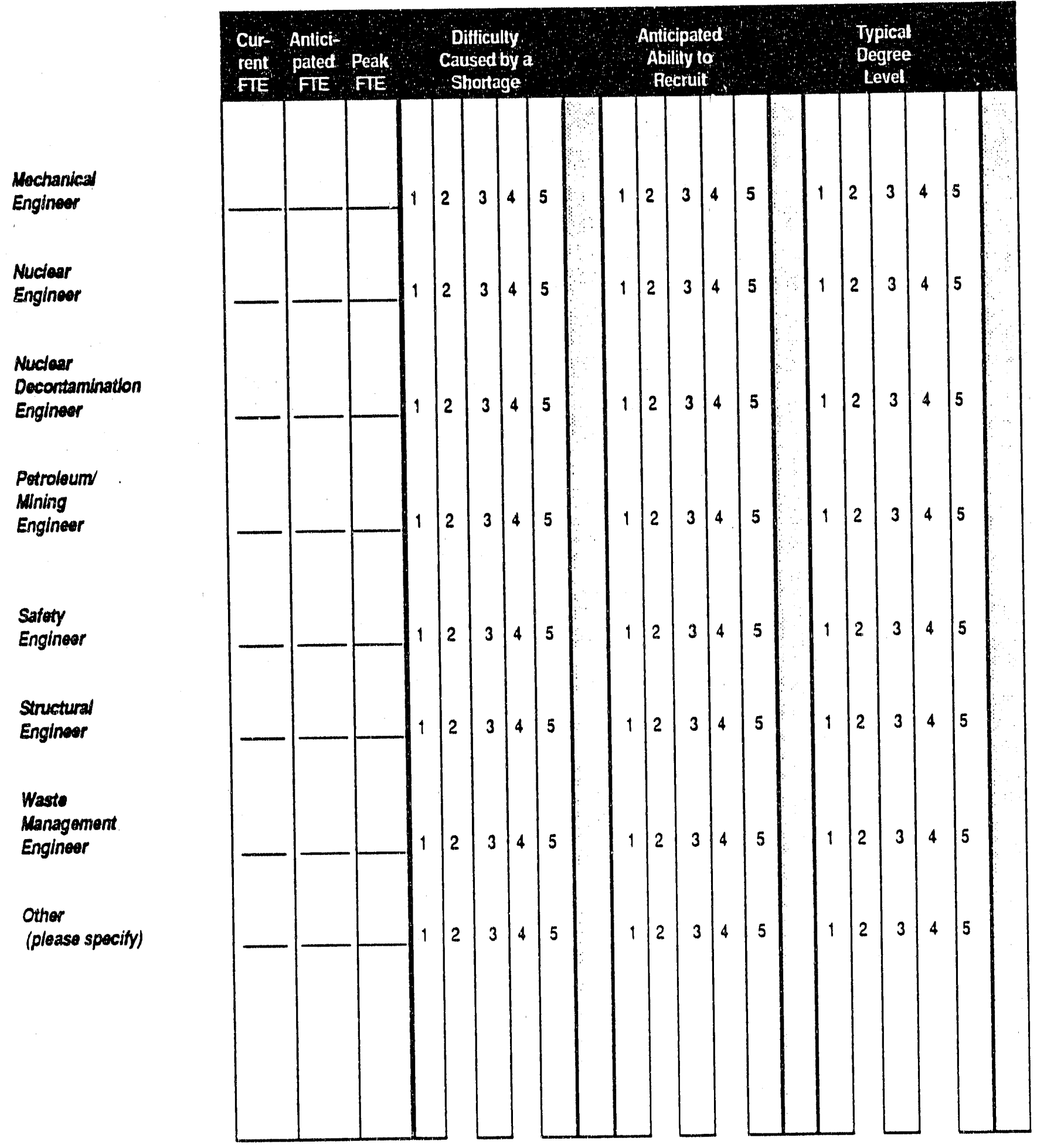

A. 13 


\section{SCIENTSTS}

Blochemist studies chemical processes of living organisms and conducts reseurch to determine action of foods, drugs, serums, hormones, and ocher substances on tissues and vital processes of living organisms.

Blologist studies the reproduction, growth and development, strucuure, life processes, behavior, and classification of living organisms. Applies these findings to prevent disease maintain and promote health in plant and animal life. (aquatic biologist, botanist entomologist, physiologist, or cycologist)

Chemist conducts research, analysis, synthesis and experimentation on chemical compounds for purposes of developing new processes, compounds, and analytical techniques. (process chemist, havandous materials chemist, or geochemist)

Ecologist studies piants or animals wo determine the effect of environmental influences, such as rainfall, temperature, altiuide and kind and quantity of food. (bovanist, soil scientist, range manager, forest ecologist and soil conservacionist)

Envinnmentat Sclentist uses know ledge of principles and concepts of various scientific and engineering disciplines cecipations to develop methods of abating or controlling sources of environmental pollutants. (meteorologist, oceanographer)

Goologist studies composition, structure, and physieal and biological history of the earth's crust. Applies knowlenige of chernistry, physics, biology and mathematics to explain these phenomena and to help locate miseral. geochermal and petroleurn deposits and underground water resources.

Hytrologist and Hydrogeologist " studies distribution, disposition anc stvelopment of waters of land areas. Develops technical approaches for large groundwater recovery and treatment projects.

Heatth Ptysictst' reconmends and develops policies and procedures related to health physics issues. Develops, implements and evaluates research, training and monitoring programs to protect all personnel.

Matertats Selentst conducts scientific studies to understand, characterize and develop materials leading wo potential uses for the benefit of science and emerging technologies. (metallurgist when not engineering-oriented)

Mathematclan conducts research in fundamental mathematics and in application of mathematical techniques to science, management and other fields. (applied mathemasician or research mathematician) 


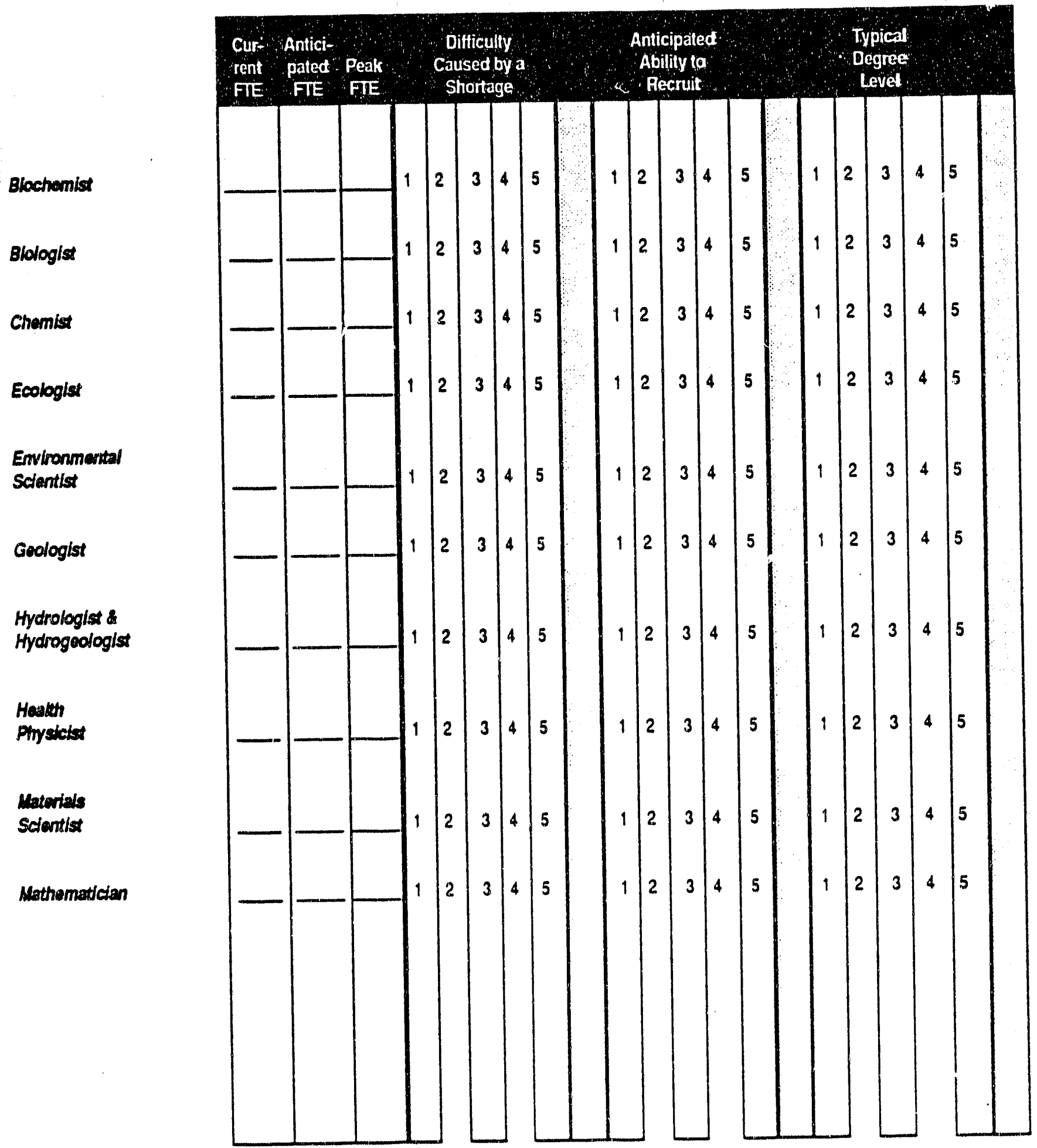

A. 15 


\section{SCIENTISTS \\ (continued)}

Operattons Roseancher analyzes management and operational problems and formulates mathematical or simulation models of problems for solution by computers or other methods.

Pitysicist conducts research into phases of physical phenomena; develops theories and laws on basis of observation and experiments; and devises methods to apply laws and theories of physics to industry, medicine and other fields. (nuclear physicist, experimental physicist, or atomic physicist)

Seismologist studies and interprets seisnic data to locate earthquakes and earthquake faults. Conducts research on seismic forces affecting deformative movements of earth.

Statstctan conducts research into mathematical theories and proofs that form basis of science of statistics and develops statistical methodology. Analyzes data from tests and experimental designs.

Other please specify and provide estimates for scientific occupations not listed above that may be involved in ER/WM activities. 
SCENTISTS

(continued)

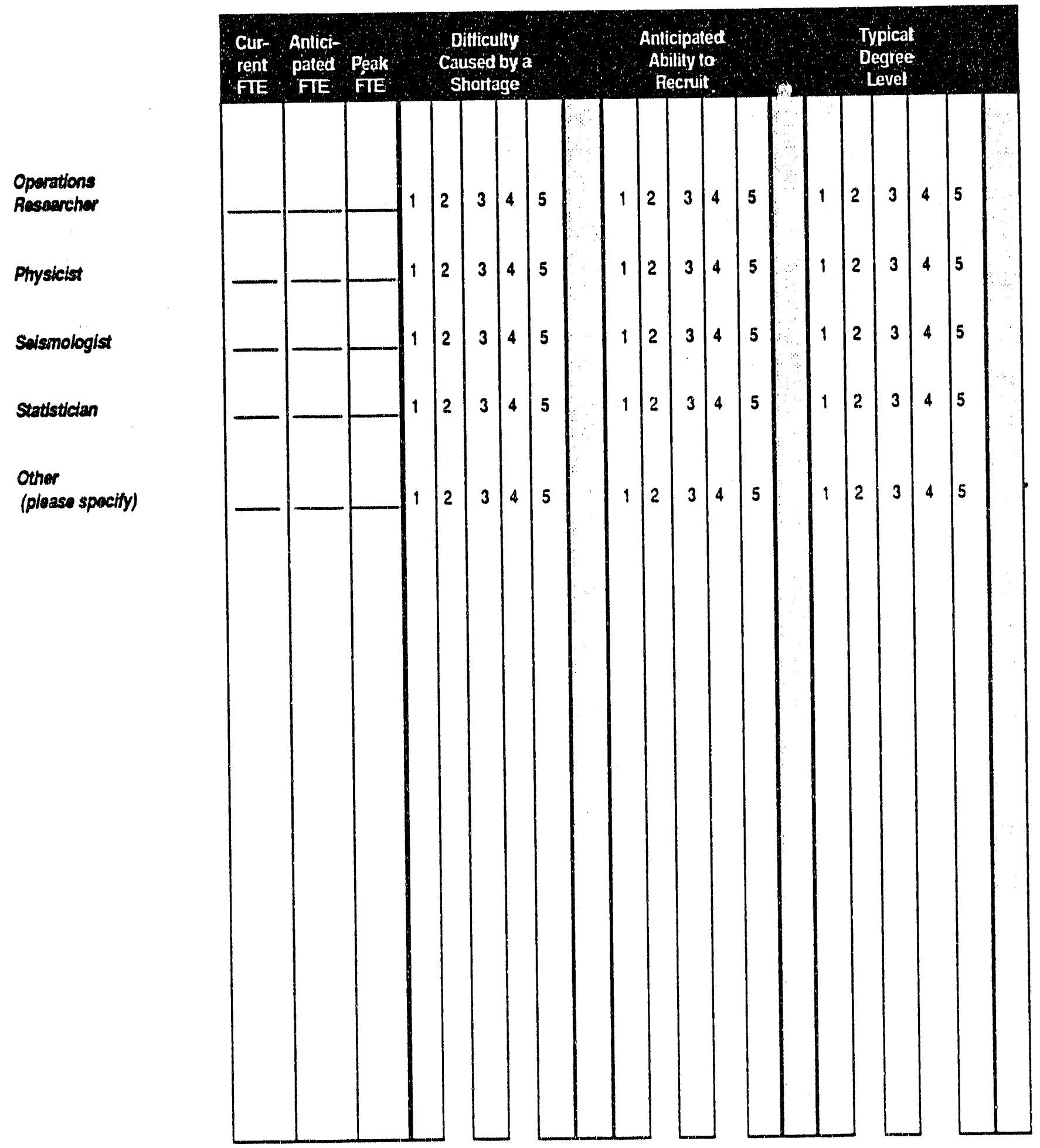

A. 1.7 


\section{ADMINISTRATIVE \& OTHER OCCUPATIONS}

Administrattve Assistant and Clerteal Worker provide support services such as keeping accounts, entering and tracking data, typing, and other general non-hazardous task. (project administrator, administrative clerk, data processing clerk, or clerk-typist)

Estimator prepares cost estimates and/or schedules for manufacturing of products, consmuction projects or services to aid management in bidding on, manufacturing, or determining price of projects or services (scheduler).

Project Manager plans, organizes, directs or coordinates activities of other professional and technical and support workers. Their management responsibilities require a background consistent with that described for engineers, etc.

Risk Assessment Spectallst * evaluates human health and environmental impacts associated with environmental or hazardous waste releases and exposures. Generates and evaluates toxicity profiles, performs statistical analysis of environmental monitoring data, compiles dose-response parameters, and calculates both noncarcinogenic and carcinogenic health risks.

Technical Writer develops, writes and edits material for reports, manuals, and related technical and administra! ve publications.

Trainer prepares an', conducts training programs for employees. Combines requisite technical knowledge with appropriate instructional methods to conduct meetings, workshops or individualized training sessions. Tests trainees to mensure their learning progress and to evaluate effectiveness of training presentations.

Other plense specify and provide estimates for administrative and other occupations not listed above that may be involved in ER/WM activities. 


\section{Adninistrative \\ Assistant and Clerical Worker}

Estimator

Project Manager

Risk

Assessment

Manager

Tectunical

Writer

Trainer

Other

(pleaso specity)

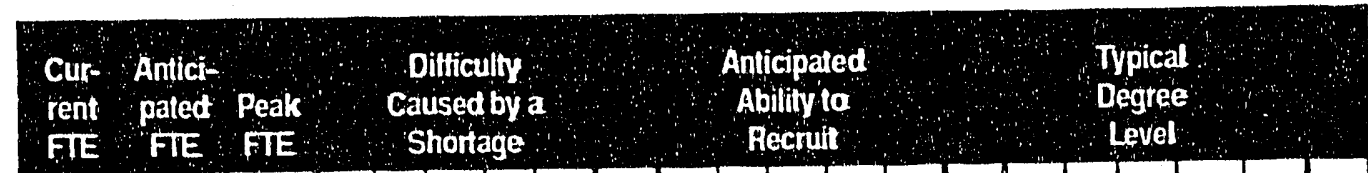
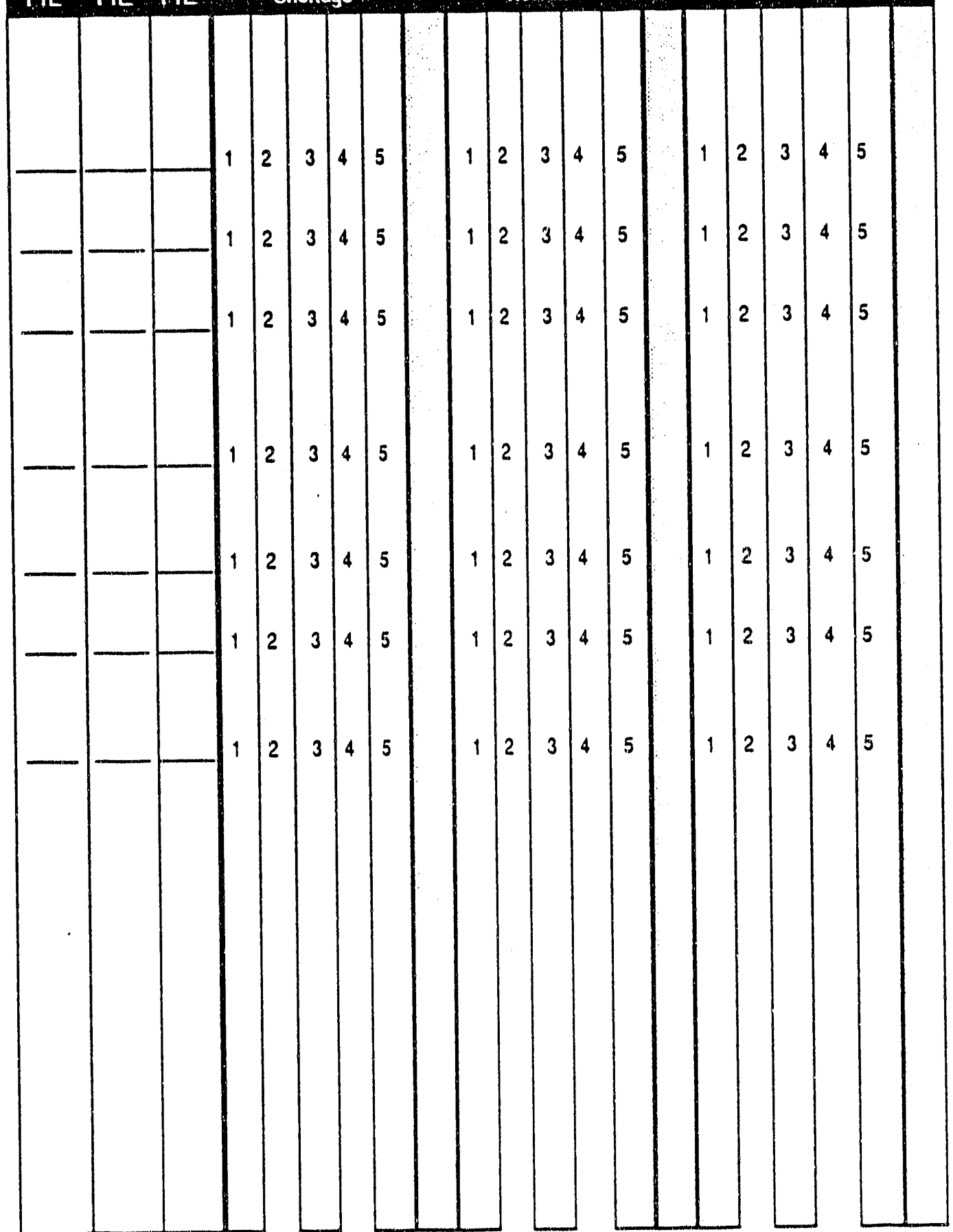

A. 19 
How confident are you in the judgments you made in this survey?

\begin{tabular}{|c|c|c|}
\hline$\widehat{\text { Confident }}$ & $\frac{21-40 \%}{\text { Confident }}$ & ${ }_{\text {Confident }}^{41-60 \%}$ \\
\hline
\end{tabular}

How do you currently handle occupations you find hard to fill?

What do you think are the main causes of recruiting difficulties you face?

Generally, where to people go after they leave your organization? (i.e., other contractors, DOE, other industries?).

Technicians:

Engineers:

Scientists:

What can be done to remedy these difficulties?

Which questions on the survey did you find most difficult to answer? 
APPENDIX B

SURVEY OF CURRENT HIRING CONDITIONS 
Environmental Restoration/Waste Management Activities Survey of Current Hiring Conditions
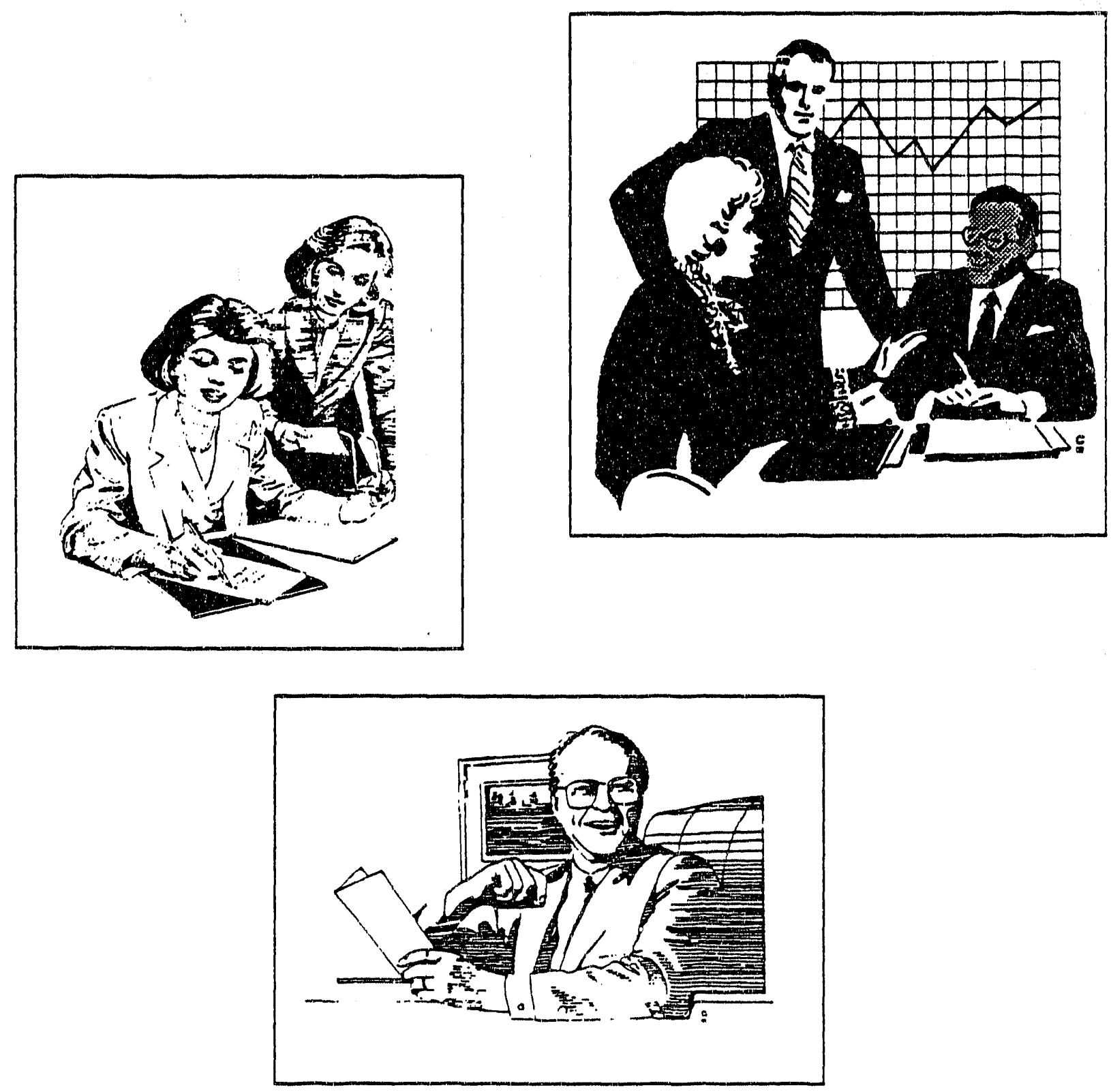


\section{Instructions}

Fifty-three technical, support, engineering and scientific occupations relevant to EM activities are listed. For each occupation you'll estimate certain parameters. Your estimates will be used to make manpower and workforce transition projections that the Office of Technology Development (OTD) will use to direct resources into education and employee development programs. This exercise, therefore, is a critical element of ensuring that there will be individuals who can assume the jobs needed to fulfill ER/WM Five Year Plan goals.

Assumptions are a necessary part of any survey instrument. For this exercise please assume:

- you will use current technology to meet EM/Five Year Plan goals

- you are estimating the requirements for EM programs for your organization at your location only

- estimates are based on the 1993-1997 Five Year Plan

Please determine:

1. The difficulty you would experience meeting Five Year Plan goals with a shortage of workers in each occupation by circling the appropriate number.

2. EM program needs for additional employees in each occupation by circling the appropriate number.

3. The current ease/difficutty you have recruiting qualified individuals in each occupation by circling the appropriate number.

4. Your anticipated ease/difficulty recruiting qualified individuals in each occupation over the years $1993-1997$ by circling the appropriate number.

5. The current annual turnover in each occupation by circling the appropriate number.

We realize that specific job titles and responsibilities often vary across organizations. Therefore, functional definitions for each occupational title have been adapted form the Dictionary of Occupational Tilles. Please base your estimates for each occupation on the definitions. Spaces marked other are available for you to specify occupations not listed in the survey which you feel are important for EM activities.

The last page contains space for open-ended comments. One of the goals of this survey is to identify occupations crucial or unique to EM activities. If you have knowledge of particular specialities or sub-specialties not identified on the form please note them in the spaces provided. We are especially interested in learning of occupations which cut across traditional disciplines.

If you have questions or comments feel free to call

Dr. Robert E. Lewis

(509) $376-4744$, FTS $444-4744$

or

Dr. Christopher W. Holmes

(509) 376-5893, FTS 444-5893
Our fax number is:

(509) 376.5484

Our address is:

Battelle Pacific Northwest Laboratory

P.O. Box 999, K6-66

Richland, WA 99352 


\section{Background Information}

The following background information permits a more thorough analysis of the data. Please identify whether your organization is DOE or contractor, your site, and EM program.

The results of the study will be made available through normal channels. If you would like a copy sent directly to you please provide your full address.

Name:

Organization:

_ DOE Contractor

Site

Your title: 


\section{ENGINEERING TECHNICIANS}

Chemical Engineering Techniclan applies chemical engineering principles and technical skills to assist a chemical engineer in developing, improving and testing chemical-plant processes, products and equipment. May set up apparadus, collect data and help write reports. (chemical engineering assistant, or chemical tab technician)

Clvil Engineering Techrician conducts surveys and inspects existing infrastructure systems such as wastewater treatment, irrigation, and roads, as well as environmental thealth and management systems. Sets up and maintains equipment, tabulates data, and prepares reports in consultation with a civil engineer. (civil engineering assistant, associate engineer, engineering technician, or surveyor)

Computer Operator oversees the operations of computer facilities and remedies software-related off-normal conditions. Operates peripheral machines, such as tape machines and printers, to provide data access to computer users. May advise computer users regarding the capabilities of computing resources, use of operating systems, file transfer and management, etc. (computer technician, computer consultant, systems consultant, or computer lab assistant)

Drafter prepares working plans and detailed drawings from rough or detailed sketches or notes for engineering or manufacturing purposes according to specified dimensions. Utilizes knowledge of various machines, engineering practices, mathematics, building materials, and other physical sciences to complete drawings. May use computerassisted drafting (CAD) equipment and be designated CAD drafter.

Electrical/Electronic Techniclan applies electrical/electronic theory and related knowledge to test and modify, lay out, troubleshoot and repair electronic or electrical equipment. Adjusts and maintains test equipment and generally works in consultation with an electrical/electronic engineer. May do bench-or fieldwork. (electronic technician/specialist, computer technician, or electrical technician)

Mechanical Engineering Techniclan develops and tests machinery and equipment, applying knowledge of mechanical engineering technology, under direction of engineering staff. May set up and conduct tests of complete mechanical units or components. (mechanical engineering assistant, mechanic, or field equipment technician)

Surveying and Mapping Techniclan performs surveying and mapping duties to obtain data pertaining to angles, elevations, points and contours used for consuruction, mapmaking, boundary location, mining or other purposes. Calculates mapmaking information from field notes using reference tables.

surveyors, cartographers, or geodeists.

- Definitions marked with an asterisk are drawn from 1991 Environmental and Waste Industry Compensation Survey. Copyright William M. Mercer, Inc. Denver, CO. Used with permission. 
ENGINEERING

TECHNICLANS

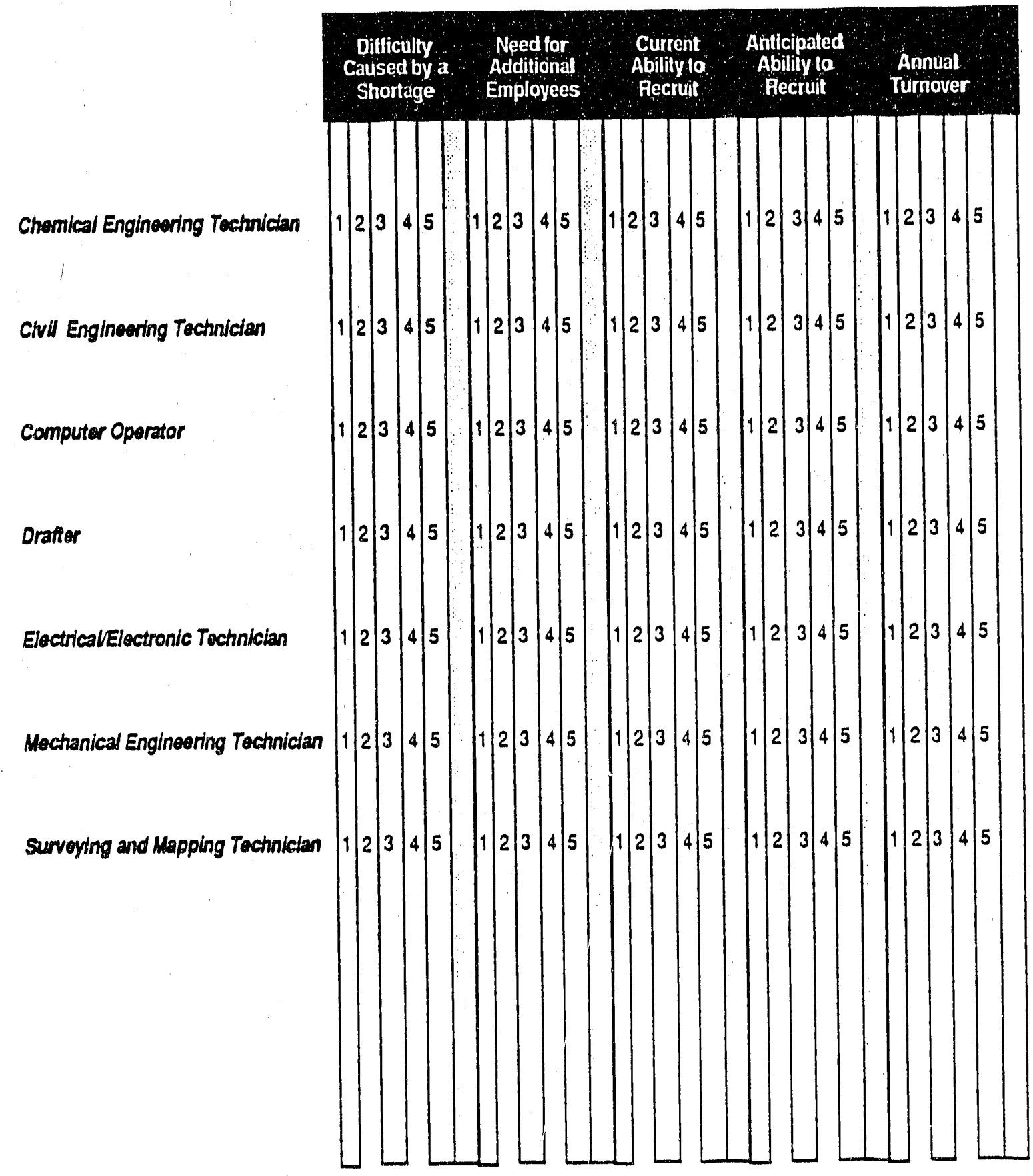

B. 5 


\section{PHYSICAL \& LIFE SCIENCES TECHNICIANS \& TECHNOLOGISTS}

Chemical Technologist conducts chemical and physical laboratory tests to assist scientists in making qualitative and quantitative analyses for work involving experimental, theoretical or practical application of chemistry and related sciences.

Health Physics Tectnsician monitors personnel, plant facilities and work environment to detect radioactive contamination using radiation detectors and other instruments. Assesses worker exposure, operating practices, and material contamination in hazardous waste disposal areas. Works with health physicist to determine exposure limits of personnel and decontamination recommendations (physical science technician, dosimetry technician).

Industrial Hyglenist conducts health programs to recognize, eliminate and control occupational health hazards and diseases. Evaluates exposure to ionizing and non-ionizing radiation and recommends measures to insure maximum employee protection. Prepares reports, participates in educational meetings, and collaborates with occupational physicians.

Industrial Safety and Health Tectnniclan plans and directs safety and health activities to evaluate and control environmental hazards. Tests noise and air levels, maintains and calibrates instruments, administers hearing test, develops and monitors emergency action plans, investigates accidents and prepares accident reports. Recommends changes in policies and procedures to prevent accident and illness.

Radiation Protection Specialist tests and monitors equipment and environment to detect and control radiation hazards. Visits sites to assess the adequacy of shielding and operator competence. Explains changes in shielding or processes needed to conform to regulations. 
PHYSTCAL \& LIFE SCEENCES

TECHNICLANS \& TECHNOLOGSTS

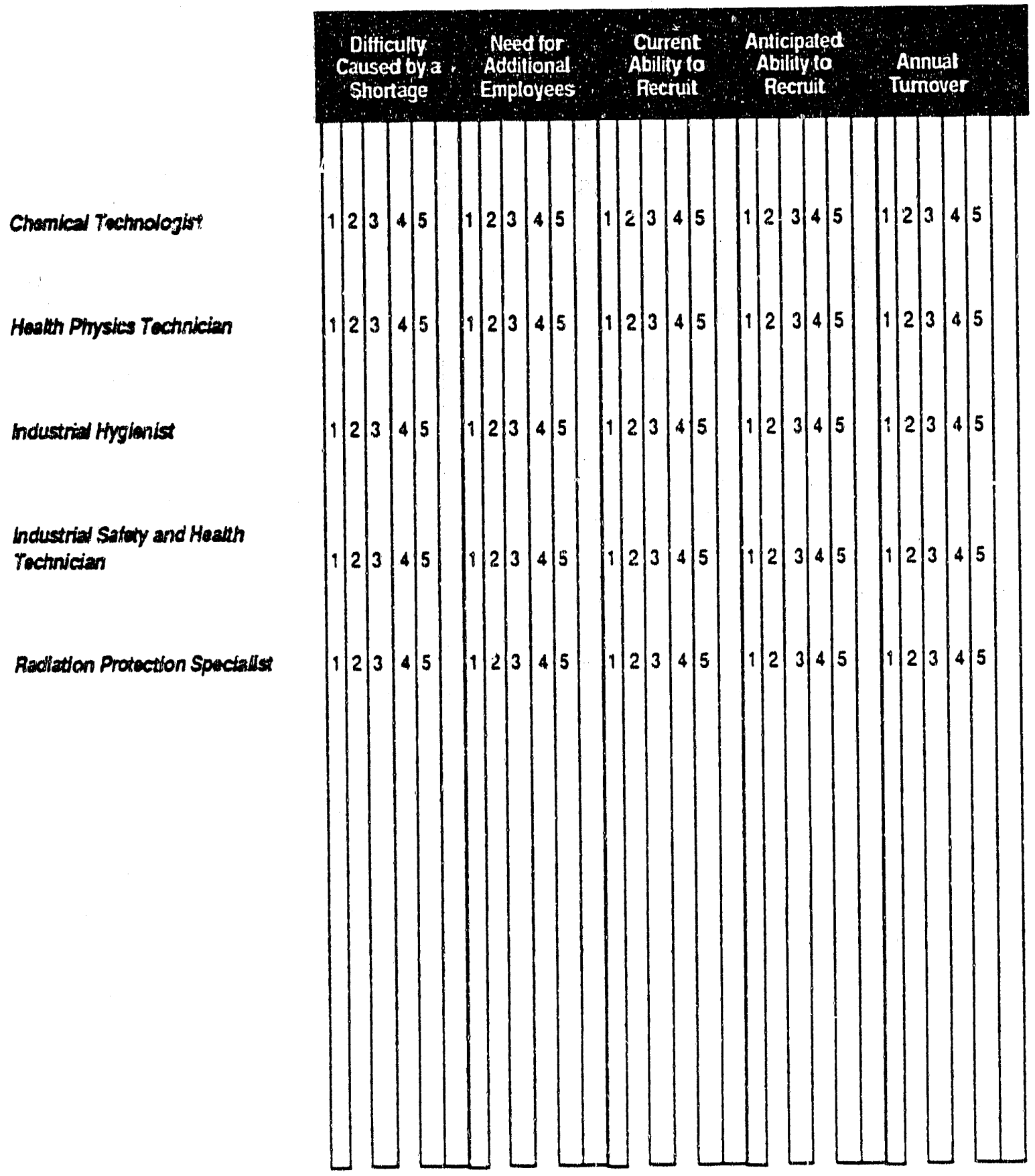

R. 7 


\section{ENVIRONMENTAL \& WASTE MANAGEMENT TECHNICIANS}

Drlller uses drilling or boring machines to sink wells or holes for experimental, exploratory, or monitoring purposes only. Do not include construction excavation occupations. (Driller operator, machine driller, prospecting driller, pipe tester, core driller, well driller, rotary driller, testing-tool operator, well puller, or rig operator.

Environmen Sciences Technician conducts tests and field investigations to obtain data for use by environmental, engineering and scientific personnel in determining sources and methods of controlling pollutants in air, water and soil. Uses knowledge of agriculture, chemistry, meteorology and engineering principles and applied tochnologies. May work under the supervision of civil, chemical or environmental engineers or physical or earth scientists. (environmental field technician, site monitor specialist, hydrographer, soil tester, geological assistant, or environmental analyst)

Hazandous Waste Management Spectallst conducts studies on hazandous waste management projects and provides information on treament and containment of hazardous waste. Under the general supervision of a scientist or manager, participases in developing hazardous waste rules and regulations, assesses available hazardous waste treatment and disposal altematives, and provides technical assistance in the event of an emergency. May provide inputs that help evaluate the economic impact of various treatment and disposal alternatives and write reports.

Materfal Handler loads, unloads and moves hazardous or non-hazardous materinls within or near plants or field sites. Uses knowledge of radiation and effects of radiation to protect self and environment when working with hazardous materials. May operate heavy equipment. (hazardous material handler, rad-waste disposal technician, hazardous landfill technician, or heavy equipment operator)

Nuclear Waste Process Operator controls equipment to decontaminate, neutralize and dispose of radioactive waste liquids collected from chemical processing operations. Tests samples for mdioactivity and records data. May monitor panelboard to control operation of recovery systems that store or dispose of radioactive waste.

Remedlation Specialist " under general supervision performs non-routine and occasionally heavy labor tasks related to on-site hazardous waste remediation. Collects samples and maintains record logs. Uses knowledge of radiation effects of radiation to protect self and environment when working with hazandous materials. Generally operates light and heavy equipment.

Other please specify and provide estimates for technical positions not listed above that maybe involved in ER/WM accivicies. 


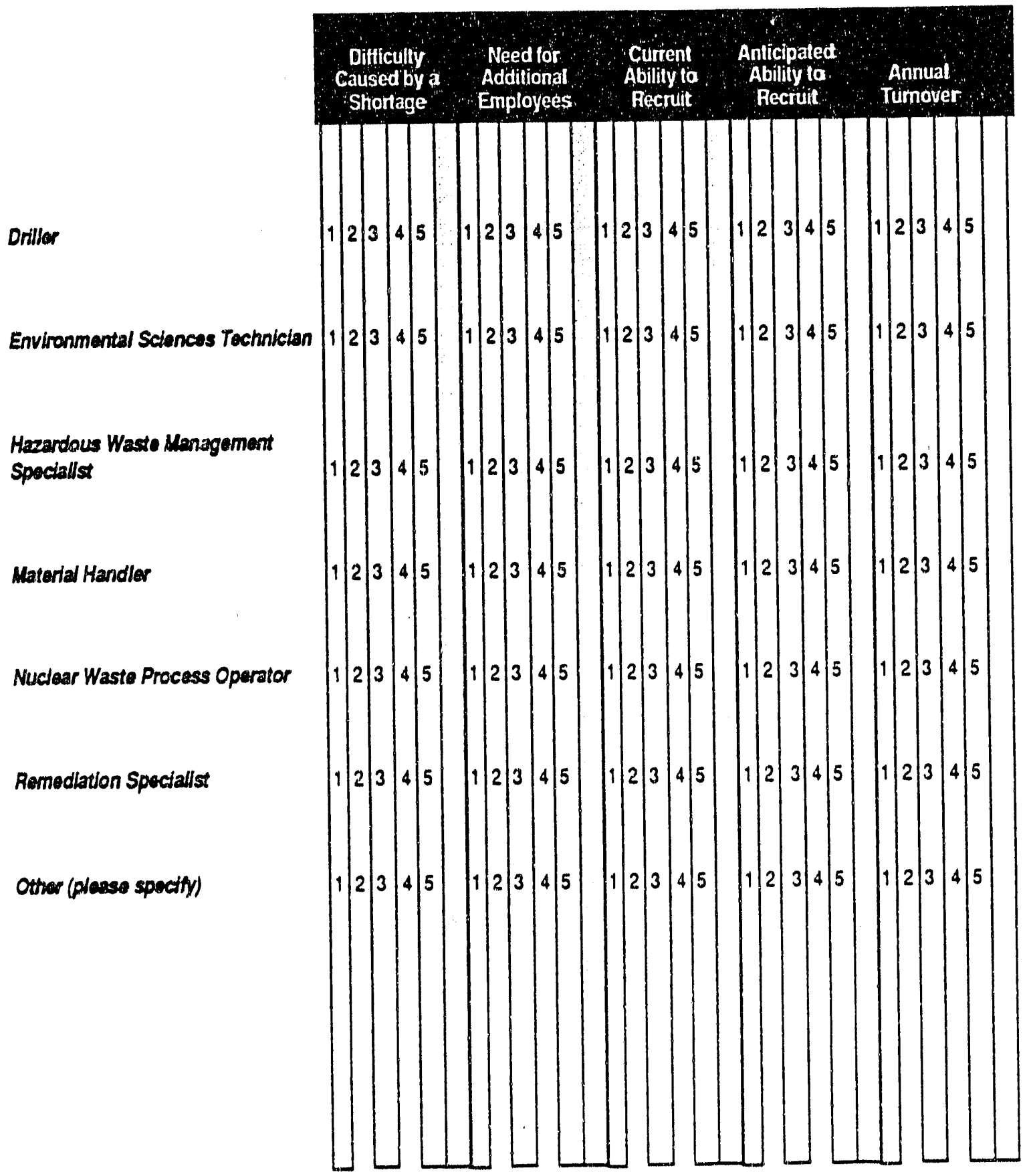

B. 9 


\section{ENGINEERS}

Chomkal Enginoer designs equipment and develops processes for manufacturing chemicals and related products utilizing principles and technology of chemistry, physics, mathematics, engineering, and related physical and natural sciences. Analyzes procedures, oversees workers, designs equipment and performs tests. Do not include those employees with chemical engineering backgrounds who work primarily or exclusively as environmental engineers.

Civi Enginear plans, designs, and directs construction and maintenance of structures and facilities, such as raads, dams, and irrigation and sanitary systems. Include the following job titles: sanitary engineer and transportation engineer. Do not include occupations concerned with the design and construction of hazardous waste sites when those occupations are commonly known as environmental engineers.

Computer Engineer develops software and efficient computer (non-hardware) operating systems. Makes extensive use of mathematics, statistics, logic and computer programming languages. (computer programmer, programmer/analyst, computer scientist, software developer, or software engineer)

Environmental Enginear applies engineering knowledge and technology to identify, solve, or alleviate environmental problems. Include engineers with formal training in civil and chemical engineering who specialize in environmental problems and do not hold the title of chemical engineer or civil engineer. (industrial health engineer, pollution control engineer, or environmental research engineer)

Eectricallectronic Engineer applies the Laws of electrical energy and the principles of engineering for the generation, transmission and use of electricity. May design, manufacture, and/or test electrical or electronic systems or components.

Industrtal Engineer plans utilization of production facilities and personnel $w$ improve efficiency of operations in industrial establishments. Establishes work measurement programs, analyzes utilization of manpower, and plans space layout of facilities. (quality-contral engineer)

Irrigatton Engineer plans, designs and oversees construction of irrigation projects. Plans and designs irrigation fixtures and installation of fixares. Conducts research on problems of soil drainage and conservation, applying knowledge of civil engineering.

Materials Engineer evaluates, plans and implements processes to develop new materials to meet product specifications, performance standards, and cost specifications. (metallurgical engineer or ceramic engineer) 


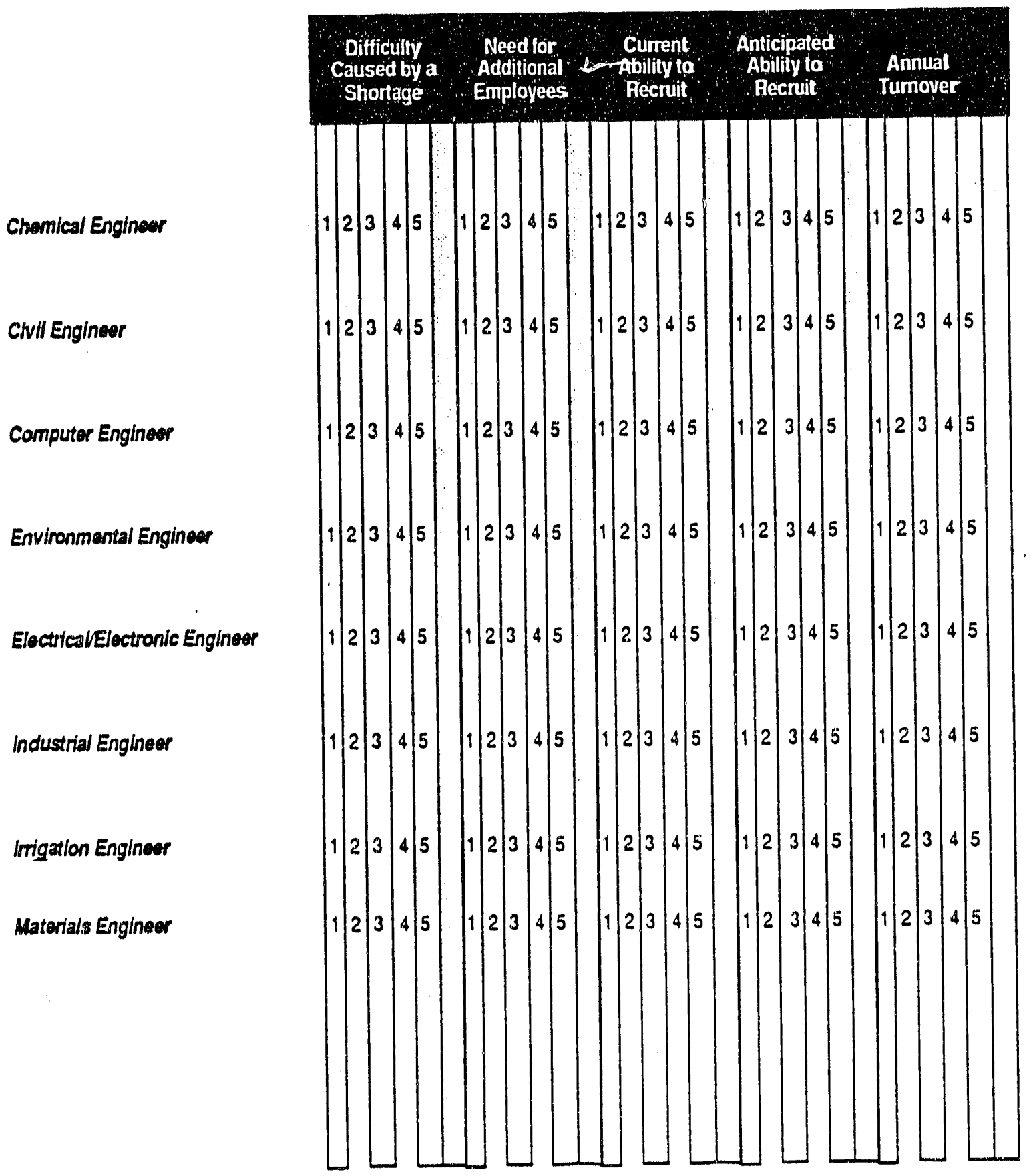




\section{ENGINEERS \\ (continued)}

Mochanical Enginer plans and designs mechanical and/or electromechanical systems or products. Plans and directs engineering personnel in the fabrication of equipment and test-control apparatus. (heat-transfer engineer, controls and instrumentation engineer, or hydraulic engincer). Product design engineer or test engineer when mechanical engineering principles are used primarily.

Nuclear Engineer designs, develops and tests nuclear equipment and systems; monitors testing, operation and maintenance of nuclear reactors. Studies nuclear fuel cycle to define most economical uses of nuclear material and safest means of waste products disposal. (nuclear-fuels reclamation engineer, nuclear-criticality engineer or nuclear-fuels research engineer)

Nuclear Decontamination Englneer applies principals of nuclear and chemical engineering to decontaminate radioactive equipment and work areas in nuclear plants, laboratories and other facilities. Minimizes the risk to personnel and the volume of waste.

Petroleumaning Engineer includes occupacions concemed with the extraction of minerals from the earth. Plans and develops mining excavations and well drillings. Accessory techniques include those used in metallurgy and geology. Directs engineering and lechnical personnel through the drilling, boring, cutting, excavating and grading processes. Typical specializations are according to the activities or substance involved. (geological engineer, engineering geologist, exploration engineer, coal engineer or mineral extraction engineer)

Safery Engineer applies knowledge of industrial processes, mechanics, chemistry, psychology, and industrial health and safety laws w prevent or correct injurious environmental conditions and minimize effects of human traits that create hazards to life and property or reduce warkes morale and efficiency.

Structural Englneer directs or participates in planning, designing or reviewing plans for erection of structures requiring stress analysis. May inspect existing projects and recommend repair and replacement of defective members or rebuilding of entire structure.

Waste Management Engineer designs, implements and tests systems and procedures to reduce volume and dispose of waste materiais and contaminated objects including nuclear waste. Advises management on selection of lands suitable for use as waste disposal sites and on establishment of effective safety, operating, and closure procedures.

Other please specify and provide estimates for any engineering occupations not listed above that maybe involved in ER/WM activities. 
ENGINEERS

(continued)

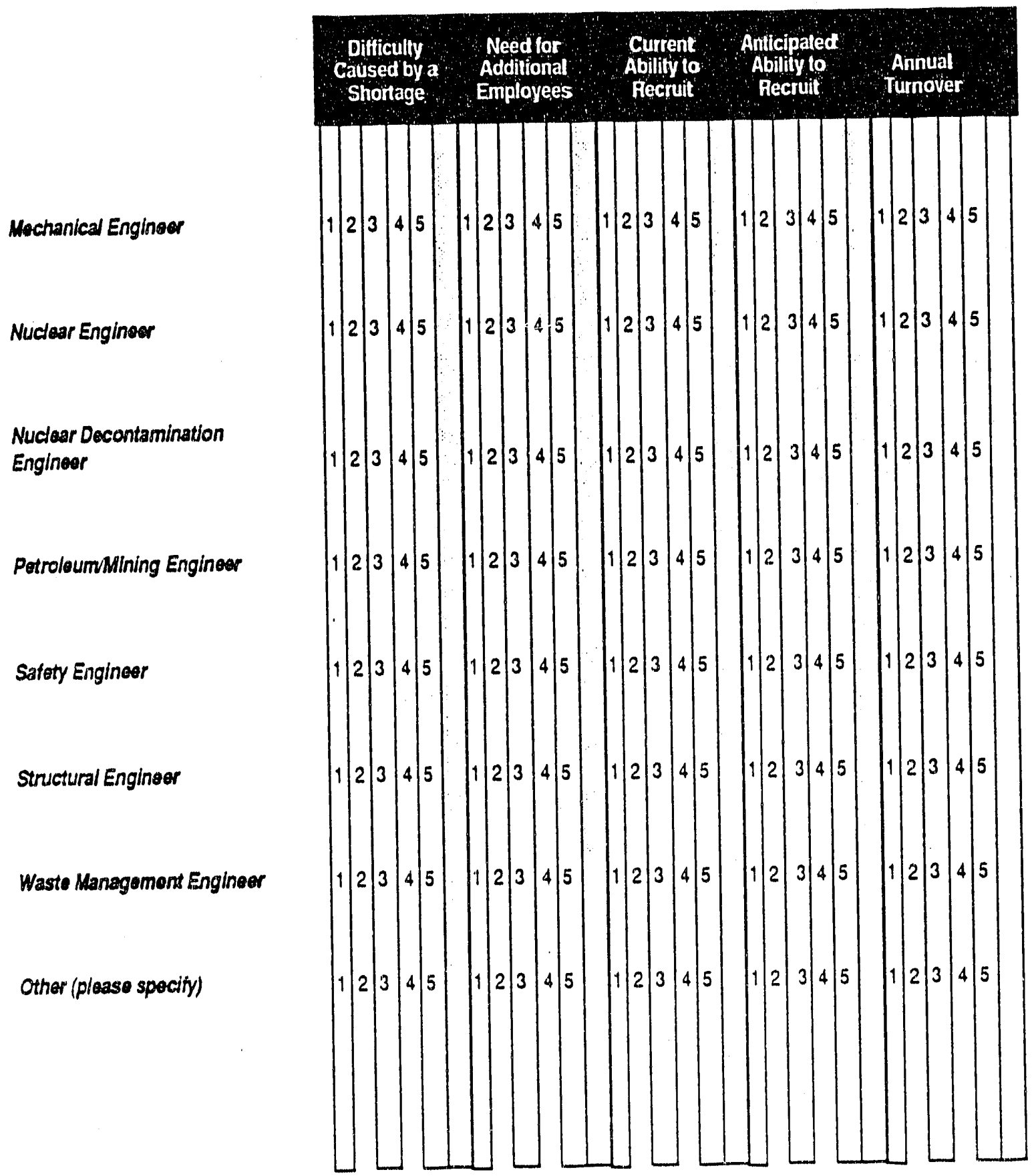

B. 13 


\section{SCIENTISTS}

Blochem/st studies chemical processes of living organisms and conducts research to determine action of foods, drugs, serums, hormones, and other substances on tissues and vital processes of living organisrns.

Blologist studies the reproduction, growth and development, structure, life processes, behavior, and classification of living organisms. Applies these findings to prevent disease maintain and promote health in plant and animal life. (aquatic biologist, botanist entomologist, physiologist, or cytologist)

Chemist conducts research, analysis, synthesis and experimentation on chemical compounds for purposes of developing new processes, compounds, and analytical techniques. (process chemist, hazondous materials chemist, or geochemist)

Ecologist studies plants or animals to determine the effect of environmental influences, such as rainfall, temperature, altuude and kind and quantity of food. (botanist, soil scientist, range manager, forest ecologist and soil conservationist)

Environmental Sclentist uses knowledge of principles and concepts of various scientific and engineering disciplines occupations to develop methods of abating or controlling sources of environmental pollutants. (meteorologist, oceanographer)

Geologist studies composition, structure, and physical and biological history of the earth's crust. Applies knowledge of chemistry, physics, biology and mathematics to explain these phenomena and to help locate mineral, geothermal and petroleum deposits and underground water resources.

Hydrologist and Hydrogeologist " studies distribution, disposition and development of waters of land areas. Develops technical approaches for large groundwater recovery and treatment projects.

Health Physicist * recommends and develops policies and procedures related to health physics issues. Develops, implements and evaluates research, training and monitoring programs to protect all personnel.

Matertals Scientst conducts scientific studies to understand, characterize and develop materials leading to potential uses for the benefit of science and emerging technologies. (metallurgist when not engineering -oriented)

Mathematclan conducts research in fundamental mathematics and in application of mathematical techniques to science, management and other fields. (applied mathematician or research mathematician) 
Blochemist

Blologist

Chemist

Ecologist

Environmental Scientist

Geologist

Hydrologist \& Hydrogeologist

Health Physicist

Materials Scientist

Mathematician

\begin{tabular}{|c|c|c|c|c|}
\hline $\begin{array}{l}\text { Difticully } \\
\text { Caused by a } \\
\text { Shoitaca }\end{array}$ & $\begin{array}{l}\text { Needlor } \\
\text { Additional } \\
\text { Emplovees }\end{array}$ & $\begin{array}{l}\text { Current } \\
\text { Ability to } \\
\text { Pecrutit }\end{array}$ & $\begin{array}{l}\text { Anticipaled } \\
\text { Abilify to } \\
\text { Pecruit }\end{array}$ & $\begin{array}{l}\text { Annual } \\
\text { Tumover }\end{array}$ \\
\hline
\end{tabular}

\begin{tabular}{llllllllllllllllll|l|l|l|l|l|l|l|l}
1 & 2 & 3 & 4 & 5 & 1 & 2 & 3 & 4 & 5 & 1 & 2 & 3 & 4 & 5 & 1 & 2 & 3 & 4 & 5 & 1 & 2 & 3 & 4 & 5
\end{tabular}

$\begin{array}{llllllllllllllllllllllllllllll}1 & 2 & 3 & 4 & 5 & 1 & 2 & 3 & 4 & 5 & 1 & 2 & 3 & 4 & 5 & 1 & 2 & 3 & 4 & 5 & 1 & 2 & 3 & 4 & 5\end{array}$

$\begin{array}{llllllllllllllllllllllllllllll}1 & 2 & 3 & 4 & 5 & 1 & 1 & 2 & 3 & 4 & 5 & 1 & 2 & 3 & 4 & 5 & 1 & 2 & 3 & 4 & 5 & 1 & 1 & 2 & 3 & 4 & 5\end{array}$

$\begin{array}{llllllllllllllllllllllllllllll}1 & 2 & 3 & 4 & 5 & 1 & 2 & 3 & 4 & 5 & 1 & 2 & 3 & 4 & 5 & 1 & 2 & 3 & 4 & 5 & 1 & 2 & 3 & 4 & 5\end{array}$

\begin{tabular}{lllllllllllllllllll|lllllllllllll}
1 & 2 & 3 & 4 & 5 & 1 & 2 & 3 & 4 & 5 & 1 & 2 & 3 & 4 & 5 & 1 & 2 & 3 & 4 & 5 & 1 & 2 & 3 & 4 & 5
\end{tabular}

$\begin{array}{llllllllllllllllllllllllllllll}1 & 2 & 3 & 4 & 5 & 1 & 2 & 3 & 4 & 5 & 1 & 2 & 3 & 4 & 5 & 1 & 2 & 3 & 4 & 5 & & 1 & 2 & 3 & 4 & 5\end{array}$

$\begin{array}{lllllllllllllllllllllllllllll}1 & 2 & 3 & 4 & 5 & 1 & 2 & 3 & 4 & 5 & 1 & 2 & 3 & 4 & 5 & 1 & 1 & 2 & 3 & 4 & 5 & 1 & 2 & 3 & 4 & 5\end{array}$

$\begin{array}{lllllllllllllllllllllllllllll}1 & 2 & 3 & 4 & 5 & 1 & 2 & 3 & 4 & 5 & 1 & 2 & 3 & 4 & 5 & 1 & 2 & 3 & 4 & 5 & 1 & 2 & 3 & 4 & 5\end{array}$

$\begin{array}{lllllllllllllllllllllllllllll}1 & 2 & 3 & 4 & 5 & 1 & 2 & 3 & 4 & 5 & 1 & 2 & 3 & 4 & 5 & 1 & 2 & 3 & 4 & 5 & 1 & 2 & 3 & 4 & 5\end{array}$

$\begin{array}{lllllllllllllllllllllllllllllllll}1 & 2 & 3 & 4 & 5 & 1 & 2 & 3 & 4 & 5 & 1 & 2 & 3 & 4 & 5 & & 1 & 2 & 3 & 4 & 5 & & 1 & 2 & 3 & 4 & 5 & \end{array}$ 


\section{SCIENTISTS \\ (continued)}

Operations Researchor analyzes management and operational problems and formulates mathematical or simulation models of problems for solution by computers or other methods.

Physiclst conducts research into phases of physical phenomena; develops theories and laws on basis of observation and experiments; and devises methods to apply laws and theories of physics to industry, medicine and other fields. (nuclear physicist, experimental physicist, or atomic physicist)

Selsmologist studies and interprets seismic data to locate earthquakes and earthquake faults. Conducts research on seismic forces affecting deformative movements of earth.

Statistician conducts research into mathematical theories and proofs that form basis of science of statistics and develops statistical methodology. Analyzes data from tests and experimental designs.

Other please specify and provide estimates for scientific occupations not listed above that may be involved in ER/WM activities. 
SCIENTISTS

(continued)

Operations Researcher

Physicist

Soismologist

Statistician

Other (please specify)

\begin{tabular}{|c|c|c|c|c|}
\hline $\begin{array}{l}\text { Difficully } \\
\text { Caused by a } \\
\text { Shortage }\end{array}$ & $\begin{array}{l}\text { Need for } \\
\text { Addilional } \\
\text { Employees }\end{array}$ & $\begin{array}{l}\text { Current } \\
\text { Abilily to } \\
\text { Peeruit }\end{array}$ & $\begin{array}{l}\text { Antigipated } \\
\text { Ability ta } \\
\text { Pecritit }\end{array}$ & $\begin{array}{l}\text { Annual: } \\
\text { Tumover }\end{array}$ \\
\hline
\end{tabular}

$\begin{array}{llllllllllllllllllllllllllllll}1 & 2 & 3 & 4 & 5 & 5 & 1 & 2 & 3 & 4 & 5 & 1 & 1 & 2 & 3 & 4 & 5 & 1 & 2 & 3 & 4 & 5 & 1 & & 2 & 3 & 4 & 5\end{array}$

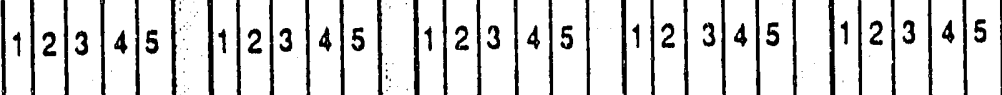

$\begin{array}{llllllllllllllllllllllllllll}1 & 2 & 3 & 4 & 5 & 1 & 2 & 3 & 4 & 5 & 1 & 2 & 3 & 4 & 5 & 1 & 2 & 3 & 4 & 5 & 1 & 1 & 3 & 3 & 4 & 5\end{array}$

$\begin{array}{lllllllllllllllllllllllllllll}1 & 2 & 3 & 4 & 5 & 1 & 2 & 3 & 4 & 5 & 1 & 2 & 3 & 4 & 5 & 1 & 2 & 3 & 4 & 5 & 1 & 2 & 3 & 4 & 5\end{array}$

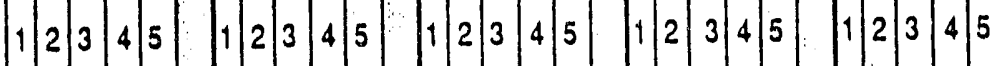




\section{ADMINISTRATTVE \& OTHER OCCUPATIONS}

Administratye Assistant and Clerical Worker provide support services such as keeping accounts, entering and tracking data, typing, and other general non-hazardous task. (project administrator, administrative clerk, data processing clerk, or clerk-typist)

Estumator prepares cost estimates and/or schedules for manufacturing of products, construction projects or services to aid management in bidding on, manufacturing, or determining price of projects or services (scheduler).

Project Manager plans, organizes, directs or coordinates activities of ocher professional and technical and support workers. Their management responsibilities require a background consistent with that described for engineers, etc.

Risk Assessment Specialist * evaluates human health and environmental impacts associated with environmental or hazardous waste releases and exposures. Generates and evaluates toxicity profiles, performs statistical analysis of environmental monitoring data, compiles dose-response parameters, and calculates both noncarcinogenic and carcinogenic health risiss.

Technical Writer develops, writes and edits material for reports, manuals, and related technical and administrative publications.

Trainer prepares and conducts training programs for employees. Combines requisite technical knowledge with appropriate instructional methods to conduct meetings, workshops or individualized training sessions. Tests trainees to measure their learning progress and to evaluate effectiveness of training presentations.

Other please specify and provide estimates for administrative and other occupations not listed above that may be involved in ER/WM activities. 


\section{ADMINISTRATTVE \&}

TECHNICLANS

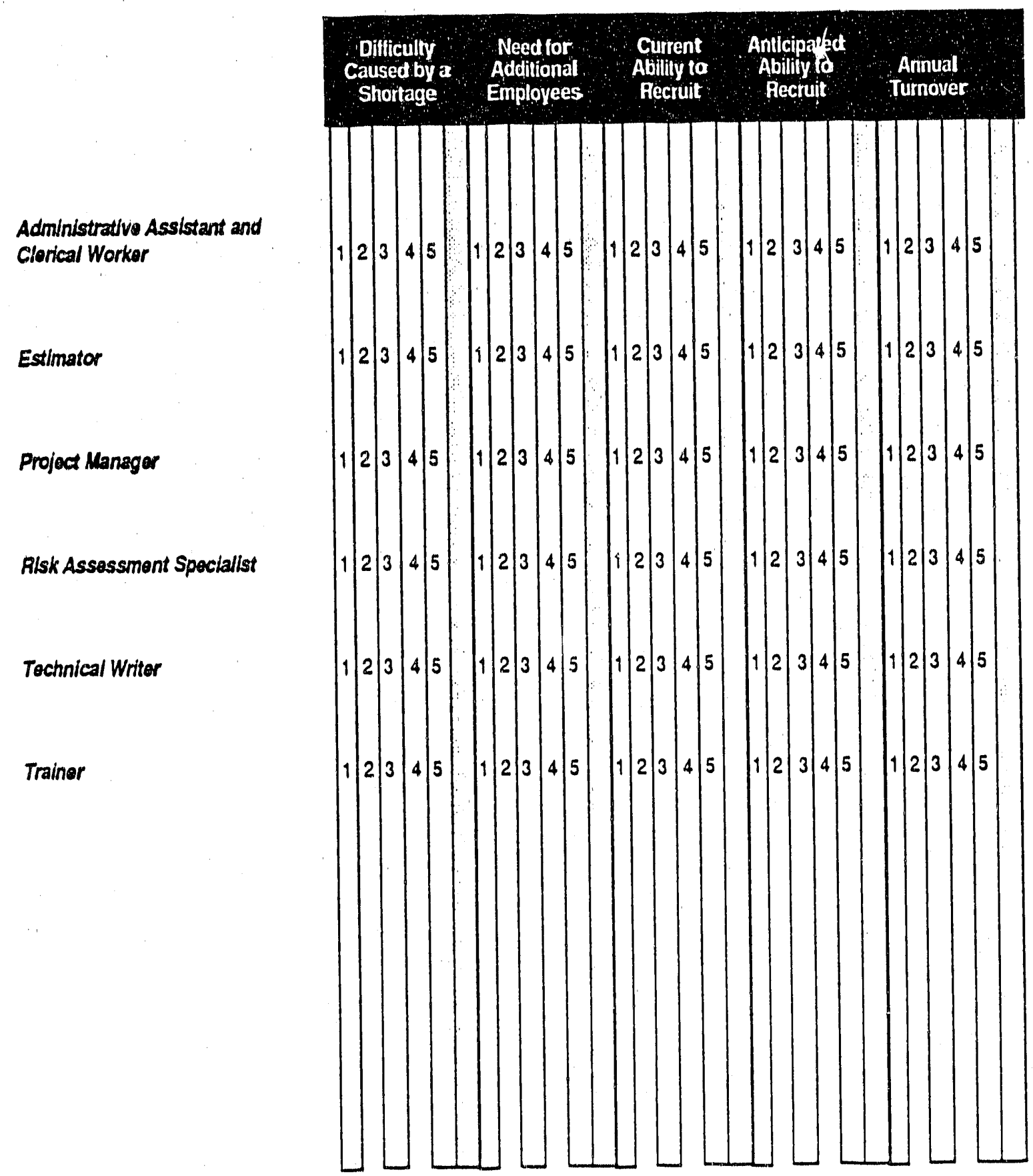

B. 19 
How confident are you in the judgments you made in this survey?

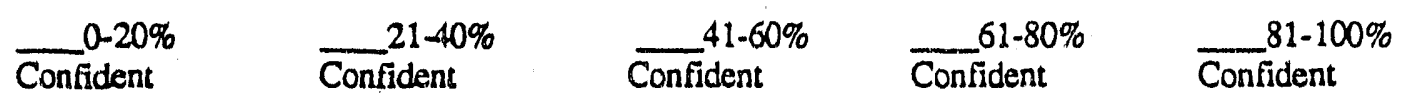

How do you currently handle occupations you find hard to fill?

What do you think are the main causes of recruiting difficulties you face?

What difficulties do you experience in recruiting minorities?

Generally, where do people go after they leave your organization? (i.e., other contractors, DOE, other industries?)

Technicians:

Engineers:

Scientists:

What geographical areas do you recruit from for.

Technicians:

Engineers:

Scientists:

Which questions on this survey did you find most difficult to answer? 


\section{Linkages with Universities:}

Who in your organization marages university relations and/or science and engineering education programs?

Please list the schools your organization interacts with, formally or informally.

Which of these interactions resulted in students or faculty joining your organization as pernanent employees?

Please name three or four research/technical people in your organization who took part in these academic interactions. 
APPENDIX C

MODERATOR'S GUIDE FOR PROGRAM/PROJECT MANAGERS WORKSHOPS 


\section{Moderator's Guide to Manpower Workshops}

\section{GROUP COMPOSITION}

-Facilitators

-Appropriate participants-those who operate at the program level with an understanding of the broad program and its short and long term staffing needs. Examples would be contractor program managers and government TPOs.

\section{GROUND RULES}

Roles of moderator, assistant, observers. The use that will be made of the information.

\section{PURPOSE}

The DOE Office of Technology Development (OTD) has begun a research effort to determine whether an adequate supply of technical, engineering, and scientific personnel are available to meet the goals of the Environmental Restoration and Waste Management (EM) Five Year Plan. As part of this effort, OTD is examining the characteristics of the current workforce and attempting to anticipate the likely makeup of the workforce in the future. This study is being conducted for the DOE by PNL. We are asking for your assistance in this effort to ensure that the information conveyed to DOE accurately represents the view of the field offices and contractors.

\section{SURVEY DISTRIBUTION}

-Distribute the survey.

- Clarify questions.

-Allow sufficient time (approx. 45 mins. to one hr.) for participants to complete the survey.

\section{FOCUS GROUP}

Conduct a $11 / 2$ to 2 hour focus group with the participants to assess: reactions to the survey; anticipated workforce needs and availability; broad organizational or institutional factors difficult to tap through surveys; and, minority, women's, workforce diversity, and other issues considered important by the participants.

Issues related to the survey--how helpful was the survey for focusing thoughts on manpower planning issues and what, if anything, can be done to make it more effective?

-confidence in ratings:how comfortable did respondents feel?; did the rating scales and questions strike at the core of the manpower planning difficulties faced by the respondents?; did the rating scales and questions prompt ideas and approaches not previously considered?

-are there better ways of identifying important occupations?; should more (less) occupational titles be used?; should the definitions be more general (detailed)?

-are there occupations that will be affected by the EM initiative not listed in the survey that can be affected by education and development programs?

-did the structure of the survey improve your estimates relative to a less structured approach?

$$
\text { C.1 }
$$


-what information would help you make better staffing/manpower estimates?: better information; more timely information; better direction; more clearly specified EM programs?

Issues related to the need for employees--what is the size and composition of the workforce needed to do the EM job during the span of the Five Year Plan 1993-1997?

-what is the most difficult aspect of recruiting for EM relevant occupations? What are your recruiting strategies?

-what are the technical issues/plans/programs that need to be communicated in order to make manpower planning more accurate?

-what do you do when it is difficult to find people with the right qualifications? If cross-discipline hiring occurs how does it tend to work out? What training is needed? Does the training tend to be formal or does it occur on the job?

-what are the likely developments in technology related to EM efforts? Do these complicate or simplify your manpower planning and staffing decisions? Why?

-what part of your program management responsibilities does manpower planning play? Which people do you rely upon for information you need to make these estimates?

-which occupations are likely to be in particularly high demand; can the skills these people will need be specified clearly or is too much still up in the air?

-what training/development needs arise as a consequence of EM directives?

-do any institutional constraints exist to conveying to upper management "the real" figures--those that reflect the number of employees needed instead of "approved" or "washed" figures?

-do you plan for support occupations and/or non-scientific or non-engineering occupations (e.g. legal professions, regulatory analysts, etc.)? How do you utilize the skills of these individuals?

-are there any occupations which will experience short term (less than 5 years) shifts in demand? How do you handle these situations?

Issues related to the supply of emplovees--what is the likely availability of human resources to fill the need created by the emphasis on EM activities and how can it be affected favorably from DOE's perspective?

-is there a fair amount of coordination with other programs (NE, DP, etc.) to anticipate likely availability from within DOE and its contractors?

-do recruitment difficulties appear to be local or national in scope? How does this differ across various occupational titles?

-what are the cultural/geographical/political factors that affect the local supply of employees. How may these be remedies or used to the advantage of DOE?

-how "available" for EM funded activities are employees with well-developed skills in programs targeted for reduced funding. In other words, are the skill sets readily transferable, will transfer require on-the-job training, formal training, only recertification, combinations of the above? 
-how much training are employees expected to need in order to hit the deck running? Does this vary across technical, engineering, and science jobs? across degree level?

-which untapped pipelines might exist? What incentives are there to recruit creatively?

-who primarily recruits in the job market, HR or technical people? Does this differ by the government/contractor distinction?

-what is the impact, if any, of the closure of DoD facilities and sites?

-do degree requirements put artificial constraints on the availability of qualified employees? Can experience be a viable substitute for education?

-what degree needs are the most difficult to fill? Can you list other degrees that are used in lieu of the preferred degree?

-what degree fields need to exist to fill projected job openings, i.e. can you list some hybrid fields that may become popular/needed? 
APPENDIX D

MODERATOR'S GUIDE FOR HUMAN RESOURCE MANAGERS WORKSHOPS 


\section{Moderator's Guide to Manpower Workshops}

\section{GROUP COMPOSITION}

-Facilitators

-Appropriate participants-those in human resources intimately involved with workforce planning and transition issues, recruiting, and university/secondary school outreach, internship, or cooperative programs.

\section{GROUND RULES}

Roles of moderator, assistant, observers. The use that will be made of the information.

\section{PURPOSE}

The DOE Office of Technology Development (OTD) has begun a research effort to determine whether an adequate supply of technical, engineering, and scientific personnel are available to meet the goals of the Environmental Restoration and Waste Management (EM) Five Year Plan. As part of this effort, OTD is examining the characteristics of the current workforce and attempting to anticipate the likely makeup of the workforce in the future. This study is being conducted for the DOE by PNL. We are asking for your assistance in this effort to ensure that the information conveyed to DOE accurately represents the view of the field offices and contractors.

\section{SURVEY DISTRIBUTION}

-Distribute the survey.

-Clarify questions.

-Allow sufficient time (approx. 45 mins.) for participants to complete the survey.

\section{FOCUS GROUP}

Conduct a $11 / 2$ to 2 hour focus group with the participants to assess: reactions to the survey; anticipated workforce needs and availability; broad organizational or institutional factors difficult to tap through surveys; and, minority, women's, workforce diversity, and other issues considered important by the participants.

Issues related to the survey--how helpful was the survey for focusing thoughts on manpower planning issues and what, if anything, can be done to make it more effective?

-confidence in ratings: how comfortable did respondents feel?; did the rating scales and questions strike at the core of the manpower planning difficulties faced by the respondents?; did the rating scales and questions prompt ideas and approaches not previously considered?

-are there better ways of identifying important occupations?; should more (less) occupational titles be used?; should the definitions be more general (detailed)?

-are there occupations that will be affected by the EM initiative not listed in the survey that can be affected by education and development programs?

-did the structure of the survey improve your estimates relative to a less structured approach?

$$
\text { D. } 1
$$


-what information would help you make better staffing/manpower estimates?: better information; more timely information; better direction; more clearly specified EM programs?

Issues related to the need for employees--what is the size and composition of the workforce needed to do the EM job during the span of the Five Year Plan 1993-1997?

-what is the most difficult aspect of recruiting for EM relevant occupations? What are your recruiting strategies?

-what are the technical issues/plans/programs that need to be communicated in order to make manpower planning more accurate?

-what do you do when it is difficult to find people with the right qualifications? If cross-discipline hiring occurs how does it tend to work out? What training is needed? Does the training tend to be formal or does it occur on the job?

-how adaptable have current pipelines been when new needs arose? Were there approaches taken then that could help the current transition to EM activities?

-what are the likely developments in technology related to EM efforts? Do these complicate or simplify your manpower planning and staffing decisions? Why?

-which occupations are likely to be in particularly high demand; can the skills these people will need be specified clearly or is too much still up in the air?

-what training/development needs arise as a consequence of EM directives?

-do you plan for support occupations and/or non-scientific or non-engineering occupations (e.g. legal professions, regulatory analysts, etc.)? How do you utilize the skills of these individuals?

-are there any occupations which will experience short term (less than 5 years) shifts in demand? How do you handle these situations?

Issues related to the supply of employees--what is the likely availability of human resources to fill the need created by the emphasis on EM activities and how can it be affected favorably from DOE's perspective?

-is there a fair amount of coordination with other programs (NE, DP, etc.) to anticipate likely availability from within DOE and its contractors?

-what barriers exist to recruiting people with the proper backgrounds?

-what are the regional issues that affect the recruitment of employees in general and women and minorities in particular?

-do recruitment difficulties appear to be local or national in scope? How does this differ across various occupational titles?

-what are the cultural/geographical/political factors that affect the local supply of employees. How may these be remedies or used to the advantage of DOE?

-how "available" for EM funded activities are employees with well-developed skills in programs targeted for reduced fiunding. In other words, are the skill sets readily transferable, will transfer

$$
0.2
$$


'require on-the-job training, formal training, only recertification, combinations of the above?

-how much training are employees expected to need in order to hit the deck running? Does this vary across technical, engineering, and science jobs? across degree level?

-which positions typically merit salary exemptions, have extended vacancies, low application rates, etc.?

-which untapped pipelines might exist? What incentives are there to recruit creatively?

-what reasons are commonly given for turning down job offers? Does this vary by occupational title, deg level, program? How may these be counteracted?

-who primarily recruits in the job market, HR or technical people? Does this differ by the government/contractor distinction?

-what is the impact, if any, of the closure of DoD facilities and sites?

-do degree requirements put artificial constraints on the availability of qualified employees? Can experience be a viable substitute for education?

-what degree needs are the most difficult to fill? Can you list other degrees that are used in lieu of the preferred degree?

-what degree fields need to exist to fill projected job openings, i.e. can you list some hybrid fields that may become popular/needed?

What is the impact, of any, of your benefits package on recruiting qualified individuals? 
APPENDIX E

JOB SORTS ON ALL VARIABLES FOR ALL SITES 
TABLE E.1. Descriptive Statistics for Relative Ratings

\begin{tabular}{llllll} 
Variable & N & Minimum & $\underline{\text { Maximum }}$ & $\underline{\text { Mean }}$ & $\underline{\text { S.D. }}$ \\
\hline HR_DIFF & 57 & 1.40 & 3.80 & 2.68 & 0.57 \\
HR_NEED & 57 & 1.50 & 3.50 & 2.50 & 0.51 \\
HR_REC_C & 57 & 2.00 & 3.60 & 2.70 & 0.44 \\
HR_REC_A & 57 & 2.00 & 3.75 & 2.75 & 0.49 \\
HR_TURN & 57 & 1.20 & 2.80 & 1.59 & 0.34 \\
PM_DIFF & 53 & 1.43 & 3.70 & 2.84 & 0.45 \\
PM_REC_A & 1.86 & 3.60 & 2.74 & 2.74 & 0.47 \\
PM_EDUC & 53 & 1.48 & 4.56 & 3.32 & 0.84
\end{tabular}

S.D. = Standard Deviation, HR_DIFF = Difficulty Caused by a Shortage, HR_NEED = Need for AdditionaT-Employees, HR-REC_A = Anticipated Ease of Recruitment, HR-REC-C = Current Ease of Recruitment, HR_TURN = Current Annual Turnover, PM_DIFF = Difficulty Caused By a Shortage, PM_REC $A=$ Anticipated Ability to Recruit, PM EDUC = Typical Degree Level, $* * \bar{p}<\overline{0} .01 ; * p<0.05$. Statistics based on data from 121 WNAS surveys and 54 SCHC surveys. 


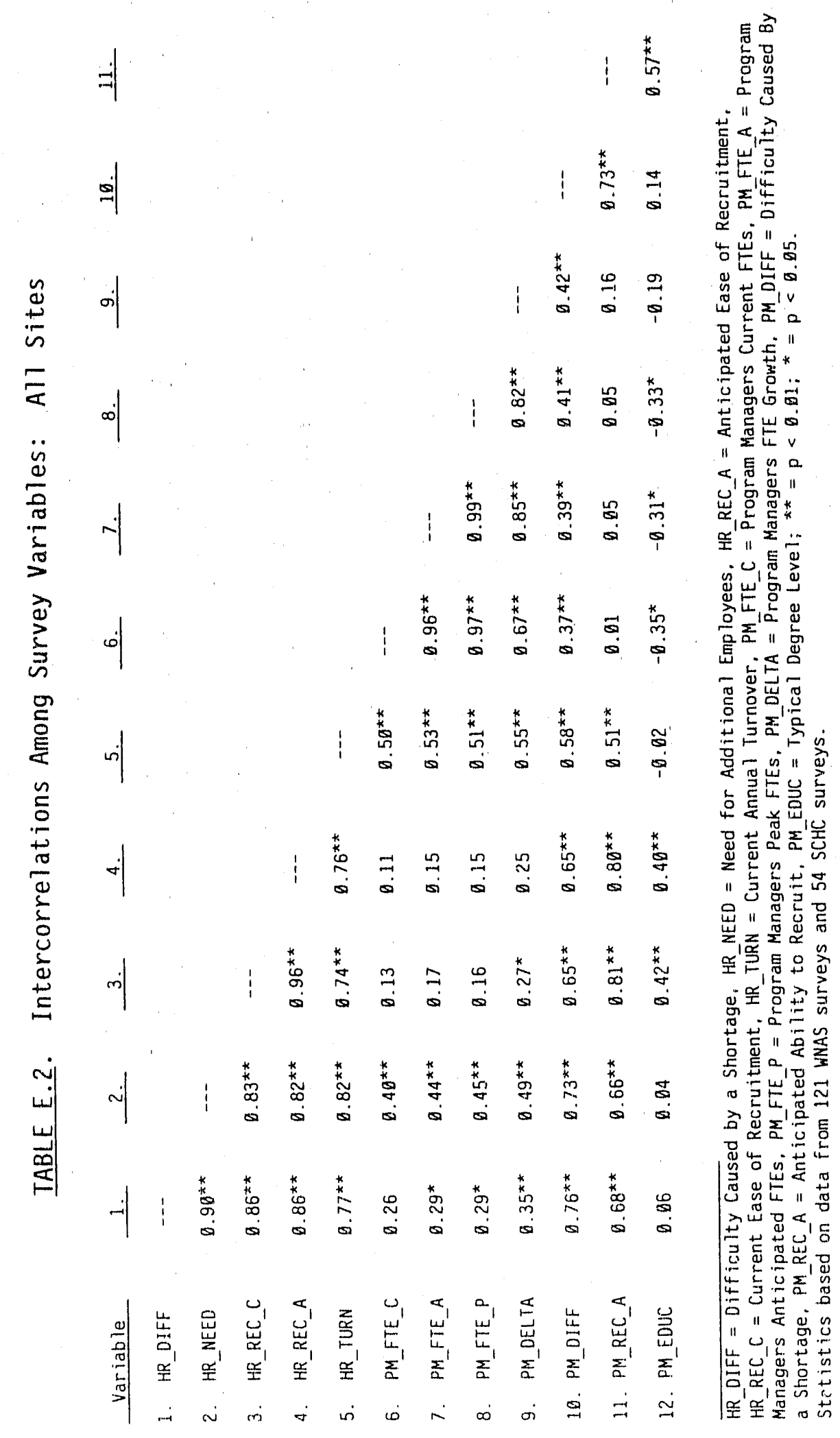

E.2 


\section{TABLE E.3. Job Titles Sorted By Change in FTEs (PM_Delta)}

\begin{tabular}{|c|c|c|c|c|}
\hline Job Title & PM_FTE_C & PM_FTE_A & PM_FTE_P & PM_DELTA \\
\hline *Summary Techs & 284 & 902 & 902 & 618 \\
\hline Environ Engtneer & 515 & 801 & 915 & 286 \\
\hline Admin_Clerical & 987 & 1270 & 1461 & 283 \\
\hline Chemical Engineer & 525 & 789 & 932 & 264 \\
\hline Project Manager & 619 & 870 & 992 & 251 \\
\hline Mechantca 1 Engineer. & 495 & 742 & 811 & 247 \\
\hline Materfal Handler & 398 & 610 & 660 & 212 \\
\hline *Summary Eng ineers & 150 & 348 & 348 & 198 \\
\hline NucWaste Process Oper & 615 & 782 & 814 & 167 \\
\hline Other Technician & 416 & 567 & 603 & 151 \\
\hline Chemist & 371 & 483 & 569 & 112 \\
\hline HazWasteMan Spec & 181 & 282 & 326 & 101 \\
\hline Environ Scientist & 200 & 300 & 375 & 100 \\
\hline other Eng ineer & 161 & 260 & 279 & 99 \\
\hline H_phystos Tech & 451 & 549 & 693 & 98 \\
\hline Safety Engineer & 59 & 146 & 167. & 87 \\
\hline Chem Tech & 289 & 373 & 451 & 84 \\
\hline Civil Engineer & 315 & 399 & 528 & 84 \\
\hline Environ Sciences Tech & 249 & 332 & 4,38 & 83 \\
\hline WasteMan Engineer & 214 & 291 & 376 & 77 \\
\hline Computer Engineer & 164 & 237 & 280 & 73 \\
\hline Electric_tronic Engineer & 215 & 288 & 323 & 73 \\
\hline Health Physicist & 102 & 172 & 282 & 70 \\
\hline Nuc lear Decon Engineer & 40 & 107 & 119 & 67 \\
\hline Hydrol_Hydrogeologist & 132 & 199 & 244 & 67 \\
\hline Technical Writer & 110 & 174 & 222 & 64 \\
\hline Nuc lear Engineer & 117 & 178 & 185 & 61 \\
\hline Trainer & 134 & 193 & 226 & 59 \\
\hline Chemical Eng Tech & 125 & 184 & 236 & 59 \\
\hline Computer Oper & 123 & 180 & 228 & 57 \\
\hline Drafter & 158 & 213 & 314 & 55 \\
\hline Other Administrator & 271 & 325 & 356 & 54 \\
\hline Ind Hygien ist & 56 & 107 & 1,33 & 51 \\
\hline Industrial Engineer & 113 & 158 & 163 & 45 \\
\hline *Summary Scientist & 149 & 193 & 217 & 44 \\
\hline Ind Safety_Health Tech & 84 & 126 & 203 & 42 \\
\hline Rad Protect Spec & 87 & 127 & 185 & 40 \\
\hline Structural Engineer & 59 & 96 & 117 & 37 \\
\hline Risk Assess Manager & 50 & 86 & 115 & 36 \\
\hline Electri_tronic Tech & 179 & 214 & 234 & 35 \\
\hline Civil Eng Tech & 43 & 73 & 102 & 30 \\
\hline Geologist & 191 & 220 & 283 & 29 \\
\hline Mech Engin Tech & 128 & 154 & 176 & 26 \\
\hline other Scient ist & 52 & 76 & 89 & 24 \\
\hline Estimator & 187 & 210 & 305 & 23 \\
\hline Materials Engineer & 44 & 67 & 69 & 23 \\
\hline Biochemist & 18 & 40 & 49 & 22 \\
\hline Biologist & 45 & 67 & 91 & 22 \\
\hline Survey_Map Tech & 19 & 40 & 62 & 21 \\
\hline Remediation Specialist & 102 & 121 & 161 & 19 \\
\hline Statistician & 16 & 35 & 37 & 19 \\
\hline Phys ic ist & 27 & 42 & 43 & 15 \\
\hline Materials Scientist & 16 & 31 & 32 & 15 \\
\hline Ecologist & 37 & 52 & 75 & 15 \\
\hline Mathematician & 18 & 28 & 33 & 10 \\
\hline
\end{tabular}

Mix of $B S$ and Advanced Most ly Associate Mix of BS and Advanced Mostly Bache lor Mix of BS and Advanced HS or less

Most iy Associate HS or less Mix of BS and Advanced Mix of AS and BS Mix of $B S$ and Advanced Mostly Associate Mostly Associate Most ly Bache lor Mix of AS and BS Mix of $B S$ and Advanced Mix of AS and BS Mix of $B S$ and Advanced Mostly Bache lor Most ly Bache lor Mix of BS and Advanced Mix of BS and Advanced Mix of BS and Advanced $M+x$ of $A S$ and $B S$ $M I X$ of $B S$ and Advanced Mix of AS and BS Most ly Associate Mix of AS and BS Mostly Associate HS or less Most ly Bache lor Mostly Bache lor

Mix of AS and BS Mix of $A S$ and $B S$ Mix of BS and Advanced Most ly Bache lor Mostly Associate Most ly Associate Mix of $B S$ and Advanced Most ly Associate Mostly Associate Mix of AS and BS Mix of BS and Advanced Most ly Pho

Mix of BS and Advanced Most ly Associate Mix of $A S$ and $B S$ Mix of BS and Advanced Mix of $B S$ and Advanced Mix of BS and Advanced Mix of $B S$ and Advanced Mix of $B S$ and Advanced 
TABLE E.3. (Contd)

Job Tit:le

Petrol Mining Engineer

Opers Researcher

Se ismolog ist

Irrigation Engineer

Driller
PH_FTE_C

PH_FTE_A

38
14
7
13
63

7

5

PH_FTE_P
58
14
9
14
113

PH_DEL_TA

9

* Respondent Combined FTE Values Across All Job Tit les Statistics based on data from 121 WNAS surveys and 54 SCHC surveys.

\section{Degree}

Mix of BS and Advanced $M i x$ of $B S$ and Advanced Most ly $\mathrm{PhD}$

Mix of $A S$ and $B S$

Most ly Associate 


\section{TABLE E.4. Job Titles Sorted by Project Manager's Ratings of Anticipated Ability to Recruit (PM_Rec_A)}

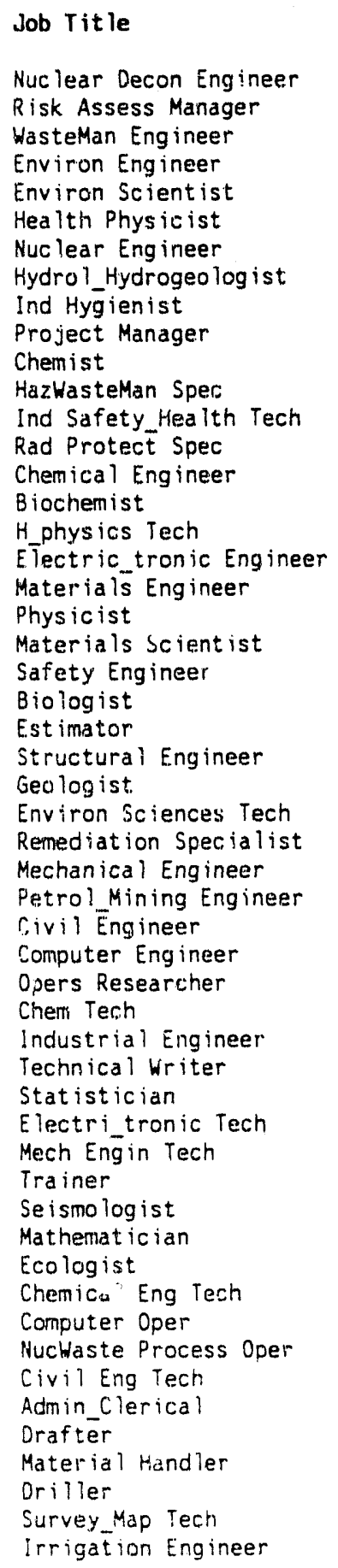

\section{PM_REC_A}

3.68
3.58
3.49

3.49286

$3.48 \quad 100$

3.38

$3.38 \quad 61$

$3.30 \quad 67$

$3.22 \quad 51$

$3.22 \quad 251$

$3.19-112$

$3.18 \quad 101$

$3.18 \quad 42$

$3.17 \quad 40$

$3.14 \quad 284$

$3.88 \quad 22$

$3.06 \quad 98$

2.89

2.89

$2.88 \quad 15$

$2.83 \quad 15$

$2.74 \quad 87$

2.74

2.72

$2.72 \quad 37$

2.68

$2.68 \quad 83$

$2.65 \quad 19$

$2.65 \quad 247$

2.63

$2.62 \quad 84$

$2.62 \quad 73$

2.69

2.55

2.54

2.54

2.53

2.52

2.50

2.49

2.44

2.40

2. 38

2. 38

2.38

2. 28

2.05

2.84

2.00

1.97

1.94

1.89

1.86

\section{Degree}

Mix of 85 and Advanced Most ly Bache lor Mix of $B S$ and Advanced Mix of BS and Advanced Mix of BS and Advanced Mix of $B S$ and Advanced Mix of BS and Advanced Mix of BS and Advanced Most ly Bachelor Most ly Bachelor

Mix of BS and Advanced $M i x$ of $A S$ and $B S$

Mix of $A S$ and $B S$

Mix of $A S$ and $B S$

Mix $O^{\circ} B S$ and Advanced Mostly PhD

Most ly Associate

Most ly Bache lor

Mix of $B S$ and Advanced Mix of $B S$ and Advanced Mix of $B S$ and Advanced Mostly Bachelor

Mix of $B S$ and Advanced Mix of $A S$ and $B S$

Mix of BS and Advanced Mix of BS and Advanced Mix of A.S and BS Mix of $A S$ and $B S$ Mix of BS and Advanced Mix of BS and Advanced Mix of BS and Advanced Most ly Bachelor

Mix of BS and Advanced Mix of AS and BS Most ly Bacilelor Mix of $A S$ and $B S$ Mix of BS and Advanced Mostly Associate Most ly Associate Mix of AS and BS Most ly PhD

Mix of BS and Advanced Mix of BS and Advanced Most ly Associate Mix of $A S$ and $B S$ Most ly Associate Most ly Associate Most ly Associate Mostly Associate HS or less

Mostly Associate Most iy Associate Mix of AS and BS

Statistics based on data from 121 WNAS surveys and 54 SCHC surveys. 


\section{TABLE E.5. Job Titles Sorted By Project Manager's Ratings of Difficulty Caused by Shortage (PM_Diff)}

\author{
Job Title \\ Project Manager \\ H_physics Tech \\ Chemist \\ WasteMan Engineer \\ Risk Assess Manager \\ Driller \\ Environ Scientist \\ Environ Engineer \\ Rad Protect Spec \\ Hydrol_Hydrogeo log ist \\ Nuc lear Decon Engineer \\ HazWasteMan Spec \\ Health Physicist \\ Chemical Engineer \\ Ind Safety_Health Tech \\ Ind Hygien ist \\ Electric_tronic Engineer \\ Nuc lear Eng ineer \\ Environ Scienves Tech \\ Mechanical Engineer \\ Safety Eng ineer \\ Trainer. \\ Chem Tech \\ Est imator \\ Geologist \\ Admin_Clerical \\ NucWaste Process Oper \\ Civil Engineer \\ Statistician \\ Physicist \\ Materials Scient ist \\ Petrol_Mining Engineer \\ Technical Writer \\ Computer Eng ineer \\ Material Handler \\ Structural Engineer \\ Electri tronic Tech \\ Computer Oper \\ Mech Eng in Tech \\ Materials Engineer \\ Remediation Specialist \\ Industrial Engineer \\ Ecologist \\ Biologist \\ Mathematician \\ Chemical Eng Tech \\ Opers Researcher \\ Drafter \\ Biochemist \\ Se ismo logist \\ Survey Map Tech \\ Civil Ëng Tech \\ Irrigation Engineer
}

\section{PM_DIFF}

3.70

3.62

3.50

3.49

3.45

3.44

3.44

3.42

3.37

3.33

3.32

3.32

3.23

3.23

3.21

3.11

3.11

3.09

2.94

2.93

2.93

2.91

2.91

2.87

2.84

2.79

2.79

2.77

2.76

2.75

2.75

2.75

2. 68

2.67

2.63

2.60

2. 58

2. 55

2.51

2. 50

2. 50

2. 50

2. 50

2.47

2. 45

2.41

2.46

2. 36

2. 31

2. 22

2. 15

2.13

1. 43

\section{PM_DELTA Degree}

251

98

112

77

36

$-5$

00

286

40

67

67

101

70

264

42

51

73

61

83

247

87

59

84

23

29

283

167

84

19

15

15

64

73

212

37

35

57

26

23

19

45

15

22

10

59

7

55

2.2

2
21

21

30
-1
Most ly Bachelor Mostly Associate Mix of BS and Advanced Mix of BS and Advanced Mostly Bachelor Mostly Associate Mix of BS and Advanced $M i x$ of $B S$ and Advanced Mix of AS and BS

Mix of $B S$ and Advanced Mix of BS and Advanced Mix of AS and BS

Mix of $B S$ and Advanced Mix of $B S$ and Advanced Mix of $A S$ and $B S$ Most ly Bachelor Mostly Bachelor Mix of $B S$ and Advanced $M i x$ of $A S$ and $B S$

Mix of $B S$ and Advanced Most ly Bache lor

Mix of $A S$ and $B S$

$M i x$ of $A S$ and $B S$

Mix of AS and BS

Mix of BS and Advanced Most ly Associate Most ly Associate

Mix of BS and Advanced Mix of BS and Advanced Mix of BS and Advanced Mix of BS and Advanced Mix of BS and Advanced Mix of AS and BS Most ly Bache lor HS or less Mix of BS and Advanced Most ly Associate Mix of $A S$ and $B S$ Mostly Associate Mix of $B S$ and Advanced Mix of AS and BS Mostly Bachelor Mix of BS and Advanced Mix of BS and Advanced Mix of BS and Advanced Most ly Associate Mix of $B S$ and Advanced Most ly Associate Most ly PhD

Most iy PhD Mostly Associate Most ly Associate Mix of $A S$ and $B S$

Statistics based on data from 121 WNAS surveys and 54 SCKC surveys. 


\section{TABLE E.6. Job Titles Sorted By Human Resource Personnel's Ratings of Difficulty Caused By Shortage (HR_Diff)}

Job Title

Health Phys ic ist

Environ Engineer

WasteMan Engineer

Rad Protect Spec

Nuclear Decon Engineer

Risk Assess Manager

Chemist

Hydrol_Hydrogeolog ist

$H$ physics Tech

Ind Hygien ist

Environ Scientist

HazWasteMan Spec

Chemical Engineer

Project Manager

Remediation Specialist

Environ Sciences Tech

Ind Safety_Health Tech

Chemical Eng Tech

Safety Eng ineer

Geologist

Chem Tech

Nuc lear Eng ineer

Driller

Physicist

Materials Scient ist

Nuchaste Process Oper

Adm in Clerical

Computer Eng ineer

Survey Map Tech

Biochemist

Technical Writer

Computer Oper

Statistician

Mech Eng in Tech

Mechanical Engineer

Trainer

Material Handler

Civil Eng Tech

Opers Researcher

Est imator

Electri tronic Tech

Materiais Engineer

Ecologist

Civil Eng ineer

Electric tronic Engineer

Drafter

Biologist

Se ismolog ist

Structura? Eng ineer

Mathematician

Industrial Engineer

Irrigation Engineer

Petrol Mining Engineer

\section{HR_DIFF}

3.66

3.56

3.52

3.37

3.31

3.29

3.28

3.28

3.28

3.27

3.27

3.19

3.18

3.12

3.04

2.96

2.93

2.88

2.86

2.79

2.78

2.73

2.73

2.59

2.57

2.53

2.53

2.52

2.50

2.47

2.46

2.43

2.40

2.39

2. 39

2.38

2.38

2.38

2.27

2. 26

2.25

2.23

2.20

2. 16

2. 14

2.04

2.00

2.80

1.81

1.81

1.76

1.58

1. 43
PM_DELTA

78

286

77

40
67

36

112

67

98

51

100

101

264

251

19

83

42

59
87

87
29

84

61

$-5$

15

15

$16 ?$

283

73
21

- 22

64

57

19

26

247
59

212

30

7

23
35
23

23

15
84
73

73
55

55
22
2

2

37

10

45

$-1$

Statistics based on data from 121 WNAS surveys and 54 SCHC surveys. 
I\&BLEE.7. Job Titles Sorted By Human Resource Personnel's Ratings of Need for Additional Employees (HR_Need)

\section{Job Tit le}

Environ Eng ineer

Health Physicist

Environ Scient ist

WasteMan Engineer

H physics Tech

Chemical Engineer

Nuclear Decon Engineer

HazWasteMan Spec

Chemist

Hydrol_Hydrogeo log ist

Admin_Clerica 1

Risk Assess Manager

Ind Hyg ien ist

Environ Sciences Tech

Remediation Specialist

Rad Protect Spec

Project Manager

Safety Engineer

Chem Tech

Ind Safety_Health Tech

Nuc lear Eng ineer

Chemical Eng Tech

Ecologist

Computer Engineer

Technical Writer

Mechanical Engineer

Geologist

Electri_tronic Tech

Physicist

Materials Scientist

Trainer

Estimator

Civil Engineer

Opers Researcher

Computer Oper

Mech Engir. Tech

NucWaste Process Oper

Biochemist

Material Handler

Drafter

Statistician

Civil Eng Tech

Survey Hap Tech

Electric_tronic Engineer

Driller

Mathematician

Biologist

Materials Engineer

Se ismo log ist

Structural Engineer

Petrol.mining Engineer

Industrial Engineer

Irrigation Engineer

\section{HR_NEED}

3.56

3.28

3.26

3.25

3.21

3.12

3.08

3.66

3.86

3.03

3.90

2.95

2.94

2.92

2.88

2.81

2.78

2.71

2.69

2.68

2.58

2.52

2.58

2.48

2.46

2.39

2.38

2.38

2.35

2.33

2.33

2.32

2.31

2.27

2.24

2. 22

2.21

2.21

2. 19

2.15

2. 13

2.12

2.08

2.87

2.06

1.88

1.83

1.82

1.80

1.63

1.68

1.57

1.50

\section{PM_DELTA}

286

70

100

77
98

264

264
67

101

112
67

283

36

51

83

19

40

251

87

84

42

61

59
15

73

64
247

247

29
35

15

15

59

23

84
7

57

26

22
212

55

19

21

73
-5

10

22

23

2

37

9
45

$-1$
Degree

Mix of $B S$ and Advanced

Mix of $B S$ and Advanced

Mix of BS and Advanced

Mix of $B S$ and Advanced Most ly Associate

Mix of BS and Advanced Mix of $B S$ and Advanced Mix of AS and BS

Mix of BS and Advanced Mix of BS and Advanced Most ly Associate Most ly Bache lor Most ly Bachelor Mix of AS and BS Mix of $A S$ and $B S$ Mix of AS and BS Most ly Bache lor Mostly Bachelor Mix of $A S$ and $B S$ Mix of $A S$ and $B S$ Mix of $B S$ and Advanced Most ly Associate Mix of BS and Advanced Most ly Bache lor Mix of AS and BS Mix of $B S$ and Advanced Mix of BS and Advanced Most ly Associate

Mix of BS and Advanced Mix of BS and Advanced Mix of $A S$ and $B S$ Mix of $A S$ and $B S$ Mix of $B S$ and Advanced Mix of BS and Advanced Mix of $A S$ and $B S$ Most ly Associate Most ly Associate Mostly Pho HS or less Most ly Associate Mix of BS and Advanced Most ly Associate Mostly Associate Most iy Bache lor Most ly Associate Mix of BS and Advanced Mix of BS and Advanced Mix of $B S$ and Advanced Most ly PhD

Mix of $B S$ and Advanced Mix of $B S$ and Advanced Most ly Bachelor Mix of $A S$ and $B S$

Statistics based on data from 121 WNAS surveys and 54 SCHC surveys. 


\section{TABLE E.8. Job Titles Sorted By Human Resource Personnel's Ratings of Current Ability to Recruit (HR_Rec_C)}

Job Title
Health Physicist
WasteMan Engineer
Environ Engineer
Chemical Eng ineer
Nuclear Decon Eng ineer
Ind Hygienist
Hydrol_Hydrogeologist
Project Manager
Physicist
HazWasteMan Spec
Safety Engineer
H_physics Tech
Environ Scient ist
Chemist
Risk Assess Manager
Opers Researcher
Rad Protect Spec
Ind Safety_Health Tech
Remediation Specialist
Nuclear Engineer
Biochemist
Materials Engineer.
Materials Scientist
Computer Engineer
Statistician
Geologist
Chem Tech
Ecologist
Environ Sciences Tech
Chemical Eng Tech
Estimator
Technical Writer
Mechanical Engineer
Civil Eng ineer
Electric_tronic Engineer
Trainer
Mech Engin Tech
Survey_Map Tech
Admin_Clerical
Drafter
Electri_tronic Tech
Computer Oper
Material Handler
Civil Eng Tech
Biologist
Seismologist
Mathematician
Structura! Engineer
NucWaste Process Oper
Driller
Petrol_Mining Engineer
Industrial Engineer
Irrigation Engineer

\section{HR_REC_C}

3.48

3.39

3.37

3.24

3.23

3.22

3.19

3.19

3.19

3.06

3.04

3.03

3.00

3.00

3.00

3.00

2.93

2.86

2.83

2.88

2.78

2.76

2.75

2.74

2.71

2.70

2.67

2.64

2.64

2.62

2.59

2.56

2.50

2.41

2. 38

2.36

2.35

2.33

2.31

2.30

2.29

2.24

2.24

2. 24

2.23

2.28

2.13

2.13

2.11

2.09

2.00

2.00

2.00
PM_DELTA

70

77

286

264

67

51
67

251

15

101

87

98
100

112

36

7

40

42

19

61

22

23

15

73

19

29

84

15

83

59
23

64

247

84

73

59

26

21

283

55

35

57

212

30

22
2

2
10

10
37

167

$-5$

3

45

Statistics based on data from 121 WNAS surveys and 54 SCHC surveys. 


\section{TABLE E.9. Job Titles Sorted By Human Resource Personnel's Ratings of Anticipated Ability to Recruit (HR_Rec_A)}

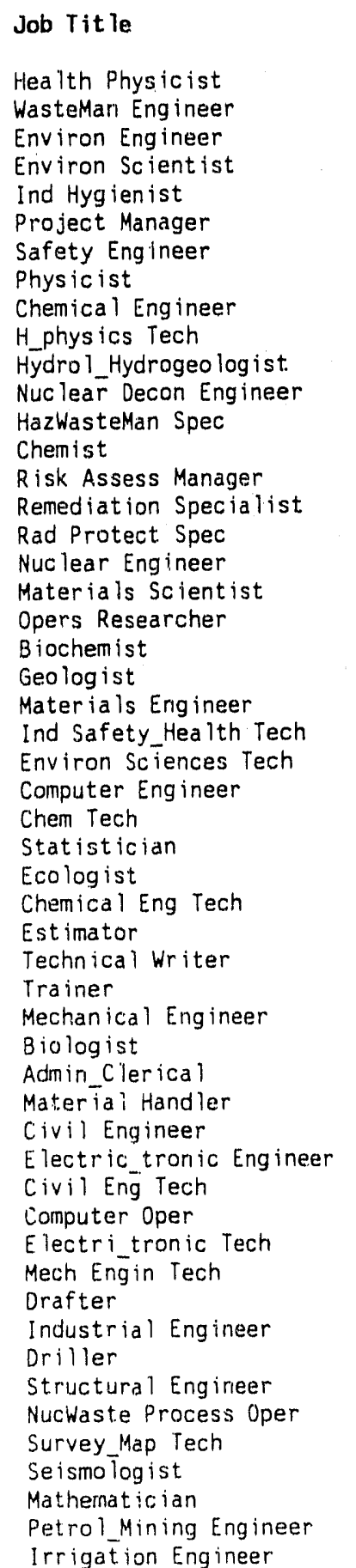

\section{HR_REC_A}

3.65

3.42

3.38

3.30

3.29

3.29

3.26

3.25

3.24

3.17

3.16

3.15

3.13

3.96

3.05

3.04

3.84

2.96

2.95

2.89

2.83

2.82

2.81

2.78

2.76

2.74

2.74

2.71

2.71

2.69

2.67

2.65

2. 48

2.45

2.41

2. 39

2.38

2.34

2.31

2.29

2. 28

2.22

2.19

2.15

2.10

2.89

2.06

2.05

2.00

2.00

2.00

2.00

2.00

\section{PM_DELTA}

70

286
100

51

251

87

15

264

98

67

101

112

36

19

40

61

15

7

22

29

23

42

73

84

19

15

- 59

23

64

59
247

22

283

212

84

73

30

57

35

26

55
45
-5

-5
37

37
167

167
21

2

10

9

Stat istics based on data from 121 WNAS surveys and 54 SCHC surveys

\section{Degree}

Mix of $B S$ and Advanced Mix of BS and Advanced Mix of BS and Advanced Mix of BS and Advanced Most ly Bache lor Most ly Bache lor Most ly Bache lor Mix of BS and Advanced Mix of BS and Advanced Most ly Associate Mix of BS and Advanced Mix of $B S$ and Advanced Mix of $A S$ and $B S$ Mix of $B S$ and Advanced Most ly Bache lor Mix of $A S$ and $B S$

Mix of $A S$ and $B S$ Mix of $B S$ and Advanced Mix of BS and Advanced Mix of BS and Advanced Most ly PhD

Mix of $B S$ and Advanced Mix of BS and Advanced Mix of AS and BS Mix of $A S$ and $B S$ Most ly Bachelor Mix of AS and BS Mix of $B S$ and Advanced Mix of $B S$ and Advanced Most ly Associate Mix of $A S$ and $B S$ Mix of $A S$ and $B S$ Mix of $A S$ and $B S$ Mix of $B S$ and Advanced Mix of BS and Advanced Most ly Associate

HS or less

Mix of BS and Advanced Most ly Bache lor Mostly Associate Mix of AS and BS Most ly Associate Most ly Associate Most ly Associate Most ly Bache lor Most ly Associate Mix of BS and Advanced Most ly Associate Most ly Associate Mostly PhD

Mix of $B S$ and Advanced Mix of BS and Advanced Mix of $A S$ and $B S$ 


\section{TABLE E.10. Job Titles Sorted By Human Resource Personnel's Ratings of Annual Turnover (HR_Turn)}

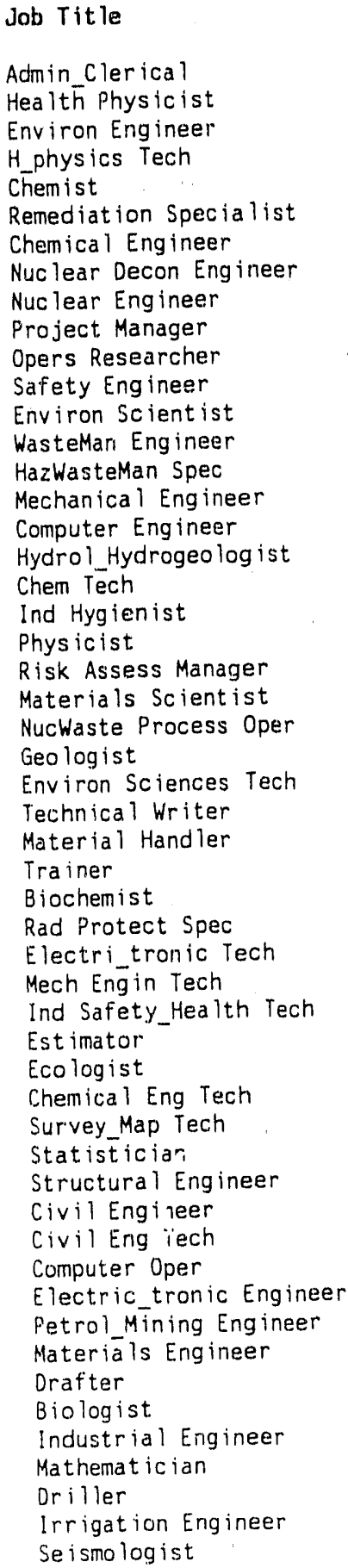

\section{HR_TURN}

2.70

?. 54

2. 39

2.36

2.32

2.32

2.26

2.25

2.25

2.24

2.22

2.20

2.18

2.17

2.17

2.15

2.08

2.07

2.04

2.00

2.00

2.80

2.00

2.00

1.96

1.96

1.96

1.95

1.95

1.94

1.92

1.90

1.90

1.88

1.85

1.85

1.84

1.82

1.77

1.75

1.73

1.73

1.78

1.67

1.63

1.57

1.57

1.55

1.50

1.50

1.45

1.27

1.20

\section{PM_DELTA}

286
98

112

112
19

264

67

61

251

Statistics based on data from 121 WNAS surveys and 54 SCHC surveys.

\section{Degree}

Mostly Associate

Mix of BS and Advanced Mix of BS and Advanced Most ly Associate

Mix of BS and Advanced Mix of AS and BS

Mix of BS and Advanced Mix of BS and Advanced Mix of BS and Advanced Most ly Bache lor

Mix of BS and Advanced Most ly Bache ior

Mix of BS and Advanced Mix of BS and Advanced Mix of $A S$ and $B S$

Mix of BS and Advanced Most ly Bachelor

Mix of BS and Advanced Mix of AS and BS Most ly Bachelor Mix of BS and Advanced Most ly Bachelor Mix of BS and Advanced Most ly Associate Mix of BS and Advanced $M i x$ of $A S$ and $B S$ Mix of AS and BS HS or less

Mix of $A S$ and BS Most ly PhD

Mix of AS and BS Most ly Associate Most ly Associate Mix of AS and BS Mix of $A S$ and $B S$ Mix of $B S$ and Advanced Mostly Associate Mostly Associate Mix of BS and Advanced Mix of BS and Advanced Mix of $8 S$ and Advanced Mosity Associate Mix of $A S$ and $B S$ Most ly Bachelor Mix of $B S$ and Advanced Mix of BS and Advanced Mostly Associate

Mix of 85 and Advanced Mostly Bachelor Mix of BS and Advanced Mostly Associate Mix of AS and BS Mostly PhD 


\section{APPENDIX $F$}

SIMPLE STATISTICS INTERCORRELATION AMONG

VARIABLES AND JOB SORTS ON ALL VARIABLES

FOR ALBUQUERQUE ONLY 
TABLE F.1. Descriptive Statistics for Relative Ratings

$\begin{array}{llcccc}\text { Variable } & \text { N } & \text { Minimum } & \text { Maximum } & \text { Mean } & \underline{\text { S.D. }} \\ \text { HR_DIFF } & 50 & 1.00 & 5.00 & 2.54 & 0.88 \\ \text { HR_NEED } & 50 & 1.00 & 4.00 & 2.11 & 0.65 \\ \text { HR_REC_C } & 50 & 1.00 & 4.00 & 2.11 & 0.66 \\ \text { HR_REC_A } & 50 & 1.00 & 4.00 & 2.23 & 0.68 \\ \text { HR_TURN } & 50 & 1.00 & 2.80 & 1.62 & 0.41 \\ \text { PM_DIFF } & 53 & 1.00 & 3.75 & 2.45 & 0.67 \\ \text { PM_REC_A } & 50 & 1.00 & 3.67 & 2.26 & 0.59 \\ \text { PM_EDUC } & 53 & 1.50 & 5.00 & 3.84 & 0.88\end{array}$

S.D. = Standard Deviation, HR_DIFF = Difficulty Caused by a Shortage, HR NEED = Need for Additional-Employees, HR-REC_A = Anticipated Ease of Recruitment, HR-REC-C = Current Ease of Recruitment, HR_TURN = Current Annual Turnover, PM DIFF = Difficulty Caused By a Shortage, PM_REC A = Anticipated Ability to Recruit, PM EDUC = Typical Degree Leve1, $* \star \bar{p}<\overline{0} .01 ; * p<0.05$. Statistics based on data from 9 WNAS surveys and 7 SCHC surveys. 


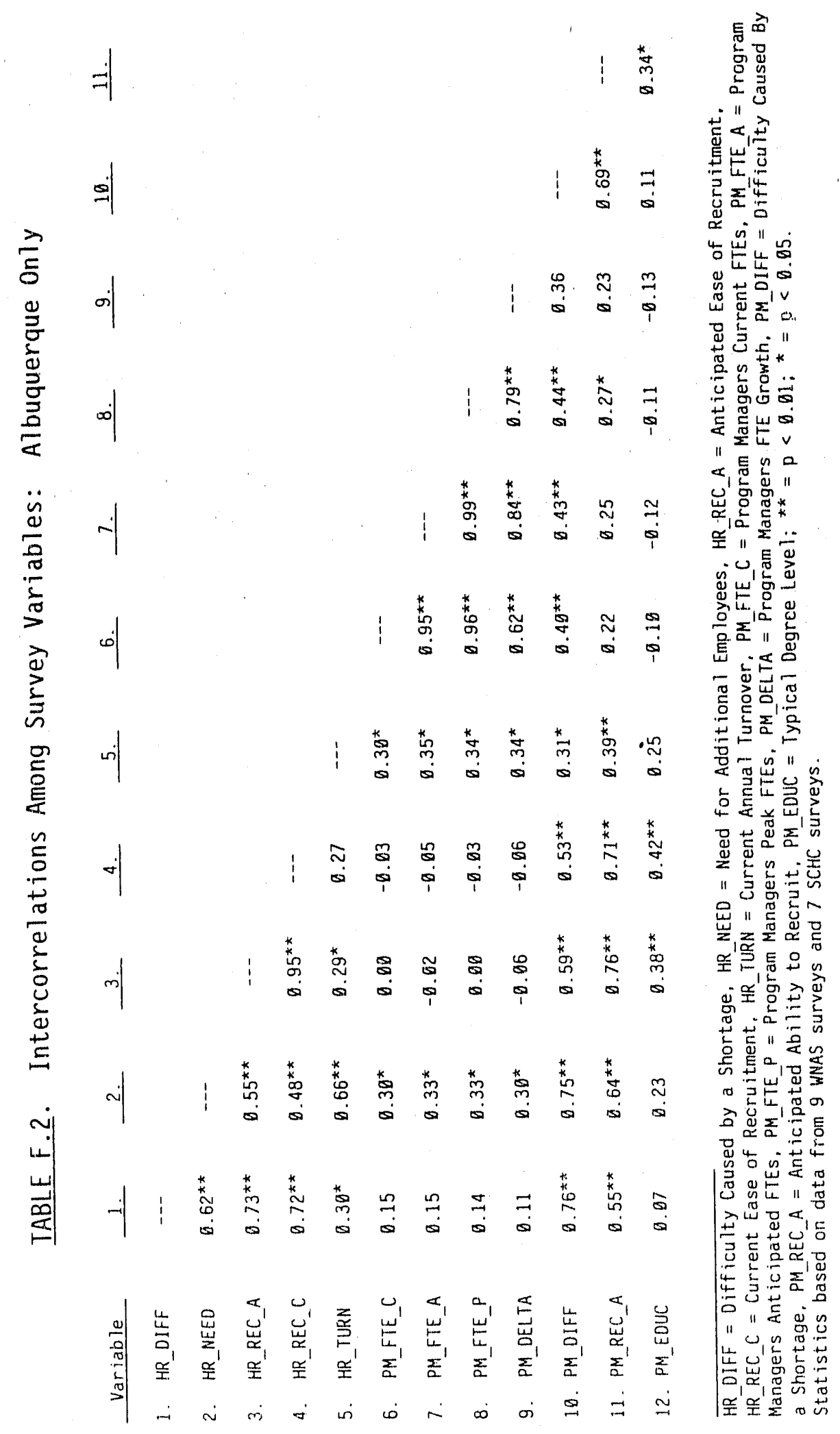

F.2 


\section{TABLE F.3. Job Titles Sorted By Change in FTEs (PM_Delta)}

\begin{tabular}{|c|c|c|c|c|c|}
\hline Job Title & PH_FTE_C & PM_FTE_A & PM_FTE_P & PM_DELTA & Degree \\
\hline HazWasteMan Spec & 39 & 69 & 79 & 30 & Mix of AS and BS \\
\hline Admin_Clerioal 1 & 39 & 66 & 77 & 27 & Mostly Associate \\
\hline Chemical Eng ineer & 17 & 38 & 50. & 21 & Mix of BS and Advanced \\
\hline Mechanical Engineer & 9 & 23 & 25 & 14 & Mix of BS and Advanced \\
\hline Chemtcal Eng Tech & 19 & 32 & 49 & 13 & Mix of $A S$ and $B S$ \\
\hline Environ Engineer & 28 & 41 & 48 & 13 & Mix of BS and Advanced \\
\hline Technical Writer & 8 & 21 & 23 & 13 & Most ly Bache lor \\
\hline Electri_tronic Tech & 15 & 27 & 32 & 12 & Mix of AS and BS \\
\hline Environ Scientist & 18 & 29 & 34 & 11 & Mostiy PhD \\
\hline Chemist. & 18 & 27 & 33 & 9 & Mostly Pho \\
\hline Health Physicist & 8 & 17 & 22 & 9 & Mix of BS and Advanced \\
\hline NucWaste Process Oper & 9 & 18 & 24 & 9 & Mix of $A S$ and $B S$ \\
\hline Biochemist & 5 & 13 & 21 & 8 & Mostly Pho \\
\hline Chern Tech & 20 & 28 & 39 & 8 & $M+x$ of $A S$ and $B S$ \\
\hline Geologist & 28 & 36 & 41 & 8 & Mostly PhD \\
\hline Mech Engin Tech & 9 & 17 & 19 & 8 & Mix of $A S$ and $B S$ \\
\hline Other Scientist & 5 & 13 & 13 & 8 & Mostly Assoc late \\
\hline Computer Oper & 17 & 24 & 27 & 7 & Mix of AS and BS \\
\hline Ecologist & 11 & 18 & 21 & 7 & Mostly PhD \\
\hline WasteMan Eng ineer & 10 & 17 & 17 & 7 & Mix of BS and Advanced \\
\hline Civil Eng Tech & 8 & 14 & 18 & 6 & Mix of AS and BS \\
\hline Computer Eng ineer & 12 & 18 & 23 & 6 & Mix of BS and Advanced \\
\hline Safety Eng Ineer & 2 & 8 & 12 & 6 & Mix of BS and Advanced \\
\hline Statistician & 1 & 7 & 9 & 6 & Most ly PhD \\
\hline Estimator & 18 & 23 & 24 & 5 & Mostly Bachelor \\
\hline Hydro I_Hydrogeo log ist & 20 & 25 & 35 & 5 & Mostly PhD \\
\hline Ind Safety_Health Tech & 7 & 12 & 20 & 5 & Mix of AS and BS \\
\hline Mathematician & 11 & 16 & 21 & 5 & Mostly Pho \\
\hline Nuclear Decon Engineer & $\theta$ & 5 & 9 & 5 & Mix of BS and Advanced \\
\hline Rad Protect Spec & 4 & 9 & 13 & 5 & Most ly Bache lor \\
\hline Biologist & 10 & 14 & 21 & 4 & Mostly Pho \\
\hline Orafter & 10 & 14 & 15 & 4 & Mix of $A S$ and $B S$ \\
\hline H_physics Tech & 5 & 8 & 10 & 3 & Mix of $A S$ and $B S$ \\
\hline Nuclear Engineer & 9 & 12 & 16 & 3 & Mostly Pho \\
\hline Opers Researcher & 2 & 5 & 5 & 3 & Mix of BS and Advanced \\
\hline Risk Assess Manager & 1 & 4 & 4 & 3 & Mostly Bachelor \\
\hline Industrial Engineer & 1 & 3 & 4 & 2 & Mix of BS and Advanced \\
\hline Materials Scientist & 2 & 4 & 4 & 2 & Mostly PhD \\
\hline Physicist & 6 & 8 & 8 & 2 & Mostly PhD \\
\hline Project Manager & 31 & 33 & 48 & 2 & Most ly Bache lor \\
\hline Seismologist & $\theta$ & 2 & 4 & 2 & Mostly PhD \\
\hline Ind Hygien ist & 3 & 4 & 4 & 1 & Mostly Advanced \\
\hline Other Eng ineer & 1 & 2 & 2 & 1 & Mostly Associate \\
\hline Petrol_Mining Eng ineer & 2 & 3 & 3 & 1 & Mix of BS and Advanced \\
\hline Remediation Specialist & 1 & 2 & 2 & 1 & Mostly Advanced \\
\hline Trainer & 1 & 2 & 2 & 1 & Most ly Bachelor \\
\hline Civil Eng ineer & 34 & 34 & 48 & $\theta$ & Mix of BS and Advanced \\
\hline Oriller & 1 & 1 & 1 & $\theta$ & HS or less \\
\hline Electric_tronic Engineer & 3 & 3 & 4 & $\theta$ & Mix of $B S$ and Advanced \\
\hline Environ S̄ciences Tech & 25 & 25 & 48 & $\theta$ & Mix of $A S$ and $B S$ \\
\hline Irrigation Engineer & $\theta$ & $\theta$ & 0 & $\theta$ & Most ly Bache lor \\
\hline Material Handler & 2 & 2 & 4 & $\theta$ & Mostly Associate \\
\hline Materials Engineer & $\theta$ & $\theta$ & D & $\theta$ & Mix of BS and Advanced \\
\hline Other Administrator & 2 & 2 & 3 & $\theta$ & HS or less \\
\hline Other Technician & $\theta$ & $\theta$ & $\theta$ & $\theta$ & HS or less \\
\hline Structural Engineer & $\theta$ & $\theta$ & $\theta$ & $\theta$ & Mix of BS and Advanced \\
\hline Survey Map Tech & 3 & 3 & 6 & $\theta$ & Mostly Associate \\
\hline
\end{tabular}

Statistics based on data from 9 WNAS surveys and 7 SCHC surveys 


\section{TABLE F.4. Job Titles Sorted By Project Manager's Ratings of Difficulty Caused By Shortage (PM_Rec_A)}

\author{
Job Title \\ Health Physicist \\ Rad Protect Spec \\ Remediation Specialist \\ Nuc lear Decon Eng ineer \\ Risk Assess Manager \\ Project Manager \\ Environ Scientist \\ Chemical Engineer \\ HazWasteMan Spec \\ Estimator \\ Environ Sciences Tech \\ Environ Engineer \\ Hydrol_Hydrogeo log ist \\ WasteMan Engineer \\ Ind Safety Health Tech \\ $H$ physics Tech \\ Biochemist \\ Biologist. \\ Ind Hygienist \\ Nuc lear Eng ineer \\ Chem Tech \\ Statistician \\ Computer Oper \\ Petrol_Mining Engineer \\ Electri tronic Tech \\ Chemical Eng. Tech \\ Ecologist \\ Materials Scientist \\ Seismolog ist \\ Physicist \\ Electric tronic Engineer \\ Geologist \\ Admin_Clerical \\ Computer Engineer \\ Mechanical Eng ineer \\ NucWaste Process Oper \\ Civil. Eng Tech \\ Chemist \\ Mech Eng in Tech \\ Drafter \\ Opers Researcher \\ Safety Engineer \\ Mathematician \\ Technical Writer \\ Civil Engineer \\ Materials Engineer \\ Material Handler \\ Structural Engineer \\ Drilier \\ Industrial Engineer \\ Survey_Map Tech \\ Trainer \\ Irrigation Engineer
}

\section{PM_REC_A}

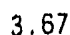

3.33

3.33

3.28

3.00

3.00

3.00

2.86

2.83

2.80

2.80

2.71

2.67

2.67

2.68

2.68

2.60

2.60

2.50

2.50

2.40

2.40

2.40

2.25

2.20

2.29

2.20

2.20

2.20

2.20

2.20

2.17

2.00

2.00

2.90

2.00

2.80

1.80

1.80

1.80

1.80

1.75

1.75

1.67

1.67

1.67

1.67

1.67

1.50

1.50

1.33

1.00

1.00
PM_DELTA

9

5

3

2

11

21

30

5

0

13

5

7

5

3
8

4

1

8

6

7

12

13

7
2

2

2

8

8
27

27

6
14

9

9
6

9

8

8
4
3

3
6

5

13

13
0
0

0
$\theta$
$\theta$

$\theta$

2

0

1
Degree

Mix of BS and Advanced

Mostly Bache lor

Mostly Advanced

Mix of BS and Advanced

Mostly Bache lor

Mostly Bachelor

Mostly PhO

Mix of BS and Advanced

Mix of AS and BS

Mostly Bachelor

Mix of AS and BS

Mix of BS and Advanced

Mostly PhD

Mix of BS and Advanced

$M+x$ of $A S$ and $B S$

Mix of AS and BS

Mostly PhiD

Mostly PhD

Most ly Advanced

Mostly Pho

Mix of AS and BS

Most ly PhD

Mix of AS and BS

Mix of $B S$ and Advanced

$M i x$ of $A S$ and $B S$

Mix of $A S$ and $B S$

Most ly Pho

Mostly Pho

Mostly PhO

Mostly Pho

Mix of $B S$ and Advanced

Mostly PhD

Mostly Associate

Mix of BS and Advanced

Mix of BS and Advanced

Mix of $A S$ and $B S$

Mix of $A S$ and BS

Mostly PhD

Mix of AS and BS

Mix of $A S$ and $B S$

Mix of $B S$ and Advanced

Mix of $B S$ and Advanced

Mostly Pho

Mostly Bachelor

Mix of BS and Advanced

Mix of BS and Advanced Mostly Associate

Mix of BS and Artvanced HS or less

Mix of BS and Advanced

Mostly Associate

Mostly Bachelor

Mostly Bachelor

Statistics based on data from 9 WNAS surveys and 7 SCHC surveys. 


\section{TABLE F.5. Job Tities Sorted By Project Manager's Ratings of Difficulty Caused by Shortage (PM_Diff)}

Job Title
Risk Assess Manager
Health Phys icist
Hydrol_Hydrogeologist
Project Manager
Environ Scientist
WasteMan Eng ineer
Rad Protect Spec
Admin_Clerical
Ind Safety_Health Tech
Nuclear Decon Engineer
HazWasteMan Spec
Environ Engineer
Chemist
Chem Tech
Drfller
Electritronic Tech
Mech Engin Tech
Estimator
H_physics Tech
Ind Hyglenist
Chemical Eng Tech
Biochemist
Statistician
Environ Sciences Tech
Biologist
Technical Writer
Geologist
Remediation Specialist
Civil Engineer
Chernical Engineer
Safety Engineer
Mathematician
Computer Oper
Ecologist
Drafter
Materials Scientist
Seismologist
Nuclear Engineer
Computer Engineer
Opers Researcher
Industrial Engineer
Physicist
Electric_tronic Engineer
Mechanical Engineer
NucWaste Process Oper
Petrol_Mining Engineer
Trainer
Materials Engineer
Material Handler
Structural Engineer
Survey Map Tech
Civil Eng Tech
Irrigation Engineer

\begin{tabular}{|c|c|}
\hline PM_DIFF & PM_DELT \\
\hline 3.75 & 3 \\
\hline 3.67 & 9 \\
\hline 3.50 & 5 \\
\hline 3.38 & 2 \\
\hline 3.33 & 11 \\
\hline 3.33 & 7 \\
\hline 3.33 & 5 \\
\hline 3.29 & 27 \\
\hline 3.20 & 5 \\
\hline 3.20 & 5 \\
\hline 3.17 & 30 \\
\hline 3.00 & 13 \\
\hline 3.60 & 9 \\
\hline 3.00 & 8 \\
\hline 3.00 & 0 \\
\hline 2.80 & 12 \\
\hline 2.80 & 8 \\
\hline 2.80 & 5 \\
\hline 2.80 & 3 \\
\hline 2.75 & 1 \\
\hline 2.60 & 13 \\
\hline 2.60 & 8 \\
\hline 2.60 & 6 \\
\hline 2.60 & $\theta$ \\
\hline 2.40 & 4 \\
\hline 2.33 & .13 \\
\hline 2.33 & 8 \\
\hline 2.33 & 1 \\
\hline 2.33 & $\theta$ \\
\hline 2.29 & 21 \\
\hline 2.25 & 6 \\
\hline 2.25 & 5 \\
\hline 2.20 & 7 \\
\hline 2.20 & 7 \\
\hline 2.20 & 4 \\
\hline 2.20 & 2 \\
\hline 2.20 & 2 \\
\hline . 2.17 & 3 \\
\hline 2.80 & 6 \\
\hline 2.00 & 3 \\
\hline 2.00 & 2 \\
\hline 2.00 & 2 \\
\hline 2.00 & $\emptyset$ \\
\hline 1.83 & 14 \\
\hline 1.75 & 9 \\
\hline 1.75 & 1 \\
\hline 1.67 & 1 \\
\hline 1.67 & $\theta$ \\
\hline 1.33 & $\theta$ \\
\hline 1.33 & $\theta$ \\
\hline 1.33 & $\theta$ \\
\hline 1.20 & 6 \\
\hline 1.00 & $\theta$ \\
\hline
\end{tabular}

\section{Degree}

Mostly Bache lor Mix of BS and Advanced Most ly Pho Most ly. Bache lor Mostly PhD Mix of BS and Advanced Most ly Bache lor Mostly Associate Mix of AS and BS MiX of $B S$ and Advanced Mix of $A S$ and $B S$ MiX of $B S$ and Advanced Mostly Pho

Mix of AS and BS HS or less Mix of AS and BS Mix of AS and BS Mostly Bache lor Mix of AS and BS Most ly Advanced MiX of AS and BS Mostly PhD Mostly PhD Mix of AS and BS Most ly Pho Most ly Bache lor Mostly PhD Mostly Advanced Mix of $B S$ and Advanced Mix of BS and Advanced Mix of BS and Advanced Mostly PhD

Mix of AS and BS Most ly PhD Mix of AS and BS Mostly PhD Mostly PhD Mostly Pho Mix of BS and Advanced Mix of $B S$ and Advanced MiX of $B S$ and Advanced Mostly PhD

Mix of $B S$ and Advanced Mix of $B S$ and Advanced Mix of $A S$ and $B S$ Mix of BS and Advanced Most ly Bachelor Mix of BS and Advanced Most ly Associate Mix of BS and Advanced Mostly Associate Mix of AS and BS Most ly Bache lor

Statistics based on data from 9 WNAS surveys and 7 SCHC surveys. 
TABLE F.6. Job Titles Sorted By Human Resource Personnel's Ratings of Difficulty Caused By Shortage (HR_Diff)

Job Title
Driller
Risk Assess Manager
Rad Protect Spec
Environ Engineer
Health Physicist
Environ Scient ist
Hydrol Hydrogeologist
Admin_Clerical
Project Manager
Estimator
WasteMan Engineer
Nuclear Decon Engineer
Nuclear Engineer
Remediation Specialist
Chemical Eng Tech
Hphysics Tech
Chem Tech
NucWaste Process Oper
HazWasteMan. Spec
Ind Hygienist
Geologist
Chemist
Trainer
Environ Sciences Tech
Mechanical Engineer
Safety Engineer
Chemical Engineer
Ind Safety_Health Tech
Biochemist
Materials Scientist
Civil Engineer
Computer Oper
Electric tronic Engineer
Computer Engineer
Mech Engin Tech
Technical Writer
Materials Engineer
Material Handler
Industrial Engineer
Petrol_Mining Engineer
Electri_tronic Tech
Ecologist
Structural Engineer
Biologist
Civil Eng Tech
Drafter
Mathernatician
Survey Map Tech
Irrigation Engineer
Statistician
Seismologist
Physicist
Opers Researcher

\begin{tabular}{|c|c|}
\hline$H R \_D I F F$ & PM_DEL T \\
\hline 4.50. & $\theta$ \\
\hline 4.33 & 3 \\
\hline 4.00 & 5 \\
\hline 3.71 & 13 \\
\hline 3.60 & 9 \\
\hline 3.50 & 11 \\
\hline 3.50 & 5 \\
\hline 3.50 & 27 \\
\hline 3.33 & 2 \\
\hline 3.33 & 5 \\
\hline 3.33 & 7 \\
\hline 3.00 & 5 \\
\hline 2.80 & 3 \\
\hline 2.75 & 1 \\
\hline 2.75 & 13 \\
\hline 2.67 & 3 \\
\hline 2.67 & 8 \\
\hline 2.67 & 9 \\
\hline 2.60 & 30 \\
\hline 2.60 & 1 \\
\hline 2.60 & 8 \\
\hline 2.50 & 9 \\
\hline 2.50 & 1 \\
\hline 2.40 & $\theta$ \\
\hline 2.40 & 14 \\
\hline 2.40 & 6 \\
\hline 2.33 & 21 \\
\hline 2.33 & 5 \\
\hline 2.33 & 8 \\
\hline 2.33 & 2 \\
\hline 2.33 & $\theta$ \\
\hline 2.25 & 7 \\
\hline 2.00 & $\theta$ \\
\hline 2.00 & 6 \\
\hline 2.00 & 8 \\
\hline 2.00 & 13 \\
\hline 2.00 & $\theta$ \\
\hline 2.00 & $\theta$ \\
\hline 1.83 & 2 \\
\hline 1.75 & 1 \\
\hline 1.67 & 12 \\
\hline 1.67 & \\
\hline 1.67 & $\theta$ \\
\hline 1.33 & 4 \\
\hline 1.33 & 6 \\
\hline 1.33 & 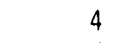 \\
\hline 1.33 & 5 \\
\hline 1.33 & $\theta$ \\
\hline 1.00 & $\theta$ \\
\hline 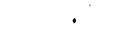 & 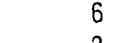 \\
\hline . & \\
\hline . & \\
\hline & \\
\hline
\end{tabular}

Degree

HS or less

Most iy Bache lor Most ly Bachelor

Mix of BS and Advanced Mix of BS and Advanoed

Most ly Ph.J

Mostly PhD

Mostly Associate

Most ly Bachelor

Most ly Bachelor

Mix of BS and Advanced

Mix of BS and Advanced

Most ly PhD

Mostly Advanced

Mix of AS and BS

Mix of $A S$ and $B S$

Mix of $A S$ and $B S$

Mix of AS and BS

Mix of $A S$ and $B S$

Most ly Advanced

Most 7y PhD

Mostly PhD

Most ly Bachelor

Mix of AS and BS

Mix of BS and Advanced

Mix of $B S$ and Advanced

Mix of BS and Advanced

Mix of AS and BS

Most ly PhD

Mostly PhD

Mix of $B S$ and Advanced

Mix of $A S$ and $B S$

Mix of BS and Advanced

Mix of BS and Advanced

Mix of AS and BS

Mostly Bachelor

Mix of BS and Advanced

Most ly Associate

Mix of BS and Advanced

Mix of $B S$ and Advanced

Mix of $A S$ and $B S$

Most Ty PhD

Mix of BS and Advanced Mostily PhD

Mix of AS and BS Mix of AS and BS Most ly PhD Mostly Associate

Most ly Bache lor Mostly PhD

Mostly PhD

Most ly PhD

Mix of BS and Advanced

Statistics based on data from 9 WNAS surveys and 7 SCHC surveys. 


\section{TABLE F.7. Job Titles Sorted By Human Resource Personnel's Ratings of Need for Additional Employees (HR_Need)}

Job Title
Risk Assess Manager
Environ Scient ist
Health Physicist
Environ Engineer
Hydrol Hydrogeologist
Admin_Clerica?
Project Manager
Estinator
H_physics Tech
Rad Protect Spec
WasteMar, Engineer
Trainer
Chemical Engineer
Geologist
Nuclear Decon Engineer
Ind Safety_Health Tech
Biochemist
Remediation Specialist
Cnemist
Nuclear Engineer
HazWasteMan Spec
Eiviron Sciences Tech
Safety Engineer
Driller
Chemical Eng Tech
Chem Tech
Mechanical Engineer
Computer Engineer
Technical Writer
Ind Hygienist
Electric tronic Engineer
Materials Engireer
Material Handler
PetrolMining Engineer
NucWaste Process Oper
Materials Scient ist
Mech Engin Tech
Electri_tronic Tech
Ecologist
Structural Engineer
Biologist
Computer Oper
Civi Engineer
Industrial Engineer
Drafter
Matnematician
Survey Map Tech
Civil Erg Tech
Irrigation Engineer
Statistician
Seismologlst
Physicist
Ocers Researuner

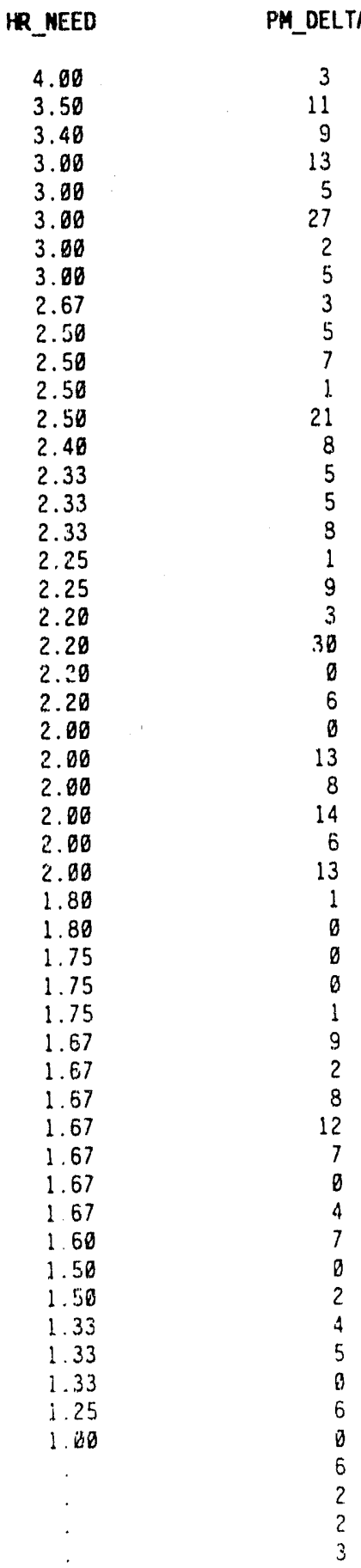

Statistics based on data from 9 hNAS surveys and 7 SCHC surveys. 


\section{TABLE F.8. Job Titles Sorted By Human Resource Personnel's Ratings of Current Ability to Recruit (HR Ret_C)}

Job Tit le

Hydrol_Hydrogeo log ist

Rad Prötect Spec

Remediation Specialist

Environ Engineer

Project Manager

Health Physicist

Risk Assess Manager

$H$ physics Tech

Nuclear Decon Engineer

WasteMan Eng ineer

Geologist

Ind Safety_Health Tech

Biochemist

Materials Scient ist

Environ Scientist

Petrol_Mining Engineer

Nuc lear Eng ineer

HazWasteMan Spec

Safety Engineer

Mechanica? Engineer

Ind Hygienist

Chemical Eng ineer

Estimator

Trairier

Environ Sciences Tech

Driller

Chemical Eng Tech

Chem Tech

Computer Eng ineer

NucWaste Process Oper

Biologist

Industrial Engineer

Chemist

Materials Engineer

Ecologist

Structural Engineer

Survey Map Tech

Electric tronic Engineer

Computer Oper

Adrnin Clerical

Technical Writer

Material Handler

Civil Eng Tech

Civil Engineer

Drafter

Mathemat ician

Mech Eng in Tech

Electri tronic Tech

Irrigation Engineer

Statistician

Seismolog ist

Physic ist

Opers Researcher
HR_REC C

3.67

3.50

3.25

3.14

3.00

2.80

2.67

2.67

2.67

2.50

2.40

2.33

2.33

2.33

2.25

2.25

2.20

2.20

2.20

2.20

2.20

2.17

2.00

2.00

2.00

2.00

2.00

2.00

2. .00

2.00

2.00

1. 83

1.75

1.75

1.67

1.67

1.67

1.60

1.60

1.50

1.50

1.50

1.50

1.33

1.33

1. 33

1.00

1.00

1.00
PH DELTA

5

1

13

2

9

3

3

7

8

5

2

11

1
3

30

8

14

2

21

5

6

8
13

13
8

8

6
9

4

?

9

7

0

0

7

2.7

13

6

6

4

5

8

12

6

2

2

Statistics based on data from 9 WNAS surveys and 7 SCHC surveys.

Degree

Mostly PhD

Mosti iy Bache lor

Most ly Advanced

Mix of BS and Advanced

Most iy Bache lor

Mix of $B S$ and Advanced

Most ly Bachelor

Mix of AS and BS

Mix of $B S$ and Advanced

Mix of $B S$ and Advanced

Most ly PhD

Mix of $A S$ and $B S$

Most ly PhD

Mostly Pho

Most ly PhD

Mix of $B S$ and Advanced

Most ly Pho

Mix of AS and BS

Mix of BS and Advanced

Mix of BS and Advanced

Most ly Advanced

Mix of BS and Advariced

Mostly Bachelor

Mostly Bache lor

Mix of AS and BS

HS or less

Mix of $A S$ and $B S$

$M i x$ of $A S$ and $B S$

Mix of BS and Advanced

Mix of AS and BS

Most ly Pho

Mix of BS and Advanced

Most ly Pho

Mix of BS and Advanced

Mostly PhD

Mix of $B S$ and Advanced

Most ly Associate

Mix of $B S$ and Advanced

Mix of $A S$ and $B S$

Mostly Associate

Most ly Bache lor

Most ly Associate

Mix of AS and BS

Mix of BS and Aodvanced

Mix of $A S$ and $B S$

Most ly Pro

Mix of $A S$ and $B S$

Mix of AS and BS

Most ly Bache lor

Most ly PhD

Most.ly PhO

Mostly PhD

Mix of $B S$ and Advanced 


\section{TABLE F.9. Job Titles Sorted By Human Resource Personnel's Ratings of Anticipated Ability to (HR_Rec_A)}

\begin{tabular}{|c|c|c|}
\hline Job Title & HR_REC_A & PM_DELTF \\
\hline Rad Protect Spec & 3.75 & 5 \\
\hline Project Manager & 3.67 & 2 \\
\hline Hydrol__Hydrogeo log ist & 3.50 & 5 \\
\hline Reniediation Specialist & 3.50 & 1 \\
\hline Health Physicist & 3.00 & 9 \\
\hline Risk Assess Manager & 3.00 & 3 \\
\hline H_physics Tech & 3.00 & 3 \\
\hline WasteMan Eng ineer & 2.83 & 7 \\
\hline Environ Engineer & 2.67 & 13 \\
\hline Nuclear Decon Eng ineer & 2.67 & 5 \\
\hline Estimator & 2.67 & 5 \\
\hline Environ Scient ist & 2.50 & 11 \\
\hline Geologist & 2.40 & 8 \\
\hline HazWasteMan Spec & 2.40 & 30 \\
\hline Ind Hyg ienist & 2.40 & 1 \\
\hline Environ Sciences Tech & 2.40 & $\theta$ \\
\hline Ind Safety_Health Tech & 2.33 & 5 \\
\hline Biochem ist ${ }^{-}$ & 2.33 & 8 \\
\hline Materials Scientist & 2.33 & 2 \\
\hline Chemical Eng ineer & 2.33 & 21 \\
\hline Biologist & 2.33 & 4 \\
\hline Petrol Mining Engineer & 2.25 & 1 \\
\hline Nuc lear Eng ineer & 2.20 & 3 \\
\hline Safety Engineer & 2.20 & 6 \\
\hline Mechanical Engineer & 2.20 & 14 \\
\hline Trainer & 2.00 & 1 \\
\hline Driller & 2.00 & $\theta$ \\
\hline Chemical Eng Tech & 2.00 & 13 \\
\hline Chem Tech & 2.00 & 8 \\
\hline Computer Engineer & 2.00 & 6 \\
\hline Nuchaste Process Oper & 2.00 & 9 \\
\hline Materials Engineer & 2.80 & 6 \\
\hline Structural Eng ineer & 2.00 & 0 \\
\hline Technical Writer & 2.00 & 13 \\
\hline Industrial Engineer & 1.83 & 2 \\
\hline C'nemist & 1.75 & 9 \\
\hline Admin Clerical & 1.75 & 27 \\
\hline Material Handler & 1.75 & $\theta$ \\
\hline Ecologist & 1.67 & 7 \\
\hline Survey_Map Tech & 1.67 & 8 \\
\hline Computer Oper & 1.60 & 7 \\
\hline Civil Eng Tech & 1.50 & 6 \\
\hline Civil Engineer & 1.50 & 0 \\
\hline Electric_tronic Engineer & 1.46 & 0 \\
\hline Drafter & 1.33 & 4 \\
\hline Mathematician & 1.33 & 5 \\
\hline Mech Engin Tech & 1.33 & 8 \\
\hline Electri tronic Tech & 1.33 & 12 \\
\hline irrigat ion Engineer & 1.00 & $\theta$ \\
\hline Statistician & . & 6 \\
\hline Se ismolog ist & . & 2 \\
\hline Physicist & & 2 \\
\hline Opers Researcher & & 3 \\
\hline
\end{tabular}

\section{Degree}

Mostly Bachelor Most ly Bache lor Mostly PhD

Mostly Advanced

Mix of $\mathrm{BS}$ and Advanced Most ly Bache lor Mix of AS and BS Mix of $B S$ and Advanced Mix of BS and Advanced Mix of BS and Advanced Most ly Bache lor Mostly PhD Mostly Pho Mix of AS and BS Most ly Advanced Mix of AS and BS Mix of AS and BS Mastly PhD Mostly PhD Mix of BS and Advanced Most ly PhD

Mix of $B S$ and Advanced Mostly PhD

Mix of $B S$ and Advanced Mix of BS and Advanced Mostly Bachelor HS or less Mix of $A S$ and $B S$ Mix of AS and BS Mix of $B S$ and Advanced Mix of $A S$ and $B S$

Mix of $B S$ and Advanced Mix of $B S$ and Advanced Most ly Bache lor

Mix of $B S$ and Advanced Most ly PhD

Mostly Associate Mostly Associate

Mostly PhD

Mostly Assoc iate

Mix of $A S$ and $B S$

$M i x$ of $A S$ and $B S$

Mix of BS and Advanced Mix of $B S$ and Advanced Mix of AS and BS

Mostly PhD

Mix of $A S$ and $B S$

Mix of $A S$ and $B S$

Most ly Bache lor

Mostly PhD

Most.ly Pho

Mostly PhD

Mix of BS and Advanced

Statistics based on data from 9 WNAS surveys and 7 SCHC surveys. 
TABLE F.10. Job Titles Sorted By Human Resource Personnel's Ratings of Annual Turnover (HR_Turn)

\begin{tabular}{|c|c|c|}
\hline Job Title & HR_TURN & PH_DELT \\
\hline Hea Ith Physic ist & 2.80 & 9 \\
\hline Admin_Clerical & 2.75 & 27 \\
\hline Envirōn Engineer & 2.57 & 13 \\
\hline Environ Scientist & 2.25 & 11 \\
\hline Remediation Specialist & 2.00 & 1 \\
\hline Estimator & 2.90 & 5 \\
\hline Trainer & 2.90 & 1 \\
\hline Technical Writer & 2.00 & 13 \\
\hline Chemical Engineer & 1.83 & 21 \\
\hline Environ Sciences Tech & 1.80 & 0 \\
\hline Safety Engineer & 1.80 & 6 \\
\hline Mechanical Engineer & 1.80 & 14 \\
\hline Chemist & 1.75 & 9 \\
\hline Material Handler & 1.75 & $\theta$ \\
\hline Project Manager & 1.67 & 2 \\
\hline Hydrol_Hydrogeologist & 1.67 & 5 \\
\hline Risk Asssess Manager & 1.67 & 3 \\
\hline H_physics Tech & 1.67 & 3 \\
\hline Nuc lear Decon Engineer & 1.67 & 5 \\
\hline Ind Safety Heaith Tech & 1.67 & 5 \\
\hline Biochem ist & 1.67 & 8 \\
\hline Materials Scientist & 1.67 & 2 \\
\hline Biologist & 1.67 & 4 \\
\hline Nuc lear Eng ineer & 1.67 & 3 \\
\hline NucWaste Process Oper & 1.67 & 9 \\
\hline Structural Engineer & 1.67 & $\theta$ \\
\hline Civil Engineer & 1.67 & $\theta$ \\
\hline Geologist & 1.60 & 8 \\
\hline HazWasteMan Spec & 1.60 & 30 \\
\hline Ind Hygienist & 1.60 & 1 \\
\hline Computer Oper & 1.60 & 7 \\
\hline Rad Protect Spec & 1.50 & 5 \\
\hline Petrol_Mining Engineer & 1.50 & 1 \\
\hline Computēr Eng ineer & $1.5 \emptyset$ & 6 \\
\hline Materials Engineer & 1.50 & $\theta$ \\
\hline Industrial Engineer & 1.50 & 2 \\
\hline Electric tronic Engineer & 1.40 & 0 \\
\hline WasteMan Eng ineer & 1.33 & 7 \\
\hline Chem Tech & 1.33 & 8 \\
\hline Ecologist & 1.33 & 7 \\
\hline Survey_Map Tech & 1.33 & $\theta$ \\
\hline Mathematician & 1.33 & 5 \\
\hline Civil Eng Tech & 1.25 & 6 \\
\hline Driller & 1.00 & 0 \\
\hline Chemical Eng Tech & 1.00 & 13 \\
\hline Drafter & 1.09 & 4 \\
\hline Mech Eng in Tech & 1.00 & 8 \\
\hline Electri_tronic Tech & 1.00 & 12 \\
\hline Irrigat $\overline{i o n}$ Engineer & 1.00 & 0 \\
\hline Statistician & . & 6 \\
\hline Se ismologist & & 2 \\
\hline Physic ist & & 2 \\
\hline Opers Researcher & & 3 \\
\hline
\end{tabular}

\section{Degree}

Mix of $B S$ and Advanced Most ly Associate Mix of $B S$ and Advanced Mostly PhD

Most ly Advanced Most ly Bachelor Most ly Bachelor Mostly Bachelor

Mix of $B S$ and Advanced $M i x$ of $A S$ and $B S$

Mix of BS and Advanced Mix of $B S$ and Advanced Most ly PhD

Most ly Associate Mostly Bachelor

Mostly PhD

Most ly Bachelor

Mix of AS and BS

Mix of $B S$ and Advanced Mix of $A S$ and $B S$

Mostly PhD

Mostly PhD

Mostly PhD

Most ly PhD

Mix of AS and BS

Mix of $B S$ and Advanced Mix of $B S$ and Advanced Most ly PhD

Mix of $A S$ and BS

Most ly Advanced

Mix of AS and BS

Most ly Bache lor

Mix of BS and Advanced Mix of BS and Advanced Mix of BS and Advanced Mix of BS and Advanced Mix of BS and Advanced Mix of $B S$ and Advanced Mix of $A S$ and $B S$

Mostly Pho

Mostly Associate Mostly PhD

Mix of $A S$ and $B S$ HS or less

Mix of AS and BS Mix of $A S$ and $B S$ Mix of $A S$ and $B S$ Mix of AS and BS Most ly Bache lor

Most ly PhiD

Mostly Pho

Mostly PhD

Mix of $B S$ and Advanced

Statistics based on data from 9 WNAS surveys and 7 SCHC surveys 
APPENDIX G

SIMPLE STATISTICS INTERCORRELATION AMONG

VARIABLES AND JOB SORTS ON ALL VARIABLES

FOR CHICAGO ONLY 
IABLE G.1. Descriptive Statistics for Relative Ratings

\begin{tabular}{lccccc} 
Variable & N & Minimum & Maximum & $\underline{\text { Mean }}$ & $\underline{\text { S.D. }}$ \\
\hline HR_DIFF & 4.4 & 1.00 & 5.00 & 2.83 & 1.07 \\
HR_NEED & 44 & 1.00 & 4.00 & 2.44 & 0.83 \\
HR_REC_C & 44 & 2.00 & 5.00 & 3.10 & 0.69 \\
HR_REC_A & 43 & 2.00 & 4.00 & 3.08 & 0.62 \\
HR_TURN & 43 & 1.00 & 3.00 & 1.35 & 0.53 \\
PM_DIFF & 26 & 1.00 & 5.00 & 3.01 & 1.24 \\
PM_REC_A & 25 & 2.00 & 4.00 & 2.89 & 0.53 \\
PM_EDUC & 18 & 1.00 & 4.00 & 2.81 & 0.75
\end{tabular}

S.D. = Standard Deviation, HR DIFF = Difficulty Caused by a Shortage, HR NEED = Need for Additional Employees, HR-REC_A = Anticipated Ease of Recruitment, HR-REC-C = Current Ease of Recruitment, HR TURN = Current Annual Turnover, PM DIFF = Difficulty Caused By a Shortage, PM-REC $A=$ Anticipated Ability to Recruit, PM EDUC = Typical Degree Level, $\star * \bar{p}<\overline{0} .01 ; * p<0.05$. Statistics based on data from 4 WNAS surveys and 7 SCHC surveys. 


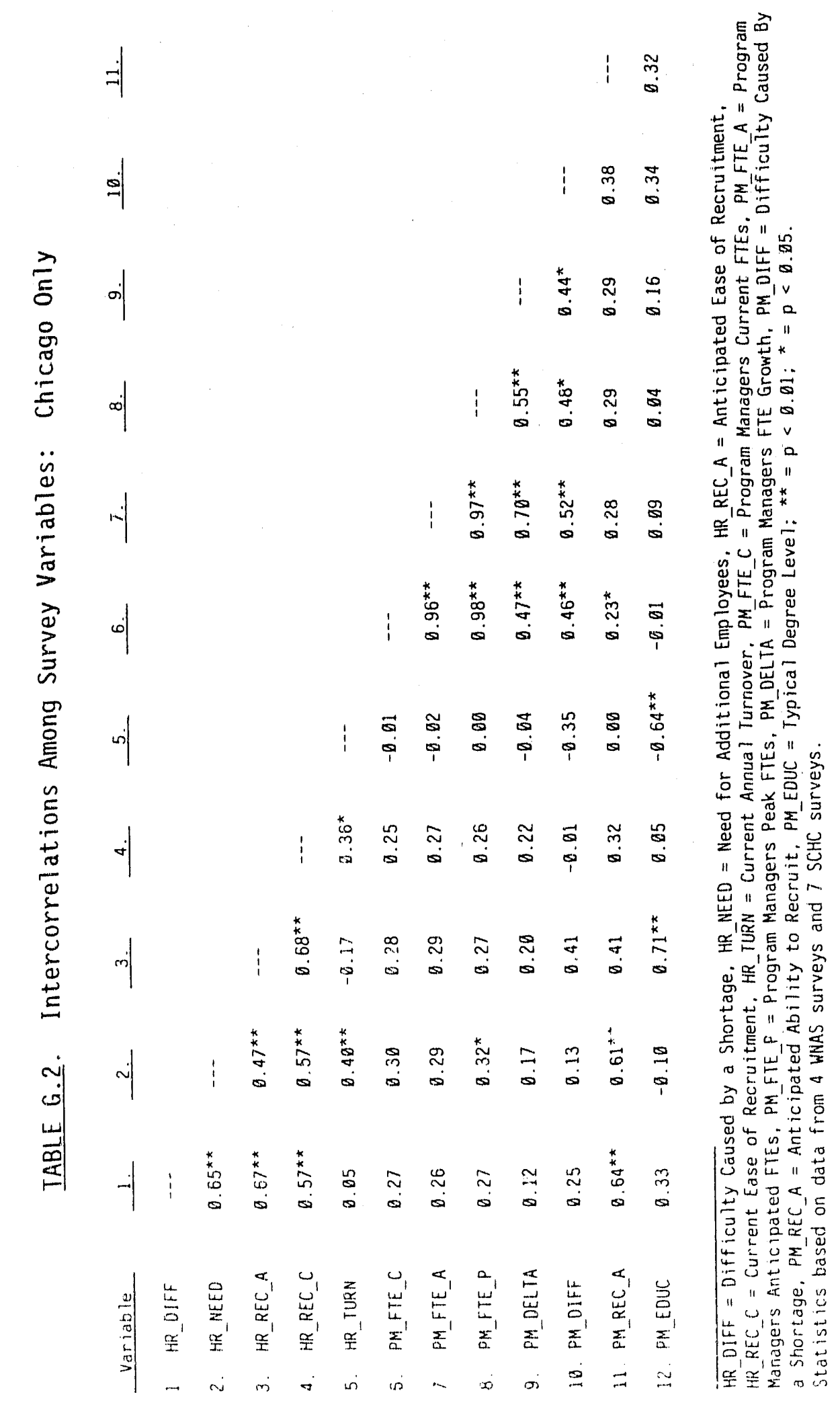

G.2 


\section{TABLE G.3. Job Titles Sorted By Change in FTEs (PM_De1ta)}

\begin{tabular}{|c|c|c|c|c|c|}
\hline Job Title & PM_FTE_C & PM_FTE_A & PM_FTE_P & PH_DELTA & Degree \\
\hline H_physics Tech & 7 & 16 & 16 & 9 & Mix of AS and BS \\
\hline Material Handler & 30 & 36 & 41 & 6 & HS or less \\
\hline Other Technician & 6 & 12 & 12 & 6 & HS or less \\
\hline NucWaste Process Oper & 2. & 5 & 5 & 3 & Mostly Associate \\
\hline Computer Oper & 1 & 3 & 4 & 2 & Most ly Bache lor \\
\hline Mechanical Eng ineer & 2 & 4 & 4 & 2 & Most ly Bachelor \\
\hline Nuc lear Decon Eng ineer & 2 & 4 & 4 & 2 & Most ly Bachelor \\
\hline Chemical Engineer & $\theta$ & 1 & 1 & $i$ & Mostly Bachelor \\
\hline Drafter & 0 & 1 & 1 & 1 & Most ly Associate \\
\hline Electri_tronic Tech & $\theta$ & $i$ & 1 & 1 & Most ly Associate \\
\hline Environ Sciences Techi & $\theta$ & 1 & $\theta$ & 1 & HS or less \\
\hline Estimator & $\theta$ & 1 & 1 & 1 & Mix of $A S$ and $B S$ \\
\hline Ind Hygien ist & 1 & 2 & 3 & 1 & HS or less \\
\hline Mech Eng in Tech & $\theta$ & 1 & 1 & 1 & Mostly Associate \\
\hline Project Manager & 6 & 7 & 7 & 1 & Mix of $A S$ and $B S$ \\
\hline Technical Writer & 1 & 2 & 2 & 1 & Mix of $A S$ and $B S$ \\
\hline Trainer & 1 & 2 & 2 & 1 & Mix of $A S$ and $B S$ \\
\hline WasteMan Engineer & 7 & 8 & 12 & 1 & Mostly Bachelor \\
\hline Biochemist & $\theta$ & $\emptyset$ & $\theta$ & $\theta$ & Mostly Associate \\
\hline Blologist & $\theta$ & $\theta$ & $\theta$ & $\emptyset$ & Mostly Associate \\
\hline Chem Tech & 0 & $\theta$ & $\theta$ & $\emptyset$ & HS or less \\
\hline Chemical Eng Tech & $\theta$ & $\theta$ & $\theta$ & $\theta$ & HS or less \\
\hline Chemist & $\theta$ & $\theta$ & 9 & $\theta$ & Most ly Associate \\
\hline Civil Eng Tech & $\theta$ & $\theta$ & $\theta$ & $\theta$ & HS or less \\
\hline Civil Engineer & $\theta$ & $\theta$ & $\theta$ & $\emptyset$ & Most ly Associate \\
\hline Computer Eng ineer & $\theta$ & $\theta$ & $\theta$ & 0 & Most ly Associate \\
\hline Oriller & $\theta$ & $\theta$ & $\theta$ & $\emptyset$ & HS or less \\
\hline Ecologist & $\theta$ & $\theta$ & $\theta$ & $\emptyset$ & Most ly Associate \\
\hline Electric_tronic Engineer & 0 & $\theta$ & $\theta$ & $\theta$ & Most ly Associate \\
\hline Environ Ëngineer & 11 & 11 & 23 & $\emptyset$ & Mostly Bachelor \\
\hline Geologist & $\theta$ & $\theta$ & $\emptyset$ & $\emptyset$ & Most ly Associate \\
\hline HazWasteMan Spec & 3 & 3 & 4 & $\theta$ & HS or less \\
\hline Health Physicist & 1 & 1 & 1 & $\theta$ & Mix of BS and Advanced \\
\hline Hydrol_Hydrogeo log ist & $\theta$ & $\theta$ & $\theta$ & $\theta$ & Mostiy Associate \\
\hline Ind Safety Health Tech & 1 & 1 & 1 & 9 & HS or less \\
\hline Industrial Eng ineer & $\theta$ & $\theta$ & $\theta$ & $\emptyset$ & Most ly Associate \\
\hline Irrigation Engineer & 8 & $\theta$ & 0 & $\theta$ & HS or less \\
\hline Materials Engineer & $\theta$ & $\theta$ & $\theta$ & $\theta$ & Most ly Associate \\
\hline Materials Scientist & $\theta$ & $\theta$ & 0 & $\theta$ & Most ly Associate \\
\hline Mathemat ician & $g$ & $\theta$ & $\theta$ & $\emptyset$ & Most ly Associate \\
\hline Nuc lear Eng ineer & $\theta$ & 0 & $\theta$ & $\theta$ & Mostiy \\
\hline Opers Researcher & $\emptyset$ & $\theta$ & $\theta$ & $\theta$ & Most ly Associate \\
\hline Other Engineer & $\theta$ & 0 & $\theta$ & $\theta$ & Mostly Associate \\
\hline Other scient ist & $\theta$ & $\theta$ & $\theta$ & $\theta$ & Most ly Associate \\
\hline Petrol Mining Engineer & $\theta$ & $\theta$ & $\theta$ & 0 & Most ly Associate \\
\hline Physicist & $\emptyset$ & $\theta$ & $\theta$ & $\theta$ & Most ly Associate \\
\hline Rad Protect Spec & 1 & 1 & 1 & $\emptyset$ & HS or less \\
\hline Remediation Specialist & $\theta$ & $\theta$ & $\theta$ & $\theta$ & HS or less \\
\hline Risk Assess Manager & $\theta$ & $\theta$ & $\theta$ & $\theta$ & HS or less \\
\hline Safety Engineer & $\theta$ & $\theta$ & 0 & $\theta$ & Most iy Associate \\
\hline Se ismologist & $\theta$ & $\theta$ & 0 & $\theta$ & Most ly Associate \\
\hline Statistician & $\theta$ & $\theta$ & 0 & $\theta$ & Most ly Associate \\
\hline Structural Engineer & 0 & $\theta$ & $\theta$ & $\theta$ & Most ly Associate \\
\hline Survey_Map Tech & $\theta$ & $\theta$ & 0 & $\theta$ & HS or less \\
\hline Adinin_Clerica? & 7 & 5 & 3 & -2 & HS or less \\
\hline Other Administrator & 2 & 8 & 2 & -2 & HS or less \\
\hline Environ Scientist & 7 & 4 & 11 & -3 & Most ly Bachelor \\
\hline
\end{tabular}

Statistics based on data from 4 WNAS surveys and 7 SCHC surveys. 
IABLE G.4. Job Titles Sorted by Project Manager's Ratings of Anticipated Ability to Recruit (PM_Rec_A)

\section{Job Title}

H_physics Tech

HazWasteMan Spec

Environ Engineer

WasteMan Engineer

Material Handler

Technical Writer

Ind Hyg ien ist

Project Manager

Ind Safety_Health Tech

Rad Protect Spec

Mechanical Eng ineer

Nuclear Decon Engineer

Health Physicist.

Environ Scient ist

Electri_tronic Tech

Mech Eng in Tech

Chemical Eng Tech

Civil Eng Tech

Trainer

NucWaste Process Oper

Computer Oper

Estimator

Admin_Clerical

Drafter

Chemical Engineer

Survey Map Tech

Environ Sciences Tech

Biochemist

Biologist

Chem Tech

Chemist

Civil Engineer

Computer Engineer

Driller

Ecologist

Electric_tronic Engineer

Geolog ist

Hydrol_Hydrogeologist

Industrial Eng ineer

Irrigation Engineer

Materials Engineer

Materials Scientist

Mathematician

Nuc lear Engineer

Opers Researcher

Petrol_Mining Engineer

Physicist

Remediation Specialist

$R$ isk Assess Manager

Safety Eng ineer

Seismologist.

Stat istician

Structural Engineer

\section{PM_REC_A}

PM_DEL.TA

4.00
4.00
3.50
3.33
3.00
3.00
3.00
3.00
3.00
3.00
3.00
3.00
3.00
3.00
3.00
3.00
3.00
3.00
2.50
2.50
2.50
2.00
2.00
2.00
2.00

Statistics based on data from a WNAS surveys and 7 SCHC surveys.

\section{Degree}

Mix of AS and BS HS or less

Most ly Bache lor Most ly Bache lor

HS or less

Mix of AS and BS

HS or less

Mix of AS and BS

HS or iess

HS or less

Most ly Bachelor

Mostly Bachelor

Mix of BS and Advanced

Most ly Bachelor

Mostly Associate

Mostly Associate

HS or less

HS or less

Mix of AS and BS Mostly Associate

Mostly Bachelor

Mix of AS and BS

HS or less

Mostly Associate

Mostly Bachelor

HS or less

HS or less

Most iy Associate

Mostly Associate

HS or less

Mostly Associate

Mostly Associate

Most.ly Associate

HS or less

Mostly Associate

Mostly Associate

Mostly Associate

Mostly Associate

Most ly Associate

HS or less

Most ly Associate

Most ly Associate

Most ly Associate

Mostly Associate

Most ly Associate

Mostly Associate

Most ly Associate

HS or less

HS or less Most ly Associate

Most ly Associate

Mostly Associate

Most ly Associate 


\section{TABLE G.5. Job Titles Sorted By Project Manager's Ratings of Difficulty Caused by Shortage (PM_Diff)}

\begin{tabular}{|c|c|c|}
\hline Job Tit: le & PM_DIFF & PM_DEL \\
\hline H physics Tech & 5.00 & 9 \\
\hline Material Handler & 5.00 & 6 \\
\hline Technical Writer & 5.00 & 1 \\
\hline Trainer & 4.50 & 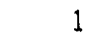 \\
\hline Ind Hygienist & 4.00 & 1 \\
\hline Project Manager & 4.00 & \\
\hline Ind Safety_Health Tech & 4.00 & $\theta$ \\
\hline Rad Protect Spec & 4.00 & $a$ \\
\hline Environ Engineer & $3: 50$ & $\emptyset$ \\
\hline WasteMan Engineer & 3.33 & \\
\hline NucWaste Process Oper & 3.00 & \\
\hline Mechanical Engineer & 3.00 & \\
\hline Nuclear Decon Engineer & 3.00 & \\
\hline Estimator & 3.60 & \\
\hline HazWasteMan Spec & 3.00 & \\
\hline Hea 1th Physicist & 3.00 & $\emptyset$ \\
\hline Environ Scientist & 3.00 & -3 \\
\hline Computer Oper & 2.50 & \\
\hline Admin Clerical & 2.33 & -2 \\
\hline Drafter & 2.00 & \\
\hline Electri tronic Tech & 2.00 & \\
\hline Mech Eng in Tech & 2.00 & \\
\hline Chemical Engineer & 1.00 & \\
\hline Chemical Eng Tech & 1.00 & \\
\hline Civil Eng Tech & 1.00 & $\theta$ \\
\hline Survey Map Tech & 1.00 & $y$ \\
\hline Environ Sciences Tech & . & \\
\hline Biochemist & . & \\
\hline Biologist & . & $\emptyset$ \\
\hline Chem Tech & . & $\theta$ \\
\hline Chemist & . & $\theta$ \\
\hline Civil Engineer & . & \\
\hline Computer Eng ineer & . & $\emptyset$ \\
\hline Driller & . & $\emptyset$ \\
\hline Ecologist & . & $\ell$ \\
\hline Electric_tronic Engineer & . & \\
\hline Geologis $\bar{t}$ & . & \\
\hline Hydrol_Hydrogeologist & . & \\
\hline Industrial Eng ineer & . & \\
\hline Irrigation Engineer & . & $k$ \\
\hline Materials Engineer & . & \\
\hline Materials Scientist & . & \\
\hline Mathematician & . & \\
\hline Nuc lear Eng ineer & . & \\
\hline Opers Researcher & . & \\
\hline Petrol_Mining Engineer & . & \\
\hline Physicist & . & \\
\hline Remediation Specialist & . & \\
\hline Risk Assess Manager & . & \\
\hline Safety Engineer & . & \\
\hline Se ismolog ist & . & \\
\hline Statistician & . & \\
\hline Structural Engineer & & \\
\hline
\end{tabular}

PM_DELTA Degree

Mix of AS and BS HS or less Mix of $A S$ and $B S$ Mix of AS and BS HS or less

Mix of AS and BS

HS or less

HS or less

Mostly Bachelor Mostly Bachelor Most. ly Associate Mostly Bache lor Mostly Bache lor MiX of AS and BS HS or less

Mix of BS and Advanced Most ly Bachelor Most.ly Bache lor HS or less

Mostly Associate Mostly Associate Mostly Associate Most ly Bachelor HS or less

HS or less HS or less HS or less Mostly Associate Most ly Associate HS or less Most ly Associate Mestly Associate Most ly Associate HS or less

Most Ty Associate Most ly Associate Most ly Associate Mostly Associate Most. ly Associate HS or less

Most ly Associate Mostly Associate Mostly Associate Mostly Associate Mostly Associate Mostly Associate Most ly Associate HS or less HS or less Most ly Associate Mostly Associate Mostly Associate Most ly Associate

Statistics based on data from 4 WNAS surveys and 7 SCHC surveys. 
TABLE G.6. Job Titles Sorted By Human Resource Personnel's Ratings of Difficulty Caused By Shortage (HR_Diff)

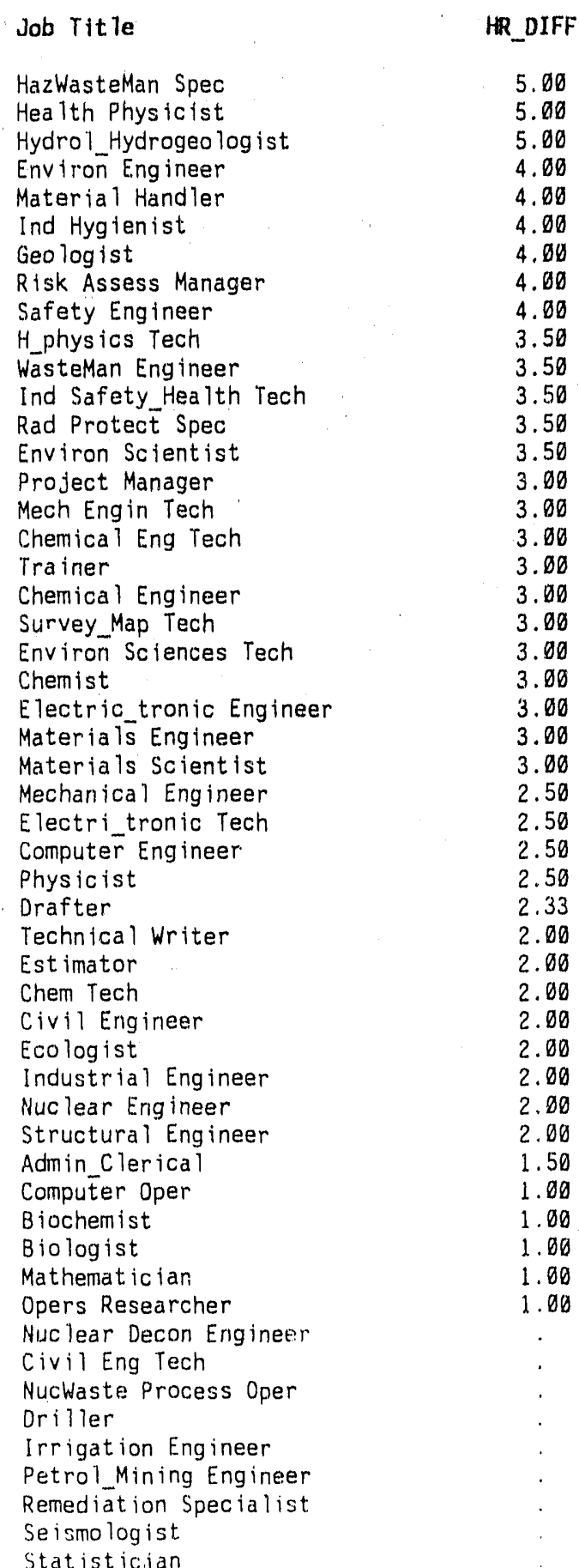

\section{PM_DELTA Degree}

HS or less

Mix of BS and Advanced

Most ly Associate

Most ly Bache lor

HS or less

HS or less

Most ly Associate

HS or less

Most ly Associate

Mix of AS and BS

Most ly Bachelor

HS or less

HS or less

Mostly Bachelor

Mix of AS and BS

Most ly Associate HS or less

Mix of AS and BS

Most ly Bachelor

HS or less

HS or less

Most ly Associate

Most ly Associate

Most ly Associate

Most ly Associate

Most ly Bache lor

Mostly Associate

Most ly Associate

Most ly Associate

Most ly Associate

Mix of AS and BS

Mix of AS and BS

HS or less

Most ly Associate

Most ly Associate

Most. ly Associate

Most ly Assuciate

Mostly Associate

HS or less

Most ly Bache lor

Most ly Associate

Most ly Associate

Most ly Assuciate

Most ly Assoc iate

Most ly Bachelor

HS or less

Most ly Associate

HS or less

HS or less

Mostly Associate

HS or less

Mostly Associate

Most ly Associate

Statistics based on data from 4 WNAS surveys and $7 \mathrm{SCHC}$ surveys 


\section{TABLE G.7. Job Titles Sorted By Human Resource Personne7's Ratings of Need for Additional Employees (HR_Need)}

Job Tit le

HazWasteMan Spec

Ind Hygien ist

H_physios Tech

WasteMan Engineer

Rad Protect Spec

Environ Scientist

Hea ith Physicist

Environ Engineer

Material Handler

Risk Assess Manager

Safety Engineer

Ind Safety_Heaith Tech

Chemical Engineer

Survey_Map Tech

Envirun Sciences Tech

Chemist

Mechanical Engineer

Electritronic Tech

Physicist

Nuc lear Engineer

Drafter

Project Manager

Mech Eng in Tech

Electric tronic Engineer

Civil Engineer

Admin Clerical

Hydrol_Hydrogeo logist

Geo $\log$ ist

Chemical Eng Tech

Trainer

Materials Scientist

Computer Eng ineer

Technical Writer

Chem Tech

Ecologist

Industrial Engineer

Computer Oper

Materials Engineer

Estimator

Structural Engineer

Biochemist

Biologist

Mathemat ician

Opers Researcher

Nuc lear Decon Eng ineer

Civil Eng Tech

NucWaste Process Oper

Oriller

Irrigation Engineer

Petrol_Mining Engineer

Remediation Specialist

Se ismo log ist

Statistician
HR_NEED

4.00

3.50

3.50

3.50

3.50

3.50

3.00

3.00

3.00

3.00

3.00

3.00

3.00

3.00

3.00

3.90

3.00

3.00

3.00

3.90

2.67

2.50

2.50

2.50

2.50

2.50

2.00

2.00

2.00

2.00

2.00

2.00

2.00

2.00

2.00

2.00

1.50

1.00

1.00

1.00

1.00

1.00

1.00

1.00

Statistics based on data from 4 WNAS surveys and 7 SCHC surveys.

\author{
PM_DELTA
}

$\theta$

1

9

0

$-3$

0

$\theta$

6

$\emptyset$

b

1

1

2

1

0

1

1

0

0
-2

$-2$

0

0

1

1

1

$\theta$

2

2

1

0

$\theta$

0

2

9
3

0

0

$\theta$

$\theta$

Degree

HS or less

HS or less

Mix of AS and BS

Most ly Bachelor

HS or less

Mostly Bachelor

Mix of BS and Advanced

Most ly Bachelor

HS or less

HS or less

Most ly Associate

HS or less

Mostly Bachelor

HS or less

HS or less

Mostly Associate

Mostly Bachelor

Mostly Associate

Mostly Associate

Mostly Associate

Mostly Associate

Mix of AS and BS

Mostly Associate

Mostly Assoclate

Most ly Associate

HS or less

Mostly Associate

Mostly Associate

HS or less

Mix of AS and BS

Most ly Associate

Mostly Associate Mix of AS and BS HS or less

Mostly Associate Mostly Associate Mostly Bachelor Most ly Associate Mix of AS and BS Mostly Assoclate Mostly Associate Mostly Associate Mostly Associate Mostly Associate Most iy Bachelor HS or less Mnst ly Associate HS or less HS or less Most ly Associate HS or less Mostly Associate Mostly Assuciate 
TABLE G.8. Job Titles Sorted By Human Resource Personnel's Ratings of Current Ability to Recruit (HR_Rec_C)

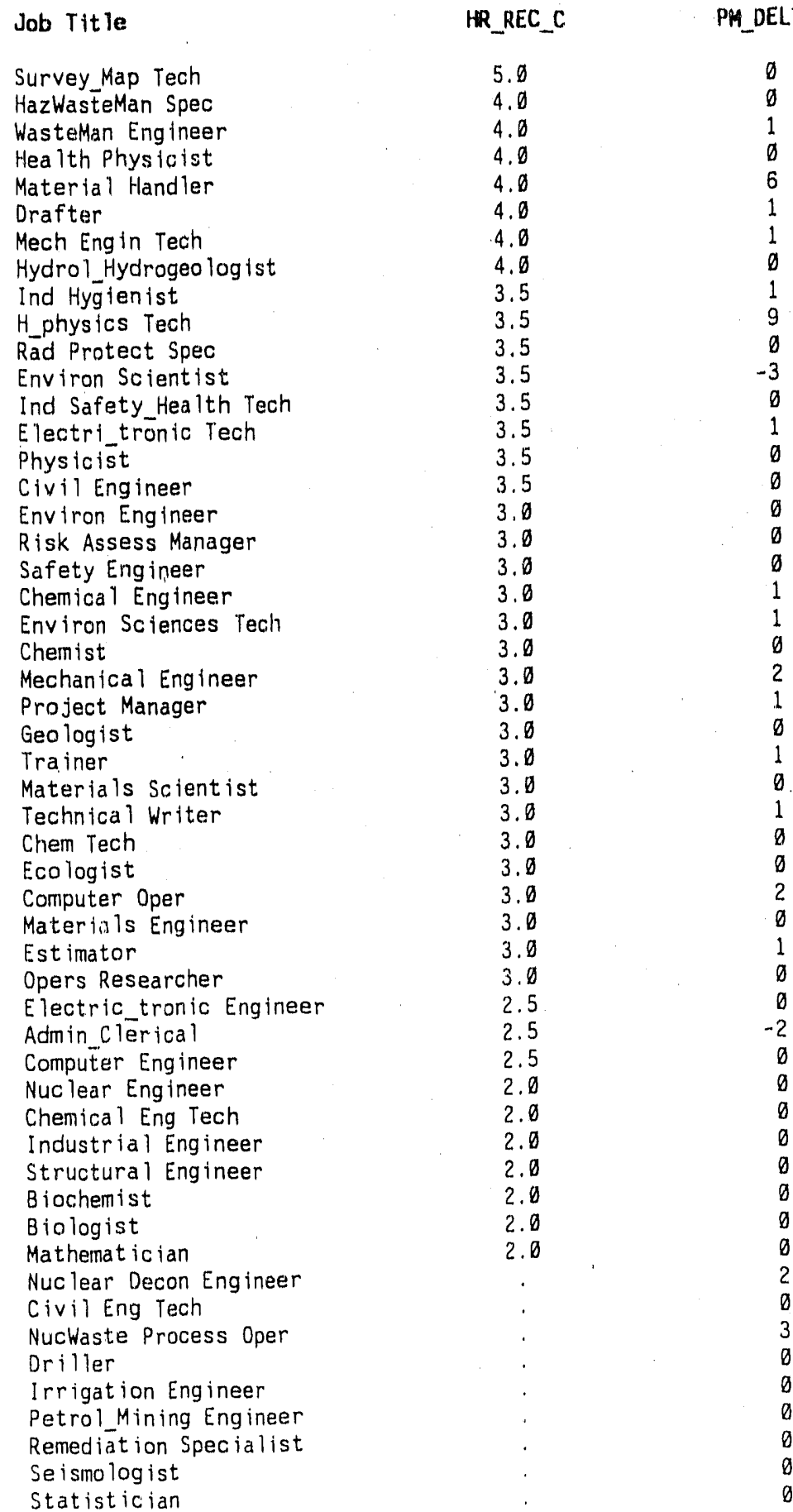

\section{Degree}

HS or less

HS or less

Mostly Bachelor

Mix of BS and Advanced

HS or less

Mostly Assoclate

Mostly Associate

Most ly Assoctate

HS or less

Mix of AS and BS

HS or less

Most 1y Bachelor

HS or less

Most ly Associate

Mostly Associate

Mostly Associate

Mostly Bachelor

HS or less

Mostly Assuciate

Mostly Bachelor

HS or less

Mostly Associate

Most ly Bache lor

Mix of AS and BS

Mostly Associate

Mix of $A S$ and $B S$

Mostly Associate

Mix of AS and BS

HS or less

Mostly Assoctate Most ly Bache lor

Mostly Associate Mix of AS and BS Most ly Associate Mostly Associate HS or less

Mostly Associate Mostly Associate HS or less Mostly Associate Most ly Associate Most ly Associate Most ly Associate Mostly Associate Most ly Bachelor HS or less

Most ly Associate HS or less HS or less Most ly Associate HS or less

Most ly Associate Mostly Associate

Statistics based on data from 4 WNAS surveys and 7 SCHC surveys. 


\section{TABLE G.9. Job Titles Sorted By Human Resource Personnel's Ratings of Anticipated AbiTity to Recruit (HR_Rec_A)}

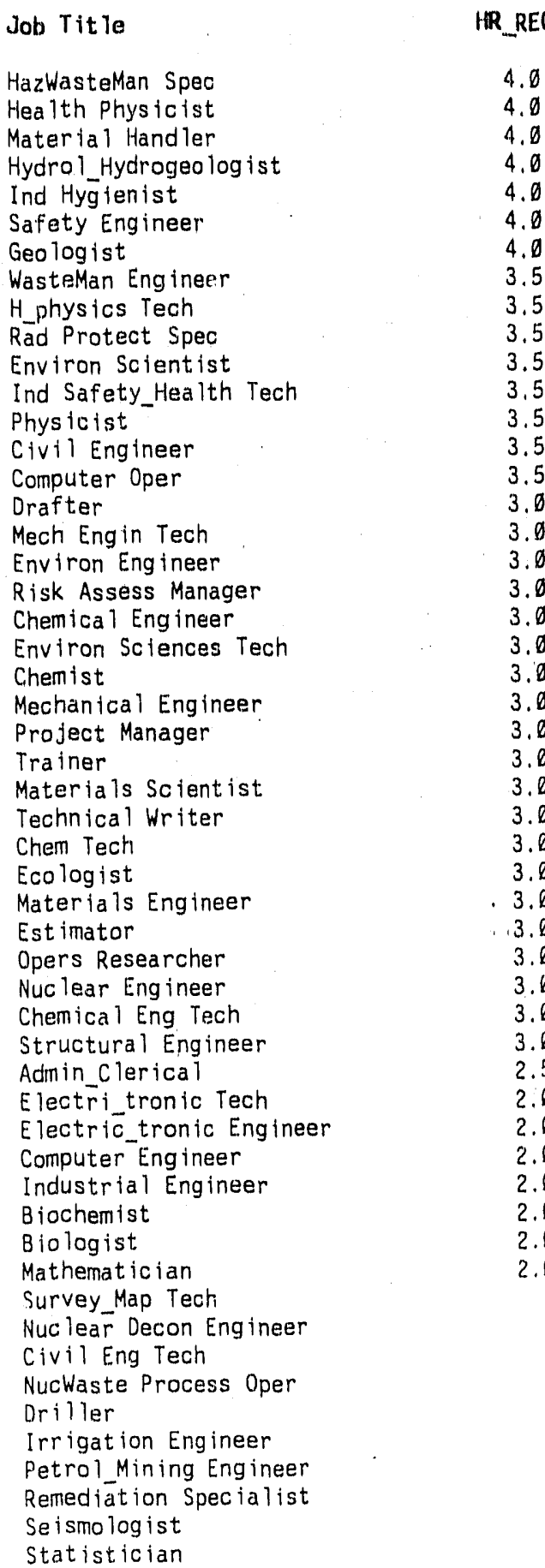

PM_DELTA Degree

$4.0 \quad 0 \quad$ HS or less

$4.0 \quad 0 \quad$ Mix of BS and Advanced

$4.9 \quad 6 \quad$ HS or less

$4.0 \quad 0 \quad$ Mostly Associate

1 HS or less

$4.0 \quad 0 \quad$ Most ly Associate

4.0 0 Mostly Assoc late

$.5 \quad 1 \quad$ Mostly Bachelor

$5 \quad 9 \quad$ Mix of AS and BS

HS or less

Most ly Bachelor

HS or less

Most ly Assoclate

Most ly Associate

Mostly Bachelor

Most ly Associate

Mostly Associate

Most ly Bachelor

HS or less

Most ly Bachelor

HS or less

Most ly Assoctate

Mostly Bachelor

MlX of AS and BS

Mix of AS and BS

Most ly Associate

Mix of AS and BS

HS or less

Most ly Associate Most ly Associate

Mix of AS and BS

Mostly Associate

Most ly Associate

HS or less

Most ly Associate HS or less

Mostly Associate Mostly Associate Most ly Associate Mostly Associate Most ly Associate Most ly Associate Most ly Associate HS or less Most ly Bachelor HS or less Most ly Associate HS or less HS or less Most ly Associate HS or less Most ly Associate Most ly Associate

Statistics based on data from 4 WNAS surveys and 7 SCHC surveys. 
TABLE G.10. Job Titles Sorted By Human Resource Personnel's Ratings of Annual Turnover (HR_Turn)

Job Tit le

Environ Sciences Tech

Survey Map Tech

WasteMan Engineer

Environ Scient ist

Mech Engin Tech

Admin Clerical

Electri_tronic Tech

Electric tronic Engineer

Computer Engineer

Drafter

Ind Hygien ist.

H.physics Tech

Rad Protect Spec

Ind Safety_..Health Yech

Physic ist

Mechanical Engineer

Project Manager

HazWasteman Spec

Health Physicist

Material Handler

Hydrol_Hydrogeo log ist

Safety Eng ineer

Geologist.

Civil Enginer $r$

Computer Oper

Environ Engineer

Risk Assess Manager

Chemical Engineer

Chemist

Trainer

Materials Scientist

Technical hriter

Chem Tech

Ecologist

Materials Engineer

Est imator

Opers Researcher

Chemical Eng Tech

Structural Eng ineer

Industrial Engineer

Biochemist

Biologist.

Mathemat ic ian

Nuc lear Eng ineer

Nuclear Decon Engineer

Civil Eng Tech

NucWaste Process Oper

Driller

irrigation Engineer

Petrol Mining Engineer

Remediation Specialist

Se ismologist

Statistician

\section{HR_TURK}

3.00

3.00

2.00

2.80

2.80

2.00

2.00

2.80

2.80

1.67

1.50

1.50

1.50

1.50

1.50

1.50

1.50

1.00

1.00

1.00

1.00

1.00

1.00

1.00

1.00

1.00

1.00

1.00

1.00

1.80

1.00

1.00

1.00

1.00

1.09

1.00

1.00

1.90

1.00

1.00

1.00

1.08

1.00
PM_DELTA

1

1

$-3$

1

$-2$

1

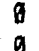

1

1

8

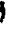

1

0

0

6

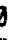

6

2

0

b

1

b

a

1

a

0

0

1

0

0

0

$$
0
$$

Statistics based an data from 4 WNAS surveys and 7 SCHC surveys.

\section{Degree}

HS or iess

HS or less

Mostly Bachelor

Most ly Bachelor

Most ly Associate

HS or less

Most ly Associate

Most ly Assoc iate

Mostly Associate

Most ly Associate

HS or less

Mix of AS and BS

HS or less

HS or less

Mostly Associate

Mostly Bache lor

Mix of $A S$ and $B S$

HS or less

Mix of $B S$ and Advanced

HS or less

Mostly Associate

Mostly Associate

Mostly Associate

Most ly Associate

Mostly Bachelor

Mostly Bachelor

HS or less

Most ly Bachelor

Most ly Associate

Hix of $A S$ and $B S$

Mostly Associate

Mix of $A S$ and $B S$

HS or less

Mostly Astiociate Mostly As::ociate Mix of $A S$ and $B S$ Most iy Associate HS or less

Mostly Associate Mostly Associate Mostly Associate Mostly Associate Mostly Associate Most ly Associate Most ly Bachelor HS or less Mostly Associate HS or less HS or less Most ly Associate HS or less

Mostly Associate Mostly Associate 
APPENDIX H

SIMPLE STATISTICS INTERCORRELATION AMONG VARIABLES AND JOB SORTS ON ALL VARIABLES FOR FERNALD ONLY 
TABLE H.1. Descriptive Statistics for Relative Ratings

\begin{tabular}{llcccc} 
Variable & N & Minimum & Maximum & Mean & $\underline{\text { S.D. }}$ \\
\hline HR_DIFF & 47 & 1.00 & 4.00 & 2.82 & 0.86 \\
HR_NEED & 47 & 1.00 & 5.00 & 2.31 & 0.91 \\
HR_REC_C & 47 & 1.00 & 5.00 & 2.37 & 0.79 \\
HR_REC_A & 47 & 1.00 & 5.00 & 2.27 & 0.78 \\
HR_TURN & 45 & 1.00 & 3.00 & 1.80 & 0.49 \\
PM_DIFF & 52 & 1.00 & 4.20 & 2.75 & 0.73 \\
PM_REC_A & 52 & 1.00 & 4.00 & 2.72 & 0.67 \\
PM_EDUC & 52 & 1.00 & 4.00 & 3.01 & 0.90
\end{tabular}

S.D. = Standard Deviation, HR DIFF $=$ Difficulty Caused by a Shortage, HR NEED = Need for Additional Employees, HR-REC A = Anticipated Ease of Recruitment, HR-REC-C = Current Ease of Recruitment, HR TURN = Current Annual Turnover, PM DIFF = Difficulty Caused By a Shortage, PM_REC A = Anticipated Ability to Recruit, PMEEUC $=$ Typical Degree Level, $* * \bar{p}<\overline{0} .01 ; * p<0.05$. Statistics based on data from 13 WNAS surveys and I SCHC survey. 


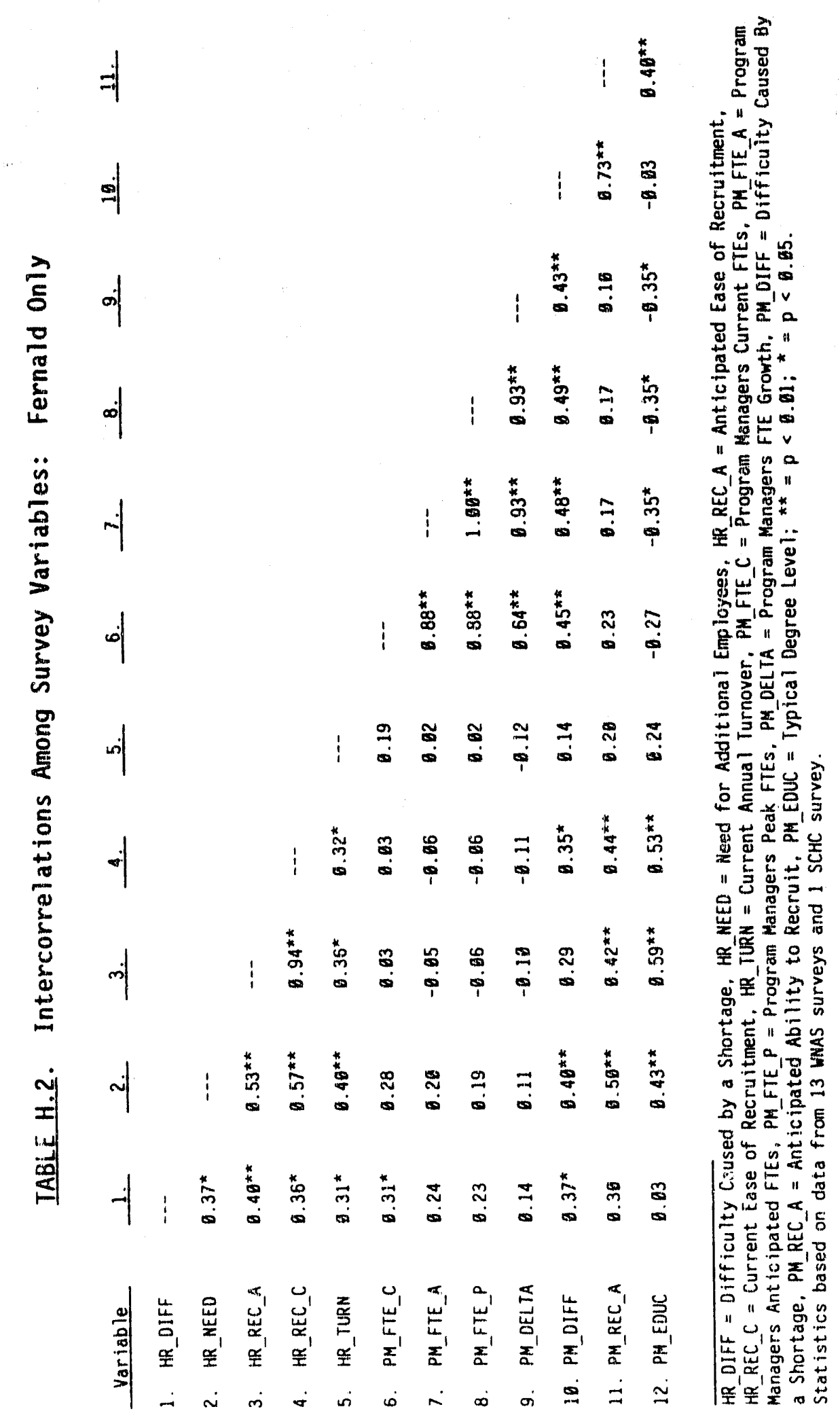

H. ? 


\section{TABLE H.3. Job Titles Sorted By Change in FTEs (PM_Delta)}

\begin{tabular}{|c|c|c|c|c|}
\hline Job Title & PH_FTE_C & PH_FTE_A & PH_FTE_P & PN_DELTA \\
\hline Material Handler & 25 & 133 & 133 & 188 \\
\hline H_physics Tech & 81 & 160 & 157 & 79 \\
\hline Mechanical Engineer & 26 & 185 & 185 & 79 \\
\hline Nuchlaste Process Oper & 25 & 95 & 95 & 78 \\
\hline Civil Engineer & 28 & 91 & 91 & 63 \\
\hline Environ Engineer & 48 & 104 & 184 & 56 \\
\hline Admin_Clerical & 89 & 138 & 138 & 49 \\
\hline Project Manager & 45 & 93 & 93 & 48 \\
\hline Environ Sciences Tech & 36 & 33 & 82 & 47 \\
\hline Other Technician & 18 & 56 & 56 & 38 \\
\hline Trainer & 19 & 53 & 53 & 34 \\
\hline Drafter & 11 & 44 & 45 & 33 \\
\hline Electric tronic Engineer & 11 & 41 & 37 & 30 \\
\hline Safety Eng ineer & 7 & 37 & 37 & 30 \\
\hline HazWasteMan Spec & 12 & 41 & 44 & 29 \\
\hline Estimator & 15 & 43 & 43 & 28 \\
\hline Chem Tech & 32 & 55 & 57 & 23 \\
\hline Chenical Eng ineer & 25 & 48 & 44 & 23 \\
\hline Chemist & 61 & 82 & 82 & 21 \\
\hline Ind Safety_Health Tech & 24 & 45 & 46 & 21 \\
\hline Other Engiñeer & 23 & 44 & 44 & 21 \\
\hline Renediation Specialist. & 32 & 53 & 53 & 21 \\
\hline Computer Oper & 13 & 31 & 31 & 18 \\
\hline Technical Writer & 12 & 29 & 29 & 17 \\
\hline Hea Ith Physicist & 20 & 35 & 35 & 15 \\
\hline Hydrol_Hydrogeolog ist & 10 & 25 & 25 & 15 \\
\hline Nuclear Decon Engineer & 9 & 24 & 2.4 & 15 \\
\hline Environ Scientist & 19 & 31 & 31 & 12 \\
\hline Rad Protect Spec & 11 & 23 & 24 & 12 \\
\hline Risk Assess Manager & 10 & 22 & 22 & 12 \\
\hline Survey_Map Tech & 1 & 13 & 14 & 12 \\
\hline Computer Engineer & 10 & 20 & 22 & 10 \\
\hline Nuc lear Engineer & 11 & 21 & 21 & 10 \\
\hline Structural Eng ineer & 6 & 16 & 16 & 10 \\
\hline Other Administrator & 17 & 26 & 26 & 9 \\
\hline Chemical Eng Tech & $B$ & 8 & 8 & 8 \\
\hline Driller & 14 & 22 & 20 & 8 \\
\hline Ind Hygien ist & 14 & 22 & 24 & 8 \\
\hline WasteMan Engineer & 4 & 11 & 11 & 7 \\
\hline Mech Engin Tech & $\theta$ & 6 & 6 & 6 \\
\hline Electri tronic Tech & 7 & 12 & 13 & 5 \\
\hline MateriaTs Engineer & 8 & 4 & 4 & 4 \\
\hline Biologist & 2 & 4 & 4 & 2 \\
\hline Civil Eng Tech & 2 & 4 & 4 & 2 \\
\hline Ecologist & 5 & 7 & 7 & 2 \\
\hline Materials Scientist & 0 & 2 & 2 & 2 \\
\hline Petrol_Mining Engineer & 2 & 4 & 4 & 2 \\
\hline Statistician & 1 & 3 & 3 & 2 \\
\hline Blochemist & 1 & 2 & 2 & 1 \\
\hline Mathematician & $\theta$ & 1 & 1 & 1 \\
\hline Opers Researcher & 1 & 2 & 2 & 1 \\
\hline Geologist & $\theta$ & 0 & $\theta$ & 0 \\
\hline Irrigation Engineer & $\theta$ & $\theta$ & $\theta$ & $\theta$ \\
\hline Physicist & $\theta$ & 8 & $\theta$ & $\theta$ \\
\hline Seismo logist & $\theta$ & $\theta$ & $\theta$ & $\theta$ \\
\hline Other Scientist & 12 & 6 & 19 & -6 \\
\hline Industrial Engineer & 13 & 4 & 6 & -9 \\
\hline
\end{tabular}

Degree

HS or less

Most ly Associate

Mix of $8 S$ and Advanced HS or less

Mix of $B S$ and Advanced Mix of Bis and Advanced

HS or less

Most ly Bache lor

Most ly Associate HS or less

Mix of AS and BS

Mostly Associate

Most ly Bachelor

Mix of BS and Advanced

Mix of AS and BS

Mix of AS and BS

Mostly Associate

Mix of BS and Advanced Mix of BS and Advanced

Most ly Associate

Most iy Associate

Mostly Associate

Mostly Associate

Mostly Associate

$M 1 x$ of $B S$ and Advancen

Mix of BS and Advanced

Most ly Bachelor

Mix of BS and Actvanced

$M+x$ of $A S$ and BS

Mostly Bachelor

Mostly Associate

Mix of AS and BS

Mix of BS and Advanced Mix of 85 and Advanced HS or less

Most ly Associate

HS or less

$M i x$ of $A S$ and $B S$

Mix of BS and Advanced

Mostly Associate

Most ly Associate

Mostly Bachelor

Mix of BS and Advanced

Mostly Associate

Most ly Bachelor

Mix of BS and Advanced

Mostly Bachelor

Most ly Bachelor

Mix of BS and Advanced

$M i x$ of $B S$ and Advanced

Mix of $B S$ and Advanced

Mostly Associate

Mix of $A S$ and $B S$

$M i x$ of $B S$ and Advanced

Mix of BS and Advanced

Mostly Associate

Mostly Bachelor

Statistics based on data from 13 WNAS surveys and i SCHC survey. 


\section{TABLE H.4. Titles Sorted by Project Manager's Ratings of Anticipated Ability to Recruit (PM_Rec_A)}

\section{Job Title}

WasteMan Eng ineer Nuclear Decort Engineer Risk Assess Manager

Environ Scientist

Environ Engineer

Health Physicist

Project Manager

Opers Researcher

$H$ physics Tech

Hydro l_Hydrogeo log ist

HazWasteMan Spec

Remediation Specialist

Nuc lear Engineer

Est imator

Ind Hygien ist

Computer Engineer

Civil Engineer

Chemical Eng ineer

Rad Protect Spec

Chemist

Structural Engineer

Environ Sciences Tech

Electric tronic Engineer

Mathematician

Ind Safety Health Tech

Industrial Engineer

Mechanical Engineer

Trainer

Mech Eng in Tech

Civil Eng Tech

Materials Scient ist

Biochemist

Chem Tech

Technical Writer

Nuclaste Process Oper

Computer Oper

Biologist

Survey_Map Tech

Drafter

Chemical Eng Tech

Ecologist

Safety Eng ineer

Material Handler

Adnin Clerical

PetrōlMining Engineer

Electri tronic Tech

Materiaīs Engineer

Statistician

Phys ic ist

Seismologist

Driller

Irrigation Engineer

Geologist

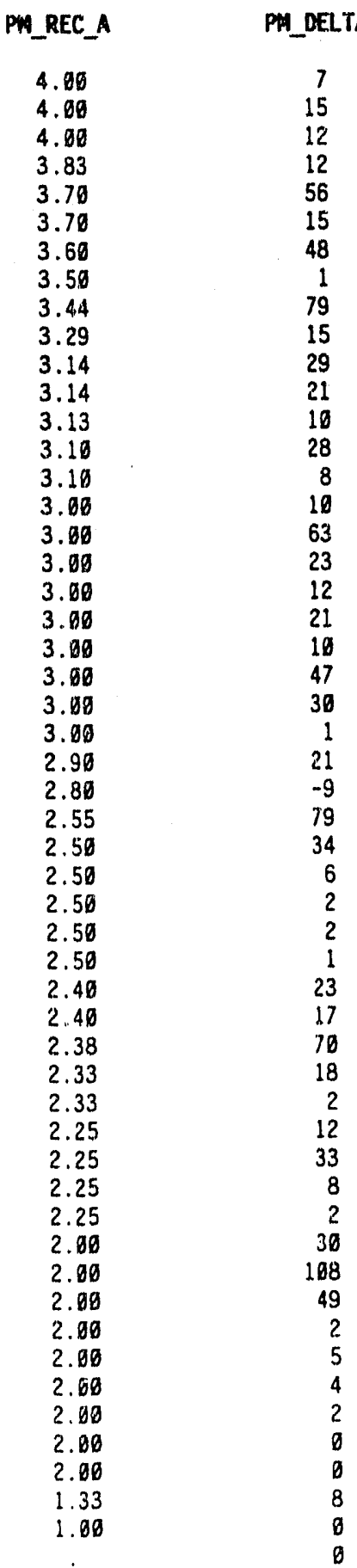

Stat istics based on data from 13 WNAS surveys and 1 SCHC survey.

\section{Degree}

Mix of BS and Advanced Most ly Bache lor

Mostly Bache lor

Mix of BS and Advanced

Mix of BS and Advanced Mix of $B S$ and Advanced Mostly Bache lor

Mix of BS and Advanced Mostly Associate

Mix of BS and Advanced Mix of AS and BS Mostly Associate $M i x$ of BS and Advanced Mix of $A S$ and $B S$ Mix of AS and BS Mix of AS and BS Mix of $B S$ and Advanced $M i x$ of $B S$ and Advanced Mix of $A S$ and $B S$

Mix of BS and Advanced Mix of BS and Advanced Mostly Associate Most ly Bache lor Mix of BS and Advanced Mostly Associate Mostly Bachelor Mix of $B S$ and Advanced Mix of AS and BS Mostly Associate Mostly Associate Mix of BS and Advanced Mix of BS and Advanced Mostly Associate Mostly Associate

HS or less

Most ly Associate

Mix of BS and Advanced Mostly Asscciate Mostly Associate Mostly Associate

Most ly Bache lor

Mix of BS and Advanced

HS or less

HS or less

Mostly Bachelor

Mostly Associate

Mostly Bachelor

Most ly Bachelor

Mix of $B S$ and Advanced

Mix of BS and Advanced

HS or less

Mix of AS and BS

Mostly Associate 


\section{IABLE H.5. Titles Sorted By Project Manager's Ratings of Difficulty Caused by Shortage (PM_Diff)}

Job rit le

Project Manager

$H$ phys ics Tech

WasteMan Engineer

Nuclear Decon Engineer

Risk Assess Manager

Computer Engineer

Environ Engineer

HazWasteMan Spec

Health Physicist

Civil Engineer

Chemical Eng ineer

Remediation Specialist

Nuclear Eng ineer

Rad Protect Spec

Environ Scientist

Chemist

NucWaste Process Oper

Safety Engineer

Chem Tech

Structura 1 Engirieer

Mechanical Engineer

Est imator

Ind Hygienist

Environ Sciences Tech

Trainer

Hydrol Hydrogeo log ist

Material Hand ler

Ind Safety_Health Tech

Survey Map Tech

Mech Engin Tech

Civil Eng Tech

Drafter

Admin Clerical

Electric_tronic Engineer

Computer Oper

Technical Writer

Chemical Eng Tech

Ecologist

Petrol Mining Engineer

Nathematician

Opers Researcher

Driller

Biologist

Electri tronic Tech

Industrial Engineer

Materials Engineer

Materials Scientist

Biochemist

Statistician

Irrigation Engineer

Physicist

Seismo logist

Geologist

\section{PN DIFF}

4.28

3.89

3.80

3.67

3.67

3.67

$3.5 \%$

3.43

3.49

3.36

3.30

3.25

3.25

3.22

3.17

3.11

3.00

3.90

3.00

3.80

2.91

2.90

2.90

2.88

2.88

2.86

2.80

2.80

2.75

2.75

2.75

2.63

2.62

2.50

2.50

2.50

2.50

2.58

2.56

2.58

2.50

2.33

2.33

2.25

2.20

2.00

2.00

1.50

1.00

1.60

1.00

1.06

\begin{tabular}{r} 
PH_DELTA \\
\hline 48 \\
79 \\
7 \\
15 \\
12 \\
18 \\
56 \\
29 \\
15 \\
63 \\
23 \\
21 \\
10 \\
12 \\
12 \\
21 \\
79 \\
30 \\
23 \\
19 \\
79 \\
28 \\
8 \\
47 \\
34 \\
15 \\
198 \\
21 \\
12 \\
6 \\
2 \\
33 \\
49 \\
30 \\
18 \\
17 \\
8 \\
2 \\
2 \\
1 \\
1 \\
8 \\
2 \\
5 \\
-9 \\
4 \\
2 \\
1 \\
2 \\
9 \\
9 \\
9
\end{tabular}

\section{Degree}

Mostiy Bache lor Mostly Associate Mix of BS and Advanced Most ly Bache lor Most iy Bache lor $M i x$ of $A S$ and $B S$ Mix of BS and Advanced Mix of AS and BS Mix of $B S$ and Advanced Mix of BS and Advanced Mix of BS and Advanced Most ly Assoc iate

Mix of BS and Advanced Mix of $A S$ and $B S$

Mix of $B S$ and Advanced Mix of BS and Advanced HS or less

Mix of BS and Advanced Most ly Associate Mix of $B S$ and Advanced Mix of BS and Advanced Mix of $A S$ and $B S$

Mix of AS and BS Most.ly Assoc late Mix of AS and BS Mix of BS and Advanced HS or less

Most ly Associate Mostly Associate Most ly Associate Most ly Associate Most ly Assoc iate HS or less Most ly Bache lor Most ly Associate Mostly Associate Mostly Associate Most ly Bachelor Most ly Bache lor Mix of BS and Advanced Mix of BS and Advanced HS or less

Mix of BS and Advanced Most ly Associate Most ly Bache lor Most ly Bache lor Mix of $B S$ and Advanced Mix of $B S$ and Advanced Most ly Bachelor Mix of AS and BS Mix of BS and Advanced Mix of $B S$ and Advanced Most ly Associate

Statistics based on data from 13 WNAS surveys and 1 SCHC survey. 


\section{TABLE H.6. Job Titles Sorted By Human Resource PersonneT's Ratings of Difficulty Caused By Shortage (HR_Diff)}

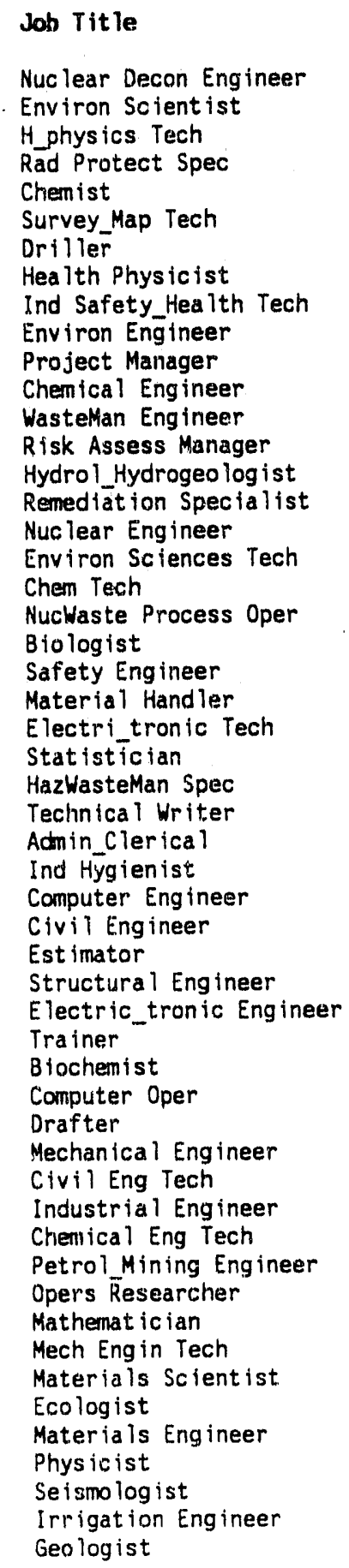

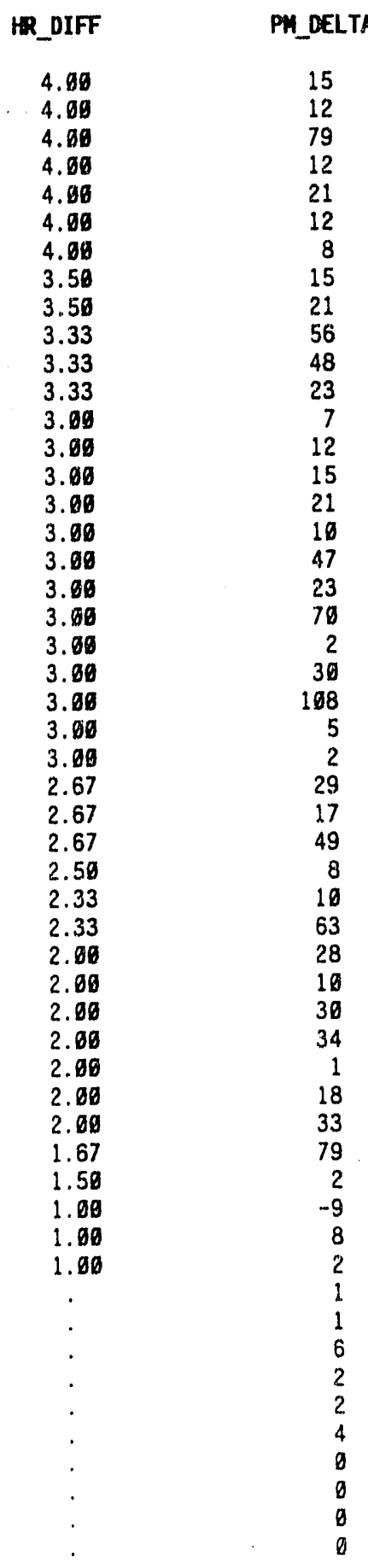

Statistics basect on data from 13 WNAS surveys and 1 SCHC survey.

\section{Degree}

Mostly Bachelor Mix of BS and Advanced Mostily Associate $M i x$ of $A S$ and BS Mix of BS and Advanced Mostly Associate HS or less Mix of BS and Advanced Mostly Associate Mix of BS and Advanced Mostly Bache lor Mix of BS and Advanced Mix of BS and Advanced Most ly Bache lor Mix of BS and Advanced Most ly Associate Mix of $B S$ and Advanced Mostly Associate Mostly Associate HS or less Mix of BS and Advancied Mix of BS and Advanceld HS or less

Most.ly Associate Mostly Bachelor Mix of AS and BS Most ly Associate HS or less

Mix of AS and BS $M i x$ of $A S$ and $B S$ Mix of $B S$ and Advanced Mix of AS and BS Mix of BS and Advanced Mostly Bachelor Mix of AS and BS Mix of BS and Advanced Most ly Associate Host ly Associate Mix of BS and Advanced Most ly Associate Mostly Bache lor Most ly Associate Most ly Bache lor Mix of BS and Advanced Mix of BS and Advanced Mostily Associate Mix of BS and Advanced Mostly Bachelor Mostly Bachelor Mix of BS and Advanced Mix of $B S$ and Advanced Mix of $A S$ and $B S$ Most ly Associate 
TABLE H.7. Job Titles Sorted By Human Resource Personnel's Ratings of Need for Additional Employees (HR_Need)

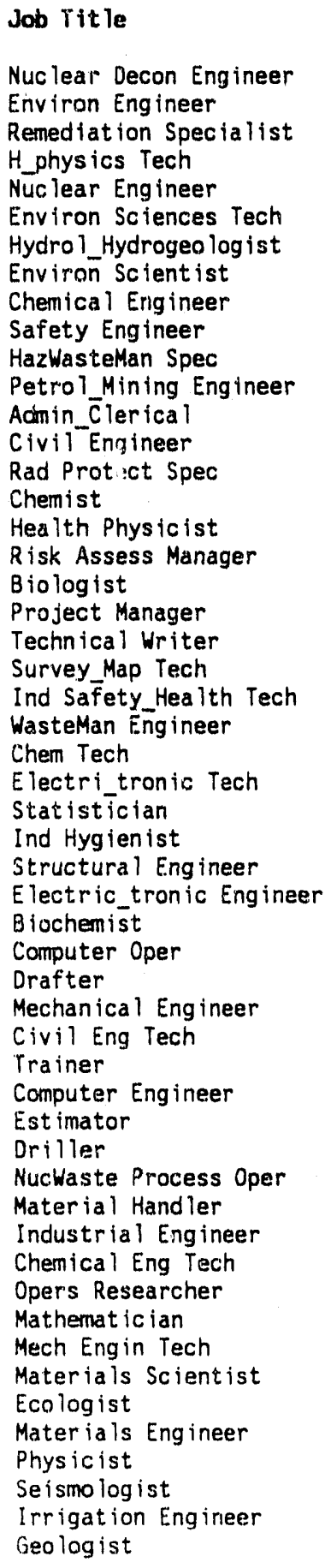

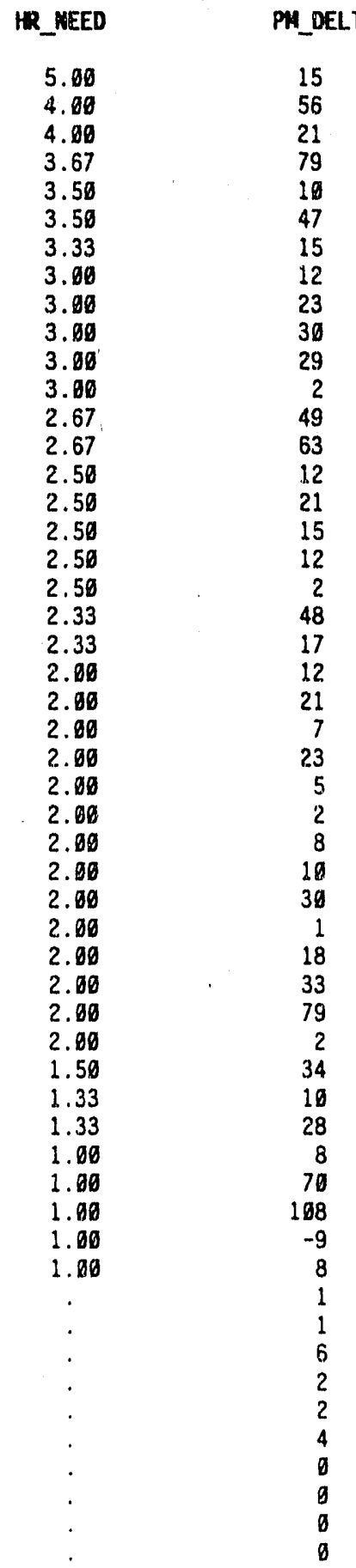

\section{Degree}

Mostly Bachelor Mix of $B S$ and Advanced Most ly Associate Most ly Associate Mix of BS and Advanced Mostly Associate Mix of BS and Advanced Mix of $B S$ and Advanced Mix of BS and Advanced Mix of BS and Advanced Mix of AS and BS Most ly Bache lor HS or less

Mix of BS and Advanced MiX of AS and BS

Mix of $B S$ and Advanced Mix of $B S$ and Advanced Most iy Bache lor

Mix of $8 S$ and Advanced Mostly Bachelor Most ly Assoc iate Most ly Associate Mostly Assoc iate Mix of BS and Advanced Mostly Associate Mostly Assoc iate Mostly Bache lor Mix of $A S$ and $B S$ Mix of BS and Advanced Mostly Bachelor Mix of BS and Advanced Mostly Associate Mostly Associate Mix of $B S$ and Advanced Most ly Associate Mix of AS and BS Mix of AS and BS Mix of AS and BS HS or less

HS or less

HS or less

Most ly Bache lor Most ly Associate

Mix of $B S$ and Advanced Mix of $B S$ and Advanced Most ly Associate Mix of $B S$ and Advanced Most ly Bachelor Most ly Bache lor Mix of $B S$ and Advanced Mix of BS and Advanced Mix of AS and BS Mostly Associate

Statistics based on data from 13 WNAS surveys and 1 SCHC survey. 
TABLE H.8. Job Titles Sorted By Human Resource Personnel's Ratings of Current Ability to Recruit (HR_Rec_C)

\section{Job Title}

Safety Engineer

Nuc lear Decon Engineer

Hea ith Physicist

Environ Engineer

$H$ physics Tech

Hydrol_Hydrogeologist

Environ Sctentist

Chemical Eng ineer

WasteMan Engineer

Chem Tech

Electri_tronic Tech

Biochemist

HazWasteMan Spec

Project Manager

Nuc lear Eng ineer

Chemist

Risk Assess Manager

Ind Safety_Health Tech

Ind Hygienist

Electric tronic Engineer

TechnicaT Writer

Orafter

Computer Eng ineer

Remediation Specialist

Environ Sciences Tech

Petrol_Mining Engineer

Civil Engineer

Rad Protect Spec

Biologist

Survey_Map Tech

Statistician

Structural Engineer

Computer Oper

Mechanical Engineer

Civil Eng Tecr

Admin Clerical

Est imätor

Trainer

Chemical Eng Tech

Driller

NucWaste Process Oper

Material Handler

Industrial Engineer

Opers Researcher

Mathenatician

Mech Eng in Tech

Materials Scientist

Ecologist

Materials Engineer

Physicist

Seismologist

Irrigation Engineer

Geologist

\section{HR_REC_C}

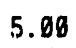

4.00

3. 50

3.33

3.33

3.33

3.00

3.80

3.00

3.00

3.06

3.60

2.67

2.67

2.50

2.50

2.50

2.50

2.50

2.50

2.33

2.33

2.33

2.00

2.60

2.00

2.00

2.06

2.80

2.00

2.00

2.00

2.00

2.08

2.00

1.67

1.67

1.50

1.58

1.00

1.00

1.00

1.00

Statistics based on data from 13 WNAS surveys and 1 SCHC survey.

\section{PN_DELTA}

30

15

15

79

15

12

23

7
23

5

1

48

16

21

12

21
8

30

17

33

10

21
47

2

63

12

2
12

2

10

18
79

2

49

28

34

8
79

108

$-9$

1

1

2

2

4

g

o
Degree

Mix of BS and Advanced Most ly Bachelor

Mix of BS and Advanced Mix of BS and Advanced Most ly Assoc late

Mix of BS and Advariced Mix of BS and Advanced Mix of BS and Advanced Mix of $Q S$ and Advanced Most ly Associate

Most ly Associate

Mix of $B S$ and Advanced

Mix of AS and BS

Most ly Bachelor

Mix of BS and Advanced Mix of BS and Advanced Most ly Bachelor

Most ly Associate

Mix of AS and BS

Mostly Bachelor

Most ly Associate

Most ly Associate

Mix of AS and BS

Most ly Associate

Most ly Associate

Most ly Bachedor

Mix of BS and Advanced Mix of AS and BS

Mix of $B S$ and Advanced Most ly Associate

Most ly Bache lor

Mix of BS and Advanced Most ly Associate

$M i x$ of $B S$ and Advanced Most ly Associate HS or less

Mix of AS and BS

Mix of A.S and BS Most. ly Associate

HS or less

HS or less

HS or less

Most ly Bachelor

Mix of $B S$ and Advanced Mix of BS and Advanced Most ly Associate

Mix of $B S$ and Advanced Most ly Bachelor

Most ly Bachelor

Mix of BS and Advariced Mix of $B S$ and Advanced Mix of AS and BS

Most ly Associate 


\section{TABLE H.9. Job Titles Sorted By Human Resource Personnel's Ratings of Anticipated Ability to Recruit (HR_Rec_A)}

\section{job Title}

Safety Engineer

Health Physicist

H physics Tech

Hydrci_Hydrogeo log ist

Nuc lear Decon Eng ineer

Environ Engineer

Environ Scient ist

Chemica? Engineer

WasteMan Engineer

Electri_tronic Tech

Biochemist

HazWasteMan Spec

Nuc lear Engineer

Chemist

Risk Assess Manager

Ind Safety Health Tech

Ind Hygien ist

Electric tronic Engineer

Biologist

Project Manager

Technical Writer

Chem Tech

Drafter

Computer Engineer

Remediation Specialist

Environ Sciences Tech

Petrol Mining Engineer

Civil Engineer

Rad Protect Spec

Survey_Map Tech

Statistician

Structural Engineer

Mechanical Engineer

Admin_Clerical

Estimator

Civil Eng Tech

Trainer

Computer Oper

Chemical Eng Tech

Driller

NucWaste Process Oper

Materlal Hand ler

Industrial Engineer

Opers Researcher

Mathemat ician

Mech Eng in Tech

Materials Scientist

Ecologist

Materials Engineer

Physicist

Se ismologist

Irrigation Engineer

Geologist

\section{HR_REC_A}

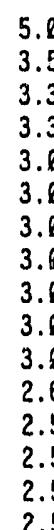

3.50

3.33

3.33

3.00

3.60

3.00

3.00

3.60

3.00

3.90

2.67

2.56

2.50

2.50

2.58

2.50

2.58

2.50

2.33

2.33

2.00

2.00

2.00

2.00

2.06

2.60

2.80

2.00

2.00

2.00

2.00

2.00

1.67

1.67

1.50

1.50

1.33

1.60

1.06

1.00

1.00

1.90

\section{PH_DEL.TA}

30

15

79

15

15

12

23

7

5

29

16

21

12

21

8
30

2

48

17

23

33

10

21

47

2

63
12

12

2

10

79

28

2

34

18

8
8
70

70
108

108
-9

$-9$

Statistics based on data from 13 WNAS surveys and 1 SCHC survey.

\section{Degree}

Mix of BS and Advanced Mix of BS and Advanced Most ly Associate

Mix of $B S$ and Advanced Most ly Bache lor

$M$ IX of $B S$ and Advanced Mix of $B S$ and Advanced Mix of BS and Advanced Mix of BS and Advanced Most iy Associate

Mix of BS and Advanced $M$ ix of $A S$ and $B S$

Mix of $B S$ and Advanced Mix of BS and Advanced Most ly Bache lor Mostily Associate Mix of AS and BS Mostly Bache lor Mix of $B S$ and Advanced Most ly Bache lor Most ly Associate Mostly Assoc late Most ly Assoc late

Mix of AS and BS

Most ly Associate

Most ly Associate

Most ly Bache lor

Mix of BS and Advanced Mix of AS and BS Mostly Associate.

Most ly Bache lor

Mix of BS and Advanced Mix of BS and Advanced HS or less

Mix of AS and BS

Most ly Associate

Mix of AS and BS

Most ly Associate

Mostily Associate

HS or less

HS or less

HS or less

Most ly Bache lor

Mix of BS and Advanced Mix of BS and Advanced Most ly Associate

Mix of BS and Advanced Mostly Bache lor Most. ly Bachelor

Mix of BS and Advanced $M i x$ of BS and Advanced Mix of AS and BS Most ly Associate 
TABLE H.10. Job Titles Sorted By Human Resource Personnel's Ratings of Annual Turnover (HR_Turn)

Job Title

WasteMan Engineer

Driller

H physics Tech

Hydro 1_Hydrogeologist

Hea lth Phys ic ist

Nuc lear Decon Engineer

Environ Engineer

Environ Scientist

Electri tronic Tech

Biochemist

HazWastellan Spec

Nuc lear Eng ineer

Chemist

Ind Safety_Heaith Tech

Ind Hygien ist

Biologist

Project Manager

Chem Tech

Remediation Specialist

Environ Sciences Tech

Civil Engineer

Statistician

Structural Engineer

Admin_Clerical

Civil-Eng Tech

Trainer

Chemical Eng ineer

Risk Assess Mariager

Technical Writer

Drafter

Rad Protect Spec

Mechanical Engineer

Est imator

Computer Oper

Electric_tronic Engineer

Computer Engineer

Survey_Map Tech

Chemical 1 Eng Tech

NucWaste Process Oper

Material Handler

Industrial Engineer

Safety Eng ineer

Petrol Mining Engineer

Opers Researcher

Mathematician

Mech Eng in Tech

Materials Scientist

Ecologist

Materials Engineer

Physicist

Se ismolog ist

Irrigation Engineer Geologist

\section{HR_TURH}

3.0

3.0

2.5

2.5

2.8

2.0

2.0

2.0

2.9

2.9

2.0

2.0

2.0

2.0

2.0

2.0

2.0

2.0

2.0

2.0

2.8

2.0

2.0

2.0

2.0

2.9

1.5

1.5

1.5

1.5

1.5

1.5

1.5

1.5

1.0

1.0

1.0

1.0

1.0

1.0
PM_DELTA

7

8
79

79

15

15

15

56

12

1

29

10

21

21

8

2

48
23

21

47

63

2

10

49

2

34

23

12

33

12

79

28

18

30

10

12

8
70

70
108

$-9$

30

2

1

1

6

2

4

0

0

0

Statistics based on data from 13 WNAS surveys and 1 SCHC survey. 
APPENDIX I

SIMPLE STATISTICS INTERCORRELATION AMONG

VARIABiES AND JOB SURTS ON ALL VARIABLES

FOR GRAND JUNCTION ONLY 
TABLE [.1. Descriptive Statistics for Relative Ratings

\begin{tabular}{lccccc} 
Variable & N & Minimum & Maximum & Mean & S.D. \\
\hline HR_DIFF & 0 & $\cdot$ & $\cdot$ & $\cdot$ & $\cdot$ \\
HR_NEED & 0 & $\cdot$ & $\cdot$ & $\cdot$ & $\cdot$ \\
HR_REC_C & 0 & $\cdot$ & $\cdot$ & $\cdot$ & $\cdot$ \\
HR_REC_A & 0 & $\cdot$ & $\cdot$ & $\cdot$ & $\cdot$ \\
HR_TURN & 0 & $\cdot$ & $\cdot$ &. &. \\
PM_DIFF & 38 & 1.00 & 4.00 & 3.32 & 0.84 \\
PM_REC_A & 37 & 2.00 & 5.00 & 3.41 & 1.07 \\
PM_EDUC & 38 & 2.00 & 4.00 & 2.92 & 0.71
\end{tabular}

S.D. = Standard Deviation, HR_DIFF = Difficulty Caused by a Shortage, HR NEED = Need for Additional Employees, HR-REC $A=$ Anticipated Ease of Recruitment, HR-REC-C = Current Ease of Recruitment, HR TURN = Current Annual Turnover, PM_DIFF = Difficulty Caused By a Shortage, PM_REC A $=$ Anticipated Ability to Recruit, PM EDUC = Typical Degree Level, $\star \star \bar{p}<\overline{0} .01 ; * p<0.05$. Statistics based on data from I WNAS survey and 0 SCHC, surveys. 


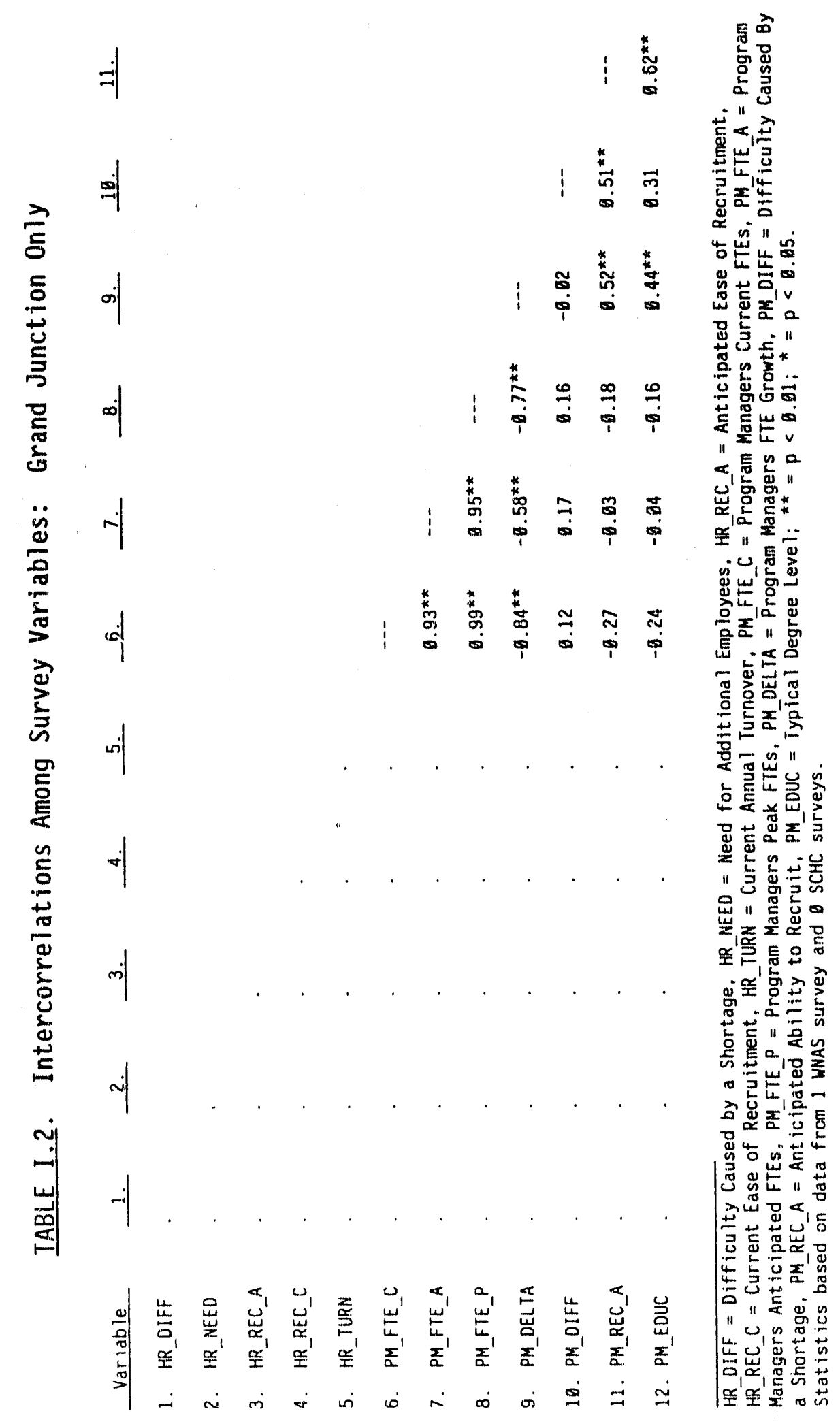




\section{IABLE 1.3. Job Sorted By Change in FTEs (PM_Delta)}

\begin{tabular}{|c|c|c|c|c|c|}
\hline Job Title & PH_FTE_C & PH_FTE_A & PH_FTE_P & PM_DELTA & Degree \\
\hline Environ Engineer & 3 & 18 & 18 & 15 & Mix of BS and Advanced \\
\hline Hydro I_Hydrogeologist & 3 & 8 & 8 & 5 & Mix of BS and Advanced \\
\hline WasteMan Eng ineer & 8 & 5 & 5 & 5 & Mix of BS and Advanced \\
\hline Chemical Eng ineer & 1 & 5 & 5 & 4 & Mix of BS and Advanced \\
\hline Environ Scient ist & 3 & 6 & 10 & 3 & Mix of BS and Advanced \\
\hline Technical Writer & 9 & 12 & 15 & 3 & Mix of AS and BS \\
\hline Biologist & 3 & 5 & 5 & 2 & Mostly Bache lor \\
\hline Chemical Eng Tech & 1 & 3 & 5 & 2 & Mostly Associate \\
\hline Hea lth Physicist & 3 & 5 & 5 & 2 & Mix of $B S$ and Advanced \\
\hline Material Handler & 2 & 4 & 6 & 2 & Mix of is and BS \\
\hline Physicist & 3 & 5 & 5 & 2 & Most ly Bachelor \\
\hline Chem Tech & 4 & 5 & 5 & 1 & Mostly Associate \\
\hline Ind Hygienist & 4 & 5 & 5 & 1 & Mix of AS and BS \\
\hline Risk Assess Manager & 4 & 5 & 5 & $i$ & $\because x$ of AS and BS \\
\hline Biochemist & $\ddot{\theta}$ & $\theta$ & $\theta$ & $\theta$ & Mostly Associate \\
\hline Chemist & 20 & 20 & 25 & 0 & Mix of BS and Advanced \\
\hline Civil Eng Tech & $\theta$ & 0 & $\theta$ & 0 & Mostiy Associate \\
\hline Computer Oper & 5 & 5 & 5 & 0 & Mostly Associate \\
\hline Ecologist & 6 & 0 & 0 & 0 & Mostly Associate \\
\hline Electric_tronic Engineer & 6 & 0 & 0 & 0 & Mostly Assoi:iate \\
\hline Estimator & 3 & 3 & 3 & $\theta$ & Mix of $A S$ and $B S$ \\
\hline H_physics Tech & 6 & $\theta$ & $\theta$ & $\theta$ & Mostly Associate \\
\hline Industrial Engineer & 0 & 8 & 0 & $\theta$ & Mostly Associate \\
\hline Irrigation Engineer & 6 & $\theta$ & 0 & 0 & HS or less \\
\hline Materials Engineer & 0 & 0 & $\theta$ & 0 & Mostly Associate \\
\hline Materials Scientist & 0 & 9 & $\theta$ & 0 & Mostly Associate \\
\hline Mathematician & 0 & 0 & $\theta$ & 0 & Mostly Associate \\
\hline Mech Engin Tech & $\emptyset$ & $\theta$ & 9 & 0 & HS or less \\
\hline NucWaste Process Oper & $\theta$ & $\theta$ & $\theta$ & $\theta$ & HS or less \\
\hline Nuclear Decon Engineer & $\theta$ & $\theta$ & $\ddot{\theta}$ & $\theta$ & Mostly Associate \\
\hline Nuclear Engineer & $\theta$ & $\theta$ & $\emptyset$ & 0 & Mustly. Associate \\
\hline Opers Researcher & $\theta$ & 0 & $\theta$ & $\theta$ & Mostly Associate \\
\hline Other Administrator & $\theta$ & 0 & 0 & 0 & HS or less \\
\hline Other Engineer & $\theta$ & $\ddot{0}$ & 0 & $\theta$ & Most ly Associate \\
\hline Other Scientist & 0 & 0 & $\theta$ & 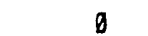 & Mostly Associate \\
\hline Other Technician & 0 & 0 & 0 & $\theta$ & HS or less \\
\hline Project Manager & 50 & 50 & 60 & 0 & Mix of $A S$ and $B S$ \\
\hline Rad Protect Spec & 5 & 5 & 5 & 0 & Mix of AS and BS \\
\hline Safety Engineer & 2 & 2 & 2. & $\theta$ & Mix of BS and Advanced \\
\hline Se ismolog ist & $\theta$ & $\theta$ & $\emptyset$ & $\theta$ & Mostly Associate \\
\hline Statistician & $\theta$ & $\theta$ & $\emptyset$ & 0 & Mostly Associate \\
\hline Survey_Map Tech & 4 & 4 & 4 & 0 & Mostly Associate \\
\hline Mechanical Engineer & 2 & 1 & 2 & -1 & Mostly Bachelor \\
\hline Petrol Mining Eng ineer & 1 & $\theta$ & $i$ & $-i$ & Mostly Bacheior \\
\hline Drafter & 3 & 1 & 3 & -2 & Mostly Associate \\
\hline Structural Engineer & 4 & 2 & 4 & -2 & Mostly Bachelor \\
\hline Trainer & 5 & 3 & 5 & -2 & Mix of $A S$ and $B S$ \\
\hline Driller & 8 & 4 & 8 & -4 & Most ly Associate \\
\hline Environ Sciences Tech & 8 & 4 & 8 & -4 & Mix of AS and BS \\
\hline Electri tronic Tech & 14 & 8 & 14 & .6 & Mostly Associate \\
\hline HazWastēMan Spec & 12 & 6 & 18 & -6 & Mix of $A S$ and $B S$ \\
\hline Ind Safety Health Tech & 12 & 6 & 12 & -6 & Mix of AS and BS \\
\hline Civil Engineer & 15 & 8 & 15 & -7 & Most ly Bachelor \\
\hline Geologist & 16 & 8 & 16 & -8 & Mostly Bachelor \\
\hline Computer Eng ineer & 20 & 10 & 2.0 & -10 & Most ly Bachelor \\
\hline Remediat ion Special ist & 38 & 10 & 45 & -28 & Mostly Associate \\
\hline Admin_Clerical & 115 & 78 & 120 & -45 & Most ly Associate \\
\hline
\end{tabular}

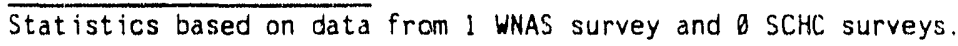




\section{TABLE 1.4. Titles Sorted by Project Manager's Ratings of Anticipated Ability to Recruit (PM_Rec_A)}

\author{
Job Title \\ Environ Engineer \\ Health Physicist \\ Chemist \\ Environ Scient ist \\ Physicist \\ WasteMan Engineer \\ Hydrol Hydrogeo logist \\ Technical Writer \\ Material Handler \\ Ind Hygienist. \\ Risk Assess Manager \\ Est imator \\ H_physics Tech \\ Project Manager \\ Rad Protect Spec \\ Trainer \\ HazWastellan Spec \\ Ind Safety_Health Tech \\ Biologist \\ Safety Engineer \\ Structural Engineer \\ Geolog ist \\ Chem Tech \\ Computer Oper \\ Environ Sciences Tech \\ Chemical Engineer \\ Chemical Eng Tech \\ Computer Engineer \\ Remediation Specialist \\ Survey Map Tech \\ Oriller \\ Electri tronic Tech \\ Civil Engineer \\ Admin_Clerical \\ Mechañical Engineer \\ Drafter \\ Petrol Mining Engineer \\ Civil Eng Tech \\ Mech Eng in Tech \\ $B$ iochem ist \\ Ecologist \\ Electric tronic Engineer \\ Industriāl Engineer \\ Irrigation Engineer \\ Materials Engineer \\ Materials Scientist \\ Mathenat ician \\ MucWaste Process Oper \\ Nuclear Decon Engineer \\ Nuc lear Engineer \\ Opers Researcher \\ Se ismologist \\ Statistician
}

\section{PM_REC_A}

5

5

3

3

3$$
3
$$$$
3
$$$$
3
$$$$
2
$$$$
2
$$

Statistics based on data from 1 WNAS survey and 0 SCHC surveys.

\section{PH_DELTA}

15

2

0

3

5

5

3

2

1

1

0

0

$-2$

$-6$

$-6$

2

0
-2

$-8$

1

$-4$

4

2
-16

$-28$

0

-4
-6

$-7$

$-45$

$-1$

$-2$

$-1$

0

0

$\theta$

b

a

0

$b$

b

9

a

6

\section{Degree}

Mix of BS and Advanced Mix of $B S$ and Advanced Mix of $B S$ and Advanced Mix of BS and Advanced Most ly Bachelor Mix of BS and Advanced Mix of BS and Advanced $M i x$ of $A S$ and $B S$ $M i x$ of $A S$ and $B S$ $M i x$ of $A S$ and $B S$ Mix of $A S$ and $8 S$ Mix of $A S$ and $B S$ Mostly Associate Mix of $A S$ and $B S$ $M i x$ of $A S$ and $B S$ $M i x$ of $A S$ and $B S$ $M i x$ of $A S$ and $B S$ Mix of $A S$ and $B S$ Mostly Bachelor Mix of BS and Advanced Most ly Bachelor Mostly Bachelor Most ly Assnciate Mostly Associate Mix of AS and BS Mix of $B S$ and Advanced Most ly Associate Most ly Bachelor Mostly Associate Mostly Associate Most ly Associate Mostly Associate Most ly Bachelor Mostly Assoclate Most ly Bi che lor Mostly Associate Most ly Bachelor Mostiy Associate HS or less Most ly Associate Mostly Associate Mostly Associate Mostly Associate HS or less Mostly Associate Mostly Associate Mostly Associate HS or less Most ly Associate Mostly Associate Mostly Associate Mostly Associate Most ly Associate 


\section{TABLE 1.5. Titles Sorted By Project Manager's Ratings of Difficulty Caused by Shortage (PM_Diff)}

\section{Job Title}

Environ Engineer

Hydro 1_Hydrogeo logist

Technical Writer

Health Physicist

Material Handler

Ind Hygien ist

Risk Assess Manager

Chemist

Est imator

$H$ physics Tech

Project Manager

Rad Protect Spec

Safety Eng ineer

Structural Engineer

Trainer

HazWasteMan Spec

Ind Safety_Health Tech

Geolog ist

Computer Engineer

Remediation Specialist

Enytron Scient ist

Biologist

Phys ic ist

Chem Tech

Computer Oper

Survey_Map Tech

Oriller

Environ Sciences Tech

Electri_tronic Tech

Civil Engineer

Admin_Clerical

Chemical Engineer

Chemical Eng Tech

Civil Eng Tech

Mech Engin Tech

Mechanical Engineer

Drafter

Petrol_Mining Engineer

WasteMan Engineer

Biochernist

Ecologist

Electric tronic Engineer

Industrial Engineer

Irrigation Engineer

Materials Engineer

Materials Scientist

Mathematician

NucWaste Process Oper

Nuclear Decon Engineer

Nuclear Engineer

Opers Researcher

Se ismologist

Statistician

\section{PM_DIFF}

4

4

4

4

4

4

4

4

4

4

3

(3)

3

3

3

3

3

3

3

3

3
2

2

2

2

2

Statistics based on data from 1 WNAS survey and 1 SCHC surveys.

\section{PH_DELTA Degree}

15

5

2

2

1

1

o

0

(6)

0

0
-2

$-2$

$-6$

$-6$

$-8$

$-10$

$-28$

2

2

1

0

$-4$

$-4$

$-6$

$-7$

$-45$

4

2

$\emptyset$

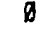

$-1$

$-2$

-1
5

a

b

0

a

0

8

9

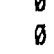

$\theta$

$\theta$

g

0
Mix of BS and Advanced Mix of BS and Advanced Mix of AS and BS

Mix of $B S$ and Advanced Mix of AS and BS

Mix of AS and BS Mix of $A S$ and $B S$ $M i x$ of $B S$ and Advanced Mix of AS and BS Most ly Associate Mix of AS and BS Mix of AS and BS Mix of BS and Advanced Mostly Bache lor Mix of AS and BS Mix of $A S$ and $B S$ Mix of AS and BS Mostly Bache lor Mostly Bache lor Mostly Associate Mix of $B S$ and Advanced Mostly Bache lor Mostly Bachelor Mostly Associate Mostly Associate Mostiy Associate Mostly Associate Mix of AS and BS Mostly Associate Mostly Bache lor Most ly Associate Mix of BS and Advanced Mostly Associate Mostly Associate HS or less Mostly Bache lor Most ly Associate Most ly Bache lor Mix of BS and Advanced Mostly Associate Mostly Associate Mostly Associate Mostly Associate HS or less

Mostly Associate Most ly Associate Mostly Associate HS or less

Mostly Asssociate Mostly Associate Mostly Associate Most ly Associate Mostly Associate 
TABLF I.6. Job Titles Sorted By Human Resource Personnel's Ratings
of Difficulty Caused By Shortage (HR_Diff)

Job Title

Environ Engineer

Health Physicist

Chenist

Environ Scient ist

Physicist

WasteMan Engineer

Hydrol_Hydrogeolog ist

Technical Writer

Material Handler

Ind Hygienist

Risk Assess Manager

Est imator

$H$ physics Tech

Project Manager

Rad Protect Spec

Trainer

HazWasteMan Spec

Ind Safety Health Tech

Biologist

Safety Engineer

Structural Engineer

Geplogist.

Chem Tech

Computer Oper

Environ Sciences Tech

Chemical Eng ineer

Chemical Eng Tech

Computer Eng ineer

Remediation Specialist

Survey_Hap Tech

Driller

Civil Engineer

Adm in Clerica 1

Mechañical Engineer

Drafter

Petrol Mining Engineer

Civil Eng Tech

Mech Engin Tech

Biochemist

Ecologist

Electric tronic Engineer

Industriāl Engineer

Irrigation Engineer

Materials Engineer

Materials Scient ist

Mathematician

Nuchaste Process Oper

Nuc lear Decon Eng ineer

Nuc lear Eng ineer

Opers Researcher

Se ismo log ist

Statistician
Electri_tronic Tech

H.DIFF

PM_DELTA

15

2

6

3

2

5

3

2

1

1

0

0

0

$-2$

$-6$

$-6$

2

$-2$

$-8$

1

0
-4

4
2

$-10$

$-28$

0
-4

$-6$

$-7$

$-45$

$-1$

$-2$

$-1$

a

0

9

Statistics based on data from 1 WNAS survey and 0 SCHC surveys.

\section{Degree}

Mix of BS and Advanced Mix of BS and Advanced Mix of BS and Advanced Mix of BS and Advanced Most ly Bache lor

Mix of BS and Advanced Mix of $B S$ and Advanced $M i x$ of $A S$ and $B S$ Mix of $A S$ and $B S$ Mix of AS and BS Mix of $A S$ and $B S$ Mix of AS and BS Most.ly Associate Mix of AS and BS Mix of AS and BS $M i x$ of AS and BS Mix of AS and BS $M i x$ of $A S$ and $B S$ Most ly Bache lor Mix of BS and Advanced Most ly Bache lor Most ly Bachelor Most ly Associate Mostly Associate Mix of AS and BS Mix of BS and Advanced Most ly Associate Most ly Bache lor Most ly Associate Mostly Associate Mostly Associate Mostly Associate Most ly Bache lor Most ly Assoc tate Mostly Bachelor Most iy Associate Most iy Bache lor Mostly Associate HS or less Mostly Associate Mostly Associate Most ly Associate Most ly Associate HS or less

Most ly Associate Most ly Associate Most ly Associate HS or less Mostly Associate Most ly Associate Most ly Associate Mostly Associate Most ly Associate 
TABLE 1.7. Job Titles Sorted By Human Resource Personnel's Ratings of Need for Additional Employees (HR_Need)

Jab rit le

Environ Engineer

Hea lth Physicist

Chemist

Environ Scient ist

Phys ic ist.

WasteMan Engineer

Hydrol Hydrogeo logist

Technical Writer

Material Handler

Ind Hygienist

Risk Assess Manager

Est imator

H_physics Tech

Project Manager

Rad Protect Spec

Trainer

HazWasteMan Spec

Ind Safety Health Tech

Biologist

Safety Engineer

Structura I Engineer

Geologist

Chem Tech

Computer Oper

Environ Sciences Tech

Chenical Ergineer

Chemical Eng Tech

Computer Engineer

Remediation Specialist

Survey_Map Tech

Driller

Electri_tronic Tech

Civil Eñgineer

Admin Clerical

Mechañical Engineer

Drafter

Petrol_Mining Engineer

Civil Eng Tech

Mech Ing in Tech

Biochemist

Ecologist

Electric tronic Engineer

Industrial Engineer

Irrigation Engineer

Materials Engineer

Materials Scientist

Mathematician

NucWaste Process Oper

Nuc lear Decon Engineer

Nuc lear Eng ineer

Opers Researcher

Se ismo logist

Statistician
HR_MEED

PH_DELIA

15

2

0

3

2

5

5

3

2

1

1

$\theta$

$\vartheta$

0
-2
-6

$-6$

$-6$

2

$-2$

$-8$

4

0
-4

4
2
-10

$-10$

$-28$

6

$-4$

$-6$

$-7$

$-45$

$-1$

$-2$

$-1$

0

$\emptyset$

$\theta$

8

6

0

$\theta$

8

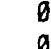

$\theta$

b

8

0

0
Degree

Mix of BS and Advanced Mix of BS and Advanced Mix of $B S$ and Advanced Mix of BS and Advanced Mostly Bacheior

Mix of BS and Advanced Mix of BS and Advanced Mix of AS and 8S Mix of AS and BS Mix of AS and BS Mix of AS and BS Mix of AS and BS Mostly Associate Mix of AS and BS Mix of AS and BS $M i x$ of $A S$ and $B S$ Mix of AS and BS Mix of $A S$ and $B S$ Most ly Bachelor Mix of BS and Advanced Mostly Bachelor Mostly Bachelor Most ly Associate Mostly Associate Mix of AS and BS Mix of BS and Advanced Mostly Associate Most ly Bache lor Most ly Associate Most ly Associate Most ly Associate Most ly Associate Most ly Bache lor Mostly Associate Most ly Bachelor Most ly Associate Most ly Bachelor Mostly Associate HS or less

Most ly Associate Most ly Associate Mostly Associate Mostly Associate HS or less Most ly Associate Most ly Associate Most ly Associate HS or less Mostly Associate Mostly Associate Most ly Associate Mostly Associate Mastly Associate

Statistics based on data from 1 WNAS survey and $\emptyset$ SCHC surveys. 


\section{TABLE 1.8. Job Tities Sorted By Human Resource Personnel's Ratings of Current Ability to Recruit (HR_Rec_C)}

\section{Jab Title}

Environ Eng ineer Hea th Phys ic ist Chemist.

Environ Scientist

Physic ist

Wastellan Engineer

Hydrol_Hydrogeologist

Technical Writer

Material Handler

Ind Hyglenist

Risk Assess Manager

Est imator

H_physics Tech

Project Manager

Rad Protect Spec

Trainer

HazWasteMan Spec

Ind Safety_Health Tech

Biologist

Safety Eng ineer

Structural Engineer

Geo log ist

Chem Tech

Computer Oper

Environ Sciences Tech

Chernical Eng ineer

Chemical Eng Tech

Computer Engineer

Remediation Specialist

Survey Map Tech

Oriller

Electri tronic Tech

Civil Engineer

Admin Clerical

Mechañical Engineer

Orafter

Petrol Mining Engineer

Civil Eng Tech

Mech Engin Tech

Biochemist

Ecologist

Electric tronic Engineer

Industrial Engineer

Irrigation Engineer

Materials Engineer

Materials Scient ist

Mathemat ician

Nuckaste Process Oper

Nuc lear Decon Engineer

Nuc lear Eng ineer

Opers Researcher

Se ismo logist

Statistician

\section{HR_REC_C}

PH_DELTA

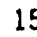

2

5

3

2

1

1

0

0

$-2$

$-6$

$-6$

2

8

$-2$

$-8$

1

1
-4

4

2
-10

$-28$

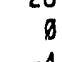

-4
-6

-6
-7

-7
-45

-45
-1
-2

$-2$

$-1$

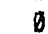

6

0

9

0

g

$\theta$

0

$\theta$

$\theta$

$\theta$

$\theta$

0

0

\section{Degree}

Mix of BS and Advanced Mix of $B S$ and Advanced Mix of BS and Advanced Mix of $B S$ and Advanced Most ly Bachelor Mix of BS and Advanced $M i x$ of $B S$ and Advanced Mix of AS and BS $M i x$ of $A S$ and $B S$ Mix of AS and BS Mix of AS and BS Mix of AS and BS Most ly Associate Mix of AS and BS Mix of AS and BS Mix of $A S$ and $B S$ $M i x$ of $A S$ and $B S$ Mix of AS and BS Most ly Bache lor Mix of BS and Advanced Most ly Bache lor Mostly Bache lor Most ly Associate Most ly Associate Mix of AS and BS Mix of BS and Advanced Most ly Associate Most ly Bache lor Mostly Associate Most ly Associate Most ly Associate Mostly Associate Most ly Bachelor Most ly Associate Most ly Bachelor Mostly Associate Most ly Bachelor Most ly Associate HS or less

Mostly Associate Mostly Associate Mostly Associate Most ly Associate HS or less

Mostly Associate Most ly Associate Most ly Associate HS or less

Most ly Associate Mostly Associate Most ly Associate Most ly Associate Most ly Associa'te

Statistics based on data from I WNAS survey and SCHC surveys. 


\title{
TABLE 1.9. Job Tit7es Sorted By Human Resource Personnel's Ratings of Anticipated Ability to Recruit (HR_Rec_A)
}

\author{
Job Title \\ Environ Engineer \\ Health Physicist \\ Chemist \\ Environ Scientist \\ Physicist \\ WasteMan Engineer \\ Hydrol_Hydrogeo logist \\ Technical Writer \\ Material Handler \\ Ind Hygien ist \\ Risk Assess Manager \\ Est imator \\ H_physics Tech \\ Project Manager \\ Rad Protect Spec \\ Trainer \\ HazWasteMan Spec \\ Ind Safety Health Tech \\ Biologist \\ Safety Engineer \\ Structural Engineer \\ Geologist \\ Chem Tech \\ Computer Oper \\ Environ Sciences Tech \\ Chemical Eng ineer \\ Chemical Eng Tech \\ Computer Eng ineer \\ Remediation Specialist \\ Survey_Map Tech \\ Driller \\ Electri tronic Tech \\ Civil Eñgineer \\ Admin Clerical \\ Mechañical Engineer \\ Drafter \\ Petrol Mining Engineer \\ Civil Eng Tech \\ Mech Eng in Tech \\ Biochemist \\ Ecologist \\ Electric tronic Engineer \\ Industriāl Engineer \\ Irrigation Engineer \\ Materials Engineer \\ Materials Scientist \\ Mathematician \\ NucWaste Process Oper \\ Nuclear Decon Engineer \\ Nuc lear Eng ineer \\ Opers Researcher \\ Se ismologist \\ Statistician
}

HR_REC_A

PN_DELTA

Degree

Mix of BS and Advanced Mix of BS and Advanced Mix of BS and Advanced Mix of BS and Advanced Most ly Bachelor

Mix of BS and Advanced Mix of BS and Advanced $M i x$ of $A S$ and $B S$ $M i x$ of $A S$ and $B S$ $M i x$ of $A S$ and $B S$ $M i x$ of $A S$ and $B S$ Mix of AS and BS Most ly Associate Mix of AS and BS Mix of AS and BS $M$ MX of $A S$ and $B S$ Mix of AS and BS Mix of AS and BS Most ly Bachelor Mix of $B S$ and Advanced Most ly Bachelor Most iy Bachelor Most ly Associate Most ly Associate Mix of $A S$ and $B S$ Mix of $B S$ and Advanced Mostly Associate Most ly Bachelor Most. ly Associate Most ly Associate Mostly Associate Most ly Associate Most ly Bachelor Most ly Associate Most ly Bachelor Most ly Assoc iate Mostly Bachelor Most ly Associate HS or less Most iy Associate Most ly Associate Most ly Associate Most ly Associate HS or less Most ly Associate Mostly Associate Most ly Associate HS or less Most ly Associate Most ly Associate Mostly Associate Most ly Associate Most ly Associate

Statistics based on data from 1 WNAS survey and $\theta$ SCHC surveys. 

TABLE I.10. Job Titles Sorted By Human Resource Personnel's Ratings
of Annual Turnover (HR_Turn)

Job Tit le

Environ Engineer Health Physicist

Chemist

Environ Scientist

Physicist

WasteMan Engineer

Hydrol Hydrogeo log ist

Technical Writer

Material Handler

Ind Hygien ist

Risk Assess Manager

Est imator

H_physics Tech

Project Manager

Rad Protect Spec

Trainer

HazWasteMan Spec

Ind Safety Health Tech

Biologist

Safety Eng ineer

Structural Engineer

Geologist

Chem Tech

Computer Oper

Environ Sciences Tech

Chernical Engineer

Chemical Eng Tech

Computer Eng ineer

Remediation Specialist

Survey_..Map Tech

Driller

Electri_tronic Tech

Civil Engineer

Adm in_Clerical

Mechañical Engineer

Drafter

Petrol Mining Engineer

Civil Eng Tech

Mech Engin Tech

Biochemist

Ecologist

Electric tronic Engineer

Industrial Engineer

Irrigation Engineer

Materials Engineer

Materials Scientist

Mathematician

Nucbaste Process Oper

Nuclear Decon Engineer

Nuc lear Eng ineer

Opers Researcher

Se isino log ist

Statistician

\section{HR_TRRM}

PH_DELTA

15

2

3

5

2

1

9

0

b

$-2$

-6
-6

2

0

$-2$

$-8$

1

0

$-4$

4

-10
-28

a

$-4$

$-6$

$-7$

$-45$

$-1$

$-2$

$-1$

$\theta$

g

g

b

0

g

9

0

$\theta$

$a$

0

0
Degree

Mix of $B S$ and Advanced Mix of BS and Advanced Mix of $B S$ and Advanced Mix of BS and Advanced Most ly Bachelor

Mix of BS and Advanced Mix of $B S$ and Advanced Mix of $A S$ and $B S$ Mix of AS and BS Mix of AS and BS $M i x$ of $A S$ and $B S$ Mix of AS and BS Most ly Associate Mix of AS and BS $M i x$ of $A S$ and $B S$ Mix of $A S$ and $B S$ Mix of AS and BS Mix of AS and BS Most ly Bache lor Mix of BS and Advanced Most ly Bachelor Most ly Bachelor Most ly Associate Most ly Associate Mix of AS and BS Mix of $B S$ and Advanced Most iy Associate Most ly Bachelor Most ly Associate Mostly Associate Most ly Associate Most ly Associate Most ly Bache lor Most ly Associate Most ly Bachelor Most ly Associate Most ly Bache lor Mostly Associate HS or less Most ly Associate Mostly Associate Most ly Associate Most ly Associate HS or less

Most ly Associate Most ly Associate Most ly Associate HS or less

Most ly Associate Mostly Associate Most ly Associate Most ly Associate Most ly Associate

Statistics based on data from 1 WNAS survey and $\theta$ SCHC surveys. 
APPENDIX $\mathrm{J}$

SIMPLE STATISTICS INTERCORRELATION AMONG

VARIABLES AND JOB SORTS ON ALI. VARIABLES

FOR IDAHO ONLY 
TABLE J.1. Descriptive Statistics for Relative Ratings

\begin{tabular}{llcccc} 
Variable & $\underline{N}$ & $\frac{\text { Minimum }}{1.00}$ & $\underline{\text { Maximum }}$ & $\underline{\text { Mean }}$ & $\underline{\text { S.D. }}$ \\
\hline HR_DIFF & 51 & 1.00 & 4.50 & 2.84 & 0.85 \\
HR_NEED & 51 & 1.00 & 4.00 & 2.65 & 0.83 \\
HR_REC_C & 50 & 1.00 & 4.50 & 2.91 & 0.74 \\
HR_REC_A & 51 & 1.00 & 4.50 & 3.05 & 0.75 \\
HR_TURN & 51 & 1.00 & 3.67 & 2.46 & 0.58 \\
PM_DIFF & 50 & 1.50 & 5.00 & 3.23 & 0.70 \\
PM_REC_A & 50 & 1.67 & 5.00 & 2.97 & 0.65 \\
PM_EDUC & 50 & 1.33 & 4.60 & 3.07 & 0.87
\end{tabular}

S.D. = Standard Deviation, HR_DIFF = Difficulty Caused by a Shortage, HR NEED = Need for Additional-Employees, HR-REC_A = Anticipated Ease of Recruitment, HR-REC-C = Current Ease of Recruitment, HR_TURN = Current Annual Turnover, PM DIFF = Difficulty Caused By a Shortage, PM_REC $A=$ Anticipated Ability to Recruit, PM EDUC $=$ Typical Degree Level, $* * \bar{p}<\overline{0} .01 ; * p<0.05$. Statistics based on data from 31 WNAS surveys and 4 SCHC surveys. 


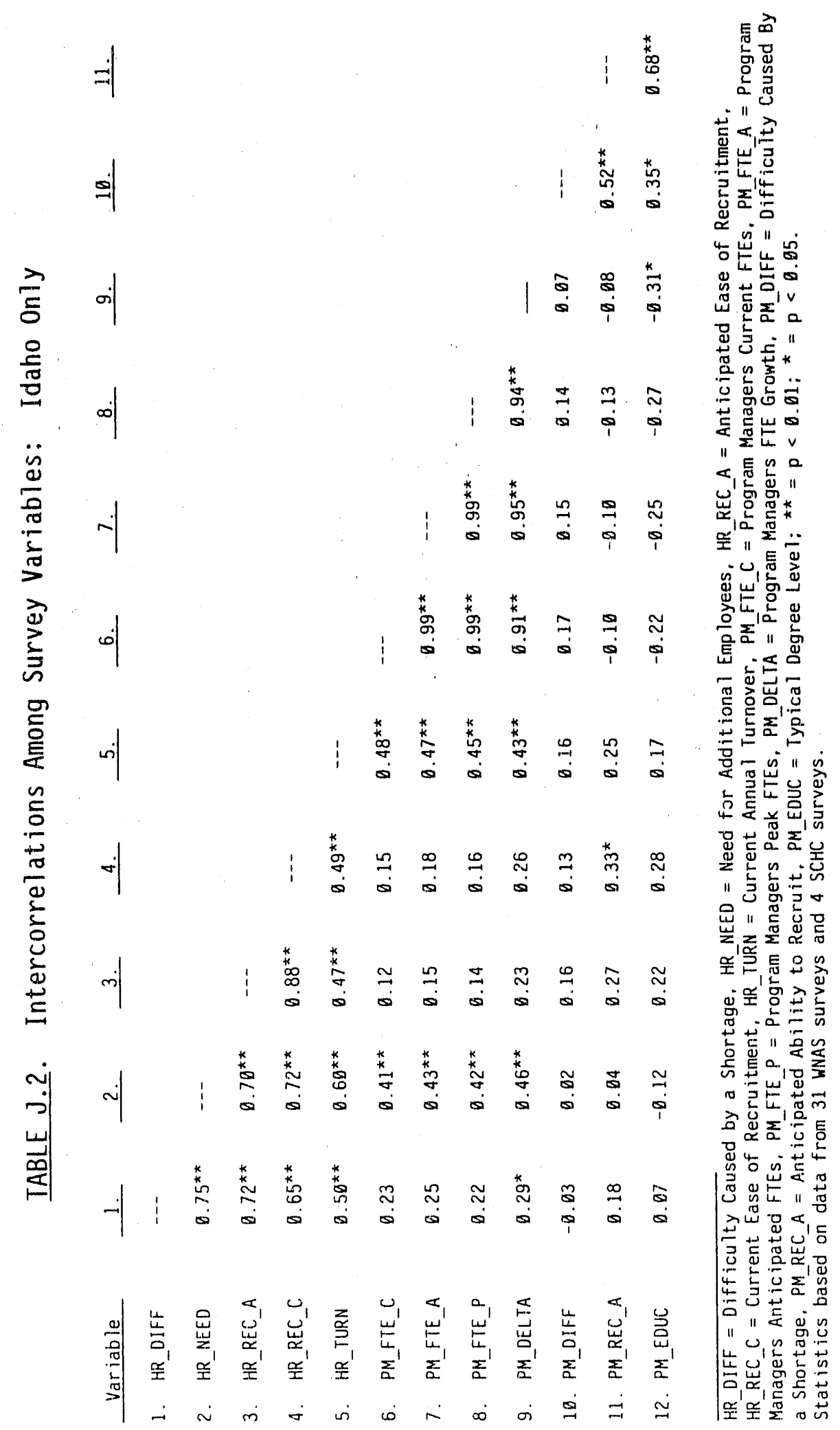




\section{TABLE J.3. Job Sorted By Change in FTES (PM_Delta)}

\begin{tabular}{|c|c|c|c|c|}
\hline Job Title & PM_FTE_C & PH_FTE_A & PH_FTE_P & PH_DELTA \\
\hline Adnin Clerical & 196 & 264 & 315 & 68 \\
\hline Chemical Engineer & $11 \%$ & 164 & 186 & 47 \\
\hline Project Manager & 133 & 189 & 2.98 & 47 \\
\hline Environ Engineer & 94 & 139 & 154 & 45 \\
\hline Nidchaste Process Oper & 105 & 147 & 155 & 42 \\
\hline H_physics Tech & 66 & 180 & 122 & 34 \\
\hline Environ Scientist & 45 & 74 & 87 & 29 \\
\hline Hechanica I Engineer & 98 & 127 & 154 & 29 \\
\hline Chemical ting Tech & 19 & 44 & 50 & 25 \\
\hline Chem Tech & 57 & 81 & 95 & 24 \\
\hline Other Technician & 60 & 84 & 92 & 24 \\
\hline Computer Engineer & 32 & 55 & 58 & 23 \\
\hline Material Handler & 39 & 62 & 80 & 23 \\
\hline Safety Engineer & 20 & 43 & 49 & 23 \\
\hline Wastekan Engineer & 83 & 103 & 118 & 20 \\
\hline Ind Safety_Health Tech & 2 & 20 & 27 & 18 \\
\hline Electri_trcnic Tech & 14 & 31 & 35 & 17 \\
\hline Environ Sciences Tech & 18 & 35 & 45 & 17 \\
\hline Ind Hygienist & 12 & 29 & 39 & 17 \\
\hline Technical Writer & 29 & 46 & 70 & 17 \\
\hline Civil Engineer & 38 & 46 & 63 & 16 \\
\hline Chemist & 45 & 60 & 88 & 15 \\
\hline Orafter & 44 & 59 & $\Gamma$ & 15 \\
\hline Nuclear Engineer & 30 & 45 & 46 & 15 \\
\hline Electric tronic Engineer & 36 & 50 & 66 & 14 \\
\hline Other Administrator & 30 & 44 & 46 & 14 \\
\hline Rad Protect Spec & 7 & 21 & 24 & 14 \\
\hline Structural Engineer & 29 & 43 & 62 & 14 \\
\hline Other Engineer & 28 & $4 !$ & 49 & 13 \\
\hline Remediation Specialist & 5 & 18 & 23 & 13 \\
\hline Estimator & 11 & 23 & 54 & 12 \\
\hline Trainer & 38 & 50 & 58 & 12 \\
\hline HazWasteMan Spec & 7 & 17 & 20 & 10 \\
\hline Mech Engin Tech & 18 & 28 & 35 & 10 \\
\hline Nuclear Decon Fngineer & 12 & 22 & 27 & 10 \\
\hline Risk Assess Manager & 11 & 21 & 28 & 10 \\
\hline Civil Eng Tech & 2 & 10 & 23 & 8 \\
\hline Health Physicisi & 8 & 16 & 21 & 8 \\
\hline Materia Is Engineer & 13 & 19 & 20 & 6 \\
\hline Computer Oper & 12 & 17 & 23 & 5 \\
\hline Industrial Engineer & 12 & 17 & 18 & 5 \\
\hline Hydrol_Hydrogeologist & 9 & 13 & 17 & 4 \\
\hline Petrol Mining Engineer & 0 & 4 & 4 & 4 \\
\hline Survey_Map Tech & 2 & 6 & 19 & 4 \\
\hline Geologist & 16 & 19 & 24 & 3 \\
\hline Biochemist & 2 & 4 & 5 & 2 \\
\hline Phys ic ist & 3 & 5 & 6 & 2 \\
\hline Statisicician & 1 & 3 & 3 & 2 \\
\hline Materia is Scientist & 5 & 6 & 7 & 1 \\
\hline Biologist & 1 & 1 & 1 & $\theta$ \\
\hline Ecologist & 1 & 1 & 1 & $\theta$ \\
\hline Irrigation Engineer & 4 & 4 & 4 & $B$ \\
\hline Mathematician & 0 & 8 & $\partial$ & $\theta$ \\
\hline Opers Researcher & 1 & 1 & 1 & ib \\
\hline Other Scient ist & 1 & 1 & 1 & 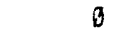 \\
\hline Seismologist & $\theta$ & $\theta$ & 0 & $B$ \\
\hline Orilier & 18 & 15 & 35 & -3 \\
\hline
\end{tabular}

Degree

HS or less

Mix of BS and Advanced

Most ly Bache lor

Mix of BS and Advanced

HS or less

Most ly Associate

Mix of BS and Advanced

Most ly Bachelor

Mostly Associate

Mix of AS and BS

HS or less

Most ly Bachelor

HS or less

Most ly Bachelor

Most ly Bachelor

Mix of AS and BS

HS or less

Most ly Associate

$M i x$ of $A S$ and $B S$

Mix of AS and BS

Most ly Bachelor

Mix of BS and Advanced

Most ly Associate

Mix of BS and Advanced

Mostily Bachelor

HS or less

Mix of $A S$ and $B$ S

Mix of BS and Advanced

Mast ly Associate

Mostly Associate

Mix of AS and BS

$M i x$ of $A S$ and $B S$

Mix of $A S$ and $B S$

Most ly Associate

Mix of BS and Aovanced

Most ly Advanced

Mostly Associate

Mix of $B S$ and Advanced

Mix of $B S$ and Advanced

Mostly Associate

Most ly Bachelor.

Mix of BS and Advariced

Mix of $B S$ and Advanced Most ly Associate

Most ly Bachelor

Mix of BS and Advanced

Most ly Bachelor

Mix of $8 S$ and Advanced Mix of BS and Advanced Most ly Bachelor

Mix of $B S$ and Advanced

HS or less

Mostly Associate

Mix of $B S$ and Advanced

Most iy Associace

Most ly Asscciate

Mix of $A S$ and $B S$

Stat stics based on data from 31 WhAS surveys and 4 SCHC surveys. 


\section{TABLE J.4. Titles Sorted by Project Manager's Ratings of Anticipated Ability to Recruit (PM_Rec_A)}

Job ritle

Opers Researcher

Risk Assess Manager

Hydro I_Hydrogeo log ist

Ind Hygien ist

Ind Safety_Health Tech

Petrol Mining Engineer

Envirōn Eng ineer

Environ Scientist

Nuc lear Eng ineer

Biochemist.

Project Manager

Chemist

Chemical Engineer

Materials Scientist

WasteMan Engineer

Materials Engineer

Rad Protect Spec

Safety Eng ineer

Physicist

Electric_tronic Engineer

Est imator

Elect-i_tronic Tech

Structural Engineer

Health Physicist

Nuc lear Decon Engineer

Ecologist

HazWasteMan Spec

Industrial Engineer

Survey_Map Tech

$H$ physics Tech

Driller

Mechanical Engineer

Technical Writer

Chern Tech

Computer Eng ineer

Mech Eng in Tech

Remediation Specialist

Civil Engineer

Statistician

Geo log ist

Trainer

NucWaste Process Oper

Material Handler

Admin_Clerical

Chemical Eng Tech

Environ Sciences Tech

Computer Oper

Biologist

Drafter

Civil Eng Tech

Irrigation Engineer

Mathemat ic ian

Se ismolog ist
PM_REC_A

PM_DELTA

5.00

4.20

4.00

4.00

3.80

3.67

3.62

3.56

3.50

3.50

3.43

3.43

3.41

3.33

3.25

3.25

3.20

3.11

3.00

3.90

3.00

3.00

3.00

3.00

3.00

3.00

3.00

3.00

3.00

2.90

2.80

2.80

2.73

2.71

2.70

2.67

2.60

2.56

2. 50

2.50

2.43

2.40

2. 33

2.19

2.13

2.00

2.00

2.00

1.86

1.67

9
10
4
17
18
4
45
29
15
2
47
15
47
1
29
6
14
23
2
14
12
17
14
8
10
9
10
5
4
34
-3
29
17
24
23
10
13
16
2
3
12
42
23
68
25
17
5
0
15
8
0
0
0

Statistics based on data from 31 WNAS surveys and 4 SCHC surveys.

\section{Degree}

Mix of $B S$ and Advanced Most ly Advanced

Mix of BS and Advanced Mix of $A S$ and $B S$

Mix of AS and BS Mix of $B S$ and Advanced Mix of $B S$ and Advanced Mix of $B S$ and Advanced Mix of BS and Advanced Mix of BS and Advanced Most ly Bachelor

Mix of BS and Advanced Mix of $B S$ and Advanced Mix of BS and Advanced Most ly Bache lor

Mix of $B S$ and Advanced Mix of AS and BS Mostly Bachelor Mostly Bachelor Mostly Bachelor Mix of AS and BS HS or less

Mix of BS and Advanced Mix of BS and Advanced $M i x$ of $B S$ and Advanced Mix of $B S$ and Advanced Mix of AS and BS Mostly Bachelor Most iy Associate Most iy Associate

Mix of AS and BS Most ly Bachelor Mix of AS and BS Mix of $A S$ and $B S$ Most ly Bachelor Mostly Associate Most ly Associate Most ly Bache lor Mix of BS and Advanced Most ly Bachelor Mix of AS and BS HS or less HS or less HS or less Mostly Associate Mostly Associate Mostly Associate Most ly Bachelor Mostly Associate Mostly Associate HS or less Mostly Associate Mostly Associate 


\section{TABLE J.5. Titles Sorted By Project Manager's Ratings of Difficulty Caused by Shortage (PM_Diff)}

Job Title
Petrol Mining Engineer
Opers Researcher
Physicist
Project Manager
Oriller
Chemist
Electric tronic Engineer
H_physics Tech
Hydrol_Hydrogeologist
Materials Scientist
Chemical Engineer
WasteMan Engineer
Environ Scientist
Environ Engineer
Materials Engineer
Statistician
Mechanical Engineer
Estimator
Ind Safety Health Tech
Rad Protect Spec
Electri_tronic Tech
Computer Engineer
Ind Hygienist
NucWaste Process Oper
Structural Engineer
Health Physicist
Orafter
Nuclear Engineer
Safety Engineer
Civil Engineer
Admin Clerical
Chem Tech
Trainer
Nuclear Decon Engineer
Risk Assess Manager
Geologist
Ecologist
Technical Writer
Environ Sciences Tech
HazWasteMan Spec
Mech Engin Tech
Civil Eng Tech
Material Handler
Industrial Eng ineer
Computer Oper
Remediation Specialist
Chemical Eng Tech
Biochemist
Biologist
Survey Map Tech
Irrigation Engineer
Mathematician
Seismologist

\begin{tabular}{|c|c|}
\hline PH_DIFF & PH_DEL.TA \\
\hline 5.00 & 4 \\
\hline 5.00 & $\theta$ \\
\hline 4.50 & 2 \\
\hline 4.29 & 47 \\
\hline 4.20 & -3 \\
\hline 4.00 & 15 \\
\hline 3.92 & 14 \\
\hline 3.70 & 34 \\
\hline 3.67 & 4 \\
\hline 3.67 & 1 \\
\hline 3.59 & 47 \\
\hline 3.57 & $2 \theta$ \\
\hline 3.56 & 29 \\
\hline 3.54 & 45 \\
\hline 3.50 & 6 \\
\hline 3.50 & 2 \\
\hline 3.47 & 29 \\
\hline 3.43 & 12 \\
\hline 3.40 & 18 \\
\hline 3.40 & 14 \\
\hline 3.38 & 17 \\
\hline 3.30 & 23 \\
\hline 3.29 & 17 \\
\hline 3.20 & 42 \\
\hline 3.20 & 14 \\
\hline 3.20 & 8 \\
\hline 3.17 & 15 \\
\hline 3.17 & 15 \\
\hline 3.11 & 23 \\
\hline 3.11 & 16 \\
\hline 3.10 & 68 \\
\hline 3.00 & 24 \\
\hline 3.00 & 12 \\
\hline 3.00 & 10 \\
\hline 3.00 & 10 \\
\hline 3.00 & 3 \\
\hline 3.00 & $\theta$ \\
\hline 2.91 & 17 \\
\hline 2.80 & 17 \\
\hline 2.80 & 10 \\
\hline 2.78 & 10 \\
\hline 2.67 & 8 \\
\hline 2.50 & 23 \\
\hline 2.50 & 5 \\
\hline 2.40 & 5 \\
\hline 2.20 & 13 \\
\hline 2.11 & 25 \\
\hline 2.00 & 2 \\
\hline 2.00 & $\theta$ \\
\hline 1.50 & 4 \\
\hline . & $\theta$ \\
\hline . & $\theta$ \\
\hline 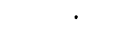 & $\theta$ \\
\hline
\end{tabular}

Degree

Mix of BS and Advanced Mix of $B S$ and Advanced Most ly Bache lor Most ly Bache lor Mix of AS and BS Mix of BS and Advanced Most ly Bache lor Mostly Associate Mix of BS and Advanced Mix of BS and Advanced Mix of BS and Advanced Most ly Bache lor Mix of BS and Advanced Mix of BS and Advanced Mix of BS and Advanced Mix of BS and Advanced Most ly Bachelor $M i x$ of $A S$ and $B S$ Mix of AS and BS Mix of AS and BS HS or less Most ly Bache lor Mix of AS and BS HS or less

Mix of BS and Advanced Mix of BS and Advanced Most ly Associate

Mix of BS and Advanced Most ly Bachelor Most ly Bachelor HS or less

Mix of $A S$ and $B S$ Mix of $A S$ and $B S$ Mix of BS and Advanced Most ly Advanced Most ly Bachelor Mix of $B S$ and Advanced Mix of AS and BS Mostly Associate Mix of AS and BS Most ly Associate Most ly Associate HS or less

Most ly Bachelor Most ly Associate Most ly Associate Most ly Associate Mix of BS and Advanced Most ly Bachelor Most ly Associate HS or less Most ly Associate Most ly Associate

Statistics based on data from 31 WNAS surveys and 4 SCHC surveys. 


\section{TABLE J.6. Job Titles Sorted By Human Resource Personnel's Ratings of Difficulty Caused By Shortage (HR_Diff)}

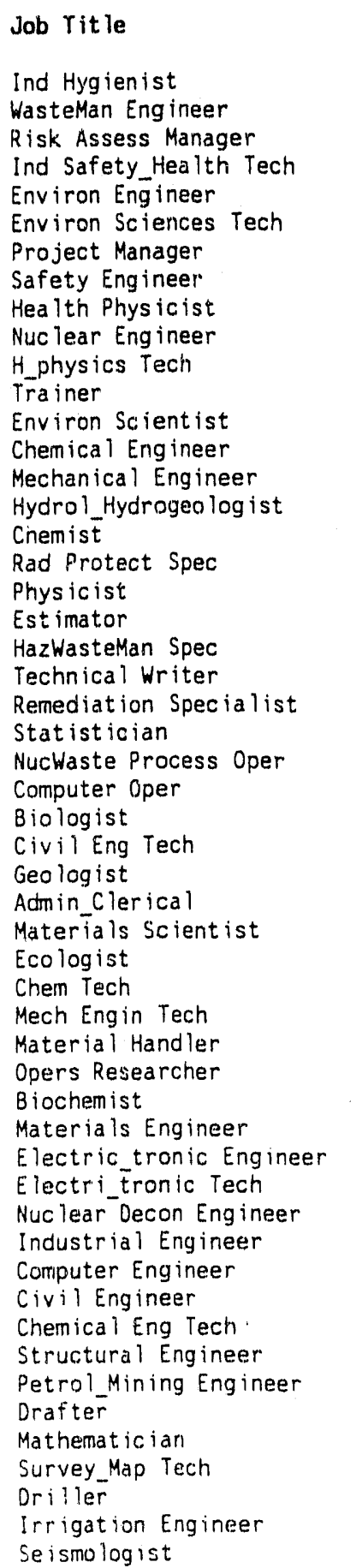

\begin{tabular}{|c|c|}
\hline DIFF & PH_DELT \\
\hline 4.50 & 17 \\
\hline 4.50 & 20 \\
\hline 4.00 & 10 \\
\hline 4.90 & 18 \\
\hline 4.80 & 45 \\
\hline 4.90 & 17 \\
\hline 3.67 & 47 \\
\hline 3.67 & 23 \\
\hline 3.67 & 8 \\
\hline 3.50 & 15 \\
\hline 3.50 & 34 \\
\hline 3.50 & 12 \\
\hline 3.33 & 29 \\
\hline 3.33 & 47 \\
\hline 3.33 & 29 \\
\hline 3.90 & 4 \\
\hline 3.00 & 15 \\
\hline 3.00 & 14 \\
\hline 3.00 & 2 \\
\hline 3.00 & 12 \\
\hline 3.00 & 10 \\
\hline 3.00 & 17 \\
\hline 3.00 & 13 \\
\hline 3.00 & 2 \\
\hline 3.00 & 42 \\
\hline 3.00 & 5 \\
\hline 3.00 & 0 \\
\hline 3.00 & 8 \\
\hline 2.67 & 3 \\
\hline 2.67 & 68 \\
\hline 2.50 & 1 \\
\hline 2.50 & 0 \\
\hline 2.50 & 24 \\
\hline 2.50 & 10 \\
\hline 2.50 & 23 \\
\hline 2.00 & 0 \\
\hline 2.00 & 2 \\
\hline 2.00 & 6 \\
\hline 2.00 & 14 \\
\hline 2.00 & 17 \\
\hline 2.00 & 10 \\
\hline 2.00 & 5 \\
\hline 2.00 & 23 \\
\hline 2.00 & 16 \\
\hline 2.90 & 25 \\
\hline 1.50 & 14 \\
\hline 1.00 & 4 \\
\hline 1.00 & 15 \\
\hline 1.00 & 0 \\
\hline & 4 \\
\hline . & -3 \\
\hline & 0 \\
\hline
\end{tabular}

Statistics based on data from 31 WHAS surveys and 4 SCHC surveys

\section{Degree}

Mix of AS and BS

Most ly Bachelor

Most ly Advanced

Mix of AS and BS

Mix of $B S$ and Advanced

Mostly Associate

Most ly Bache lor

Most ly Bachelor

Mix of BS and Advanced

Mix of BS and Advanced

Most ly Associate

Mix of AS and BS

Mix of $B S$ and Advanced

Mix of BS and Advanced

Most ly Bachelor.

Mix of BS and Advanced

Mix of BS and Advanced Mix of AS and BS

Most ly Bache lor

Mix of $A S$ and $B S$

Mix of AS and BS

Mix of AS and BS

Most ly Associate

Mix of BS and Advanced HS or less

Mostly Associate

Most ly Bachelor

Mostly Associate

Most ly Bachelor

HS or less

Mix of $B S$ and Advanced Mix of BS and Advanced Mix of AS and BS

Mostly Associate

HS or less

Mix of BS and Advanced Mix of $B S$ and Advanced Mix of $B S$ and Advanced Most ly Bache lor

HS or less

Mix of BS and Advanced Mostly Bachelor Mostly Bachelor Most ly Bachelor Mostly Associate Mix of $B S$ and Advanced Mix of $B S$ and Advanced Hostly Associate Mostly Associate Mostly Associate Mix of AS and BS HS or less Mostly Associate 
IABLE ].7. Job Tities Sorted By Human Resource Personnel's Ratings of Need for.Additional Employees (HR_Need)

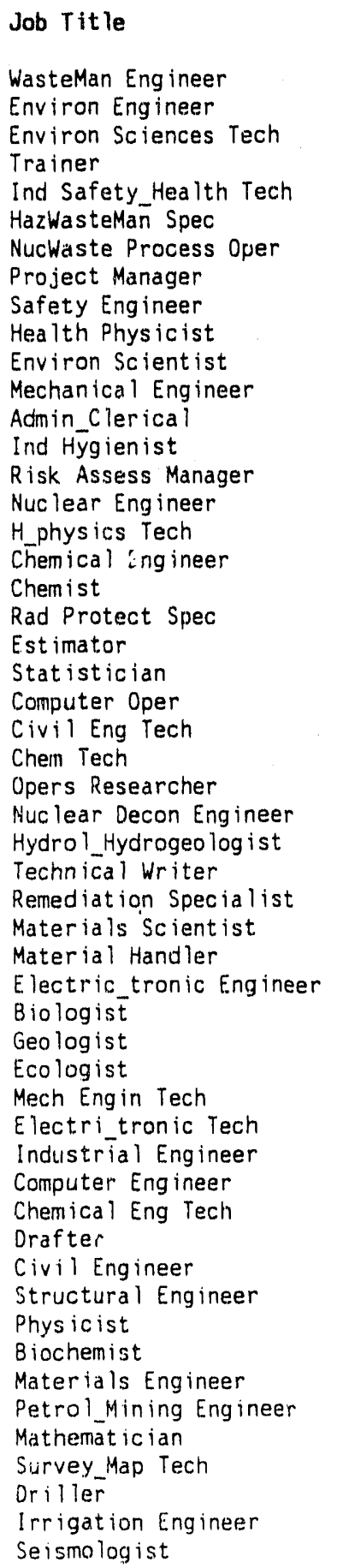

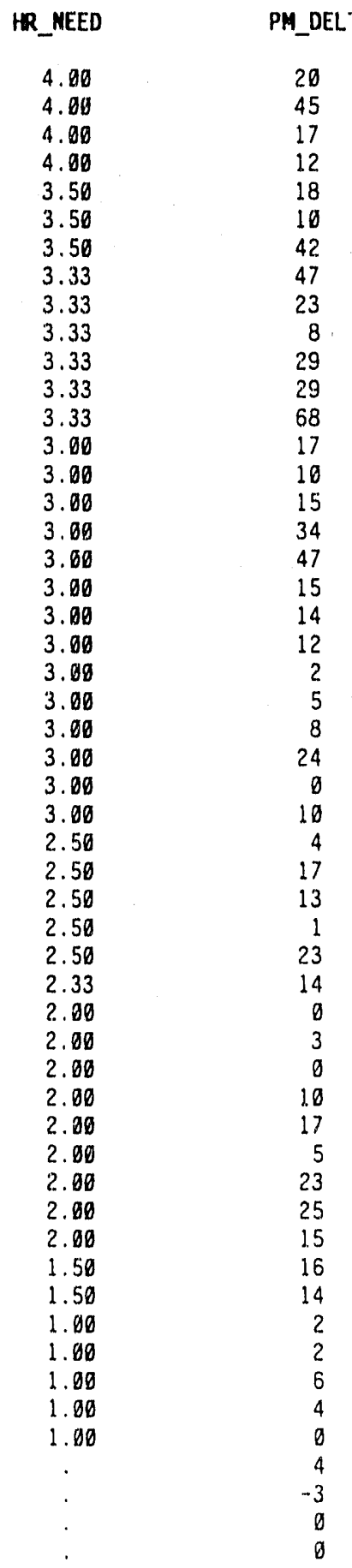

Statistics bered on data from 31 WNAS surveys and 4 SCHC surveys. 
TABLE J.8. Job Titles Sorted By Human Resource Personnel's Ratings of Current Ability to Recruit (HR_Rec_C)

Job Tit.le

Risk Assess Manage

Environ Sciences Tech

Trainer

Project Manager

Ind Hygienist.

Estimator

Environ Engineer

Safety Engineer

Environ Scientist

WasteMan Eng ineer

Ind Safety_Health Tech

HazWasteMan Spec

Nuc lear Eng ineer

Chemical Eng ineer

Chemist

Nucldaste Process Oper

Health Physicist

Mechanical Engineer

Rad Protect Spec

Statistician

Computer Oper

Civil Eng Tech

Opers Researcher

Nuclear Decon Eng ineer

Materials Scient ist

Electric tronic Engineer

Geologist.

Computer Engineer

Petrol_Mining Engineer

H physics Tech

Chem Tech

Hydrol Hydrogeo log ist

Technical Writer

Remediation Specialist

Material Handler

Ecologist

Mech Eng in Tech

Civil Engineer

Structural Engineer

Materials Engineer

Admin_Clerical

Biologist

Electri tronic Tech

Industrial Engineer

Biochemist

Drafter

Physic ist

Mathematician

Chemical Eng Tech

Survey_Map Tech

Driller

Irrigation Engineer

Se ismologist
HR_REC_C

\subsection{0}

4.00

4.00

4.00

4.00

4.00

3.67

3.67

3.67

3.50

3.50

3.50

3.50

3.33

3.33

3.00

3.00

3.00

3.00

3.00

3.00

3.00

3.00

3.00

3.00

3.00

3.00

3.90

3.90

2.50

2.50

2.50

2.50

2.50

2.50

2.56

2.50

2.50

2.50

2.50

2.33

2.90

2.00

2.00

2.00

1.50

1.00

1.00
PM_DELTA

10

17

12

47
17

12

45

23

29

20

18

10

15

47

15

42

8

29

14

2
5

8

$\theta$

10

1

14

3
23

4

4
34

24

4

17

13
23

0

10

16

14

6
68

0

17

5

2
15

2

0
25

25
4

$-3$

0
Statistics based on data from 31 WNAS surveys and 4 SCHC surveys.

\section{Degree}

Most ly Advanced Most ly Associate Mix of AS and BS Most ly Bache lor Mix of $A S$ and $B S$

Mix of $A S$ and $B S$ Mix of $B S$ and Advanced Most ly Bachelor Mix of BS and Advanced Most ly Bachelor Mix of AS and BS Mix of $A S$ and $B S$

Mix of BS and Advanced Mix of BS and Advanced Mix of BS and Advanced HS or less

Mix of BS and Advanced Most ly Bachelor Mix of $A S$ and $B S$ Mix of $B S$ and Advanced Most ly Associate Mostly Associate Mix of BS and Advanced Mix of BS and Advanced Mix of BS and Advanced Most ly Bachelor Most ly Bachelor Most.ly Bachelor Mix of BS and Advanced Mostly Associate. Mix of AS and BS

Mix of BS and Advanced Mix of $A S$ and $B S$ Mostly Associate HS or less

Mix of BS and Advanced Most ly Associate Mostly Bachelor

Mix of BS and Advanced Mix of BS and Advanced HS or less Most ly Bachelor HS or less Mostly Bachelor Mix of BS and Advanced Mostly Associate Mostly Bachelor Mostly Associate Mostly Associate Mostly Associate Mix of AS and BS HS or less Mostly Associate 


\title{
TABLE 0.9. Job Titles Sorted By Human Resource Personnel's Ratings of Anticipated Ability to Recruit (HR_Rec_A)
}

Job Title
Risk Assess Manager
Safety Eng ineer
Environ Sciences Tech
Trainer
Ind Hygienist
Estimator
Environ Scientist
WasteMan Engineer
Civil Eng Tech
Project Manager
Environ Engineer
Chemical Engineer
Ind Safety_Health Tech
Nuclear Engineer
Materials Scientist
Chemist
Health Physicist
HazWasteMan Spec
NucWaste Process Oper
Rad Protect Spec
Statistician
Computer Oper
Opers Researcher
Nuilear Decon Engineer
Electric tronic Engineer
Geologist
Computer Engineer
PetrolMining Engineer
Hphysics Tech
HydrolHydrogeologist
Remediation Specialist
Material Handler
Ecologist
Materials Engineer
Chemical Eng Tech
Mechanical Engineer
Admin_Clerical
Chem Tech
Technical Writer
Mech Eng in Tech
Civil Eng ineer
Structural Engineer
Biologist
Electri_tronic Tech
Industrial Engineer
Biochemist
Drafter
Physicist
Mathemat ician
Survey_Map Tech
Driller
Irrigation Engineer
Seismologist

\begin{tabular}{|c|c|}
\hline$H R \_R E C \_A$ & PH_DELT \\
\hline 4.50 & 10 \\
\hline 4.33 & 23 \\
\hline 4.60 & 17 \\
\hline 4.90 & 12 \\
\hline 4.80 & 17 \\
\hline 4.60 & 12 \\
\hline 4.00 & 29 \\
\hline 4.00 & 20 \\
\hline 4.00 & 8 \\
\hline 3.67 & 47 \\
\hline 3.67 & 45 \\
\hline 3.67 & 47 \\
\hline 3.50 & 18 \\
\hline 3.50 & 15 \\
\hline 3.50 & 1 \\
\hline 3.33 & 15 \\
\hline 3.33 & 8 \\
\hline 3.00 & 10 \\
\hline 3.00 & 42 \\
\hline 3.00 & 14 \\
\hline 3.00 & 2 \\
\hline 3.60 & 5 \\
\hline 3.00 & $\emptyset$ \\
\hline 3.00 & 10 \\
\hline 3.00 & 14 \\
\hline 3.00 & 3 \\
\hline 3.60 & 23 \\
\hline 3.00 & 4 \\
\hline 3.00 & 34 \\
\hline 3.00 & 4 \\
\hline 3.00 & 13 \\
\hline 3.00 & 23 \\
\hline 3.00 & $\theta$ \\
\hline 3.00 & 6 \\
\hline 3.00 & 25 \\
\hline 2.67 & 29 \\
\hline 2.67 & 68 \\
\hline 2.50 & 24 \\
\hline 2.50 & 17 \\
\hline 2.00 & 10 \\
\hline 2.00 & 16 \\
\hline 2.00 & 14 \\
\hline 2.00 & $\emptyset$ \\
\hline 2.00 & 17 \\
\hline 2.00 & 5 \\
\hline 2.00 & 2 \\
\hline 2.00 & 15 \\
\hline 2.00 & 2 \\
\hline 1.80 & $\theta$ \\
\hline & \\
\hline & $\begin{array}{r}-3 \\
0\end{array}$ \\
\hline & $\theta$ \\
\hline
\end{tabular}

\author{
Degree \\ Most ly Advanced \\ Mostly Bachelor \\ Mostly Associate \\ Mix of $A S$ and $B S$ \\ $M i x$ of $A S$ and $B S$ \\ $M i x$ of $A S$ and $B S$ \\ Mix of BS and Advanced \\ Most ly Bachelor \\ Mostly Associate \\ Most ly Bachelor \\ Mix of $B S$ and Advanced \\ Mix of BS and Advanced \\ Mix of AS and BS \\ Mix of $B S$ and Advanced \\ Mix of BS and Advanced \\ Mix of $B S$ and Advanced \\ Mix of $B S$ and Advanced \\ Mix of $A S$ and $B S$ \\ HS or less \\ Mix of AS and BS \\ Mix of BS and Advanced \\ Mostly Associate \\ Mix of BS and Advanced \\ Mix of BS and Advanced \\ Most ly Bache lor \\ Mostly Bachelor \\ Most ly Bachelor \\ Mix of BS and Advanced \\ Most ly Associate \\ Mix of BS and Advanced \\ Most ly Associate \\ HS or less \\ Mix of $B S$ and Advanced \\ Mix of BS and Advanced \\ Mostily Associate \\ Most ly Bache lor \\ $H S$ or less \\ Mix of $A S$ and $B S$ \\ Mix of $A S$ and $B S$ \\ Most ly Associate \\ Mostly Bachelor \\ Mix of BS and Advanced \\ Most ly Bachelor \\ HS or less \\ Most ly Bache lor \\ Mix of BS and Advanced \\ Most ly Associate \\ Mostly Bache lor \\ Most ly Associate \\ Mostly Associate \\ Mix of AS and BS \\ HS or less \\ Most ly Associate
}

Statistics based on data from 31 WNAS surveys and 4 SCHC surveys 
TABLE J.10. Job Tities Sorted By Human Resource Personnel's Ratings of Annuall Turnover (HR_Turn)

Job Title

Environ Engineer
Admin_Clerical
WasteMan Eng ineer
Risk Assess Manager
Safety Eng ineer
Trainer
Ind Hygien ist
Environ Scient ist
Civil Eng Tech
Project Manager
Nuclear Engineer
Opers Researcher
Nuclear Decon Engineer
Computer Engineer
Mechanical Engineer
Industrial Engineer
Chemical Engineer
Chemist
Health Physicist
Estimator
Materials Scientist
HazWasteMan Spec
NucWaste Process Oper
H_physics Tech
Remediation Specialist
Chem Tech
Technical Writer
Geologist
Environ Sciences Tech
Ind Safety Health Tech
Rad Protect Spec
Statistician
Computer Oper
Electric tronic Engineer
Petrol_Mining Engineer
Material Handler
Ecologist
Mech Eng in Tech
Civil Engineer
Structural Engineer
Biologist
Electri tronic Tech
Biochemist
Physicist
Mathematician
Hydrol Hydrogeologist
Materials Engineer
Drafter
Chemical Eng Tech
Survey_Map Tech
Driller
Irrigat ion Engineer
Seismologist.

\section{HR_TURH}

3.67

3.67

3.50

3.00

3.00

3.00

3.00

3.00

3.00

3.00

3.00

3.00

3.00

3.00

3.00

3.00

2.67

2.67

2.67

2.50

2.50

2.50

2.50

2.50

2.50

2.50

2.50

2. 33

2. 60

2.610

2.00

2.80

2.00

2.00

2.00

2.00

2.00

2.00

2.00

2.00

2.00

2.00

2.00

2.00

2.00

1.50

1.50

1.50

1.00

\section{PM_DELTA}

45

68

26

10

23

12

17

29

8

47

15

10

10

23
29

5

47

47
15
8

8

12

1

42

34

13

24

17
3

3
17

18

14

2

14

4

23

10

16

14

1
17

2

2

4

6
15

15
25

25
4

-3
0

Statistics based on data from 31 WNAS surveys and 4 SCHC surveys.

\section{Degree}

Mix of BS and Advanced

HS or less

Mostly Bachelor

Most ly Advanced

Most iy Bache lor

Mix of $A S$ and $B S$

Mix of $A S$ and $B S$

Mix of $B S$ and Advanced

Most ly Associate

Most ly Bache lor

Mix of BS and Advanced

Mix of BS and Advanced Mix of BS and Advanced Mostly Bachelor Most ly Bache lor Most ly Bache lor Mix of BS and Advanced Mix of BS and Advanced Mix of BS and Advanced Mix of AS and BS

Mix of $B S$ and Advanced Mix of $A S$ and $B S$ HS or less Most ly Associate Mostly Associate Mix of AS and BS Mix of AS and BS Mostly Bachelor Most ly Associate Mix of $A S$ and $B S$ Mix of $A S$ and $B S$ Mix of BS and Advanced Mostly Associate Most ly Bache lor Mix of $B S$ and Advanced HS or less

Mix of BS and Advanced Most ly Associate Mostly Bachelor Mix of BS and Advanced Most ly Bachelor HS or less Mix of $B S$ and Advanced Mostly Bachelor Mostly Associate Mix of $B S$ and Advanced Mix of BS and Advanced Mostly Associate Most ly Associate Most ly Associate Mix of AS and BS HS or less Most ly Associate 
APPENDIX K

SIMPLE STATISTICS INTERCORRELATION AMONG

VARIABLES AND JOB SORTS ON ALL VARIABLES

FOR KANSAS CITY ONLY 
IABLE K.1. Descriptive Statistics for Relative Ratings

$\begin{array}{llcccc}\text { Variable } & \text { N } & \text { Minimum } & \text { Maximum } & \text { Mean } & \underline{\text { S.D. }} \\ \text { HR_DIFF } & 40 & 1.00 & 3.00 & 1.47 & 0.72 \\ \text { HR_NEED } & 40 & 1.00 & 3.00 & 1.45 & 0.68 \\ \text { HR_REC_C } & 40 & 1.00 & 4.00 & 1.55 & 0.75 \\ \text { HR_REC_A } & 40 & 1.00 & 4.00 & 1.77 & 0.97 \\ \text { HR_TURN } & 40 & 1.00 & 4.00 & 1.52 & 0.82 \\ \text { PM_DIFF } & 31 & 1.00 & 5.00 & 2.36 & 1.42 \\ \text { PM_REC_A } & 31 & 1.00 & 5.00 & 2.02 & 1.10 \\ \text { PM_EDUC } & 31 & 1.33 & 5.00 & 3.43 & 1.04\end{array}$

S.D. = Standard Deviation, HR_DIFF = Difficulty Caused by a Shortage, HR NEED $=$ Need for Additional Employees, HR-REC $A=$ Anticipated Ease of Recruitment, HR-REC-C = Current Ease of Recruitment, HR_TURN = Current Annual Turnover, PM_DIFF $=$ Difficulty Caused By a Shortage, PM_REC $A=$ Anticipated Ability to Recruit, PM EDUC = Typical Degree Level, ${ }^{\star *} \overline{\mathrm{p}}<\overline{0} .01 ; * . \mathrm{p}<0.05$. Statistics based on data from 6 WNAS surveys and 1 SCHC survey. 


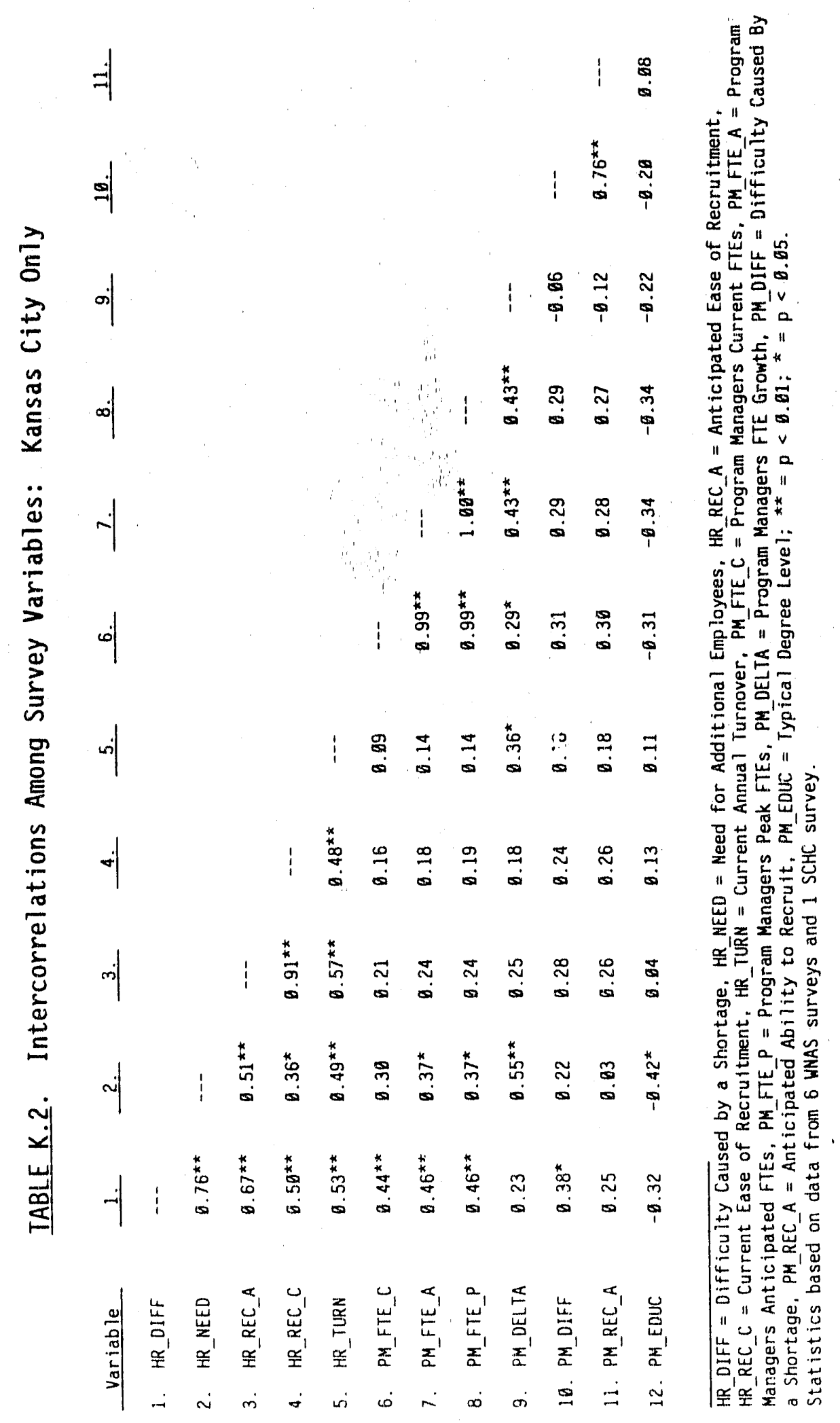

K.2 


\section{TABLE K.3. Job Titles Sorted By Change in FTEs (PM_Delta)}

\begin{tabular}{|c|c|c|c|c|c|}
\hline Jab Tit:le & PH_FTE_C & PH_FTE_A & PH_FTE_P & PM_DELTA & Degree \\
\hline Remediation Spectalist & 12 & 29 & 20 & 8 & Most ly Associate \\
\hline Adnin_Clerical & 31 & 35 & 35 & 4 & Mostly Associate \\
\hline Survey_Map Tech & 2 & 6 & 6 & 4 & Most ly Assoo iate \\
\hline Chemicāl Eng ineer & 2 & 5 & 5 & 3 & Most ly Pho \\
\hline Environ Eng ineer & 14 & 17 & 17 & 3 & Mix of BS and Advanced \\
\hline Hydrol_Hydrogeologist & 2 & 5 & 5 & 3 & MIX of BS and Advanced \\
\hline Chem Tech & 6 & 8 & 8 & 2 & Mix of AS and BS \\
\hline Computer Eng ineer & $\theta$ & 2 & 2 & 2 & Mix of BS and Advanced \\
\hline Computer Oper & 4 & 6 & 6 & 2 & Most ly Associate \\
\hline Health Physicist & 0 & 2 & 2 & 2 & Mix of BS and Advanced \\
\hline Ind Hygienist & 2 & 4 & 4 & 2 & Most ly Bache lor \\
\hline Material Handler & 32 & 34 & 34 & 2 & HS or less \\
\hline Mechanical Engineer & $\theta$ & 2 & 2 & 2 & Mix of BS and Advanced \\
\hline Project Manager & 22 & 24 & 24 & 2 & Most ly Bache lor \\
\hline WasteMan Engineer & 3 & 5 & 5 & 2 & Mix of BS and Advanced \\
\hline Civil Engineer & 2 & 3 & 3 & $i$ & Most ly PhD \\
\hline Ind Safety_Health Tech & 2 & 3 & 3 & $i$ & Most ly Associate \\
\hline Biochem ist & 0 & $\emptyset$ & $\theta$ & $\theta$ & Mostly Associate \\
\hline Biologist & $\emptyset$ & $\theta$ & $\theta$ & $\theta$ & Mostly Associate \\
\hline Chenical Eng Tech & $\theta$ & $\theta$ & $\theta$ & 8 & HS or less \\
\hline Chemist & 40 & 40 & 40 & $\theta$ & Mix of $B S$ and Advanced \\
\hline Civil Eng Tech & $\theta$ & 0 & 0 & $\theta$ & HS or less \\
\hline Drafter & 4 & 4 & 4 & $\theta$ & Most ly Associate \\
\hline Driller & 8 & 8 & 8 & $\theta$ & Most ly Assoc tate \\
\hline Ecologist & $\theta$ & $\theta$ & $\theta$ & $\theta$ & Mostly Associate \\
\hline Electri_tronic Tech & 2 & 2 & 2 & $\theta$ & Mostly Assoctate \\
\hline Electric_tronic Engineer & 1 & 1 & 1 & $\theta$ & MIX of BS and Advanced \\
\hline Environ Sctences Tech & 24 & 24 & 26 & $\theta$ & Most ly Associate \\
\hline Environ Scientist & 8 & 8 & 8 & $\theta$ & Mix of BS and Advanced \\
\hline Est imator & 2 & 2 & 2 & $\theta$ & Most ly Bache lor \\
\hline Geolog ist & 10 & 10 & 10 & $\theta$ & Mix of BS and Advanced \\
\hline H_physics Tech & $\theta$ & $\theta$ & $\theta$ & $\theta$ & HS or less \\
\hline HazWasteMan Spec & 18 & 18 & 18 & $\theta$ & Most ly Bache lor \\
\hline Industrtal Engineer & $\theta$ & $\theta$ & $\theta$ & $\theta$ & Most ly Associate \\
\hline Irrigation Engineer & $\theta$ & $\theta$ & $\theta$ & $\theta$ & HS or less \\
\hline Materials Engineer & $\emptyset$ & $\theta$ & $\theta$ & 0 & Most iy Assoc iate \\
\hline Materials Scientist & $\theta$ & $\theta$ & $\theta$ & $\theta$ & Most ly Associate \\
\hline Mathematician & $\theta$ & $\theta$ & $\theta$ & 0 & Mostly Assoc late \\
\hline Mech Eng in Tech & 8 & $\theta$ & $\theta$ & $\theta$ & tis or less \\
\hline NucWaste Process Oper & $\theta$ & 0 & $\theta$ & $\theta$ & HS or less \\
\hline Nuclear Decon Engineer & $\theta$ & 0 & $\theta$ & $\theta$ & Mostly Assoc late \\
\hline Nuc lear Engineer & $\emptyset$ & $a$ & $\theta$ & $\theta$ & Mostly Associate \\
\hline Opers Researcher & $\theta$ & $\theta$ & $\theta$ & $\theta$ & Mostly Assoc iate \\
\hline other Adninistrator & 1 & $i$ & $i$ & $\theta$ & HS or less \\
\hline Other Eng Ineer & $\theta$ & $\ddot{\theta}$ & $\theta$ & $\theta$ & Most ly Associate \\
\hline Other Scient ist & $\theta$ & $\theta$ & $\theta$ & $\theta$ & Most ly Associate \\
\hline other Technician & $\theta$ & $\theta$ & $\theta$ & $\theta$ & HS or less \\
\hline Petrol_Mining Engineer & $\theta$ & $\theta$ & $\theta$ & 6 & Mostly Associate \\
\hline Physicist & $\theta$ & $\theta$ & 0 & $\theta$ & Mostly Associate \\
\hline Rad Protect Spec & $\theta$ & 0 & 0 & $\theta$ & HS or less \\
\hline Risk Assess Manager & 1 & 1 & 1 & $\theta$ & Most ly Advanced \\
\hline Safety Engineer & $\theta$ & $\dot{\theta}$ & $\theta$ & $\theta$ & Most ly Associate \\
\hline Seismologist & $\theta$ & 9 & $\theta$ & $\theta$ & Mostiy Associate \\
\hline Statistician & $\theta$ & $\theta$ & $\theta$ & $\theta$ & Mostiy Associate \\
\hline Structural Engineer & 2 & 2 & 2 & $\theta$ & Mix of $B S$ and Advanced \\
\hline Technical Writer & 2 & 2 & 2 & $\theta$ & Most ly Bachelor \\
\hline Trainer & 1 & 1 & $i$ & $\theta$ & Most ly Bache lor \\
\hline
\end{tabular}

Statistics based on data from 6 WNAS surveys and 1 SCHC survey. 


\section{TABLE K.4. Titles Sorted by Project Manager's Ratings of Anticipated Ability to Recruit (PM_Rec_A)}

\section{Job Tit le}

Chemist

WasteMan Engineer

Ind Safety Hea 1th Tech

Environ Scientist

Computer Oper

HazWasteMan Spec

Hydrol_Hydrogeologist

Environ Engineer

Geologist

Oriller

Ind Hygienist

Chemical Engineer

Electri tronic Tech

Risk Assess Manager

Adnin_Clerical

Project Manager

Environ Sciences Tech

Civil Engineer

Drafter

Survey Map Tech

Remediation Specialist

Mechanical Eng ineer

Material Handler

Chem Tech

Computer Eng ineer

Health Physicist

Electric tronic Engineer

Estimator

Structural Engineer

Technical Writer

Trainer

Biochemist

Biologist

Chemical Eng Tech

Civil Eng Tech

Ecologist

H_physics Tech

Industrial Engineer

Irrigation Engineer

Materials Engineer

Materials Scientist

Maithematician

Mech Eng in Tech

NucWaste Process Oper

Nuc lear Decon Eng ineer

Nuc lear Engineer

Opers Researcher

Petrol Mining Engineer

Physicist

Rad Protect Spec

Safety Eng ineer

Se ismo logist

Statistician

\section{PH_REC_A}

5.00

4.00

4.00

4.00

3.00

3.00

3.00

2.80

2.33

2.00

2.00

2.00

2.00

2.00

1.83

1.80

1.75

1.67

1.67

1.33

1.33

1.90

1.00

1.00

1.00

1.00

1.00

1.00

1.00

1.00

1.00
Statistics based on data from 6 WNAS surveys and 1 SCHC survey
PM_DELTA

ด

0

0

6

4

1

6

4

\section{Degree}

Mix of BS and Advanced Mix of BS and Advanced Mostly Associate

Mix of BS and Advanced Mostly Associate Mastly Bachelor Mix of BS and Advanced Mix of BS and Advanced Mix of BS and Advanced Mostly Associate Mostly Bache lor Mostly PhD

Mostly Associate Mostly Advanced Mostly Associate Most ly Bache lor Mostly Associate Mostly PhD

Mostly Associate Mostly Associate Mostly Associate Mix of BS and Advanced HS or less

Mix of AS and BS Mix of $B S$ and Advanced Mix of BS and Advanced Mix of BS and Advanced Mostly Bache lor Mix of BS and Advanced Mostly Bachelor Most ly Bachelor Mostly Associate Mostly Associate HS or less

HS or less Mostly Associate

HS or less Mostly Associate HS or less Mostly Associate Mostly Associate Mostly Associate HS or less HS or less Mostly Associate Mostly Associate Mostly Associate Mostly Associate Mostly Assuciate HS or less

Mostly Associate Mostly Associate Mostly Associate 


\section{TABLE K.5. Titles Sorted By Project Manager's Ratings of Difficulty Caused by Shortage (PM_Diff)}

\begin{tabular}{|c|}
\hline 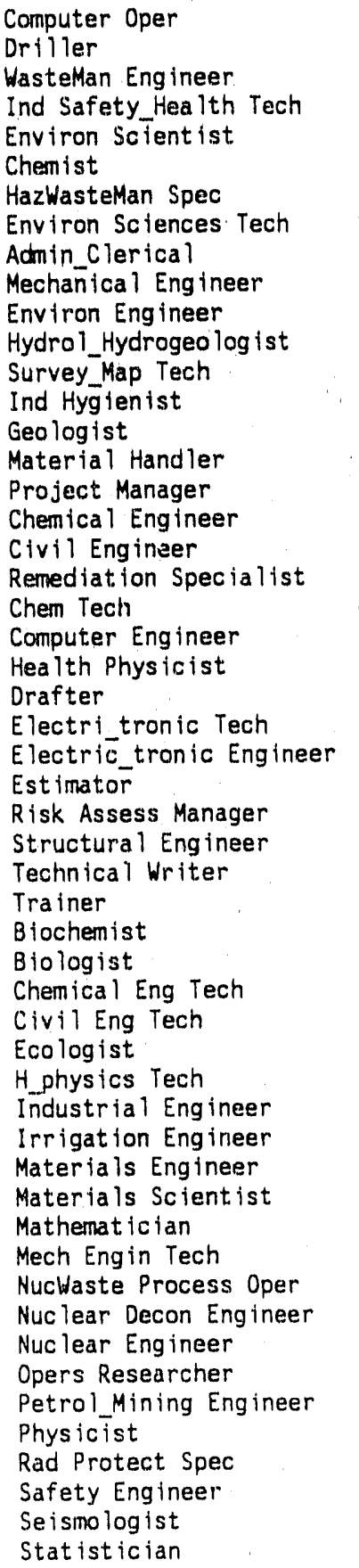 \\
\hline
\end{tabular}

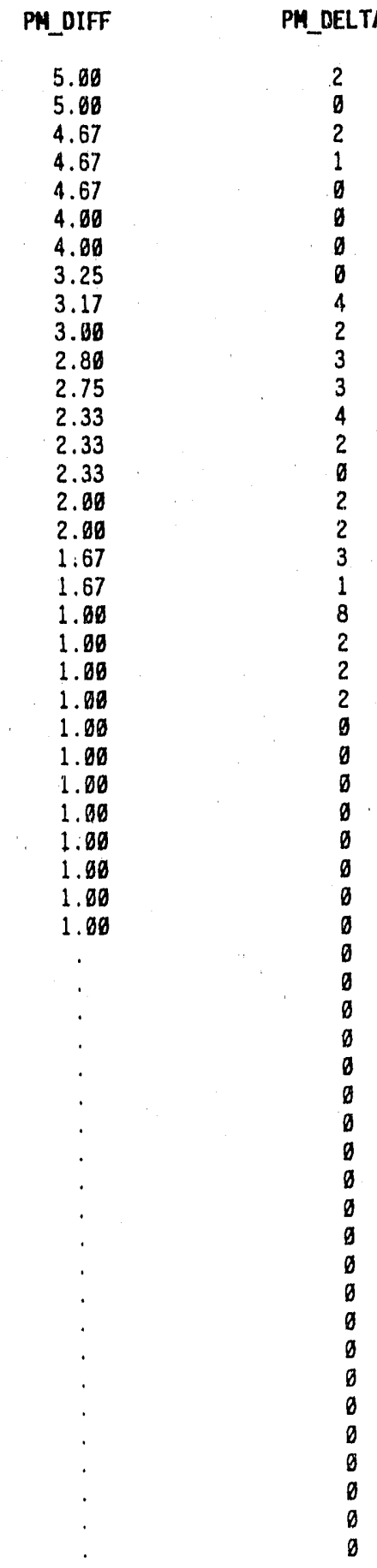

Mostly Associate Mostly Associate Mix of BS and Advanced Most ly Associate Mix of BS and Advanced Mix of $B S$ and Advanced Mostly Bachelor Mostly Associate Mostly Associate Mix of $B S$ and Advanced Mix of BS and Advanced Mix of BS and Advanced Most ly Assoctate Mostly Bachelor

Mix of BS and Advanced HS or less

Mostly Bachelor Mostly Pho

Mostly PhD Mostly Associate Mix of AS and BS Mix of BS and Advanced Mix of BS and Advanced Mostly Associate Mostly Associate

Mix of BS and Advanced Most ly Bachelor Most ly Advanced Mix of BS and Advanced Mostly Bachelor Most ly Bachelor Mostly Associate Mostly Associate HS or less HS or less Most ly Associate HS or less Mostly Associate HS or less Mostly Associate Mostly Associate Mostly Associate HS or less HS or less Most ly Associate Mostly Associate Hostly Associate Mostly Associate Mostly Associate HS or less Mostiy Associate Mostly Associate Most ly Associate

$\overline{\text { Statistics based on data }}$ from 6 WNAS surveys and 1 SCHC survey. 


\section{TABLE K.6. Job Titles Sorted By Human Resource Personnel's Ratings of Difficulty Caused By Shortage (HR_Diff)}

\author{
Job Title \\ HazWasteHan Spec \\ Geologist \\ Ind Hygien ist \\ Adnin Clerical \\ $H$ physics Tech \\ Chenist \\ Ind Safety Hea ith Tech \\ Computer Oper \\ Hydrol Hydrugeo log ist \\ Environ Sciences Tech \\ Remediation recialist \\ Material Handier \\ Chem Tech \\ Rad Protect Spec \\ WasteMan Engineer \\ Environ Scient ist \\ Environ Engineer \\ Chemical Eng ineer \\ Electri_tronic Tech \\ Risk Assess Manager \\ Project Manager \\ Civil Engineer \\ Orafter \\ Mechanical Engineer \\ Computer Engineer \\ Health Physic ist \\ Electric tronic Engineer \\ Estimator \\ Structural Engineer \\ Technical Writer \\ Trainer \\ Chemical Eng Tech \\ Industrial Engineer \\ Materia is Engineer \\ Materials Scient ist \\ Mathematician \\ Mech Eng in Tech \\ Physicist \\ Safety' Engineer \\ Statistician \\ Oriller \\ Survey Map Tech \\ Biochenist \\ Biolagist \\ Civil Eng Tech \\ Ecologist \\ Irrigation Engineer \\ NucWaste Process Oper \\ Nuclear Decon Engineer \\ Nuc lear Eng ineer \\ Opers Researcher \\ Petrol Mining Engineer \\ Seismo logist
}

HR_DIFF

2

2

2

2

2

2

2

2

1

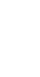

Statistics based on dara from 6 WNAS surveys ard 1 SCHC survey

\section{PH_DELTA}

0

a

2

4

6

1

2

3

8

2

2

0

2

3

3

8

0

1

8

2

2

2

0

0

8

9

9

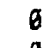

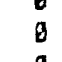

a

0

b

0

$\theta$

4

4

0

0

9

B

8

a

8

8

\section{Degree}

Mostily Bachelor Mix of BS and Advanced Mostly Bache lor Most ly Associate HS or less

Mix of BS and Advanced

Mostly Associate

Mostly Associate

Mix of BS and Advanced

Most ly Associate

Mostly Associate

HS or less

Mix of AS and BS

HS or less

Mix of $B S$ and Adyanced $M$ Mix of $B S$ and Advanced Mix of BS and Advanced Mostly PhD

Most ly Associate

Most ly Advanced

Most ly Bache lor

Most ly PhD

Most ly Associate

Mix of $B S$ and Advanced Mix of BS and Advanced Mix of 85 and Advanced Mix of BS and Advanced Mostly Bache lor Mix of $B S$ and Advanced Most iy Bache lor Mostly Bachelor HS or less

Mostily Associate Mostly Associate Most ly Associate Mostly Associate HS or less Mostly Associate Most ly Associate Mostiy Associate Most ly Associate Mostly Associate Mostly Associate Most ly Associate HS or less

Most ly Associate HS or less HS or less Mostly Associate Most ly Associate Mostly Associate Mostly Assoc rate Most ly Associate 
TABLE K.7. Job Titles Sorted By Human Resource Personnel's Ratings of Need for Additional Employees (HR_Need)

Job Title

Ind Hyg ien ist Admin_Clerica

Computer Oper Remediation Specialist

HazWasteMan Spec

Geologist

$H$ physics Tech

Ind Safety Hea ith Tech

Hydrol_Hydrogeo log ist

Environ Sciences Tech

Material Handler

Chem Tech

Risk Assess Manager

Computer Eng ineer

Chemist

Rad Protect Spec

Wastellan Engineer

Environ Scientist

Environ Engineer

Chemical Engineer

Electri_tronic Tech

Project Manager

Civil Engineer

Orafter

Mechanical Engineer

Health Physicist

Electric tronic Engineer

Estimator

Structural Engineer

Technical Writer

Trainer

Chemical Eng Tech

Industrial Engineer

Materials Engineer

Materials Scientist

Mathemat ic iar

Mech Eng in Tech

Physicist

Safety Engineer

Statistician

Driller

Survey Map Tech

Biochem ist

Biologist

Civil Eng Tech

Ecologist

Irrigation Engineer

NucWaste Process Oper

Nuclear Decon Engineer

Nuclear Eng ineer

Opers Researcher

Petrol Mining Engineer

Se ismoTogist

\section{HR_MEED}

3

3

3

3

2

2

2

2

2

2

2

2

2

2

1

1

1

1

Statistics based on data from 6 WMAS surveys and I SCHC survey.

\section{PH_DELTA \\ Degree}

Most iy Bachelor Most ly Associate Most ly Associate Mostly Associate Mostly Bachelar Mix of BS and Advanced HS or less

Most ly Associate Mix of BS and Advanced Mostly Associate HS or less

Mix of AS and BS Most ly Advanced Mix of BS and Advanced Mix of BS and Advanced HS or less

Mix of BS and Advanced Mix of BS and Advanced Mix of BS and Adyanced Most ly Pho

Mostly Associate Most ly Bachelor Most ly PhD Mostly Associate Mix of $8 S$ and Advanced Mix of BS and Advanced Mix of BS and Advanced Most ly Bachelor Mix of $B S$ and Advanced Most iy Bachelor Most ly Bache lor HS or less Most ly Associate Most ly Associate Most ly Associate Mostly Associate HS or less

Most ly Associate Mostly Associate Most ly Associate Most ly Associate Mostly Associate Mostly Associate Mostly Associate HS or less Most.ly Associate HS or less HS or less Mostly Associate Most iy Associate Most ly Associate Mostly Associate Mostly A3sociate 
TABLE K.8. Job Titles Sorted By Human Resource Personnel's Ratings of Current Ability to Recruit (HR_Rec_C)

Job Tit le

Heaith Physicist

HazWasteMan Spec

$H$ physics Tech

Hydrol_Hydrogeologist

Ind Hygienist

Admin_Clerical

Computer Oper

Remediation Specialist

Geologist

Environ Sciences Tech

Risk Assess Manager

Chem ist

Rad Protect Spec

Environ Scientist

Environ Engineer

Physicist

Safety Engineer

Ind Safety_Heaith Tech

Material Handler

Chem Tech

Computer Eng ineer

WasteMan Eng ineer

Chemical Engineer

Electri_tronis Tech

Project Manager

Civil Engineer

Drafter

Mechanical Engineer

Electric tronic Engineer

Estimator

Structural Engineer

Technical Writer

Trainer

Chemical Eng Tech

Industrial Engineer

Materials Eng ineer

Materials Scient ist.

Mathematician

Mech Eng in Tech

Statistician

Oriller

Survey Map Tech

Biochemist

Biologist.

Civil Eng Tech

Ecologist.

Irrigation Engineer Nucluaste Process Oper Nuclear Decon Engineer

Nuc lear Engineer

Opers Researcher

Petrol_Mining Engineer

Se ismo logist

\section{HR_REC_C}

PN_DELTA

2

0

8

3

2

4
2

2

8

g

0

g

0

3

0

1

2

2

2

2

3

6

2

1

2

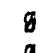

0

0

0

$\theta$

\section{B}

8

9

0

4

9

\section{0}

3

$a$

b

0

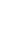

Statistics based on data from 6 WNAS surveys and 1 SCHC survey. 


\section{TABLE K.9. Job Tities Sorted By Human Resource Personnel's Ratings of Anticipated Ability to Recruit (HR_Rec_A)}

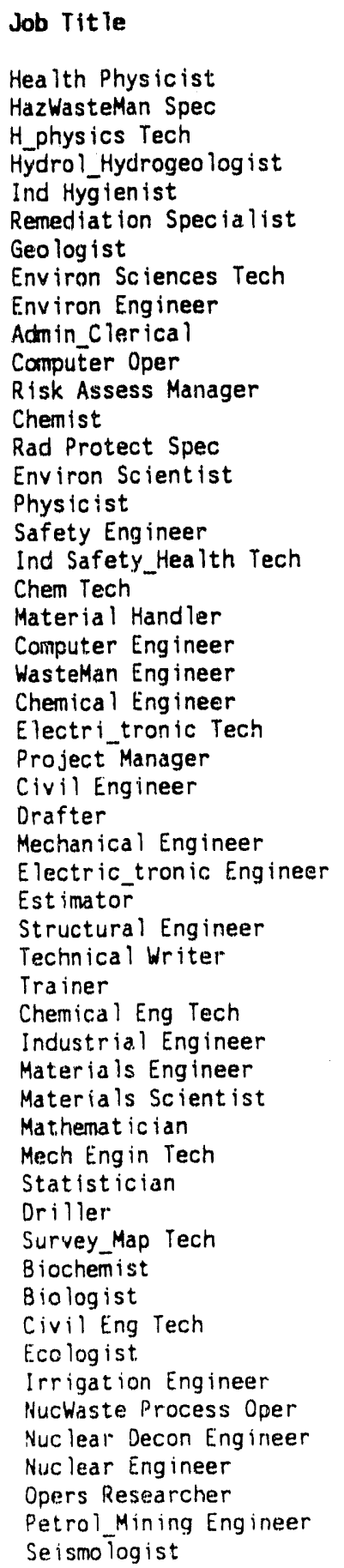

\section{HR_REC_A}

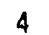

4
4

4

3

3

3

3

3

3
2

2

2

2
2

2

2

2

1

Statistics based on data from 6 WNAS surveys and 1 SCHC survey.

\section{Degree}

Mix of BS and Advanced Most ly Bachelor HS or less

Mix of BS and Advanced Mostly Bachelor Mostly Associate Mix of BS and Advanced Mostly Associate Mix of BS and Advanced Mostly Associate Most ly Associate Most ly Advanced Mix of BS and Advanced HS or less Mix of BS and Advanced Mostly Associate Mostly Associate Most ly Associate Mix of AS and BS HS or less

Mix of BS and Advanced Mix of $B S$ and Advanced Mostly Pho Mostly Associate Mostly Bache lor Most ly Pho

Most ly Associate Mix of BS and Advanced Mix of BS and Advanced Mostly Bachelor. Mix of BS and Advanced Most ly Bache lor Most ly Bachelor HS or less Most ly Associate Most ly Associate Mostly Associate Most ly Associate HS or less Most ly Associate Mostly Associate Mostly Associate Mostly Associate Most ly Associate HS or less Mostly Associate HS or less

HS or less Most ly Associate Mostly Associate Mostly Associate Most ly Associate Mostly Associate 


\section{TABLE K.10. Job Titles Sorted By Human Resource Personnel's Ratings of Annual Turnover (HR_Turn)}

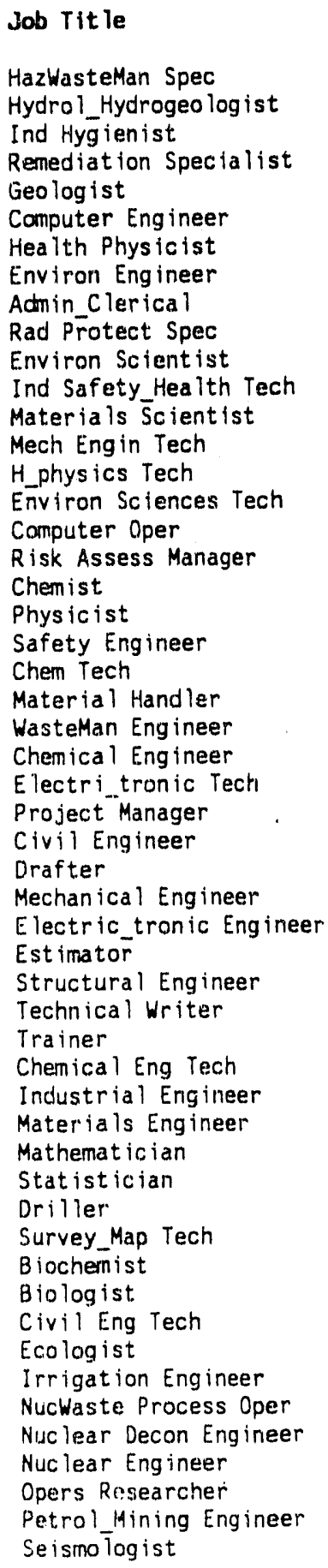

HazWasteMan Spec Hydrol_Hydrogeologist Ind Hyg ienist.

Degree

Most ly Bache lor Mix of BS and Advanced Most ly Bache lor Most ly Associate Mix of BS and Advanced Mix of $B S$ and Advanced Mix of $B S$ and Advanced Mix of BS and Auvanced Most iy Associate HS or less

Mix of BS and Advanced Mostly Associate Most ly Associate HS or less

HS or less

Most.ly Associate Mostly Assoc iate Mostly Advanced Mix of BS and Advanced Most ly Associate Mostly Associate Mix of AS and BS HS or less

Mix of BS and Advanced Most ly PhD

Mostly Associate Mostly Bache lor

Mostly PhD

Most ly Associate

Mix of BS and Advanced Mix of $B S$ and Advanced Most ly Bache lor

Mix of $B S$ and Advanced Most ly Bache lor Most ly Bache lor HS or less Mostly Associate Mostly Associate Most ly Associate Most ly Associate Most ly Associate Mostly Associate Mostly Associate Most ly Associate HS or less Most ly Associate HS or less HS or less Most ly Associate Most ly Associate Mostly Associate Mostly Associate Mostly Associate

Statistics based on data from 6 WNAS surveys and 1 SCHC survey. 


\section{APPENDIX L}

\section{SIMPLE STATISTICS INTERCORRELATION AMONG VARIABLES AND JOB SORTS ON ALL VARIABLES \\ FOR MOUND ONLY}


TABLE L.1. Descriptive Statistics for Relative Ratings

\begin{tabular}{|c|c|c|c|c|c|}
\hline Variable & $\underline{N}$ & Minimum & Maximum & Mean & S.D. \\
\hline HR_DIFF & 0 & • & ' & . & · \\
\hline HR_NEED & 0 & - & • & $\cdot$ & · \\
\hline HR_REC_C & 0 & . & - & • & . \\
\hline$H R \_R E C \_A$ & 0 & - & . & - & - \\
\hline HR_TURN & 0 & . & . & - & - \\
\hline PM_DIFF & 0 & - & . & - & - \\
\hline PM_REC_A & 0 & . & - & - & - \\
\hline PM_EDUC & 0 & · & - & - & - \\
\hline
\end{tabular}

S.D. = Standard Deviation, HR_DIFF = Difficulty Caused by a Shortage, HR NEED = Need for Additional Employees, HR-REC_A = Anticipated Ease of Recruitment, HR-REC-C = Current Ease of Recruitment, HR TURN = Current Annua 7 Turnover, PM_DIFF = Difficulty Caused By a Shortage, PM_REC A = Anticipated Ability to Recruit, PM_EDUC = Typical Degree Level, $* * \bar{p}<\overline{0} .01 ; * p<0.05$. Statistics based on data from 1 WNAS survey and 1 SCHC survey. Surveys only contained FTE data. 


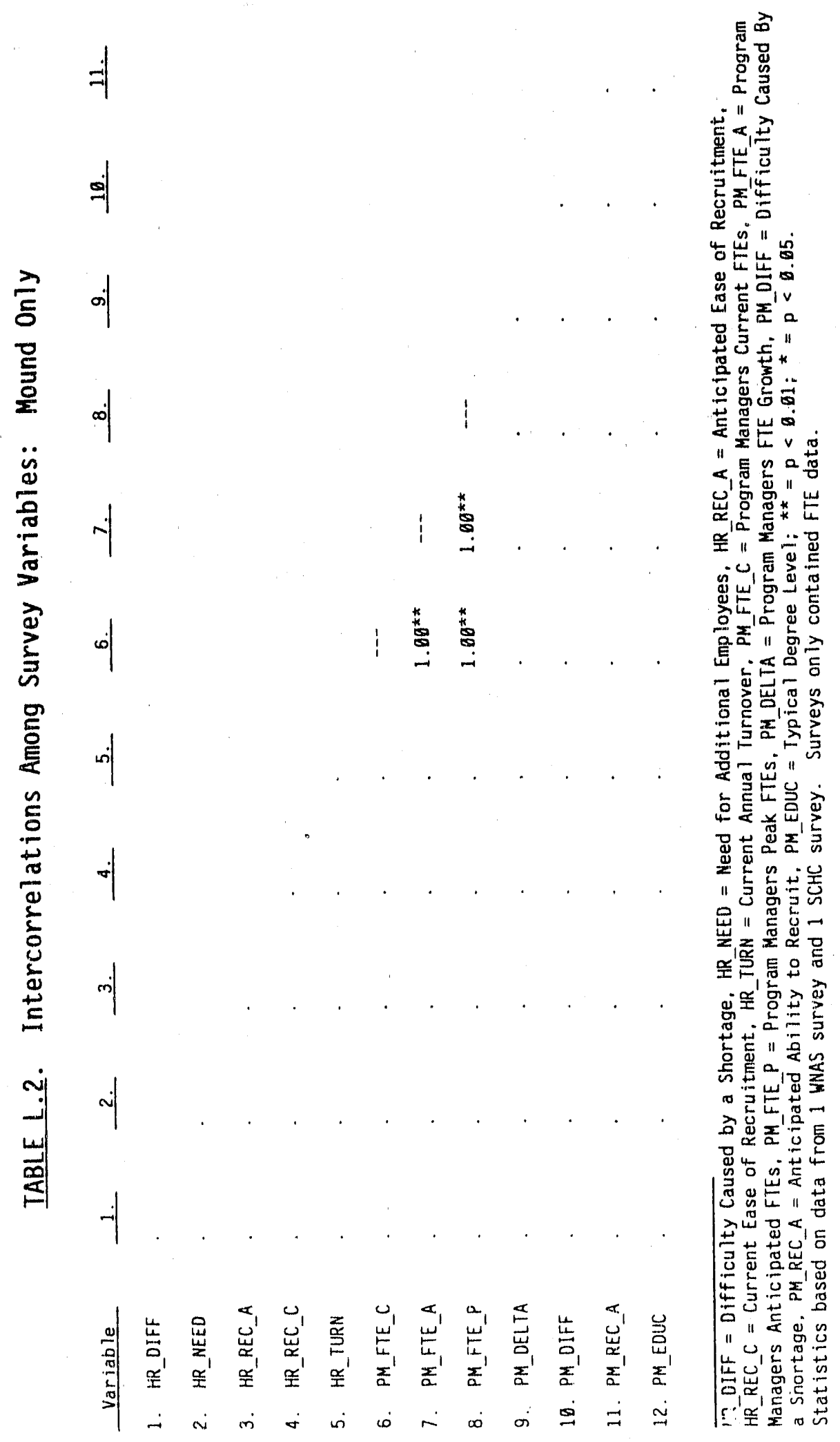




\section{TABLE L.3. Job Titles Sorted By Change in FTEs (PM_Delta)}

\begin{tabular}{|c|c|c|c|c|c|}
\hline Job Title & PM_FTE_C & PH_FTE_A & PH_FTE_P & PH_DELTA & Degree \\
\hline Admin_Clerical & 2 & 2 & 2 & $\theta$ & HS or less \\
\hline Biochemist & $\theta$ & $\theta$ & $\theta$ & $\theta$ & Mostly Associate \\
\hline Biologist & $\theta$ & $\theta$ & $\theta$ & $\theta$ & Mostly Associate \\
\hline Chem Tech & $\theta$ & $\theta$ & $\theta$ & $\theta$ & HS or less \\
\hline Chemical Eng Tech & $\theta$ & $\theta$ & $\theta$ & $\theta$ & HS or less \\
\hline Chemical Eng ineer & $\theta$ & $\theta$ & $\theta$ & $\emptyset$ & Mostly Associate \\
\hline Chemist & $\theta$ & $\emptyset$ & $\theta$ & $\theta$ & Hostly Associate \\
\hline Civil Eng Tech & 0 & $\theta$ & $\theta$ & $\theta$ & HS or less \\
\hline Civil Engineer & $\theta$ & $\theta$ & $\theta$ & $\theta$ & Most ly Associate \\
\hline Computer Eng ineer & $\theta$ & $\theta$ & $\theta$ & 8 & Mostly Associate \\
\hline Computer Oper & $\theta$ & $\theta$ & $\theta$ & $\theta$ & HS or less \\
\hline Drafter & $\emptyset$ & $\theta$ & $\theta$ & $\theta$ & HS or less \\
\hline Driller. & $\theta$ & $\theta$ & $\theta$ & $\theta$ & HS or less \\
\hline Ecologist & $\theta$ & $\theta$ & $\theta$ & $\theta$ & Most ly Associate \\
\hline Electri_tronic Tech & $\theta$ & $\theta$ & $\theta$ & $\theta$ & HS or less \\
\hline Electric_tronic Engineer & $\theta$ & $\theta$ & 6 & $\theta$ & Mostly Associate \\
\hline Environ Engineer & 4 & 4 & 4 & $\theta$ & Most ly Associate \\
\hline Environ Sciences Tech & $\theta$ & $\theta$ & $\theta$ & $\theta$ & HS or less \\
\hline Environ Scient ist & $\theta$ & $\theta$ & $\theta$ & $\theta$ & Mostly Associate \\
\hline Estimator & $\theta$ & 0 & $\theta$ & $\emptyset$ & HS or less \\
\hline Geologist & $\theta$ & $\theta$ & $\theta$ & $\theta$ & Mostly Associate \\
\hline H_physics Tech & $\theta$ & $\theta$ & 0 & $\theta$ & HS or less \\
\hline HazWasteMan Spec & 0 & $\emptyset$ & 6 & $\theta$ & HS or less \\
\hline Heaith Physicist & $\theta$ & $\theta$ & $\theta$ & $\theta$ & Mostly Associate \\
\hline Hydrol_Hydrogeologist & 8 & $\theta$ & $\theta$ & $\theta$ & Mostly Associate \\
\hline Ind $\mathrm{Hyg}$ ien ist & $\emptyset$ & $\theta$ & $\theta$ & $\theta$ & HS or less \\
\hline Ind Safety Health Tech & $\theta$ & $\theta$ & $\theta$ & $\theta$ & HS or less \\
\hline Industrial"Eng ineer & $\theta$ & $\theta$ & $\emptyset$ & $\theta$ & Hostly Associate \\
\hline Irrigation Engineer & $\theta$ & $\theta$ & $\theta$ & 0 & HS or less \\
\hline Material Handler & $\emptyset$ & $\theta$ & $\theta$ & $\theta$ & HS or less \\
\hline Materials Engineer & $\theta$ & $\theta$ & $\theta$ & $\theta$ & Mostly Associate \\
\hline Materials Scientist & $\theta$ & $\theta$ & $\theta$ & $\theta$ & Mostly Associate \\
\hline Mathemat ician & $\theta$ & 0 & $\theta$ & $\ddot{\theta}$ & Mostly Associate \\
\hline Mech Eng in Tech & 8 & $\theta$ & $\theta$ & $\emptyset$ & HS or less \\
\hline Mechanical Engineer & $\theta$ & $\theta$ & $\theta$ & $\theta$ & Most ly Assoc late \\
\hline NucWaste Process Oper & $\theta$ & $\theta$ & $\theta$ & $\emptyset$ & HS or less \\
\hline Nuc lear Decon Engineer & $\theta$ & $\theta$ & $\theta$ & $\theta$ & Mostly Associate \\
\hline Nuc lear Engineer & 0 & $\theta$ & 6 & $\theta$ & Mostly Associate \\
\hline Opers Researcher & $\theta$ & $\theta$ & 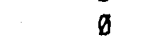 & $\theta$ & Mostly Associate \\
\hline Other Adninistrator & $\theta$ & $\theta$ & $\theta$ & 6 & HS or less \\
\hline Other Engineer & $\theta$ & $g$ & $\theta$ & $\theta$ & Mostly Associate \\
\hline Other Scient ist & $\theta$ & $\theta$ & 0 & 0 & Mostly Associate \\
\hline Other Technician & $\theta$ & 0 & $\theta$ & $\theta$ & HS or less \\
\hline Petrol_Mining Engineer & $\emptyset$ & 0 & a & $\theta$ & Mostly Associate \\
\hline Physicist & $\theta$ & $\theta$ & $\emptyset$ & $\theta$ & Mostly Assoclate \\
\hline Project Manager & $\theta$ & $\theta$ & $\theta$ & $\theta$ & HS or less \\
\hline Rad Protect Spec & $\theta$ & $\theta$ & $\theta$ & $\theta$ & HS or less \\
\hline Remediation Specialist & $\theta$ & $\theta$ & $\theta$ & $\theta$ & HS or less \\
\hline Risk Assess Manager & $\theta$ & $\theta$ & $\theta$ & $\theta$ & HS or less \\
\hline Safety Engineer & $b$ & $\theta$ & $\theta$ & $\theta$ & Mostly Associate \\
\hline Seismologist & $\theta$ & $\theta$ & $\ddot{\theta}$ & 9 & Mostly Associate \\
\hline Statistician & 8 & $\theta$ & $\theta$ & $\theta$ & Mostly Assoclate \\
\hline Structural Eng ineer & $\theta$ & $\theta$ & $\emptyset$ & $\theta$ & Mostly Associate \\
\hline Survey_Map Tech & $\theta$ & $\theta$ & 6 & $\theta$ & HS or less \\
\hline Technical Writer & $\theta$ & $\theta$ & $\theta$ & 0 & HS or less \\
\hline Trainer & $\theta$ & $\theta$ & $\theta$ & 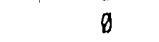 & HS or less \\
\hline WasteMan Engineer & 8 & $\theta$ & $\emptyset$ & $\theta$ & Mostly Associate \\
\hline
\end{tabular}

Statistics based on data from 1 WNAS survey and 1 SCHC survey. Surveys only contained FTE data. 


\section{TABLE L.4. Titles Sorted by Project Manager's Ratings of Anticipated Ability to Recruit (PM_Rec_A)}

\section{Job Title}

Admin Clerical

Biochemist

Biologist

Chem Tech

Chemical Eng Tech

Chemical Engineer

Chemist

Civil Eng Tech

Civil Engineer

Computer Engineer

Computer Oper

Drafter

Drtller

Ecologist

Electri_tronic Tech

Electric tronic Engineer

Environ Eng ineer

Environ Sciences Tech

Environ Scientist

Estimator

Geo logist

$H$ physics Tech

HazWasteMan Spec

Hea lth Physicist

Hydrol_Hydrogeo log ist

Ind Hyg ien ist

Ind Safety Heaith Tech

Industrial Eng ineer

Irrigat ion Engineer

Material Handler

Materials Engineer

Materia ls Scient ist

Mathematician

Mech Eng in Tech

Mechanical Eng ineer

NucWaste Process Oper

Nuc lear Decon Engineer

Nuc lear Engineer

Opers Researcher

Petrol Mining Engineer

Physicist

Project Manager

Rad Protect Spec

Remediation Specialist

Risk Assess Manager

Safety Eng ineer

Se ismologist

Statistician

Structural Engineer

Survey Map Tech

Technical Writer

Trainer

WasteMan Engineer
PH_REC_A

PM_OELTA

6

0

0

$\theta$

0

0

0

0

9

0

0

0

0

8

9

9

9

$g$

$g$

9

9

6

0

0

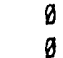

0

0
0
9

0

g

0
9
Degree

HS or less Mostly Associate Most ly Associate

HS or less

HS or less Mostly Associate

Most ly Associate

HS or less

Most ly Associate

Most ly Associate

HS or less

HS or less

HS or less

Most ly Associate

HS or less

Most ly Assoc late

Most ly Associate

HS or less

Most ly Associate

HS or less

Most ly Associate

HS or less

HS or less

Most ly Associate

Mostly Associate

HS or less

HS or less

Most ly Associate

HS or less

HS or less

Most ly Associate

Mostly Associate

Mostly Associate

HS or less

Mostly Associate HS or less

Mostly Associate Most ly Associate

Most ly Associate

Mostly Associate

Mostly Associate

HS or less

HS or less

HS or less

HS or less

Mostly Associate

Mostly Associate

Most ly Associate

Most ly Associate

HS or less

HS or less

HS or less

Mostly Associate

Statistics based on data from 1 WNAS survey and 1 SCHC survey. Surveys only contained FTE data. 


\title{
TABLE L.5. Titles Sorted By Project Manager's Ratings of Difficulty Caused by Shortage (PM_Diff)
}

\author{
Job Title \\ Admin_Clerical \\ Biochemist \\ Biologist \\ Chem Tech \\ Chemical Eng Tech \\ Chemical Engineer \\ Chemist \\ Civil Eng Tech \\ Civil Eng ineer \\ Computer Eng ineer \\ Computer Oper \\ Drafter \\ Driller \\ Ecologist \\ Electri tronic Tech \\ Electric_tronic Engineer \\ Environ Ëngineer \\ Environ Sciences Tech \\ Environ Scient ist \\ Estimator \\ Geologist \\ H_physics Tech \\ HazWasteMan Spec \\ Health Physicist \\ Hydrol_Hydrogeolog ist \\ Ind Hygien ist \\ Ind Safety_Health Tech \\ Industrial Engineer \\ Irrigation Engineer \\ Material Handler \\ Materials Engineer \\ Materials Scientist \\ Mathematician \\ Mech Eng in Tech \\ Mechanical Engineer \\ NucWaste Process Oper \\ Nuc lear Decon Eng ineer \\ Nuc lear Engineer \\ Opers Researcher \\ Petrol_Mining Engineer \\ Physicist \\ Project Manager \\ Rad Protect Spec \\ Renediation Specialist \\ Risk Assess Manager \\ Safety Eng ineer \\ Se ismologist \\ Statistician \\ Structural Engineer \\ Survey Map Tech \\ Technical Writer \\ Trainer \\ WasteMan Engineer
}

PM_DIFF

PM_DELTA

Degree

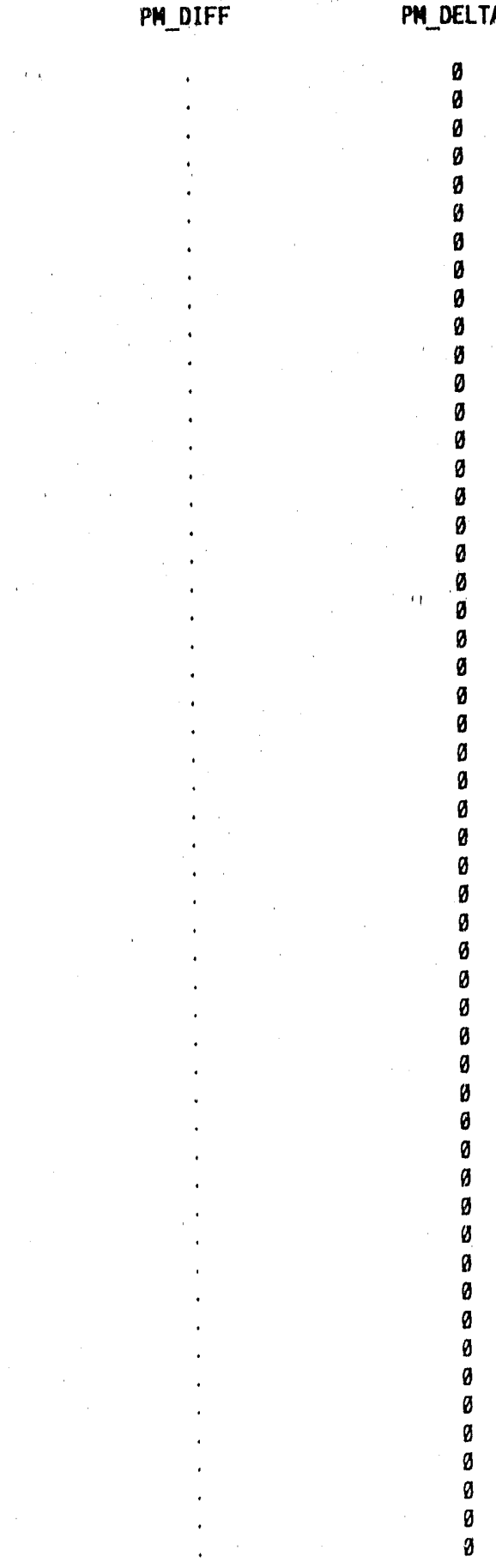

HS or less

Most ly Associate

Most ly Associate

HS or less

HS or less

Most ly Associate

Most ly Assoc late

HS or less

Most ly Assoc late

Most ly Associate

HS or less

HS or less

HS or less

Most ly Associate

HS or less

Most ly Associate

Most ly Associate

HS or less

Most ly Assoclate

HS or less

Most ly Associate

HS or less

HS or less

Most ly Assoc late

Most ly Associate

HS or less

HS or less

Most ly Associate

HS or less

HS or less

Most ly Associate

Most ly Associate

Most ly Associate

HS or less

Most ly Associate

HS or less

Most ly Associate

Most ly Associate

Most ly Associate

Most ly Associate

Most ly Associate

HS or less

HS or less

HS or less

HS or less

Most ly Associate

Most ly Assoc iate

Most ly Associate

Most ly Associate

HS or less

HS or less

HS or less

Most ly Associate

Statistics based on data from 1 WNAS survey and 1 SCHC survey. Surveys only contained FTE data. 
TABLE L.6. Job Titles Sorted By Human Resource Personnel's Ratings of Difficulty Caused By Shortage (HR_Diff)

Job Title
Admin_Clerical
Blochemist
Blologist
Chem Tech
Chemical Eng Tech
Chemical Engineer
Chemist
Civil Eng Tech
Civil Engineer
Computer Engineer
Computer Oper
Drafter
Driller
Ecologist
Electri_tronic Tech
Electric tronic Engineer
Environ Engineer
Environ Sciences Tech
Environ Scientist
Estimator
Geologist
H_physics Tech
HazWasteMan Spec
Health Physicist
Hydrol_Hydrogeclogist
Ind Hygienist
Ind Safety_Health Tech
Industrial Engineer
Irrigation Engineer
Material Handler
Materials Engineer
Materials Scientist
Mathematician
Mech Engin Tech
Mechanical Engineer
NucWaste Process Oper
Nuclear Decon Engineer
Nuclear Engineer
Opers Researcher
Petrol_Mining Engineer
Physicist
Project Manager
Rad Protect Spec
Remediation Specialist
Risk Assess Manager
Safety Engineer
Seismologist
Statistician
Structural Engineer
Survey_Map Tech
Technical Writer
Trainer
WasteMan Engineer

HR_DIFF

PH_DELTA

8

$\theta$

0

$\theta$

$\theta$

ด

0

g

0

0

$\theta$

$\theta$

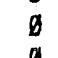

$\theta$

9

g

0

6

0

0

6

0

0

$\theta$

$\theta$

$g$

$\theta$

0

$\theta$

0

$\theta$

$\theta$

$\emptyset$

$\theta$

$\theta$

$\theta$

0

$\theta$

$\theta$

$\theta$

0

$g$

0

Statistics based on data from 1 WNAS survey and 1 SCHC survey. Surveys only contained FTE data. 


\section{TABLE L.7. Job Titles Sorted By Human Resource Personnel's Ratings of Need for Additional Employees (HR_Need)}

Job Title

Admin_Clerical
Blochemist
Biologist
Chem Tech
Chemical Eng Tech
Chemical Eng ineer
Chemist
Civil Eng Tech
Civil Engineer
Computer Engineer
Computer Oper
Drafter
Oriller
Ecologist
Electri-tronic Tech
Electric tronic Eng ineer
Environ Engineer
Environ Sciences Tech
Environ Scient ist
Estimator
Geologist
H_physics Tech
HazWasteMan Spec
Health Physicist
Hydrol Hydrogeologist
Ind Hygienist
Ind Safety Health Tech
Industrial Engineer
Irrigation Engineer
Material Handler
Materlals Engineer
Materials Scientist
Mathematiclan
Mech Engin Tech
Mechanical Engineer
NucWaste Process Oper
Nuclear Decon Engineer
Nuclear Eng ineer
Opers Researcher
Petrol Mining Engineer
Physicist
Project Manager
Rad Protect Spec
Remediation Specialist
Risk Assess Manager
Safety Engineer
Seismologist
Statistician
Structural Engineer
Survey Map Tech
Technical Writer
Trainer
WasteMan Engineer

\section{HR_NEED}

\section{PM_DELTA}

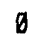

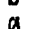

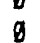

0

$\theta$

$\theta$

$\theta$

$\theta$

$\theta$

D

$\theta$

b

0

$\theta$

$\theta$

0

g

0

a

$\theta$

$\theta$

9

$\theta$

0

$\theta$

$\theta$

$\theta$

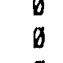

$\theta$

Degree

HS or less Most ly Assoclate Mos ly Associate HS or less

HS or less Most ly Assoclate Most ly Associate HS or less

Mostly Associate Most ly Associate HS or less

HS or less HS or less Most ly Associate HS or less Mostly Associate Most ly Associate HS or less

Mostly Associate HS or less Most ly Associate. HS or less

HS or less

Mostly Associate Most ly Associate HS or less HS or less Most ly Associate HS or less

HS or less Most ly Associate Mostly Associate Most ly Associate HS or less Most ly Associate HS or less

Mostly Associate Mostly Associate Mcst iy Associate Mostly Associate Mostly Associate HS or less HS or less HS or less HS or less Most ly Associate Mostly Associate Mostly Associate Mostly Associate HS or less HS or less HS or less Mostly Associate

Statistics based on data from 1 WNAS survey and 1 SCHC survey. Surveys only contained FTE data. 


\title{
TABLE L.8. Job Titles Sorted By Human Resource Personnel's Ratings of Current Ability to Recruit (HR_Rec_C)
}

\author{
Job Title \\ Admin Clerical \\ 8 iochemist \\ Biologist \\ Chem Tech \\ Chemical Eng Tech \\ Chemical Engineer \\ Chemist \\ Civil Eng Tech \\ Civil Engineer \\ Computer Eng ineer \\ Computer Oper \\ Drafter \\ Oriller \\ Ecologist \\ Electri_tronic Tech \\ Electric tronic Engineer \\ Environ Engineer \\ Environ Sciences Tech \\ Environ Scientist \\ Est imator \\ Geologist \\ H_physics Tech \\ HazWasteMan Spec \\ Health Physicist \\ Hydro 1_Hydrogeo log ist \\ Ind Hyg ien ist \\ Ind Safety Health Tech \\ Industrial Engineer \\ Irrigation Engineer \\ Material Handler \\ Materials Engineer \\ Materials Scientist \\ Mathematician \\ Mech Eng in Tech \\ Mechanical Eng ineer \\ NucWaste Process Oper \\ Nuclear Decon Eng ineer \\ Nuc lear Eng ineer \\ Opers Researcher \\ Petral Mining Engineer \\ Physicist. \\ Project Manager \\ Rad Protect Spec \\ Remediation Specialist \\ Risk Assess Manager \\ Safety Engineer \\ Seismologist \\ Statistician \\ Structural Engineer \\ Survey Map Tech \\ Technical Writer \\ Trainer \\ WasteMan Engineer
}

HR_REC_C

PM_DELTA

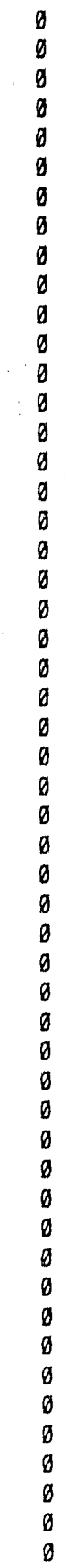

Degree

HS or less

Most ly Assoolate

Most ly Associate

HS or less

HS or less

Mostly Associate

Most ly Associate

HS or less

Most ly Associate

Mostly Associate

HS or less

HS or less

HS or less

Most ly Associate

HS or less

Most ly Associate

Mostly Associate

HS or less

Mostly Associate

HS or less

Mostly Associate

HS or less

HS or less

Mostly Associate

Mostly Associate

HS or less

HS or less

Most ly Associate

HS or less

HS or less

Mostly Associate

Mostly Associate

Most ly Assoc late

HS or less

Most ly Associate

HS or less

Mostly Associate Most ly Associate

Mostly Associate

Most ly Associate

Most ly Associate

HS or less

HS or less

HS or less

HS or less

Most ly Associate

Most ly Associate

Mostly Associate

Most ly Associate

HS or less

HS or less

HS or less

Most ly Associate

Statistics based on data from 1 WNAS survey and 1 SCHC survey. Surveys only contained FTE data. 


\section{TABLE L.9. Job Titles Sorted By Human Resource Personnel's Ratings of Anticipated Ability to Recruit (HR_Rec_A)}

AR_REC_A

PM_DELTA

Degree

HS or less

Mast ly Associate

Most ly Associate

HS or less

HS or less

Mostly Associate

Most ly Associate

HS or less

Most ly Associate

Most ly Associate

HS or less

HS or less

HS or less

Most ly Associate

HS or less

Most iy Associate

Most ly Associate

HS or less

Mostly Associate

HS or less

Most ly Associate

HS or less

HS or less

Mostly Associate

Most ly Associate

HS or less

HS or less

Most ly Associate

HS or less

HS or less

Mostly Associate

Most ly Associate

Most ly Associate

HS or less

Mostly Associate

HS or less

Most ly Associate Most ly Associate Most ly Associate Most ly Associate Most ly Associate HS or less

HS or less HS or less HS or less Mostly Associate Most ly Associate Mostly Associate Most ly Associate HS or less HS or less HS or less Most ly Associate

Statistics based on data rom 1 WHAS survey and 1 SCHC survey, Surveys only contained FTE data. 

TABLE L.10. Job Titles Sorted By Human Resource Personnel's Ratings
of Annual Turnover (HR_Turn)

\begin{tabular}{|c|c|c|}
\hline Job Title & HR_TURA & PM_DEL \\
\hline Admin_Clerical & . & $\theta$ \\
\hline Biochēem ist & . & 0 \\
\hline Biologist & . & 0 \\
\hline Chem Tech & . & $\theta$ \\
\hline Chernical Eng Tech & . & $g$ \\
\hline Chemical Engineer & . & 0 \\
\hline $\begin{array}{l}\text { Chemist } \\
\text { Civil Eng Tech }\end{array}$ & $\cdot$ & 9 \\
\hline $\begin{array}{l}\text { Civil Eng Tech } \\
\text { Civil Engineer }\end{array}$ & · & 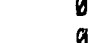 \\
\hline $\begin{array}{l}\text { Civil Engineer } \\
\text { Computer Eng ineer }\end{array}$ & $\cdot$ & $g$ \\
\hline $\begin{array}{l}\text { Computer Eng ineer } \\
\text { Computer Oper }\end{array}$ & $\dot{.}$ & $\theta$ \\
\hline $\begin{array}{l}\text { Computer Oper } \\
\text { Drafter }\end{array}$ & $\dot{.}$ & $\theta$ \\
\hline $\begin{array}{l}\text { Dratter } \\
\text { Dritler }\end{array}$ & . & 0 \\
\hline Ecologist & . & 0 \\
\hline Electri_tronic Tech & . & $\theta$ \\
\hline Electric tronic Engineer & $\cdot$ & $\theta$ \\
\hline Environ Engineer & $\cdot$ & $\theta$ \\
\hline Environ Sciences Tech & $\cdot$ & 8 \\
\hline Environ Scientist & $\cdot$ & $\theta$ \\
\hline Est imator & $\cdot$ & $\theta$ \\
\hline Geologist & $\cdot$ & 0 \\
\hline $\begin{array}{l}\text { H_physics Tech } \\
\text { HazWasteMan Spec }\end{array}$ & $\dot{.}$ & 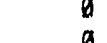 \\
\hline $\begin{array}{l}\text { HazWasteMan Spec } \\
\text { Health Physicist }\end{array}$ & $\dot{.}$ & 8 \\
\hline $\begin{array}{l}\text { Hea ith Physicist } \\
\text { Hydrol Hydrogeologist }\end{array}$ & $\dot{.}$ & $\theta$ \\
\hline $\begin{array}{l}\text { Hydrol_Hydrogeo logist } \\
\text { Ind Hygien ist }\end{array}$ & : & 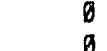 \\
\hline $\begin{array}{l}\text { Ind Hygienist } \\
\text { Ind Safety Health Tech }\end{array}$ & : & b \\
\hline $\begin{array}{l}\text { Ind Safety Health Tech } \\
\text { IndustrialEngineer }\end{array}$ & . & $\begin{array}{l}\theta \\
\theta\end{array}$ \\
\hline $\begin{array}{l}\text { Industrial Eng ineer } \\
\text { Irrigation Eng ineer }\end{array}$ & . & 0 \\
\hline $\begin{array}{l}\text { Irrigation Engineer } \\
\text { Material Handler }\end{array}$ & . & $\begin{array}{l}b \\
0\end{array}$ \\
\hline $\begin{array}{l}\text { Material Handler } \\
\text { Materials Engineer }\end{array}$ & . & $\theta$ \\
\hline $\begin{array}{l}\text { Materials Engineer } \\
\text { Materials Scientist }\end{array}$ & . & 0 \\
\hline $\begin{array}{l}\text { Materials Scientist } \\
\text { Mathematician }\end{array}$ & " & 0 \\
\hline $\begin{array}{l}\text { Mathemat ician } \\
\text { Mech Eng in Tech }\end{array}$ & . & 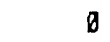 \\
\hline $\begin{array}{l}\text { Mech Engin Tech } \\
\text { Mrchanical Engineer }\end{array}$ & . & 0 \\
\hline NucWaste Process Oper & . & $B$ \\
\hline Nuclear Decon Engineer & . & $B$ \\
\hline Nuc lear Eng ineer & . & $\theta$ \\
\hline Opers Researcher & . & 0 \\
\hline Petrol_Mining Engineer & . & 0 \\
\hline Physicist & . & $\theta$ \\
\hline Project Manager & . & $\emptyset$ \\
\hline Rad Protect Spec & . & $\emptyset$ \\
\hline Renediation Specialist & . & 0 \\
\hline Risk Assess Manáger & . & 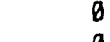 \\
\hline Safety Engineer & · & $\theta$ \\
\hline Se ismologist & . & $\begin{array}{l}\theta \\
a\end{array}$ \\
\hline Statistician & $\cdot$ & $g$ \\
\hline Structural Eng ineer & . & 8 \\
\hline Survey_Map Tech & . & a \\
\hline Technical Writer & . & $\theta$ \\
\hline Trainer & . & $\theta$ \\
\hline WasteMan Engineer & . & \\
\hline
\end{tabular}

\author{
Degree \\ HS or less \\ Most ly Associate \\ Mostly Associate \\ HS or less \\ HS or less \\ Mostly Associate \\ Most ly Associate \\ HS or less \\ Most ly Associate \\ Mostly Associate \\ HS or less \\ HS or less \\ HS or less \\ Most ly Associate \\ HS or less \\ Mostly Associate \\ Mostly Associate \\ HS or less \\ Most ly Associate \\ HS or less \\ Mostly Associate \\ HS or less \\ HS or less \\ Mostly Associate \\ Mostly Associate \\ HS or less \\ HS or less \\ Mostly Associate \\ HS or lass \\ HS or less \\ Mostly Associate \\ Most ly Associate \\ Most ly Associate \\ HS or less \\ Host ly Associate \\ HS or less \\ Mostly Associate \\ Mostly Associate \\ Mostly Associate \\ Mostly Associate \\ Most ly Associate \\ HS or less \\ HS or less \\ HS or less \\ HS or less \\ Most iy Associate \\ Most ly Associate \\ Most ly Associate \\ Most ly Associate \\ HS or less \\ HS or less \\ HS or less \\ Mostly Associate
}

Statistics based on data from ! WNAS survey and I SCHC survey. Surveys only contained FTE data. 


\section{APPENDIX M}

\section{SIMPLE STATISTICS INTERCORRELATION AMONG \\ VARIABLES AND JOB SORTS ON ALL VARIABLES \\ FOR NEVADA ONLY}


TABLE M.1. Descriptive Statistics for Relative Ratings

$\begin{array}{llcccc}\text { Variable } & \text { N } & \text { Minimum } & \text { Maximum } & \underline{\text { Mean }} & \underline{\text { S.D. }} \\ \text { HR_DIFF } & 11 & 2.00 & 4.00 & 2.82 & 0.75 \\ \text { HR_NEED } & 10 & 1.00 & 3.00 & 2.20 & 0.63 \\ \text { HR_REC_C } & 11 & 2.00 & 4.00 & 2.82 & 0.75 \\ \text { HR_REC_A } & 11 & 2.00 & 4.00 & 2.82 & 0.75 \\ \text { HR_TURN } & 10 & 2.00 & 3.00 & 2.40 & 0.52 \\ \text { PM_DIFF } & 32 & 1.71 & 5.00 & 3.01 & 0.79 \\ \text { PM_REC_A } & 32 & 1.86 & 5.00 & 3.12 & 0.68 \\ \text { PM_EDUC } & 32 & 1.57 & 5.00 & 3.55 & 0.80\end{array}$

S.D. = Standard Deviation, HR_DIFF = Difficuity Caused by a Shortage, HR NEED = Need for Additional Employees, HR-REC_A = Anticipated Ease of Recruitment, HR-REC-C = Current Ease of Recruitment, HR TURN = Current Arnual Turnover, PM DIFF = Difficulty Caused By a Shortage, PM REC $A=$ Anticipated Ability to Recruit, PM EDUC = Typical Degree Level, ${ }^{* \star} \bar{p}<\overline{0} .01 ; * p<0.05$. Statistics based on data from 7 WNAS surveys and 1 SCHC survey. 


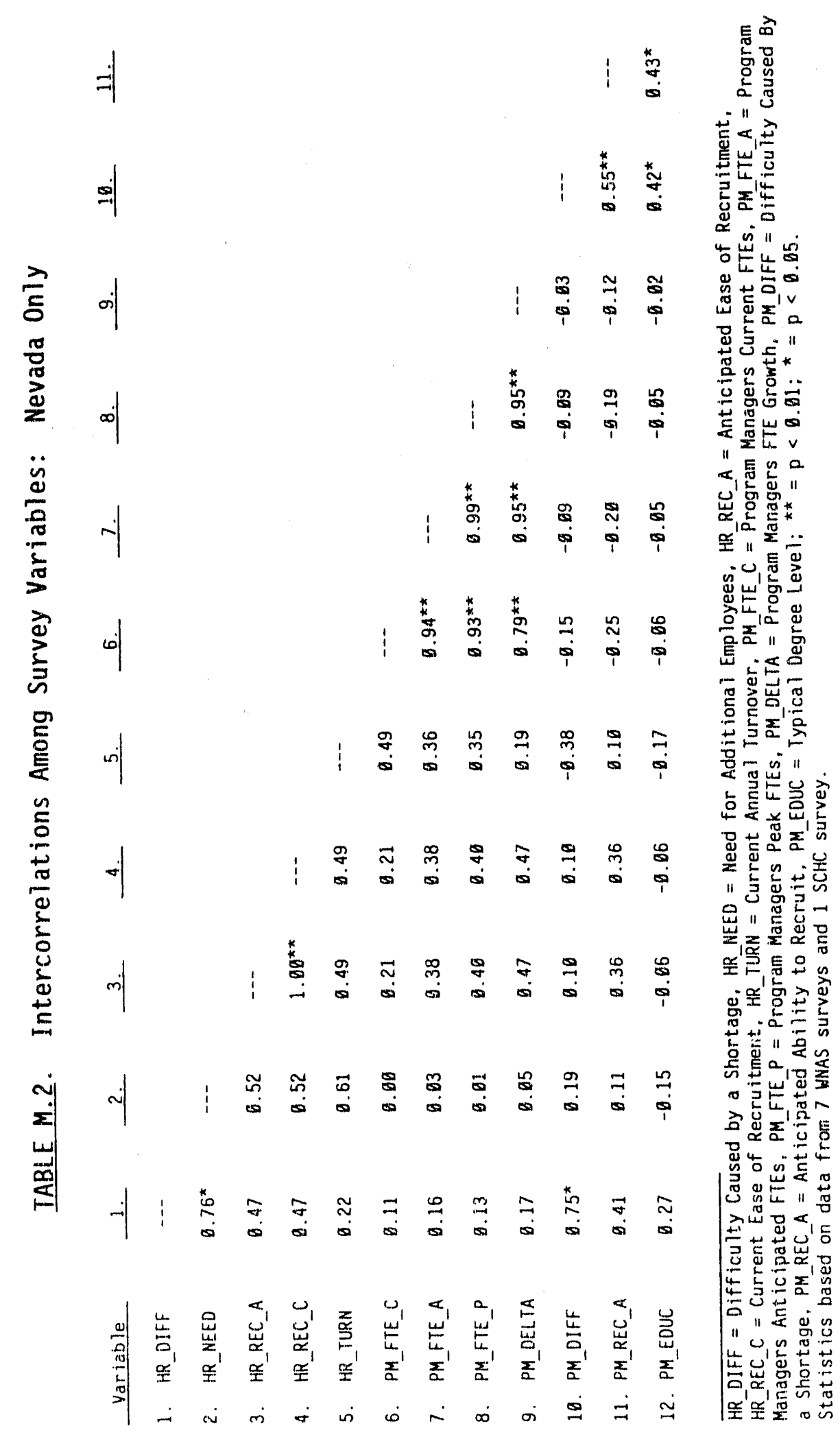

M. 2 


\section{TABLE M.3. Job Titles Sorted By Change in FTEs (PM_Delta)}

\begin{tabular}{|c|}
\hline $\begin{array}{l}\text { Project Manager } \\
\text { Hydrol_Hydrogeologist } \\
\text { Environ Scientist } \\
\text { Admin_Clerical } \\
\text { Electri_tronic Tech } \\
\text { Geologist } \\
\text { Health Physicist } \\
\text { Civil Engineer } \\
\text { H_physics Tech } \\
\text { HazWasteMan Spec } \\
\text { Mechanical Engineer } \\
\text { Environ Engineer } \\
\text { Other Administrator } \\
\text { Other Scientist } \\
\text { Physicist } \\
\text { Technical Writer } \\
\text { WasteMan Eng ineer } \\
\text { Biologist } \\
\text { Chemist } \\
\text { Computer Engineer } \\
\text { Orafter } \\
\text { Electric_tronic Engineer } \\
\text { Ind Hygienist } \\
\text { Mech Engin Tech } \\
\text { Computer Oper } \\
\text { Ecologist } \\
\text { Estimator } \\
\text { Ind Safety_Health Tech } \\
\text { Other Technician } \\
\text { Petrol_Mining Engineer } \\
\text { Rad Protect Spec } \\
\text { Risk Assess Manager } \\
\text { Biochemist } \\
\text { Chem Tech } \\
\text { Chemical Eng Tech } \\
\text { Chemical Engineer } \\
\text { Civil Eng Tech } \\
\text { Oriller } \\
\text { Environ Sciences Tech } \\
\text { Industrial Engineer } \\
\text { Irrigation Engineer } \\
\text { Material Handler } \\
\text { Materials Engineer } \\
\text { Materials Scientist } \\
\text { Mathematician } \\
\text { NucWaste Process Oper } \\
\text { Nuclear Decon Engineer } \\
\text { Nuclear Engineer } \\
\text { Opers Researcher } \\
\text { Other Engineer } \\
\text { Remediation Specialist } \\
\text { Safety Engineer } \\
\text { Seismologist } \\
\text { Statistician } \\
\text { Structural Engineer } \\
\text { Survey_Map Tech } \\
\text { Trainer }\end{array}$ \\
\hline
\end{tabular}

\begin{tabular}{|c|c|}
\hline PH_FTE_C & PH_FTE_A \\
\hline 6 & 21 \\
\hline 11 & 23 \\
\hline 8 & 18 \\
\hline 13 & 22 \\
\hline 1 & 6 \\
\hline 6 & 11 \\
\hline 6 & 11 \\
\hline 1 & 5 \\
\hline 4 & 8 \\
\hline 3 & 7 \\
\hline$g$ & 4 \\
\hline 3 & 6 \\
\hline 1 & 4 \\
\hline 5 & 8 \\
\hline 1 & 4 \\
\hline 2 & 5 \\
\hline 1 & 4 \\
\hline 1 & 3 \\
\hline 2 & 4 \\
\hline 5 & 7 \\
\hline$\theta$ & 2 \\
\hline$\theta$ & 2 \\
\hline 2 & 4 \\
\hline 2 & 4 \\
\hline 4 & 5 \\
\hline 2 & 3 \\
\hline 0 & 1 \\
\hline$\theta$ & 1 \\
\hline$\theta$ & 1 \\
\hline 3 & 4 \\
\hline 0 & 1 \\
\hline$b$ & 1 \\
\hline$\theta$ & 6 \\
\hline$\theta$ & $\theta$ \\
\hline$\theta$ & $\theta$ \\
\hline$b$ & $\theta$ \\
\hline$\emptyset$ & 0 \\
\hline$\theta$ & $\theta$ \\
\hline$\theta$ & $\theta$ \\
\hline$\theta$ & $\theta$ \\
\hline$\theta$ & $b$ \\
\hline$\theta$ & $\theta$ \\
\hline$\theta$ & $B$ \\
\hline 8 & $\theta$ \\
\hline 1 & 1 \\
\hline$\theta$ & $\theta$ \\
\hline$\theta$ & $\theta$ \\
\hline 8 & $\theta$ \\
\hline$\theta$ & $\theta$ \\
\hline 8 & $\theta$ \\
\hline$\theta$ & $\theta$ \\
\hline$B$ & $\theta$ \\
\hline 1 & 1 \\
\hline 3. & 3 \\
\hline$\theta$ & 0 \\
\hline$\theta$ & 0 \\
\hline 8 & $\theta$ \\
\hline
\end{tabular}

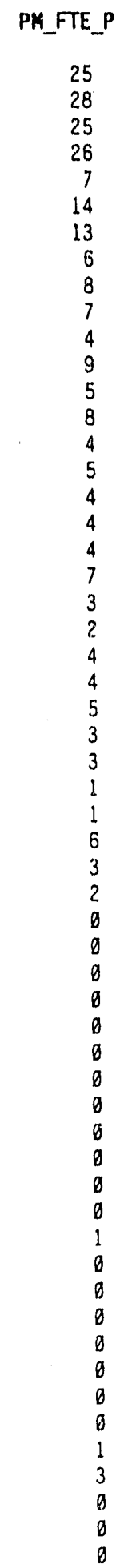

PM_DELTA Degree

Most ly Bache lor Mix of $B S$ and Advanced Mix of $B S$ and Advanced Most ly Associate Mostly Associate Mix of BS and Advanced Mix of BS and Advanced Most ly Bachelor Mostly Bachelor Mix of AS and BS Mix of $B S$ and Advanced Mix of BS and Advanced HS or less

Mostly Associate

Mix of $B S$ and Advanced Mix of $A S$ and $B S$

Mix of BS and Advanced Mix of BS and Advanced Mix of BS and Advanced Most ly Bachelor Most ly Associate Most ly Bachelor Mostly Bachelor Most ly Associate Mix of AS and BS Mix of BS and Advanced Mix of AS and BS Most ly Bachelor HS or less

Most ly Bachelor Mix of AS and BS Mix of AS and $8 S$ Most ly Associate HS or less HS or less Most ly Associate HS or less HS or less HS or less Mostily Associate HS or less HS or less Most ly Associate Most ly Associate Most ly PhD HS or less Most ly Associate Most ly Associate Most ly Associate Most ly Associate HS or less Most ly Associate Mix of BS and Advanced Mostly PhD Most ly Associate HS or less HS or less

Statistics based on data from 7 WNAS surveys and 1 SCHC survey. 


\section{TABLE M.4. Titles Sorted by Project Manager's Ratings of Anticipated Ability to Recruit (PM_Rec_A)}

\begin{tabular}{|c|c|c|}
\hline Job Title & PH_REC_A & PH_DEL \\
\hline Ind Hygienist & 5.00 & 2 \\
\hline Ind Safety_Health Tech & 4.00 & 1 \\
\hline Rad Protect $\bar{t}$ Spec & 4.00 & 1 \\
\hline Mathematician & 4.66 & $\theta$ \\
\hline Se ismolog ist & 4.00 & $\theta$ \\
\hline Hea 1th Physicist & 3.80 & 5 \\
\hline WasteMan Engineer & 3.67 & 3 \\
\hline Hydrol_Hydrogeologist & 3.60 & 12 \\
\hline Environ Engineer & 3.50 & 3 \\
\hline Risk Assess Manager & 3.50 & 1 \\
\hline Mech Engin Tech & 3.50 & 2 \\
\hline HazWasteMan Spec & 3.33 & 4 \\
\hline H_physics Tech & 3.80 & 4 \\
\hline Physicist & 3.00 & 3 \\
\hline Electric_tronic Engineer & 3.00 & 2 \\
\hline Estimato $\vec{r}$ & 3.00 & 1 \\
\hline Project Manager & 3.00 & 15 \\
\hline Environ Scientist & 3.00 & 10 \\
\hline Electri_tronic Tech & 3.00 & 5 \\
\hline Chemist & 3.60 & 2 \\
\hline Mechanical Engineer & 3.60 & 4 \\
\hline Ecologist & 3.60 & 1 \\
\hline Geologist & 2.75 & 5 \\
\hline Technical Writer & 2.75 & 3 \\
\hline Biologist & 2.67 & 2 \\
\hline Civil Engineer & 2.60 & 4 \\
\hline Statistician & 2.50 & $\theta$ \\
\hline Computer Eng ineer & 2.50 & 2 \\
\hline Petrol_Mining Eng ineer & 2.33 & 1 \\
\hline Computēr Oper & 2.00 & 1 \\
\hline Drafter & 2.80 & 2 \\
\hline Admin_Clerical & 1.86 & 9 \\
\hline Biochēmist & . & $\theta$ \\
\hline Chem Tech & . & $\theta$ \\
\hline Chemical Eng Tech & . & 8 \\
\hline Chemical Engineer & . & $\theta$ \\
\hline Civil Eng Tech & . & $\theta$ \\
\hline Driller & . & $\emptyset$ \\
\hline Environ Sciences Tech & . & $a$ \\
\hline Industrial Engineer & . & $\emptyset$ \\
\hline Irrigation Engineer & . & $\theta$ \\
\hline Material Handler & . & $\theta$ \\
\hline Materlals Engineer & . & $\theta$ \\
\hline Materials Scientist & . & 9 \\
\hline NucWaste Process Oper & . & $\theta$ \\
\hline Nuc lear Decon Eng ineer & . & $\theta$ \\
\hline Nuc lear Eng ineer & . & $\theta$ \\
\hline Opers Researcher & . & $B$ \\
\hline Remediation Specialist & . & $\theta$ \\
\hline Safety Eng ineer & . & $\theta$ \\
\hline Structural Engineer & . & $\theta$ \\
\hline Survey_Map Tech & . & $g$ \\
\hline Trainer & . & $\emptyset$ \\
\hline
\end{tabular}

Statistics based on data from 7 WNAS surveys and 1 SCHC survey. 


\section{IABLE M.5. Titles Sorted By Project Manager's Ratings of Difficulty Caused by Shortage (PM_Diff)}

Job Title
H_physics Tech
Physicist
Electric tronic Engineer
Ind Hygienist
Ind Safety_Health Tech
Rad Protect Spec
Mathematician
Estimator
Hydrol_Hydrogeologist
Health Physicist
WasteMan Engineer
Environ Engineer
Project Manager
Environ Scientist
Risk Assess Manager
Seismologist
Statistician
Geologist
HazWasteMan Spec
Computer Oper
Civil Engineer
Electri_tronic Tech
Technical Writer
Chemist
Computer Engineer
Drafter
Mechanical Engineer
Blologist
Mech Eng in Tech
Ecologist
Petrol Mining Eng ineer
Admin_Clerical
Biochemist
Chem Tech
Chemical Eng Tech
Chemical Engineer
Civil Eng Tech
Oriller
Environ Sciences Tech
Industrial Engineer
Irrigation Engineer
Matertal Handler
Materials Engineer
Materials Scient ist
NucWaste Process Oper
Nuclear Decon Engineer
Nuclear Engineer
Opers Researcher
Remediation Specialist
Safety Engineer
Structural Engineer
Survey_Map Tech
Trainer

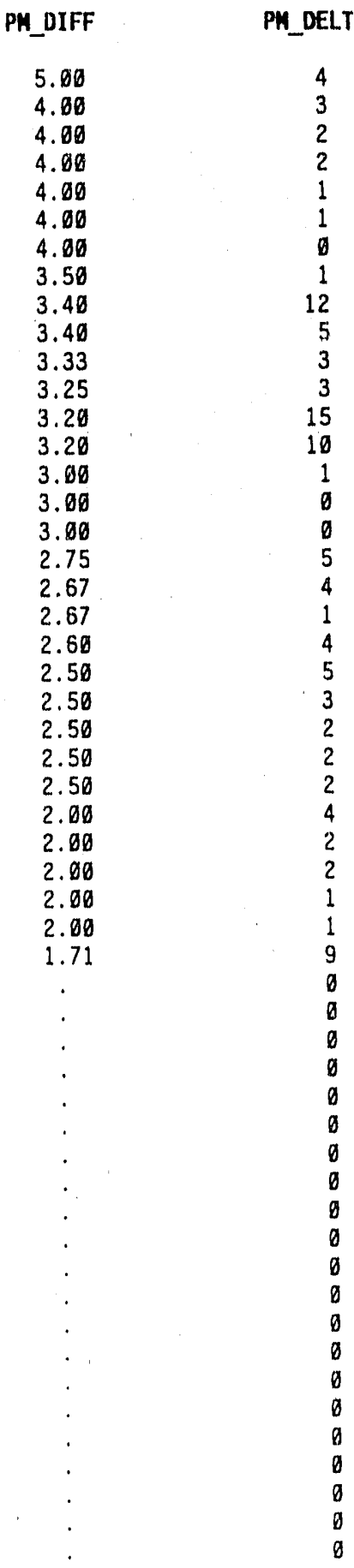

\section{Degree}

Most ly Bache lor Mix of BS and Advanced Most ly Bache lor Most ly Bache lor Most ly Bachelor MiX of AS and BS Most iy PhD

Mix of $A S$ and $B S$

Mix of $B S$ and Advanced Mix of $B S$ and Advanced Mix of $B S$ and Advanced Mix of $B S$ and Advanced Most ly Bache lor

Mix of BS and Advanced Mix of AS and BS

Mix of $8 S$ and Advanced Most ly Pho

Mix of BS and Advanced Mix of AS and BS Mix of AS and BS Most ly Bachelor Most ly Associate $M+x$ of $A S$ and $B S$ Mix of BS and Advanced Most ly Bache lor Most ly Assoclate Mix of $B S$ and Advanced Mix of BS and Advanced Most ly Associate Mix of BS and Advanced Most ly Bache lor Most ly Associate Most Ty Associate HS or less HS or less Most ly Assoc iate HS or less HS or less HS or less Most ly Assoc iate HS or less HS or less Most ly Associate Most ly Associate HS or less Most ly Associate Most ly Associate Most ly Associate HS or less Most ly Associate Most ly Associate HS or less HS or less

Statistics based on data from 7 WNAS surveys and 1 SCHC survey. 


\section{TABLE M.6. Job Titles Sorted By Human Resource Personne1's Ratings of Difficulty Caused By Shortage (HR_Diff)}

\author{
Job Title \\ Hydrol Hydrogeo log ist \\ Project Manager \\ Civil Engineer \\ Statistician \\ Computer Oper \\ Oraftei \\ Geolog : \\ Technical Writer \\ Biologist \\ Adnin Clerical \\ Ind Hygienist \\ Ind Safety Health Tech \\ Rad Protect Spec \\ Mathematician \\ Seismologist \\ Hea 1th Physicist \\ WasteMan Engineer \\ Environ Engineer \\ Risk Assess Manager \\ Mech Eng in Tech \\ HazWasteMan Spec \\ $H$ physics Tech \\ Physicist \\ Electric tronic Engineer \\ Estimator \\ Environ Scientist \\ Electri_tronic Tech \\ Chemist \\ Mechanical Engineer \\ Ecologist \\ Computer Engineer \\ Petrol Mining Engtneer \\ Biochemist \\ Chem Tech \\ Chemical Eng Tech \\ Chemical Engineer \\ Civil Eng Tech \\ Orfller \\ Environ Sctences Tech \\ Industrial Engineer \\ Irrigation Engineer \\ Material Handler \\ Materials Engineer \\ Materials Scientist \\ NucWaste Process Oper \\ Nuc lear Decon Engineer \\ Nuc lear Engineer \\ Opers Researcher \\ Remediation Speciallst \\ Safety Engineer \\ Structural Engineer \\ Survey Map Tech \\ Trainer
}

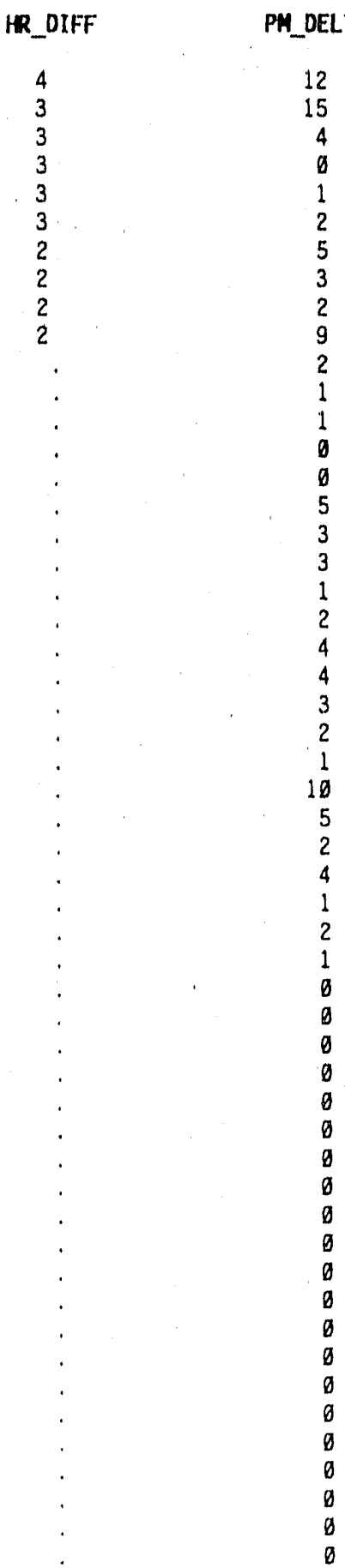

Statistics based on data from 7 WNAS surveys and 1 SCHC survey.

\section{Degree}

Mix of BS and Advanced Most ly Bache lor Mostly Bachelor Mostly PhD

MiX of AS and BS Most ly Assoc late

Mix of $B S$ and Advanced Mix of AS and BS

Mix of $B S$ and Advanced Most ly Assoc iate Most ly Bache lor Most ly Bachelor $M i x$ of $A S$ and BS Most ly PhD

Mix of $B S$ and Advanced Mix of BS and Advanced Mix of BS and Advanced Mix of BS and Advanced Mix of AS and BS Most ly Associate Mix of AS and BS Most]y. Bachelor

Mix of BS and Advanced Most ly Bachelor

Mix of AS and BS

Mix of $B S$ and Advanced Most ly Associate Mix of BS and Advanced Mix of BS and Advanced Mix of BS and Advanced Most ly Bachelor Mostly Bachelor Mostly Associate HS or less HS or less

Most ly Associate HS or less

HS or less

HS or less

Mostly Associate

HS or less

HS or less

Most ly Associate Mostly Associate HS or less Most ly Assoclate Most ly Associate Most ly Associate HS or less

Mostly Associate Most ly Associate HS or less HS or less 


\section{TABLE M.7. Job Titles Sorted By Human Resource Personnel's Ratings of Need for Additional Employees (HR_Need)}

\section{Job Title}

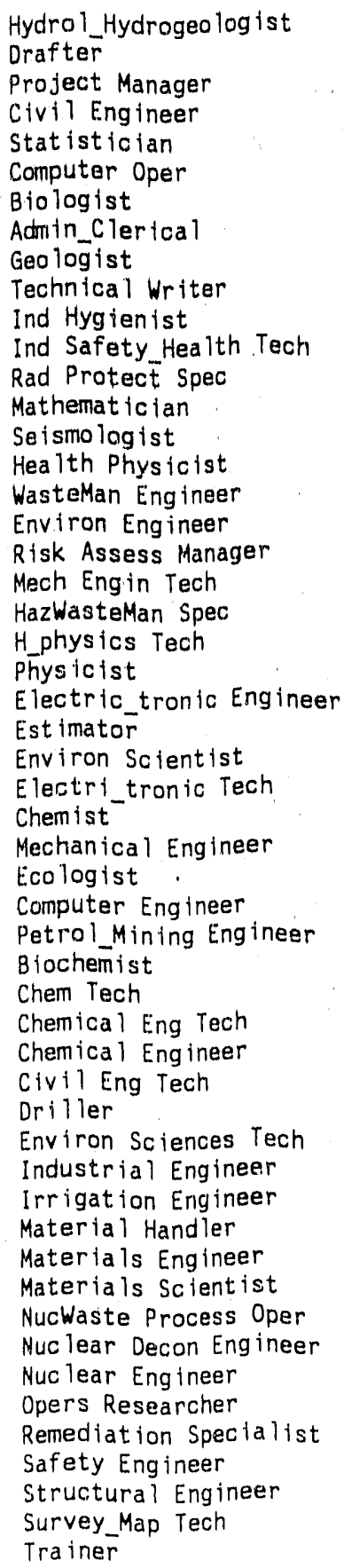

\section{HR_MEED}

PH_DELTA

Statistics based on data from 7 WNAS surveys and 1 SCHC survey.

\section{Degree}

Mix of $B S$ and Advanced Mostly Associate Most ly Bachelor Most ly Bache lor Most ly Pho

Mix of $A S$ and $B S$

Mix of BS and Advanced Most ly Associate

Mix of BS and Advanced Mix of AS and BS Mostly Bachelor Mostly Bachelor Mix of AS and BS Most ly PhD Mix of $B S$ and Advanced Mix of $B S$ and Advanced Mix of BS and Advanced Mix of BS and Advanced Mix of AS and BS Most ly Assoctate Mix of AS and BS Most ly Bachelor Mix of BS and Advanced Most ly Bachelor Mix of AS and BS Mix of $B S$ and Advanced Mostly Associtate Mix of $B S$ and Advanced Mix of BS and Advanced Mix of BS and Advanced Most ly Bachelor Mostly Bachelor Most ly Associate HS or less HS or less Most ly Associate HS or less HS or less HS or less Most ly Associate HS or less HS or less Most ly Associate Most ly Associate HS or less Most ly Associate Most ly Assoclate Most ly Associate HS or less Most ly Associate Most ly Associate HS or less HS or less 


\section{TABLE M.8. Job Titles Sorted By Human Resource Personne1's Ratings of Current Ability to Recruit (HR_Rec_C)}

\section{Job ritle}

Hydrol Hydrogeo logist

Civil Engineer

Drafter

Profect Manager

Btologist

Admin Clerical

Statistiotan

Computer Oper

Geologist

Technical Writer

Ind Hygienist

Ind Safety Health Tech

Rad Protect Spec

Mathematician

Seismologist

Health Phys ic ist

WasteMan Engineer

Environ Engineer

Risk Assess Manager

Mech Eng in Tech

HazWasteMan Spec

H_physics Tech

Phys tcist

Electric_tronic Engineer

Estimator

Environ Scientist

Electri tronic Tech

Chemist

Mechanical Engineer

Ecologist

Computer Engineer

Petrol Mining Engineer

Biochemist

Chem Tech

Chemical Eng Tech

Chemical Engineer

Civil Eng Tech

Driller

Environ Sciences Tech

Industrial Engineer

Irrigation Engineer

Materlal Handler

Materials Engineer

Materials Scient ist

NucWaste Pracess Oper

Nuc lear Decon Engineer

Nuclear Eng ineer

Opers Researcher

Remediation Specialist

Safety Engineer

Structural Engineer

Trainer
Survey_Map Tech

$H R_{-}$REC_C

PH_DELTA

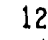

4

2
15

2

9

0

1

3

2

1

1

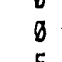

5

3

1

2
4

4

3

2

1

10

5

4

1

1

Statistics based on data from 7 WNAS surveys and 1 SCHC survey.
Degree

Mix of BS and Advanced Most ly Bachelor

Mostly Assoclate Mostly Bachelor

Mix of BS and Advanced

Most ly Assoctate

Mostly PhD

Mix of AS and BS

MiX of $B S$ and Advanced

MiX of AS and BS

Mostly Bachelor

Mostly Bachelor

Mix of AS and BS

Mostiy PhD

Mix of $B S$ and Advanced

Mix of $B S$ and Advanced

MiX of $B S$ and Advanced

$M+X$ of $B S$ and Advanced

Mix of AS and BS

Mostly Associate

$M i x$ of $A S$ and $B S$

Mostly Bachelor

Mix of BS and Advanced

Mostly Bachelor

Mix of $A S$ and $B S$

Mix of BS and Advanced Mostly Assoclate

Mix of BS and Advanced

Mix of $B S$ and Advanced

Mix of BS and Advanced

Mostly Bachelor

Mostly Bachelor

Mostly Associate

HS or less

HS or less

Mostly Associate

HS or less

HS or less

HS or less

Mostly Associate

HS or less

HS or less

Most ly Associate

Mostly Associate HS or less

Mostly Associate Mostly Associate Mostly Associate HS or less

Most ly Associate

Mostly Associate

HS or less

HS or less

\section{8}




\section{TABLE M.9. Job Titles Sorted By Human Resnurce Personnel's Ratings of Anticipated Ability to Recruit (HR_Rec_A)}

\author{
Jab Title \\ Hydro 1_Hydrogeo logist \\ Civil Engineer \\ Drafter \\ Project Manager \\ Biologist \\ Adnin_Clerical \\ Statistician \\ Computer Oper \\ Geologist \\ Technical Writer \\ Ind Hygienist \\ Ind Safety_Health Tech \\ Rad Protect Spec \\ Mathematiofian \\ Seismologist \\ Health Physicist \\ WasteMan Engineer \\ Environ Englneer \\ Risk Assess Manager \\ Mech Eng in Tech \\ HazWasteMan Spec \\ $H$ physics Tech \\ Phiysicist \\ Electric tronic Engineer \\ Estimator \\ Enyiron Scientist \\ Electri_tronic Tech \\ Chemist \\ Mechantcal Engineer \\ Ecologist \\ Computer Eng ineer \\ Petrol_Mining Engineer \\ Biochemist \\ Chem Tech \\ Chemical Eng Tech \\ Chemical Engineer \\ Civil Eng Tech \\ Orfller \\ Environ Sciences Tech \\ Industrial Engineer \\ Irrigation Engineer \\ Material Handler \\ Materials Engineer \\ Materials Scientist \\ NucWaste Process Oper \\ Nuclear Decon Engineer \\ Nuc lear Eng ineer \\ Opers Researcher \\ Remediation Specialist \\ Safety Engineer \\ Structural Eng ineer \\ Survey Map Tech \\ Trainer
}

HR_REC_A

PH_DELTA

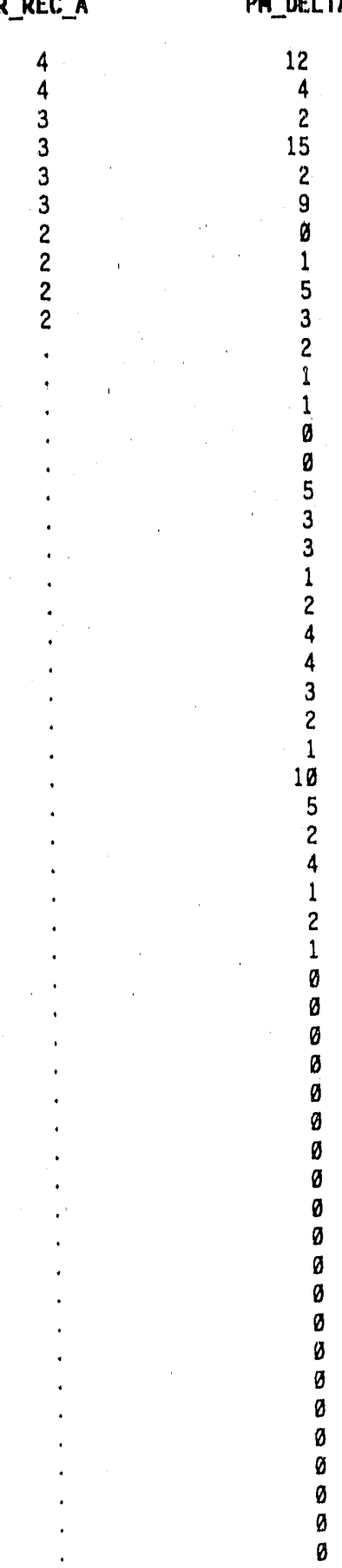

Statistics based on data from 7 WNAS surveys and 1 SCHC survey.
Degree

Mix of $B S$ and Advariced Most ly Bache lor Mostly Associate Most.ly Bache lor Mix of BS and Advanced Most ly Assoc iate Mostly PhD

Mix of $A S$ and $B S$ MiX of $B S$ and AC'variced Mix of $A S$ and $B S$ Most ly Bache lor Most ly Bache lor Mix of AS and BS Mostly PhD

Mix of $B S$ and Advanced Mix of $B S$ and Advanced Mix of $B S$ and Advanced Mix of BS and Advanced Mix of AS and BS Mostly Assoclate Mix of AS and BS Most ly Bachelor Mix of BS and Advanced Most ly Bachelor Mix of $A S$ and $B S$ Mix of $B S$ and Advanced Mostly Assoclate

Mix of $B S$ and Advanced Mix of BS and Advanced Mix of BS and Advanced Mostly Bachelor Most ly Bache lor Mostly Associate HS or less

HS or less Mostly Associate HS or less HS or less HS or less Mostly Associate HS or less HS or less Mostly Associate Mostly Associate HS or less

Most ly Assoclate Mostly Associate Most ly Associate HS or. less Mostly Associate Most ly Associate HS or less HS or less 
TABLE M.10. Job TitTes Sorted By Human Resource Personnel's Ratings of Annual Turnover (HR_Turn)

\author{
Job Title \\ Hydrol_Hydrogeologist \\ Biologist \\ Admin Clerical \\ Civiliengineer \\ Project Manager \\ Statistician \\ Computer Oper \\ Geologist \\ Technical Writer \\ Drafter \\ Ind Hygien ist \\ Ind Safety Health Tech \\ Rad Protect Spec \\ Mathematictan \\ Se ismologist \\ Health Physicist \\ WasteMan Engineer \\ Environ Engineer \\ $R$ isk Assess Manager \\ Mech Eng in Tech \\ HazWasteMan Spec \\ H_physics Tech \\ Physicist \\ Electric_tronic Engineer \\ Estimator \\ Environ Scient ist \\ Electri_tronic Tech \\ Chemist \\ Mechanical Engineer \\ Ecologist \\ Computer Engineer \\ Petrol_Mining Engineer \\ Blochernist \\ Chem Tech \\ Chemical Eng Tech \\ Chemical Eng ineer \\ Civil Eng Tech \\ Driller \\ Environ Sciences Tech \\ Industrial Engineer \\ Irrigation Engineer \\ Material Handler \\ Materials Engineer \\ Materials Scientist \\ NucWaste Process Oper \\ Nuclear Decon Engineer \\ Nuc lear Engineer \\ Opers Researcher \\ Remediation Specialist \\ Safety Eng ineer \\ Structural Engineer \\ Survey_Map Tech \\ Trainer
}

HR_TURA

PH_DELTA

Degree

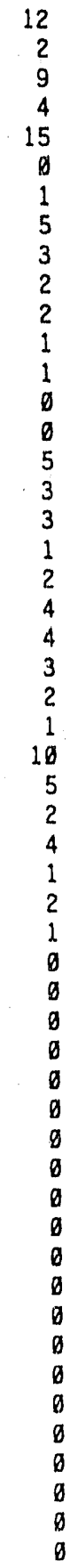

Mix of BS and Advanced Mix of BS and Advanced Most ly Associate Most ly. Bache lor Mostly Bachelor Mostly PhD

Mix of AS ard BS

$M i x$ of $B S$ and Advanced Mix of AS and BS Most ly Assoc late Most ly Fache lor

Mostly Bachelor Mix of AS and BS Mostly Pho

Mix of BS and Advanced Mix of $B S$ and Advanced Mix of $B S$ and Advanced Mix of $B S$ and Advanced $M i x$ of $A S$ and $B S$ Most 1y Associate Mix of AS and BS Most iy Bache lor

Mix of BS and Advanced Most ly Bache lor

Mix of AS and BS Mix of BS and Advanced Most ly Assoc late Mix of BS and Advanced Mix of BS and Advanced Mix of $B S$ and Advanced Most ly Bache lor Most ly Bache lor Most iy Associate HS or less HS or less Mostly Associate HS or less

HS or less HS or less

Most ly Associate HS or less

HS or less

Mostly Associate Most ly Associate HS or less

Most ly Associate Most ly Associate Most ly Associate HS or less Most ly Associate Most ly Assoc iate HS or less HS or less

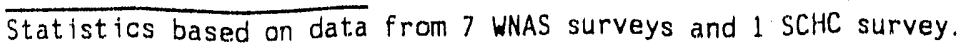


APPENDIX $N$

SIMPLE STATISTICS INTERCORRELATION AMONG

VARIABLES AND JOB SORTS ON ALL VARIABLES

FOR OAK RIDGE ONLY 
IABI.E N.1. Descriptive Statistics for Relative Ratings

$\begin{array}{llcccc}\text { Variable } & \text { N } & \text { Minimum } & \text { Maximum } & \text { Mean } & \underline{\text { S.D. }} \\ \text { HR_DIFF } & 56 & 1.00 & 4.00 & 2.23 & 0.96 \\ \text { HR_NEED } & 56 & 1.00 & 4.33 & 2.36 & 0.91 \\ \text { HR_REC_C } & 56 & 1.00 & 4.50 & 2.54 & 0.96 \\ \text { HR_REC_A } & 56 & 1.00 & 5.00 & 2.62 & 1.02 \\ \text { HR_TURN } & 56 & 1.00 & 3.00 & 1.51 & 0.63 \\ \text { PM_DIFF } & 44 & 1.00 & 4.00 & 2.77 & 0.78 \\ \text { PM_REC_A } & 42 & 1.00 & 4.00 & 2.70 & 0.77 \\ \text { PM_EDUC } & 43 & 1.60 & 4.00 & 3.28 & 0.72\end{array}$

S.D. = Standard Deviation, HR DIFF = Difficulty Caused by a Shortage, HR NEED = Need for Additional-Employees, HR-REC_A = Anticipated Ease of Recruitment, HR-REC-C = Current Ease of Recruitment, HR TURN $=$. Current Annual Turnover, PII DIFF = Difficulty Caused By a Shortage, PM-REC $A=$ Anticipated Ability to Recruit, PM_EDUC = Typical Degree Level, $* \star \bar{p}<\overline{0} .01 ; * p<0.05$. Statistics based on data from 10 WNAS surveys and $4 \mathrm{SCHC}$ surveys. 


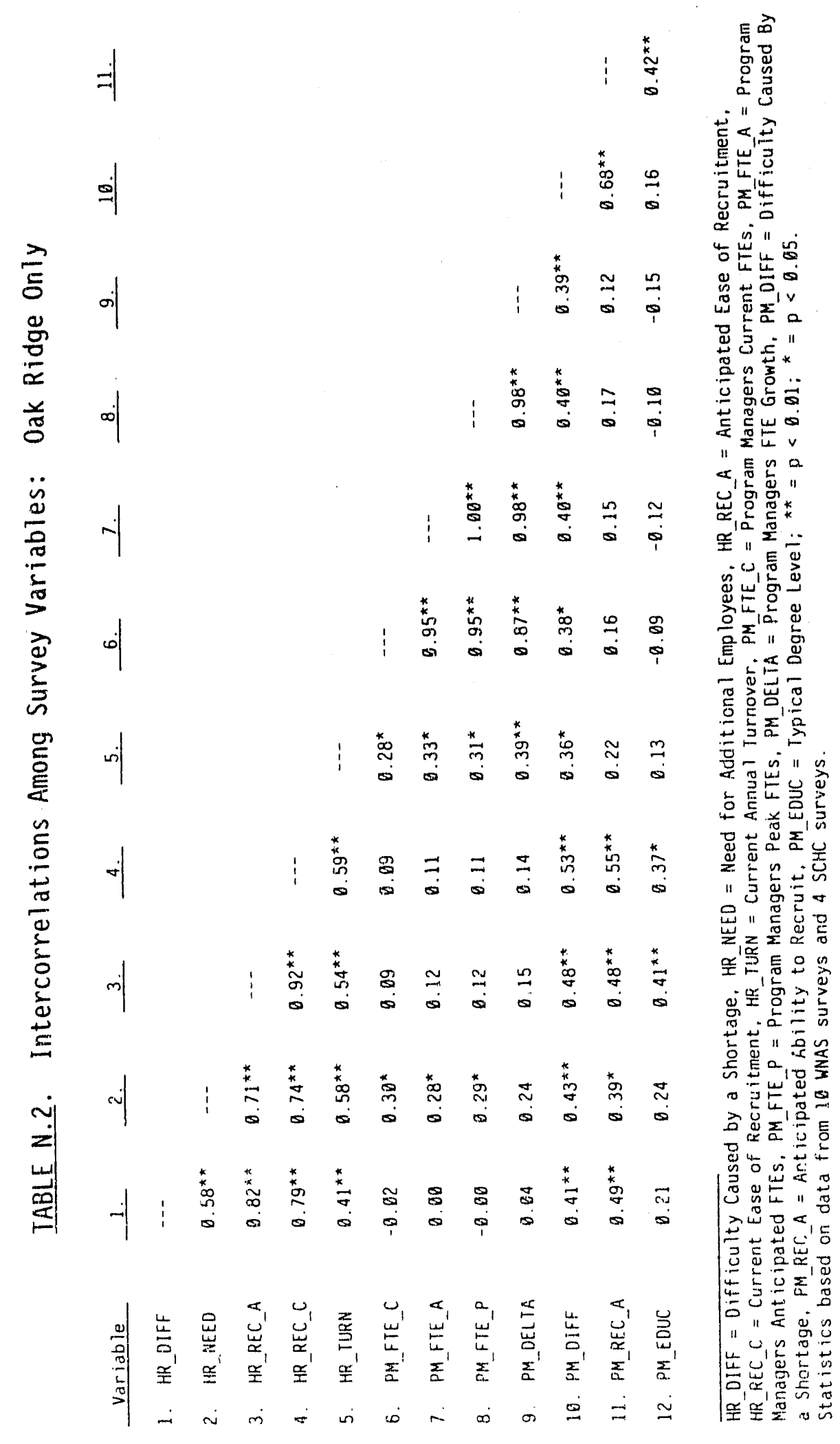

N. 2 


\section{TABLE N.3. Job Titles Sorted By Change in FTES (PM_Delta)}

\begin{tabular}{|c|c|c|c|c|c|}
\hline Job Tit le & PM_FTE_C & PM_FTE_A & PM_FTE_P & PM_DELTA & Degree \\
\hline $\begin{array}{l}\text { *Summary Techs } \\
\text { * Summary Engineers }\end{array}$ & 284 & $\begin{array}{l}902 \\
348\end{array}$ & $\begin{array}{l}902 \\
348\end{array}$ & $\begin{array}{l}618 \\
198\end{array}$ & \\
\hline * Summary Eng ineers & $\begin{array}{l}150 \\
119\end{array}$ & $\begin{array}{l}348 \\
194\end{array}$ & & $\begin{array}{r}198 \\
75\end{array}$ & \\
\hline $\begin{array}{l}\text { Project Manager } \\
\text { Admin Clerical }\end{array}$ & $\begin{array}{r}119 \\
81\end{array}$ & $\begin{array}{l}194 \\
138\end{array}$ & $\begin{array}{l}199 \\
144\end{array}$ & $\begin{array}{l}75 \\
57\end{array}$ & Most ly Bachelor \\
\hline $\begin{array}{ll}\text { Material Handler } \\
\text { *Summary Scient ist }\end{array}$ & 57 & 105 & 105 & 48 & Mostly Associate \\
\hline *Summary Scient ist & 149 & 193 & 217 & 44 & \\
\hline Hydrol_Hydrogeologist & 24 & 50 & 54 & 26 & Mix of BS and Advanced \\
\hline Enviroñ Engineer & 68 & 90 & 100 & 22 & Mix of BS and Advanced \\
\hline Other Eng ineer & 17 & 37 & 37 & 20 & Mostly Associate \\
\hline Chemical Eng ineer & 41 & 59 & 59 & 18 & Mostly Bachelor \\
\hline Chem ist & 23 & 36 & 36 & 13 & Mix of BS and Advanced \\
\hline Health Physicist & 12 & 25 & 26 & 13 & Mix of BS and Advanced \\
\hline Civil Engineer & 29 & 41 & 42 & 12 & Mix of BS and Advanced \\
\hline H_physics Tech & 10 & 21 & 21 & 11 & Mix of $A S$ and $B S$ \\
\hline Other Technician & 21 & 32 & 33 & 11 & HS or less \\
\hline Chemical Eng Tech & 26 & 36 & 36 & 10 & Mix of $A S$ and $B S$ \\
\hline Ind Hygien ist & 9 & 19 & 20 & 18 & Mix of AS and BS \\
\hline Trainer & 20 & 30 & 35 & 10 & Most ly Bache lor \\
\hline WasteMan Engineer & 33 & 43 & 44 & 10 & Mix of BS and Advanced \\
\hline HazWasteMan Spec & 19 & 28 & 28 & 9 & Mostly Bachelor \\
\hline Technical Writer & 12 & 21 & 24 & 9 & Mix of $A S$ and $B S$ \\
\hline Estimator & 7 & 15 & 16 & 8 & Mix of $A S$ and $B S$ \\
\hline Industrial Engineer & 8 & 16 & 16 & 8 & Most ly Bachelor \\
\hline Other Administrator & 15 & 23 & 27 & 8 & HS or less \\
\hline Safety Engineer & 5 & 13 & 13 & 8 & Most ly Bachelor \\
\hline Computer Oper & 22 & 29 & $31^{\circ}$ & 7 & Mix of $A S$ and $B S$ \\
\hline Geologist & 11 & 18 & 18 & 7 & Mix of $B S$ and Advanced \\
\hline Mechanical Engineer & 16 & 23 & 23 & 7 & Most ly Bachelor \\
\hline Risk Assess Manager & 6 & 1.3 & 17 & 7 & Mostly Bache lor \\
\hline Biologist & 9 & 15 & 15 & 6 & Mix of BS and Advanced \\
\hline Environ Scientist & 24 & 30 & 35 & 6 & Mix of $B S$ and Advanced \\
\hline Ind Safety_Health Tech & 7 & 12 & 12 & 5 & Mix of $A S$ and $B S$ \\
\hline Nuclear Decon Eng ineer & 4 & 9 & 11 & 5 & Mix of $B S$ and Advanced \\
\hline Chem Tech & 8 & 12 & 12 & 4 & HS or less \\
\hline Civil Eng Tech & 4 & 8 & 8 & 4 & Most ly Associate \\
\hline NucWaste Process Oper & 37 & 41 & 41 & 4 & Mostly Associate \\
\hline Other Scient ist & 4 & 8 & 8 & 4 & Mostly Associate \\
\hline Rad Protect Spec & 5 & 9 & 9 & 4 & HS or less \\
\hline Biochemist & 7 & 10 & 10 & 3 & Mostly Associate \\
\hline Nuclear Engineer & 9 & 12 & 12 & 3 & Mix of BS and Advanced \\
\hline Statistician & 4 & 7 & 7 & 3 & Mix of $B S$ and Advanced \\
\hline Ecologist & 5 & 7 & 7 & 2 & Mix of BS and Advanced \\
\hline Materials Scientist & 2 & 4 & 4 & 2 & Mostly Associate \\
\hline Mech Engin Tech & 5 & 7 & 7 & 2 & Mix of $A S$ and $B S$ \\
\hline Structural Engineer & 5 & 7 & 7 & 2 & Mix of BS and Advanced \\
\hline Survey_Map Tech & 2 & 4 & 4 & 2 & Mix of AS and BS \\
\hline Drafter & 5 & 6 & 6 & 1 & Most iy Associate \\
\hline Electri_tronic Tech & 4 & 5 & 6 & 1 & Mix of $A S$ and $B S$ \\
\hline Electric_tronic Engineer & 3 & 4 & 4 & 1 & Most ly Bache lor \\
\hline Environ Sciences 7 ach & 2 & 3 & 3 & 1 & HS or less \\
\hline Mathemat ician & 2 & 3 & 3 & 1 & Mix of BS and Advanced \\
\hline Opers Researcher & 1 & 2 & 2 & 1 & Mix of BS and Advanced \\
\hline Driller & 4 & 4 & 6 & $\theta$ & Most ly Associate \\
\hline Irrigation Engineer & $\theta$ & $\theta$ & $\theta$ & 0 & HS or less \\
\hline Materials Engineer & $\theta$ & 0 & 0 & $\emptyset$ & Mostly Associate \\
\hline Petrol Mining Engineer & $\theta$ & 0 & $\theta$ & B & Most iy Associate \\
\hline
\end{tabular}


TABLE N.3. (Contd)

\begin{tabular}{|c|c|c|c|c|c|}
\hline Jab Title & PH_FTE_C & PH_FTE_A & PH_FTE_P & PH_DELTA & Degree \\
\hline Physicist & 0 & 0 & 0 & 0 & Mostly Associate \\
\hline Remediation Specialist & 0 & 0 & 0 & 0 & Mostly Associate \\
\hline Seismologist & 0 & 0 & 0 & 0 & Mostly Associate \\
\hline Computer Eng ineer & 37 & 33 & 48 & -4 & Mix of BS and Advanced \\
\hline
\end{tabular}

* Respondent Combined FTE Values Across All Job Titles

statistics based on data from 10 WiNAS surveys and 4 SCHC surveys. 


\section{IABLE N.4. Titles Sorted by Project Manager's Ratings of Anticipated Ability to Recruit (PM_Rec_A)}

Job Title
H_physics Tech
HazWasteMan Spec
Nuclear Engineer
Environ Scient ist
Risk Assess Manager
Nuclear Oecon Engineer
Hydrol_Hydrogeologist
Environ Engineer
Ind Hygienist
Structural Engineer
Health Physicist
WasteMan Engineer
Project Manager
NucWaste Process Oper
Ind Safety_Health Tech
Computer Engineer
Technical Writer
Opers Researcher
Trainer
Geologist
Material Handler
Chemical Eng ineer
Chemist
Estimator
Civil Engineer
Safety Engineer
Chemical Eng Tech
Statistician
Admin_Clerical
Mathematician
Civil Eng Tech
Ecologist
Industrial Engineer
Computer Oper
Mechanical Engineer
Mech Engin Tech
Survey_Map Tech
Electri_tronic Tech
Electric_tronic Eng ineer
Oriller
Drafter
Biologist
Rad Protect Spec
Chem Tech
Biochemist
Materials Scientist
Environ Sciences Tech
Irrigation Engineer
Materials Engineer
Petrol_Mining Engineer
Physicist
Remediation Specialist
Seismologist

\begin{tabular}{|c|c|}
\hline PH_REC_A & PM_DELTA \\
\hline 4.00 & 11 \\
\hline 4.00 & 9 \\
\hline 4.00 & 3 \\
\hline 3.80 & 6 \\
\hline 3.75 & 7 \\
\hline 3.75 & 5 \\
\hline 3.60 & 26 \\
\hline 3.57 & 22 \\
\hline 3.50 & 10 \\
\hline 3.50 & 2 \\
\hline 3.43 & 13 \\
\hline 3.33 & 10 \\
\hline 3.29 & 75 \\
\hline 3.00 & 4 \\
\hline 3.00 & 5 \\
\hline 3.00 & -4 \\
\hline 3.00 & 9 \\
\hline 3.00 & 1 \\
\hline 2.67 & 10 \\
\hline 2.50 & 7 \\
\hline 2.50 & 48 \\
\hline 2.50 & 18 \\
\hline 2.50 & 13 \\
\hline 2.50 & 8 \\
\hline 2.33 & 12 \\
\hline 2.33 & 8 \\
\hline 2.33 & 10 \\
\hline 2.33 & 3 \\
\hline 2.00 & 57 \\
\hline 2.60 & 1 \\
\hline 2.00 & 4 \\
\hline 2.00 & 2 \\
\hline 2.00 & 8 \\
\hline 2.00 & 7 \\
\hline 2.00 & 7 \\
\hline 2.00 & 2 \\
\hline 2.00 & 2 \\
\hline 2.00 & 1 \\
\hline 2.60 & 1 \\
\hline 2.80 & $\theta$ \\
\hline 1.33 & 1 \\
\hline 1.00 & 6 \\
\hline 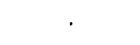 & 4 \\
\hline 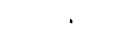 & 4 \\
\hline . & 3 \\
\hline . & 2 \\
\hline$\cdot$ & 1 \\
\hline$\cdot$ & $\theta$ \\
\hline$\cdot$ & $\theta$ \\
\hline . & 0 \\
\hline . & $\theta$ \\
\hline · & $\theta$ \\
\hline
\end{tabular}

Statistics based on data from 10 WNAS surveys and 4 SCHC surveys. 


\section{TABLE N.5. Titles Sorted By Project Manager's Ratings of Difficulty Caused by Shortage (PM_Diff)}

\author{
Job Title \\ Hydrol_Hydrogeologist \\ H_physics Tech \\ HazWasteMan Spec \\ Geolog ist \\ NucWaste Process Oper \\ Project Manager \\ Risk Assess Manager \\ Ind Hygien ist \\ Environ Eng ineer \\ Structural Engineer \\ Environ Scientist \\ Health Physic ist \\ Admin Clerical \\ Material Handler \\ Chemica) Engineer \\ Chemist \\ Civil Engineer \\ Safety Engineer \\ Ind Safety_Health Tech \\ Nuc lear Decon Engineer \\ Rad Protect Spec \\ Mathematician \\ Est imator \\ Chemical Eng Tech \\ Trainer \\ WasteMan Engineer \\ Civil Eng Tech \\ Ecologist \\ Computer Eng ineer \\ Technical Writer \\ Industrial Engineer \\ Computer Oper \\ Mechanical Eng ineer \\ Chem Tech \\ Nuc lear Engineer \\ Hech Eng in Tech \\ Survey Map Tech \\ Electrit tronic Tech \\ Electric tronic Engineer \\ Opers Researcher \\ Driller \\ Stat istician \\ Drafter \\ Biologist \\ Biochemist \\ Materials Scientist \\ Environ Sciences Tech \\ Irrigation Engineer \\ Materials Engineer \\ Petrol Mining Engineer \\ Physicist \\ Remediation Specialist \\ Seismologist
}

\section{PM_DIFF}

PM_DELTA

4.00
4.00
4.00
4.00
4.00

3.86

3.75

3.67

3.57

3.50

3.40

3.29

3.17

3.00

3.80

3.06

3.00

3.09

3.00

3.00

3.00

3.80

2.75

2.67

2.67

2.67

2.50

2.50

2.50

2.00

2.90

2.00

2.00

2.00

2.00

2.00

2.00

2.00

2.00

2.00

2.00

1.67

1.67

1.00

\section{Degree}

Mix of $B S$ and Advanced

Mix of AS and BS

Mostly Bachelor

Mix of BS and Advanced Mostly Associate Mostly Bachelor Mostly Bachelor. Mix of $A S$ and $B S$

Mix of BS and Advanced Mix of BS and Advanced Mix of $B S$ and Advanced Mix of BS and Advanced Most ly Associate Most ly Associate Mostly Bachelor

Mix of BS and Advanced Mix of BS and Advanced Mostly Bache lor $M i x$ of $A S$ and $B S$ Mix of BS and Advanced HS or less

Mix of BS and Advaniced Mix of $A S$ and $B S$ $M i x$ of $A S$ and $B S$ Mostly Bachelor Mix of $B S$ and Advanced Most ly Associate Mix of BS and Advanced Mix of BS and Advanced Mix of $A S$ and $B S$ Most ly Bache lor Mix of AS and BS Mostly Eachelor HS or less

Mix of BS and Advanced $M i x$ of $A S$ and $B S$ Mix of $A S$ and $B S$ Mix of $A S$ and $B S$ Most ly Bachelor Mix of $B S$ and Advanced Mostly Associate Mix of BS and Advanced Most ly Associate

Mix of BS and Advanced Mostly Associate Mostly Associate HS or less

HS or less

Most ly Associate Mostly Associate Mostly Assoriate Most ly Associate Mostly Associate

Statistics based on data from 10 WNAS surveys and 4 SCHC surveys.

N. 6 


\section{TABLE N.6. Job Titles Sorted By Human Resource Personne1's Ratings of Difficulty Caused By Shortage (HR_Diff)}

\begin{tabular}{|c|c|c|}
\hline Job Title & HR_DIFF & PM_DELTA \\
\hline Nuc lear Decon Eng ineer & 4.00 & 5 \\
\hline Hydrol_Hydrogeolog ist & 4.00 & 26 \\
\hline Health Physicist & 4.00 & 13 \\
\hline Ind Hygienist & 3.67 & 10 \\
\hline WasteMan Eng ineer & 3.67 & 10 \\
\hline H_physics Tech & 3.50 & 11 \\
\hline Environ Eng ineer & 3.50 & 22 \\
\hline Chemist & 3.50 & 13 \\
\hline Rad Protect Spec & 3.50 & 4 \\
\hline Safety Eng ineer & 3.33 & 8 \\
\hline Environ Scient ist & 3.25 & 6 \\
\hline HazWasteMan Spec & 3.00 & 9 \\
\hline Geologist & 3.00 & 7 \\
\hline Chemical Eng Tech & 3.00 & 10 \\
\hline Survey_Map Tech & 3.00 & 2 \\
\hline Chem Tech & 3.00 & 4 \\
\hline Risk Assess Manager & 2.50 & 7 \\
\hline Chemical Eng ineer & 2.50 & 18 \\
\hline Environ Sciences Tech & 2.50 & 1 \\
\hline Remediation Specialist & 2.50 & $\theta$ \\
\hline Technical Writer & 2.33 & 9 \\
\hline Estimator & 2.25 & 8 \\
\hline Ind Safety_Heaith Tech & 2.00 & 5 \\
\hline Material Handler & 2.00 & 48 \\
\hline Statistician & 2.90 & 3 \\
\hline Civil Eng Tech & 2.00 & 4 \\
\hline Ecologist & 2.00 & 2 \\
\hline Mech Engin Tech & 2.00 & 2 \\
\hline Driller & 2.00 & $\emptyset$ \\
\hline Biochemist & 2.00 & 3 \\
\hline Materials Engineer & 2.00 & $\theta$ \\
\hline Physicist & 2.00 & $\theta$ \\
\hline Nuc lear Engineer & 1.67 & 3 \\
\hline Mechanical Engineer & 1.67 & 7 \\
\hline NucWaste Process Oper & 1.50 & 4 \\
\hline Trainer & 1.50 & 10 \\
\hline Industrial Engineer & 1.50 & 8 \\
\hline Computer Oper & 1.50 & 7 \\
\hline Electric tronic Engineer & 1.50 & 1 \\
\hline Drafter & 1.50 & $i$ \\
\hline Biologist & 1.50 & 6 \\
\hline Project Manager & 1.33 & 75 \\
\hline Civil Engineer & 1.33 & 12 \\
\hline Structural Engineer & 1.00 & 2 \\
\hline Computer Eng ineer & 1.00 & -4 \\
\hline Opers Researcher & 1.00 & 1 \\
\hline Admin_Clerical & 1.00 & 57 \\
\hline Mathemat ician & 1.00 & 1 \\
\hline Electri tronic Tech & 1.00 & 1 \\
\hline MateriaTs Scientist & 1.00 & 2 \\
\hline Irrigation Engineer & 1.80 & 0 \\
\hline Petrol Mining Eng ineer & 1.00 & $\theta$ \\
\hline Se ismo Togist & 1.00 & $\theta$ \\
\hline
\end{tabular}

statistics based on data from 10 WNAS surveys and 4 SCHC surveys. 
TABLE N.7. Job Titles Sorted By Human Resource Personnel's Ratings of Need for Additional Employees (HR_Need)

\begin{tabular}{|c|c|c|}
\hline Job Tit le & HR_NEED & PM_DELTA \\
\hline WasteMan Eng ineer & 4.33 & 10 \\
\hline HazWasteMan Spec & 4.00 & 9 \\
\hline Ecologist & 4.00 & 2 \\
\hline Est imator & 3.67 & 8 \\
\hline Environ Engineer & 3.50 & 22 \\
\hline Chemist & 3.50 & 13 \\
\hline Risk Assess Manager & 3.50 & 7 \\
\hline Environ Sciences Tech & 3.50 & 1 \\
\hline Health Physicist & 3.33 & 13 \\
\hline H_physics Tech & 3.00 & 11 \\
\hline Environ Scientist & 3.00 & 6 \\
\hline Survey_Map Tech & 3.00 & 2 \\
\hline Remediation Specialist & 3.06 & $\theta$ \\
\hline Technical Writer & 3.90 & 9 \\
\hline Biochemist & 3.00 & 3 \\
\hline Project Manager & 3.89 & 75 \\
\hline Computer Eng ineer & 3.00 & -4 \\
\hline Adinin_Clerical & 3.00 & 57 \\
\hline Mathematician & 3.00 & 1 \\
\hline Hydrol Hydrogeolog ist & 2.67 & 26 \\
\hline Ind Hygien ist & 2.67 & 10 \\
\hline Civil Engineer & 2.67 & 12 \\
\hline Rad Protect Spec & 2.50 & 4 \\
\hline Chemical Eng Tech & 2.50 & 10 \\
\hline Chem Tech & 2.50 & 4 \\
\hline Chemical Eng ineer & 2.50 & 18 \\
\hline Statistician & 2.50 & 3 \\
\hline Safety Eng ineer & 2.33 & 8 \\
\hline Nuc lear Decon Engineer & 2.90 & 5 \\
\hline Geologist & 2.00 & 7 \\
\hline Material Handler & 2.00 & 48 \\
\hline Driller & 2.00 & $\theta$ \\
\hline Physicist & 2.00 & $\theta$ \\
\hline Nuc lear Eng ineer & 2.00 & 3 \\
\hline NucWaste Process Oper & 2.00 & 4 \\
\hline Trainer & 2.00 & 10 \\
\hline Materials Engineer & 1.67 & 9 \\
\hline Ind Safety_Health Tech & 1.50 & 5 \\
\hline Civil Eng Tech & 1.50 & 4 \\
\hline Mech Engin Tech & 1.50 & 2 \\
\hline Industrial Engineer & 1.50 & 8 \\
\hline Electric tronic Engineer & 1.50 & 1 \\
\hline Orafter & 1.50 & 1 \\
\hline Biologist & 1.50 & 6 \\
\hline Mechanical Enginter & 1.33 & 7 \\
\hline Computer Oper & 1.00 & 7 \\
\hline Structural Engineer & 1.00 & 2 \\
\hline Opers Researcher & 1.80 & 1 \\
\hline Electritronic Tech & 1.90 & 1 \\
\hline Materials Scientist & 1.00 & 2 \\
\hline Irrigation Engineer & 1.00 & $g$ \\
\hline Petrol Mining Engineer & 1.80 & $\theta$ \\
\hline Se ismologist & 1.00 & $\theta$ \\
\hline
\end{tabular}

\section{Degree}

Mix of $B S$ and Advariced Most ly Bache lor

Mix of BS and Advanced Mix of AS and BS

Mix of $B S$ and Advanced Mix of BS and Advanced Most ly Bache lor

HS or less

Mix of $B S$ and Advanced Mix of $A S$ and $B S$

Mix of $B S$ and Advanced Mix of AS and BS Mostly Associate Mix of AS and BS Mostly Associate Most ly Bache lor Mix of BS and Advanced Most ly Associate Mix of $B S$ and Advanced Mix of $B S$ and Advanced Mix of $A S$ and $B S$

Mix of BS and Advanced HS or less

Mix of AS and BS

HS or less

Most ly Bache lor

Mix of BS and Advanced Most ly Bache lor

Mix of $B S$ and Advanced Mix of BS and Advanced Most ly Associate Most ly Associate Mostly Associate Mix of $B S$ and Advanced Mostly Associate Most ly Bache lor Most ly Associate Mix of $A S$ and $B S$ Mostly Associate Mix of AS and BS Mostly Bachelor Most ly Bache lor Mostly Associate Mix of BS and Advanced Mostly Bache lor Mix of AS and BS Mix of BS and Advanced Mix of $B S$ and Advanced Mix of $A S$ and $B S$ Mostly Associate HS or less Mostly Associate Mostly Assuciate

Statistics based on data from 10 WNAS surveys and 4 SCHC surveys. 


\section{TABLE N.8. Job Titles Sorted By Human Resource Personnel's Ratings of Current Ability to Recruit (HR_Rec_C)}

Job Title

Risk Assess Manager

Ecologist

Health Physicist

Hydrol_Hydrogeo logist

Nuclear Decon Engineer

Environ Engineer

WasteMan Eng ineer

Estimator

HazWasteMan Spec

Chemist

Environ Scientist

Geologist

Ind Hygien ist

Materials Engineer

Environ Sciences Tech

$H$ physics Tech

Remediation Specialist

Biochemist

Rad Protect Spec

Chemical Eng Tech

Chem Tech

Ind Safety_Health Tech

Safety Engineer

Nuc lear Eng ineer

Technical Writer

Project Manager

Chemical Eng ineer

Stat istician

Material Harlder

Physicist

Civil Engineer

Survey Map Tech

Mathematician

Driller

NucWaste Process Oper

Trainer

Civil Eng Tech

Mech Eng in. Tech

Biologist

Mechanical Eng ineer

Admin Clerical

Computer Engineer

Industrial Engineer

Electric tronic Engineer

Coinputer Oper

Irrigation Engineer

Drafter

Structural Engineer

Opers Researcher

Electri tronic Tech

Materials Scientist

Petrol Mining Engineer

Seismologist

\section{HR_REC_C}

4.50

4.00

4.00

4.00

4.00

3.75

3.67

3.67

3.50

3.50

3.50

3.50

3.33

3.33

3.60

3.00

3.00

3.90

3.00

3.00

3.60

3.00

2.67

2.67

2.50

2.50

2.50

2.50

2.50

2.50

2.33

2.00

2.00

2.00

2.90

2.00

2.00

2.00

2.00

2.00

1.67

1.50

1.50

1.50

1.50

1.50

1.00

1.06

1.00

1.00

1.00

1.00

1.00
PM_DELTA

7

5

22

10

8

6

7

10

0

11

11

4

5

8

9

8

0

2

1

0

4

2

6

7

57
-4

$-4$

8

7

$\theta$

1

2

1

$\frac{1}{2}$

0
Degree

Most ly Bachelor Mix of BS and Advanced Mix of $B S$ and Advanced Mix of BS and Advanced Mix of BS and Advanced Mix of BS and Advanced Mix of BS and Advanced Mix of AS and BS Mostly Bache lor Mix of BS and Advanced Mix of BS and Advanced Mix of BS and Advanced Mix of AS and BS Mostly Associate HS or less.

Mix of AS and BS Most ly Associate Most ly Associate HS or less

Mix of AS and BS HS or less

Mix of AS and BS Mostly Bachelor Mix of BS and Advanced Mix of AS and BS Most ly Bache lor Mostly Bachelor Mix of $B S$ and Advanced Mostly Associate Most.ly Associate Mix of $B S$ and Advanced Mix of AS and BS Mix of $B S$ and Advanced Most ly Assoc late Most ly Associate Most ly Bache lor Mostly Associate Mix of AS and BS Mix of $B S$ and Advanced Most ly Bachelor Most ly Associate Mix of BS and Advanced Most ly Bache lor Mostly Bache lor Mix of AS and BS HS or less Mostly Associate Mix of BS and Advanced Mix of $B S$ and Advanced Mix of AS and BS Mostly Associate Mostly Associate Mostly Associate

Statistics based on data from 10 WNAS surveys and 4 SCHC surveys. 

TABLE N.9. Job Titles Sorted By Human Resource Personnel's Ratings
of Anticipated Ability to Recruit (HR_Rec_A)

Job Title
Risk Assess Manager
Ecologist
Health Physicist
Hydrol_Hydrogeologist
Environ Engineer
Environ Scientist
WasteNan Engineer
Estimator
Geologist
Ind Hygienist
Nuclear Decon Engineer
HazWasteMan Spec
Chemist
Rad Protect Spec
Materials Engineer
Safety Engineer
Environ Sciences Tech
H_physics Tech
Biochemist
Chemical Eng Tech
Nuclear Engineer
Project Manager
Chemical Engineer
Remediation Specialist
Chem Tech
Technical Writer
Statistician
Material Handler
Physicist
Civil Eng Tech
Biologist
Civil Engineer
Ind Safety_Health Tech
SurveyMap Tech
Mathematician
Driller
Trainer
Mech Engin Tech
Mechanical Engineer
Industrial Engineer
Electric_tronic Engineer
NucWaste Process Oper
Computer Engineer
Computer Oper
Irrigation Engineer
Orafter
Admin_Clerical
Structural Engineer
Opers Researcher
Electri_tronic Tech
Materials Scient ist
Petrol_Mining Engineer
Seismologist

\begin{tabular}{|c|c|}
\hline HR_REC_A & PH_DELTA \\
\hline $\begin{array}{l}4.50 \\
4.00\end{array}$ & $\begin{array}{l}7 \\
2\end{array}$ \\
\hline $\begin{array}{l}4.00 \\
4.00\end{array}$ & 13 \\
\hline 4.00 & 26 \\
\hline 4.00 & 22 \\
\hline 4.09 & 6 \\
\hline 3.67 & 10 \\
\hline 3.67 & 8 \\
\hline 3.67 & 7 \\
\hline 3.67 & 10 \\
\hline 3.50 & 5 \\
\hline 3.50 & 9 \\
\hline 3.50 & 13 \\
\hline 3.50 & 4 \\
\hline 3.33 & $\theta$ \\
\hline 3.33 & 8 \\
\hline 3.00 & 1 \\
\hline 3.00 & 11 \\
\hline 3.00 & 3 \\
\hline 3.00 & 10 \\
\hline 3.00. & 3 \\
\hline 3.00 & 75 \\
\hline 3.00 & 18 \\
\hline 2.50 & $\theta$ \\
\hline 2.50 & 4 \\
\hline 2.50 & 3 \\
\hline 2.50 & 3 \\
\hline 2.50 & 48 \\
\hline 2.50 & $\theta$ \\
\hline 2.50 & 4 \\
\hline 2.50 & 6 \\
\hline 2.33 & 12 \\
\hline 2.00 & 5 \\
\hline 2.00 & 2 \\
\hline 2.00 & 1 \\
\hline 2.90 & $\theta$ \\
\hline 2.00 & 10 \\
\hline 2.00 & 2 \\
\hline 2.00 & 7 \\
\hline 2.00 & 8 \\
\hline 2.00 & 1 \\
\hline 1.50 & 4 \\
\hline 1.50 & -4 \\
\hline 1.50 & 7 \\
\hline 1.50 & $\theta$ \\
\hline 1.50 & 1 \\
\hline 1.33 & 57 \\
\hline 1.00 & 2 \\
\hline 1.00 & 1 \\
\hline 1.00 & 1 \\
\hline 1.00 & 2 \\
\hline 1.00 & $\theta$ \\
\hline 1.00 & $\theta$ \\
\hline
\end{tabular}

Degree

Most ly Bache lor Mix of $B S$ and Advanced Mix of BS and Advanced Mix of BS and Advanced Mix of $B S$ and Advanced Mix of $B S$ and Advanced Mix of BS and Advanced $M+x$ of $A S$ and $B S$

Mix of $B S$ and Advanced Mix of AS and BS Mix of BS and Advanced Most ly Bachelor Mix of BS and Advanced HS or less Mostly Associate Most ly Bachelor HS or less Mix of AS and BS Most ly Associate Mix of AS and BS Mix of $B S$ and Advanced Most ly Bache lor Most ly Bachelor Most ly Associate HS or less Mix of $A S$ and $B S$ Mix of BS and Advanced Most ly Associate Most ly Associate Most ly Associate Mix of $B S$ and Advanced Mix of BS and Advanced Mix of $A S$ and $B S$ Mix of AS and BS Mix of BS and Advanced Mostly Associate Most ly Bache lor Mix of AS and BS Most ly Bache lor Most ly Bache lor Mostly Bachelor Most ly Associate Mix of BS and Advariced Mix of AS and BS HS or less Most. ly Associate Mostly Associate Mix of BS and Advanced Mix of BS and Advanced Mix of AS and BS Mostly Associate Most ly Associate Most ly Associate

Statistics based on data from 10 WNAS surveys and 4 SCHC surveys. 
TABLEN.10. Job Titles Sorted By Human Resource Personnel's Ratings of Annual Turnover (HR_Turn)

\begin{tabular}{|c|c|c|}
\hline Job Tit le & HR_TURN & PM_DELT \\
\hline Ecologist & 3.00 & 2 \\
\hline Geolog ist & 3.00 & 7 \\
\hline Project Manager & 3.00 & 75 \\
\hline Risk Assess Manager & 2.50 & 7 \\
\hline Remediation Specialist & 2.50 & $\emptyset$ \\
\hline Chem Tech & 2.50 & 4 \\
\hline Health Physicist & 2.33 & 13 \\
\hline HazWasteMan Spec & 2.00 & 9 \\
\hline Chemist & 2.00 & 13 \\
\hline H_physics Tech. & 2.00 & 11 \\
\hline Biochem ist & 2.00 & 3 \\
\hline Material Handler & 2.00 & 48 \\
\hline Survey_Map Tech & 2.00 & 2 \\
\hline Admin Clerical & 2.00 & 57 \\
\hline Hydrō_Hydrogeolog ist & 1.67 & 26 \\
\hline WasteMän Engineer & 1.67 & 10 \\
\hline Est imator & 1.67 & 8 \\
\hline Environ Scientist & 1.50 & 6 \\
\hline Nuc lear Decon Engineer & 1.50 & 5 \\
\hline Rad Protect Spec & 1.50 & 4 \\
\hline Chemica 1 Eng Tech & 1.50 & 10 \\
\hline Nuc lear Eng ineer & 1.50 & 3 \\
\hline Technical Writer & 1.50 & 9 \\
\hline Biologist & 1.50 & 6 \\
\hline Drafter & 1.50 & 1 \\
\hline Ind Hygienist & 1.33 & 10 \\
\hline Environ Engineer & 1.25 & 22 \\
\hline Materials Engineer & 1.00 & $\theta$ \\
\hline Safety Eng ineer & 1.00 & 8 \\
\hline Environ Sciences Tech & 1.00 & 1 \\
\hline Chemical Engineer & 1.00 & 18 \\
\hline Statistician & 1.00 & 3 \\
\hline Physicist & 1.00 & $\theta$ \\
\hline Civil Eng Tech & 1.00 & 4 \\
\hline Civil Engineer & 1.00 & 12 \\
\hline Ind Safety Health Tech & 1.00 & 5 \\
\hline Mathematician & 1.00 & 1 \\
\hline Driller & 1.00 & $\theta$ \\
\hline Trainer & 1.00 & 10 \\
\hline Mech Eng in Tech & 1.00 & 2 \\
\hline Mechanical Engineer & 1.00 & 7 \\
\hline Industrial Engineer & 1.00 & 8 \\
\hline Electric tronic Engineer & 1.00 & 1 \\
\hline NucWaste Process Oper & 1.00 & 4 \\
\hline Computer Engineer & 1.00 & -4 \\
\hline Computer Oper & 1.00 & 7 \\
\hline Irrigation Engineer & 1.00 & 0 \\
\hline Structural Engineer & 1.00 & 2 \\
\hline Opers Researcher & 1.00 & 1 \\
\hline Electri_tronic Tech & 1.00 & $i$ \\
\hline Materia Ts Scientist & 1.00 & 2 \\
\hline Petrol Mining Engineer & 1.00 & 0 \\
\hline Seismōog ist & 1.00 & $\theta$ \\
\hline
\end{tabular}

\section{Degree}

Mix of BS and Advanced Mix of $B S$ and Advanced Most ly Bache lor Most ly Bache lor Most ly Associate HS or less Mix of BS and Advanced Mostly Bachelor Mix of BS and Advanced $M i x$ of $A S$ and $B S$ Most ly Associate Mostly Associate Mix of AS and BS Most ly Associate Mix of BS and Advanced Mix of BS and Advanced $M i x$ of $A S$ and $B S$ Mix of $B S$ and Advanced Mix of BS and Advanced HS or less

Mix of AS and BS Mix of BS and Advanced $M i x$ of $A S$ and $B S$ Mix of BS and Advanced Most ly Associate Mix of $A S$ and $B S$ Mix of $B S$ and Advanced Mostly Associate Most ly Bache lor HS or less Most ly Bache lor Mix of BS and Advanced Most ly Associate Most ly Assoc late Mix of $B S$ and Advanced Mix of AS and BS Mix of $B S$ and Advanced Most.ly Associate Mostly Bachelor Mix of A.S and BS Most ly Bache lor Most ly Bachelor Most ly Bache lor Mostly Associate Mix of BS and Advanced Mix of AS and BS HS or less

Mix of BS and Advanced Mix of $B S$ and Advanced Mix of AS and BS Most ly Associate Most ly Associate Most ly Associate

Statistics based on dafa from 10 WNAS surveys and 4 SCHC surveys. 
APPENDIX 0

SIMPLE STATISTICS INTERCORRELATION AMONG

VARIABLES AND JOB SORTS ON ALL VARIABLES

FOR PANTEX ONLY 
TABLE 0.1. Descriptive Statistics for Relative Ratings

\begin{tabular}{llcccc} 
Variable & N & Minimum & Maximum & Mean & $\underline{\text { S.D. }}$ \\
\hline HR_DIFF & 28 & 2.00 & 3.00 & 2.36 & 0.49 \\
HR_NEED & 28 & 1.00 & 3.00 & 2.00 & 0.27 \\
HR_REC_C & 28 & 2.00 & 3.00 & 2.04 & 0.19 \\
HR_REC_A & 28 & 2.00 & 2.00 & 2.00 & 0.00 \\
HR_TURN & 27 & 1.00 & 3.00 & 2.04 & 0.34 \\
PM_DIFF & 30 & 1.00 & 4.00 & 2.53 & 0.73 \\
PM_REC_A & 30 & 1.00 & 5.00 & 2.30 & 0.76 \\
PM_EDUC & 30 & 1.00 & 5.00 & 3.13 & 0.96
\end{tabular}

S.D. = Standard Deviation, HR_DIFF = Difficulty Caused by a Shortage, HR_NEED = Need for Additiona1-Employees, HR-REC_A = Anticipated Ease of Recruitment, HR-REC-C = Current Ease of Recruitment, HR TURN = Current Annua 7 Turnover, PM DIFF = Difficulty Caused By a Shortage, PM_REC $A=$ Anticipated Ability to Recruit, PMEEUC = Typical Degree Leve1, $* * \bar{p}<\overline{0} .01 ; * p<0.05$. Statistics based on data from 2 WNAS surveys and I SCHC survey. 


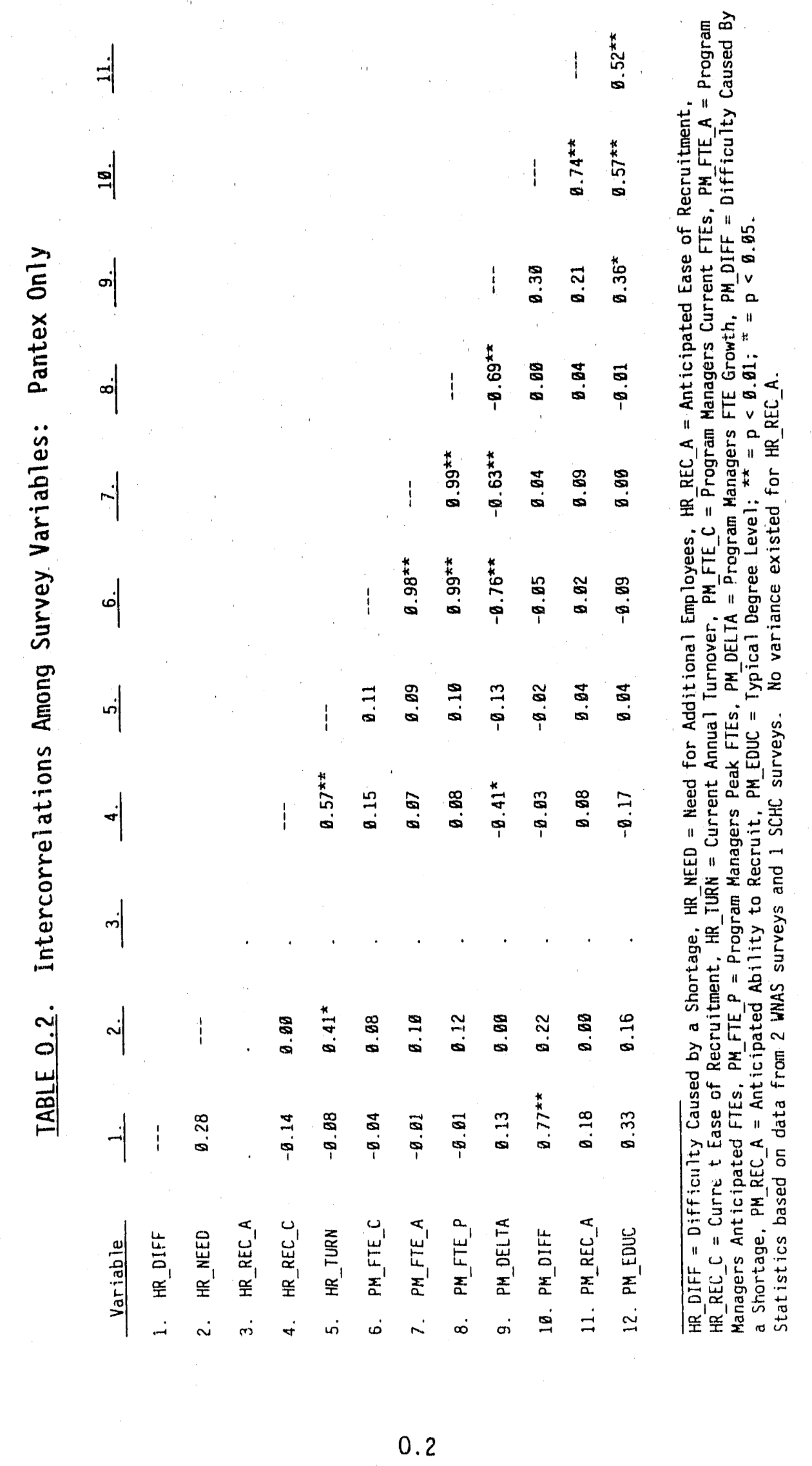




\section{IABLE 0.3. Job Titles Sorted By Change in FTEs (PM_Delta)}

\begin{tabular}{|c|c|c|c|c|c|}
\hline Job Title & PM_FTE_C & PH_FTE_A & PM_FTE_P & PH_DELTA & Degree \\
\hline Electri_tronic Tech & 1 & 2 & 3 & 1 & Mostiy Associate \\
\hline Environ Engineer & 6 & 7 & 15 & $i$ & Mix of BS and Advanced \\
\hline Admin_Clerical & 2 & 2 & 4 & $\theta$ & HS or less \\
\hline Biochemist & $\theta$ & $\theta$ & 6 & 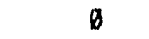 & Mostly Associate \\
\hline Biologist & 2 & 2 & 4 & $\theta$ & Mix of BS and Advanced \\
\hline Civil Eng Tech & 6 & 6 & 15 & $\theta$ & Mix of $A S$ and $B S$ \\
\hline Computer Engineer & 4 & 4 & 10 & D & Mix of BS and Advanced \\
\hline Drafter & 3 & 3 & 6 & 0 & Mostly Associate \\
\hline Ecologist & b & 0 & $\theta$ & $\theta$ & Most ly Associate \\
\hline Electric_tronic Engineer & 0 & 0 & $\theta$ & $\theta$ & Mostly Associate \\
\hline Environ Scientist & 6 & 6 & 14 & $\theta$ & Mix of BS and Advanced \\
\hline HazWasteMan Spec & 2 & 2 & 4 & 0 & Most iy Bachelor \\
\hline Health Physicist & 4 & 4 & 10 & $\theta$ & Mix of BS and Advanced \\
\hline Ind Hyg ien ist & 5 & 5 & 13 & $\theta$ & Most ly Advanced \\
\hline Irrigation Engineer & 0 & $\theta$ & $\theta$ & $\emptyset$ & HS or less \\
\hline Materials Engineer & 3 & $\theta$ & $\theta$ & $B$ & Mostiy Associate \\
\hline Materials Scientist & 0 & $\theta$ & $\theta$ & $\theta$ & Mostiy Associate \\
\hline Mathematician & $\theta$ & $\theta$ & $\theta$ & $b$ & Most ly Associate \\
\hline Mech Eng in Tech & $\theta$ & $\theta$ & 8 & D & HS or less \\
\hline Mechanical Engineer & 1 & 1 & 2 & $\theta$ & Host iy Bache lor \\
\hline NucWaste Process Oper & D & $\theta$ & 0 & $\emptyset$ & HS or less \\
\hline Nuc lear Decon Engineer & 0 & $\theta$ & 8 & 0 & Mostly Associate \\
\hline Nuc lear Eng ineer & $\theta$ & 8 & b & $\theta$ & Mostly Associate \\
\hline Opers Researcher & 0 & $\theta$ & 0 & $\theta$ & Most ly Associate \\
\hline Other Administrator & $\theta$ & $\theta$ & $\theta$ & $B$ & HS or less \\
\hline Other Engineer & $\theta$ & $\theta$ & $B$ & $\emptyset$ & Hostly Associate \\
\hline Other Scient ist & $\theta$ & $\theta$ & $\theta$ & $\theta$ & Most ly Associate \\
\hline Other Technician & $B$ & 0 & B & 0 & HS or less \\
\hline Petrol_Mining Engineer & $\theta$ & $\theta$ & 6 & 0 & Most ly Associate \\
\hline Physicist & 0 & B & 8 & $\theta$ & Mostly Associate \\
\hline Project Manager & 1 & 1 & 2 & $\theta$ & Mostly Bachelor \\
\hline Rad Protect Spec & $\theta$ & $B$ & $\theta$ & $\theta$ & HS or less \\
\hline Remediation Specialist & 0 & 0 & a & $\theta$ & HS or less \\
\hline Risk Assess Manager & $\theta$ & 0 & 0 & $\theta$ & HS or less \\
\hline Safety Engineer & 4 & 4 & 10 & 0 & Mix of $B S$ and Advanced \\
\hline Se ismolog ist & $\theta$ & $\theta$ & $\theta$ & 0 & Mostly Associate \\
\hline Statistician & $\theta$ & 9 & 6 & 8 & Most ly Associate \\
\hline Structural Engineer & $\theta$ & $\theta$ & $\theta$ & 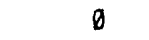 & Mostly Associate \\
\hline Technical Writer & 6 & 0 & 0 & 9 & HS or less \\
\hline Trainer & $\emptyset$ & $\theta$ & 8 & $B$ & HS or less \\
\hline WasteMan Eng ineer & $D$ & 0 & $\theta$ & $\theta$ & Most iy Associate \\
\hline Civil Engineer & 6 & 5 & 12 & -1 & Most ly Bachelor \\
\hline Driller & 5 & 4 & 18 & -1 & Mostly Associate \\
\hline Estimator & 1 & 0 & 1 & -1 & Hix of $A S$ and $B S$ \\
\hline Geologist & 6 & 5 & 12 & -1 & Most ly Bache lor \\
\hline H physics Tech & 5 & 4 & 11 & -1 & Mix of $A S$ and $B S$ \\
\hline Hydrol_Hydrogeologist & 5 & 4 & 10 & -1 & Mix of BS and Advanced \\
\hline Ind Safety Health Tech & 5 & 4 & 11 & -1 & Mix of AS and BS \\
\hline Industrial Engineer & 1 & $B$ & 1 & -1 & Most iy Bache lor \\
\hline Survey Map Tech & 4 & 3 & 8 & $-i$ & Mostly Associate \\
\hline Chemical Engineer & 9 & 7 & 18 & -2 & Mostily Bachelor \\
\hline Chemist & 7 & 5 & 14 & -2 & Mix of $B S$ and Adranced \\
\hline Computer Oper & 7 & 5 & 15 & -2 & Mostiy Associate \\
\hline Chem Tech & 21 & 19 & 43 & -3 & Most 1y Associate \\
\hline Chemical Eng Tech & 9 & 6 & 16 & -3 & Most ly Associate \\
\hline Enviror Sciences Yech & 19 & 16 & 43 & -3 & Mix of $A S$ and $B S$ \\
\hline Material Handler & 8 & 4 & 12 & -4 & HS or less \\
\hline
\end{tabular}

Statistics based on data from 2 WHAS surveys and: SCHC survey. 


\section{TABLE 0.4. Titles Sorted by Project Manangr's Ratings of Anticipated Ability to Recruit (PM_Rec_A)}

Job Title

Biologist

Environ Engineer

Environ Scientist

Project Manager

Geologist

Chemical Eng ineer

Chemist

Chem Tech

Chemical Eng Tech

Civil Engineer

Civil Eng Tech

Hea ith Physicist

Ind Hygienist

Driller

Hydrol Hydrogeo log ist

Computér Oper

Electri tronic Tech

Computer Eng ineer

Drafter

HazWesteMan Spec

Mechanical Engineer

Safety Engineer

Estimator

$H$ physics Tech

Ind Safety_Health Tech

Industrial Eng ineer

Survey Map Tech

Environ Sciences Tech

Admin Clerical

Mater $\bar{i} a l$ Handler

Biochemist

Ecologist

Electric tronic Engineer

Irrigation Engineer

Materials Engineer

Materials Scientist

Mathematician

Mech Eng in Tech

NucWaste Process Oper

Nuc lear Decon Engineer

Nuclear Engii.eer

Opers Researcher

Petrol Mining Engineer

Physicist

Rad Protect Spec

Renediation Specialist

$R$ isk Assess Manager

Se ismolog ist.

Statistician

Structural Engineer

Technical Writer

Trainer

WasteMan Eng ineer

\section{PH_REC_A}

PH_DELTA

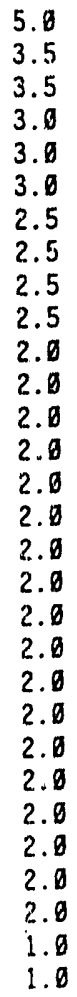

3.5

3.5

3.0

3.

2.5

2.5

2.5

2.5

2.8

.

.

2.0

2.0

2.0

2.0

2.0

2.0

2.8

2.0

2.0

2.0

2.8

1.0

.

Statistics based on data from 2 WNAS surveys and 1 SCHC survey.

Degree

Mix of BS and Advanced Mix of $B S$ and Advanced Mix of BS and Advanced Most ly Bachelor Mostly Bachelor Most iy Bache lor Mix of BS and Advanced Most ly Associate Most ly Associate Most ly Bache lor Mix of $A S$ and $B S$ Mix of $B S$ and Advanced Most ly Advanced Most ly Associate

inix of BS and Advanced Mostily Associate Most ly Associate Mix of BS and Advanced Most ly Associate Most ly Bachelor Mostly Bachelor Mix of $B S$ and Advanced Mix of $A S$ and $B S$ Mix of $A S$ and $B S$ Mix of AS and BS Most ly Bachelor Mostly Associate $M i x$ of $A S$ and $B S$ HS or less

HS or less

Most ly Associate Mast ly Associate Most ly Associate HS or less

Most ly Associate Most ly Associate Mostly Associate HS or less

HS or less Most ly Associate Most ly Associate Most iy Associate Most ly Associate Mostly Associate HS or less HS or less HS or less Most iy Associate Most ly Associate Most ly Associate HS or less

HS or less Mostly Associate 


\section{TABLE 0.5. Titles Sorted By Project Manager's Ratings of Difficulty Caused by Shortage (PM_Diff)}

PH_DIFF

PH_DELTA

Degree

\author{
Jab Title \\ Biologist \\ Project Manager \\ Environ Engineer \\ Environ Scientist \\ Geologist \\ Chemist \\ Civil Eng Tech \\ Health Physicist \\ Ind Hygien ist \\ Driller \\ Hydrol Hydrogeo logist \\ Chemicäl Engineer \\ Coniputer Oper \\ Chem Tech \\ Chemical Eng Tech \\ Electri_tronic Tech \\ Admin Clerical \\ Computer Eng ineer \\ Drafter \\ HazWasteMan Spec \\ Mechanical Engineer \\ Safety Eng ineer \\ Civil Engineer \\ Estimator \\ $H$ physics Tech \\ Ind Safeity_Heaith Tech \\ Industrial Eng ineer \\ Survey_Map Tech \\ Environ Sciences Tech \\ Material Handler \\ Biochernist \\ Ecolog ist \\ Electric_tronic Engineer \\ Irrigation Engineer \\ Materia is Engineer \\ Materials Scient ist \\ Mathenatician \\ Mech Eng in Tech \\ NucWaste Process Oper \\ Nuclear Decon Eng ineer \\ Nuc lear Engineer \\ Opers Researcher \\ Petrol Mining Engineer \\ Physicist \\ Rad Protect Spec \\ Remediation Specialist \\ Risk Assess Manager \\ Se ismologist \\ Statistician \\ Structural Engineer \\ Technical Writer \\ Trainer \\ WasteMan Eng ineer
}

4.0

4.9

3.5

3.5

Statistics based on data from 2 WNAS surveys and 1 SCHC survey.
Mix of BS and Advanced Mostly Bachelor

Mix of BS and Advanced Mix of BS and Advanced Mostly Bachelor

Mix of BS and Advanced Mix of AS and BS

Mix of BS and Advanced Mostly Advanced

Most ly Associate

Mix of BS and Advanced

Mostly Bachelor

Mostly Associate

Mostly Associate

Mostly Associate

Mostly Associate

HS or less

Mix of $B S$ and Advanced

Most ly Associate

Most ly Bachelor

Most ly Bachelor

Mix of $B S$ and Advanced

Mostly Bachelor

$M i x$ of $A S$ and $B S$

Mix of AS and BS

Mix of $A S$ and $B S$

Most ly Bachelor

Most ly Associate

Hix of AS and $8 S$

HS or less

Mostly Associate

Mostly Associate

Most ly Associate

HS or less

Mostly Associate

Mostly Associate

Mostly Associate

HS or less

HS or less

Mostly Associate

Mostly Associate

Mostly Associate

Mostly Associate

Mostly Associate

HS or less

HS or less

HS or less

Most iy Associate

Mostly Associate

Mostly Associate

HS or less

HS or less

Mostly Associate 


\section{TABLE 0.6. Job Titles Sorted By Human Resource Personnel's Ratings of Difficulty Caused By Shortage (HR_Diff)}

\author{
Job Title \\ Environ Engineer \\ Project Manager \\ Geologist \\ Chemist \\ Civil Eng Tech \\ Health Physicist \\ Ind Hygienist \\ Driller \\ Hydrol Hydrogeolog ist \\ Computer Oper \\ Environ Scientist \\ Chemical Eng ineer \\ Chem Tech \\ Chemical Eng Tech \\ Civil Engineer \\ Computer Engineer \\ Orafter \\ HazWasteMan Spec \\ Safety Engineer \\ Est imator \\ $H$ physics Tech \\ Ind Safety Health Tech \\ Survey_Map Tech \\ Environ Sciences Tech \\ Adnin Clerical \\ Rad Protect Spec \\ Risk Assess Manager \\ Technical Writer \\ Biologist \\ Electri_tronic Tech \\ Mechanical Engineer \\ Industrial Engineer \\ Material Handler \\ Biochemist \\ Ecologist \\ Electric tronic Engineer \\ Irrigation Fngineer \\ Materials Engineer \\ Materials Scientist \\ Mathematician \\ Mech Eng in Tech \\ NucWaste Process Oper \\ Nuc lear Decon Engineer \\ Nuc lear Eng ineer \\ Opers Researcher \\ Petrol Mining Engineer \\ Phys ic ist \\ Rerrediation Specialist \\ Se ismo log ist \\ Statistician \\ Structural Engineer \\ Trainer \\ WasteMan Engineer
}

HR_DIFF

3

3

3

3

3

3

3

3

3

3

2

2

2

2

2.

2

2

2

2

2

2

2

2

2

2

Statistics based on data from 2 WNAS surveys and 1 SCHC survey
PM_DELTA Degree

Mix of BS and Advanced Most ly Bachelor

Most ly Bache lor

Mix of BS and Advanced

Mix of AS and BS

Mix of BS and Advanced

Most ly Advanced

Most ly Associate

Mix of BS and Advanced

Most ly Assoc iate

Mix of BS and Advanced

Most ly Bache lor

Most ly Associate

Most ly Associate

Most ly Bache lor

Mix of BS and Advanced

Most ly Assoc iate

Most ly Bache lor

Mix of $B S$ and Advanced

Mix of $A S$ and $B S$

$M i x$ of $A S$ and $B S$

Mix of AS and BS

Most ly Associate

Mix of $A S$ and $B S$

HS or less

HS or less

HS or less

HS or less

Mix of BS and Advanced

Most ly Associate

Most ly Bache lor

Most ly Bachelor

HS or less

Most.ly Associate

Mostly Associate

Mostly Associate

HS or less

Most ly Associate

Most ly Associate

Most ly Associate

HS or less

HS or less

Most ly Associate

Most ly Associate

Mostly Associate

Mostly Associate

Most ly Associate

HS or less

Mostly Associate Mostly Associate Most ly Associate HS or less

Most ly Associate 
TABLE 0.7. Job Titles Sorted By Human Resource Personnel's Ratings of Need for Additional Employees (HR_Need)

Job Title

Civil Eng Tech

Environ Engineer

Project Manager

Geolog ist

Chemist

Health Physic ist

Ind Hyg ien ist

Driller

Hydrol_Hydrogeologist

Computēr Oper

Environ Scient ist

Chemical Engineer

Chem Tech

Chemical Eng Tech

Civil Engineer

Computer Engineer

HazWasteMan Spec

Safety Eng ineer

Est imator

$H$ physics Tech

Ind Safety_Hea ith Tech

Survey Map Tech

Environ Sciences Tech

Admin C.lerica 1

Rad Protect Spec

Risk Assess Manager

Technical Writer

Drafter

Biologist

Electri_tronic Tech

Mechanical Engineer

Industrial Engineer

Material Handler

Biochemist

Ecologist

Electric tronic Engineer

Irrigation Engineer

Materials Engineer

Materials Scientist

Mathenlat ician

Mech Eng in Tech

NucWaste Process Oper

Nuc lear Decon Eng ineer

Nuclear Eng ineer

Opers Researcher

Petrol Mining Eng ineer

Physicist

Remediation Specialist

Se ismo log ist

Statistician

Structural Engineer

Trainer

WasteMan Engineer

\section{HR MEED}

PH_DELTA

$\theta$

1

$-1$

$-2$

0

0

$-1$

$-2$

9

$-2$

$-3$

$-3$

$-1$

0

0

$-1$

$-1$

-1
-1
-3

$-3$

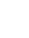

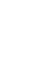

0

statistics based on data from 2 WNAS surveys and 1 SCHC survey.

\section{Degree}

Mix of $A S$ and $B S$

Mix of $B S$ and Advanced

Most ly Bache lor

Mostly Bachelor

Mix of BS and Advanced Mix of BS and Advanced Most ly Advanced

Mostly Associate

Mix of BS and Advanced

Mostly Associate

Mix of BS and Advanced Most ly Bachelor

Mostly Associate

Mostly Associate

Most ly Bachelor

Mix of BS and Advanced

Mostly Bachelor

Mix of $B S$ and Advanced

Mix of AS and BS

$M i x$ of $A S$ and $B S$

Mix of AS and BS

Mostly Associate

Mix of AS and BS

HS or less

HS or less

HS or less

HS or less

Most ly Associate

Mix of BS and Advanced Mostly Associate

Mastly Bachelor Most ly Bachelor

$$
\text { HS or less }
$$

Mostly Associate Mostly Associate Mostly Associate HS or less

Most.ly Associate Mostly Associate Mostly Associate HS or less

HS or less

Most ly Associate Mostly Associate Most iy Associate Mostily Associate Mostly Associate HS or less

Mostly Associate Mostly Associate Mostly Associate HS or less

Mostly Associate 
TABLE 0.8. Job Titles Sorted By Human Resource Personnel's Ratings of Current Ability to Recruit (HR_Rec_C)

Job Titile

Chentisis Eng Tech

Cisifl Englrech

Environ Ehg inear

Project Marrager

Geologist

Chemist

Health Physicist

Ind Hygienist

Oriller

Hydrol Hydrogeo log ist

Computer Oper

Environ Scientist

Chemical Engineer

Chem Tech

Civil Engineer

Computer Eng ineer

HazWasteMan Spec

Safety Engineer

Estimator

H physics Tech

Ind Safety_Health Tech

Survey Map Tech

Environ Sciences Tech

Admin_Clerical

Rad Protect Spec

Technical Writer

Drafter

Biologist

Electri_tronic Tech

Mechanical Engineer

Indusirial Engineer

Material Handler

Biochemist

Ecologist

Electric tronic Engineer

Irrigation Engineer

Materials Engineer

Materials Scientist

Mathematician

Mech Eng in Tech

NucWaste Process Oper

Nuc lear Decon Eng ineer

Nuc lear Eng ineer

Opers Researcher

Petrol Mining Engineer

Physicist

Remediation Specialist

Seismologist

Stat istician

Structurai Engineer

Trainer

WasteMan Engineer
Risk Assess Manager

\section{HR_REC_C}

PH_DELTA

$-3$

0

a

$-1$

$-2$

0

9

$-1$

$-1$

$-2$

$-2$

$-3$

$-1$

0

$\emptyset$

-1
-1
-1

$-1$

-1
-3

$-3$

0

0

0

0

1

$-1$

$-4$

$\theta$

g

$\theta$

0

$B$

0

0

0

9

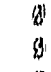

IJ

g

8

o

$B$

Stat istics based on data frorn 2 WNAS surveys and 1 SCHC survey.

\section{Degree}

Mostiy Assoc iate

Mix of AS and BS

Mix of BS and Advanced

Most ly Bachelor

Mostly Bachelor

Mix of BS and Advanced

Mix of BS and Advanced

Most ly Advanced

Mostly Assoclate

Mix of BS and Advanced

Most ly Associate

Mix of $B S$ and Advanced

Mostly Bachelor

Mostly Associate

Mostly Bachelor

Mix of BS and Advanced

Mostly Bachelor

Mix of $B S$ and Advanced

$M i x$ of $A S$ and $B S$

$M i x$ of $A S$ and $B S$

Mix of AS and BS

Mostly Associate

Mix of AS and BS

HS or less

HS or less

HS or less

HS or less

Most iy Associate

Mix of BS and Advanced

Mostly Associate

Most ly Bache lor

Most ly Bache lor

HS or less

Mostly Associate

Mostly Associate

Most.ly Associate

HS or less

Mostly Associate

Most ly Associate Most ly Associate

HS or less

HS or less

Most ly Associate Mostly Associate Most ly Associate Most ly Associate Most ly Associate HS or less Mostly Associate Most ly Associate Mostly Associate HS or less Most ly Associate 


\section{TABLE 0.9. Job Titles Sorted By Human Resource Personnel's Ratings of Anticipated Ability to Recruit (HR_Rec_A)}

\section{Job Title}

Chemical Eng Tech

Civil Eng Tech

Environ Engineer

Project Manager

Geolog ist

Chemist

Hea th Physicist

Ind Hyg ien ist

Driller

Hydrol_Hydrogeologist

Computer Oper

Environ Scientist

Chemical Eng ineer

Chem Tech

Civil Engineer

Computer Eng ineer

HazWasteMan Spec

Safety Engineer

Estimator

H_physics Tech

Ind Safety_Health Tech

Survey Map Tech

Environ Sciences Tech

Admin Clerical

Rad Protect Spec

Risk Assess Manager

Technical Writer

Drafter

Biologist

Electri tronic Tech

Mechanical Engineer

Industrial Engineer

Material Handler

Biochemist

Ecologist

Electric tronic Engineer

Irrigation Engineer

Materials Engineer

Materials Scient ist

Mathernatician

Mech Eng in Tech

NucWaste Process Oper

Nuclear Decon Engineer

Nuc lear Eng ineer

Opers Researcher

Petrol_Mining Engineer

Physicist

Remediation Sperialist

Se ismologist

Statistician

Structural Engineer

Trainer

WasteMan Eng ineer

\section{HR_REC_A}

2

2

2

2

2

2

2

2

2

2

2

2

2

2

2

2

2

2

2

2
2

2

2

2

2
2

Statistics based on data from 2 WNAS surveys and 1 SCHC survey.

\section{PH_DELTA}

$-3$

1

9

$-1$

$-2$

0

$-1$

$-1$

$-2$

-2
-3

$-3$

$-1$

0

0

-1
-1

$-1$

$-1$

$-3$

0

0

0

0

1

-1
-4

$-4$

$\theta$

0

0

$b$

$\theta$

$\theta$

0

9

b

b

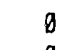

0

0

0

$\theta$

\section{Degree}

Most ly Assoc iate

Mix of AS and BS

Mix of BS and Advanced

Most ly Bache lor

Most ly Bache lor

Mix of BS and Advanced

Mix of BS and Advanced

Most ly Advanced

Most ly Associate

Mix of BS and Advanced

Most Ty Associate

Mix of BS and Advanced

Most ly Bache lor

Most ly Assoc iate

Most ly Bachelor

Mix of BS and Advanced

Most ly Bache lor

Mix of BS and Advanced

Mix of AS and BS

Mix of AS and BS

Mix of AS and BS

Most ly Associate

Mix of AS and BS

HS or less

HS or less

HS or less

HS or less

Most ly Associate

Mix of BS and Advanced

Most ly Associate

Most ly Bache lor

Most ly Bachelor

HS or less

Most ly Associate

Most ly Associate

Most ly Associate

HS or less

Most ly Associate

Most ly Assoc iate

Most ly Associate

HS or less

HS or less

Most ly Associate

Most ly Associate

Mostly Associate

Mostly Associate

Most ly Associate

HS or less

Most.ly Associate

Most ly Associate

Most ly Associate

HS or less

Mostly Associate 
TABLE 0.10. Job Titles Sorted By Human Resource Personnel's Ratings of Annual Turnover (HR_Turn)

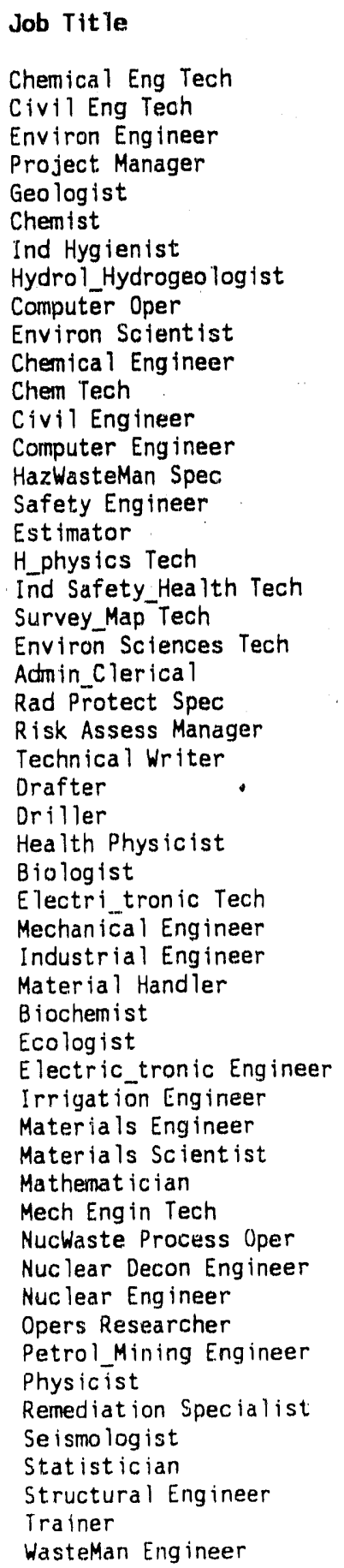

\section{Degree}

Mostly Associate Mix of AS and BS Mix of $B S$ and Advanced Most ly Bachelor Most ly Bachelor Mix of BS and Advanced Mostly Advanced Mix of BS and Advanced Most ly Assoc late Mix of BS and Advanced Most ly Bache lor Most ly Assoc iate Most ly Bache lor Mix of BS and Advanced Most ly Bache lor Mix of BS and Advanced Mix of AS and BS Mix of AS and BS Mix of AS and BS Most ly Associate Mix of AS and BS HS or less HS or less HS or less HS or less Most ly Associate Mostly Associate Mix of BS and Advanced Mix of BS and Advanced Mostly Associate Mostly Bache lor Most ly Bache lor HS or less

Mostly Associate Most ly Associate Most ly Assoc tate HS or less

Mostly Associate Most ly Associate Mostly Associate HS or less HS or less Most ly Associate Mostly Associate Mostly Associate Mostly Associate Mostly Associate HS or less Mostly Associate Mostly Assoc iate Mostly Associate HS or less Mostly Associate

Statistics based on data from 2 WNAS surveys and 1 SCHC survey 


\section{APPENDIX $P$}

SIMPLE STATISTICS INTERCORRELATION AMONG VARIABLES AND JOB SORTS ON ALL VARIABLES FOR PINELLAS ONLY 
TABLE P.1. Descriptive Statistics for Relative Ratings

\begin{tabular}{|c|c|c|c|c|c|}
\hline Variable & $\underline{N}$ & Minimum & Maximum & Mean & S.D. \\
\hline HR_DIFF & 0 & . & . & . & . \\
\hline HR_NEED & 0 & . & . & . & . \\
\hline HR_REC_C & 0 & . & . & . & \\
\hline HR_REC_A & 0 & . & . & . & . \\
\hline HR_TURN & 0 & . & . & . & \\
\hline PM_DIFF & 17 & 2.00 & 5.00 & 3.85 & 0.93 \\
\hline PM_REC_A & 17 & 1.00 & 5.00 & 3.21 & 1.13 \\
\hline PM EDUC & 17 & 1.00 & 5.00 & 3.38 & 1.19 \\
\hline
\end{tabular}

S.D. = Standard Deviation, HR_DIFF $=$ Difficulty Caused by a Shortage, HR_NEED = Need for Additional-Employees, HR-REC_A = Anticipated Ease of Recruitment, HR-REC-C = Current Ease of Recruitment, HR TURN = Current Annual Turnover, PM DIFF = Difficulty Caused By a Shortage, PM-REC A = Anticipated Ability to Recruit, PMEDUC = Typical Degree Level, ${ }^{* *} \bar{p}<\overline{0} .01 ; * p<0.05$. Statistics based on data from 2 WNAS surveys and 0 SCHC surveys. 


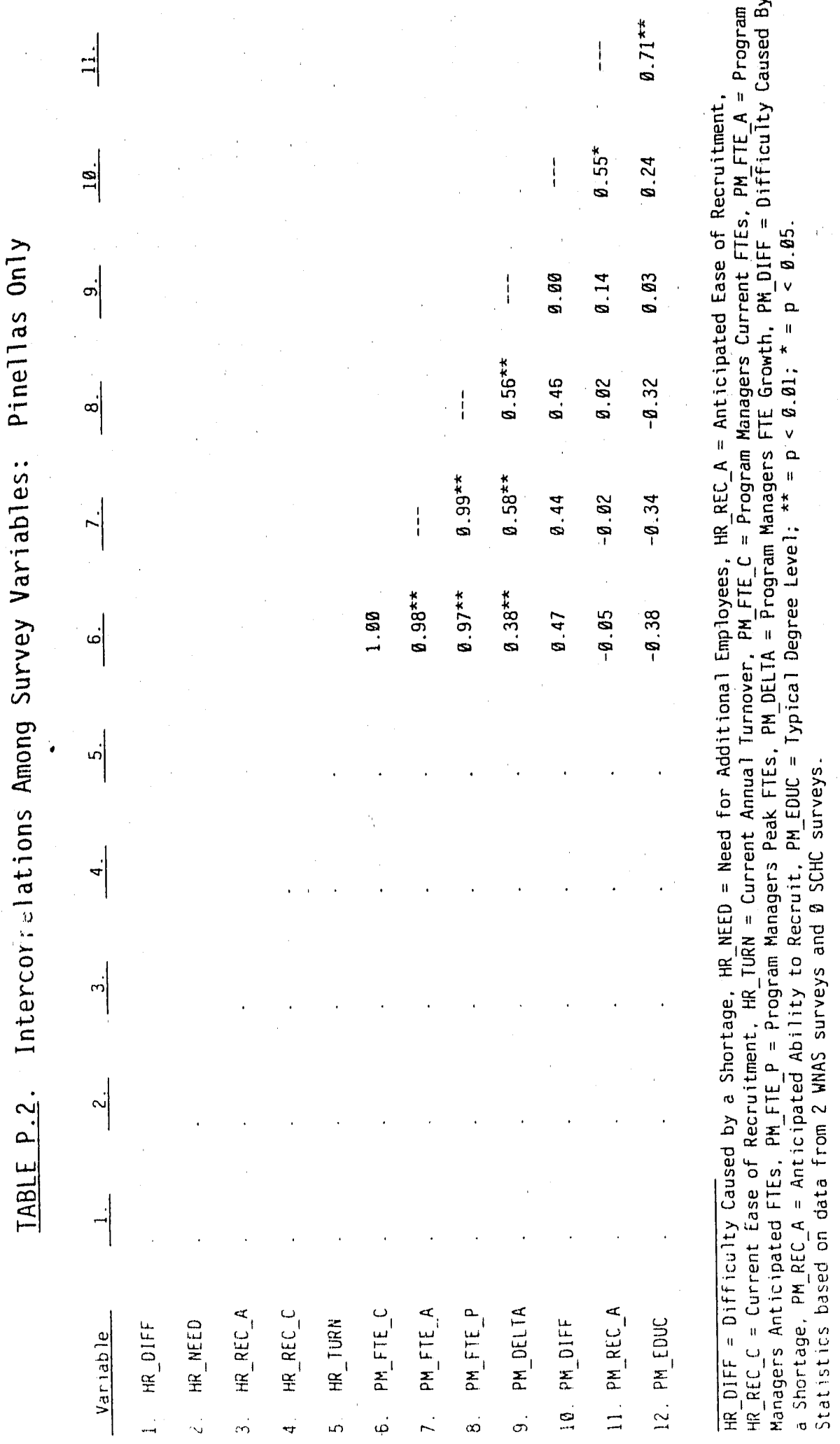




\section{TABLE P.3. Job Titles sorted By Change in FTES (PM_Delta)}

\begin{tabular}{|c|c|c|c|c|c|}
\hline Job Title & PM_FTE_C & PM_ETE_A & PH_FTE_P & PM_DELTA & Degree \\
\hline Chemical Engineer & 1 & 3 & 3 & 2 & Mix of BS and Advanced \\
\hline Environ Sciences Tech & $\theta$ & 1 & 1 & 1 & Mostly Associate \\
\hline Environ Sclent ist & $\theta$ & 1 & 1 & 1 & Mix of BS and Advanced \\
\hline HazWasteMan Spec & 2 & 3 & 3 & 1 & Mostly Bachelor \\
\hline Material Handler & 10 & 11 & 11 & 1 & HS or less \\
\hline WasteMan Engineer & $\theta$ & $i$ & 1 & 1 & Mix of BS and Advanced \\
\hline Admin_Clertcal & $\theta$ & $\theta$ & $\theta$ & $\theta$ & Mostly Associate \\
\hline Biochemist & $\theta$ & $\emptyset$ & $\theta$ & $\emptyset$ & Most ly Associate \\
\hline Btologist & 0 & $\theta$ & $\theta$ & $\theta$ & Most ly Associate \\
\hline Chem Tech & $\theta$ & $\theta$ & $\theta$ & $\theta$ & HS or less \\
\hline Chemical Eng Tech & $\theta$ & $\theta$ & $\theta$ & $\theta$ & HS or less \\
\hline Chemist & $\theta$ & $\theta$ & $\theta$ & $\theta$ & Most ly Associate \\
\hline Civil Eng Tech & $\theta$ & $\theta$ & $\theta$ & $\theta$ & $M+x$ of $A S$ and $B S$ \\
\hline Civil Engineer & $\theta$ & $\theta$ & $\theta$ & $\theta$ & Mostly Pho \\
\hline Computer Eng ineer & $\theta$ & $\theta$ & $\theta$ & $\theta$ & Mostly Associate \\
\hline Computer Oper & $\theta$ & $\theta$ & $\theta$ & $\theta$ & HS or less \\
\hline Drafter & $\theta$ & $\theta$ & $\theta$ & $\theta$ & Mostily Associate \\
\hline Driller & $\theta$ & $\theta$ & $\emptyset$ & $\theta$ & HS or less \\
\hline Ecolog ist & $\theta$ & $\theta$ & $\theta$ & $\theta$ & Most!y Associate \\
\hline Electri_tronic Tech & $\emptyset$ & $\theta$ & $\theta$ & $\theta$ & HS or less \\
\hline Electric_tronic Engineer & $\theta$ & $\theta$ & $\theta$ & $\theta$ & Mostly Associate \\
\hline Environ Eng ineer & 1 & 1 & 1 & $\theta$ & Most ly Pho \\
\hline Est imator & $\theta$ & $\theta$ & $g$ & $\theta$ & HS or less \\
\hline Geologist & $\theta$ & $\theta$ & $\theta$ & $\theta$ & Mix of BS and Advanced \\
\hline H_physics Tech & $\theta$ & $\theta$ & $\theta$ & $\theta$ & HS or less \\
\hline Health Physicist & $\theta$ & $\theta$ & $\theta$ & $\theta$ & Mostly Associate \\
\hline Hydrol Hydrogeologist & $\theta$ & $\theta$ & $\theta$ & $\theta$ & Mix of $B S$ and Advanced \\
\hline Ind Hygienist & $\theta$ & $\theta$ & $\emptyset$ & $\theta$ & HS or less \\
\hline Ind Safety_Health Tech & $\theta$ & $\theta$ & $\theta$ & $\theta$ & HS or less \\
\hline IndustrialEngineer & $\theta$ & $\theta$ & 0 & $\theta$ & Mostly Associate \\
\hline Irrigation Engineer & $\theta$ & 0 & $\theta$ & $\theta$ & HS or less \\
\hline Materials Eng ineer & $\theta$ & $\theta$ & $\theta$ & $\theta$ & Mostily Associate \\
\hline Materials Scientist & 9 & $\theta$ & $\theta$ & $\theta$ & Mostly Associate \\
\hline Mathematician & $\theta$ & $\theta$ & $\theta$ & $\theta$ & Most ly Associate \\
\hline Mech Eng in Tech & 0 & $\theta$ & $\theta$ & $\theta$ & HS or less \\
\hline Mechanical Engineer & $\theta$ & $\theta$ & $\theta$ & $\theta$ & Mostly Associate \\
\hline NucWaste Process Oper & 0 & $\theta$ & $\theta$ & 0 & HS or less \\
\hline Nuc lear Decon Eng ineer & $\theta$ & $\theta$ & $\theta$ & 0 & Most ly Associate \\
\hline Nuc lear Eng ineer & $\theta$ & $\theta$ & $\theta$ & $\theta$ & Most ly Associate \\
\hline Opers Researcher & $\theta$ & $\theta$ & $\theta$ & $\theta$ & Mostiy Associate \\
\hline other Administrator & $\theta$ & $\theta$ & 1 & $\theta$ & HS or less \\
\hline Other Engineer & $\theta$ & $\theta$ & $\theta$ & $\theta$ & Most ly Associate \\
\hline Other Scient ist & $\theta$ & $\theta$ & $\theta$ & $\theta$ & Mostly Associate \\
\hline Other Technician & 1 & 1 & 1 & $\theta$ & HS or less \\
\hline Petrol_Mining Eng ineer & $\theta$ & $\theta$ & $\theta$ & $\theta$ & Most ly Associate \\
\hline Physicist. & $\theta$ & $\theta$ & $\theta$ & $\theta$ & Mostly Associate \\
\hline Project Manager & 3 & 3 & 4 & $\theta$ & Most ly Bachelor \\
\hline Rad Protect. Spec & 1 & 1 & 1 & $\theta$ & Mix of $A S$ and $B S$ \\
\hline Remediation Specialist & $\theta$ & $\theta$ & $\theta$ & $\theta$ & HS or less \\
\hline Risk Assess Manager & $\theta$ & 2 & $\theta$ & $\theta$ & HS or less \\
\hline Safety Eng ineer & $\theta$ & $\theta$ & $\theta$ & $\theta$ & Mostly Associate \\
\hline Se ismo log ist & $\theta$ & $\theta$ & $g$ & $\theta$ & Most ly Associate \\
\hline Statistician & $\theta$ & $\theta$ & $\theta$ & $\theta$ & Mositly Associate \\
\hline Structural Engineer & $\theta$ & $\theta$ & g & $\theta$ & Most ly Associate \\
\hline Survey_Map Tech & 0 & $\theta$ & 0 & $\theta$ & Most ly Associate \\
\hline Technical Writer & 1 & 1 & 1 & $\theta$ & Most ly Bachelor \\
\hline Tralner & 0 & $\mathrm{j}$ & $\theta$ & $\theta$ & HS or less \\
\hline
\end{tabular}

statistics based on data fom 2 WNAS surveys and 9 SCHC surveys. 


\section{TABLE P.4. Titles Sorted by Project Manager's Ratings of Anticipated Ability to Recruit (PM_Rec_A)}

Job Title

Environ Engineer

Project Manager

Environ Scientist

HazWasteMan Spec

Civil Engineer

Rad Protect Spec

WasteMan Eng ineer

Chemical Eng ineer

Techntcal Writer

Environ Sciences Tech

Civil Eng Tech

Hydrol Hydrogeo log ist

Materiäl Handler

Survey_Map Tech

Geologist

Drafter

Admin_Clerical

Blochemist

Biologist

Chem Tech

Chemical Eng Tech

Chemist

Computer Engineer

Computer Oper

Driller

Ecologist

Electri tronic Tech

Electric_tronic Engineer

Estimatoor

H_physics Tech

Health Physicist

Ind Hygienist

Ind Safety_Health Tech

Industrial Engineer

Irrigation Engineer

Materials Engineer

Materials Scientist

Mathematician

Mech Eng in Tech

Mechanical Engineer

Nuchaste Process Oper

Nuclear Decon Engineer

Nuc lear Eng ineer

Opers Researcher

Petrol Mining Eng ineer

Physicist

Remediation Specialist

Risk Assess Manager

Safety Engineer

Seismologist

Statistician

Structural Engineer

Trainer

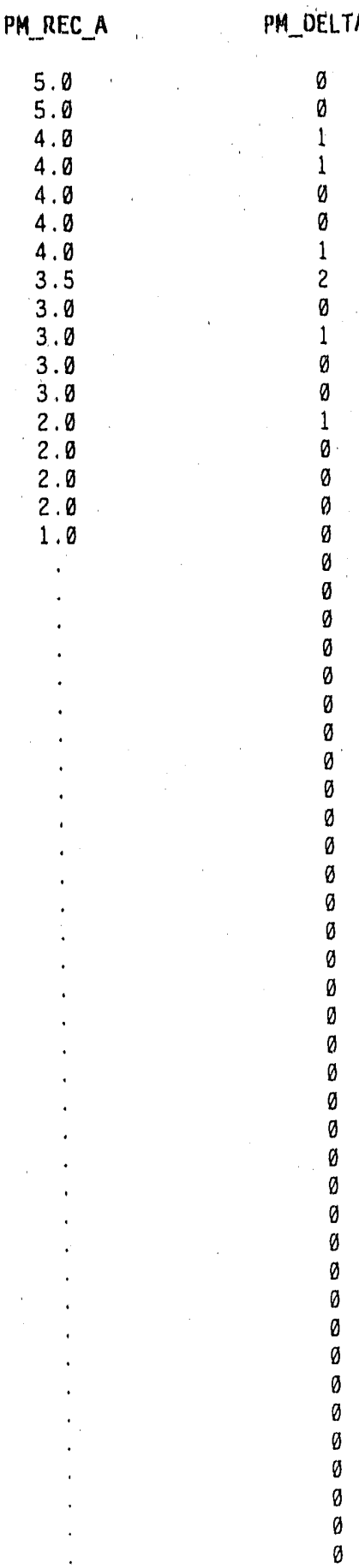

Degree

Mostly PhD

Mostly Bachelor

Mix of BS and Advanced

Most ly Bache lor

Mostly PhD

Mix of AS and BS

Mix of $B S$ and Advanced

Mix of BS and Advanced

Mostly Bache lor

Most ly Assoc late

$M+x$ of $A S$ and $B S$

MIX of $B S$ and Advanced

HS or less

Mostily Associate

Mix of BS and Advanced

Mostly Associate

Mostly Associate

Mostly Associate

Most ly Associate

HS or less

HS or less

Mostly Associate

Most ly Associate

HS or less

HS or less

Mostly Associate

HS or less

Most ly Associate

HS or less

HS or less

Most ly Associate

HS or less

HS or less

Mostly Associate

HS or less

Most ly Associate Mostly Associate Mostly Associate HS or less Most ly Associate HS or less Mostly Associate Most ly Associate Most ly Associate Most ly Associate Most ly Associate HS or less HS or less Most ly Associate Mostly Associate Mostly Associate Most ly Associate HS or less

Statistics based on data from 2 WNAS surveys and $\emptyset$ SCHC surveys. 


\section{TABLE P.5. TitTes Sorted By Project Manager's Ratings of Difficulty Caused by Shortage (PM_Diff)}

\section{Job Title}

Material Hand ler Environ Engineer Project Manager Technical Writer Environ Sciences Tech

Environ Scientist

HazWasteMan Spec

Civil Eng Tech

Civil Engineer

Hydrol Hydrogeologist

Rad Protect Spec

Survey Map Tech

Chemtcal Engineer

WasteMan Eng ineer

Geologist

Admin_Clerical

Draftēr

Biochemist

Biologist

Chem Tech

Chemical Eng Tech

Chemist

Computer Eng ineer

Computer Oper

Driller

Ecologist

Electri tronic Tech

Electric tronic Engineer

Estimator

$H$ physics Tech

Health Phys ic ist

Ind Hygien ist

Ind Safety_Hea?th Tech

Industrial Engineer

Irrigation Engineer

Materials Engineer

Materials Scientist

Mathematician

Mech Engin Tech

Mechanical Engineer

NucWaste Process Oper

Nuclear Decon Engineer

Nuc lear Eng ineer

Opers Researcher

Petrol Mining Engineer

Physicist

Remediation Specialist

Risk Assess Manager

Safety Eng ineer

Seismologist

Statistician

Structural Engineer

Trainer

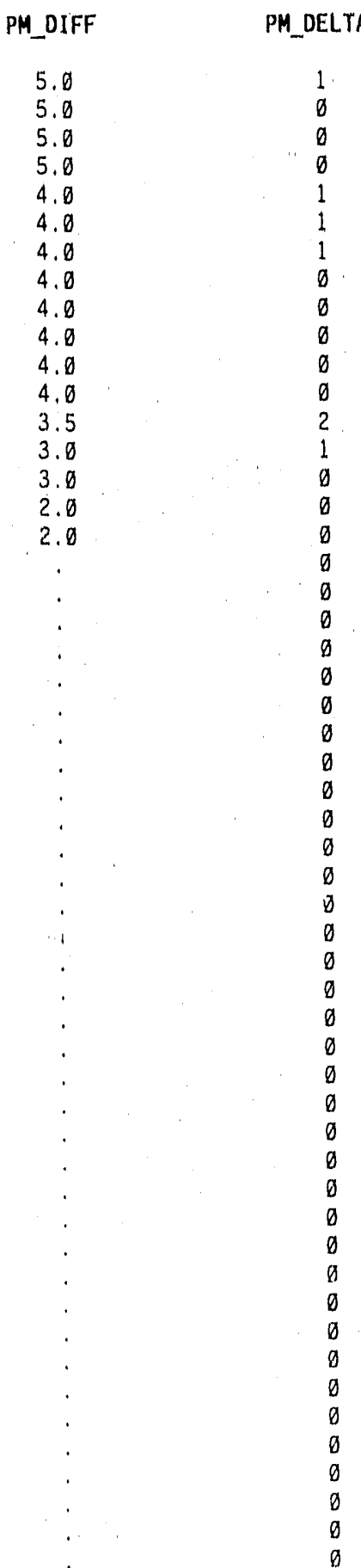

Statistics based on data from 2 WNAS surveys and $\emptyset$ SCHC surveys.

\section{Degree}

HS or less

Most iy Pho

Mostly Bache lor

Mostly Bache lor

Mostly Associate

Mix of BS and Advanced

Most ly Bache lor

MIX of AS and BS

Most ly Pho

Mix of BS and Advanced

Mix of AS and BS

Most ly Associate

Mix of BS and Advanced

Mix of BS and Advanced

Mix of BS and Advanced

Most ly Associate

Mostly Associate

Mostly Associate

Mostly Associate

HS or less

HS or less

Mostly Associate

Mostly Associate

HS or less

HS or less

Most ly Associate

HS or less

Most ly Associate

HS or less

HS or less

Most ly Associate

HS or less

HS or less

Most ly Associate

HS or less

Mostly Associate

Mostly Associate

Mostly Associate

HS or less

Most ly Associate

HS or less

Most ly Associate

Most ly Associate

Most ly Associate

Most ly Associate Most ly Associate

HS or less

HS or less

Mostly Associate Most ly Associate Most ly Associate Most ly Associate HS or less 

TABLE P.6. Job Titles Sorted By Human Resource Personnel's Ratings
of Difficulty Caused By Shortage (HR_Diff)

\author{
Job Title \\ Environ Engineer \\ Project Manager \\ Environ Scient ist \\ HazWasteMan Spec \\ Civil Eng ineer \\ Rad Protect Spec \\ WasteMan Engineer \\ Chemical Engineer \\ Technical Writer \\ Environ Sciences Tech \\ Civil Eng Tech \\ Hydrol_Hydrogeologist \\ Material Handler \\ Survey_Map Tech \\ Geologist \\ Drafter

IR_DIFF

PM_DELTA

Degree

Mostly PhD

Most ly Bachelor

Mix of BS and Advanced

Most ly Bachelor

Mostly Pho

Mix of AS and BS

Mix of $B S$ and Advanced

Mix of BS and Advanced

Most ly Bache lor

Most ly Associate

Mix of AS and BS

Mix of $B S$ and Advanced HS or less

Mostly Associate

Mix of BS and Advanced

Mostly Associate

Most ly Associate

Mostly Associate

Most iy Associate

HS or less

HS or less

Most ly Associate

Mostly Associate

HS or less

HS or less

Most ly Associate

HS or less

Most ly Associate

HS or less

HS or less

Mostly Associate

HS or less

HS or less

Most ly Associate

HS or less

Mostly Associate

Most ly Associate

Most ly Associate

HS or less

Most ly Asisociate

HS or less

Most ly Associate Most ly Associate Mostly Associate Most ly Associate Most ly Associate HS or less

HS or less Most ly Associate Most ly Associate Most ly Associate Most ly Associate HS or less

Statistics based on data from 2 WNAS surveys and a SCHC surveys. 
IABLE P.7. Job Titles Sorted By Human Resource Personnel's Ratings of Need for Additional Employees (HR_Need)

Job Title

Environ Engineer Project Manager

Environ Scientist

HazWasteMan Spec

Civil Engineer

Rad Protect Spec

WasteMan Engineer

Chemical Engineer

Technical Writer

Environ Sciences Tech

Civil Eng Tech

Hydrol_Hydrogeologist

Material Handler

Survey_Map Tech

Geologist

Drafter

A.dmin Clerical

$B$ iochein ist

Biologist

Chem Tech

Chemical Eng Tech

Chemist

Computer Eng ineer

Computer Oper

Driller

Ecologist

Electri tronic Tech

Electric_tronic Engineer

Est imator

H physics Tech

Health Physicist

Ind Hygien ist

Ind Safety_Heaith Tech

Industrial Eng ineer

Irrigation Engineer

Materials Engineer

Materials Scient ist

Mathematician

Mech Engin Tech

Mechanical Engineer

NucWlaste Process Oper

Nuc lear Decon Engineer

Nuclear Eng ineer

Opers Researcher

Petrol Mining Engineer

Physic ist

Remediation Specialist

$R$ isk Assess Manager

Safety Eng ineer

Seismologist

Stat istician

Structural Eng ineer

Trainer

\section{HK_NEED}

PM_DELTA

$\theta$

0

1

1

0

1

2

a

1

0

?

1

$\theta$

$\emptyset$

0

6

0

0

$\theta$

0

$\theta$

0

$\theta$

0

$\theta$

0

I

0

0

$\emptyset$

$\theta$

$\theta$

$\theta$

$\theta$

$\theta$

0

$\theta$

$\theta$

$\theta$

0

9

0

\section{Degree}

Mostly PhD

Most ly Bachelor

Mix of BS and Advanced

Most ly Bachelor

Most ly Pho

Mix of $A S$ and $B S$

Mix of $B S$ and Advanced Mix of BS and Advanced

Most ly Bache lor

Mostly Associate

Mix of AS and BS

Mix of BS and Advanced

HS or less

Most ly Associate

Mix of BS and Advanced

Most ly Associate

Most ly Associate

Most ly Associate

Most ly Associate

HS or less

HS or less

Mostly Associate

Mostly Associate

HS or less

HS or less

Mostly Associate

HS or less

Mostly Associate

HS or less

HS or less

Mostly Associate

HS or less

his or less

Most ly Associate

HS or less

Mostiy Associate

Most ly Associate

Most ly Associate

HS or less

Most ly Associate

HS or less

Mostly Associate

Most ly Associate

Most ly Associate

Most ly Associate

Mostly Associate

HS or less

HS or less

Mostly Associate

Most ly Associate

Most ly Associate

Most ly Associate

HS or less

Statistics based on data from 2 WNAS surveys and $\theta$ SCHC surveys. 


\section{TABLE P.8. Job Titles Sorted By Human Resource Personnel's Ratings of Current Ability to Recruit (HR_Rec_C)}

HR_REC_C

PH_DELTA

Degree

\author{
Job Tit le \\ Environ Engineer \\ Project Manager \\ Environ Scient ist \\ HazWasteMan Spec \\ Civil Engineer \\ Rad Protect Spec \\ WasteMan Eng ineer \\ Chemical Engineer \\ Technical Writer \\ Environ Sciences Tech \\ Civil Eng Tech \\ Hydrol_Hydrogeo log ist \\ Material Handler \\ Survey_Map Tech \\ Geologist \\ Drafter \\ Admin Clerical \\ Biochemist \\ Biologist \\ Chem Tech \\ Chemical Eng Yech \\ Chemist \\ Computer Engineer \\ Computer Oper \\ Driller \\ Ecologist \\ Electri_tronic Tech \\ Electric tronic Engineer \\ Estimator \\ H_physics Tech \\ Health Physicist \\ Ind Hygien ist \\ Ind Safety Health Tech \\ Industrial Engineer \\ Irrigation Engineer \\ Materials Engineer \\ Materials Scientist \\ Matliematician \\ Mech Eng in Tech \\ Mechanical Engineer \\ Nuchaste Process Oper \\ Nuclear Decon Engineer \\ Nuc lear Engineer \\ Opers Researcher \\ Petrol Mining Engineer \\ Physicist \\ Remediation Specialist \\ Risk Assess Mänager \\ Safety Engineer \\ Se ismo logist \\ Stat ist ician \\ Structural Engineer \\ Trainer
}

0
0
1
1
0
0
1
2
0
1
0
0
1
0
0
0
0
0
0
0
0
0
0
0
0
0
0
0
0
0
0
0
0
0
0
0
0
0
0
0
0
0
0
0
0
0
0
0
0
0
0

Statistics based on data from 2 WNAS surveys and $\theta$ SCHC surveys
Mostily Pho

Mostly Bacine lor

Mix of BS and Advanced

Mostly Bache lor

Mostly PhD

Mix of AS and BS

Mix of BS and Advanced

Mix of $B S$ and Advanced

Most ly Bachelor

Mostly Associate

Mix of AS and BS

Mix of BS and Advanced

HS or less

Most ly Associ iate

Mix of BS and Advanced

Mostly Associate

Mostly Associate

Mostly Associate

Mostly Associate

HS or less

HS or less

Mostly Associate

Most ly Associate

HS or less

HS or less

Mostly Associate

HS or less

Mostly Associate

HS or less

HS or less

Most ly Associate

HS or less

HS or less

Mostly Associate

HS or less

Mostly Associate

Mostly Associate

Mostly Associate

HS or less

Most iy Associate

HS or less

Mostly Associate Most ly Assuciate Most ly Associate Mostly Associate Most ly Associate HS or less

HS or less Most ly Assoclate Mostly Associate Most ly Associate Mostly Associate HS or less 


\section{TABLE P.9. Job Titles Sorted By Human Resource Personnel's Ratings of Anticipated Ability to Recruit (HR_Rec_A)}

Job Title

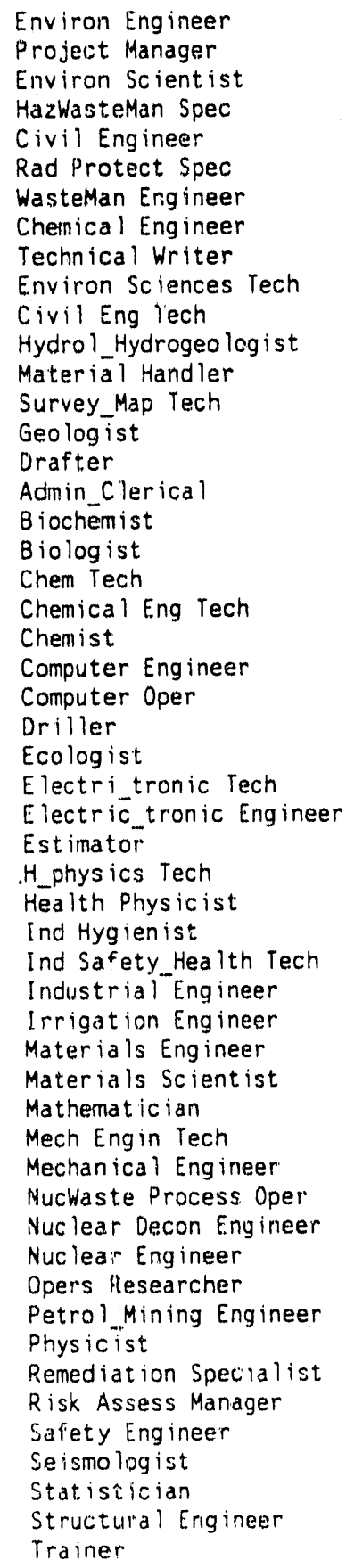

Statistics based on data from 2 WIAS surveys and 0 SCHC surveys.

\begin{tabular}{|c|c|c|}
\hline HR_REC_A & PM_DELTA & Degree \\
\hline . & $\theta$ & Mostly PhD \\
\hline . & $\theta$ & Most ly Bache lor \\
\hline . & 1 & Mix of BS and Advanced \\
\hline . & 1 & Most ly Bache lor \\
\hline . & $\theta$ & Mostly PhD \\
\hline . & $\theta$ & Mix of AS and BS \\
\hline . & 1 & Mix of $B S$ and Advanced \\
\hline . & 2 & Mix of BS and Advanced \\
\hline . & $\theta$ & Most ly Bache lor \\
\hline . & 1 & Mostly Associate \\
\hline . & 0 & Mix of $A S$ and $B S$ \\
\hline . & $\theta$ & Mix of $B S$ and Advanced \\
\hline . & 1 & HS or less \\
\hline . & $\theta$ & Mostly Associate \\
\hline . & $\theta$ & Mix of BS and Advanced \\
\hline . & 0 & Most ly Associate \\
\hline . & $\theta$ & Mostly Associate \\
\hline . & $\theta$ & Most ly Associate \\
\hline . & $\theta$ & Mostly Associate \\
\hline . & $\theta$ & HS or less \\
\hline . & 8 & HS or less \\
\hline . & 0 & Most ly Associate \\
\hline . & $\theta$ & Most ly Associate \\
\hline . & 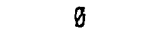 & HS or less \\
\hline . & $\theta$ & HS or less \\
\hline . & 0 & Mostly Associate \\
\hline . & 0 & HS or less \\
\hline . & $\theta$ & Mostly Associats \\
\hline . & $\theta$ & HS or less \\
\hline . & $\theta$ & HS or less \\
\hline . & $\theta$ & Most ly Associate \\
\hline . & $\theta$ & HS or less \\
\hline . & D & HS or less \\
\hline . & $\theta$ & Most ly Assuciate \\
\hline . & $\theta$ & HS or less \\
\hline . & $B$ & Most ly Associate \\
\hline . & $\theta$ & Mostly Associate \\
\hline . & $\theta$ & Mostly Associate \\
\hline . & 0 & HS or less \\
\hline . & $\theta$ & Most ly Associate \\
\hline . & $\theta$ & HS or less \\
\hline . & $\theta$ & Must iy Associate \\
\hline . & $\emptyset$ & Mostly Associate \\
\hline . & 0 & Mostly Associate \\
\hline . & $\theta$ & Mostly Associate \\
\hline . & 6 & Mostly Associate \\
\hline 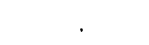 & $\theta$ & HS or less \\
\hline . & 0 & HS or less \\
\hline . & $\theta$ & Most ly Associate \\
\hline . & 8 & Mostly Associate \\
\hline & 0 & Most ly Associate \\
\hline . & $\theta$ & Mostly Associate \\
\hline & $g$ & HS or less \\
\hline
\end{tabular}




\title{
TABLE P.10. Job Titles Sorted By Human Resource Personnel's Ratings of Annual Turnover (HR_Turn)
}

\author{
Job Title \\ Environ Engineer \\ Project Manager \\ Environ Scient ist \\ KazWasteMan Spec \\ Civil Engineer \\ Rad Protect Spec \\ WasteMan Engineer \\ Chemical Engineer \\ Technical Writer \\ Environ Sciences Tech \\ Civil Eng Tech \\ Hydrol_Hydrogeologist \\ Material Handler \\ Survey Map Tech \\ Geologist \\ Drafter \\ Admin Clerical \\ Biochëmist \\ Biologist \\ Chem Tech \\ Chemical Eng Tech \\ Chemist \\ Computer Engineer \\ Computer Oper \\ oriller \\ Ecologist \\ Electri tronic Tech \\ Electric tronic Engineer \\ Estimator \\ H_physics Tech \\ Health Physicist \\ Ind Hygien ist \\ Ind Safety_Health Tech \\ Industrial Engineer \\ Irrigation Eng ineer \\ Materials Engineer \\ Materials Scient ist \\ Mathematician \\ Mech Engin Tech \\ Mechanical Engineer \\ NucWaste Process Oper \\ Nuclear Decon Engineer \\ Nuclear Engineer \\ Opers Researcher \\ Petrol Miring Engineer \\ Physicist \\ Remediation Specialist \\ Risk Assess Manager \\ Safety Engineer \\ Se : smo log ist \\ Statistician \\ Structural Engineer \\ Trainer
}

HR_TURM

PM_DELTA

Degree

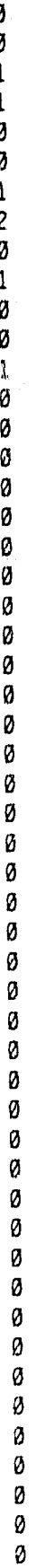

Most ly Pho

Most ly Bache lor

Mix of BS and Advanced

Most ly Bache lor

Mostly PhD

Mix of $A S$ and $B S$

$M i x$ of $B S$ and Advanced

Mix of BS and Advanced

Most ly Bachelor

Most ly Associate

$M i x$ of $A S$ and $B S$

Mix of $B S$ and Advanced

HS or less

Most ly Associate

Mix of BS and Advanced

Mestly Associate

Mostly Associate

Most ly Associate

Most ly Associate

HS or less

H.S or less

Most ly Associate

Most ly Associate

HS or less

HS or less

Mostly Associate

HS or less

Most ly Associate

HS or less

HS or less

Most ly Associate

HS or less

HS or less

Most ly Associate

HS or less

Mostly Associate

Most ly Associate

Most ly Associate

HS or less

Most ly Associate

HS or less

Most ly Associate

Most ly Associate

Most ly Associate

Most ly Associate

Most ly Associate

HS or less

HS or less

Mostly Associate Most ly Associate Mostly Associate Most ly Associate HS or less

Statistics based on data from ? WNAS surveys and $D$ SCHC surveys 
APPENDIX Q

SIMPLE STATISTICS INTERCORRELATION AMONG VARIABLES AND JOB SORTS ON ALL VARIABLES FOR RICHLAND ONLY 
TABLE Q.1. Descriptive Statistics for Relative Ratings

$\begin{array}{llcccc}\text { Variable } & \underline{N} & \frac{\text { Minimum }}{\text { Naximum }} & \text { Mean } & \underline{\text { S.D. }} \\ \text { HR_DIFF } & 56 & 1.50 & 5.00 & 2.99 & 0.65 \\ \text { HR_NEED } & 56 & 1.50 & 5.00 & 2.95 & 0.67 \\ \text { HR_REC_C } & 56 & 1.50 & 5.00 & 3.00 & 0.63 \\ \text { HR_REC_A } & 56 & 1.50 & 5.00 & 3.03 & 0.68 \\ \text { HR_TURN } & 56 & 1.17 & 5.00 & 2.48 & 0.59 \\ \text { PM_DIFF } & 52 & 1.00 & 4.50 & 2.96 & 0.72 \\ \text { PM_REC_A } & 52 & 1.00 & 5.00 & 2.96 & 0.76 \\ \text { PM_EDUC } & 52 & 1.17 & 5.00 & 3.24 & 0.98\end{array}$

S.D. = Standard Deviation, HR_DIFF $=$ Difficulty Caused by a Shortage, HR_NEED = Need for Additional Employees, HR-REC_A = Anticipated Ease of Recruitment, HR-REC-C = Current Ease of Recruitment, HR TURN = Current Annua 1 Turnover, PM DIFF = Difficulty Caused By a Shortage, PM_REC $A=$ Anticipated Ability to Recruit, PM EDUC = Typical Degree Level, ** $\bar{p}<\overline{0} .01 ; * p<0.05$. Statistics based on data from 19 WNAS surveys and 16 SCHC surveys. 


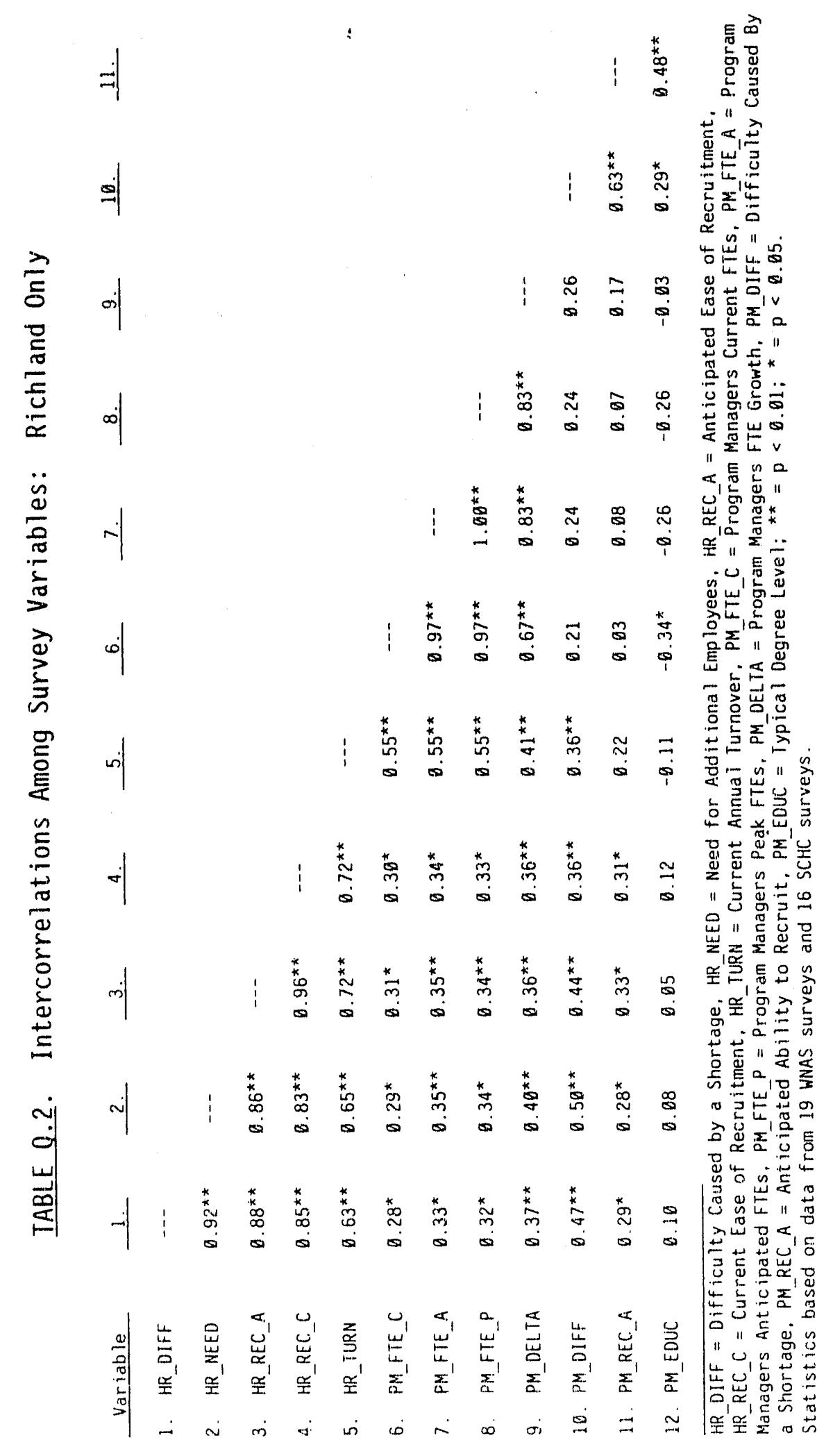

Q.2 


\section{TABLE Q.3. Job Titles Sorted By Change in FTEs (PM_Delta)}

\begin{tabular}{|c|c|}
\hline Job Title & PM_FTE_C \\
\hline Chemical Eng ineer & 224 \\
\hline Environ Engineer & 168 \\
\hline Admin_Clerical & 246 \\
\hline Mechañical Engineer & 273 \\
\hline Chem ist & 115 \\
\hline Other Technician & 303 \\
\hline Civil Engineer & 73 \\
\hline Computer Eng ineer & 24 \\
\hline Project Manager & 111 \\
\hline Industrial Engineer & 51 \\
\hline Other Engineer & 86 \\
\hline H_physics Tech & 186 \\
\hline Electric tronic Engineer & 115 \\
\hline Environ Sciences Tech & 73 \\
\hline Nuclear Decon Eng ineer & 4 \\
\hline Chem Tech & 95 \\
\hline$G \geq 0 \log$ ist & 69 \\
\hline Nuc lear Eng ineer & 46 \\
\hline Safety Engineer & 5 \\
\hline Drafter & 30 \\
\hline Environ Scientist & 13 \\
\hline WasteMan Engineer & 24 \\
\hline Health Physicist & 17 \\
\hline Computer Oper & 10 \\
\hline Material Handler & 78 \\
\hline Materials Engineer & 19 \\
\hline Structural Engineer & 9 \\
\hline Civil Eng Tech & 14 \\
\hline HazWasteMan Spec & 31 \\
\hline Other Administrator & 79 \\
\hline Estimator & 21 \\
\hline Other Scientist & 24 \\
\hline Rad Protect Spec & 9 \\
\hline Chemical Eng Tech & 36 \\
\hline Trainer & 32 \\
\hline Hydrol_Kydrogeologist & 9 \\
\hline Materials Scient ist & 5 \\
\hline Biochemist & 3 \\
\hline Biologist & 8 \\
\hline Ind Hygienist & 1 \\
\hline Ind Safety_Health Tech & 1 \\
\hline Risk Assess Manager & 4 \\
\hline Statistician & 5 \\
\hline Ecologist & 4 \\
\hline Mathematician & 4 \\
\hline Physicist & 10 \\
\hline Opers Researcher & 2 \\
\hline Petrol_Mining Engineer & 3 \\
\hline Remediätion Specialist & 6 \\
\hline NucWaste Process Oper & 254 \\
\hline Technical Writer & 20 \\
\hline Driller & $\theta$ \\
\hline Irrigation Engineer & 9 \\
\hline Seismologist & 4 \\
\hline Survey_Map Tech & $\theta$ \\
\hline Electri_tronic Tech & 113 \\
\hline Mech Enḡin Tech & 64 \\
\hline
\end{tabular}

\begin{tabular}{|c|c|}
\hline PM_FTE_A & PH_FTE_P \\
\hline 371 & 386 \\
\hline 241 & 251 \\
\hline 373 & 390 \\
\hline 387 & 410 \\
\hline 164 & 164 \\
\hline 350 & 370 \\
\hline 118 & 118 \\
\hline 69 & 70 \\
\hline 156 & 164 \\
\hline 92 & 92 \\
\hline 126 & 134 \\
\hline 225 & 227 \\
\hline 148 & 163 \\
\hline 106 & 106 \\
\hline 30 & 30 \\
\hline 118 & 136 \\
\hline 92 & 93 \\
\hline 67 & 69 \\
\hline 25 & 25 \\
\hline 49 & 49 \\
\hline 31 & 31 \\
\hline 42 & 42 \\
\hline 33 & 33 \\
\hline 25 & 26 \\
\hline 92 & 98 \\
\hline 33 & 33 \\
\hline 22 & 22 \\
\hline 26 & 26 \\
\hline 43 & 43 \\
\hline 91 & 91 \\
\hline 32 & 34 \\
\hline 35 & 35 \\
\hline 20 & 20 \\
\hline 45 & 46 \\
\hline 41 & 46 \\
\hline 17 & 18 \\
\hline 13 & 13 \\
\hline 10 & 10 \\
\hline 15 & 15 \\
\hline 8 & 8 \\
\hline 7 & 7 \\
\hline 10 & 10 \\
\hline 11 & 11 \\
\hline 8 & 8 \\
\hline 7 & 7 \\
\hline 13 & 13 \\
\hline 4 & 4 \\
\hline 5 & 6 \\
\hline 8 & 8 \\
\hline 255 & 273 \\
\hline 21 & 27 \\
\hline 0 & 0 \\
\hline 9 & 9 \\
\hline 4 & 4 \\
\hline$\theta$ & $\theta$ \\
\hline 112 & 113 \\
\hline 58 & 70 \\
\hline
\end{tabular}

\section{PM_DELTA Degree}

147 Mix of $B S$ and Advanced

133

127

114

49

47

45

45

45

41

40

39

33

26

23

23

21

20

19

1.8

18

16

15

14

14

13

12

12

11

11

11

9

8

8 Mostly Bachelor Most ly Associate Most ly Bachelor Mix of BS and Advanced HS or less Most ly Bachelor Most ly Bachelor Most ly Bachelor Most ly Bachelor Most ly Associate Mix of AS and BS Most ly Bachelor Mix of AS and BS Mix of BS and Advanced Most ly Associate Mix of $B S$ and Advanced Mix of BS and Advanced Most ly Bachelor Most ly Associate Mix of $B S$ and Advanced Mix of BS and Advanced Mix of AS and BS HS or less

Most ly Bachelor Mostly Bachelor HS or less

Mix of AS and BS HS or less

Most ly Associate Mostly Associate Mix of AS and BS Most ly Associate Most ly Associate Mix of $B S$ and Advanced Most. ly PhD

Mix of $B S$ and Advanced Mix of $B S$ and Advanced Mostly Bachelor Most ly Bachelor Most ly Bache lor Mostly PhD

Mostly Pho Most ly Bache lor Mix of BS and Advanced Mix of $B S$ and Advanced Mix of BS and Advanced HS or less HS or less Most iy Associate HS or less

Mix of AS and Mix of BS and hiv inced Most ly Associate Mostly Associate Mostly Assnciate $M i x$ of $B S$ and Advanced

Statistics based on data from 19 WNAS surveys and 16 SCHC surveys. 


\section{TABLE 0.4. Titles Sorted by Project Manager's Ratings of Anticipated Ability to Recruit (PM_Rec_A)}

\author{
Job Title \\ Ind Hygien ist \\ Ind Safety_Health Tech \\ Materials Scient ist \\ Nuc lear Eng ineer \\ $H$ physics Tech \\ Hydrol_Hydrogeo log ist \\ Nuc lear Decon Eng ineer \\ Biochemist \\ Environ Eng ineer \\ Chemical Eng ineer \\ Rad Protect Spec \\ Chem Tech \\ Hea th Physicist \\ Geologist \\ Chem ist \\ Environ Sciences Tech \\ Trainer \\ Materials Engineer \\ Electric tronic Engineer \\ Environ Scient ist \\ Computer Engineer \\ Project Manager \\ Statistician \\ HazWasteMan Spec \\ Mechanical Engineer \\ Safety Eng ineer \\ WasteMan Engineer \\ Petrol Mining Engineer \\ Electri_tronic Tech \\ Structural Engineer \\ Biologist \\ Industrial Engineer \\ Phys ic ist \\ Civil Engineer \\ Technical Writer \\ Computer Oper \\ Orafter \\ Irrigation Engineer \\ Se ismolog ist \\ Mathemat ic ian \\ Chemical Eng Tech \\ Mech Eng in Tech \\ Est imator \\ NucWaste Process Oper \\ Admin Clerical \\ Risk Ässess Manager \\ Ecologist \\ Opers Researcher \\ Remediation Specialist \\ Material Handler \\ Civil Eng Tech \\ Survey_Map Tech \\ Driller
}

\section{PM_REC_A}

5.00

5.00

4.00

3.75

3.67

3.67

3.67

3.67

3.62

3.60

3.50

3.50

3.50

3.50

3.38

3.33

3.33

3.33

3.30

3.20

3.14

3.13

3.00

3.00

3.00

3.00

3.00

3.00

3.06

3.00

3.08

2.75

2.75

2.73

2.60

2.50

2.50

2.50

2.50

2.50

2.43

2.40

2.38

2.33

2.24

2.80

2.00

2.00

2.00

1.75

1.50

1.00

\section{PM_DELTA}

7

6

8

39

8

26

133

147

11

23

16

23

49

33

9

14
33

45

45

6

12

114
20

18

?

$-1$

13

41

3

45

15

19

0

3

9
-6

11

127

6

4

2

2

14

12

0
Degree

Most ly Bachelor Most ly Bachelor Mostly PhD

Mix of $B S$ and Advanced Mix of AS and BS Mix of BS and Advanced Mix of BS and Advanced Mix of BS and Advanced Most ly Bachelor

Mix of $B S$ and Advanced Mix of $A S$ and $B S$ Mostly Associate Mix of BS and Advanced Mix of $B S$ and Advanced Mix of BS and Advanced Mix of AS and BS Most ly Associate Most. ly Bachelor Mostly Bachelor Mix of BS and Advanced Most ly Bachelor Most ly Bachelor Mostly PhD Mix of AS and BS Most ly Bachelor Most ly Bachelor Mix of BS and Advanced Mix of BS and Advanced Most ly Associate Mostly Bachelor Mix of BS and Advanced Most ly Bachelor Mix of BS and Advanced Most ly Bachelor Mostly Associate Mix of AS and BS Most ly Associate Mix of AS and BS Mix of BS and Advanced Mostly Bachelor Mostly Associate Most ly Associate Mostly Associate HS or less

Most ly Associate Most ly Bache lor Most ly Pho Mix of $B S$ and Advanced HS or less HS or less HS or less Mostly Associate HS or less

Statistics based on data from 19 WNAS surveys and 16 SCHC surveys. 


\section{TABLE 0.5. Titles Sorted By Project Manager's Ratings of Difficulty Caused by Shortage (PM_Diff)}

Job Title
Rad Protect Spec
Chem Tech
Materials Scient ist
Ind Hygienist
Ind Safety_Health Tech
Risk Assess Manager
Chemical Engineer
Environ Engineer
Hphysics Tech
Environ Sciences Tech
Hydrol Hydrogeologist
Statistician
Chemist
Project Manager
HazWasteMan Spec
Environ Scientist
Trainer
Nuclear Engineer
Mechanical Engineer
Admin_Clerical
Electric tronic Engineer
Nuclear Decon Engineer
Safety Engineer
WasteMan Engineer
Health Physicist
Ecologist
Petrol_Mining Engineer
Electri_tronic Tech
Technical Writer
Industrial Engineer
Chemical Eng Tech
Material Handler
Physicist
NucWaste Process Oper
Computer Oper
Mech Engin Tech
Computer Engineer
Orafter
Materials Engineer
Estinator
Irrigation Engineer
Seismologist
Structura I Engineer
Civil Engineer
Geologist.
Biochemist
Biologist
Mathematician
Opers Researcher
Remediation Specialist
Civil Eng Tech
Survey_Map Tech
Oriller

\begin{tabular}{|c|c|c|}
\hline PM_DIFF & & PA_DEL \\
\hline 4.50 & & 11 \\
\hline 4.00 & & 23 \\
\hline 4.00 & & 8 \\
\hline 4.00 & & 7 \\
\hline 4.00 & & 6 \\
\hline 4.00 & & 6 \\
\hline 3.73 & & 147 \\
\hline 3.69 & & 133 \\
\hline 3.67 & & 39 \\
\hline 3.67 & & 33 \\
\hline 3.67 & & 8 \\
\hline 3.67 & & 6 \\
\hline 3.63 & & 49 \\
\hline 3.63 & & 45 \\
\hline 3.50 & & 12 \\
\hline 3.40 & & 18 \\
\hline 3.33 & & 9 \\
\hline 3.22 & & 21 \\
\hline 3.15 & & 114 \\
\hline 3.12 & & 127 \\
\hline 3.10 & & 33 \\
\hline 3.00 & & 26 \\
\hline 3.00 & & 20 \\
\hline 3.00 & & 18 \\
\hline 3.00 & & 16 \\
\hline 3.00 & & 4 \\
\hline 3.00 & & 2 \\
\hline 3.00 & . & -1 \\
\hline 2.90 & & 1 \\
\hline 2.88 & & 41 \\
\hline 2.86 & & 9 \\
\hline 2.75 & & 14 \\
\hline 2.75 & & 3 \\
\hline 2.67 & & 1 \\
\hline 2.63 & & 15 \\
\hline 2.60 & & -6 \\
\hline 2.57 & & 45 \\
\hline 2.50 & & 19 \\
\hline 2.50 & & 14 \\
\hline 2.50 & & 11 \\
\hline 2.50 & & $\theta$ \\
\hline 2.50 & & 0 \\
\hline 2.33 & & 13 \\
\hline 2.18 & & 45 \\
\hline 2.00 & & 23 \\
\hline 2.00 & & 7 \\
\hline 2.00 & & 7 \\
\hline 2.00 & & 3 \\
\hline 2.00 & & 2 \\
\hline 2.00 & & 2 \\
\hline 1.50 & & 12 \\
\hline 1.00 & & $\theta$ \\
\hline
\end{tabular}

\section{Degree}

Mix of AS and BS Mostly Associate Most ly PhD Most ly Bache lor Most ly Bache lor Most ly Bache lor Mix of BS and Advanced Most ly Bache lor Mix of $A S$ and $B S$ Mix of AS and BS Mix of $B S$ and Advanced Most ly PhD

Mix of $B S$ and Advanced Host ly Bache lor Mix of AS and BS Mix of BS and Advanced Most ly Associate Mix of BS and Advanced Most ly Bache lor Mostly Associate Most ly Bache lor Mix of BS and Advanced Most ly Bache lor Mix of $B S$ and Advanced Mix of BS and Advanced Most ly. Pho

Mix of $B S$ and Advanced Most ly Associate Most ly Associate Most ly Bache lor Most ly Associate HS or less Mix of BS and Advanced HS or less Mix of AS and BS Mostly Associate Most ly Bachelor Most ly Associate Most ly Bache lor Mostly Associate Mix of AS and BS Mix of $B S$ and Advanced Most ly Bache lor Most ly Bache lor Mix of $B S$ and Advanced Mix of BS and Advanced Mix of BS and Advanced Most ly Bache lor

Mix of BS and Advanced HS or less

HS or less Most ly Associate HS or less

Statistics based on data from 19 WNAS surveys and 16 SCHC surveys. 
IABLE 0.6. Job Titles Sorted By Human Resource Personnel's Ratings of Difficulty Caused By Shortage (HR_Diff)

\begin{tabular}{|c|c|c|}
\hline Job Title & HR_DIFF & PH_DEL \\
\hline Chemical Engineer & 4.17 & 147 \\
\hline Hea ith Physicist & 4.00 & 16 \\
\hline WasteMan Engineer & 3.80 & 18 \\
\hline Environ Engineer & 3.70 & 133 \\
\hline Risk Assess Manager & 3.60 & 6 \\
\hline Chemist & 3.58 & 49 \\
\hline Chemical Eng Tech & 3.58 & 9 \\
\hline Project Manager & 3.55 & 45 \\
\hline HazWasteMan Spec & 3.55 & 12 \\
\hline Computer Engineer & 3.44 & 45 \\
\hline Ind hygienist & 3.42 & 7 \\
\hline Nuc lear Decon Engineer & 3.40 & 26 \\
\hline Rad Protect Spec & 3.38 & 11 \\
\hline Environ Sciences Tech & 3.38 & 33 \\
\hline Safety Engineer & 3.38 & 20 \\
\hline H_physics Tech & 3.33 & 39 \\
\hline Remediation Specialist & 3.33 & 2 \\
\hline Chem Tech & 3.27 & 23 \\
\hline Environ Scientist & 3.25 & 18 \\
\hline Admin_Clerical & 3.21 & 127 \\
\hline Ind Säfety_Health Tech & 3.20 & 6 \\
\hline Phys icist & 3.14 & 3 \\
\hline Materials Scientist & 3.11 & 8 \\
\hline Computer Oper & 3.11 & 15 \\
\hline Hydrol_Hydrogeologist & 3.00 & 8 \\
\hline Biochemist & 3.00 & 7 \\
\hline Ecologist & 3.00 & 4 \\
\hline Geologist & 2.86 & 23 \\
\hline Civil Eng Tech & 2.83 & 12 \\
\hline Statistician & 2.80 & 6 \\
\hline Mechanical Engineer & 2.80 & 114 \\
\hline Opers Researcher & 2.80 & 2 \\
\hline Survey_Map Tech & 2.80 & $\theta$ \\
\hline Nuc lear Engineer & 2.78 & 21 \\
\hline NucWaste Process Oper & 2.71 & 1 \\
\hline Material Handler & 2.71 & 14 \\
\hline Materials Engineer & 2.67 & 14 \\
\hline Electri_tronic Tech & 2.64 & -1 \\
\hline Orafter & 2.63 & 19 \\
\hline Mech Engin Tech & 2.60 & -6 \\
\hline Electric_tronic Engineer & 2.56 & 33 \\
\hline Trainer & 2.44 & 9 \\
\hline Technical Writer & 2.40 & 1 \\
\hline Irrigation Engineer & 2.33 & $\theta$ \\
\hline Mathemat ician & 2.33 & 3 \\
\hline Estimator & 2.17 & 11 \\
\hline Industrial Engineer & 2.14 & 41 \\
\hline Civil Engineer & 2.14 & 45 \\
\hline Bio logist & 2.11 & 7 \\
\hline Structural Engineer & 2.00 & 13 \\
\hline Seismologist & 2.00 & $\theta$ \\
\hline Driller & 1.75 & $\theta$ \\
\hline Petrol_Mining Engineer & 1.50 & 2 \\
\hline
\end{tabular}

Statistics based on data from 19 WNAS surveys and 16 SCHC surveys. 
TABLE 0.7. Job Titles Sorted By Human Resource Personnel's Ratings of Need for Additional Employees (HR_Need)

Job Title

Chemical Engineer

Environ Engineer

Environ Scient ist

Health Physicist

WasteMan Engineer

Nuclear Decon Engineer

Adnin Clerical

Chemist

Ind Hygien ist

Safety Fing ineer

H physics Tecn

Risk Assess Manager

HazWasteman Spec

Rad Protect Spec

Hydrol_Hydrogeologis:

Chemical Eng Tech

Ecologist

Computer Engineer

Environ Sciences Tech

Remediation Specialist

Ind Safety_Heaith Tech

Project Mañager

Chem Tech

Physicist

Computer Oper

Opers Researcher

Electri_tronic Tech

Mech Engin Tech

Materials Scient ist

Geologist

Material Handler

Mechanical Engineer

Orafter

Civil Engireer

Civil Eng Tech

Biochemist

Nuc lear Eng ineer

Technical Writer

Statistician

Materials Engineer

Electric_tronic Engineer

Trainer

Irrigation Engineer

Mathemat ician

Est.mator

NucWaste Process Oper

Survey Map Tech.

Structural Engineer

Selsmoingist

Biologist

industriz? engineer

Oriller

Petrol yining Engineer

\section{HR_NEED}

3.92

3.98

3.88

3.67

3.60

3.60

3.57

3.50

3.50

3.50

3.44

$3 . \div 0$

3.40

3.38

3.38

3.33

3.25

3.22

3.13

3.11

3.10

3.09

3.69

3.00

3.00

3.00

3.80

2.90

2.89

2.86

2.86

2.80

2.75

2.71

2.87

2.57

2. 56

2.50

2.48

2.33

2.33

2. 33

2. 33

2. 33

2. 33

2. 29

2.20

2.00

2.90

1.89

1.86

1.75

1.50
PH_DELTA

147

133

18

16

18
26

127

49
7

20

39

6

12

11

8

4
45

33

2

6
45

45
23

3

15

2
-1

$-6$

23

14

114

19

45

12

7
21

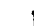

6

14

33

9

3

11

1

1
13

13

0

7
41

41
8

2

Stat ist:c,s based on data from 19 WNAS surveys and 16 SCHC surveys 


\section{TABLE 0.8. Job Titles Sorted By Human Resource Personnel's Ratings of Current Ability to Recruit (HR_Rec_C)}

Job Tit le

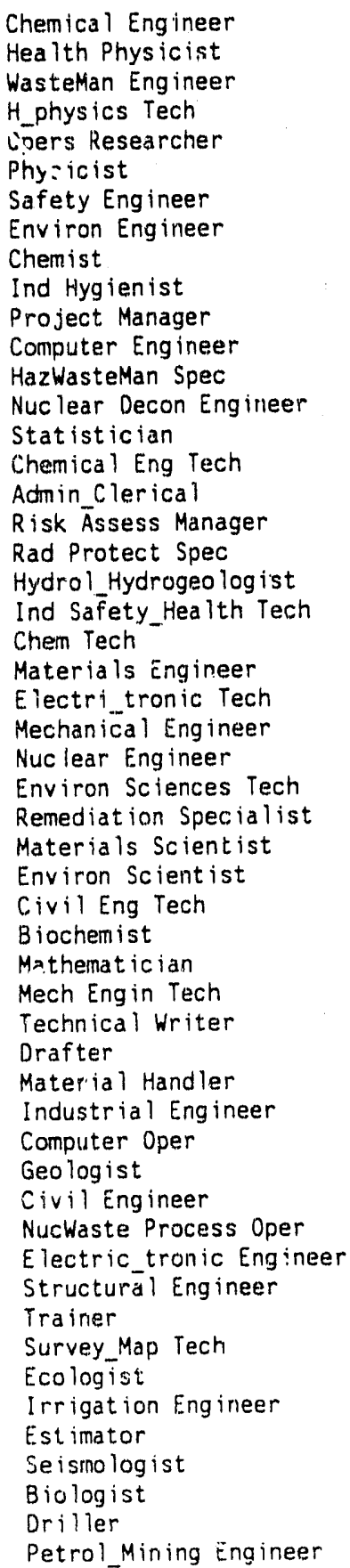

\author{
HR_REC_C
}

4.60

3.89

3.78

3.75

3.71

3.63

3.56

3.45

3.45

3.45

3.33

3.30

3.20

3.20

3.17

3.00

3.00

3.00

3.00

3.00

3.80

3.80

2.91

2.90

2. 89

2.88

2.88

2.88

2.86

2.83

2.83

2.83

2.80

2.80

2.75

2.71

2.71

2. 67

2.67

2.57

2.57

2.56

2.50

2. 44

2.48

2.33

2. 33

2. 33

2.00

2.00

1.75

1.50
PM_DELTA

147

16

18

39

2
3

20

133

49

7

\begin{tabular}{l}
45 \\
45 \\
\hline
\end{tabular}

12
26

6

9
27

6

11

8
6

23

14

-1
114

114

- 21

33

2
8
18

12

7
3
-6

$-6$

19

14

41

15

2.3

45

1

33

13

9

4

11

9

9

Statictics based on data from 19 WNAS surveys and 16 SCHC surveys. 

TABLE Q.9. Job Titles Sorted By Human Resource Personnel's Ratings
of Anticipated Ability to Recruit (HR_Rec_A)

Job Tit le

Hea ith Physicist

Chemical Eng ineer

H_physics Tech

WasteMan Engineer

Safety Engineer

Physicist

Project. Manager

Environ Engineer

Chemist

Chemical Eng Tech

Computer Eng ineer

Environ Scient ist

Ind Hygien ist

HazWasteMan Spec

Nuc lear Decon Engineer

Cheni Tech

Remediation Specialist

Materials Scientist.

Statistician

Admin Clerical

Rad Protect SFiec

Risk Assess Manager

Nuc lear Eng ineer

Electri tronic Tech

Ind Safëty_Health Tech

Mechanical Engineer

Technical Writer

Environ Sciences Tech

Meterial Handler

Industrial Engineer

Materials Engineer

Biochemist

Mech Eng in Tech

Computer Oper

Trainer

Hydrol_Hydrogeologist

Civil Eng Tech

Geologist

Civil Engineer

NucWaste Process Oper

Mathemat ician

Drafter

Electric_tronic Engineer

Ecologist

Irrigation Engineer

Survey Map Tech

Est imator

Biologist

Structural Engineer

Driller

Se ismologist

Petrol Mining Engineer
Opers Researcher
HR_REC_A

4.13

4.69

4.00

3.78

3.75

3.71

3.70

3.67

3.55

3.50

3.45

3.44

3.43

3.40

3.40

3.40

3.27

3.25

3.25

3.28

3.15

3.14

3.00

3.00

2.91

2.89

2.89

2.89

2.88

2.86

2.86

2.83

2.83

2.78

2.78

2.75

2.71

2.67

2.67

2.57

2.57

2.50

2.50

2.44

2.33

2. 33

2.25

2.20

2.13

2.00

1.75

1.50

1.50
PM_DELTA Degree

16

147

39

18

20

3

133

49

2
9

45

45
18

7

12

26

23

8

6
127

127
11

6

21

-1
6

114

1
33

14

14
41

14

7

$-6$

15

8

12

23

i5

1

3

33

4

0

0

11

13

13
0

$B$

Statistics based on data from 1.9 WNAS surveys and 16 SCHC surveys.
Mix of BS and Advanced Mix of BS and Advanced $M i x$ of $A S$ and $B S$

Mix of $B S$ and Advanced Most ly Bache lor

Mix of BS and Advanced Most ly Bachelor Most ly Bachelor Mix of BS and Advanced Mix of BS and Advanced Most ly Associate Most ly Bache lor

Mix of $B S$ and Advanced Most ly Bachelor

Mix of $A S$ and $B S$ Mix of $B S$ and Advanced Most ly Associate HS or less

Most ly PhD

Mostly PhD

Most ly Associate Mix of AS and BS Most ly Bachelor

Mix of BS and Advanced Mostly Associate Most ly Bache lor Mostly Bachelor Most ly Associate Mix of AS and BS HS or less

Most iy Bache lor Most ly Bache lor Mix of $B S$ and Advanced Most ly Associate Mix of AS and BS Most ly Associate Mix of BS and Advanced HS or less

Mix of BS and Advanced Mostly Bache lor HS or less Mostly Bachelor Most ly Associate Most ly Bachelor Mostly PhD

Mix of AS and BS Mostly Associate Most ly Associate Mix of $B S$ and Advanced Mostly Bachelor HS or less

Mix of $B S$ and Advanced Mix of BS and Advanced 
TABLE Q.10. Job Titles Sorted By Human Resource Personnel's Ratings of Annual Turnover (HR_Turn)

\begin{tabular}{|c|c|c|}
\hline Job Tit le & HR_TLRN & PM_DELTA \\
\hline Admin_Clerical & 3.31 & 127 \\
\hline Chemical Eng ineer & 3.30 & 147 \\
\hline Opers Researcher & 3.25 & 2 \\
\hline Safety Engineer & 3.14 & 20 \\
\hline Health Physicist & 3.80 & 16 \\
\hline Chemist & 3.90 & 49 \\
\hline Mechanical Engineer & 3.60 & 114 \\
\hline H_physics Tern & 2.89 & 39 \\
\hline WasteMan Engineer & 2.88 & 18 \\
\hline Computer Eng ineer & 2.88 & 45 \\
\hline Material Handler & 2.86 & 14 \\
\hline Chemical Eng Tech & 2.80 & 9 \\
\hline Nuc lear Decon Engineer & 2.80 & 26 \\
\hline Nuc lear Eng ineer & 2.80 & 21 \\
\hline Physicist & 2.67 & 3 \\
\hline Environ Eng ineer & 2.63 & 133 \\
\hline Ind Safety_Health Tech & 2.63 & 6 \\
\hline Mech Eng in Tech & 2.63 & -6 \\
\hline Project Manager & 2.60 & 45 \\
\hline Materials Scient ist. & 2.60 & 8 \\
\hline Rad Protect Spec & 2.57 & 11 \\
\hline HazWasteMan Spec & 2.56 & 12 \\
\hline Chem Tech & 2.50 & 23 \\
\hline Electri tronic Tech & 2.50 & -1 \\
\hline Structural Engineer & 2.50 & 13 \\
\hline Ind Hygienist & 2.44 & 7 \\
\hline Remediation Specialist & 2.43 & 2 \\
\hline Environ Scient ist & 2.40 & 18 \\
\hline Biochemist & 2.40 & 7 \\
\hline Risk Assess Manager & 2.33 & 6 \\
\hline NucWaste Process Oper & 2.33 & 1 \\
\hline Environ Sciences Tech & 2.29 & 33 \\
\hline Trainer & 2.29 & 9 \\
\hline Statistician & 2.25 & 6 \\
\hline Technical Writer & 2.25 & 1 \\
\hline Computer Oper & 2.25 & 15 \\
\hline Hydrol Hydrogeo logist & 2.20 & 8 \\
\hline Materiāis Engineer & 2.17 & 14 \\
\hline Civil Engineer & 2.17 & 45 \\
\hline Electric tronic Engineer & 2.13 & 33 \\
\hline Civil Eng Tech & 2.00 & 12 \\
\hline Mathemat ician & 2.00 & 3 \\
\hline Drafter & 2.00 & 19 \\
\hline Irrigation Engineer & 2.00 & $\theta$ \\
\hline Survey_Map Tech & 2.00 & $\emptyset$ \\
\hline Petrol_Mining Engineer & 2.00 & 2 \\
\hline Est imator & 1.80 & 11 \\
\hline Geologist & 1.75 & 23 \\
\hline Driller & 1.75 & $\theta$ \\
\hline Industrial Eng ineer & 1.67 & 41 \\
\hline Ecologist & 1.50 & 4 \\
\hline Se ismo log ist & 1.50 & $\theta$ \\
\hline Biologist & 1.17 & 7 \\
\hline
\end{tabular}

\section{Degree}

Most ly Associate

Mix of BS and Advanced Mix of BS and Advanced Mostly Bache lor Mix of $B S$ and Advanced $M i x$ of $\bar{B}$ i and Advanced Mostly Bachelor Mix of $A S$ and $B S$ Mix of $B S$ and Advanced Most ly Bache lor HS or less Mostly Associate Mix of $8 S$ and Advanced Mix of $B S$ and Advanced Mix of BS and Advanced Most ly Bache lor Mostly Bachelor Mostly Associate Mos: ly Bachelor Hiustly PhD Mix of AS and BS Mix of $A S$ and $B S$ Mostly Associate Mostly Associate

Most ly Bache lor Most ly Bachelor HS or less

Mix of $8 S$ and Advanced Mix of BS and Advanced Most ly Bachelor HS or less

Mix of $A S$ and $B S$ Most ly Associate Most ly PhD

Most ly Associate Mix of $A S$ and $B S$ Mix of BS and Advanced Mostly Bachelor Mostly Bachelor Mostly Bachelor HS or less

Most ly Bachelor Mostiy Associate Mix of $A S$ and $B S$ Most ly Associate Mix of BS and Advanced Mostly Associate

Mix of BS and Advanced HS or less

Most ly Bachelor

Mostly PhD

Mix of BS and Advanced Mix of BS and Advanced

Statistics based on data from 19 WNAS surveys and 16 SCHC surveys. 
APPENDIX $R$

SIMPLE STATISTICS INTERCORRELATION AMONG VARIABLES AND JOB SORTS ON ALL VARIABLES

FOR ROCKY FLATS ONLY 
IABLE R.1. Descriptive Statistics for Relative Ratings

\begin{tabular}{llcccc} 
Variable & N & Minimum & Maximum & Mean & $\underline{\text { S.D. }}$ \\
\hline HR_DIFF & 21 & 2.00 & 4.00 & 2.76 & 0.70 \\
HR_NEED & 21 & 2.00 & 4.00 & 3.43 & 0.75 \\
HR_REC_C & 21 & 1.00 & 3.00 & 2.48 & 0.75 \\
HR_REC_A & 21 & 1.00 & 3.00 & 2.48 & 0.75 \\
HR_TURN & 20 & 3.00 & 4.00 & 3.15 & 0.37 \\
PM_DIFF & 48 & 1.00 & 5.00 & 3.17 & 0.91 \\
PM_REC_A & 48 & 1.00 & 4.00 & 2.69 & 0.81 \\
PM_EDUC & 47 & 1.50 & 5.00 & 3.41 & 0.85
\end{tabular}

S.D. = Standard Deviation, HR_DIFF = Difficulty Caused by a Shortage, HR NEED = Need for Additional Employees, HR-REC $A=$ Anticipated Ease of Reçruitment, HR-REC-C = Current Ease of Recruitment, HR TURN = Current Annual Turnover, PM_DIFF = Difficulty Caused By a Shortage, PM_REC $A=$ Anticipated Abil ity to Recruit, PM EDUC = Typical Degree Leve 1, $* * \bar{p}<\overline{0} .01 ; * p<0.05$. Statistics based on data from 6 WNAS surveys and 1 SCHC survey. 


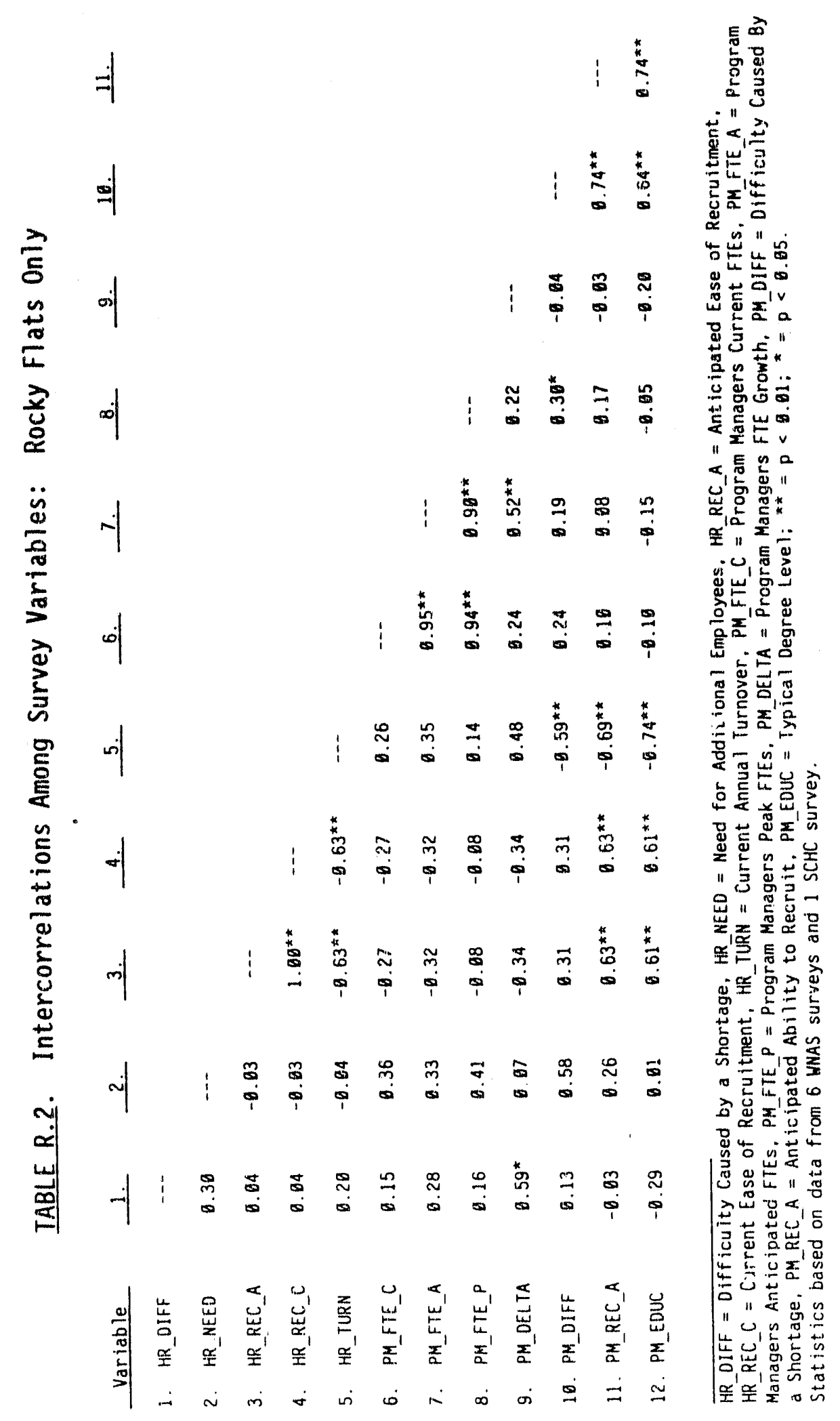

R. 2 


\section{IABLE R.3. Job Titles Sorted By Change in FTEs (PM_Delta)}

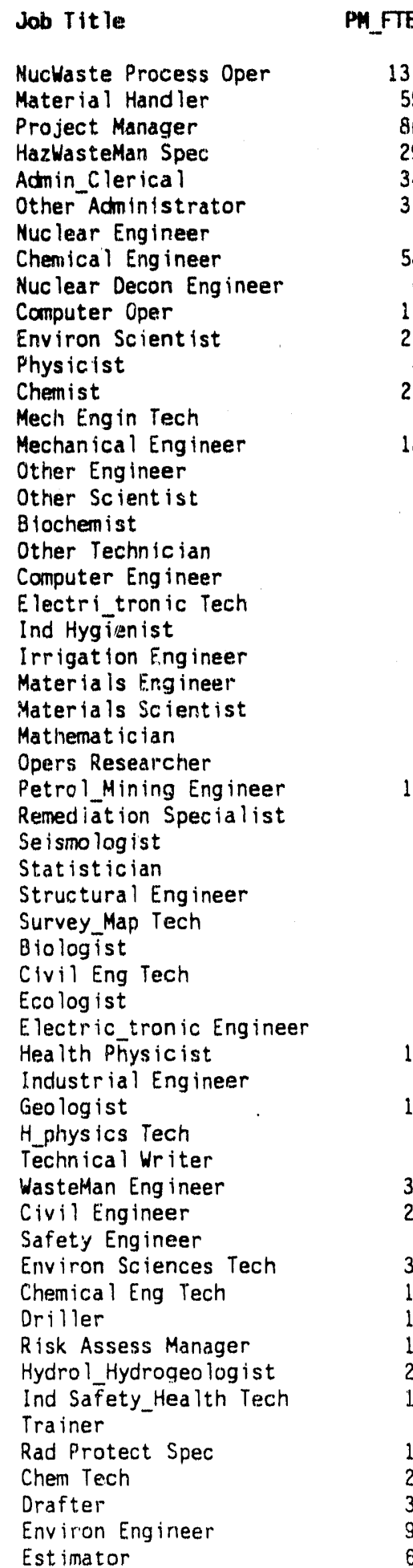

\begin{tabular}{|c|c|}
\hline FTE_C & PH_FTE_ \\
\hline 137 & $\begin{array}{r}175 \\
75\end{array}$ \\
\hline 59 & 75 \\
\hline & 93 \\
\hline 29 & 41 \\
\hline 34 & 42 \\
\hline 37 & 45 \\
\hline$\theta$ & 5 \\
\hline 58 & 62 \\
\hline$\theta$ & 4 \\
\hline 17 & 20 \\
\hline 27 & 30 \\
\hline 4 & 7 \\
\hline 27 & 29 \\
\hline 6 & 8 \\
\hline 18 & 20 \\
\hline 2 & 4 \\
\hline 1 & 3 \\
\hline$\theta$ & 1 \\
\hline 0 & 1 \\
\hline 3 & 3 \\
\hline$\theta$ & $\theta$ \\
\hline 0 & 0 \\
\hline$\theta$ & $\theta$ \\
\hline 6 & 6 \\
\hline 2 & 2 \\
\hline$\theta$ & $\theta$ \\
\hline$\theta$ & $\theta$ \\
\hline 18 & 18 \\
\hline$\theta$ & $\theta$ \\
\hline 0 & $\theta$ \\
\hline 1 & 1 \\
\hline 8 & $\theta$ \\
\hline 1 & 1 \\
\hline 9 & 8 \\
\hline 3 & 2 \\
\hline 9 & 8 \\
\hline 8 & 7 \\
\hline 10 & 9 \\
\hline 1 & 0 \\
\hline 15 & 13 \\
\hline 7 & 5 \\
\hline 4 & 2 \\
\hline 31 & 29 \\
\hline 23 & 20 \\
\hline 4 & 1 \\
\hline 37 & 33 \\
\hline 15 & 10 \\
\hline 18 & 5 \\
\hline 12 & 7 \\
\hline 20 & 14 \\
\hline 18 & 12 \\
\hline 7 & 1 \\
\hline 14 & 6 \\
\hline 23 & 14 \\
\hline 35 & 24 \\
\hline 93 & 74 \\
\hline 60 & 20 \\
\hline
\end{tabular}

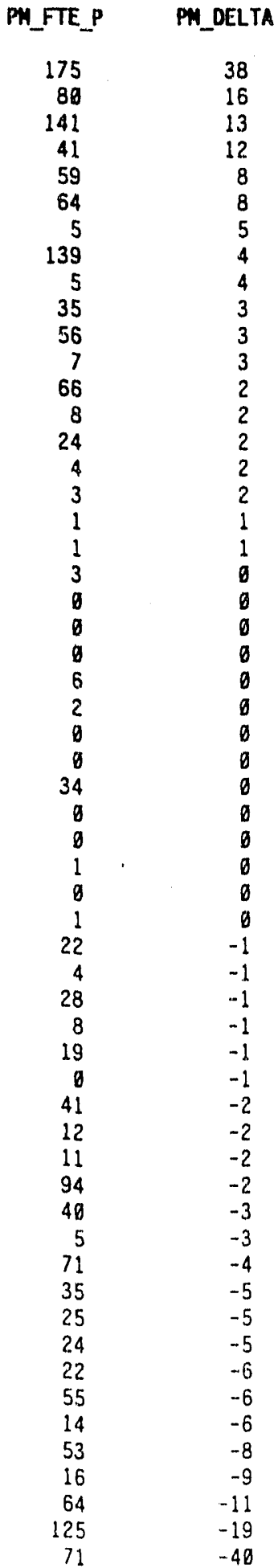

Degree

Mostly Associate Mostly Associate Most ly Bache lor Mix of $A S$ and $B S$ Most ly Associate HS or less Most ly Bachelor Mix of BS and Advanced Mix of $B S$ and Advanced Mix of AS and BS Mostly Bachelor Mostly PhD Mix of BS and Advanced Most ly Associate Mix of BS and Advanced Most ly Associate Mostily Associate Mix of BS and Advanced HS or less Most ly Bachelor Mostly Associate Mix of AS and BS HS or less Mix of BS and Advanced Mix of BS and Advanced Mostly Associate Most ly Associate Mix of BS and Advanced HS or less

Most ly Associate Mix of BS and Advanced Most ly Associate Mix of AS and BS Mix of BS and Advanced Most ly Associate

Mix of BS and Advanced Mostly Bache lor Mix of $B S$ and Advanced Mix of $B S$ and Advanced Mix of BS and Advanced Mix of AS and BS Mix of AS and BS Mix of BS and Advanced Mix of BS and Advanced Mix of BS and Advanced Mix of AS and BS Most ly Associate HS or less Most ly Advanced Mix of BS and Advanced Mix of $A S$ and $B S$ Most ly Bachelor Mix of AS and BS Mix of $A S$ and $B S$ Most ly Associate Mix of BS and Advanced Mostly Bachelor

Statistics based on data from 6 WNAS surveys and 1 SCHC survey. 


\section{TABLE R.4. Titles Sorted by Project Manager's Ratings of Anticipated Ability to Recruit (PM_Rec_A)}

\section{Job Title}

Nuc lear Decon Engineer

Biochenist

Physicist

Materials Scientist

Environ Engineer

Hydrol_Hydrogeo log ist

Project Manager

HazWasteMan Spec

Chemist

WasteMan Engineer

Electric tronic Engineer

Chemical"Eng ineer

Risk Assess Manager

Computer Eng ineer

Petrol_Mining Engineer

Statistician

Biologist

Health Physicist

Environ Scientist

Geologist

Nuc lear Eng ineer

Materials Engineer

Ecologist

Civit Eng ineer

Ind Safety Health Tech

Mechanical Engineer

Est imator

Environ Sciences Tech

Trainer

Rad Protect Spec

Technical Writer

Chem Tech

Adnin_Clerical

NucWaste Process Oper

Industrial Engineer

H_physics Tech

Safety Engineer

Material Handler

Survey Map Tech

Drafter

Computer Oper

Mech Eng in Tech

Chemical Eng Tech

Driller

Civil Eng Tech

Electri tronic Tech

Ind Hygienist

Remediation Specialist

Irrigation Engineer

Mathematician

Opers Researcher

Se ismolog ist

Structural Engineer

\section{PII_REC_A}

4.00

4.90

4.00

4.80

3.75

3.67

3.60

3.50

3.50

3.50

3.50

3.25

3.90

3.00

3.00

3.00

3.00

3.60

3.60

3.80

3.80

3.00

3.00

3.00

3.00

2.75

2.67

2.67

2.59

2.50

2.50

2.33

2.17

2.00

2.00

2.00

2.00

2.00

2.96

2.00

2.00

2.00

2.00

1.50

1.50

1.00

1.00

1.00
PN_DELTA

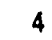

1

-19
-6

13

12

2

$-2$

$-1$

4

$-5$

0

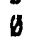

$-1$

$-1$

3

$-2$

Stat istics based on data from 6 WNAS surveys and 1 SCHC survey.

\section{Degree}

Mix of BS arid Advanced Mix of $B S$ and Advanced Mostly PhD

Mix of BS and Advanced Mix of BS and Advanced Mix of $B S$ and Advanced Mast ly Bache lor

Mix of $A S$ and $B S$

Mix of BS and Advanced Mix of $B S$ and Advanced Most ly Bachelor

Mix of BS and Advanced Most ly Advinced Most ly Bache lor Mix of $B S$ and Advanced Mix of $B S$ and Advanced Mix of BS and Advanced Mix of $B S$ and Advanced Most ly Bachelor Mix of BS and Advanced Most ly Bachelor Mix of BS and Advanced Mix of BS and Advanced Mix of BS and Advanced Mix of AS and BS

Mix of BS and Advanced Most ly Bachelor Mix of AS and BS Most ly Bachelor Mix of AS and BS Mix of AS and BS Mix of AS and BS Mostly Associate Most ly Associate Mix of BS and Advanced Mix of AS and BS Mix of BS and Advanced Most ly Associate Mix of AS and BS Most ly Associate Mix of AS and BS Most ly Associate Most ly Associate HS or less Most ly Associate Most ly Associate Mix of AS and BS HS or less HS or less Mostly Associate Mostly Associate Most ly Associate Mostly Associate 


\section{TABLE R.5. Titles Sorted By Project Manager's Ratings of Difficulty Caused by Shortage (PM_Diff)}

Job Title
Risk Assess Manager
HazWasteHan Spec
Chemical Engineer
Chiemist
Project Manager
Nuclear Decon Eng ineer
Blochemist
Computer Engineer
Petrol_Mining Engineer
Statistician
Biologist
Health Physicist
WasteMan Engineer
Estimator
Hydrol_Hydrogeologist
Chem Tech
Environ Scientist
Geologist
Trainer
Environ Engineer
NucWaste Process Oper
Adnin_Clerical
Nuclear Engineer
Physicist
Mechanical Engineer
Materials Engineer
Materials Scientist
Ecologist
Electric_tronic Engineer
Industriä Engineer
H_physics Tech
Civil Engineer
Safety Engineer
Oriller
Ind Safety_Health Tech
Rad Protect Spec
Material Handler
Environ Sciences Tech
Survey_Map Tech
Technical Writer
Urafter
Computer Oper
Mech Engin Tech
Civil Eng Tech
Chemical Eng Tech
Electri_tronic. Tech
Ind Hygienist
Remediation Specialist
Irrigation Engineer
Mathematician
Opers Researcher
Seismologist
Structural Engineer

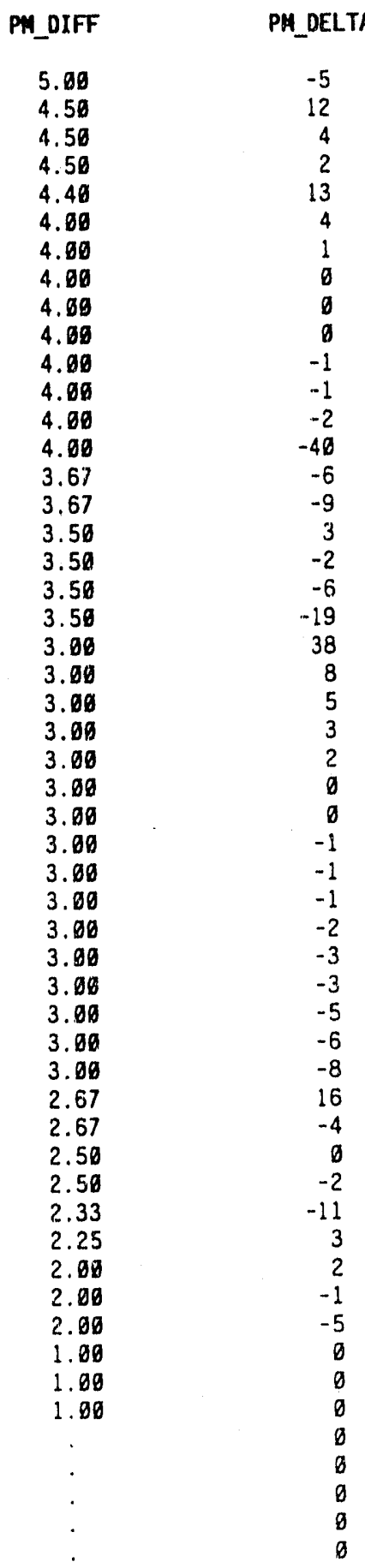

Degrex:

Most ly Advanced Mix of $A S$ and $B S$ Mix of $B S$ and Advanced Mix of BS and Advanced Most ly Bache lor

$M i x$ of BS and Advanced Mix of BS and Advanced Most ly Bache lor

Mix of $B S$ and Advanced Mix of BS and Advanced Mix of BS and Advanced Mix of BS and Advanced Mix of BS and Advanced Most ly Bachelor Mix of BS and Advanced Mix of AS and BS Mostly Bache lor $M: x$ of $B S$ and Advanced Mostly Bachelor

Mix of BS and Advanced Mostly Associate Mostly Associate Most ly Bache lor Mostly PhD

Mix of $B S$ and Advanced Mix of BS and Adyanced Mix of BS and Advanced Mix of BS and Advanced Most ly Bache lor Mix of BS and Advanced Mix of AS and BS Mix of $B S$ and Advanced Mix of BS and Advanced HS or less

Mix of AS and BS Mix of AS and BS Most ly Associate Mix of AS and BS $M i x$ of AS and BS $M+X$ of $A S$ and $B S$ Mostly Associate Mix of AS and BS Mostly Associate Mostly Associate Mostly Associate Mostly Associate Mix of AS and BS HS or less HS or less Mostly Associate Mostly Associate Mostly Associate Most ly Associate

Statistics based on data from 6 WNAS surveys and 1 SCHC survey. 


\section{TABLE R.6. Job Titles Sorted By Human Resource Personnel's Ratings of Difficulty Caused By Shortage (HR_Diff)}

\author{
Job Title \\ Nuc lear Eng ineer \\ Materials Eng ineer \\ NucWaste Process Oper \\ Biochemist \\ Chemist \\ Wastellan Engineer \\ Chemical Engineer \\ Health Physicist \\ Environ Scientist \\ Admin_Clerical \\ $H$ physics Tech \\ Safety Eng ineer \\ Structural Eng ineer \\ Environ Engineer \\ Hydrol_Hydrogeolog ist \\ Geolog ist \\ Ecologist \\ Civil Engineer \\ Mechanical Engineer \\ Chem Tech \\ Electri_tronic Tech \\ Nuclear Decon Engineer \\ Physicist \\ Materials Scientist \\ Project Manager \\ HazWasteMan Spec \\ Electric tronic Engineer \\ Risk Asséss Manager \\ Computer Eng ineer \\ Petrol_Mining Engineer \\ Statistician \\ Blologist \\ Ind Safety_Health Tech \\ Estimator \\ Environ Sciences Tech \\ Trainer \\ Rad Protect Spec \\ Technical Writer \\ Industrial Engineer \\ Material Handler \\ Survey Map Tech \\ Drafter \\ Computer Oper \\ Mech Eng in Tech \\ Chemical Eng Tech \\ Driller \\ Civil Eng Tech \\ Ind Hyg ien ist \\ Remediation Specialist \\ Irrigation Engineer \\ Mathematician \\ Opers Researcher \\ Seismologist
}

Degree

Mostly Bachelor Mix of BS and Advanced Mostly Associate

Mix of BS and Advanced Mix of BS and Advanced Mix of BS and Advanced Mix of $B S$ and Advanced Mix of BS and Advanced Mostly Bachelor Mostly Associate Mix of AS and BS Mix of BS and Advanced Most ly Associate Mix of BS and Advanced Mix of BS and Advanced Mix of BS and Advanced Mix of BS and Advanced Mix of BS and Advanced Mix of BS and Advanced $M+X$ of $A S$ and $B S$ Mostly Associate Mix of BS and Advanced Mostly Pho

Mix of BS and Advanced Mostly Bache lor Mix of AS and ES Most ly Bachelor Most iy Advanced Mostly Bachelor Mix of BS and Advanced Mix of $B S$ and Advanced Mix of BS and Advanced $M i x$ of $A S$ and $B S$ Mostly Bachelor Mix of AS and BS Mostly Bachelor Mix of $A S$ and $B S$ $M i x$ of $A S$ and $B S$ Mix of BS and Advanced Most ly Associate Mix of AS and BS Mostly. Associate Mix of AS and BS Mostly Associate Mostly Associate HS or less Mostly Associate Mix of AS and BS HS or less HS or less Mostly Associate Mostly Associate Mostly Assoctate

Statistics based on data from 6 WNAS surveys and 1 SCHC survey. 
TABLE R.7. Job Titles Sorted By Human Resource Personnel's Ratings of Need for Additional Employees (HR_Need)

\author{
Job Tit le \\ Nuc lear Eng ineer \\ NucWaste Process Oper \\ Chemist \\ WasteMan Eng ineer \\ Chemical Eng ineer \\ Health Phys ic ist \\ Admin Clerical \\ H_physics Tech \\ Environ Engineer \\ Hydrol_Hydrogeologist \\ Geologist \\ Chem Tech \\ Materials Engineer \\ Biochemist \\ Environ Scientist \\ Safety Engineer \\ Structural Engineer \\ Ecologist \\ Civill Engineer \\ Mecharical Engineer \\ Electri tronic Tech \\ Nuc lear Decon Engineer \\ Physicist \\ Materials Scientist \\ Project Manager \\ HazWasteMan Spec \\ Elictric tronic Engineer \\ Risk Assess Manager \\ Computer Eng ineer \\ Petrol Mining Engineer \\ Statistician \\ Biologist \\ Ind Safety_Health Tech \\ Estimator \\ Environ Sciences Tech \\ Trainer \\ Rad Protect Spec \\ Technical Writer \\ Industrial Engineer \\ Material Handler \\ Survey Map Tech \\ Orafter \\ Computer Oper \\ Mech Eng in Tech \\ Chemical Eng Tech \\ Driller \\ Civil Eng Tech \\ Ind Hygienist \\ Remediation Specialist \\ Irrigation Engineer \\ Mathematician \\ Opers Researcher \\ Seismologist
}

IR MEED

$P M$
PELTA
5
38
2
-2
4
-1
8
-2
-19
-6
-2
-9
0
1
3
-3
0
-1
-3
2
0
4
3
0
13
12
-1
-5
0
0
9
-1
-6
-40
-4
-6
-8
-2
-1
16
0
-11
3
2
-5
-5
-1
0
0
0
0
0
9

\section{Degree}

Most ly Bachelor

Most ly Associate

Mix of BS and Advanced

Mix of BS and Advanced

Mix of BS and Advanced

Mix of BS and Advanced

Most ly Associate

Mix of AS and BS

Mix of BS and Advanced

Mix of $B S$ and Advanced

Mix of $B S$ and Advanced

Mix of AS and BS

Mix of BS and Advanced

Mix of BS and Advanced

Mostly Bachelor

Mix of BS and Advanced

Most ly Associate

Mix of BS and Advanced

Mix of BS and Advanced Mix of BS and Advanced Most ly Associate

Mix of BS and Advanced Most ly PhD

Mix of BS and Advanced

Most ly Bachelor

Mix of AS and BS

Most ly Bachelor

Most iy Advanced

Mostly Bachelor

Mix of BS and Advanced

Mix of $B S$ and Advanced

Mix of BS and Advanced

Mix of AS and BS

Most ly Bachelor

Mix of AS and BS

Mostly Bachelor

$M i x$ of $A S$ and $B S$

Mix of $A S$ and $B S$

Mix of BS and Advanced

Most ly Associate

Mix of AS and BS

Most ly Associate

Mix of AS and BS

Most ly Associate

Most ly Associate HS or less

Most ly Associate Mix of AS and BS

HS or less

HS or less

Most ly Associate

Mostly Associate

Most ly Associate

Statistics based on data from 6 WNAS surveys and 1 SCHC survey. 


\section{TABLE R.8. Job Titles Sorted By Human Resource Personnel's Ratings of Current Ability to Recruit (HR_Rec_C)}

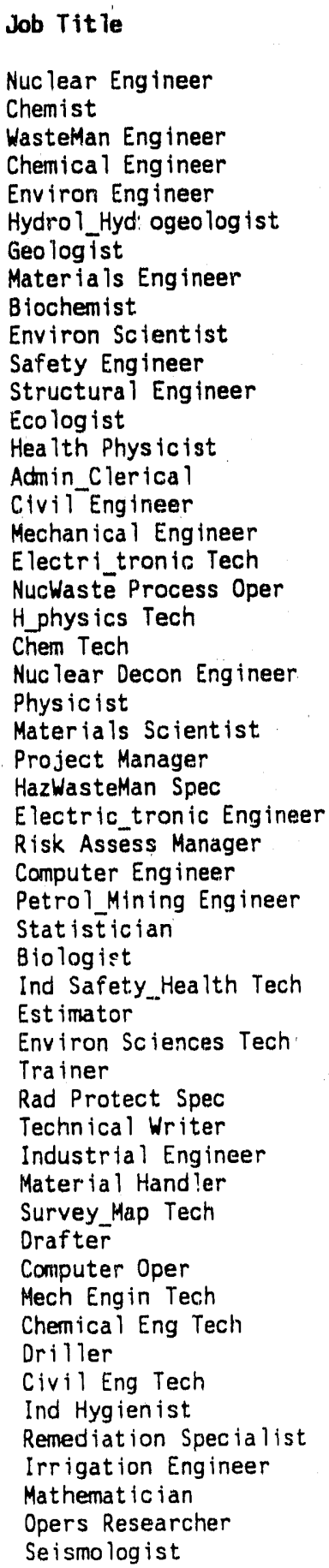

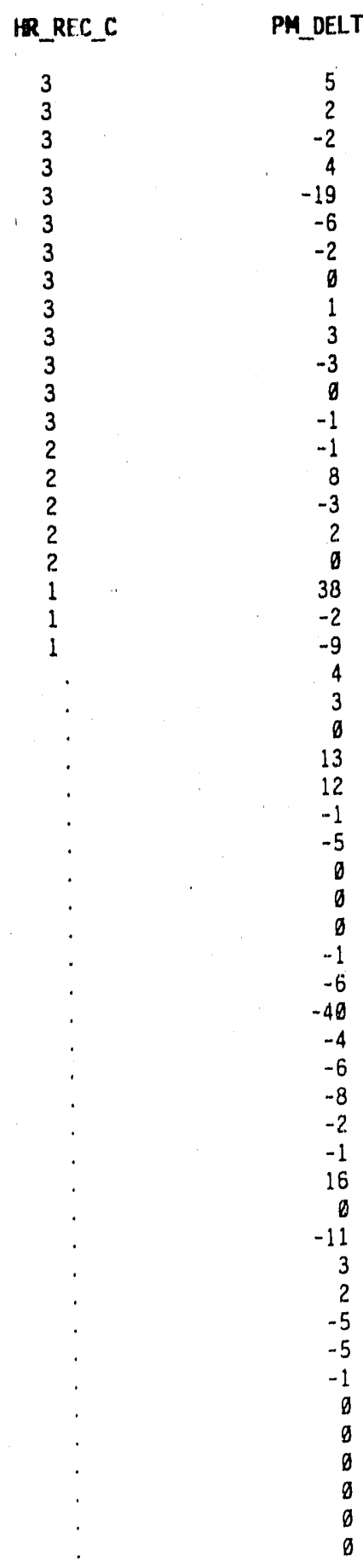

Statistics based on data from 6 WNAS surveys and 1 SCHC survey.
Degree

Mostly Bache lor Mix of BS and Advanced Mix of BS and Advanced Mix of BS and Advanced Mix of $B S$ and Advanced Mix of $B S$ and Advanced $M i X$ of $B S$ and Advanced Mix of BS and Advanced Mix of $B S$ and Advanced Most ly Bachelor Mix of BS and Advariced Mostly Associate

$M i x$ of $B S$ and Advanced Mix of $B S$ and Advanced Most ly Assoc late

$M i x$ of $B S$ and Advanced Mix of BS and Advanced Mostly Associate Mos \pm ly Associate Mix of AS and BS $M i x$ of $A S$ and $B S$ Mix of BS and Advanced Mostly PhD

Mix of BS and Advanced Most ly Bache lor

Hix of AS and BS Most iy Bachelor Most ly Advanced Most ly Bachelor

Mix of BS and Advanced Mix of BS and Advanced Mix of $B S$ and Advanced Mix of AS and BS Most ly Bachelor Mix of AS and BS Mostly Bachelor Mix of $A S$ and $B S$ Mix of AS and BS Mix of BS and Advanced Most ly Associate Mix of AS and BS Most ly Associate Mix of AS and BS Mostly Associate Most ly Associate HS or less

Most ly Associate $M 1 x$ of $A S$ and $B S$ HS or less HS or less Most ly Associate Mostly Associate Mostly Associate 

TABLE R.9. Job Titles Sorted By Human Resource Personnel's Ratings
of Anticipated Ability to Recruit (HR_Rec_A)

Job Title
Nuclear Engineer
Chemist
WasteHan Engineer
Chemical Engineer
Environ Engineer
Hydrol_Hydrogeologist
Geologist
Materials Engineer
Blochemist
Environ Scientist
Safety Engineer
Structural Engineer
Ecologist
Health Physicist
Admin_Clerical
Civil.Engineer
Mechanical,Engineer
Electri_tronic Tech
NucWaste Process Oper
H_physics Tech
Chem Tech
Nuclear Decon Engineer
Physicist.
Materials Scientist
Project Manager
HazWasteMan Spec
Electric_tronic Engineer
Risk Assess Manager
Computer Engineer
Petrol_Mining Engineer
Statistician
Biologist
Ind Safety_Health Tech
Estimator
Environ Sctences Tech
Trainer
Rad Protect Spec
Technical Writer
Industrial Engineer
Material Handler
Survey_Map Tech
Drafter
Computer Oper
Mech Engin Tech
Chemical Eng Tech
Driller
Civil Eng Tech
Ind Hygienist
Remediat ion Specialist
Irrigat ion Engineer
Mathematician
Opers Researcher
Seismologist

\begin{tabular}{|c|c|}
\hline HR_REC_ & PH_DEL. \\
\hline 3 & 5 \\
\hline 3 & 2 \\
\hline 3 & -2 \\
\hline 3 & 4 \\
\hline 3 & -19 \\
\hline 3 & -6 \\
\hline 3 & -2 \\
\hline 3 & 0 \\
\hline 3 & 1 \\
\hline 3 & 3 \\
\hline 3 & -3 \\
\hline 3 & $\theta$ \\
\hline 3 & -1 \\
\hline 2 & -1 \\
\hline 2 & 8 \\
\hline 2 & -3 \\
\hline 2 & 2 \\
\hline 2 & $\emptyset$ \\
\hline 1 & 38 \\
\hline 1 & -2 \\
\hline 1 & -9 \\
\hline$\cdot$ & 4 \\
\hline . & 3 \\
\hline . & 8 \\
\hline$\cdot$ & 13 \\
\hline . & 12 \\
\hline . & -1 \\
\hline. & -5 \\
\hline$\cdots$ & 0 \\
\hline$\cdot$ & $\theta$ \\
\hline$\cdot$ & $\emptyset$ \\
\hline$\cdot$ & -1 \\
\hline$\cdot$ & -6 \\
\hline . & -40 \\
\hline 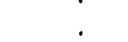 & $\begin{array}{l}-4 \\
-6\end{array}$ \\
\hline . & $\begin{array}{l}-6 \\
-8\end{array}$ \\
\hline . & -2 \\
\hline . & -1 \\
\hline . & 16 \\
\hline · & 6 \\
\hline . & -11 \\
\hline . & 3 \\
\hline$\cdot$ & 2 \\
\hline$\cdot$ & $\begin{array}{l}-5 \\
-5\end{array}$ \\
\hline$\cdot$ & $\begin{array}{l}-5 \\
-1\end{array}$ \\
\hline 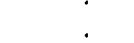 & 0 \\
\hline . & $\theta$ \\
\hline$\cdot$ & $\theta$ \\
\hline$\cdot$ & a \\
\hline . & $\theta$ \\
\hline
\end{tabular}

\section{Degree}

Most ly Bachelor Mix of BS and Advanced Mix of $B S$ and Advanced Mix of $B S$ and Advanced Mix of BS and Advanced Mix of $B S$ and Advanced Mix of BS and Advanced Mix of BS and Advanced Mix of BS and Advanced Most ly Bachelor Mix of BS and Advanced Most ly Associate Mix of $B S$ and Advanced Mix of BS and Advanced Most ly Associate Mix of BS and Advanced Mix of BS and Advanced Most ly Associate Most ly Associate Mix of AS and BS Mix of AS and BS Mix of $B S$ and Advanced Most ly Pho

Mix of BS and Advanced Most ly Bachelor Mix of AS and BS Most ly Bachelor Most ly Advanced Most iy Bachelor Mix of $B S$ and Advanced Mix of BS and Advanced Mix of BS and Advanced Mix of AS and BS Most ly Bachelor Mix of AS and BS Most ly Bachelor Mix of AS and BS Mix of AS and BS Mix of BS and Advanced Most ly Associate Mix of AS and BS Most ly Associate Mix of AS and BS Most ly Associate Mostly Associate HS or less Most ly Assoriate Mix of AS and BS HS or less HS or less Mostly Associate Most ly Associate Mostly Associate

Statistics based on data from 6 WNAS surveys and 1 SCHC survey. 
TABLE R.10. Job Titles Sorted By Human Resource Personnel's Ratings of Annual Turnover (HR_Turn)

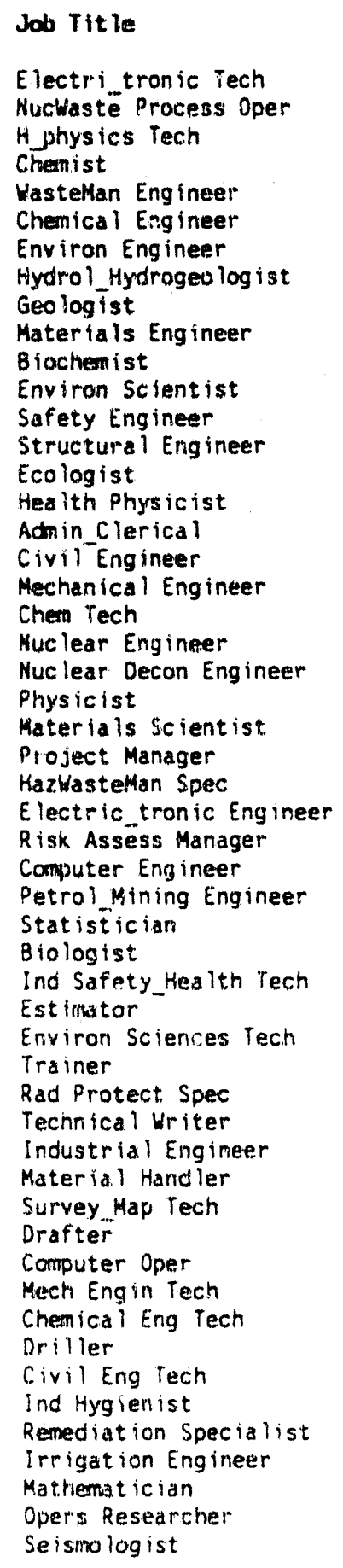

\begin{tabular}{|c|c|}
\hline HR_TLRK & PH_DELT \\
\hline 4 & $\theta$ \\
\hline 4 & 38 \\
\hline 4 & -2 \\
\hline 3 & 2 \\
\hline 3 & -2 \\
\hline 3 & 4 \\
\hline 3 & -19 \\
\hline 3 & -6 \\
\hline 3 & -2 \\
\hline 3 & $\theta$ \\
\hline 3 & 1 \\
\hline 3 & 3 \\
\hline 3 & -3 \\
\hline 3 & 0 \\
\hline 3 & -1 \\
\hline 3 & -1 \\
\hline 3 & 8 \\
\hline 3 & -3 \\
\hline 3 & 2 \\
\hline 3 & -9 \\
\hline & 5 \\
\hline & 4 \\
\hline . & 3 \\
\hline & $\theta$ \\
\hline . & 13 \\
\hline & 12 \\
\hline . & -1 \\
\hline . & -5 \\
\hline . & $\theta$ \\
\hline . & $\theta$ \\
\hline . & 0 \\
\hline . & -1 \\
\hline & -6 \\
\hline . & $-4 \theta$ \\
\hline . & -4 \\
\hline . & -6 \\
\hline . & -8 \\
\hline . & -2 \\
\hline . & -1 \\
\hline . & 16 \\
\hline . & 0 \\
\hline & -11 \\
\hline . & 3 \\
\hline . & $\begin{array}{r}2 \\
.-5\end{array}$ \\
\hline . & $\begin{array}{l}-5 \\
-5\end{array}$ \\
\hline . & -1 \\
\hline & $\theta$ \\
\hline . & 8 \\
\hline . & $\theta$ \\
\hline . & $\theta$ \\
\hline & $\theta$ \\
\hline
\end{tabular}

Statistics based on data fram 6 WNAS surveys and 1 SCHC survey.

\section{Degree}

Most ly Associate Most ly Associate Mix of AS and BS Mix of BS and Advanced Mix of BS and Advanced Mix of $B S$ and Advanced Mix of $B S$ and Advanced Mix of BS and Advanced Mix of BS and Advanced Mix of BS and Advanced Mix of BS and Advanced Mostly Bachelor Mix of BS and Advanced Most ly Associate

Mix of BS and Advanced Mix of BS and Advanced Mostly Associate Mix of BS and Advanced Mix of BS and Advanced Mix of AS and BS Most ly Bachelor Mix of $B S$ and Advanced Most iy PhD

Mix of $B S$ and Advanced Most ly Bachelor Mix of AS and BS Most ly Bachelor Most ly Advanced Most ly Bache lor Mix of BS and Advanced Mix of BS and Advanced Mix of BS and Advanced Mix of AS and BS Most ly Bache lor Mix of AS and BS Most ly Bache lor Mix of AS and BS Mix of AS and BS Mix of BS and Advanced Most ly Associate Mix of AS and BS Most ly Associate Mix of AS and BS Most ly Associate Most ly Associate HS or less Most ly Associate Mix of AS and BS HS or less HS or less Most ly Associate Most ly Associate Most ly Associate 
APPENDIX $S$

SIMPLE STATISTICS INTERCORRELATION AMONG

VARIABLES AND JOB SORTS ON ALL VARIABLES

FOR SAN FRANCISO ONLY 
TABLE S.1. Descriptive Statistics for Relative Ratings

$\begin{array}{llcccc}\text { Variable } & \text { N } & \text { Minimum } & \text { Maximum } & \text { Mean } & \underline{\text { S.D. }} \\ \text { HR_DIFF } & 47 & 2.00 & 5.00 & 3.65 & 0.73 \\ \text { HR_NEED } & 47 & 1.50 & 4.00 & 2.86 & 0.70 \\ \text { HR_REC_C } & 47 & 1.67 & 5.00 & 2.91 & 0.73 \\ \text { HR_REC_A } & 47 & 2.00 & 5.00 & 2.94 & 0.71 \\ \text { HR_TURN } & 47 & 1.00 & 2.00 & 1.33 & 0.31 \\ \text { PM_DIFF } & 19 & 2.00 & 4.00 & 3.37 & 0.60 \\ \text { PM_REC_A } & 18 & 1.00 & 4.00 & 2.50 & 0.86 \\ \text { PM_EDUC } & 18 & 1.00 & 5.00 & 3.39 & 1.09\end{array}$

S.D. = Standard Deviation, HR_DIFF = Difficulty Caused by a Shortage, HR NEED = Need for Additional-Employees, HR-REC $A$ = Anticipated Ease of Rečruitment, HR-REC-C = Current Ease of Recruitment, HR_TURN = Current Annual Turnover, PM_DIFF = Difficulty Caused By a Shortage, PM_REC_A = Anticipated Ability to Recruit, PM EDUC = Typical Degree Level, ** $\overline{\mathrm{p}}<\overline{0} .01 ; * \mathrm{p}<0.05$. Statistics based on data from 5 WNAS surveys and 3 SCHC surveys. 


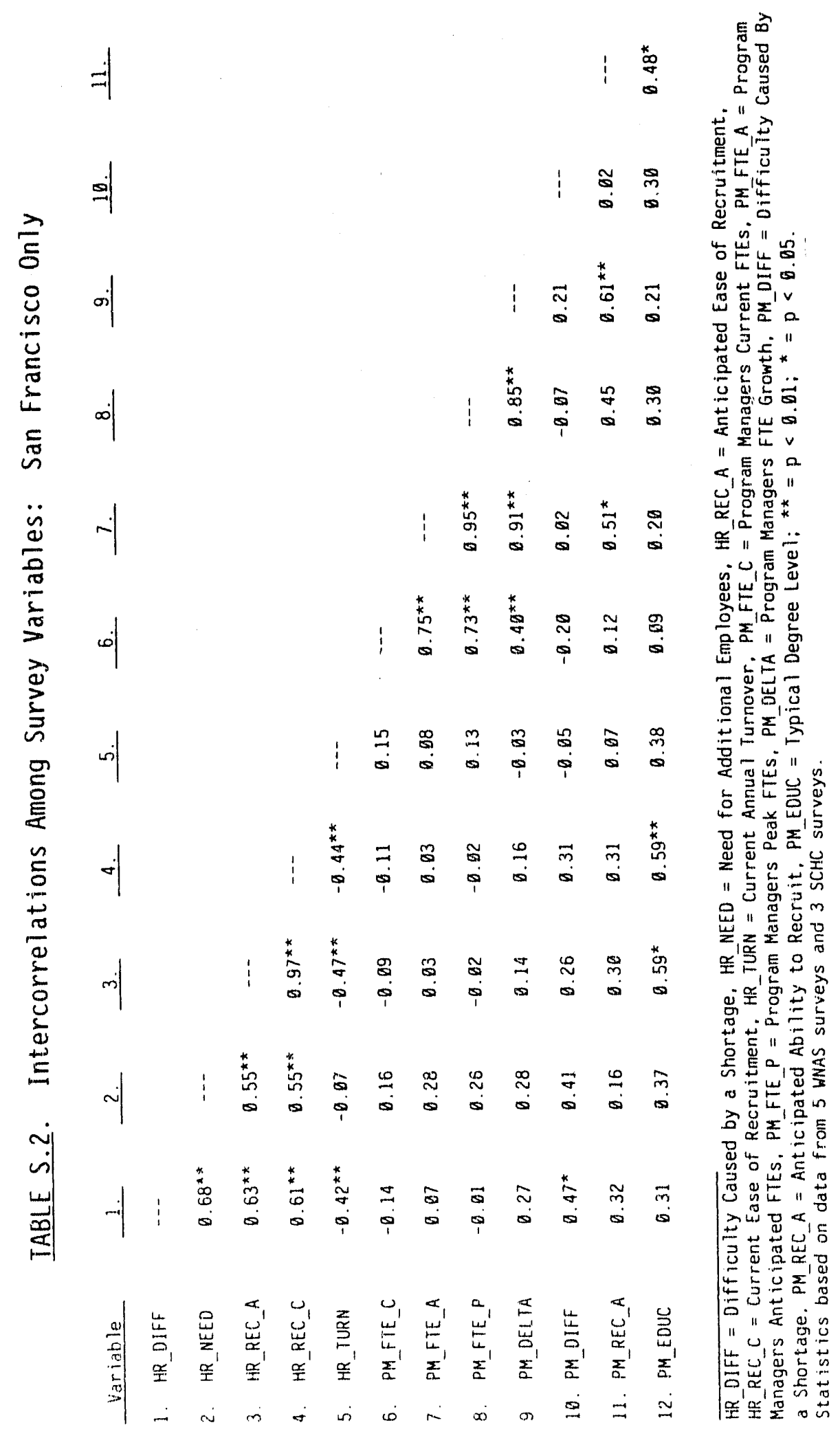


TABLE S.3. Job Titles Sorted By Change in FTES (PM_Delta)

\begin{tabular}{|c|c|c|c|c|c|}
\hline Job Title & PM_FTE_C & PH_FTE_A & PM_FTE_P & PM_DELTA & Degree \\
\hline Other Technician & 7 & 30 & 37 & 23 & HS or less \\
\hline Environ Engineer & 11 & 22 & 15 & 11 & Mix of BS and Advanced \\
\hline Environ Scientist & 1 & 8 & 8 & 7 & Mix of BS and Advanced \\
\hline Chemical Engineer & 1 & 3 & 4 & 2. & Mix of BS and Advanced \\
\hline Mech Engin Tech & $\theta$ & 2 & 2 & 2 & Mix of $A S$ and $B S$ \\
\hline Other Engineer & 4 & 6 & 9 & 2 & Mostly Associate \\
\hline Other Scient ist & $\emptyset$ & 2 & 2 & 2 & Mostly Associate \\
\hline Project Manager & 2 & 4 & 5 & 2 & Mostly Bachelor \\
\hline Rad Protect Spec & $\theta$ & 2 & 2 & 2 & Mix of AS and BS \\
\hline WasteMan Eng ineer & $\theta$ & 2 & 2 & 2 & Mix of BS and Advanced \\
\hline Chem Tech & 3 & 4 & 4 & 1 & Mix of $A S$ and $B S$ \\
\hline Other Administrator & $\theta$ & 1 & 1 & 1 & HS or less \\
\hline Technical Writer & 1 & 2 & 2 & 1 & Mix of AS and BS \\
\hline Biochemist & $\theta$ & $\theta$ & 0 & $\theta$ & Mostly Associate \\
\hline Biologist & $\theta$ & $\theta$ & $\theta$ & $\theta$ & Mistly Associate \\
\hline Chemical Eng Tech & $\theta$ & $\theta$ & $\theta$ & 0 & HS or less \\
\hline Chemist & $\theta$ & $\theta$ & $\theta$ & 8 & Mostly Associate \\
\hline Civil Eng Tech & $\theta$ & $\theta$ & $\theta$ & $\theta$ & HS or less \\
\hline Civil Engineer & 3 & 3 & 3 & $\theta$ & Mix of BS and Advanced \\
\hline Computer Eng ineer & $\emptyset$ & $\theta$ & $\theta$ & $\theta$ & Mostly Associate \\
\hline Computer Oper & $\theta$ & $\theta$ & $\theta$ & $\theta$ & HS or less \\
\hline Orafter & 0 & $\theta$ & 0 & $\theta$ & Mostly Associate \\
\hline Oriller & $\theta$ & 0 & $\theta$ & $\theta$ & HS or less \\
\hline Ecologist & $\theta$ & 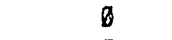 & $\theta$ & $\theta$ & Mostiy Associate \\
\hline Electri_tronic Tech & $\theta$ & $\theta$ & 6 & $\theta$ & HS or less \\
\hline Electric_tronic Engineer & $\emptyset$ & 0 & $\theta$ & $\theta$ & Mostly Associate \\
\hline Environ Sciences Tech & 1 & 1 & 3 & $\theta$ & Mix of $A S$ and $B S$ \\
\hline Est imator & $\theta$ & $\theta$ & $\theta$ & $\theta$ & HS or less \\
\hline H_physics Tech & $\theta$ & $\theta$ & $\theta$ & $\theta$ & HS or less \\
\hline HazWasteMan Spec & 0 & $\theta$ & 3 & $\theta$ & HS or less \\
\hline Health Physicist & $\theta$ & $\theta$ & $\theta$ & $\theta$ & Mostly Associate \\
\hline Ind Hyg ien ist & $\theta$ & $\theta$ & 4 & $\theta$ & Most ly Bachelor \\
\hline Ind Safety_Health Tech & $\theta$ & $\theta$ & $\theta$ & $\theta$ & HS or less \\
\hline Industrial Eng ineer & $\theta$ & $\theta$ & $\theta$ & $\theta$ & Mostly Associate \\
\hline Irrigation Engineer & $\theta$ & $\theta$ & $\theta$ & $\theta$ & HS or less \\
\hline Materials Engineer & $\theta$ & $\emptyset$ & $\theta$ & $\theta$ & Mostly Associate \\
\hline Materials Scientist & $\theta$ & $\emptyset$ & 0 & $\theta$ & Most ly Associate \\
\hline Mathemat ician & $\theta$ & $\theta$ & $\emptyset$ & $\theta$ & Mostly Associate \\
\hline Mechanical Engineer & $\theta$ & $\theta$ & 0 & $\theta$ & Mostly Associate \\
\hline NucWaste Process Oper & $\theta$ & 0 & $\theta$ & $\theta$ & HS or less \\
\hline Nuclear Decon Eng ineer & $\theta$ & $\theta$ & $\theta$ & $\theta$ & Most ly Associate \\
\hline Nuclear Eng ineer & 0 & $\theta$ & $\theta$ & ø & Mostly Associate \\
\hline Opers Researcher & $\theta$ & $\theta$ & $\theta$ & $\theta$ & Most ly Associate \\
\hline Petrol_Mining Engineer & $\theta$ & $\theta$ & $\theta$ & $\theta$ & Mostly Associate \\
\hline Phys ic ist & $\theta$ & $\theta$ & $\theta$ & $\theta$ & Mostly Associate \\
\hline Remediation Specialist & $\theta$ & $\theta$ & $\theta$ & $\theta$ & HS or less \\
\hline Risk Assess Manager & $\theta$ & $\theta$ & $\theta$ & $\theta$ & HS or less \\
\hline Safety Engineer & $\theta$ & $\theta$ & $\theta$ & 0 & Most ly Associate \\
\hline Se ismologist & $\theta$ & $\theta$ & $\theta$ & $\theta$ & Most ly Associate \\
\hline Statistician & $\theta$ & $\theta$ & $\theta$ & $\theta$ & Mostly Associate \\
\hline Structural Engineer & $\theta$ & ด & $\theta$ & $\theta$ & Mostly Associate \\
\hline Survey_Map Tech & $\theta$ & $\theta$ & $\theta$ & $\theta$ & HS or less \\
\hline Trainer & $\theta$ & $\emptyset$ & $\theta$ & $\theta$ & HS or less \\
\hline Hydrol_Hydrogeo log ist & 3 & 2 & 4 & -1 & Most ly PhD \\
\hline Geologist & 6 & 3 & 6 & -3 & Most ly PhD \\
\hline Admin_lerical & 9 & 5 & 9 & -4 & Mostly Associate \\
\hline Material Handler & 4 & 0 & 4 & -4 & Most ly Associate \\
\hline
\end{tabular}

Statistics based on data from 5 WNAS surveys and 3 SCHC surveys. 


\section{TABLE S.4. Titles Sorted by Project Manager's Ratings of Anticipated Ability to Recruit (PM_Rec_A)}

\author{
Job Title \\ WasteMan Engineer \\ Environ Eng ineer \\ Environ Scientist \\ Project Manager \\ Rad Protect Spec \\ Chem Tech \\ Environ Sciences Tech \\ Chemical Engineer \\ Technical Writer \\ Civil Engineer \\ Ind Hygienist \\ Geologist \\ Hydrol_Hydrogeo log ist \\ Mech Eñg in Tech \\ Material Handler \\ Admin Clerical \\ Oriller \\ Drafter \\ HazWasteman Spec \\ $B$ iochemist \\ Biologist \\ Chemical Eng Tech \\ Chemist \\ Civil Eng Tech \\ Computer Eng ineer \\ Computer Oper \\ Ecologist \\ Electri tronic Tech \\ Electric_tronic Engineer \\ Estimator \\ H_physics Tech \\ Health Physicist. \\ Ind Safety Health Tech \\ Industrial Eng ineer \\ Irrigation Engineer \\ Materials Engineer \\ Materials Scientist \\ Mathemat ician \\ Mechanical Eng ineer \\ NucWaste Process Oper \\ Nuclear Decon Engineer \\ Nuclear Eng ineer \\ Opers Researcher \\ Petrol Mining Engineer \\ Physicist \\ Remediation Specialist \\ $R$ isk Assess Manager \\ Safety Eng ineer \\ Se ismologist \\ Statistician \\ Structural Engineer \\ Survey Map Tech \\ Trainer
}

PM_REC_A

PM_DELYA

4.00
3.67
3.50
3.33
3.00
3.00
3.00
3.00
2.50
2.00
2.00
2.00
2.00
2.00
2.00
2.00
1.00
1.00

PM_DELTA
2
11
7
2
2
1
0
2
1
0
0
-3
-1
2
-4
-4
0
0
0
0
0
0
0
0
0
0
0
0
0
0
0
0
0
0
0
0
0
0
0
0
0
0
0
0
0
0
0
0
0
0
0
0
0

\section{Degree}

Mix of BS and Advanced Mix of BS and Advanced Mix of $B S$ and Advanced Most ly Bache lor Mix of AS and BS Mix of $A S$ and $B S$ Mix of AS and BS Mix of $B S$ and Advanced Mix of AS and BS Mix of BS and Advanced Most ly Bache lor Mostly PhD

Mostly Pho

Mix of AS and $8 S$ Most ly Associate Most iy Associate HS or less

Mostly Associate HS or less

Mostly Associate Most ly Associate HS or less

Most ly Associate HS or less

Mostly Associate HS or less

Most ly Associate

HS or less

Most ly Associate

HS or less

HS or less

Most ly Associate

HS or less

Most ly Associate

HS or less

Mostly Associate

Mostly Associate Most ly Associate Most ly Associate HS or less

Most ly Associate Most ly Associate Most ly Associate Most ly Associate Mostily Associate HS or less HS or less Mostly Associate Most ly Associate Most ly Associate Most ly Associate HS or less HS or less

Statistics based on data from 5 WNAS surveys and 3 SCHC surveys 


\section{TABLE S.5. Titles Sorted By Project Manager's Ratings of Difficulty Caused by Shortage (PM_Diff)}

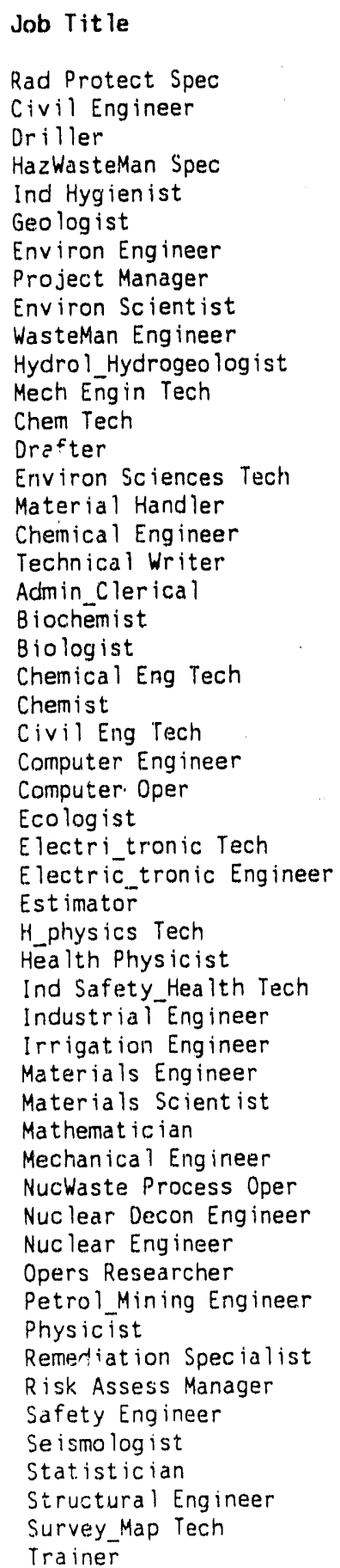

\section{PM_DIFF}

PM_DELTA

4.00
4.00
4.00
4.00
4.00
4.00
3.67
3.67
3.50
3.50
3.50
3.00
3.00
3.00
3.00
3.00
2.67
2.50
2.00

\section{Degree}

Mix of AS and BS Mix of BS and Advanced HS or less HS or less Most ly Bachelor Mostly PhD Mix of $B S$ and Advanced Most ly Bachelor Mix of BS and Advanced Mix of $B S$ and Advanced Mostly Pho Mix of AS and BS Mix of AS and BS Mostly Associate Mix of AS and BS Mostly Associate Mix of BS and Advanced Mix of AS and BS Most ly Associate Mostly Associate Mostly Associate HS or less Most iy Associate HS or less Most ly Associate HS or less Mostly Associate HS or less Most ly Associate HS or 'less HS or less Mostly Associate HS or less Most ly Associate HS or less

Mostly Associate Mostly Associate Mostly Associate Most ly Associate HS or less Most ly Associate Most ly Associate Most ly Associate Mostly Associate Mostly Associate HS or less HS or less Most ly Associate Mostly Associate Mostly Associate Most ly Associate HS or less HS or less

Statistics based on data from 5 WNAS surveys and 3 SCHC surveys. 


\section{TABLE S.6. Job Titles Sorted By Human Resource Personnel's Ratings of Difficulty Caused By Shortage (HR_Diff)}

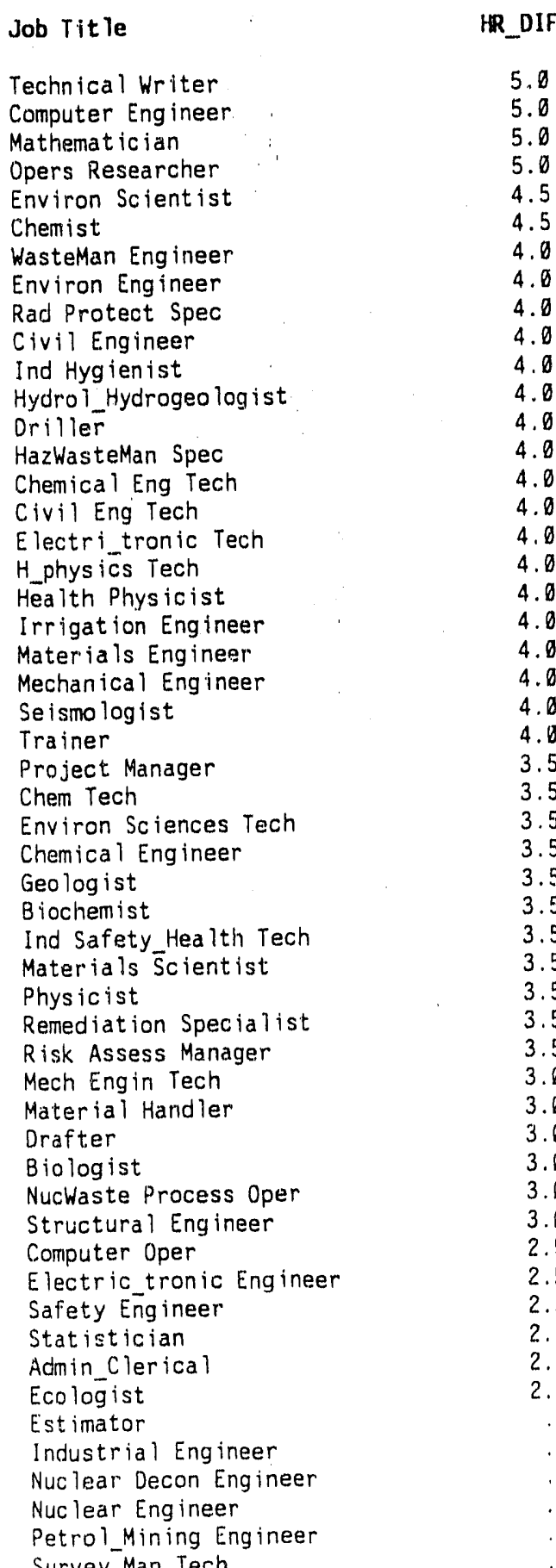

PM_DELTA
1
0
0
0
7
0
2
11
2
0
0
-1
0
0
0
0
0
0
0
0
0
0
$\theta$
0
2
1
0
2
-3
0
0
0
0
0
0
2
-4
0
0
0
0
0
0
0
0
-4
0
0
0
0
$\theta$
0
0
0

\section{Degree}

Mix of $A S$ and $B S$ Mostly Associate Mostly Associate Mostly Associate Mix of BS and Advanced Most ly Associate Mix of BS and Advanced Mix of $B S$ and Advanced Mix of $A S$ and $B S$

Mix of $B S$ and Advanced Mostly Bache lor

Mostly PhD

HS or less

HS or less

HS or less

HS or less

HS or less

HS or less

Most ly Associate HS or less

Mostly Associate Mostly Associate Mostly Associate HS or less Most ly Bache lor Mix of $A S$ and $B S$ Mix of AS and BS Mix of BS and Advanced Mostly Pho

Mostly Associate HS or less Mostly Associate Mostly Associate HS or less HS or less Mix of AS and BS Mostly Associate Most ly Associate Mostly Associate HS or less Most ly Associate HS or less Mostly Associate Mostly Associate Mostly Associate Mostly Associate Mostly Associate HS or less Most ly Associate Mostly Associate Mostly Associate Mostly Associate HS or less

Statistics based on data from 5 WNAS surveys and 3 SCHC surveys 


\section{IABLE S.7. Job Titles Sorted By Human Resource Personnel's Ratings of Need for Additional Employees (HR_Need)}

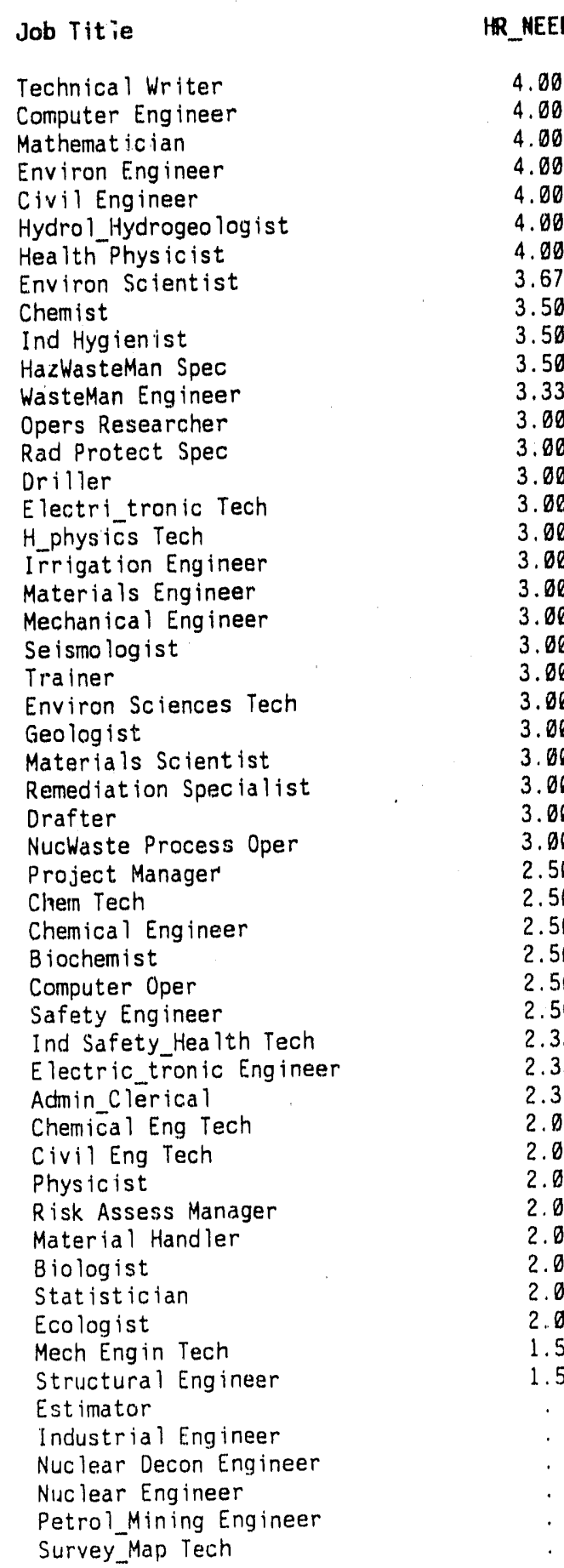

PM_DELTA
1
0
0
11
0
-1
0
7
0
0
0
2
0
2
0
0
0
0
0
0
0
0
0
-3
0
0
0
0
2
1
2
0
0
0
0
0
-4
0
0
0
0
-4
0
0
0
2
0
9
0
0
0
0
0

Degree

Mix of $A S$ and $B S$

Mostily Associate

Most ly Associate

Mix of BS and Advanced

Mix of BS and Advanced

Most ly PhD

Most ly Associate

Mix of BS and Advanced

Mostly Associate

Most ly Bache lor

HS or less

Mix of BS and Advanced

Most ly Associate

Mix of AS and $B S$

HS or less

HS or less

HS or less

HS or less

Mostly Associate

Mostly Assuciate

Mostly Associate

HS or less

Mix of AS and BS

Mostly PhD

Mostly Associate

HS or less

Most ly Associate

HS or less

Most ly Bache lor

Mix of AS and BS

Mix of BS and Advanced

Most ly Associate

HS or less

Most ly Associate

HS or less

Most ly Associate

Mostly Associate

HS or less

HS or less

Mostly Associate

HS or less

Mostly Associate

Mostly Associate

Mostly Associate

Most ly Associate

Mix of AS and BS

Most ly Associate

HS or less

Mostly Associate

Mostly Associate

Most ly Associate

Mostly Associate

HS or less

Statistics based on data from 5 WNAS surveys and 3 SCHC surveys. 
TABLE S.8. Job Titles Sorted By Human Resource Personnel's Ratings of Current Ability to Recruit (HR_Rec_C)

\section{Job Title}

Computer Engineer

Technical Writer

Mathematician

Civil Engineer

Opers Researcher

Irrigation Engineer

Materials Engineer

Health Physicist

Ind Hygien ist

Materials Scientist

Project Manager

Chemical Engineer

Physicist

WasteMan Engineer

Environ Engineer

Hydrol_Hydrogeologist

Environ Scientist

Chemist

HazWasteMan Spec

Rad Protect Spec

Mechanical Engineer

Seismologist

Geologist

Drafter

Electric tronic Engineer

Chemical Eng Tech

Structura? Engineer

H_physics Tech

Trainer

Environ Sciences Tech

Chem Tech

Biochemist

Computer Oper

Safety' Eng ineer

$B$ iologist

Statistician

Ind Safety Healich Tech

Driller

Electri tronic Tech

Remediation Specialist

NucWaste Process Oper

Civil Eng Tech

Risk Assess Manager

Material Handler

Ecologist

Mech Eng in Tech

Admin_Clerical

Estimator

Industrial Engineer

Nuclear Decon Eng ineer

Nuc lear Eng ineer

Petrol Mining Engineer

Survey Map Tech

\section{HR_REC_C}

\subsection{0}

4.90

4.00

4.00

4.00

4.00

4.00

3.50

3.50

3.50

3.50

3.50

3.50

3.33

3.00

3.00

3.00

3.00

3.00

3.00

3.00

3.00

3.00

3.00

3.00

3.00

3.00

2.50

2.50

2.50

2.50

2.50

2.50

2.50

2.50

2.50

2.33

2.80

2.08

2.00

2.00

2.00

2.00

2.00

2.00

2.00

1.67
PM_DELTA

0
1
0
0
0
0
0
0
0
0
2
2
0
2
11
-1
7
0
0
2
0
0
-3
0
0
0
0
0
0
0
1
0
0
0
0
0
0
0
0
0
0
0
0
0
0
0
0
0

Degree

Mostly Associate Mix of AS and BS Most ly Associate Mix of BS and Advanced Most ly Associate

HS or less

Most ly Assoclate Most ly Associate Most ly Bachelor Most ly Associate Most ly Bachelor Mix of BS and Advanced Mostly Associate Mix of BS and Advanced Mix of BS and Advanced Most ly PhD

Mix of BS and Advanced Most ly Associate HS or less

Mix of AS and BS Most ly Associate Mostly Associate Most ly Pho

Mostly Associate Most ly Associate HS or less

Most ly Associate HS or less HS or less Mix of AS and BS Mix of $A S$ and $B S$ Most ly Associate HS or less Mostly Associate Mostly Associate Most iy Associate HS or less HS or less HS or less HS or less HS or less HS or less HS or less Mostly Associate Mostly Associate Mix of AS and BS Mostly Associate HS or less Mostly Associate Mostly Associate Mostly Associate Mostly Associate HS or less

Statistics based on data from 5 WNAS surveys and 3 SCHC surveys. 


\section{TABLE S.9. Job Titles Sorted By Human Resource Personnel's Ratings of Anticipated Ability to Recruit (HR_Rec_A)}

Job Title

Computer Eng ineer Technical Writer Mathematician

Civil Engineer Opers Researcher Irrigation Eng ineer Materials Engineer

Health Physicist

Ind Hygienist

Materials Scientist

Project Manager

Chemical Engineer

Physicist

WasteMan Engineer

Environ Engineer

Hydrol Hydrogeologist

Environ Scientist

Chem ist

HazWasteMan Spec

Rad Protect Spec

Mechanical Eng ineer

Seismolog ist

Geologist

Drafter

Electric tronic Engineer

Chemical Eng Tech

Biochemist

Civil Eng Tech

Structural Eng ineer

H_physics Teah

Trainer

Environ Sciences Tech

Chem Tech

Computer Oper

Safety Engineer

Biologist

Statistician

Ind Safety Health Tech

Driller

Electri tronic Tech

Remediation Specialist

NucWaste Process Oper

Risk Assess Manager

Material Handler

Ecologist

Mech Eng in Tech

Admin_Clerical

Est imator

Industrial Engineer

Nuc lear Decon Engineer

Nuc lear Eng ineer

Petrol Mining Engineer

Survey Map Tech

\section{HR_REC_A}

5.00

4.00

$4: 00$

4.00

4.90

4.00

4.00

3.50

3.50

3.50

3.50

3.50

3.50

3.33

3.00

3.00

3.00

3.00

3.00

3.00

3.00

3.00

3.00

3.00

3.00

3.00

3.00

3.60

2.50

2.50

2.50

2.50

2.50

2.50

2.50

2.50

2.50

2.33

2.00

2.00

2.00

2.00

2.00

2.00

2.00

2.00

2.00

Statistics based on data from 5 WNAS surveys and 3 SCHC surveys.

\section{PM_DELTA Degree}

Mostly Associate Mix of AS and BS Most ly Associate Mix of BS and Advanced Most ly Associate HS or less Mostly Associate Mostly. Associate Most ly Bachelor Mostly Associate Most ly Bachelor Mix of BS and Advanced Mostly Associate Mix of $B S$ and Advanced Mix of BS and Advanced Mostly PhD

Mix of BS and Advanced Most ly Associate HS or less

Mix of $A S$ and $B S$ Mostly Associate Most ly Associate Most ly PhD

Mostly Associate Mostly Associate HS or less Most ly Associate HS or less Most ly Associate HS or less

HS or less Mix of AS and BS Mix of $A S$ and $B S$ HS or less

Most ly Associate Mostly Associate Mostly Associate HS or less

HS or less

HS or less

HS or less

HS or less

HS or less

Mostly Associate Most ly Associate Mix of AS and BS Mostly Associate HS or less Mostly Associate Most ly Associate Mostly Associate Most ly Associate HS or less 


\section{TABLE S.10. Job Titles Sorted By Human Resource Personnel's Ratings of Annual Turnover (HR_Turn)}

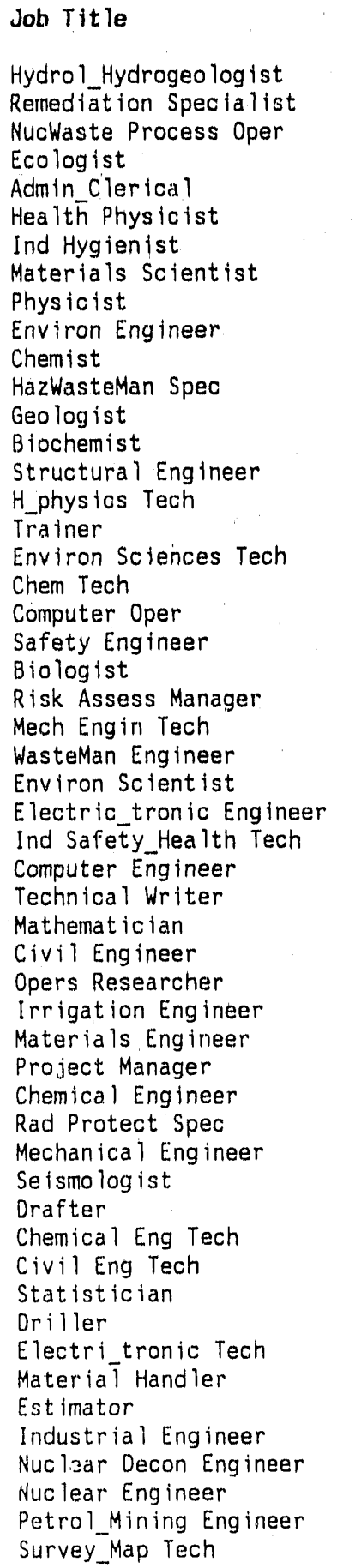

\begin{tabular}{cr} 
HR_TURN & PM_DEL \\
\hline 2.00 & -1 \\
2.00 & 0 \\
2.00 & 0 \\
2.00 & 0 \\
1.67 & -4 \\
1.50 & 0 \\
1.50 & 0 \\
1.50 & 0 \\
1.50 & 0 \\
1.50 & 11 \\
1.50 & 0 \\
1.50 & 0 \\
1.50 & -3 \\
1.50 & 0 \\
1.50 & 0 \\
1.50 & 0 \\
1.50 & 0 \\
1.50 & 0 \\
1.50 & 1 \\
1.50 & 0 \\
1.50 & 0 \\
1.50 & 0 \\
1.50 & 0 \\
1.50 & 0 \\
1.33 & 0 \\
1.33 & 0 \\
1.33 & 0 \\
1.33 & 0 \\
1.00 & 0 \\
1.00 & 0 \\
1.00 & 0 \\
1.00 & 0 \\
1.00 & 0 \\
1.00 & 0 \\
1.00 & 0 \\
1.00 & 0 \\
1.00 & 0 \\
1.00 & 0 \\
1.00 & 0 \\
1.00 & 0 \\
1.00 & 0 \\
1.00 & 0 \\
1.00 & 0 \\
1.00 & 0 \\
1.00 & 0 \\
1.00 & 0 \\
1.00 & 0 \\
. & 0 \\
. & 0 \\
. & 0 \\
1. & 0 \\
. & 0 \\
. & 0 \\
& 0 \\
1.0 & 0 \\
1.0 & 0
\end{tabular}

\section{Degree}

Most ly PhD

HS or less

HS or less

Mostly Associate

Most ly Associate

Mostly Assoc late Mostly Bachelor

Mostly Associate Mostly Associate Mix of BS and Advanced Most ly Assoclate HS or less

Most ly PhD Most ly Associate Most ly Associate HS or less

HS or less Mix of AS and BS Mix of AS and BS HS or less Most ly Associate Most ly Assoclate HS or less

Mix of $A S$ and $B S$ Mix of $8 S$ and Advanced Mix of BS and Advanced Mostly Associate HS or less

Mostly Associate Mix of AS and BS Most ly Associate $M i x$ of $B S$ and Advanced Most ly Associate HS or less

Most ly Associate Most ly Bache lor $M i x$ of $B S$ and Advanced Mix of $A S$ and $B S$ Most ly Associate Mostly Associate Most ly Associate HS or less HS or less Most ly Associate HS or less HS or less Most ly Associate HS or less Most ly Associate Most ly Associate Most ly Associate Most ly Associate HS or less

Statistics based on data from 5 WNAS surveys and 3 SCHC surveys. 
APPENDIX T

SIMPLE STATISTICS INTERCORRELATION AMONG VARIABLES AND JOB SORTS ON ALL VARIABLES

FOR SAVANNAH RIVER ONLY 
IABLE T.1. Descriptive Statistics for Relative Ratings

$\begin{array}{lccccc}\text { Variable } & \text { N } & \text { Minimum } & \text { Maximum } & \text { Mean } & \underline{\text { S.D. }} \\ \text { HR_DIFF } & 45 & 1.00 & 3.00 & 1.56 & 0.78 \\ \text { HR_NEED } & 45 & 1.00 & 4.00 & 2.09 & 0.92 \\ \text { HR_REC_C } & 45 & 1.00 & 5.00 & 2.40 & 1.12 \\ \text { HR_REC_A } & 45 & 1.00 & 5.00 & 2.36 & 1.11 \\ \text { HR_TURN } & 44 & 1.00 & 3.00 & 1.66 & 0.78 \\ \text { PM_DIFF } & 0 & . & . & . & . \\ \text { PM_REC_A } & 0 & . & . & . & . \\ \text { PM_EDUC } & 0 & . & . & . & .\end{array}$

S.D. = Standard Deviation, HR_DIFF = Difficulty Caused by a Shortage, HR NEED = Need for Additional Employees, HR-REC_A = Anticipated Ease of Recruitment, HR-REC-C = Current Ease of Recruitment, HR_TURN = Current Annual Turnover, PM_DIFF = Difficulty Caused By a Shortage, PM_REC $A=$ Anticipated Ability to Recruit, PMEDUC = Typical Degree Level, $* * \bar{p}<\overline{0} .01 ; * p<0.05$. Statistics based on data from 0 WNAS surveys and I SCHC survey. 


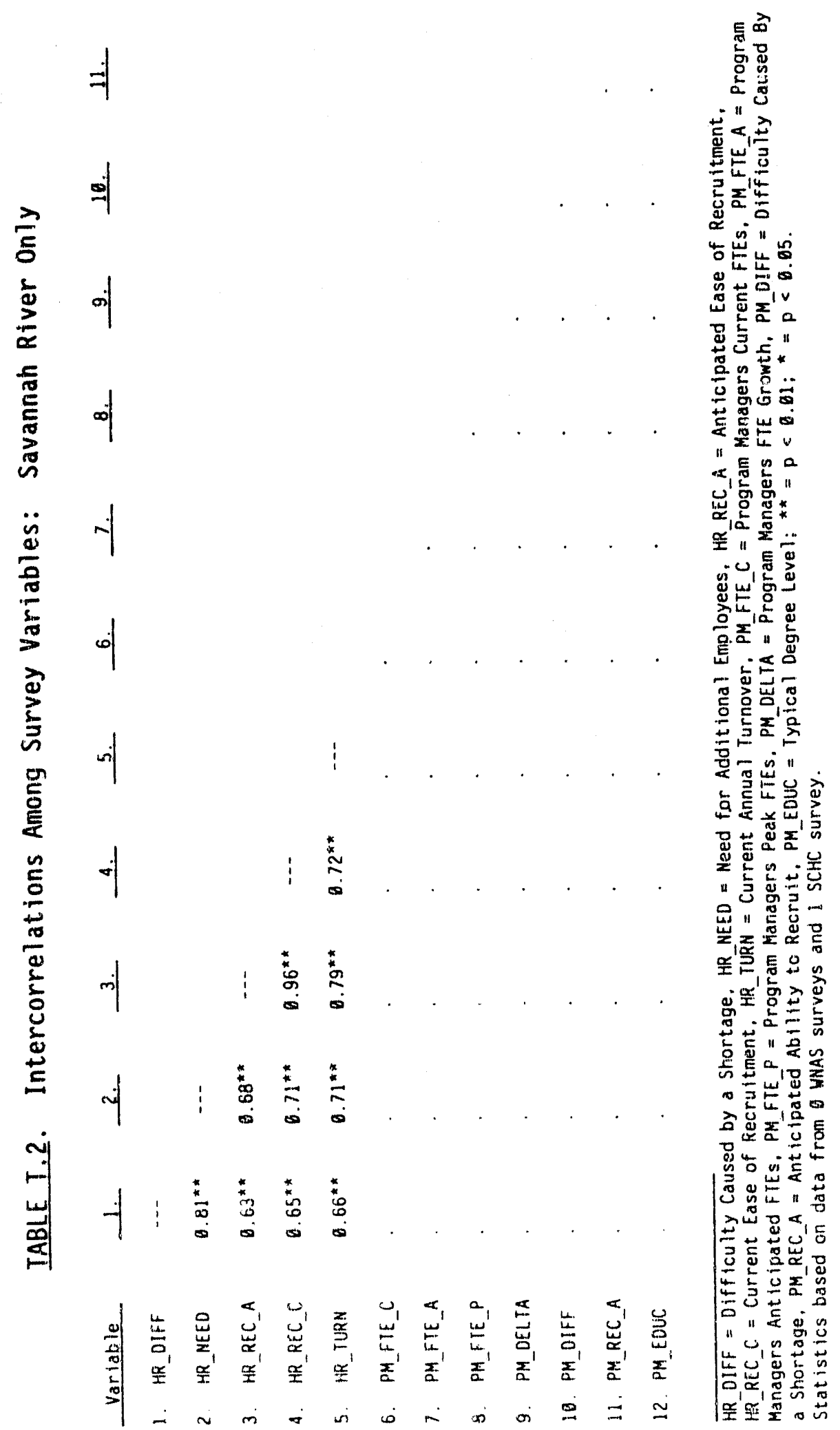




\section{TABLE T.3. Job Titles Sorted By Change in FTEs (PM_Delta)}

\begin{tabular}{|c|c|c|c|c|c|}
\hline Job Title & PA_FTE_C & PH_FTE_A & PH_FTE_P & PA_DELTA & Degree \\
\hline Adnin_Clerical & - & . & - & . & HS or less \\
\hline Biochem ist & . & . & $\cdot$ & $\cdot$ & Most ly Associate \\
\hline Biologist & $\cdot$ & · & - & $\cdot$ & Mostly Associate \\
\hline Chem Tech & $\cdot$ & . & · & $\cdot$ & HS or less \\
\hline Chemical Eng Tech & $\cdot$ & $\cdot$ & . & . & HS or less \\
\hline Chemical Engineer & . & $\cdot$ & . & $\cdot$ & Most ly Associate \\
\hline Chemist & . & $\cdot$ & $\cdot$ & $\cdot$ & Most ly Associate \\
\hline Civil Eng Tech & $\cdot$ & $\cdot$ & . & - & HS or less \\
\hline Civil Engineer & $\cdot$ & $\cdot$ & . & $\cdot$ & Mostly Associate \\
\hline Computer Eng ineer & $\cdot$ & · & $\cdot$ & $\cdot$ & Mostly Associate \\
\hline Computer Oper & $\cdot$ & $\cdot$ & · & $\cdot$ & HS or less \\
\hline Orafter & - & $\cdot$ & . & $\cdot$ & HS or less \\
\hline $\begin{array}{l}\text { Driller } \\
\text { Fcologist }\end{array}$ & $\cdot$ & $\cdot$ & • & · & HS or less \\
\hline $\begin{array}{l}\text { Ecologist } \\
\text { Electri tronic Tech }\end{array}$ & $\cdot$ & · & $\cdot$ & - & Most ly Associate \\
\hline $\begin{array}{l}\text { Electri tronic Tech } \\
\text { Electric tronic Engineer }\end{array}$ & : & - & $\cdot$ & $\cdot$ & $\begin{array}{l}\text { HS or less } \\
\text { Most ly Associate }\end{array}$ \\
\hline $\begin{array}{l}\text { Electric tronic Engineer } \\
\text { Environ Engineer }\end{array}$ & $\dot{.}$ & $\cdot$ & $\cdot$ & $\dot{.}$ & $\begin{array}{l}\text { Mostly Associate } \\
\text { Mostly Associate }\end{array}$ \\
\hline $\begin{array}{l}\text { Environ Engineer } \\
\text { Environ Sciences Tech }\end{array}$ & $\dot{.}$ & $\cdot$ & . & $\dot{.}$ & \\
\hline $\begin{array}{l}\text { Environ Sciences Tech } \\
\text { Environ Scientist }\end{array}$ & : & : & . & & Mostly Associate \\
\hline $\begin{array}{l}\text { Environ Scientist } \\
\text { Est imator }\end{array}$ & . & : & . & . & HS or less \\
\hline $\begin{array}{l}\text { Est imator } \\
\text { Geologist }\end{array}$ & . & : & & . & Mostly Associate \\
\hline & . & . & . & . & HS or less \\
\hline $\begin{array}{l}\text { H_phys ics Tech } \\
\text { HazWasteMan Spec }\end{array}$ & . & . & . & . & HS or less \\
\hline Health Physicist & . & . & . & . & Mostly Associate \\
\hline Hydrol_Hydrogeolog ist & $\cdot$ & . & . & . & Mostly Associate \\
\hline Ind Hygien ist & . & . & . & . & HS or less \\
\hline Ind Safety_Health Tech & . & . & . & . & HS or less \\
\hline Industrial-Eng ineer & . & . & . & . & Mostly Associate \\
\hline Irrigation Engineer & . & . & . & . & HS or less \\
\hline Material Handler & , & . & . & . & HS or less \\
\hline Materials Engineer & $\cdot$ & $\cdot$ & . & . & Most ly Associate \\
\hline Materia is Scientist & · & . & $\cdot$ & . & Mostly Associate \\
\hline Mathemat ician & . & . & . & . & Mostly Associate \\
\hline Mech Engin Tech & . & . & . & . & HS or less \\
\hline Mechanical Eng ineer & . & . & . & . & Most iy Associate \\
\hline NucWaste Process Oper & . & . & & . & HS or less \\
\hline Nuc lear Decon Engineer & . & · & . & . & Most ly Associate \\
\hline Nuc lear Engineer & . & . & . & . & Mostly Associate \\
\hline Opers Researcher & . & . & . & . & Mostly Associate \\
\hline Other Auministrator & . & . & . & . & HS or less \\
\hline Other Engineer & $\cdot$ & $\cdot$ & . & . & Mostly Associate \\
\hline Other Scientist & . & . & . & . & Mostly Associate \\
\hline Other Technician & . & . & . & . & HS or less \\
\hline Petrol_Mining Engineer & . & . & . & . & Mostly Associate \\
\hline Physicist & . & . & . & . & Mostly Associate \\
\hline Project Manager & . & . & . & . & HS or less \\
\hline Rad Protect Spec & . & . & . & . & HS or less \\
\hline Remediation Specialist & . & . & . & . & HS or less \\
\hline Risk Assess Manager & . & . & . & . & HS or less \\
\hline Safety Engineer & . & . & . & . & Most iy Associate \\
\hline Se ismo logist & . & . & . & . & Mostly Associate \\
\hline Statistician & . & . & . & . & Mostly Associate \\
\hline Structural Engineer & . & . & . & . & Most ly Associate \\
\hline Survey_Map Tech & . & . & & . & HS or less \\
\hline Technical Writer & . & & . & . & HS or less \\
\hline Trainer & & . & . & . & HS or less \\
\hline WasteMan Engineer & & & & . & Most ly Associate \\
\hline
\end{tabular}

Stat istics based on data from 0 WNAS surveys and 1 SCHC survey. 


\section{TABLE T.4. Titles Sorted by Project Manager's Ratings of Anticipated Ability to Recruit (PM_Rec_A)}

Job Tit le

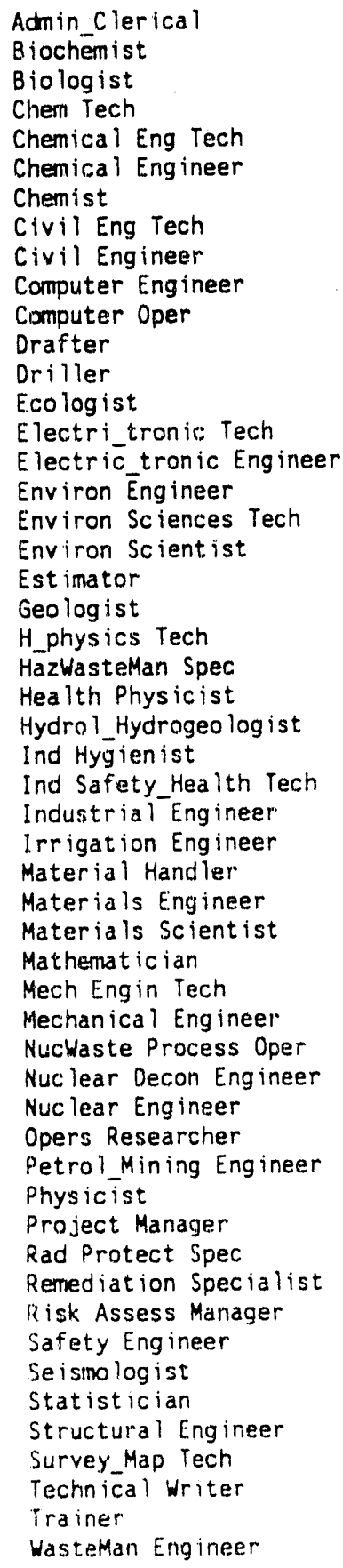

\section{PH_REC_A}

PH_DELTA

Statistics based on data from $\theta$ WNAS surveys and 1 SCHC survey.
Degree

HS or less Mostly Associate Most ly Associate

HS or less HS or less Most ly Associate Hostly Associate HS or less

Mostly Associate Most ly Associate

HS or less

HS or less

HS or less Most ly Associate HS or less Most ly Associate Mostly Associate HS or less Most ly Associate HS or less Most ly Associate

HS or less HS or less

Mostly Associate Mostly Associate HS or less HS or less Most ly Associate

HS or less HS or less

Most ly Assuciate Most ly Associate Most ly Associate HS or less Host ly As $\$ 0 C$ iate HS or less Most iy Associate Mostily Associate Most ly Associate Mostly Associate Most iy Associate HS or less HS or less HS or less HS or less Most ly Associate Most ly Associate Most ly Associate Mostly Associate HS or less HS or less HS or less Most ly Associate 


\title{
TABLE T.5. Titles Sorted By Project Manager's Ratings of Difficulty Caused by Shortage (PM_Diff)
}

\author{
Job Title \\ Admin_Clerical \\ Biochemist \\ Biologist. \\ Chem Tech \\ Chemical Eng Tech \\ Chemica I Engineer \\ Chemist \\ Civil Eng Tech \\ Civil Engineer \\ Computer Engineer \\ Computer Oper \\ Drafter \\ Driller \\ Ecologist. \\ Electri tronic Tech \\ Electric tronic Engineer \\ Environ Ëngineer \\ Environ Sciences Tech \\ Environ Scient ist \\ Estimator \\ Geolog ist. \\ $H$ physics Tech \\ HazWasteMan Spec \\ Health Physicist \\ Hydrol_Hydrogeolog ist \\ Ind Hygien ist \\ Ind Safety_Health Tech \\ Industrial Engineer \\ Irrigation Engineer \\ Material Handler \\ Materials Engineer \\ Materials Scientist \\ Mathematician \\ Mech Eng in Tech \\ Mechanical Engineer \\ NucWaste Process Oper \\ Nuclear Decon Eng ineer \\ Nuc lear Eng ineer \\ Opers Researcher \\ Petrol Mining Engineer \\ Physic ist \\ Project Manager \\ Rad Protect Spec \\ Remediation Specialist \\ Risk Assess Manager \\ Safety Eng ineer \\ Se ismo log ist \\ Statistician \\ Structural Engineer \\ Survey Map Tech \\ Technical Writer \\ Trainer \\ WasteMari Engineer
}

PH_DIFF

PM_DELTA

Degree

HS or less

Most ly Associate

Most iy Associate

HS or less

HS or less

Mostly Associate

Most ly Associate

HS or less

Most ly Associate

Most ly Assoc iate

HS or less

HS or less

HS or less

Most ly Associate

HS or less

Most ly Associate

Most ly Associate

HS or less

Most iy Associate

HS or less

Most ly Associate

HS or less

HS or less

Most ly Associate

Most ly Associate

HS or less

HS or less

Most ly Associate

HS or less

HS or less

Most ly Associate

Most ly Associate

Most ly Associate

HS or less

Most ly Associate

HS or less

Most ly Associate

Most ly Associate

Most ly Associate

Mostly Associate

Mostly Associate

HS or less

HS or less

HS or less

HS or less

Mostily Associate

Most ly Associate

Most ly Associate

Mostly Associate

HS or less

HS or less

HS or less

Mostly Associate

Statistics based on data from $\theta$ WNAS surveys and 1 SCHC survey. 

TABL.E T.6. Job Tities Sorted By Human Resource Personnel's Ratings
of Difficulty Caused By Shortage (HR_Diff)

Job Title
Chemist
Environ Engineer
Geologist
Heaith Physicist
Hydrol_Hydrogeologist
Nuclear Engineer
Project Manager
Chemical Engineer
Ecologist
Environ Scientist
H_physics Tech
Ind Hygienist
Rad Protect Spec
Statistician
Technical Writer
WasteMan Engineer
Adnin_Clerical
Biochemist
Biologist
Chem Tech
Chemical Eng Tech
Civil Engineer
Computer Engineer
Computer Oper
Orafter
Electri_tronic Tech
Electric tronic Eng ineer
HazWasteMan Spec
Industrial Engineer
Material Handler
Materials Eng ineer
Materials Scientist
Mathematician
Mech Eng in Tech
Mecharical Engineer
NucWaste Process Oper
Opers Researcher
Physicist
Remediation Specialist
Risk Assess Manager
Safety Engineer
Seismologist
Structural Engineer
Trainer
Civil Eng Tech
Driller
Environ Sciences Tech
Estimator
Ind Safety_Health Tech
lrrigation Engineer
Nuclear Decon Engineer
Petrol_Mining Engineer
Survey_Map Tech

HR_DIFF PH_DELTA Degree

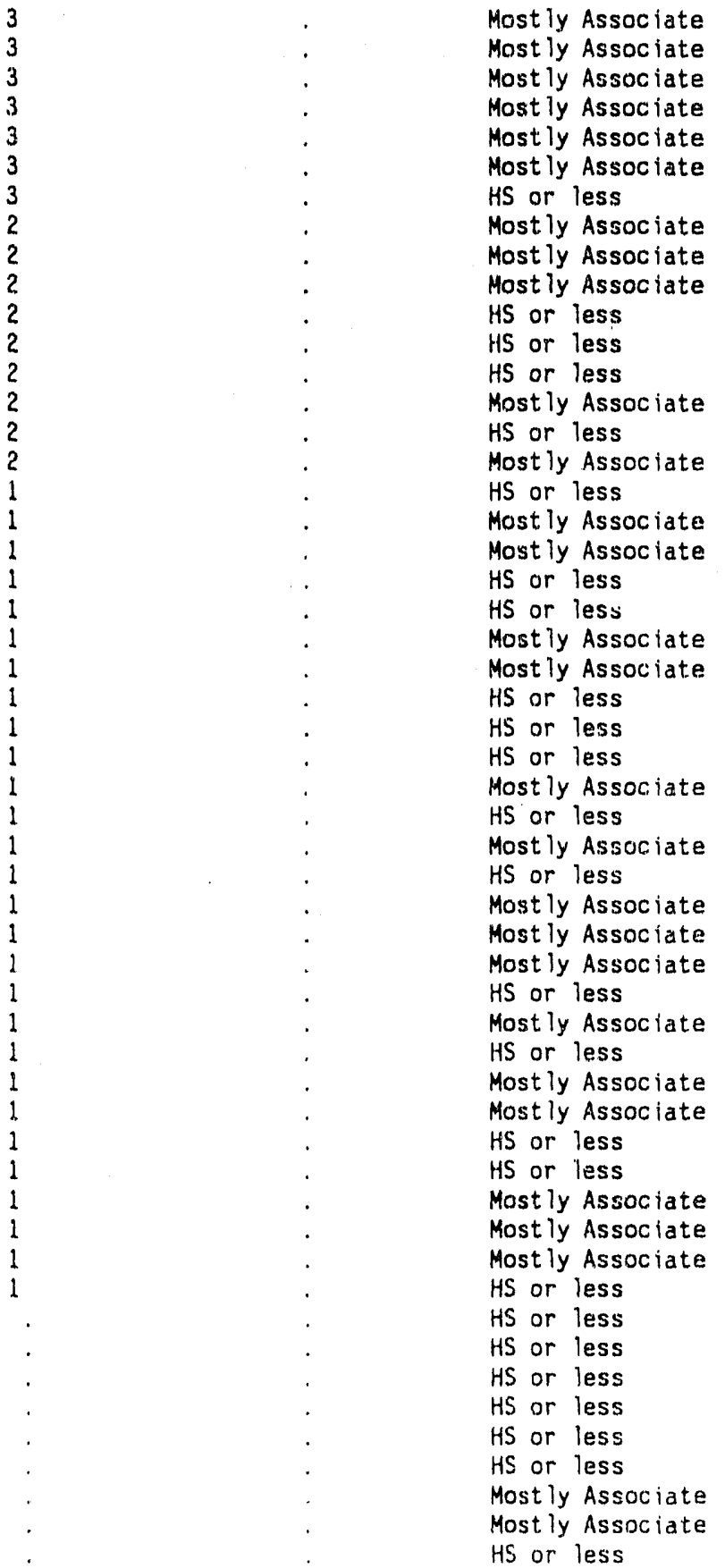

Statistics based on data from 0 WNAS surveys and 1 SCHC survey. 

TABLE T.7. Job Titles Sorted By Human Resource Personnel's Ratings of
Need for Additional Employees (HR_Need)

Job Title
Chemist
Health Physicist
Project Manager
Environ Engineer
Geologist
Hydrol_Hydrogeologist
Nuclear Engineer
Chemical Engineer
H_physics Tech
Ind Hygienist
Technical Writer
Mechanical Engineer
Ecologist
Environ Scientist
Rad Protect Spec
Statistician
WasteMan Engineer
Biologist
Chem Tech
Chemical Eng Tech
Civil Engineer
Computer Engineer
Electric_tronic Engineer
HazWasteMan Spec
Materials Engineer
Materials Scientist
Physicist
Remediation Specialist
Safety Eng ineer
Structural Engineer
Trainer
Admin_Clerical
Biochemist
Computer Oper
Drafter
Electri_tronic Tech
Industrial Engineer
Material Handler
Mathematic ian
Mech Engin Tech
NucWaste Process Oper
Opers Researcher
Risk Assess Manager
Seismologist
Civil Eng Tech
Driller
Environ Sciences Tech
Est imator
Ind Safety Heaith Tech
Irrigation Engineer
Nuclear Decon Engineer
PetrolMining Engineer
Survey_Map Tech

\section{HR_MEED}

4
4
4
3
3
3
3
3
3
3
3
3
2
2
2
2
2
2
2
2
2
2
2
2
2
2
2
2
2
2
2
1
1
1
1
1
1
1
1
1
1
1
1
1

Statistics based on data from WNAS surveys and 1 SCHC survey.
PM_DELTA

\section{Degree}

Most ly Associate Most ly Assoc iate HS or less

Most ly Associate Mostly Associate Most ly Associate Most ly Associate Mostly Associate

HS or less

HS or less

HS or less

Mostly Associate

Mostly Associate Mostly Associate HS or less

Mostly Associate Most ly Associate

Most ly Associate HS or less HS or less Mostly Associate Most ly Associate Mostly Associate HS or less Most ly Associate Mostly Associate Mostly Associate HS or less Most ly Associate Mostly Associate HS or less

HS or less Most ly Associate

HS or less HS or less HS or less Most ly Associate HS or less Most ly Associate HS or less

HS or less Most ly Associate HS or less Most ly Associate HS or less HS or less HS or less HS or less HS or less HS or less Most ly Associate Most ly Associate HS or less 

TABLE T.8. Job Titles Sorted By Human Resource Personnel's Ratings
of Current Ability to Recruit (HR_Rec_C)

Jab ritle
Health Physicist
Chemist
Environ Engineer
Nuclear Engineer
Chemical Engineer
Statistician
WasteMan Engineer
Project Manager
Hphysics Tech
Ind Hygienist
Technical Writer
Ecologist
Environ Scientist
Civil Engineer
Materials Engineer
Physicist
Safety Eng ineer
Structural Engineer
Biochemist
Seismologist
Geologist
Hydrol_Hydrogeologist
Mechanical Engineer
Rad Protect Spec
Biologist
Chem Tech
Chemical Eng Tech
Computer Engineer
HazWasteMan Spec
Materials Scient ist
Remediation Specialist
Trainer
Electric tronic Engineer
Acmin_Clerical
Computer Oper
Drafter
Electri_tronic Tech
Industrial Engineer
Material Handler
Mathematician
Mech Eng in Tech
MucWaste Process Oper
Opers Researcher
Risk Assess Marlager
Civil Eng Tech
Oriller
Environ Sciences Tech
Estimator
Ind Safety_Health Tech
Irrigation Engineer
Nuclear Decon Engineer
Petrol_Min ing Eng ineer
Survey_Map Tech

\begin{tabular}{|c|c|c|c|}
\hline HR_REC_C & PH_DELTA & & Degree \\
\hline 5 & . & & Mostly Associate \\
\hline 4 & . & & Mostly Associate \\
\hline 4 & . & & Mostly Associate \\
\hline 4 & . & & Most ly Associate \\
\hline 4 & . & & Mostly Associate \\
\hline 4 & . & " & Most ly Associate \\
\hline 4 & . & & Most ly Associate \\
\hline 3 & . & & HS or less \\
\hline 3 & . & & HS or less \\
\hline 3 & . & & HS or less \\
\hline 3 & . & & HS or less \\
\hline 3 & . & & Mostly Associate \\
\hline 3 & . & & Mostly Associate \\
\hline 3 & . & & Mostly Associate \\
\hline 3 & . & & Mastly Associate \\
\hline 3 & . & & Most ly Associate \\
\hline 3 & . & & Most ly Associate \\
\hline 3 & . & & Mostly Associate \\
\hline 3 & . & & Mostly Associate \\
\hline 3 & . & & Mostly Associate \\
\hline 2 & . & & Most ly Associate \\
\hline 2 & . & & Mostly Associate \\
\hline 2 & . & & Most ly Associate \\
\hline 2 & . & & HS or less \\
\hline 2 & . & & Mostly Associate \\
\hline 2 & . & - & HS or less \\
\hline 2 & . & & HS or less \\
\hline 2 & . & & Most ly Associate \\
\hline 2 & . & & HS or less \\
\hline 2 & . & & Mostly Associate \\
\hline 2 & . & & HS or less \\
\hline 2 & . & & HS or less \\
\hline 1 & . & & Mostly Associate \\
\hline 1 & ; & & HS or less \\
\hline 1 & . & & HS or less \\
\hline$i$ & . & & HS or less \\
\hline 1 & . & & HS or less \\
\hline 1 & . & & Most ly Associate \\
\hline 1 & . & & HS or less \\
\hline$i$ & . & & Mostly Associate \\
\hline 1 & . & & HS or less \\
\hline 1 & . & & HS or less \\
\hline 1 & . & & Mostly Associate \\
\hline 1 & . & & HS or less \\
\hline . & . & & HS or less \\
\hline . & . & & HS or less \\
\hline . & . & & HS or less \\
\hline . & . & & HS or less \\
\hline$\cdot$ & . & & HS or less \\
\hline . & . & & HS or less \\
\hline . & . & & Mostly Associate \\
\hline . & . & & Mostly Associate \\
\hline . & . & & HS or less \\
\hline
\end{tabular}

Statistics based on data from WNAS surveys and 1 SCHC survey. 
TABLE T.9. Job Titles Sorted By Human Resource Personnel's Ratings of Anticipated Ability to Recruit (HR_Rec_A)

Job Title
Health Physicist
Chemist
Environ Engineer
Nuclear Engineer
Chemical Engineer
Statistician
WasteMan Engineer
Project Manager
Technical Writer
Ecologist
Environ Scientist
Materiais Engineer
Physicist
Safety Engineer
Structural Engineer
Biochemist
Seismologist
Computer Engineer
H_physics Tech
Ind Hygienist
Civil Engineer
Geologist
HydrolHydrogeologist
Mechanical Engineer
Rad Protect Spec
Biologist
Chem Tech
Chemical Eng Tech
HazWasteMan Spec
Materlals Scient ist
Remediation Specialist
Trainer
Electric tronic Engineer
Adnin_Clerical
Computer Oper
Drafter
Electri_tronic Tech
Industrial Engineer
Material Handler
Mathematician
Mech Engin Tech
NucWaste Process Oper
Opers Researcher
Risk Assess Manager
Civil Eng Tech
Oriller
Environ Sciences Tech
Estimator
Ind Safety_Health Tech
Irrigat Ion Engineer
Nuclear Decon Engineer
PetrolMining Engineer
Survey_Map Tech

HR_REC_A PM_DELTA

4

Engineer

WasteMan Eng ineer

Project Manager

Technical Writer

Environ Scientist

Materiais Engineer

Structural Engineer

Computer Engineer

H_physics Tech

Geologist

ydrol Hydrogeologist

Biologist

Remediation Specialist

Trainer

Adinin Clerica

Electri tronic Tech

Industrial Engineer

Material Hand ler

NucWaste Process Oper

Opers Researcher

Risk Assess Manager

Civil Eng Tech

Estimator

Ind Safety_Health Tech

Statistics based on data from 0 WNAS surveys and 1 SCHC survey.

\section{Degree}

Mostly Associate Most ly Associate Mostly Associate Most Ty Associate Mostly Associate Mostly Assoctate Mostly Associate HS or less

HS or less Mostly Associate Mostly Associate Mostly Associate Mostly Associate Most ly Associate Most ly Associate Mostly Associate Most ly Associate Most ly Associate HS or less

HS or less Most ly. Associate Most ly Associate Mostly Associate Mostly Associate HS or less Most ly Associate HS or less

HS or less HS or less Mostly Associate

HS or less HS or less

Mostly Associate HS or less

HS or less HS or less

HS or less Most ly Associate HS or less Mostly Associate HS or less

HS or less Mostly Associate HS or less HS or less HS or less HS or less HS or less HS or less HS or less Mostly Associate Mostly Associate HS or less 


\title{
TABLE T.10. Job Titles Sorted By Human Resource Personnel's Ratings
} of Annual Turnover (HR_Turn)

\author{
Job Title \\ Hea 1th Physicist \\ Chemist \\ Environ Engineer \\ Chemical Eng ineer \\ Statistician \\ Project Manager \\ Physicist \\ WasteMan Eng ineer \\ Technical Writer \\ Ecologist \\ Environ Scientist \\ Safety Engineer \\ Structural Engineer \\ Computer Eng ineer \\ Geologist \\ Hydrol Hydrogeo log ist \\ Mechanical Engirieer \\ Biologist \\ Materials Scient ist \\ Trainer \\ Materials Engineer \\ Blochemist \\ Seismologist \\ $H$ physics Tech \\ Ind Hyg ien ist \\ Civil Engineer \\ Rad Protect Spec \\ Chem Tech \\ Chemical Eng Tech \\ HazWasteMan Spec \\ Remediation Specialist \\ Electric tronic Engineer \\ Aumin Clerical \\ Computer Oper \\ Drafter \\ Electri_tronic Tech \\ Industrial Engineer \\ Material Handler \\ Mathemat ic ian \\ Mech Eng in Tech \\ NucWaste Process Oper \\ Opers Researcher \\ Risk Assess Manager \\ Nuc lear Eng ineer \\ Civil Eng Tech \\ Driller \\ Environ Sciences Tech \\ Estimator \\ Ind Safety_Heaith Tech \\ Irrigation Engineer \\ Nuclear Decon Engineer \\ Petrol Mining Engineer \\ Survey_Map Tech
}

HR_TURN

PM_DELTA

Degree

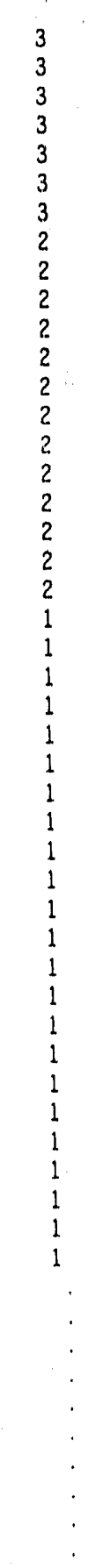

Most ly Associate Most ly Associate

Most ly Associate

Most ly Associate

Most ly Associate

HS or less

Most ly Associate

Most ly Associate

HS or less

Most ly Associate

Most ly Associace

Mostly Associate

Most ly Associate

Most ly Assoc late

Mostly Assoclate

Most ly Assoc late

Most ly Associate

Most ly Associate

Most ly Associate

HS or less

Most ly Associate

Most ly Associate

Most ly Associate

HS or less

HS or less

Most ly Associate

HS or less

HS or less

HS or less

HS or less

HS or less

Mostly Associate

HS or less

HS or less

HS or less

HS or less

Most ly Associate

HS or less

Most ly Associate

HS or less

HS or less

Mostly Associate

HS or less

Mostly Associate

HS or less

HS or less

HS or less

HS or less

HS or less

HS or less

Mostly Associate

Most ly Associate

HS or less

Statistics based on data from 6 WNAS surveys and 1 SCHC survey. 
APPENDIX U

SIMPLE STATISTICS INTERCORRELATION AMONG

VARIABLES AND JOB SORTS ON ALL VARIABLES

FOR UMTRA ONLY 
TABLE U.1. Descriptive Statistics for Relative Ratings

\begin{tabular}{llcccc} 
Variable & $\underline{N}$ & $\frac{\text { Minimum }}{1.00}$ & $\frac{\text { Maximum }}{5.00}$ & $\frac{\text { Mean }}{2.87}$ & $\underline{\text { S.D. }}$ \\
\hline HR_DIFF & 26 & 1.00 & 4.00 & 2.48 & 0.78 \\
HR_NEED & 26 & 1.00 & 5.00 & 3.79 & 0.78 \\
HR_REC_C & 26 & 2.00 & 5.00 & 4.06 & 0.73 \\
HR_REC_A & 26 & 2.50 & 4.00 & 2.46 & 0.90 \\
HR_TURN & 25 & 1.00 & 4.00 & 2.40 & 0.88 \\
PM_DIFF & 27 & 1.00 & 5.00 & 3.48 & 0.89 \\
PM_REC_A & 27 & 1.00 & 5.00 & 4.07 & 0.87 \\
PM_EDUC & 27 & 1.33 & & &
\end{tabular}

S.D. = Standard Deviation, HR_DIFF = Difficulty Caused by a Shortage, HR NEED = Need for Additional Employees, HR-REC_A = Anticipated Ease of Recruitment, HR-REC-C = Current Ease of Recruitment, HR TURN = Current Annual Turnover, PM DIFF = Difficulty Caused By a Shortage, PM_REC $A=$ Anticipated Ability to Recruit, PMEDUC = Typical Degree Level, $* * \overline{\mathrm{p}}<\overline{0} .01 ; * \mathrm{p}<0.05$. Statistics based on data from 3 WNAS surveys and 3 SCHC surveys. 


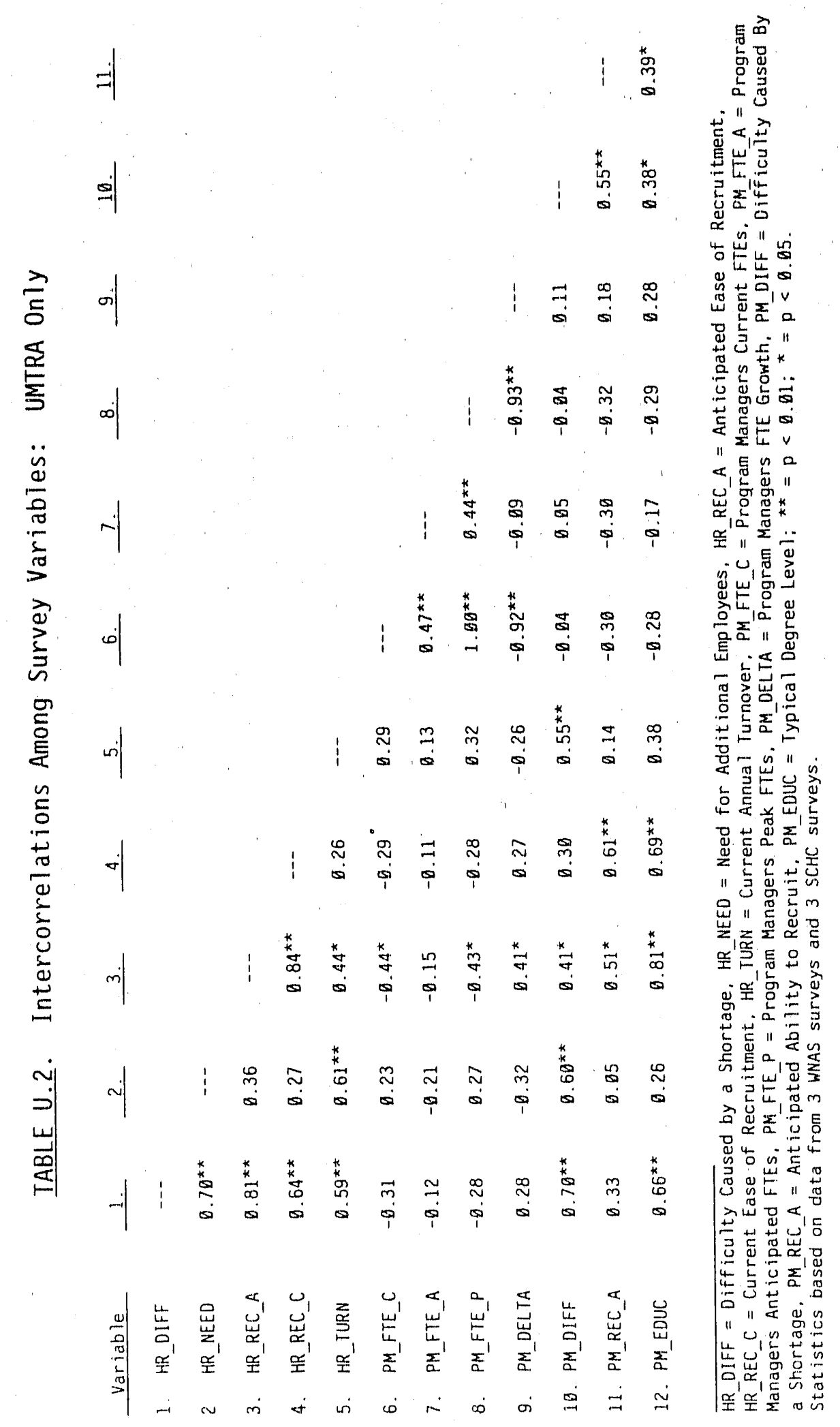




\section{TABLE U.3. Job Titles Sorted By Change in FTES (PM_Delta)}

\begin{tabular}{|c|c|c|c|c|}
\hline Job Title & PM_FTE_C & PM_FTE_A & PM_FTE_P & PM_DELTA \\
\hline Environ Engineer & 1 & 4 & 5 & 3 \\
\hline Environ Sc ient ist & 8 & 11 & 11 & 3 \\
\hline Chemical Engineer & 2 & 4 & 5 & 2 \\
\hline Estimator & 23 & 25 & 27 & 2 \\
\hline Remediation Specialtst & 8 & 10 & 10 & 2 \\
\hline WasteMan Engineer & $\emptyset$ & 2 & 2 & 2 \\
\hline Health Physioist & 8 & 9 & 10 & 1 \\
\hline other Administrator & 2 & 3 & 4 & 1 \\
\hline Project Manager & 9 & 10 & 11 & 1 \\
\hline Risk Assess Manager & 1 & 2 & 2 & 1 \\
\hline Safety Eng ineer & 2 & 3 & 3 & 1 \\
\hline Technical Writer & 2 & 3 & 4 & 1 \\
\hline Biochemist & $\theta$ & $\theta$ & $\theta$ & $\theta$ \\
\hline Btologist & $\theta$ & $\theta$ & $\theta$ & $\theta$ \\
\hline Chem Tech & $\emptyset$ & $\theta$ & $\theta$ & $\theta$ \\
\hline Chemical Eng Tech & $\theta$ & 0 & $\emptyset$ & $\theta$ \\
\hline Chemist & 2 & 2 & 3 & $\theta$ \\
\hline Civil Eng Tech & $\theta$ & $\theta$ & $\theta$ & $\emptyset$. \\
\hline Oriller & $\theta$ & $\theta$ & $\theta$ & $\theta$ \\
\hline Ecologist & $\theta$ & $\theta$ & $\theta$ & $\theta$ \\
\hline Electri_tronic Tech & $\theta$ & $\theta$ & $\theta$ & $\emptyset$ \\
\hline Electric_trontc Engineer & $\theta$ & 8 & $\emptyset$ & $\theta$ \\
\hline HazWasteMan Spec & 3 & 3 & 7 & $\theta$ \\
\hline Ind Hyg ien ist & 2 & 2 & 2 & $\theta$ \\
\hline Industrial Eng ineer & $\theta$ & $\theta$ & $\theta$ & $\theta$ \\
\hline Material Handler & $\theta$ & $\theta$ & $\theta$ & $\theta$ \\
\hline Materials Scientist & $\theta$ & $\theta$ & $\theta$ & $\theta$ \\
\hline Mathematician. & $\theta$ & $\theta$ & $\emptyset$ & $\theta$ \\
\hline Mecharical Engineer & $\theta$ & $\theta$ & $\theta$ & $\emptyset$ \\
\hline NucWaste Process Oper & $\theta$ & $\theta$ & $\theta$ & $\theta$ \\
\hline Nuc lear Decon Eng ineer & $\theta$ & $\theta$ & $\theta$ & $\theta$ \\
\hline Nuc lear Eng ineer & $\theta$ & $\theta$ & $\emptyset$ & $\theta$ \\
\hline Opers Researcher & $\theta$ & $\theta$ & $\emptyset$ & $\emptyset$ \\
\hline Other Eng ineer & $\theta$ & 9 & $\emptyset$ & $\theta$ \\
\hline Other Scient ist & $\theta$ & $\theta$ & $\emptyset$ & $\theta$ \\
\hline Other Technician & $\eta$ & 0 & $\theta$ & $\theta$ \\
\hline Petrol_Mining Eng ineer & $\theta$ & $\theta$ & $\theta$ & $\emptyset$ \\
\hline Physicist & $\theta$ & $\theta$ & $\theta$ & $\theta$ \\
\hline Se i smo log ist & $\theta$ & $\theta$ & $\emptyset$ & $\emptyset$ \\
\hline Statistician & $\theta$ & $\theta$ & $\theta$ & $\theta$ \\
\hline Structural Engineer & $\emptyset$ & $\emptyset$ & $\theta$ & $\theta$ \\
\hline Survey_Map Tech & $\theta$ & $\theta$ & $\theta$ & $\theta$ \\
\hline Trainer & $\theta$ & $\theta$ & $\theta$ & $\theta$ \\
\hline Computer Engineer & 1 & $\theta$ & 1 & -1 \\
\hline Computer Oper & 8 & 7 & 9 & -1 \\
\hline Drafter & 3 & 2 & 3 & -1 \\
\hline Irrigation Engineer & 1 & $\theta$ & 1 & -1 \\
\hline Materials Engineer & 1 & $\theta$ & 1 & -1 \\
\hline Mech Eng in Tech & 1 & $\emptyset$ & 1 & -1 \\
\hline Rad Protect Spec & 2 & 1 & 2 & -1 \\
\hline Geologist & 4 & 1 & 4 & -3 \\
\hline Hydrol_Hydrogeologist & 14 & 11 & 16 & -3 \\
\hline Ind Safety_Health Tech & 3 & $\theta$ & 5 & -3 \\
\hline Environ Sciences Tech & 6 & $\theta$ & 10 & -6 \\
\hline Admin_Clerical & 32 & 17 & 42. & -15 \\
\hline Civil"Engineer & 46 & 15 & 57 & -31 \\
\hline H physics Tech & 78 & $\theta$ & 107 & -78 \\
\hline
\end{tabular}

Degree

Mix of BS and Advanced Mix of BS and Advanced $M i x$ of $B S$ and Advanced $M i x$ of $A S$ and $B S$ Most ly Advanced Mix of $B S$ and Advanced Mix of $B S$ and Advanced HS or less Most ly Advanced Mostly Advanced Mix of BS and Advanced Most ly Bachelor Most ly Associate Mostly Associate HS or less HS or less Mostly PhD HS or less HS or less Mostly Assoctate HS or less Mostly Associate Mostly Bachelor Mostly Advanced Most ly Associate HS or less Mostly Associate Most ly Associate Mostiy Associate HS or less Mostly Associate Mostly Associate Mostly Associate Most ly Associate Mostly Associate HS or less

Mostly Associate Mostly Associate Mostly Associate Most ly Associate Mostly Associate HS or less

HS or less

Mix of BS and Advanced Most ly Bachelor Mix of AS and BS Most ly Bachelor Mix of BS and Advanced Mostly Associate Most ly Bachelor Mix of BS and Advanced Mix of 85 and Advanced Mix of AS and BS Most ly Bachelor HS or less Mix of BS and Advanced HS or less

Statistics based on data from 3 WNAS surveys and 3 SCHC surveys. 


\section{TABLE U.4. Titles Sorted by Project Manager's Ratings of Anticipated Ability to Recruit (PM_Rec_A)}

\author{
Job Title \\ Remediation Specialist \\ Risk Assess Manager \\ Ind Hyglen ist \\ HazWasteMan Spec \\ Chemist \\ Environ Sciences Tech \\ Mech Eng in Tech \\ Geologist \\ Computer Eng ineer \\ Irrigation Engineer \\ Materials Engineer \\ Technical Writer \\ Estimator \\ Rad Protect Spec \\ Computer Oper \\ Drafter \\ Environ Scient ist \\ WasteMan Engineer \\ Project Manager \\ Ctvil Engineer \\ Environ Engineer \\ Health Physicist \\ Safety Engineer \\ Hydro 1_Hydrageo log ist \\ Ind Safety_Health Tech \\ Admin Clerical \\ Chemical Engineer \\ Biochemist \\ Biologist \\ Chem Tech \\ Chemical Eng Tech \\ Civil Eng Tech \\ Driller \\ Ecologist \\ Electri tronic Tech \\ Electric tronic Engineer \\ Industrial Engineer \\ Material Handler \\ Materials Scientist \\ Mathematician \\ Mechanical Engineer \\ NucWaste Process Oper \\ Nuc lear Decon Engineer \\ Nuc lear Engineer \\ Opers Researcher \\ Petrol Mining Engineer \\ Physicist \\ Seismologist \\ Statistician \\ Structural Engineer \\ Survey Map Tech \\ Trainer \\ H physics Tech
}

\section{PM_REC_A}

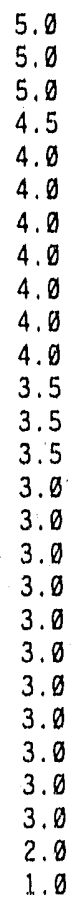

5.0

5.9

4.5

4.0

4.8

4.

4.0

4.0

4.0

3.5

3.5

9

0

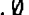

.0

9

3.9

3.0

3.0

2.8

1.0

\section{PM_DELTA}

2

1

$\emptyset$

0

$-6$

$-1$

$-3$

$-1$

$-1$

$-1$

1

2

$-1$

$-1$

$-1$

2

1

$-31$

3

1

1
-3
-3

$-3$

$-15$

2

0

0

$\theta$

$\theta$

$\theta$

0

$\theta$

0

g

$\emptyset$

$\theta$

9

0

$\theta$

$\theta$

0

$\theta$

$\theta$

$\theta$

0
-78

\section{Degree}

Most ly Advanced Most ly Advanced Most ly Advanced Most ly Bachelor Mostly PhD Most ly Bache lor Most ly Assoclate MiX of BS and Advanced Mix of BS and Advanced Mostly Bachelor Mix of BS and Advanced Mostly Bachelor Mix of AS and BS Most ly Bachelor Mostly Bachelor $M i x$ of $A S$ and $B S$ Mix of BS and Advanced Mix of BS and Advanced Most ly Advanced

Mix of BS and Advanced Mix of BS and Advanced Mix of BS and Advanced Mix of BS and Advanced Mix of BS and Advanced Mix of AS and BS HS or less

Mix of $B S$ and Advanced Mostly Associate Mostly Associate HS or less HS or less HS or less $\mathrm{HS}$ or less Mostly Associate HS or less Mostly Associate Mostly Associate HS or less Mostly Associate Mostly Associate Most ly Associate HS or less

Most ly Associate Most ly Associate Most ly Associate Most ly Associate Mostly Associate Mostly Associate Mostly Associate Most ly Associate HS or less

HS or less HS or less

Statistics based on data from 3 WNAS surveys and 3 SCHC surveys. 


\section{TABLE U.5. Titles Sorted By Project Manager's Ratings of Difficulty Caused by Shortage. (PM_Diff)}

Job Tit le

Remediation Specialist

Risk Assess Manager

Ind Hygien ist

HazWasteMan Spec

Technical Writer

Chemist

Computer Oper

Drafter

Environ Sciences Tech

Environ Scient ist

Estimator

WasteMan Engineer

Rad Protect Spec

Project Manager

Civil Engineer

Environ Engineer

Health Physicist

Safety Engineer

Mech Eng in Tech

Geologist

Hydrol Hydrogeo log ist

Ind Safety_Health Tech

Adm in_Cierica?

Chemical Engineer

Computer Eng ineer

Irrigation Engineer

Materials Engineer

Biochemist

Biologist

Chem Tech

Chemical Eng Tech

Civil Eng Tech

Driller

Ecologist

Electritronic Tech

Electric tronic Engineer

Industriāl Eng ineer

Material Handler

Materials Scientist

Ma thematician

Mechanica? Eng ineer

Nuchaste Process Oper

Nuclear Decon Engineer

Nuc lear Eng ineer

Opers Researcher

Petrol Mining Engineer

Physicist

Seismologist

Statistician

Structural Engineer

Survey Map Tech

Trainer

H physics Tech
PH_OIFF

4.00

4.00

4.80

3.50

3.00

3.00

3.00

3.00

3.00

2.58

2.58

2.50

2.50

2.33

2.33

2.90

2.00

2.00

2.00

2.017

2.80

2.00

1.67

1.00

1.00

1.88

1.00
PH_DELTA

2

1

0

D

1

$-1$

$-1$

$-6$

3

2

2

2
-1

1

$-31$

3

1

-1
-3

$-3$

-3
-3

$-15$

2

$-1$

$-1$

$-1$

a

0

0

$\theta$

0

0

0

$\theta$

$\theta$

0

0

0

$\theta$

$\theta$

0

9

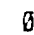

a

0

b

$-78$

\section{Degree}

Most ly Advanced Mostly Advanced Most ly Advanced Most ly Bachelor Most ly Bachelor Most ly PhD

Most iy Bachelor

Mix of AS and BS

Most ly Bachelor

Mix of BS and Advanced

Mix of AS and BS

Mix of $B S$ and Advanced Most ly Bachelor Most ly Advanced

Mix of $B S$ and Advanced Mix of BS and Advanced Mix of BS and Advanced $M i x$ of $B S$ and Advanced Most ly Asseciate

Mix of $B S$ and Advanced Mix of BS and Advanced Mix of AS and BS HS or less

Mix of $B S$ and Advarced Mix of BS and Advanced Most ly Bachelor

Mix of $B S$ and Advanced Most ly Associate Mostly Associate HS or less HS or less HS or less HS or less Mostly Associate HS or less Mostly Associate Most ly Associate HS or less

Most ly Associate Most ly Associate Most ly Associate HS or less Mostly Associate Mostly Associate Mostly Associate Most ly Associate Most ly Associate Mostly Rssociate Mostly Associate Most ly Associate

HS or less

HS or less

HS or less

Statistics based on data from 3 WNAS surveys and 3 SCHC surveys. 


\section{TABLE U.6. Job Titles Sorted By Human Resource Personnel's Ratings of Difficulty Caused By Shortage (HR_Diff)}

\author{
Job Title \\ Remediation Specialist \\ WasteMan Eng ineer \\ Risk Assess Manager \\ Ind Hygien ist \\ HazWasteilan Spec \\ Environ Scient ist \\ Environ Engineer \\ Nuc lear Eng ineer \\ Chemist \\ Environ Sciences Tech \\ Technical Writer \\ Rad Protect Spec \\ Computer Oper \\ Project Manager \\ Health Physicist \\ Civil Engineer \\ Hydrol Hydrogeolog ist \\ Geologist \\ Computer Eng ineer \\ Drafter \\ Ind Safety_Health Tech \\ $H$ pinysics Tech \\ Est imator \\ Irrigation Engineer \\ Materials Engineer \\ Adm in Clerical \\ Mech Ëng in Tech \\ Safety Eng ineer \\ Chemical Engineer \\ 8 iochemist. \\ Biolog ist \\ Chem Tech \\ Chemical Eng Tech \\ Civil Eng Tech \\ Driller \\ Ecologist \\ Electri tronic Tech \\ Electric tronic Engineer \\ Industriäl Engineer \\ Material idandler \\ Materials Scientist \\ Mathematician \\ Mechanical Engineer \\ NucWaste Process Oper \\ Nuclear Decon Eng ineer \\ Opers Researcher \\ Petrol Mining Engineer \\ Physicist \\ Se ismologist \\ Statistician \\ Structural Engineer \\ Survey Map Tech \\ Trainer
}

Statistics based on data from 3 wWAS surveys and 3 SCHC surveys
IR_DIFF

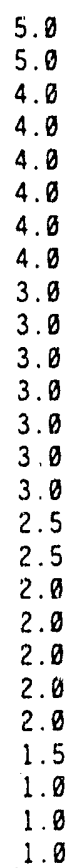

PM_DELTA

2
2
1
0
0
3
3
0
0
-6
1
-1
-1
1
1
-31
-3
-3
-1
-1
-3
-78
2
-1
-1
-15

$-15$

$-1$

1

0

0

b

8

0

a

0

$\theta$

0

0

o

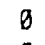

$\theta$

0

a

0

$\theta$

0

0

\section{Degree}

Mostly Advanced

Mix of BS and Advanced

Most ly Advanced

Most ly Advanced

Most ly Bachelor

Mix of BS and Advanced

$M i x$ of $B S$ and Advanced

Most ly Associate

Most ly Pho

Most ly Bache lor

Most ly Bachelor

Most. ly Bache lor

Most ly Bachelor

Mostly Advanced

Mix of $B S$ and Advanced

Mix of BS and Advanced

Mix of BS and Advanced

Mix of BS and Advanced

Mix of $B S$ and Advanced

Mix of $A S$ and $B S$

Mix of AS and BS

HS or less

Mix of AS and BS

Most ly Bache lor

Mix of BS and Advanced

HS or less

Mostly Associate

Mix of $B S$ and Advanced

Mix of BS and Advanced

Mostly Assoc iate

Mostly Associate

HS or less

HS or less

HS or less

HS or less

Mostly Associate

HS or less

Most ly Associate

Most ly Associate HS or iess

Most ly Associate Most ly Associate Most ly Associate HS or less

Most ly Associate Most ly Associate Mostly Associate Mostly Associate Most ly Associate Most ly Associate Most ly Associate HS or less HS or less 
TABLE U.7. Job Titles Sorted By Human Resource Personnel's Ratings of
Need for Additional Employees (HR_Need)

Job Title

WasteMan Engineer

H_physics Tech

Remediation Specialist

$R$ isk Assess Manager

Ind Hygien ist

HazWasteMan Spec

Environ Scient ist

Environ Engineer

Nuc lear Eng ineer

Environ Sciences Tech

Computer Oper

Ind Safety Health Tech

Technical Writer

Rad Protect. Spec

Civil Engineer

Chemist

Project Manager

Health Physicist

Hydrol_Hydrogeologist

Computer Eng ineer

Drafter

Admin Clerical

Geologist

Estimator

Irrigation Engineer

Materials Engineer

Mech Eng in Tech

Safety Eng ineer

Chemical Engineer

$B$ iochemist

Biologist

Chem Tech

Chemical Eng Tech

Civil Eng Tech

Driller

Ecologist

Electri tronic Tech

Electric tronic Engineer

Industrial Engineer

Material Handier

Materials Scient ist

Mathematician

Mechanical Engineer

NucWaste Process Oper

Nuclear Decon Engineer

Opers Researcher

Petrol Mining Engineer

Physicist

Se ismo logist

Statistician

Structural Eng ineer

Survey Map Tech

Trainer

\begin{tabular}{|c|c|}
\hline$H R$ NEED & PM_DE \\
\hline 4.0 & 2 \\
\hline 4.0 & -78 \\
\hline 3.0 & 2 \\
\hline 3.0 & 1 \\
\hline 3.0 & $\theta$ \\
\hline 3.0 & $\theta$ \\
\hline 3.0 & 3 \\
\hline 3.8 & 3 \\
\hline 3.0 & 0 \\
\hline 3.0 & -6 \\
\hline 3.0 & -1 \\
\hline 3.0 & -3 \\
\hline 2.5 & 1 \\
\hline 2.5 & -1 \\
\hline 2.5 & -31 \\
\hline 2.0 & $\theta$ \\
\hline 2.0 & 1 \\
\hline 2.0 & 1 \\
\hline 2.0 & -3 \\
\hline 2.0 & -1 \\
\hline 2.0 & -1 \\
\hline 2.0 & -15 \\
\hline 1.5 & -3 \\
\hline 1.5 & 2 \\
\hline 1.0 & -1 \\
\hline 1.0 & -1 \\
\hline$\cdot$ & -1 \\
\hline . & 1 \\
\hline . & 2 \\
\hline$\cdot$ & $\theta$ \\
\hline$\cdot$ & $\theta$ \\
\hline$\cdot$ & $\begin{array}{l}\theta \\
0\end{array}$ \\
\hline . & $\theta$ \\
\hline . & 0 \\
\hline . & $\theta$ \\
\hline . & $\emptyset$ \\
\hline . & $\theta$ \\
\hline . & 0 \\
\hline . & $\theta$ \\
\hline . & $\theta$ \\
\hline . & 9 \\
\hline · & $\theta$ \\
\hline . & $\theta$ \\
\hline . & 0 \\
\hline . & $\theta$ \\
\hline . & $\theta$ \\
\hline & 0 \\
\hline · & 0 \\
\hline . & 0 \\
\hline 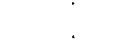 & 8 \\
\hline
\end{tabular}

Statistics based on data from 3 WINAS surveys and 3 SCHC surveys.

\section{Degree}

Mix of BS and Advanced

HS or less

Most ly Advanced

Most ly Advanced

Most ly Advanced

Most ly Bache lor

Mix of BS and Advanced

Mix of $B S$ and Advanced

Most ly Associate

Most ly Bache ior

Mostly Bachelor

Mix of $A S$ and $B S$

Most ly Bache lor

Most ly Bachelor

Mix of BS and Advanced

Most ly PhD

Most ly Advanced

Mix of $B S$ and Advanced

Mix of BS and Advanced

Mix of $B S$ and Advanced

Mix of AS and BS

HS or less

Mix of BS and Advanced

Mix of AS and BS

Most ly Bachelor

Mix of $B S$ and Advanced Mostly Associate

Mix of BS and Advanced Mix of BS and Advanced Mostly Associate Most ly Associate

HS or less

HS or less

HS or less

HS or less

Most ly Associate

HS or less

Mostly Associate

Mostly Associate

HS or less

Most ly Associate

Most ly Associate

Most iy Associate

HS or less

Mostly Associate

Most ly Associate

Mostly Associate

Most iy Associate

Most ly Associate

Mostly Associate

Most ly Associate

HS or less

HS or less 
TABLE U.8. Job Titles Sorted By Human Resource Personnel's Ratings
of Current Ability to Recruit (HR_Rec_C)

Job Tit le

WasteMan Eng ineer
Remediation Specialist
Risk Assess Manager
Ind Hygien ist
HazWasteMan Spec
Environ Scient ist
Environ Engineer
Nuclear Ergineer
Environ Sciences. Tech
Rad Protect Spec
Civil Engineer
Project Manager
Health Physicist
Computer Engineer
Irrigation Engineer
Materials Engineer
Hydrol_Hydrogeologist
Geologist
Estimator
H_physics Tech
Computer Oper
Ind Safety Health Tech
Technical Writer
Chernist
Admin_Clerical
Drafter
Mech Engin Tech
Safety Engineer
Chemical Engineer
Biochemist
Biologist
Chem Tech
Chemical Eng Tech
Civil Eng Tech
Oriller
Ecologist
Electri_tronic Tech
Electric tronic Engineer
Industrial Engineer
Material Handler
Materials Scientist
Mathematician
Mechanical Engineer
Nucwaste Process Oper
Nuclear Decon Engineer
Opers Researcher
Petrol Mining Engineer
Physicist
Seismologist
Statist ician
Structural Engineer
Survey_Map Tech
Trainer

\section{HR_REC_C}

5.0
5.0
5.0
5.0
4.5
4.0
4.0
4.0
4.0
4.0
4.0
4.0
4.0
4.0
4.0
4.0
3.5
3.5
3.5
3.0
3.0
3.0
3.0
3.0
2.5
2.0

PM_DEL.TA

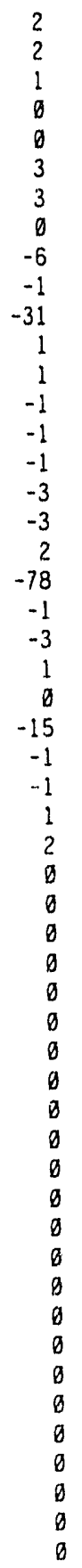

Degree

Mix of BS and Advanced Mostly Advanced Mostly Advanced Most ly Advanced Most ly Bachelor Mix of BS and Advanced Mix of $B S$ and Advanced Mostly Associate Mostly Bache lor Mostly Bachelor Mix of BS and Advanced Mostly Advanced Mix of $B S$ and Advanced Mix of $B S$ and Advanced Mostly Bachelor

Mix of BS and Advanced $M i x$ of $B S$ and Advanced Mix of $B S$ and Advanced Mix of AS and BS HS or less Mostly Bachelor Mix of AS and BS Mostly Bachelor Mostly Pho

HS or less Mix of AS and BS Most ly Associate Mix of BS and Advanced Mix of BS and Advanced Mostly Associate Mostly Associate HS or less HS or less HS or less HS or less Most ly Associate HS or less

Mostly Associate Most ly Associate HS or less Mostly Associate Mostly Associate Mostly Associate HS or less

Mostiy Associate Most ly Associate Mostly Associate Most ly Associate Most ly Associate Most ly Associate Most ly Associate HS or less HS or less

Statistics based on data from 3 WNAS surveys and 3 SCHC surveys. 


\section{TABLE U.9. Job Titles Sorted By Human Resource Personnel's Ratings of Anticipated Ability to Recruit (HR_Rec_A)}

\section{Jab Title}

WasteMan Eng ineer

Remediation Specialist

Risk Assess Manager

Ind Hygien ist

Environ Scient ist

Environ Engineer

Nuc lear Eng ineer

HazWasteMan Spec

Environ Scierices Tech

Rad Protect Spec

Civil Engineer

Project Manager

Health Physicist.

Computer Eng ineer

Irrigation Engineer

Materials Engineer

Hydrol_Hydrogeolog ist

Computer Oper

Chemist

Geo log ist

Est imator

Technical Writer

H_physics Tech

Ind Safety Health Tech

Drafter

Admin_clerical

Mech Eng in Tech

Safety Eng ineer

Chemical Engineer

Biochem ist

Biologist

Chem Tech

Chemical Eng Tech

Civil Eng Tech

Oriller

Ecologist

Electri_tronic Tech

Electric tronic Engineer

Industriāl Engineer

Material Handler

Materials Scientist

Mathematician

Mechanica 1 Engineer

NucWaste Process Oper

Nuc lear Decon Engineer

Opers Researcher

Petrol Mining Engineer

Physicist

Se ismologist

Statistician

Structural Engineer

Survey Map Tech

Trainer

\section{HR_REC_A}

5.0

5.0

5.0

5.0

5.8

5.8

5.0

4.5

4.0

4.0

4.0

4.0

4.0

4.0

4.0

4.0

4.9

4.0

4.0

3.5

3.5

3.5

3.0

3.0

3.0

2.5
PM_DELTTA

2

2

1

3

3

0

0

-6
-1

$-31$

1

$-1$

$-1$

$-1$

-3
-1
0

0
-3

2

1
-78

$-78$

$-3$

$-1$

$-15$

-1
1

2

0

$\theta$

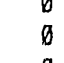

$\theta$

0

0

0

$\theta$

$\theta$

0

9

0

0

0

$\theta$

$\theta$

$\theta$

0

0
Degree

Mix of BS and Advanced Most ly Advanced

Most ly Advanced Most ly Advanced

Mix of BS and Advanced Mix of BS and Advanced Most ly Associate Most ly Bachelor Most ly Bachelor Most ly Bachelor Mix of $B S$ and Advanced Most ly Advanced Mix of BS and Advanced Mix of $B S$ and Advanced Mostly Bachelor

Mix of BS and Advanced Mix of $B S$ and Advanced Most ly Bachelor

Mostly PhD

Mix of $B S$ and Advanced

Mix of AS and BS

Most ly Bachelor

HS or less

Mix of $A S$ and $B S$

Mix of AS and BS

HS or less

Most ly Associate

Mix of BS and Advanced

Mix of $B S$ and Advanced

Most ly Associate

Mostly Associate

HS or less

HS or less

HS or less

HS or less

Most ly Associate

HS or less

Most ly Associate

Most ly Associate

HS or less

Mostly Associate

Mostly Associate

Mostily Associate

HS or less

Mostly Associate

Mostly Associate

Most ly Associate

Mostly Associate

Mostly Associate

Most ly Associate

Mostly Associate

HS or less

HS or less

Statistics based on data from 3 WNAS surveys and 3 SCHC surveys. 
TABLE U.10. Job Titles Sorted By Human Resource Personnel's Ratings of Annual Turnover (HR_Turn)

Job Title
Risk Assess Manager
Environ Scientist
Environ Engineer
H_physics Tech
WasteMan Engineer
Remediation Specialist
Ind Hygienist
Chemist
HazWasteMan Spec
Civil Engineer
Project Manager
Estimator
Technical Writer
Admin_Clerical
Environ Sciences Tech
Rad Protect Spec
Health Physicist
Computer Engineer
Computer Oper
Geologist
Drafter
Hydrol_Hydrogeologist
Irrigation Engineer
Materials Engineer
Ind Safety_Health Tech
Nuclear Engineer
Mech Engin Tech
Safety Engineer
Chemical Engineer
Biochemist
Biologist.
Chem Tech
Chemical Eng Tech
Civil Eng Tech
Dri ller
Ecologist
Electri_tronic Tech
Electric_tronic Engineer
Industrial Engineer
Material Handler
Materials Scientist
Mathematician
Mechanical Engineer
NucWaste Process Oper
Nuclear Decon Engineer
Opers Researcher
Petrol_Mining Engineer
Physicist
Seismologist
Statistician
Structural Engineer
Survey_Map Tech
Trainer

HR_TURN

4.0

4.0

4.6

4.8

3.0

3.0

3.8

3.0

2.5

2.5

2.5

2.5

2.5

2.5

2.0

2.0

2.0

2.0

2.0

2.0

2.0

1.5

1.0

1.0

1.0
PM_DELTA

$-78$

3

3
-78

2

2

0

0

$-31$

2

1

$-15$

$-6$

$-1$

1

$-1$

$-1$

$-3$

$-1$

$-3$

$-1$

$-1$

$-3$

0

$-1$

1

0

$\theta$

$\theta$

0

0

0

0

$\theta$

0

$\theta$

0

$\theta$

0

0

$\theta$

$g$

$\theta$

$\theta$

0

\section{Degree}

Most ly Advanced

Mix of BS and Advanced

Mix of $B S$ and Advanced HS or less

Mix of BS and Advanced Most iy Advanced

Most ly Advanced

Mostly Pho

Most ly Bache lor

Mix of BS and Advanced

Most ly Advanced

Mix of AS and BS

Most ly Bache lor

HS or less

Most ly Bache lor

Most ly Bache lor

Mix of BS and Advanced

Mix of BS and Advanced Most ly Bache lor

Mix of $B S$ and Advanced Mix of AS and BS

Mix of BS and Advanced Most iy Bache lor

Mix of $B S$ and Advanced Mix of AS and BS Most ly Associate Most ly Associate Mix of BS and Advanced Mix of BS and Advanced Most ly Associate Most ly Associate HS or less

HS or less

HS or less

HS or less

Most ly Associate HS or less

Mostly Associate Most ly Associate HS or less

Most ly Associate Most ly Associate Most ly Associate HS or less

Most ly Associate Most ly Associate Most ly Associate Most ly Associate Mostly Associate Mostly Associate Most ly Associate HS or less HS or less

Statistics based on data from 3 WNAS surveys and 3 SCHC surveys. 


\section{APPENDIX V}

\section{SIMPLE STATISTICS INTERCORRELATION AMONG VARIABLES AND JOB SORTS ON ALL VARIABLES FOR WEST VALLEY ONLY}


TABLE V.1. Descriptive Statistics for Relative Ratings

\begin{tabular}{|c|c|c|c|c|c|}
\hline Variable & $\underline{N}$ & Minimum & Maximum & Mean & S.D. \\
\hline HR_DIFF & 0 & . & . & . & . \\
\hline HR_NEED & 0 & . & . & . & . \\
\hline$H R \_R E C \_C$ & 0 & . & . & . & . \\
\hline HR_REC_A & 0 & . & . & . & . \\
\hline HR_TURN & 0 & . & . & $\cdot$ & . \\
\hline PM_DIFF & 36 & 1.00 & 5.00 & 2.85 & 1.08 \\
\hline PM_REC_A & 35 & 1.00 & 5.00 & 2.90 & 1.10 \\
\hline PM EDUC & 36 & 1.00 & 4.00 & 2.72 & 0.81 \\
\hline
\end{tabular}

S.D. = Standard Deviation, HR_DIFF = Difficulty Caused by a Shortage, HR_NEED = Need for Additional-Employees, HR-REC_A = Anticipated Ease of Recruitment, HR-REC-C = Current Ease of Recruitment, HR TURN = Current Annua 1 Turnover, PMDIFF = Difficulty Caused By a Shortage, PM_REC A = Anticipated Ability to Recruit, PMEDUC = Typical Degree Level, $* * \bar{p}<\overline{0} .01 ; * p<0.05$. Statistics based on data from 2 WNAS surveys and 0 SCHC surveys. 


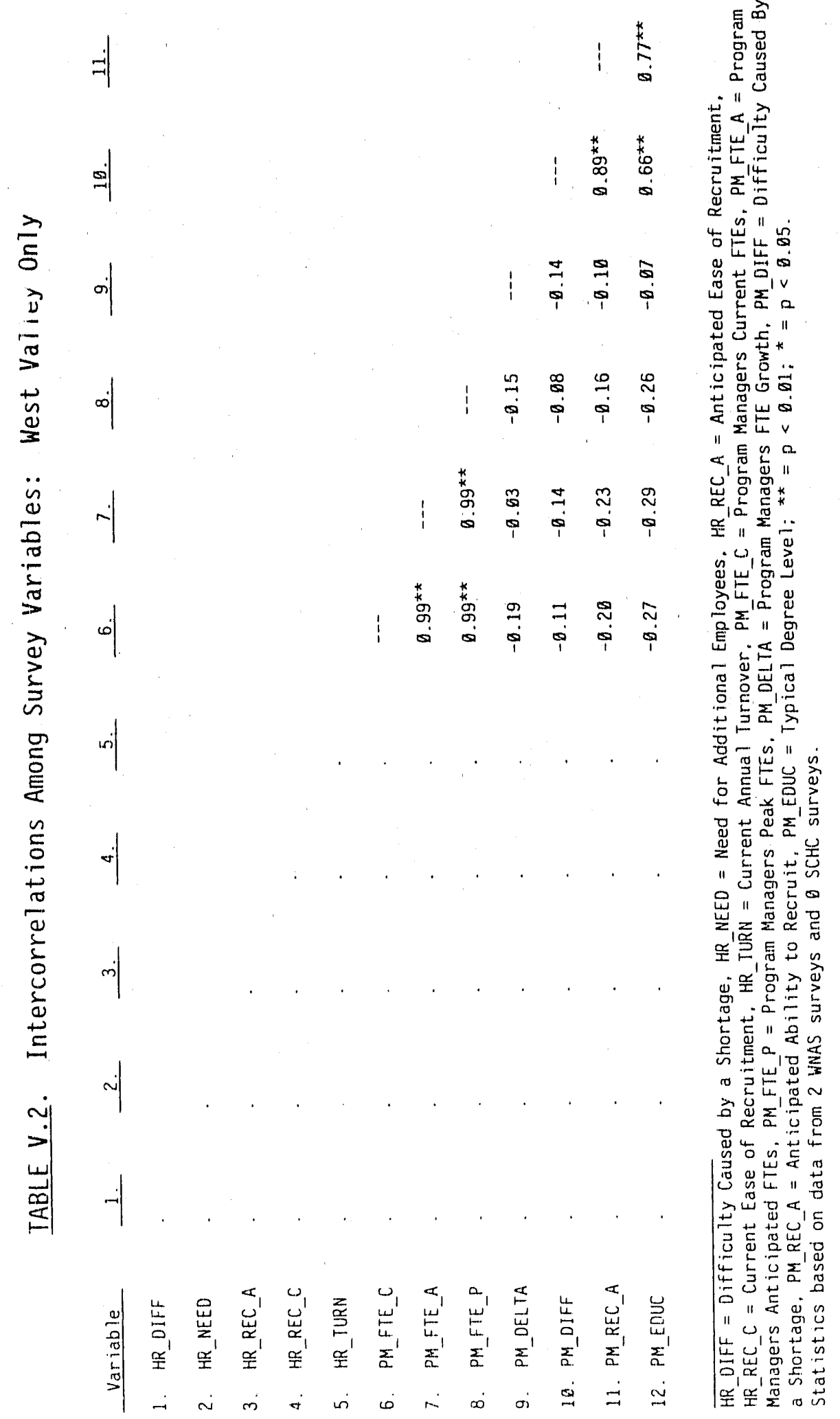




\section{TABLE V.3. Job Titles Sorted By Change in FTEs (PM_Delta)}

\begin{tabular}{|c|c|c|c|c|c|}
\hline Job Title & PM_FTE_C & PM_FTE_A & PM_FTE_P & PM_DELTA & Degree \\
\hline Chem Tech & 20 & 30 & 36 & 10 & Mostly Assoc late \\
\hline Nuc lear Eng ineer & 12 & 16 & 16 & 4 & Mix of $B S$ and Advanced \\
\hline Chemist & 11 & 14 & 14 & 3 & MIX of BS and Advanced \\
\hline Ind Hygienist & 1 & 3 & 3 & 2 & Mostly Assoc late \\
\hline Safety Eng ineer & 8 & 10 & 11 & 2 & Most ly Bache lor \\
\hline Ind Safety Health Tech & 2 & 3 & 3 & 1 & Mostly Assoctate \\
\hline WasteMan Eng ineer & 18 & 19 & 19 & 1 & Mostly Bache lor \\
\hline Adnitn_Clerical & 91 & 9.1 & 91 & $\theta$ & Mostly Associate \\
\hline Blochemist & $\theta$ & $\theta$ & $\emptyset$ & $\theta$ & Mostly Associate \\
\hline Biologist & $\theta$ & $\theta$ & $\theta$ & $\theta$ & Most ly Associate \\
\hline Chemical Eng Tech & $\theta$ & $\theta$ & $\theta$ & $\theta$ & HS or less \\
\hline Computer Engineer & 16 & 16 & 16 & $\theta$ & Most ly Bache lor \\
\hline Computer Oper & 3 & 3 & 3 & $\theta$ & Most ly Associate \\
\hline Oriller & $\theta$ & $\theta$ & $\theta$ & $\theta$ & HS or less \\
\hline Ecologist & $\theta$ & $\emptyset$ & $\theta$ & $\theta$ & Most ly Associate \\
\hline Electri_tronic Tech & 8 & 8 & 8 & $\theta$ & Most ly Assoclate \\
\hline Environ Engineer & 22 & 22 & 26 & $\theta$ & Mostly Bache lor \\
\hline Environ Sciences Tech & $\theta$ & $\theta$ & $\theta$ & $\theta$ & HS or less \\
\hline Environ Scientist & 13 & 13 & 13 & $\theta$ & Mix of BS and Advariced \\
\hline Geologist & 4 & 4 & 4 & $\theta$ & MIx of BS and Advanced \\
\hline H_physics Tech & 2 & 2 & 2 & $\emptyset$ & Mostly Associate \\
\hline HazWasteMan Spec. & 1 & 1 & 1 & $\theta$ & Mostly Assoctate \\
\hline Health Physicist & 5 & 5 & 5 & $\theta$ & Most ly Bachelor \\
\hline Hydrol_Hydrogeologist & 2 & 2 & 2 & $\theta$ & Most ly Bache lor \\
\hline Industrial Engineer & 26 & 26 & 26 & $\emptyset$ & Most ly Bache lor \\
\hline Irrigation Engineer & 0 & $\emptyset$ & $\theta$ & $\theta$ & HS or less \\
\hline Material Handler & 52 & 52 & 52 & $\theta$ & HS or less \\
\hline Materlals Engineer & 5 & 5 & 5 & $\emptyset$ & Most ly Bache lor \\
\hline Materials Scientist & $\theta$ & $\emptyset$ & $\theta$ & $\theta$ & Most ly Associate \\
\hline Mathematician & $\theta$ & $\theta$ & $\theta$ & $\theta$ & Most ly Associate \\
\hline Mech Eng in Tech & 23 & 23 & 23 & $\theta$ & Mostly Assoctate \\
\hline NucWaste Process Oper & 46 & 46 & 46 & $\theta$ & HS or less \\
\hline Nuclear Decon Engineer & 9 & 9 & 9 & $\theta$ & Most ly Bachelor \\
\hline Opers Researcher & $\theta$ & $\theta$ & 0 & $\theta$ & Mostly Associate \\
\hline Other Administrator & 85 & 85 & 85 & $\theta$ & HS or less \\
\hline Other Engineer & $\emptyset$ & $\theta$ & $\theta$ & $\theta$ & Most ly Associate \\
\hline Other Scient ist & $\dot{\theta}$ & $\theta$ & $\theta$ & $\theta$ & Mostly Associate \\
\hline Other Technician & $\theta$ & $\theta$ & $\theta$ & $\theta$ & HS or less \\
\hline Petrol_Mlning Engineer & $\theta$ & $\theta$ & $\theta$ & $\theta$ & Most ly Associate \\
\hline Physicist & $\emptyset$ & $\theta$ & $\theta$ & $\theta$ & Mostly Associate \\
\hline Project Manager & 1 & 1 & 1 & $\theta$ & Most ly Bachelor \\
\hline Rad Protect Spec & 28 & 28 & 28 & $\theta$ & Mostly Associate \\
\hline Remediation Specialist & $\theta$ & $\theta$ & $\theta$ & $\theta$ & HS or less \\
\hline Risk Assess Manager & $\emptyset$ & $\theta$ & $\theta$ & $\theta$ & HS or less \\
\hline Seismologist & $\theta$ & $\theta$ & $\theta$ & $\theta$ & Mostly Associate \\
\hline Statisticlan & $\theta$ & $\theta$ & $\theta$ & $\theta$ & Most ly Associate \\
\hline Structural Eng ineer & 4 & 4 & 4 & $\theta$ & Most ly Bachelor \\
\hline Survey_Map Tech & $\theta$ & $\theta$ & $\theta$ & $\theta$ & HS or less \\
\hline Technical Writer & 7 & 7 & 7 & $\theta$ & Mix of $A S$ and $B S$ \\
\hline Trainer & 10 & 10 & 10 & $\theta$ & Mix of AS and BS \\
\hline Civil Eng Tech & 4 & 3 & 4 & -1 & Mostly Associate \\
\hline Estimator & 26 & 22 & 26 & -4 & Mix of $A S$ and $B S$ \\
\hline Mechanical Engineer & 50 & 45 & 56 & -5 & Most ly Bachelor \\
\hline Drafter & 10 & 4 & 10 & -6 & Most ly Associate \\
\hline Electric_tronic Engineer & 38 & 32. & 38 & -6 & Most ly Bachelor \\
\hline Chemical-Engineer & 27 & 19 & 27 & -8 & Most ly Bachelor \\
\hline Civil Engineer & 25 & 10 & 30 & -15 & Most ly Bache lor \\
\hline
\end{tabular}

Statistics based on data from 2. WNAS surveys and 0 SCHC surveys. 
TABLE V.4. Titles Sorted by Project Manager's Ratings of Anticipated Ability to Recruit (PM_Rec_A)

Job Title

Nuc lear Eng tneer

Chemlst

Health Physictst

Safety Eng tneer

Environ Scientist

Hydrol_Hydrogeologist

Nuc lear Decon Engineer

Mechantca.l Engineer

Chemical Engineer

Civil Engineer

WasteMan Engineer

Electric tronic Engineer

Environ Engineer

Geo log ist

Industrial Engineer

Materlals Engineer

Structural Engineer

Trainer

Chem Tech

Electri tronio Tech

Mech Engin Tech

Technical Writer

Orafter

Ind Hygien ist

Ind Safety_Health Tech

Computer Eñgineer

HazWasteMan Spec

Rad Protect Spec

Civil Eng Tech

Estimator

Admin_Clerical

$H$ physics Tech

Material Handler

NucWaste Process Oper

Computer Oper

Project Manager

Biochemist

Biologist

Chemical Eng Tech

Driller

Ecologist

Environ Sciences Tech

Irrigation Engineer

Materials Scientist

Mathematician

Opers Researcher

Other Administrator

Other Eng ineer

other Scient ist

other Technician

Petrol_Mining Engineer

Physicist

Remediation Specialist

Risk Assess Manager

Se ismolog ist

Statistician

Survey_Map Tech

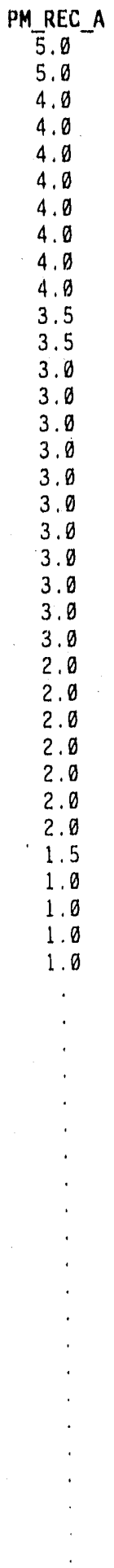

PM_DELTA

4

3

0

2

$\theta$

0
-5

-8
-15

15

$-6$

b

$\theta$

19

$\theta$

D

0

$-6$

2

1

0

0

$-1$

$-4$

0

$\theta$

0

$\theta$

$\theta$

0

$\theta$

$\theta$

o

$\theta$

$\theta$

$\theta$

$\theta$

$\theta$

$\theta$

0

0

$\theta$

$\theta$

$\theta$

8

$\theta$

\section{Degree}

Mix of BS and Advanced Mix of BS and Advanced Most ly Bachelor Most ly Bache lor Mix of BS and Advanced Most 1y Bache lor Most ly Bache lor Most ly Bache lor Most ly Bachelor Mostly Bachelor Most ly Bache lor Most ly Bache lor Most ly Bachelor MIX of BS and Advanced Mostly Bachelor Most ly Bachelor Most ly Bache lor Mix of AS and BS Most ly Associate Most ly Assoclate Mostly Associate Mix of AS and BS Most ly Assoctate Mostly Associate Most ly Associate Most ly Bache lor Most ly Associate Mostly Associate Most ly Associate Mix of AS and BS Most ly Associate Most ly Associate HS or less

HS or less Mostly Associate Most ly Bache lor Most ly Associate Most ly Associate HS or less HS or less Mostly Associate HS or less HS or less Most ly Associate Mostly Associate Most ly Associate HS or less Most ly Associate Most ly Associate HS or less

Mostly Associate Mostly Associate HS or less HS or less Mostly Associate Mostly Associate HS or less

Statistics based on data from 2 WNAS surveys and 9 SCHC surveys. 


\section{TABLE V.5. TitTes Sorted By Project Manager's Ratings of Difficulty Caused by Shortage (PM_Diff)}

Job Title

Nuc lear Eng ineer.

Chemist

Health Physicist

Safety Engineer

Environ Scient ist

Hydrol Hydrogeologist

Nuc lear Decon Engineer

Mechanical Engineer

Chemical Engineer

Civil Engineer

WasteMan Engineer

Electric tronio Engineer

Environ Eitigineer

Geologist

Industrial Engtneer

Materials Engineer

Structural Engineer

Trainer

Chem Tech

Ind Hygien ist

Ind Safety_Health Teoh

Computer Erigineer

Electri_tronic Tech

H.physics Tech

HazWasteMan Spec

Material Hand ler

Mech Engin Tech

NucWaste Process Oper

Project Manager

Rad Protect Spec

Technical Writer

Civil Eng Tech

Estimator

Drafter

Admin Clerical

Computer Oper

Biochemist

Biologist

Chemical Eng Tech

Driller

Ecologist

Environ Sciences Tech

Irrigation Engineer

Materials Scient ist

Mathematician

Opers Researcher

other Administrator

Other Engineer

Other Scientist

other Technictan

Petrol_Mining Engineer

Physicist

Remediation Specialist

Risk Assess Manager

Se ismo log ist.

Statistician

Survey Map Tech
PM_DIFF

PM_DELTA

5.0

5.0

4.0

4.0

4.8

4.0

4.0

4.0

4.0

3.5

3.5

3.0

3.0

3.0

3.0

3.0

3.0

2.0

2.0

2.0

2.0

2.0

2.0

2.0

2.9

2.0

2.0

2.8

2.0

2.0

2.0

2.0

2.0

1.5

1.0
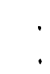

.

Statistics based on data from 2 WNAS surveys and $\theta$ SCHC surveys.
Degree

Mix of BS and Advanced Mix of $B S$ and Advanced Most ly Bache lor Mostly Bachelor

Mix of BS and Advanced Mostly Bachelor Most ly Bache lor Mostly Bachelor Most ly Bache lor Mostly Bache lor Mustly Bachelor Mostly Bachelor Most ly Bachelor Mix of BS and Advanced Mostly Bachelor Mostly Bachelor Mostly Bachelor Mix of AS and BS Mostly Assoclate Mostly Assoc late Mostly Assoc late Most ly Bache lor Most ly Assoc late Most ly Assoc late Mostly Associate HS or less. Most ly Associate HS or less Mostily Bachelor Mostly Associate Mix of $A S$ and $B S$ Most ly Assoc late Mix of $A S$ and $B S$ Most ly Assoc late Most ly Associate Mostly Associate Mostly Associate Mostly Associate HS or less HS or less Mostly Associate HS or less HS or less Mostly Associate Most ly Associate Most ly Assoc late HS or less Most ly Associate Most ly Associate HS or less Mostly Associate Mostly Associate HS or less HS or less Most ly Associate Mostly Associate HS or less 


\section{TABLE V.6. Job Titles Sorted By Human Resource Personnel's Ratings of Difficulty Caused By Shortage (HR_Diff)}

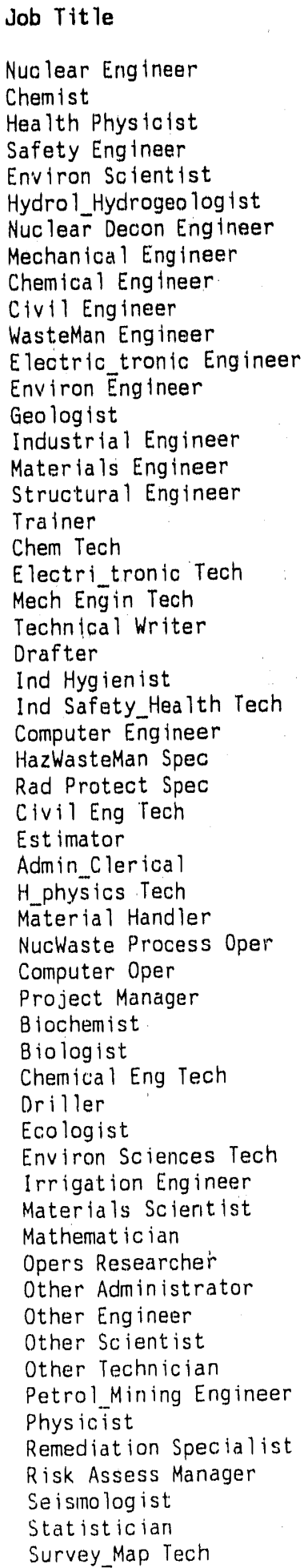

Nuc lear Eng ineer

Chemist

Health Physicist

Safety Engineer

Environ Scientist

Hydrol_Hydrogeologist

Nuc lear Decon Engineer

Mechanical Engineer

Chemical Eng ineer

Civil Engineer

WasteMan Engineer

Electric tronic Engineer

Environ Engineer

Geologist

Industrial Engineer

Materlals Engineer

Structural Engineer

Trainer

Chem Tech

Electri tronic Tech

Mech Engin Tech

Technical Writer

Drafter

Ind Hyg ien ist

Ind Safety_Health Tech

Computer Engineer

HazWasteMan Spec

Rad Protect Spec

Civil Eng Tech

Est imator

Admin Clerical

H_physics Tech

Material Handler

NucWaste Process Oper

Computer Oper

Project Manager

Biochemist

Biologist

Chemical Eng Tech

Driller

Ecologist

Environ Sciences Tech

Irrigation Engineer

Materials Scientist

Mathematician

Opers Researcher

Other Administrator

Other Eng ineer

other Scientist

Other Technician

Petrol Mining Engineer

Physicist

Remediation Specialist

Risk Assess Manager

Se ismolog ist

Statistician

Survey Map Tech

HR_DIFF

\section{PH_DELTA}

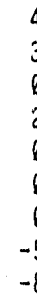

$-8$

$-15$

$-6$

$\theta$

$\theta$

.

a

$\theta$

10

0

0

$-6$

2

1

-

9
-1

\section{Degree}

MlX of BS and Advanced Mix of BS and Advanced Mostly Bachelor Mostly Bachelor Mix of BS and Advanced Most ly Bache lor Mostly Bachelor Piost ly Bachelor Most ly Bachelor Mostly Bachelor Most ly Bache lor Most ly Bachelor Most ly Bachelor Mix of BS and Advanced Mostly Bachelor Mostly Bachelor Mostly Bachelor Mix of AS and BS Mostly Associate Mostly Associate Most ly Associate Mix of AS and BS Mostly Associate Mostly Associate Mostly Associate Mostly Bachelor Mostly Associate Mostly Associate Mostly Assuciate Mix of AS and BS Most ly Associate Mostly Associate HS or less HS or less Mostly Associate Mostly Bachelor Mostly Associate Mostly Associate HS or less HS or less Mostly Associate HS or less HS or less Mostly Associate Mostly Associate Most ly Associate HS or less Mostly Associate Mostly Associate HS or less Mostly Associate Mostly Associate HS or less HS or less Mostly Associate Most ly Associate HS or less

Statistics based on data from 2 WNAS surveys and O SCHC surveys. 


\section{TABLE V.7. Job Titles Sorted By Human Resource Personnel's Ratings of Need for Additional Employees (HR_Need)}

Job Title

Nuc lear Engineer

Chemist

Health Physicist

Safety Eng ineer

Environ Scientist

Hydrol_Hydrogeologist

Nuc lear Decon Eng ineer

Mechanical Engineer

Chemical Engineer

Civil Engineer

WasteMan Engineer

Electric tronic Engineer

Environ Engineer

Geolog ist

Industrial Engineer

Materials Engineer

Structural Engineer

Trainer

Chem Tech

Electri_tronic Tech

Mech Engin Tech

Technical Writer

Orafter

Ind Hygien ist

Ind Safety Health Tech

Computer Engineer

HazWasteMan Spec

Rad Protect Spec

Civill Eng Tech

Estimator

Adm in Clerical

H physics Tech

Material Hand ler

NucWaste Process Oper

Computer Oper

Project Manager

Biochemist

Biologist

Chemical Eng Tech

Oriller

Ecologist

Environ Sciences Tech

Irrigation Engineer

Materials Scientist

Mathematician

Opers Researcher

Other Administrator

Other Eng ineer

Other Scient ist

Other Technician

Petrol Mining Engineer

Physicist

Remediation Specialist

Risk Assess Manager

Se ismolog ist

Statistician

Survey_Map Tech

\section{HR_NEED}

PM_DELTA

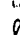

2

$\theta$

$\theta$

0

-5
-8

\section{Degree}

Mix of $B S$ and Advanced Mix of BS and Advanced Most ly Bachelor Mostly Bachelor Mix of BS and Advanced Most ly Bachelor Mostly Bachelor Most'ly Bachelor Most ly Bache lor Mostly Bachelor Most ly Bachelor Mostly Bachelor Mostly Bache lor Mix of BS and Advanced Most ly Bachelor Mostly Bachelor. Mostly Bachelor Mix of AS and BS Mostily Associate Mostly Associate Mostly Associate Mix of AS and BS Mostly Associate Mostly Associate Most ly Associate Mostly Bachelor Mostly Assuciate Mostly Associate Most ly Associate Mix of AS and BS Mostly Associate Most ly Associate HS or less HS or less Most ly Associate Mostly Bachelor Mostiy Associate Mostly Associate HS or less HS or less Most ly Associate HS or iess

HS or less Mostly Associate Most ly Associate Most ly Associate HS or less Mostily Associate Mostly Associate HS or less Mostly Associate Mostly Assoclate HS or less HS or less Mostly Associate Mostly Associate HS or less

Statistics based on data from 2 WNAS surveys and $\emptyset$ SCHC surveys. 
TABLE V.8. Job Titles Sorted By Human Resource Personnel's Ratings of Current Ability to Recruit (HR_Rec_C)

Jow Title

Nuc lear Eng ineer

Chemist

Heaith Physicist

Safety Engineer

Environ Scientist

Hydrol Hydrogeo log ist

Nuc lear Decon Engineer

Mechanical Engineer

Chemical Engineer

Civil Engineer

WasteMan Engineer

Electric tronic Engineer

Environ Engineer

Geolog ist

Industrial Engineer

Materials Engineer

Structural Engineer

Trainer

Chem Tech

Electri tronic Tech

Mech Engin Tech

Technical Writer

Orafter

Ind Hygien ist

Ind Safety_Heaith Tech

Computer Eng ineer

HazWasteman Spec

Rad Protect Spec

Civil Eng Tech

Estimator

Admin_Clerical

$H$ physics Tech

Materia? Handier

NucWaste Process Oper

Computer Oper

project Manager

Biochemist

Biologist

Chemical Eng Tech

Driller

Ecologist

Environ Sciences Yech

Irrigation Engineer

Materials Scientist

Mathematician

Opers Researcher

Other Administrator

Other Eng ineer

Other Scient ist

Other Technician

Petrol_Mining Engineer

Physicist

Remediation Specialist

Risk Assess Manager

Se ismologist

stat istician

Survey_Map Tech
HR_REC_C

PM_DELTA

4

3

0

a

0

0

$-5$

$-8$

$-15$

1
-6

0

$\theta$

$\theta$

0

0

19

0

$\theta$

$\theta$

$-6$

2

$!$

0

0

$-1$

$-4$

$\theta$

$\theta$

0

0

0

0

0

$\theta$

$\theta$

0

0

0

b

0

Statistics based on date irom? WNAS surveys and $O$ SCHC surveys.

Degree

Mix of BS and Advanced Mix of BS and Advanced Most ly Bachelor Most ly Bachelor Mix of BS and Advanced Most ly Bache lor Most ly Bache lor Mostly Bache lor Most ly Bache lor Mostly Bache lor Most ly Bache lor Mostly Bache lor Most ly Bache lor Mix of BS and Advanced Mostly Bache lor Most ly Bachelor Most ly Bachelor Mix of AS and BS Most ly Associate Most ly Associate Most ly Associate

Mix of AS and BS Mostly Associate Most iy Associate Most ly Associate Most ly Bachelor Mostly Associate Mostly Associate Mostly Associate Mix of AS and BS Mostly Associate Mostly Associate

HS or less

HS or less

Most ly Associate

Most iy Bache lor

Most ly Associate

Most ly Associate

HS or less

HS or less

Mostly Associate

HS or less

HS or less

Most ly Associate Mostly Associate

Mostly Associate IiS or less

Most ly Associate Mostly Assoriate HS or less

Mostly Associate Most ly Associate

HS or less

HS or less

Most iy Associate Most ly Associate HS or less 


\section{TABLE V.9. Job Titles Sorted By Human Resource Personnel's Ratings of Anticipated Ability to Recruit (HR_Rec_A)}

Job Tit le

Nuc lear Engineer

Chemist

Health Physicist

Safety Engineer

Environ Scient ist

Hydrol_Hydrogeologist

Nuc lear Decon Engineer

Mechanical Engineer

Chemical Eng ineer

Civil Engineer

WasteMan Engineer

Electric tronic Engineer

Environ Engineer

Geologist

Industrial Engineer

Materials Engineer

Structural Engineer

Trainer

Chem Tech

Electri tronic Tech

Mech Eng in Tech

Technical Writer

Drafter

Ind Hygien ist

Ind Safety Health Tech

Computer Eng ineer

HazWasteMan Spec

Rad Protect Spec

Civil Eng Tech

Estimator

Admin Clerical

$H$ physics Tech

Material Handler

Nuchaste Process Oper

Computer Oper

Project Manager

Biochemist

Biologist

Chemical Eng Tech

Driller

Ecologist

Environ Sciences Tech

Irrigation Engineer

Materials Scientist

Mathematician

Opers Researcher

Other Administrator

Other Engineer

Other Scient ist

Other Technic lan

Petrol Mining Engineer

Physic ist

Remediation Specialist

$R$ isk Assess Manager

Se ismo log ist

Statistician

Survey_Map Tech

\section{HR_REC_A}

PH_DELTA

4

3

2

6

0

0

$-5$

-8
-15

1
-6

-6
0

0

0

0

0

10

0

0

$-6$

2

1

D

0
-1

$-4$

$\theta$

0

$\theta$

0

$B$

$\theta$

0

is

0

0

$\theta$

0

0

0

0

$b$

0

0

0

0

$a$

\section{Degree}

Mix of BS and Advanced Mix of $B S$ and Advanced Most ly Bache lor Most ly Bache lor Mix of BS and Advanced Most ly Bache lor Most ly Bachelor Most ly Bache lor Mostly Bachelor Most ly Bache lor Most ly Bache lor Most ly Bache lor Most ly Bache lor Mix of $B S$ and Advanced Most ly Bachelor Mostly Bachelor Mostly Bachelor Mix of AS and BS Mostly Associate Mostly Associate Mostly Associate Mix of $A S$ and $B S$ Mostly Associate Most ly Associate Mostly Associate Most ly Bachelor Mostly Associate Mostly Associate Mostly Associate Mix of AS and BS Mostly Associate Mostiy Assoriate HS or less HS or less Mostly Associate Mostiy Bachelor Mostly Associate Mostly Associate HS or less HS or less Mostly Associate HS or less HS or less Most iy Associate Mostly Associate Mostly Associate HS or less Most ly Associate Mostily Associate HS or less Mostly Associate Mostly Asscciate HS or less HS or less Most ly Asscciate Most ly Associate HS or less

Statistics based on data from 2 WNAS surveys and 0 SCHC surveys. 


\section{TABLE V.10. Job Titles Sorted By Human Resource Personnel's Ratings of Annual Turnover (HR_Turn)}

HR_TURN

PM_DELTA

Degree

Mix of BS and Advanced Mix of BS and Advanced Most ly Bache lor Most ly Bachelor

Mix of BS and Advanced Most ly Bachelor Most ly Bachelor Most ly Bachelor Most ly Bache lor Most ly Bache lor Most. ly Bachelor Most ly Bache lor Most ly Bache lor Mix of BS and Advanced Most ly Bache lor Most ly Bache lor Most ly Bache lor Mix of AS and BS Most ly Associate Most. ly Associate Most ly Associate Mix of AS and BS Most ly Associate Most ly Associate Most ly Associate Most ly Bache lor Most ly Associate Most ly Associate Most ly Associate Mix of AS and BS Most ly Associate Most ly Associate HS or less HS or less Mostly Associate Most ly Bache lor Most ly Associate Most ly Associate MS or less HS or less Most ly Associate HS or less

HS or less Mostily Associate Most ly Associate Most ly Associate HS or less Most ly Associate Most ly Associate HS or less Most iy Associate Most ly Associate HS or less HS or less Most ly Associate Most iy issociate HS or less

Statistics based on data from 2 WNAS surveys and $D$ SCHC surveys. 
APPENDIX W

QUESTIONNAIRE 


\section{ER/WM Manpower Assessment Focus Group Feedback}

The researchers who attended the focus group along with you have written this summary in order to capture the main ideas, comments, and concerns that came out of the discussions. We tried to convey points that provoked a fair amount of discussion and those we spent the most time on. We would like you to quickly evaluate how well the comments characterize the group discussion.

Please keep in mind that the summary cannot convey the individual opinions of each participant. Evaluate the summary based on how well it summarizes the group's contributions.

To what extent do you think the write-up accurately reflects the points expressed during the focus group? Please circle the appropriate number.

\begin{tabular}{|c|c|c|c|c|}
\hline $\begin{array}{l}\text { Captures } \\
\text { none of the } \\
\text { main points }\end{array}$ & $\begin{array}{l}\text { Captures } \\
\text { a couple of } \\
\text { the } \\
\text { main points } \\
\text { but left } \\
\text { many out }\end{array}$ & $\begin{array}{c}\text { Captured } \\
\text { and left out } \\
\text { an equal number } \\
\text { of points }\end{array}$ & $\begin{array}{l}\text { Captures } \\
\text { many of } \\
\text { the main } \\
\text { points but } \\
\text { left a } \\
\text { couple out }\end{array}$ & $\begin{array}{l}\text { Captures } \\
\text { all of the } \\
\text { main points }\end{array}$ \\
\hline
\end{tabular}

Are there points you strongly agree with or would like to emphasize more? If so, which ones?

Are there points you strongly disagree with or would emphasize less? If so, which ones?

Is there anything you would add to the write-up? If so, what?

Is there anything you would delete from the write-up? If so, what?

Were there people who should have been present at the workshop but weren't? What positions or functions were not represented?

Please return to: R.E. Lewis or C.W.Holmes, P.O. Box 999, Richland. WA 99352. Mailstop K6-66 If you would like to receive a copy of the repori please write yoür niañe and mailstop below.

$$
\text { W.1 }
$$




\section{DISTRIBUTION}

No. of

Copies

OFFSITE

12 DOE/Office of Scientific and Technical Information

2 A. Behr DOE PR-15 FORSTL 1000 Independence Ave., S.W. Washington, DC 20585

T. H. Belt

Hazardous Waste Action Coalition

1015 15th Street, N.W., Suite 802

Washington, DC 20005

T. C. Chee

U.S. Department of Energy

EM-50, GTN

19902 Germantown Road

Germantown, MD 20874

C. Dobbins

Basic Technologies

International

4641 Montgomery Avenue, Suite 300

Bethesda, MD 20814

A. Fechter

Executive Director

Office of Scientific and

Engineering Personnel

National Research Council

2101 Constitution Avenue, N.W.

Washington, DC 20418

M. G. Finn

Oak Ridge Associated

Universities

230 Warehouse Road

P.0. Box 117

Oak Ridge, TN 37830-0117
No. of

Copies

C. Gaylord

Deputy Director

Human Resource Management

U.S. Environmental Protection Agency

401 M Street, S.W.

Washington, DC 20460

B. Hammond

U.S. Department of Energy

EM-30, GTN

19901 Germantown Road

Germantown, MD 20874

M. Harris

Vice President and Director

DOE Programs for $\mathrm{CH}^{2} \mathrm{MH} i \mathrm{ll}$

599 Oak Ridge Turnpike

Oak Ridge, TN 37830

P. Hutton

BDM International, Inc.

12850 Middlebrook Road

Suite 300

Germantown, MD 20874

D. L. Johnson

Oak Ridge Associated Universities

P.0. Box 117

230 Warehouse Road

oak Ridge, TN 37830-0117

R. Kutscher

Associate Commissioner

Bureau of Labor Statistics

Room 9216

600 E Street, N.W.

Washington, DC 20212

Distr.1 
No. of

Copies

D. F. Miller

EG\&G Idaho, Inc.

c/o U.S. Department of Energy

Organization EM-50, FORSTL

1000 Independence Avenue, S.W.

Washington, DC 20585

L. I. Middleman

Waste Policy Institute

1999 South Main Street, Suite 500

Blacksburg, VA 24060-6613

Susan Prestwich

U.S. Department of Energy

EM-50, GTN

19901 Germantown Road

Germantown, MD 20874

V. R. Tilton

Program Manager

Associated Western Universities Incorporated

4190 South Highland Drive

Suite 211

Salt Lake City, UT 84124

G. Turi

U.S. Department of Energy

EM-433, GTN

19901 Germantown Road

Germantown, MD 20874

B. Vetter

Commission on Professionals in

Science and Technology

1500 Massachusetts Avenue,

N.W., Suite 831

Washington, DC 20005
No. of

Copies

G. Williams, Ph.D.

Manager, Social and Natural

Resources Section

Environmental Assessment and Information Sciences

Division

Argonne National Laboratory

370 L'Enfant Promenade, S.W. Washington, DC 20024

B. Wi senbaker

U.S. Department of Energy

EM-40, GTN

19901 Germantown Road

Germantown, MD 20874

C. Young, Ph.D.

Social and Natural Resources Section

Environmental Assessment and Information Sciences Division

Argonne National Laboratory

9700 South Cass Avenue

Argonne, IL 60439

\section{ONSITE}

\section{U.S. Department of Energy}

J. E. 011 ero

Kaiser Engineers Hanford Company

S. W. Bork

15 Pacific Northwest Laboratory

C. W. Hoimes (8)

R. E. Lewis

Publishing Coordination

Technical Report Files (5) 

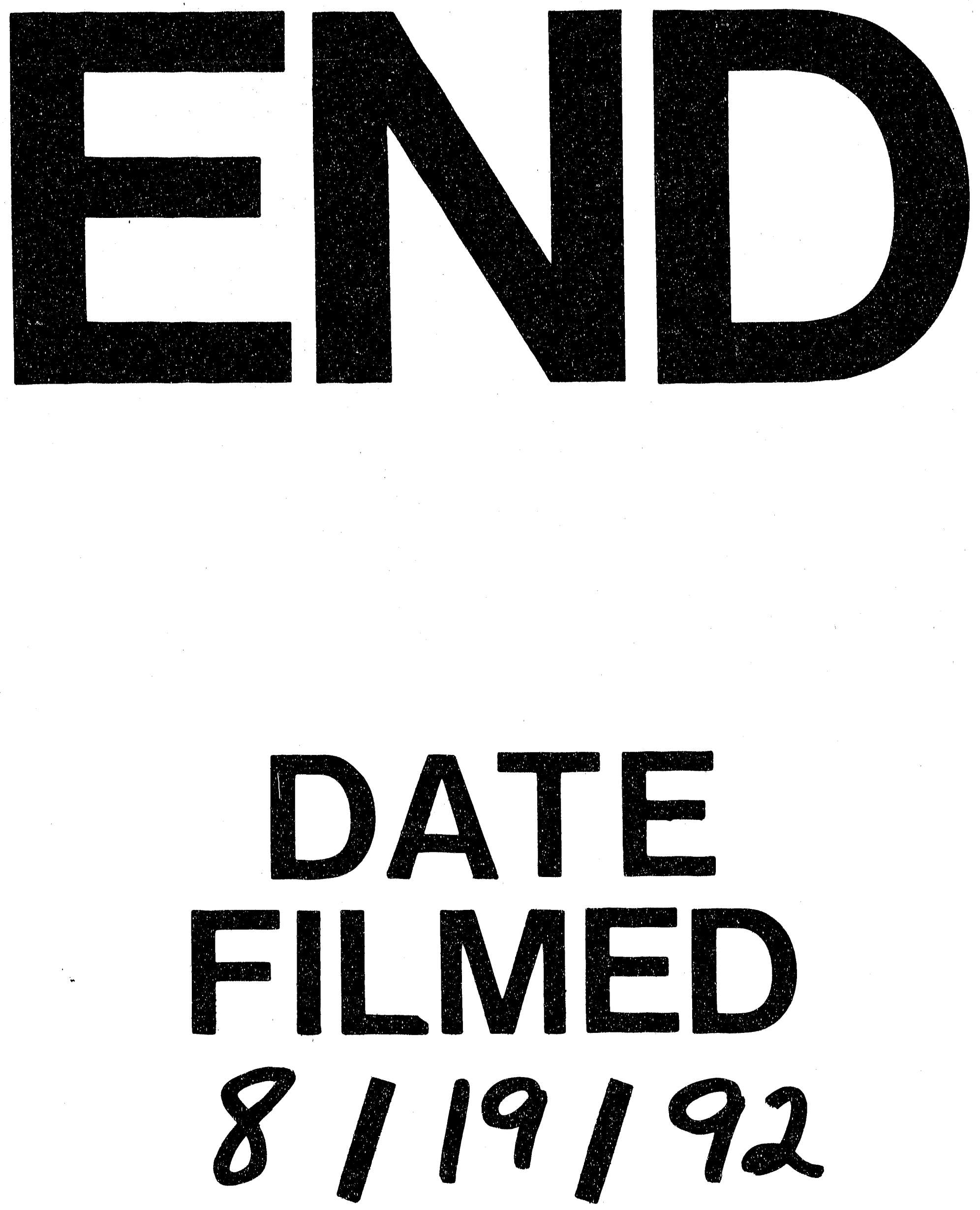

毒 
